\title{
Urban Trauma
}

The contemporary square and the New Urbanist city - Reintegrating Christchurch Cathedral Square.

Benjamin J. Chalmers

A thesis submitted to the Victoria University of Wellington in partial fulfilment of the requirements for the degree of Master of Architecture (Professional)

School of Architecture

2014 


\section{Abstract}

This topic was chosen in response to the devastation caused to Cathedral Square, Christchurch, New Zealand following earthquakes in 2010 and 2011.

Working amongst the demolition bought to attention questions about how to re-conceive the square within the rebuilt city. In particular, it raised questions as to how a central square could be better integrated and experienced as a contemporary addition to Christchurch city.

This thesis seeks to investigate the ways in which central squares can be better integrated with the contemporary city and how New Urbanist design principles can contribute toward this union.

The research principally focuses on the physical and spatial integration of the square with the contemporary city. A drawing-based analysis of select precedent case studies helped to determine early on that overall integration of the contemporary square could be attributed to several interdependent criteria. The detailed studies are supplemented further with literature-based research that narrowed the criteria to five integrative properties. These are: identity, scale and proportion, use, connectivity and natural landscape. These were synthesised, in part, from the integrative New Urbanist movement and the emerging integrative side of the more contemporary Post Urbanist movement.

The literature-based research revealed that a more inclusive approach toward New Urbanist and Post Urbanist design methodologies may also produce a more integrated and contemporary square.

Three design case studies, using the redesign of Cathedral Square, were undertaken to test this hypothesis.

The case studies found that overall, integration was reliant on a harmonious balance between the five integrative properties, concluding that squares can be better integrated with the contemporary city.

Further testing of the third concept, which embraced an allied New Urbanist / Post Urbanist approach to design, found that New Urbanism was limited in its contribution toward the integration of the square. 
Acknowledgements

Firstly I would like to thank my supervisor Chris McDonald for his invaluable guidance and patience
throughout the design of this thesis. Additionally I must thank the School of Architecture staff and

also like to thank Rebecca Powell for her support through this endeavour. 


\section{Contents}

Chapter 1. Introduction 11

Chapter 2. Theoretical Background 15

Introduction $\quad 17$

The City Square in History 19

New Urbanism and the Square 32

Post Urbanism and the Square 35

Toward an Integrated City Square $\quad 40$

Chapter 3. Precedent Case Studies 43

Introduction $\quad 44$

Methodology 45

Graphic Analysis $\quad 51$

Findings $\quad 85$ 

Chapter 4. Cathedral Square Christchurch

$\begin{array}{ll}\text { Introduction } & 101\end{array}$

Pre - earthquake Site - Analysis 103

CERA and the 100 day Blueprint 127

Toward a Design Case Study 131

Chapter 5. Design Case Studies 133

Introduction 135

$\begin{array}{ll}\text { Design Concept } 1 & 139\end{array}$

Design Concept 2

Design Concept 3

Design Discussion 218

Design Development 225

Chapter 6. Conclusion 253

Introduction 255

Integrating the Square 256

The Role of New Urbanism 258

Bibliography 263

List of Figures $\quad 267$

Appendix 275 


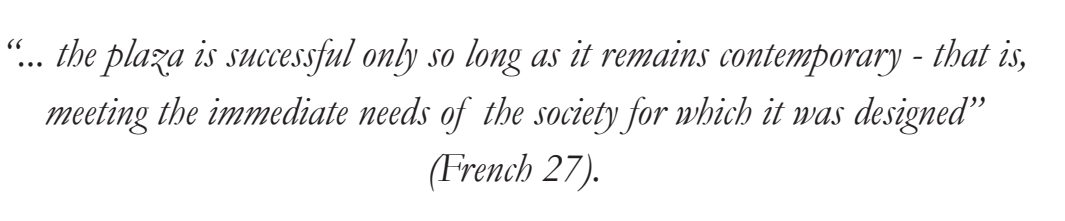




\section{$\underset{\text { Chapter } 1}{1}$}




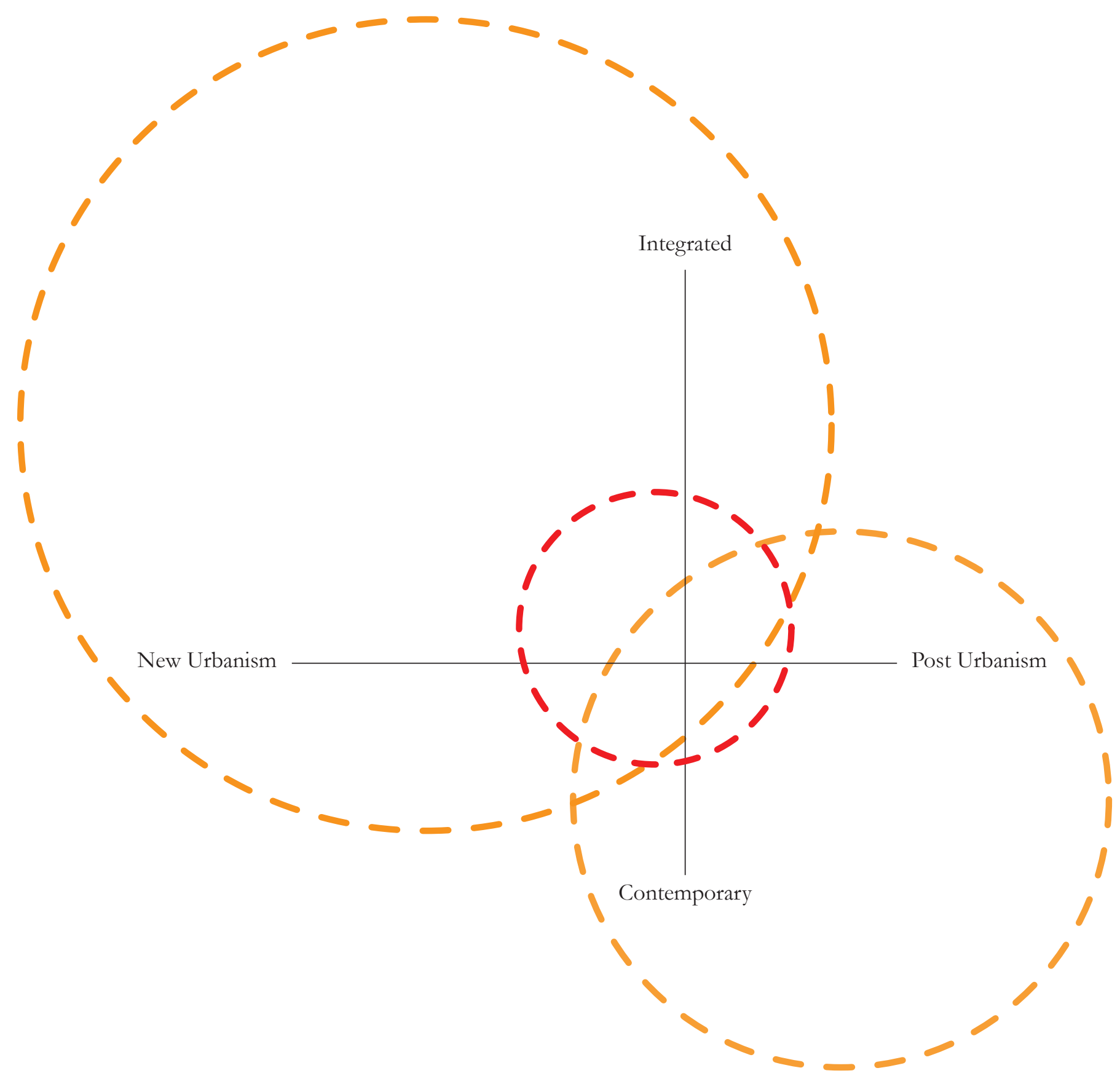

Figure 1. Diagram outlining the thesis field of enquiry. The red circle indicates the research focus.

12

Urban Trauma 
This thesis began in Christchurch Cathedral Square. Working amongst the destruction caused by the 2010 and 2011 earthquakes called into question the rebuild of the city. The ongoing demolition of buildings within the central city also raised doubt as to how suitable it would be to simply rebuild the square as it was.

This design thesis is about the physical integration of the new square with the contemporary city.

There is already a significant body of research on the integration of the square and public space in general. Much of this knowledge stems from the New Urbanist design movement. Often drawing from historical precedent, New Urbanism seeks to integrate the square with the contemporary city. However, this research is unique in that it aims to interrogate New Urbanist design principles, which are often criticised for being historically derivative. This begs the question just how contemporary such a proposal could really be.

The thesis aims to investigate, through design, the integration of the square with the contemporary city. The research begins with an extensive study of contemporary squares and moves onto developing three case study designs.

Ultimately the thesis seeks to produce three unique design case studies that demonstrate how Cathedral Square can be better integrated with Christchurch City. These three design concepts investigate how squares can be better integrated with the contemporary city and interrogate the extent as to which New Urbanism can contribute.

The scope of research is limited to the physical and spatial integration of the city square with the contemporary city. This design research is concerned with spatial concepts and architectural properties, avoiding architectural detail.

The design case studies are limited to architectural and spatial concepts as landscape architecture falls outside the author's field of expertise. The integrative properties on which the design case studies are evaluated reflects this focus, and the designs presented are not intended to be judged on the quality of any landscape design.

The design component also focuses on two specific design movements, New Urbanism and Post Urbanism. The presumption being that New Urbanism is often considered best practice for most contemporary urban design developments. Post Urbanism is introduced as a secondary theme in order to challenge this premise with this more contemporary movement.

The primary method of enquiry used in this research is the development of three unique design case studies for Cathedral Square, Christchurch. These design concepts are principally based on New Urbanism and build in Post Urbanist concepts in the third design concept. These are supplemented with drawing-based analysis of selected precedent case studies and a literature review that looks specifically at the integration of the city square. These main modes of enquiry are divided into chapters introduced below.

Chapter two investigates relevant texts concerned with the physical integration of the city square. This is to establish a set of historic integrative design principles on which much of the New Urbanist movement is based. This chapter also introduces Post Urbanism and the emerging integrative side to this contemporary urban design movement. The purpose of this chapter is to derive a succinct set of integrative design properties and contemporary urban space qualities upon which the design case studies can be assessed.

The graphic based analysis of sixteen contemporary squares makes up chapter three. The precedent studies were a way into this thesis and ensured that the initial investigations remained on the physical integration of the square. Each precedent is subject to analysis based on five integrative attributes. It must 
be noted that these initial attributes are a precursor to the integrative design properties finalised in chapter two.

As expected, the graphic analysis reveals patterns of integration, and relationships between the integrative attributes. Also, the fact that this was largely carried out before chapter two helped with more targeted reading of the literature.

Chapter four introduces the site for the design case study Cathedral Square, Christchurch. Based on existing site analysis and the Central Christchurch Development Unit's 100 day blueprint (released part way through this research) a set of site specific design criteria are established.

The three design case studies are presented in chapter five. Each design case study responds to the site-specific criteria identified in chapter four, but takes a unique approach toward the integration of the square. These schemes are each developed and presented, from which a discussion and comparison can be made in an effort to draw a conclusions and answer the research question.

The third scheme was found to have to have the best overall integration and was subsequently developed to better investigate the preliminary findings. The third concept adopts a more inclusive design methodology, introducing Post Urbanist design principles in an effort to further interrogate the extent to which New Urbanism can contribute to the integration of the square. The Post Urbanist principles also emphasise the contemporary qualities of these three designs.

Chapter six concludes the research, drawing together the findings from the design discussion and the research as a whole. This chapter is broken down by finding and concluded with a summary of findings and thoughts on further research. 
Chapter
Theoretical Background 
${ }_{16}$ U.han Trama 


\section{Introduction}

This chapter reviews the relevant literature in relation to the integration of the city square.

The chapter takes a chronological approach to the subject, beginning with the integration of the city square throughout history and then moving into contemporary approaches to urban integration and design. With such a large body of knowledge to cover this chapter in no way covers this material comprehensively. Instead the chapter focuses principally on the city square and the physical and spatial properties of integration. Particularly those properties that relate to the New Urbanist approach to integration and emerging contemporary alternatives.

The chapter is composed of three main sections: The City Square in History identifies traditional integrative properties of the square. From the Greek, Roman and Medieval square to the rational integration of the Renaissance and Colonial examples. The focus then moves into Modern Public Space, identifying the radical changes in the approach to urban design and city squares that took place during the 20th century. Reforming the Square concludes this section and summarises the impact of Modern urban design on the integration of the square and the subsequent introduction of the Place Making tradition in urban design. Various authors of this era are examined with many advocating a return to traditional urban form and design, including the integration of city squares according to traditional principles. From the Place Making tradition New Urbanism has emerged as the most integrative of these historically based approaches to contemporary city square design.

The second section New Urbanism and the Square identifies the historically derived properties of New Urbanism many of which promote the integration of the square into the city. The third section Post Urbanism and the Square identifies more contemporary, avant-garde properties of integration in relation to the square and contemporary city. Toward an Integrated City Square summarises the integrative properties identified in this chapter. These physical properties of integration are used to inform and evaluate the design case studies. 



\section{The City Square in History}

Communal space for people to gather has always been an essential part of human society, even before people began to construct towns and cities. In forming a useful definition of the traditional city square, it is best to begin with the Greek Agora (see figure 2). This was the first instance in which the square became a meaningful and physically integrated part of the city. Paul Zucker states the civilised city had reached a stage where there was a need "for a political and commercial centre for all the inhabitants together" (Zucker 27). The Agora fulfilled this need, attaining a unique spatial identity within the ancient urban form.

Zucker uses the Acropolis as comparative reference (see figure 3). The space surrounding the Parthenon was used for congregation, but the building was the dominating feature of the space. The Agora worked differently, as the buildings surrounded the congregation space. It is this amalgamation of buildings that began to contain an area of outdoor space that defines the square's basic spatial identity (R. Krier 15).

As can be seen in figure 2, architectural devices such as the Stoa and Portico face into the open space. Furthermore the surrounding buildings are composed in a way that begins to enclose the open space. Although irregular in shape, as is the case with the Asos example, Childs suggests that a "strong figural quality" is an essential element in creating a spatial identity for open space (Childs 121). The Agora exhibits this quality, with the buildings both facing into, and enclosing, the outdoor space.

The use of these buildings contributed to the identity and activity within the Agora. Often political and religious in nature, the congregations of people in and around the buildings that framed the space would in turn help activate the open space. Marketplaces and commercial uses also contributed to the vitality of the Agora as an integral piece of Greek urban form.

Nick Corbett suggests that both the spatial configuration and use of the surrounding buildings helped the square to develop a unique spatial identity amongst the surrounding urban form. 
The Agora exhibits both these properties, establishing them as principle elements of the traditional city square form.

The rise of the Roman Empire bought further developments to the city square. As new settlements were laid out, public space was more formally integrated at the planning stages. Zucker notes the fact that the squares were centrally located within the city meant the Romans were aware of the importance of integrating these gathering spaces into the built environment.

Unlike the Agora, the Roman square employed more orthogonal shapes with a much more cohesive edge to frame it (see figure 4). This continuous built edge showed an awareness of the square as its own spatial unit as opposed to leftover space between buildings (Zucker 60).

Such a formal integration of the city square would not occur again until the Renaissance.

The Medieval square was much more organic in its formation. French describes this method as an "empirical process ... generated by trial-and-error" and "achieving a solution to the form of the square over a long period of usage and infinite corrective adjustments" (French and Doty 26).

It is not hard to imagine the medieval market square beginning as a simple widening of the main thoroughfare morphing, as needs required, into more substantial spaces integral to medieval city life and urban form.

Similar to the Agora, but more pronounced due to the higher density of building, the medieval square inherits a unique spatial identity through the amalgamation of the surrounding buildings.

Camillo Sitte's figure ground plans, two of which are redrawn in figures 5 and 6 , clearly demonstrate the contrast between the square and the buildings that enclose it.

Often growing from a main thoroughfare, the medieval market square began to more explicitly integrate the street with the square.

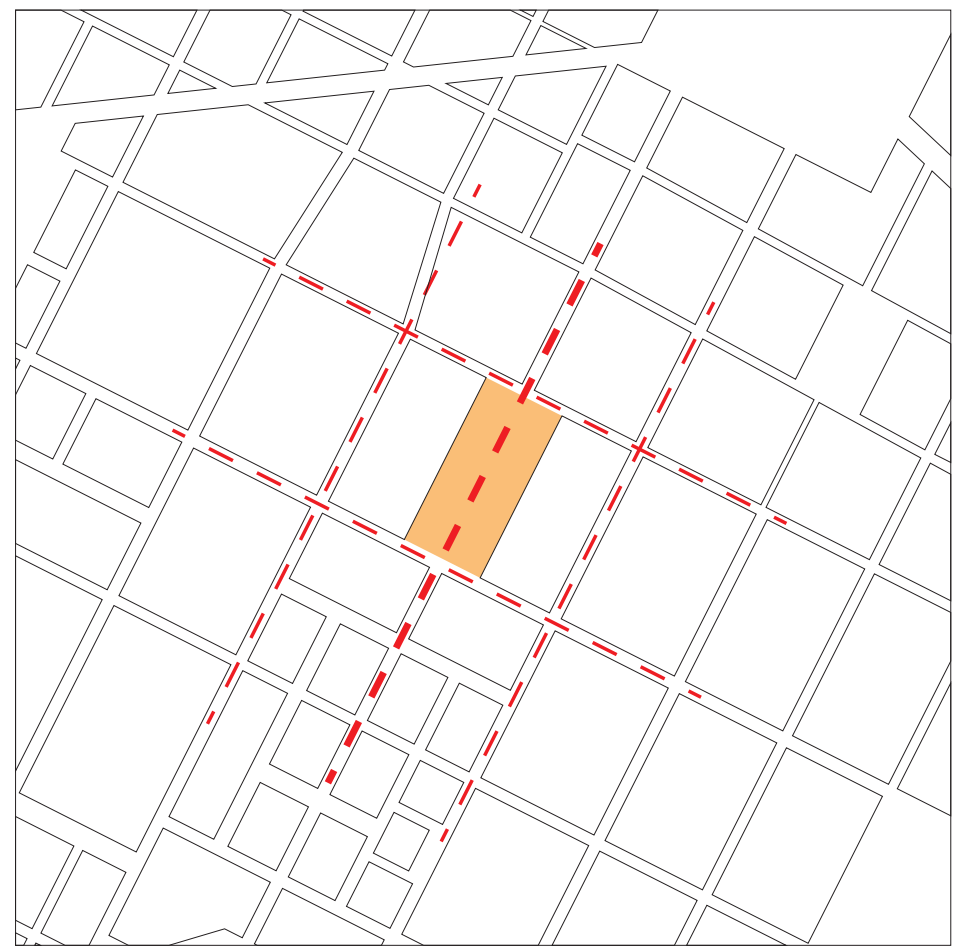

Figure 4. Author's drawing of Piazza San Carlo, Turin,

Italy.
The figure ground of Torico Square in Teruel Spain (figure 7) would suggest that this square has developed from diverging streets. This natural integration of street and square meant that it was far more accessible to the surrounding context. It also meant that a continuous flow of people and goods would bring vitality and life to the medieval square. This is an important property for a space that could easily become isolated within such a dense built environment. French gives an in depth explanation on the formation of these market squares and redrawn in figure 8 is his diagrammatic explanation of this organic process (French 63-64).

This continuous flow of life that bought such vitality to the square was born out of both necessity and recreation. The square was the only space that could support the tasks of medieval city life. It was "a site for markets, celebrations, and executions; and the place where one went to hear the news, buy food, collect water, talk politics, or watch the world go by. Indeed, it is doubtful that the medieval city could have functioned without its piazza or town square" (Marcus and Francis 1). 
Figure 5. Author's drawing of Freiburg Munster, Freiburg, Germany.

Figure 6. Author's drawing of Piazza del Santo, Padua, Italy.

Figure 7. Author's drawing of Torico Square, Teruel, Spain.
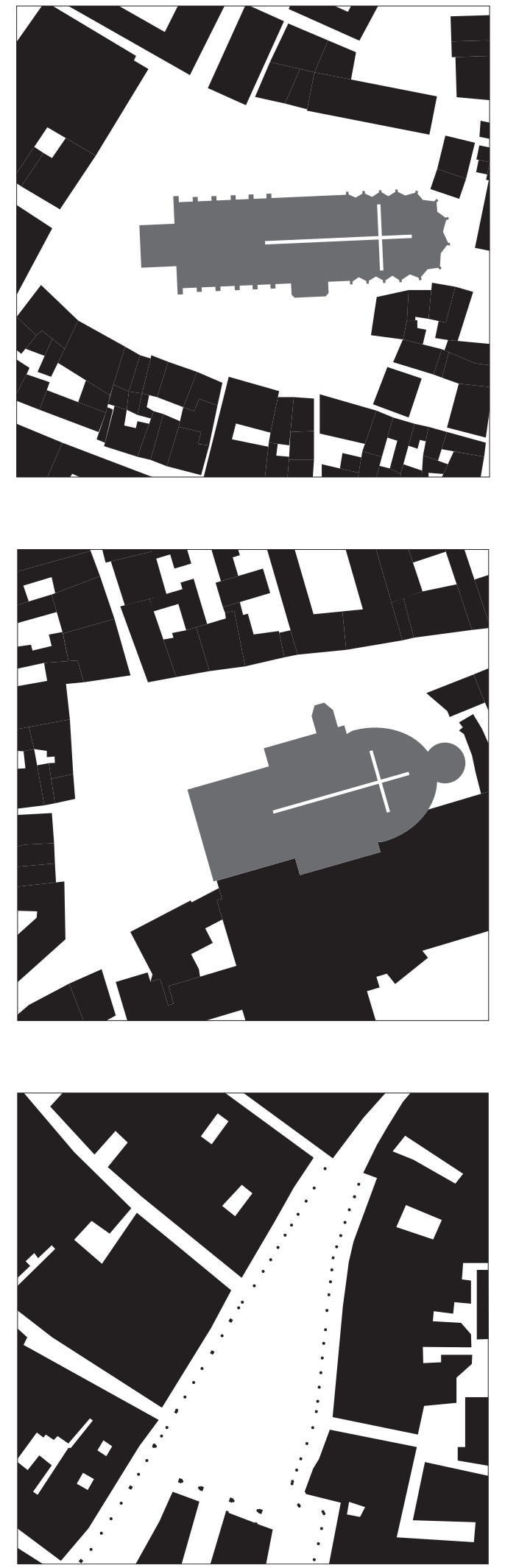

Equally as important as the Market Square was the Cathedral Square and Church Square. The importance of religion within medieval society meant that many squares integrated a church or cathedral.

Whether it was one of the surrounding buildings (figure 6) or a dominating feature of the square (figure 5), the integration of such significant buildings to medieval society is what makes these squares an integral part of the city.

The success and vitality of the square not only relies on good spatial form, but on it being able to integrate and support meaningful functions and use (R. Krier 19).

The medieval square is significant as it had an almost organic integration with the city, both in form and in use. That such successfully integrated squares could arise out of a comparatively disorganised process is testament to medieval society. However as French and Zucker note, these squares would have developed over centuries rather than being a successful exercise in rational town planning.

With the rise of the Renaissance, there was a return to awareness of the square as its own spatial unit. Theorists such as Alberti began to rationalise this urban space and developed a much more critical awareness of how these spaces related to the rest of the city. Zucker's comparison between the "volume" of the renaissance street and the "space" that is the square is helpful in understanding this: "the street itself is conceived as an agglomeration of heterogeneous buildings and not as an artistic unit. But the square, on the other hand, is unified, its single elements tied together by all possible architectural means, and here it is the space which is articulated" (Zucker 141). Of course this is not necessarily true of more contemporary urban theory, where we see a much more critical awareness in composing "good" streets. Never the less it demonstrates the separation in the spatial identity of the Renaissance Street and Square.

Childs writes at length about the implied spatial identity of the square formed through the careful composition of surrounding 
buildings. Renaissance theorists had a profound understating of how to compose buildings to create well proportioned open space between. Much like the Roman Forum, Moughtin notes that the use of strong geometrical shapes assisted in the implied form of the renaissance square. He goes on to state that the "key to enclosure in the square is the treatment of its corners" (Moughtin 99). As figures 5 to 7 , show the presence of well defined internal corners are integral to creating this implied form or spatial identity.

Scale and proportion played an equally substantial part in the formation of the renaissance square and the traditional square in general.

Renaissance designers began to theorise dimensions and ratios between building heights and the width of the square. Moughtin writes extensively on this subject, citing Alberti as stating "a proper height for the buildings about a square is one third of the breadth of the open area, or one sixth at the least" (Moughtin 100).

Sitte recommends proportions that produce much smaller squares in relation building heights around the square. He states that "the minimum dimension of a square ought to be equal the height of the principal building in it, and that its maximum dimension ought not to exceed twice that height" (Sitte 28).

Moughtin also notes how these proportions relate to our human sensory experience of the square. He notes that the above proportions overlap the angles at which the eye can best view the surrounding buildings. Citing Hegeman, Peets and Spreiregan, Moughtin writes that the minimum width of the square is equal to the tallest part of the building, or a proportion of $1: 1$. He then goes on to state that 27 degrees is the best angle to view a single building in its entirety, a proportion of 1:2. Finally, adding that 18 degrees is the angle at which we can best view a cluster of buildings, producing a proportion similar to Albertis ideal of 1:3 (Moughtin 100) (see figure 9).
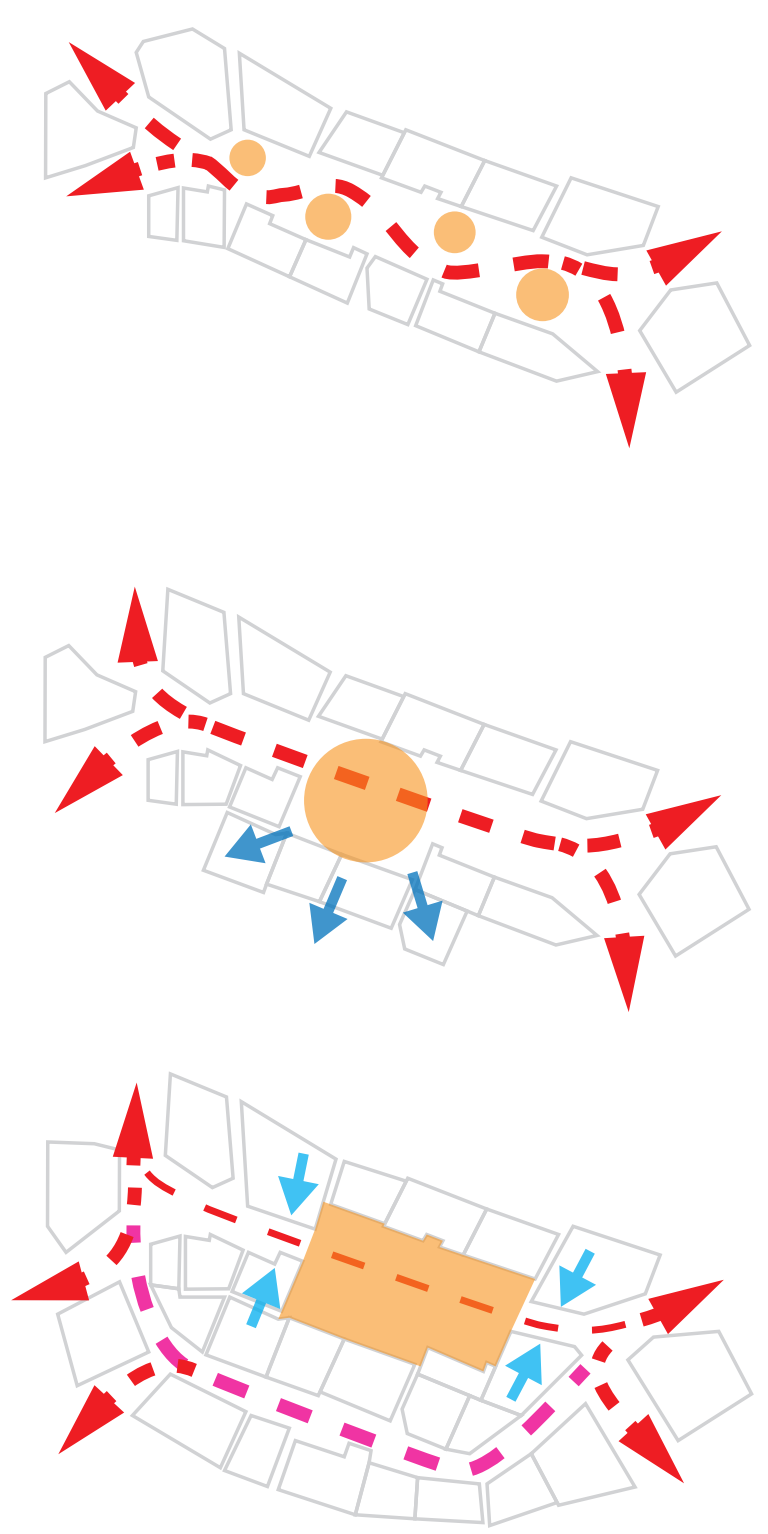


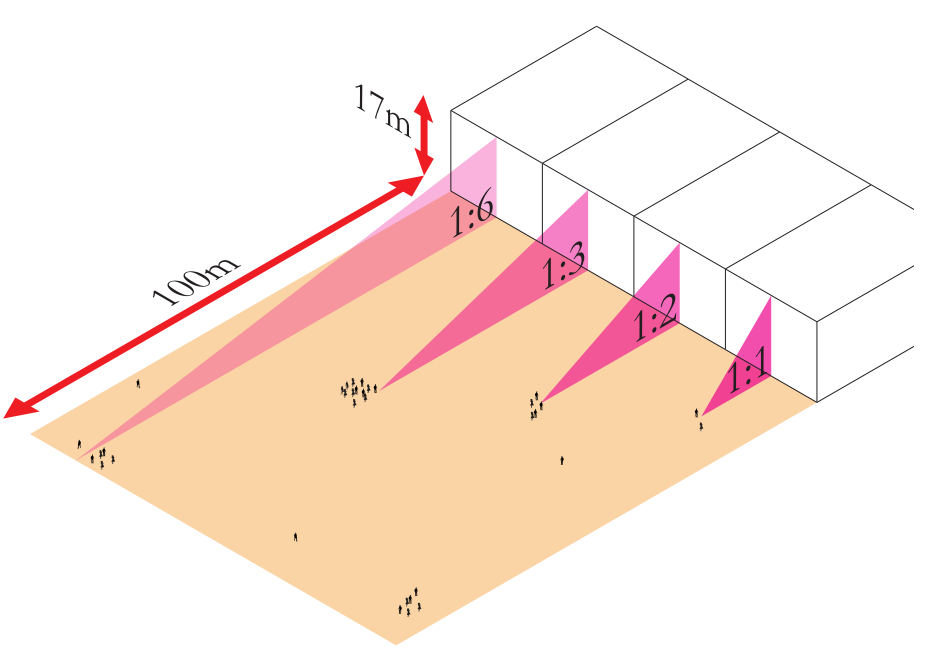

While knowing the ideal proportions for the square is useful, the most important part is that they stay within an overall scale attuned to our sensory experience of the square. As Jan Gehl states "the basic elements of city architecture are movement space and experience space" (32). The street being the movement space and the square being a space we can experience the city and its people.

Gehl has investigated this field of research even further by recommending some absolute maximum sizes for city squares based off our sensory experience of fellow inhabitants within public space as well as buildings. For example he gives a distance of roughly 100 metres as a maximum distance one can make out the shape of a person. Any further than this the actions of that person become indistinguishable, and of course, as they get closer we can make out more detailed actions (Gehl 38). Moughtin also discusses absolute sizes for squares, but gives a larger maximum dimension, of around 135 metres (Moughtin 101).

There are infinite ways in which these rules can be applied and there are successful squares that fall outside of these maximum proportions and sizes. However scale and proportion are only one property of integration, and one that relies on other properties to work overall.

It would be during this period of history when European nations began colonising newly discovered lands. According to Robert Home the rational ideals of the Renaissance and following Baroque movements were highly influential on the urban form of colonial city planning. John W. Reps outlines similar influences and both Reps and Home include the central square as an integral feature of colonial settlements.

British colonial cities such as Philadelphia and Savannah were to solidify the gridiron street pattern in North America and many other colonial settlements. More specifically though these cities harmoniously integrated the central square with the gridiron street pattern.

The main square in Philadelphia, for example, is located in the centre of the plan with four smaller spaces located within the centre of each quarter of the original city plan (figure 10).

Savannah is unique in that, unlike Philadelphia, there is no primary central square. Instead each square is laid out on axis with the gridiron streets pattern in a sequential order (figure 11).

As Savannah expanded the street pattern the sequence of squares was extended as well. "... only in the late twentieth century, when zoning practices and highway planning for the motor car changed the form of urban development, was the pattern of grids and squares abandoned in favour of road hierarchies and peripheral estates" (Home, 23).

While these city plans are rigorously orthogonal, both have well integrated public squares that break up the monotony of the gridiron street patterns. Of further interest is Reps' suggestion that the designer of Philadelphia scaled these squares to a human dimension. The generous streets were of a width that coped with the traffic of the age and the buildings were an appropriate scale to these open spaces (Reps). 
The integration of parks and planting is another unique component of colonial cities. In fact many of Savannah's squares are dominated with planting and could just as easily be classed as small parks.

More distinctive though was the British Green Belt that framed the edge of the city. The realities of pioneering life meant that this land was often contested by other colonising powers, hostility with the native people, or financial pressure to develop the land (Home 15). Nevertheless Adelaide is perhaps the best example of a colonial city that has retained the original Green Belt.

In his book, Reps also mentions the influence that other colonising powers had in integrating the city squares. The Spanish colonists had codified proportions, dimensions and building uses for city squares in the Laws of the Indies. These proportions would ensure that the square would fit with the anticipated size of the city. Furthermore this document prescribed the location of religious and public buildings relative to the square (Reps 29-30).

Despite differences in the way these colonial powers planned their settlements, the English, French and Spanish all integrated a square with the original plans of their settlements.

\section{Modern Public Space}

Cities went through unprecedented change in the 20th century. The industrial revolution bought about advances in building technology and transport that would completely change city form. The Modern movement paved the way forward in this exciting new era in architectural and urban design (Rowe and Koetter). Unfortunately, a hostile attitude towards traditional city form meant many of the integrative properties of the traditional city square were met with indifference as the Modern agenda revolutionised urban form (Favole 10).

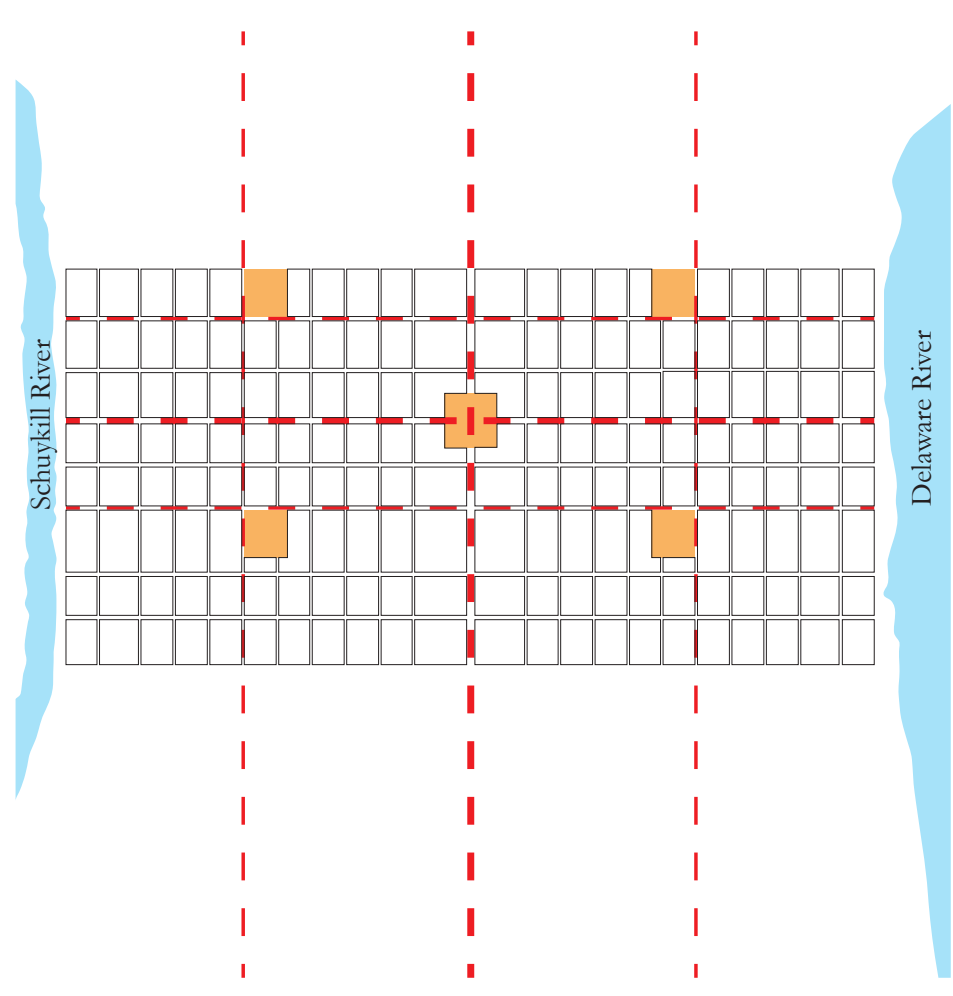

Figure 10. Author's drawing of William Penn's 1682 Plan

for Philadelphia,

Pennsylvania.

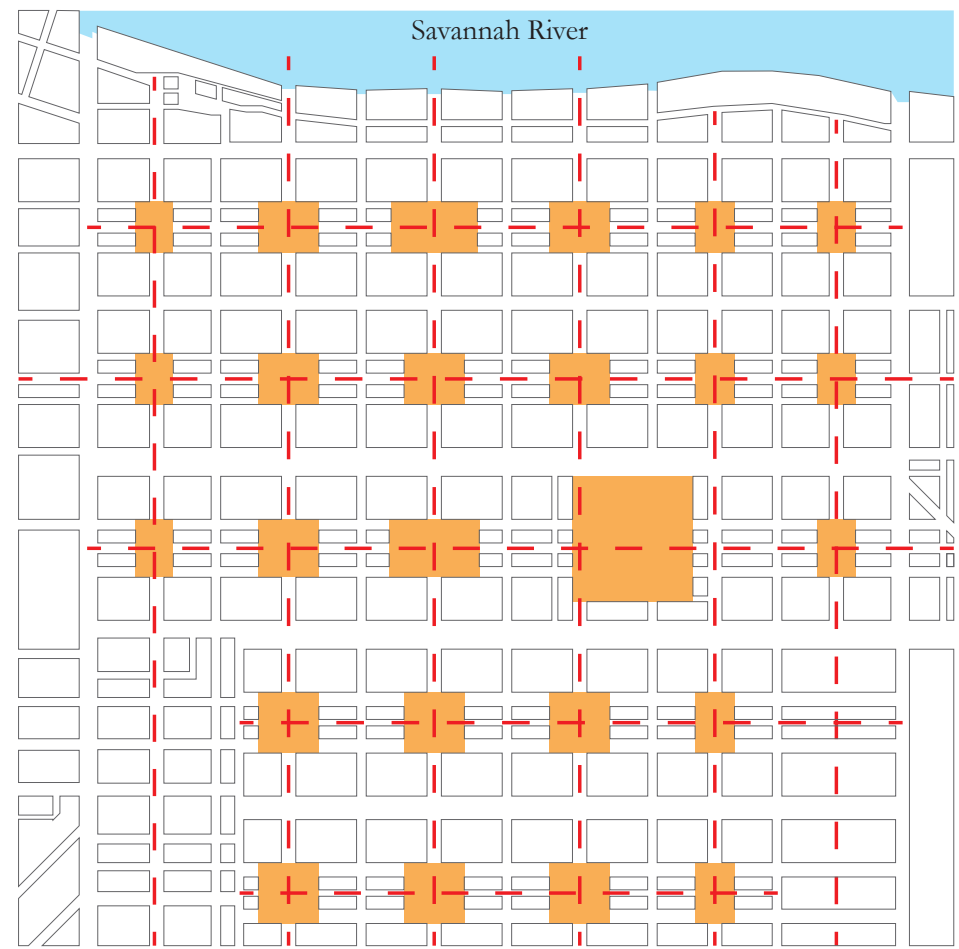

Figure 11. Author's drawing of the 1856 Plan of Savannah, Georgia. 
Figure 12. Le Corbusier's Ville Contemporaine. Source:

Alexander Tzonis,

Le Corbusier The

Poetics of Macbine

and Metaphor. New

York: Universe, 73.
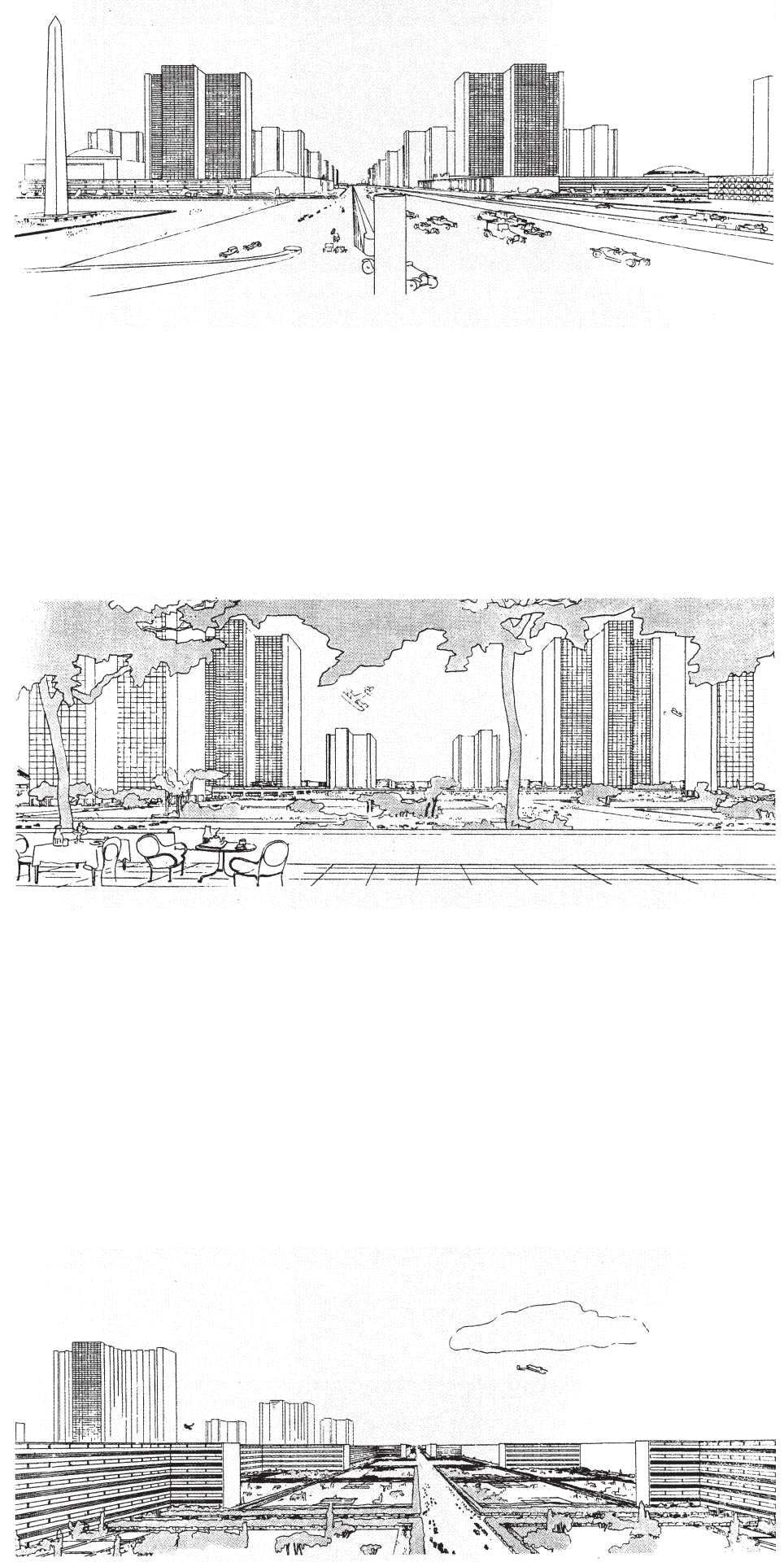


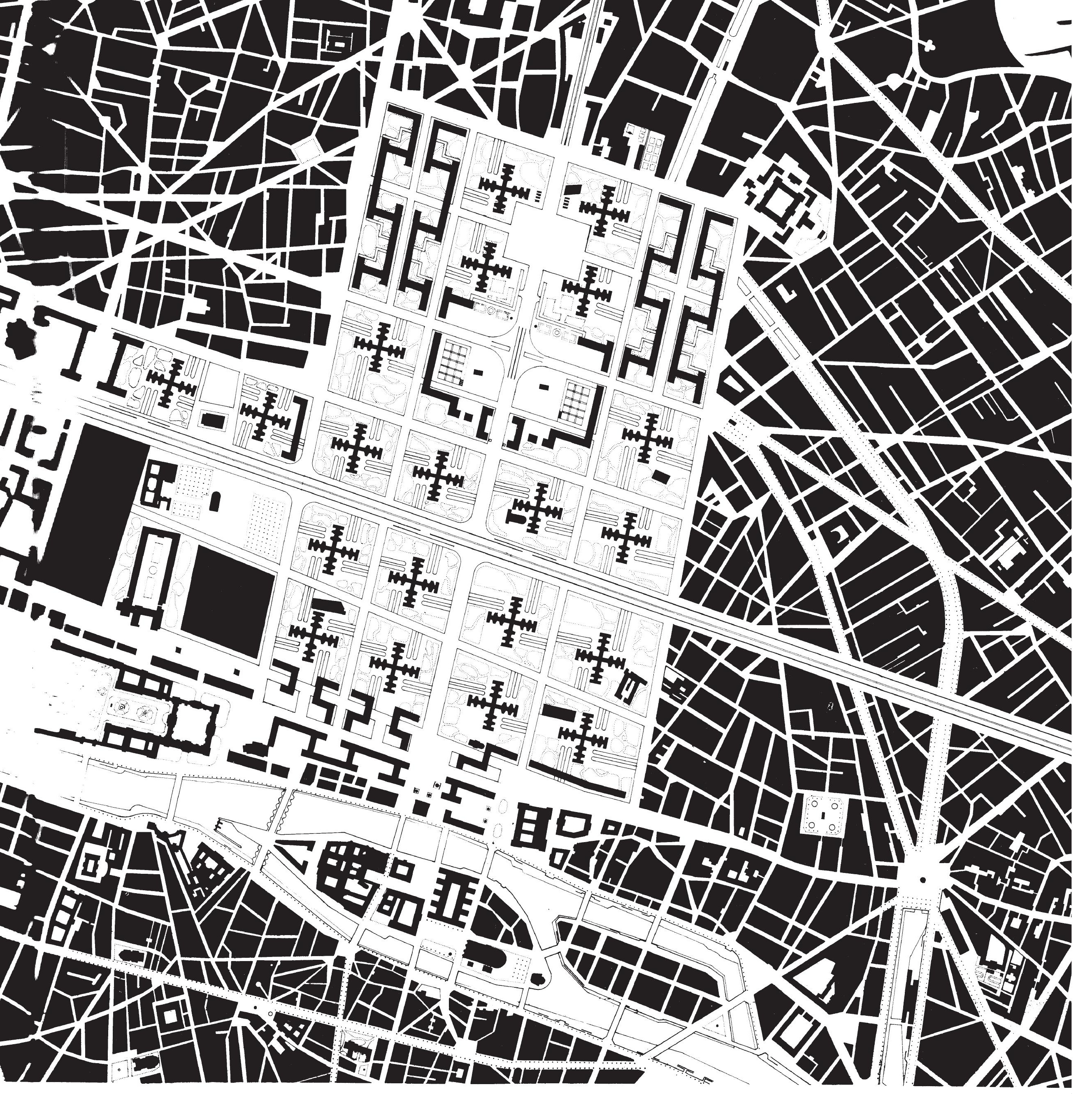


Figure 14. Author's drawing of City National Plaza, Los Angeles showing the continuity of public space.

Figure 15. Author's drawing of City

National Plaza, Los Angeles showing the barriers to the modern field of public space.

Figure 13. (opposite page) Le Cor-

busier's Plan Voisin Paris, 1925. Source: Rowe, Colin \& Fred Koetter, Collage City. Cambridge: MIT, 74-75.

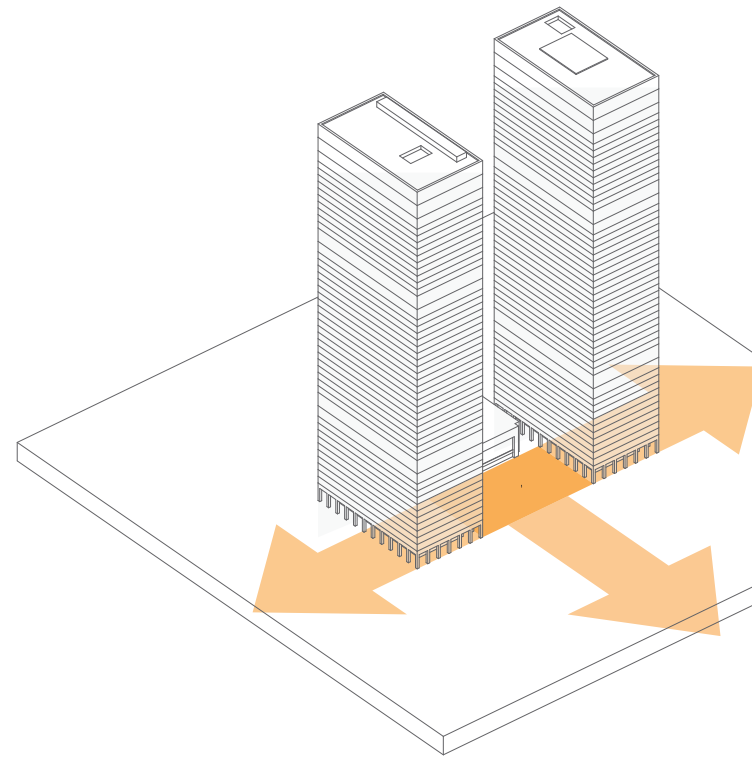

narrow-minded approach by these later modernists toward the design of these tower projects often meant that the public space around them was not as successful as early modernists, such as Corbusier had intended (Rowe and Koetter).

Illustrated in figures 14, 15 and 16 is City National Plaza in Los Angeles. Taking up a whole city block, this project illustrates the manner in which the modern square was integrated with the modernist tower.

The Meis van der Rohe inspired towers make such an overwhelming architectural statement that the square at the base is left as equally underwhelming. As French notes, one can imagine this "shaft of space as both awesome and repelling" (French 46)

The scale of the towers in proportion to the square is something writers such as Sitte could not have imagined. He warned of the ill effects of increasing the scale and proportion leading into the Modern movement, advocating for a harmonious balance between the height of the buildings and the width of the space between them.

The rules of proportion set out by theorists such as Alberti, Sitte and more recently Jan Gehl, are all based around the human experience of the square and surrounding buildings.

Modern squares, such as City National Plaza, lack a sense of human scale that often created unpleasant public space at ground level.

In some cases, increasing size of the buildings meant that the size of the square increased also. In fact a zoning law in New York allowed developers to add ten units of floor area to the top of their building if they gave up one unit of open space at the ground level (Marcus and Francis 17). Marcus and Francis go on to write this incentive was adopted by many developers and claim it led to a mentality were if open space was good, more was better (17).

Arguably this increase in the scale of open space keeps it in proportion with a city expanding both vertically and horizontally at 
its edges. But unfortunately the lack of purpose, and any form of interface between these towers and the square meant that they could not support much activity. And in many cases these over scaled and underutilised squares became less than desirable for human occupation.

There are examples of Modern buildings where the oppressive scale of incredibly tall buildings was addressed. The podium at the base of Lever House in New York created a built edge to the ground level public space that was more attuned to the human senses. It is also interesting to note that this podium was raised to retain a high level of connectivity to the surrounding context at ground level (figure 17).

Modern urban design had essentially shifted the focus from shaping outdoor space to shaping buildings. From the outside, the Modern building increasingly became a self-referencing object.

The unique spatial identity of the square, as formed by the surrounding buildings was not a property of Modern public space. The Corbusieresque concept of piloti, created a continuous flow of open space through the built edge of the square (figure 14). This ill-defined edge condition led to ambiguity in the spatial identity of the square. As Childs states "if the place is not clearly perceived, then the social territory is not easily defined" (Childs 121).

Additionally many of these squares exhibit ambiguity as to whom this space belongs to. In the case of City National Plaza the flow of space into the towers often meant the space between is perceived as belonging to the owner of the towers. The same can be said of Lever House. The lack of spatial identity and ambiguity toward public ownership meant these squares saw little use aside from those entering the associated towers and organised events.

Functionalist planning ideals of the modernist era also affected the activity and use of the square.

The segregation of work and home, with the rise of the suburb

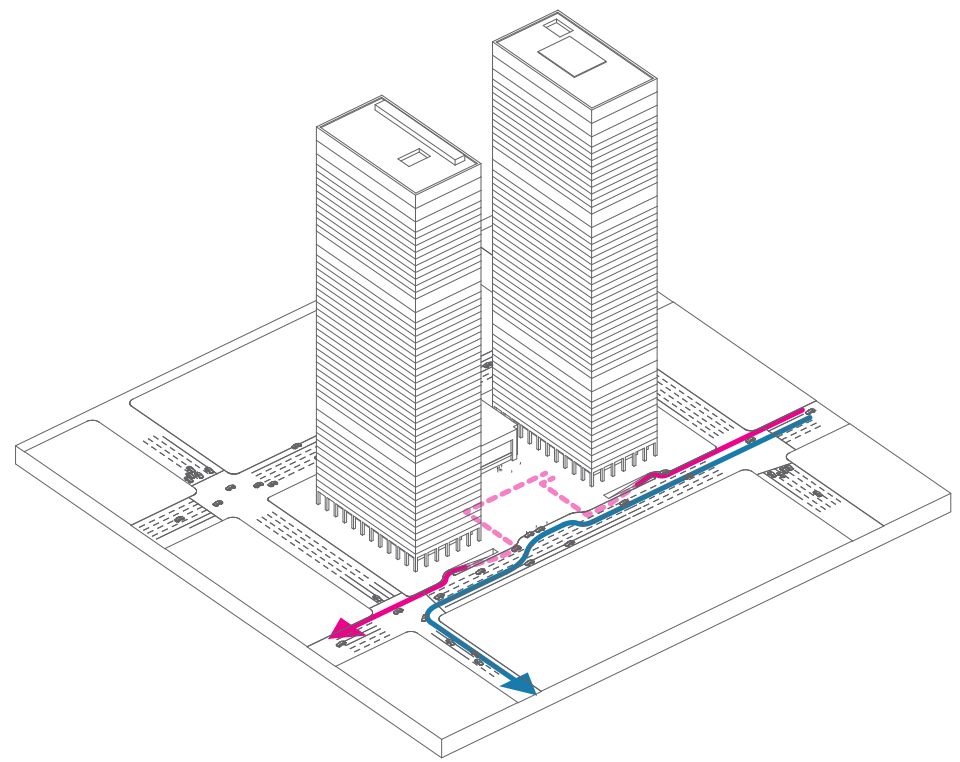

Figure 16. Author's drawing of City National Plaza, Los Angeles showing the integration of vehicular traffic with the square.

Figure 17. Author's drawing of Lever House, New York. The podium integrates the oppressive scale of the tower with the public space at ground level. 
and the further separation of office parks, industrial parks and recreational parks often meant that, unlike the traditional city, the square suffered from a "toxic overdose of single use" (L. Krier 61).

Even where city squares were associated with a building, more often than not these spaces would only be populated with a single user group at certain times. For example, lunch hours and the commute to and from work.

The modernist conception of free flow space not only allowed for unhindered pedestrian movement, but also integrated the freedom of movement afforded by the automobile.

No other single invention has changed the form of the city as significantly as the car has. Logistically the space required to operate and store them meant the modernist field of public space was quickly overrun with urban highways and car parks.

Although the automobile was an integral part of the Modern movement, they took priority over public space as urban design became more about integrating the car than designing for people (Gehl).

Even where plazas and squares were incorporated into a buildings design, they were often framed on one or more sides by roads, which physically isolated the square from the surrounding buildings and created less than desirable pedestrian connections (see figure 15).

The implications for the square were lack of people and activity, and an increased scale due to roads not providing the same level of enclosure as buildings.

The automobile has had detrimental effects on the human experience, quality and scale of the square. However it is an integral part of the sprawling contemporary city. The opportunity now lies in finding ways to better integrate more public forms of transport with the city square.

\section{Reforming the Square}

This subsection concludes the historical overview on the integration of the city square. Attention now focuses on the reform in urban design practices in response to the demerits of Modernist Urbanism. Specifically regarding the city square and how contemporary design theory proposes to reintegrate the square with the contemporary city.

Summarised below are the main factors that have led to many squares becoming disconnected from the contemporary city:

Single functions and single user groups mean that many squares lack continuous use and vitality.

Introverted buildings limit the relationship between the square and the built form.

The modernist idiom of public space as a ubiquitous field extending around and through freestanding buildings lacked identity within the urban context.

This field of free flow space often led to ambiguity in ownership and raises questions as to how public this public space is.

Prioritisation of vehicular connections fragmented urban form and isolated the square.

Increased scale and disproportion between the square and the built edge made these spaces undesirable to occupy.

Separation of buildings, increased scale and an un-cohesive built edge led to the square lacking spatial identity and containment.

The spatial consequences of Modern urban planning were ap- 


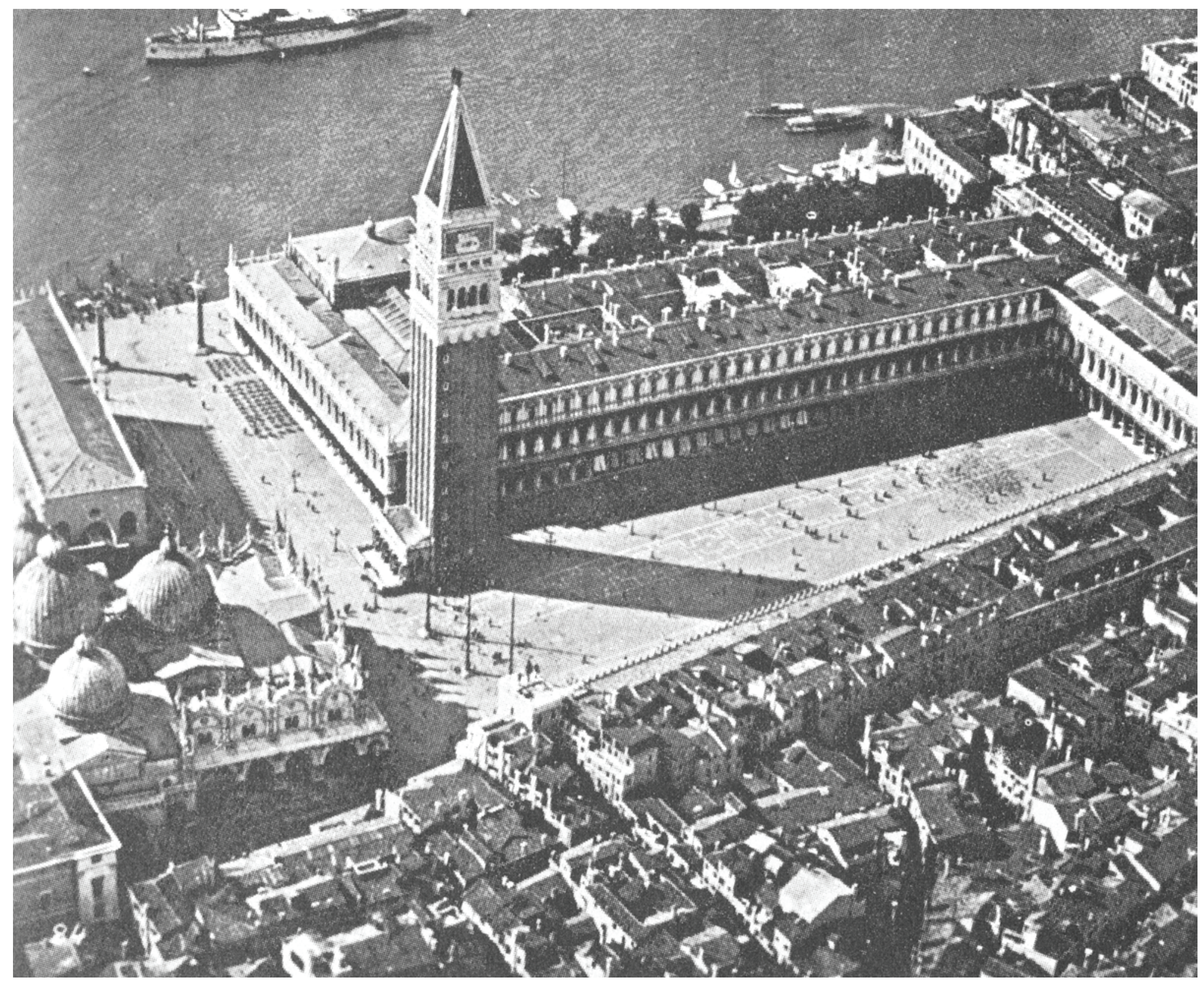

Figure 18. Piazza San Marco, Italy Source: Lynch, Kevin, The Image of the City. Cambridge: MIT, 79. 
parent, but during the 1960's people began to identify the social deficiencies in Modern public space. Mulgrave and Goodman are highly critical of modernism citing that it was generally accepted that it had failed as it did not "connect or communicate with people" (Mulgrave and Goodman, 37).

During the 1960's authors including Jane Jacobs, Jan Gehl and Kevin Lynch among others, published some of the most influential texts on this, then, emerging field of urban design.

These authors approached urban design with a strong social agenda.

While it is important to note that social interaction was part of the modernist agenda, both Jacobs and Gehl argue that the modernist urban form simply did not support this interaction. This prompted Gehl and others into years of extensive studies into urban form and the effect it has on our social and behavioural actions. The studies often concluded that traditional urban form was much more effective in fostering positive social interaction.

Jacobs argues that it was this idea, that the social interaction could be planned for in the design, was where modernism had gone wrong. She cited many instances of well-designed Modern public space, but attested that if they could not support continuous public use and spontaneous social interaction, then they failed as a place (Jacobs).

Throughout the following decades a large body of knowledge was built up around what is now known as the Place Making tradition.

"synthesising the earlier traditions, contemporary urban design is simultaneously concerned with the design of urban space as an aesthetic entity and as a behavioural setting. It focuses on the diversity and activity which help to create successful urban places, and, in particular, on how well the physical milieu supports the functions and activities taking place there" (Carmona et al 7).
The Place Making tradition recounts many of the properties inherent within the traditional city square, although it interrogates the relationship between built form, peoples behaviour, and our experience of public space far more thoroughly.

Jacobs wrote prolifically on how building use can support the activities that take place in the public realm. In particular she describes how important residential buildings can be to the life of the street. Concepts such as eyes on the street have become key considerations in urban design practice today. And although she wrote of these concepts in the context of the city street, these concepts are still applicable to the city square none the less.

Lynch is also of note here, as he theorised our spatial conception of the urban environment - our Image of the City. Lynche's concept of imageability is helpful as it theorises the physical attributes that help us perceive spaces such as the square (or nodes as he refers to them) as having a unique spatial identity (72).

Many of the attributes Lynch describes as important to a node's identity are similar to those of the traditional square: enclosure of space, strong figural form, concentration of active building uses, as well as landmark buildings (78) (see figure 18). But more specific to integration he also states that the intersection of major paths and public transit hubs are also strongly perceived as nodes.

The Place Making tradition has given rise to a range of urban design protocols that encompass the work of these early urban design reformists. Of these, New Urbanism has emerged as the most dominant with the most integrative agenda. 


\section{New Urbanism and the Square}

New Urbanism has emerged as the most influential and widely adopted of the contemporary urban design frameworks. The Congress for the New Urbanism has set out some "truly utopian goals" (Kelbaugh, "Toward an Integrated Paradigm" 13) that address much more than just the shortcomings of the preceding modern movement. The movement has an inherently integrative agenda, which seeks to create high density, mixed use, age, race and income development and public space. These compact developments are connected primarily on a local scale with highly pedestrianised public space and integrate a robust public transit system (Congress for the New Urbanism).

The movement employs neo-traditional and context-sensitive forms to recreate an urban landscape that supports traditional social interaction and the re-establishment of community (Kelbaugh, "Toward an Integrated Paradigm" 16).

In terms of the city square, it supports the property of identity through the continuous built edge and human scale and proportion, as well as incorporating mixed-use buildings to support continuous use and bring vitality to public spaces (Congress for the New Urbanism).

The principle of mixed-use development is particularly helpful in creating diversity of use within the square. Not only does it address the fragmentation of uses evident in the contemporary city, but also it brings vitality and purpose to the contemporary square. Rob Krier makes the point that a contemporary square cannot be compared with those of the past until they have been "endowed with meaningful functions" (R. Krier 19). He goes on to name a number of uses, from commercial to cultural to residential, stating that it is particularly important for contemporary central city squares to generate twenty-four hour use and activity.

Connectivity at a range of scales is another important property of integration. New Urbanism promotes pedestrian, bicycle and public transport over the use of private vehicles. So much so that it has developed its own model of Transit Oriented urban 
Design or TOD. Gehl explains that the purpose of TOD is to create highly connected, pedestrian and bicycle friendly transit hubs within city centres. These are integrated with central city squares amongst other forms of public space to generate activity and reconnect pedestrian paths while at the same time retaining connections with the contemporary city's sprawling fringe. Gehl sums up this integrative approach to urban transit by stating that "a good city landscape and good public transportation system are two sides of the same coin" (107).

Additionally it is important to note that the charter of New Urbanism does not deny the realities of automobile use within the contemporary city. The Congress for the New Urbanism state that it should be integrated in ways that will "respect the pedestrian and the form of public space".

Drawing from the work of Lynch and Gehl, New Urbanism has adopted the traditional concept of identity through the enclosure of space. Many central city projects seek to infill open space not only to create higher densities, but also to recreate continuous built edges for streets and squares.

Human scale and proportion are also important properties adopted from traditional European cities and theorists. These are especially important in creating a pleasant physical environment to encourage more pedestrian activity in and around the contemporary city square.

Drawing from the past, New Urbanism hopes to create better urban environments, and more specifically, integrated public squares. Seeking to fulfil this goal by employing many of the properties inherent in European squares identified in the historical overview.

New Urbanism offers a set of design principles that can be readily employed to design a more integrated central city square. However, it is not the intention of this thesis to design a New Urbanist city square, but to question the extent as to which it can contribute to integrating the central city square with the contemporary city.
New Urbanism is not without its critics, Marcus and Francis going as far as comparing its utopian vision to that of Corbusier's Ville Contemporaine. Arguing that like modernism, New Urbanism offers an attractive solution to the shortcomings of the contemporary city. But as Kelbaugh writes, it is questionable whether this historically based utopian vision can really offer better solutions for integrating the city square "in light of modern lifestyles and technology, especially digital media" "“Toward an Integrated Paradigm" 16).

The New Urbanist movement often imposes an urban structure that fosters more traditional social values such as face-to-face interaction and an equitable community (Kelbaugh, "Toward an Integrated Paradigm" 13). Public spaces such as the square being the physical environment that is supposed to support this community interaction. Whether the New Urbanist approach can be fully realised amongst the realities of the contemporary city form and contemporary lifestyles remains to be seen.

Many of the principles are highly historically derivative especially in relation to architectural form. The Congress for New Urbanism state the integration of individual architectural projects with context will "transcend style". While this may leave the architect free to develop facades and "refine details and forms rather than overhaul and reinvent them" (Kelbaugh "Toward an Integrated Paradigm" 16) it is fair to say that the built outcomes do not always impress or inspire in the way early Modernist towers had done or contemporary avant-garde projects do today.

It must also be noted that simply emulating European urban forms in the design of contemporary squares is fraught with issues. Different lifestyles, climate and traditions of city living and occupation mean that in many cases it is debatable, despite the physical environment supporting it, that these spaces will be adopted in the same manner internationally (Marcus and Francis 15). 


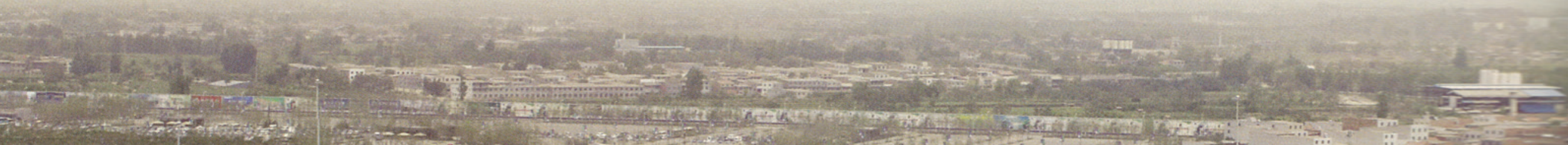

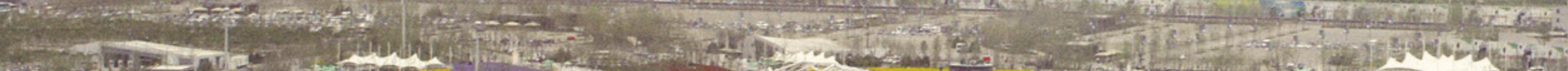

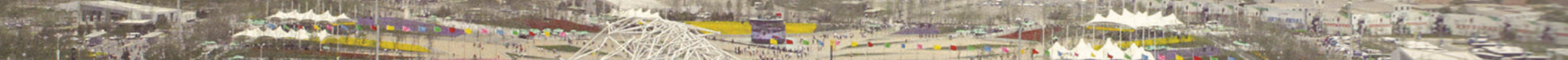

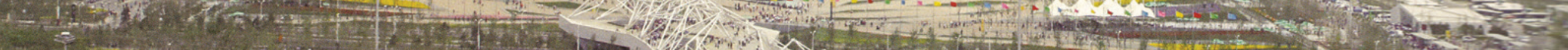
1.5.

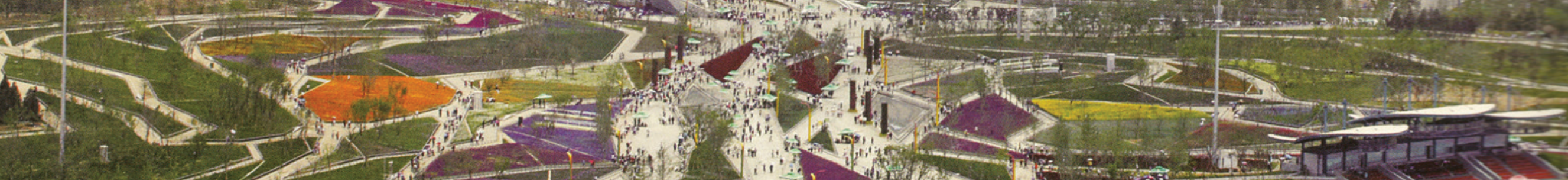

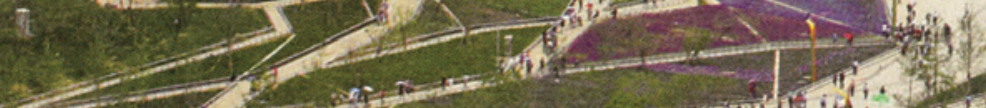

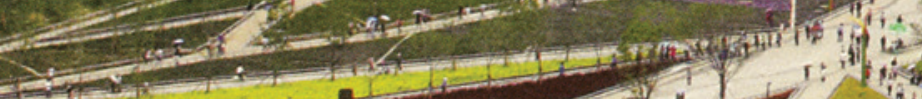

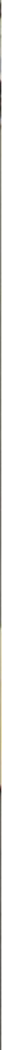




\section{Post Urbanism and the Square}

Figure 19. Flowing Gardens and Exhibition Hall, Xi'an,

China. Source:

Palma, Cristobal.

"Flowing Gardens."

Photograph. de

Muynck, Bert. "The

Xi'an Trident."

Domus. 949 (2011):

24.
Equally, if not more contemporary than New Urbanism, is Post Urbanism. A term coined by Kelbaugh, these highly antagonistic architectural projects are often seen as anti-urban, often separated from context rather than integrated. Kelbaugh describes this movement as "inspired to some extent by the city we are in" going on to state their projects:

\begin{abstract}
"welcome disconnected hypermodern buildings and shopping mall urbanism. They are also heterotopic because they discount shared values or metanarratives as no longer possible in a fragmenting world composed of isolated zones of the 'other' (e.g. the home- less, the poor, gays, militia, prisoners, minorities, etc.) as well as mainstream zones of atom-istic consumers, internet surfers, and free-range tourists" ("Three Urbanisms", 2).
\end{abstract}

Unlike New Urbanism, which looks to the past for inspiration, Post Urbanism is very much based in contemporary society.

Championed by architects and authors such as Zaha Hadid, Daniel Libeskind, Steven Holl and Rem Koolhaas, their avantgarde architectural and public space projects are somewhat selective in the way they are integrated into the contemporary city. For example where New Urbanism has a highly contextual approach to integrating public space, the free flowing, fractal, and folded building forms and landscapes characteristic of the Post Urbanist project are formed through "a series of more complex and precise choices that ... bring the actual context into focus" (Koolhaas and Mau 285). It is intentionally ambiguous statements like this that allow many Post Urbanist projects such unbounded freedom in the design of buildings and public space.

While this anti-contextual movement might seem indifferent toward traditional urban forms such as the city square, there are integrative properties emerging from this approach to urbanism that are invaluable in making the city square an integral part of the contemporary city. 
Nan Ellin's book entitled Integral Urbanism describes the more integrative properties of the Post Urbanist agenda and takes many of the properties of New Urbanist integration, such as identity, mixed use, pedestrian and public transit connectivity, and pushes them beyond their neo-traditional forms.

Ellin's book is based primarily around her five qualities of integral urbanism:

\section{Hybridity \\ Connectivity}

Porosity

Authenticity

Vulnerability

Of the most relevant to the physical integration of the square are hybridity, connectivity and porosity. "Hybridity and connectivity are about bringing activities and people together at all scales (from local to global). Porosity is about the nature of the relationships between these" (Ellin 136).

As Fraser Shields identifies in his thesis, these qualities are the most relevant to the "relationship between buildings and open space" (Shields 13) or the city square in the case of this thesis.

Hybrid use is especially helpful as it aligns with the New Urbanist principle of mixed-use buildings and mixed-use public space. However, while New Urbanism is content in mixing historically established uses in historically derived forms, the Post Urbanist project sees opportunity in mixing uses to develop new forms and spaces, a process that Koolhaas describes as "programmatic alchemy" (qtd. in Mallgrave and Goodman 185). The outcome for both however is to foster continual use and vitality of urban space.

Hybridity extends beyond the mix of uses and encompasses the spatial integration of the natural landscape and architecture.

The traditional square is characterised as an area of hard landscaping framed by buildings with a definite identity and hierar-
Building

Landscape

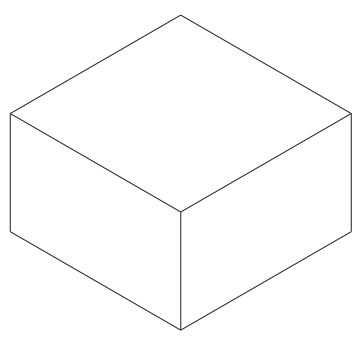

Figure 20. Author's diagram showing the Post Urbanist integration of the natural landscape.

Topography

City Square
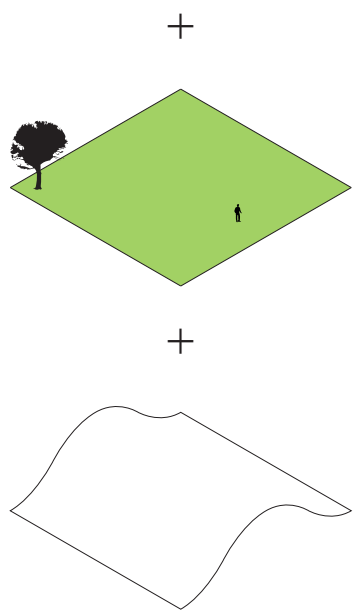

$+$

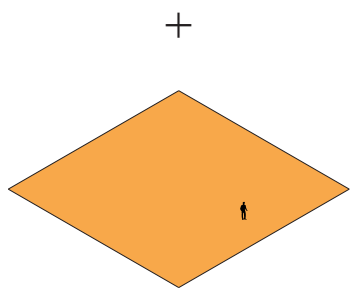

$=$

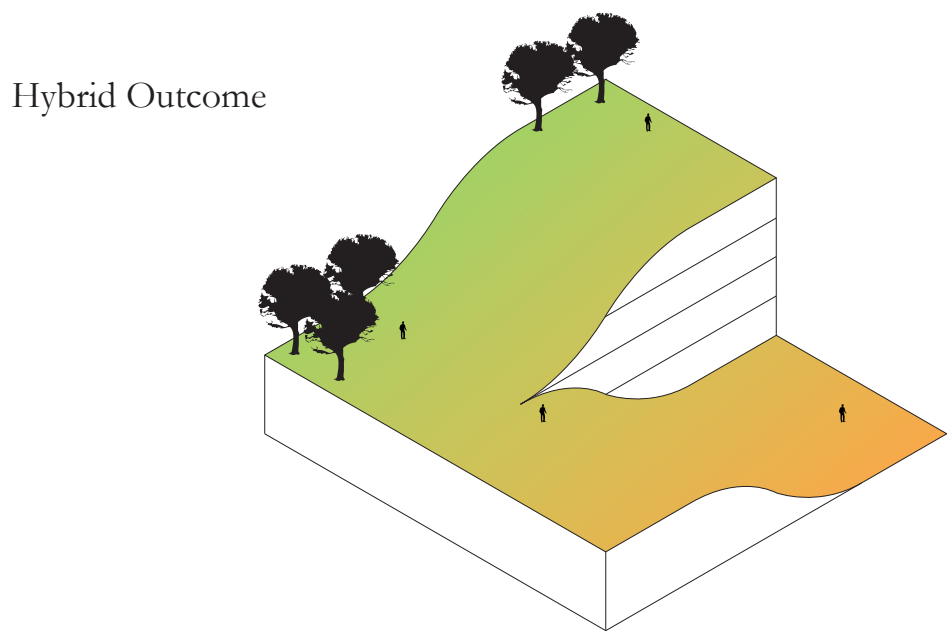


chy of space. For many this is a defining feature of the square that separates it from other urban spaces, such as the park (Marcus and Francis). However, the integration of natural landscape and urban space, including the square, is increasingly becoming a common feature of the contemporary city.

Nan Ellin points out that "design with nature" is not a recent occurrence, but something that designers have been getting better at throughout the twentieth century (75).

This integration of natural landscape with architectural and urban form is not unlike the works of Le Corbusier with his buildings in Ville Contemporaine being placed on pilotis. Although this brought landscape, architecture and Modern urban form together there is still a clear vertical separation of the two.

The Post Urbanist project seeks to take the integration of the natural landscape and architecture to a level where there is total ambiguity between the two (see figure 20).

Fraser Shields, in his thesis, describes how these projects will sometimes take this integration "to the extreme", going on to say that they often completely "blur the boundaries between ar-

Figure 21. Time Square Redux. Source: Ingels, Bjarke et al. "Time Square Redux." Illustration. BIG. n.p. Web. 18 Feb. 2013.

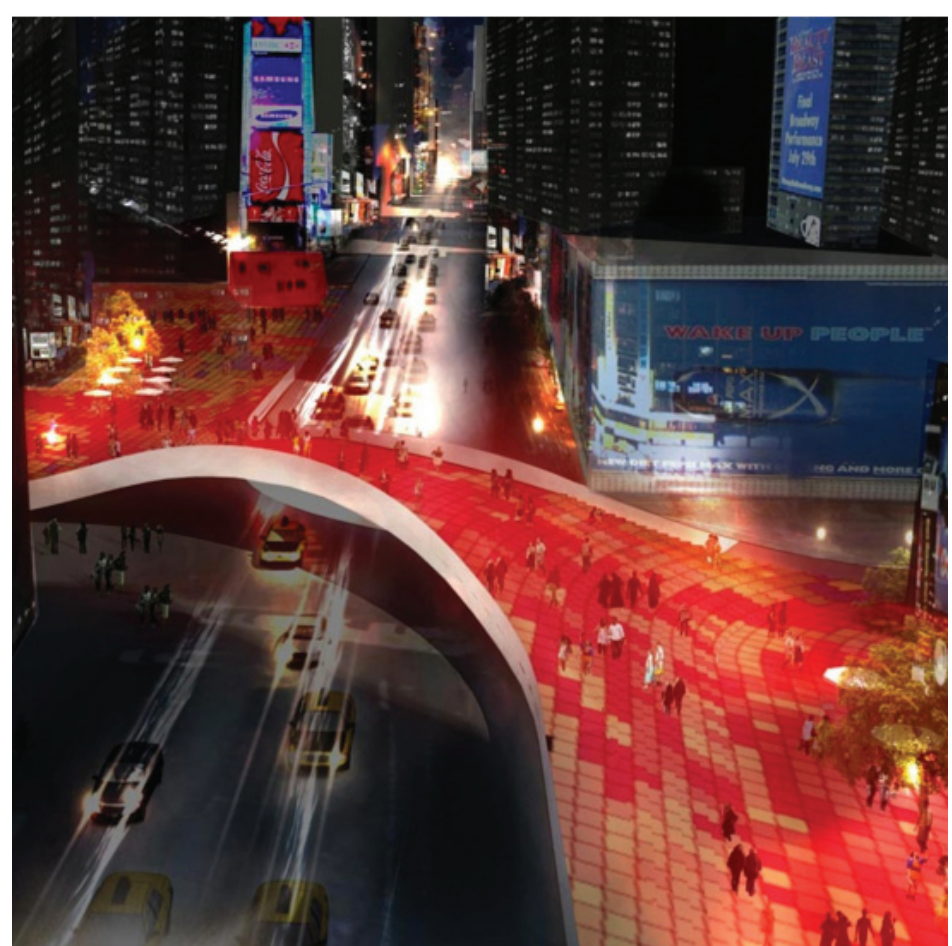

chitecture and landscape" (Shields 15).

Various terms have been invented to describe this property of Post-Urbanism. Koolhaas refers to it as "SCAPE", the combining both built form and landscape (qtd. in Ellin 54).

According to Steven Holl this integration of landscape and architecture extends to urban landform as well. Describing it as a situation where urban forms (both public space and architecture) merge with natural, topographical landscapes to create an urban "topology" (Holl 37).

Putting these terms aside, the Post Urbanist project has a clear intention to create ambiguity at the interface of public space and architecture, blending figure with ground in a way that upsets the figural qualities of the square as well as spatial hierarchy and identity. However, at the expense of traditional square geometry, the Post Urbanist square achieves a much more radical integration of natural landscape, urban landscape and architecture.

Both New Urbanism and Post Urbanism have the mutual goal of creating connections as part of integrating public space but, the scale of this connectivity differs immensely.

New Urbanism's promotion of high-density centrality and prioritised pedestrian connections inevitably puts it at odds with the needs of contemporary vehicular transit. Nevertheless there are methods to successfully integrate the two, albeit with some sacrifice on the part of traffic planners.

The Post Urbanist approach to integrating pedestrian, vehicular connections often proposes to do so without compromise.

There are many examples of Post Urbanist projects that integrate both pedestrian and vehicular flows with topological forms. Projects by the Bjarke Ingels Group use connectivity, both pedestrian and vehicular, in generating form. Most notably would be a concept design developed for New York's Times Square (figure 21). This design proposes to unify and connect the isolated parts of Times Square with a bridge over the flow of traffic that divides them. This concept creates pedestrian con- 
nections and retains vehicular connections by vertically dividing the two, with a porous architectural form that integrates both.

Other Post Urbanists, such as Koolhaas, are more content in designing buildings that are better integrated with contemporary automobile dependant urbanism. Where larger scales of connectivity are prioritised. Koolhaas' description of Atlanta City is enlightening on this property as he states that it has no resemblance to the traditional city. This sparsely populated city has no sense of centrality, at least not when you consider it in the context of its airport (Koolhaas and Mau 835).

"Its strongest contextual givens are vegetal and infrastructural: forest and roads. Atlanta is not a city; it is a landscape" (Koolhaas 835). Koolhaas' investigations into Atlanta City are interesting, as even though we have already discussed how over investment in vehicular connectivity can have a negative effect on the square, Koolhaas argues that it is important that the contemporary cities be connected at both local and global scales in a world of increasingly internationally mobile people. From a Post Urbanist's perspective it is important that the square retains large-scale connections with the more dispersed functions of the contemporary city, such as airports and shopping mall districts.

Porosity, as already noted, "is about the nature of the relationship between" hybridity and connectivity (Ellin 136). Looking at Holl's World Design Park Complex project (figure 22) we can see that this project literally has a porous building skin that allows for the plantings within the public space to be "weaved" together (Holl 37).

The traditional and neo-traditional square favours the creation of identity through enclosure and definite edges with a strong adherence to Cartesian space. The Post Urbanist project seeks to create identity through dramatic forms, skins and "folds". This last item of folding is where contemporary urban form differs from the traditional "framing" of public space (Ellin 14). The articulation of the ground plane into over and around

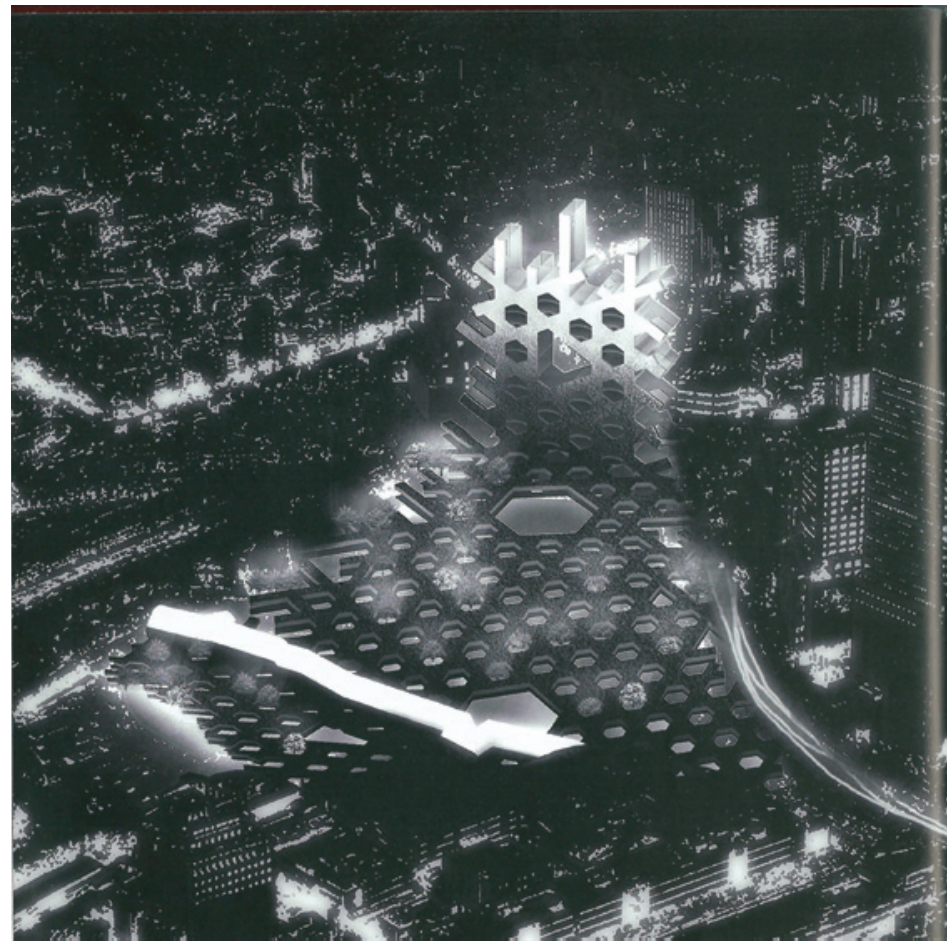

Figure 22. Steven Holl's World Design Park Complex,

Seoul, Korea. Source: Holl, Steven, Urbanisms, Working with Doubt New York: Princeton Architectural, 36. buildings integrates the landscape of the square with the building. In doing so, the constructed landscape becomes integral to the building, unifying their formal and spatial identity.

Porosity is particularly important in creating connections and integrating movement networks. Holl writes about urban porosity in terms of pedestrian connectivity. Describing it as the "experiential phenomena of spatial sequences with, around, and between which emotions are triggered" (Holl 22). He goes on to describe how we experience the urban environment in partial views dictated by the built form, and the movement of the pedestrian.

Nan Ellin also writes about how these partial views and movements can be altered and informed through porous architectural design. These experiential qualities of urban space are similar to Sitte's artistic descriptions of urbanism. Much of his book discusses the visual and spatial delight we get from the narrow entrances to a square, the revelation as we move through sequences of squares, and the visual delight of non-orthogonal geometries of the medieval square. 


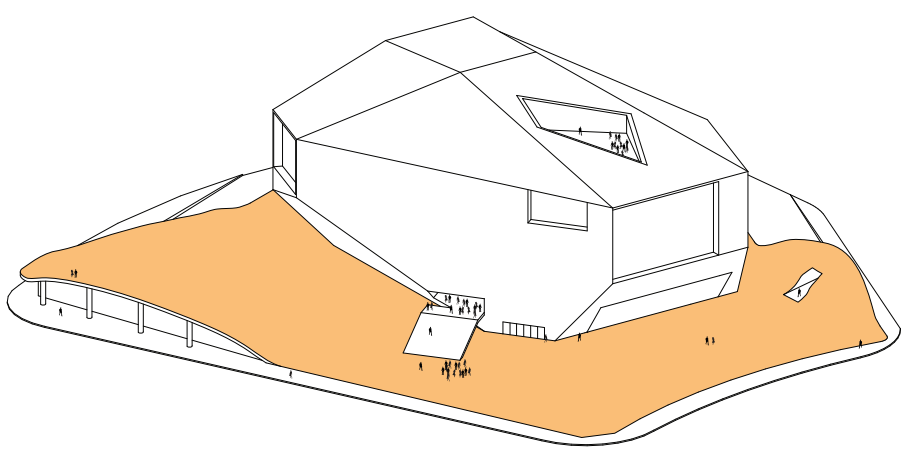

The point of interest here is that both New Urbanism and Post Urbanism are trying to articulate public space to create a unique spatial experience and identity, or imageability as Lynch calls it. But the concept of porous forms creates more integrated public spaces where dramatic architectural forms not only enhance the experience and identity of the space between buildings, but allow other properties to be integrated such as natural landscapes and pedestrian connectivity.

In many cases, despite the integrative agenda of Post Urbanism, trying to create too many connections on too many levels often mean that scale and proportion are neglected.

Integrating both car and pedestrian is an example of where a conflict of scales occurs. Experiencing architecture from a moving car and as a pedestrian requires different levels of detail, scale and proportions. In many cases, despite its fractal forms and dramatic geometry, the Post Urbanist project still excludes the pedestrian by employing a scale outside of the human comfort zone.
Koolhaas' Casa de Musica (figure 23) is an example similar the Arco towers used earlier. Both are object-like (Casa de Musica provocatively so) buildings in the centre of a street bounded city block. However, unlike the city national plaza, the manipulated ground plane around the Casa de Musica begins to play with the scale and the sense of enclosure. For example, the ground is raised enough in two corners to create a canopy over the footpath with an active street front. Additionally the other side of the mound creates a (albeit vague) sense of enclosed space between the main building and the street. Regardless of whether this was the intention, the point is that the freedom of form making afforded by the Post Urbanist approach means that there are opportunities to manipulate buildings and landscapes to be more palatable to the human sense of scale. 
The main findings identified in this chapter are that the city square developed throughout history as an integrated piece of the central city urban environment. Along with streets and buildings, it is a unique and primary piece of urban form.

Throughout the 20th century the square was transformed in response to the shortcomings of traditional city form and the needs of the new and exciting Modern movement.

While Modernism addressed the need for healthier cities better suited to modern living, the city square suffered as a result. Other factors that contributed to the decline in the quality of the square were diminished practical and recreational use of the square, increased scale and disproportion to buildings, ambigu-

\section{Toward an Integrated City Square} ity in ownership, dominant vehicular routes leading to poor pedestrian connectivity and isolation of the square.

These are the conditions that we find many city squares in today, disconnected open spaces lacking many of the properties that made them an integral part of the traditional city.

Most importantly, this chapter found that there are two contemporary strains of thought that seek to remedy this issue. Both have an integrative agenda, although the anticipated formal outcomes differ greatly.

New Urbanism is the most historically derivative of the two. It ultimately seeks to reintegrate the city square as a meaningful part of the contemporary urban fabric, by employing traditional integrative properties of urban design. These were identified as identity through enclosure, human scale and proportion, connections primarily pedestrian and public transit, and integration of building uses that activate the square as both a recreational and functional element of the contemporary city.

It was also found that New Urbanism is often criticised for being too historically derivative. The neo traditional building forms, as well as the spatial form of the square, can often stifle architectural creativity. And it is questionable whether this nostalgic approach to urban design can truly work in the contemporary city. 
Post Urbanism has an equally integrative agenda. Although as Kalbaugh's articles suggest: if New Urbanism is exceedingly nostalgic, Post Urbanism is perhaps overly optimistic of the future. The avant-garde nature of the free flowing, folded and fractal forms of this movement are often criticised as being anti-contextual - disconnected rather than integrated. However three qualities were identified from Ellins book Integral Urbanism - hybridity, connectivity and porosity. These properties reveal the more integrative side to the Post Urbanist project.

Interestingly the integrative properties of both New Urbanism and Post Urbanism overlap.

For example, hybrid building use and mixed building use are more or less the same thing. Connectivity is another although there are disparities as to the level of connectivity.

Perhaps the most interesting finding was that hybridity, along with porosity, encompasses the mixing of architectural and natural landforms. Creating topological urban forms that not only integrate the natural landscape, but aid in integrating other aspects of the contemporary city square.

In moving forward it is helpful to summarise the findings of this chapter in a set of integrative design properties that can assist the design case study chapter. These are derived from both New Urbanism and Post Urbanism under the presumption that New Urbanist design principles alone may not, in fact, produce an integrated contemporary square.

These properties then are derived based on the work of Rowe and Koetter who suggest we need to conceive of urban design as a "collage . . . because collage is a method deriving its virtue from its irony, because it seems to be a technique for using things and simultaneously disbelieving in them" (Rowe and Koetter 149). A useful approach to design when the intention of this thesis is to remain critical of New Urbanism, but also test, through design, how helpful it can be.
Briefly outlined below are the five properties of integration derived from this chapter. These will be used to inform the design case studies.

\section{Scale and Proportion}

Scale and proportion are two basic properties of architectural and urban design. It is included here largely in response to the ever-increasing scale of the city over the last century and the negative affect this has had on the quality of the square. Particularly in terms of people's use and spatial experience. Derived primarily from New Urbanism, these properties are vital toward the contextual integration of the square and preserving a sense of spatial identity.

\section{Identity}

Identity is not unlike Lynche's concept of imageability. This property is closely related to built form and is about the unique spatial experience of the square. This property is drawn primarily from New Urbanism as it is historically derived urban form that is most attributed with the creation of spatial identity. Although, the Post Urbanist principles of porosity and the free flowing building/landform can also be helpful in creating a sense of spatial identity. In addition to the idea that these free flowing forms can be beneficial to integrating other properties, creating better overall integration.

\section{Use}

Building use is important to the integration of the square as throughout history the use of the surrounding buildings have had a direct impact on the use of the square.

Both New Urbanism and Post Urbanism recognise the fact that 
combinations of building uses can have a positive effect on the vitality and integration of public space with buildings. Of particular note is the importance of integrating public buildings with the square, the main library or town hall for example.

\section{Connectivity}

Connectivity is of course essential to the integration of the city square. Both New Urbanism and Post Urbanism share this property, but the way in which it is addressed differs.

New Urbanism is hierarchical in its approach. From dedicated pedestrian only zones and streets, to shared zones of varying pedestrian/vehicular prioritisation. There is also a particular emphasis on integrating public transit with public space and reducing auto dependency.

Post Urbanism on the other hand can be seen to embrace the automobile culture. Connections at all scales from pedestrian paths to freeways are designed and integrated to preserve their "flows". Topological and porous architectures are used to create raised walkways, tunnels or subterranean roads that integrate different flows on multiple levels.

\section{Natural Landscape}

Natural landscape is a property derived from both New Urbanism and Post Urbanism. In includes the environmentally conscious integration of green roofs and natural storm water drainage associated with the New Urbanist project. As well as the renewed interest in integrating the natural features of the city with public space such as water fronts and parks.

Most notably though, this property also includes the integration of the natural landscape as a driver for architectural and urban form or topological urban form.

Over all is important to remember that for better overall integra- tion, these properties cannot be considered individually. Similar to the finding of the following precedent design chapter, over investment of one property may in fact be harmful to another. For example an overly connected square might have an ambiguous spatial identity. Or large areas of topological landforms may have too larger a scale which alienates human occupants.

Whatever the case, it is important to remember that better overall integration relies on finding the right balance. 


\section{Chaperer 3 \\ Precedent Case Studies}




\section{Introduction}

The previous chapter discussed the historical and theoretical background in relation to the city square.

This chapter looks at how recent built examples of city squares have been integrated with the contemporary city. This will help gain an insight into how these squares are physically integrated into the city fabric and bridge the gap between the theory, and reality, of integrating the city square.

This chapter is primarily graphic, with each precedent being reproduced in a figure ground plan. Five selected attributes are then mapped over this plan to determine the level of integration the square has with each of them. The attributes are: Street Pattern, Public Transit Routes, Landscape Features, Soft Building Edges and Hierarchy of Space.

The figure ground drawings are a well established technique in urban analysis however, they do privilege plan based information. While some of the analysis is based on three dimensional information (for example soft built edges and hierarchy of space) it is reproduced here in plan view for the ease of comparison.

The concluding diagrams to this chapter begin to present the information in three dimensions. However, it is the design case study chapter where these three dimensional concepts are more fully explored.

It must be noted that this portion of the research was carried out before the background chapter was written. In doing so more targeted reading of the theoretical material was possible. Additionally, as a way into this architectural/urban thesis, it ensured the focus would remain on the physical properties of integration. Finally, it has to be noted that this portion of the research was largely completed before the introduction of New Urbanism into the research. Therefore this chapter is primarily focussed on the integration of contemporary city squares. 


\section{Methodology}

This graphic analysis was modelled on three authors: Great Public Squares by Robert F Gatje, To Scale by Eric J Jenkins, and Kelly Clarke's Thesis, Hidden Territories.

Each use scaled figure ground plans to compare the physical attributes of different city squares. The exception is Kelly Clarke's Thesis which investigated New Zealand secondary schools. In addition to the figure ground drawings his mapping studies included a set of analytical overlays. Each set examined the level of integration the school had with its context.

The plan-based analysis employed in this thesis follows similar parameters to the authors cited above. The figure ground drawing covers a 600 by 600 metre area, with the square located in the centre (see figure 24). This establishes a 300 metre radius of context around the square. The 300 metre radius also coincides with a leisurely five minute walk in all directions proximate to the square. Each precedent has been drawn to the same scale with the same limitations for ease of comparison.

As is convention, each square has also been orientated with north being up the page.

Originally all the plans were drawn to a scale of 1:2500. The only exception to this is the hierarchy of space plan, which was drawn at half scale of 1:1250 to improve the clarity of the drawing.

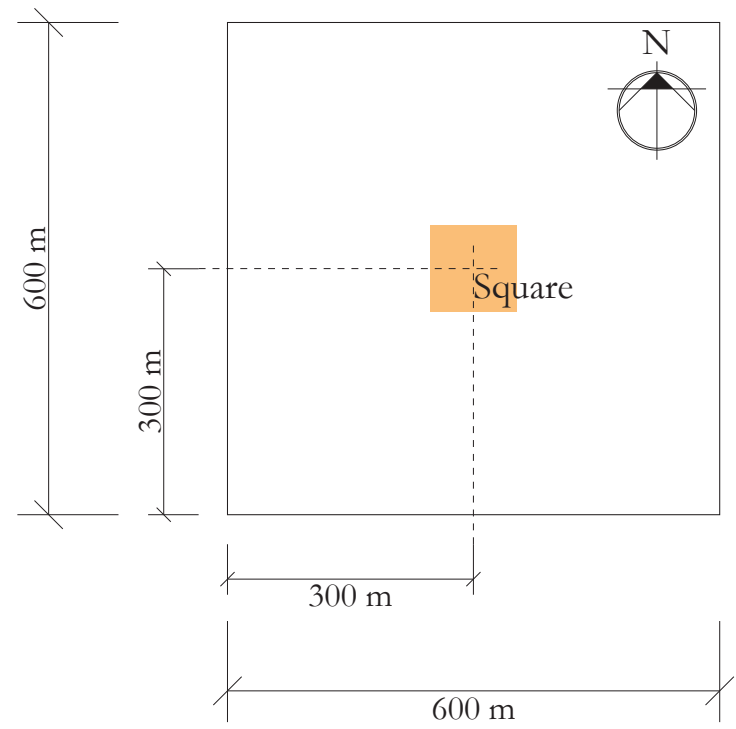


Bonn Square

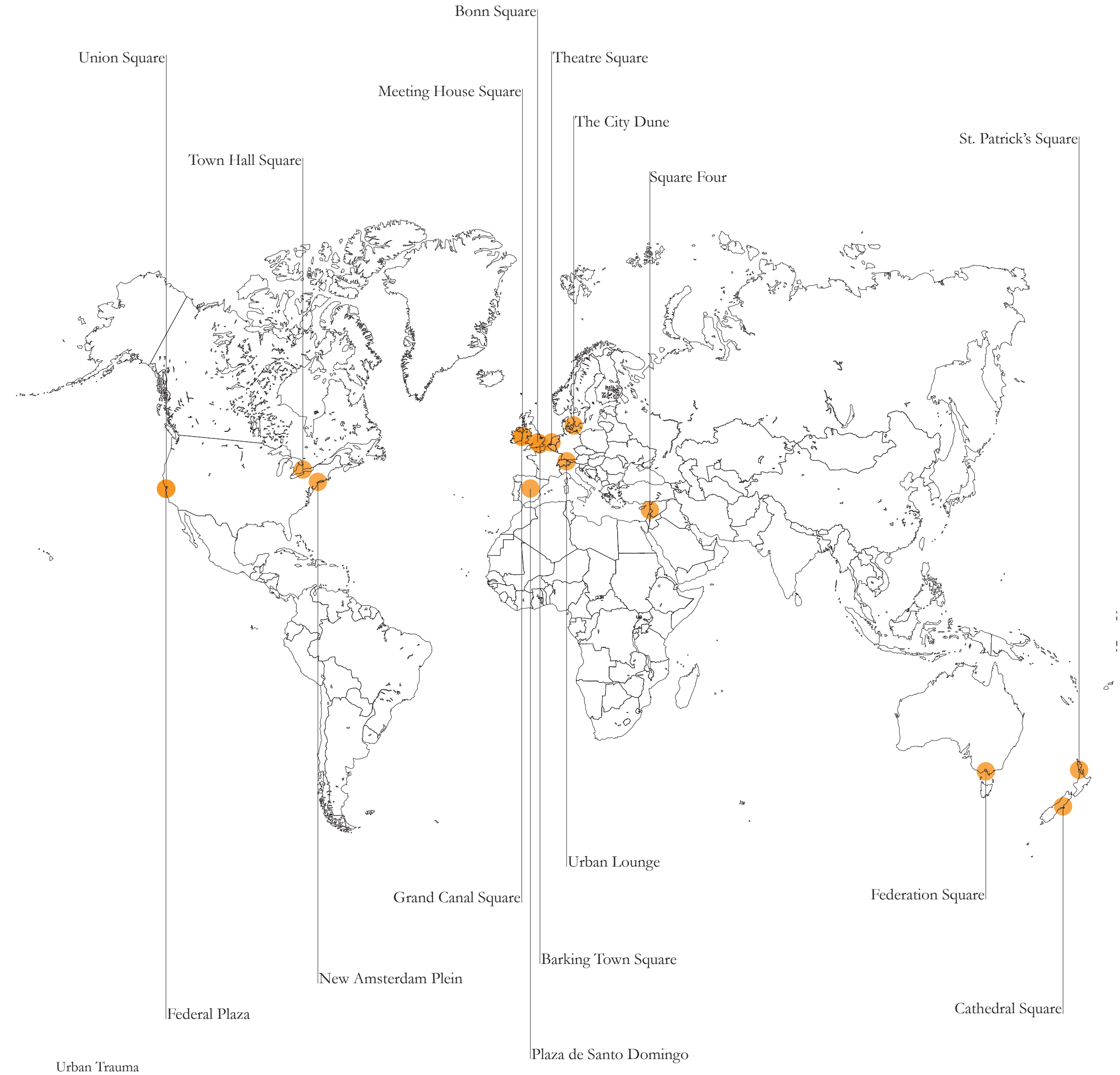


The information from which the plans were based was collected from Google maps and Bing maps.

Google Streetview was also used to gather three dimensional information for the graphical overlays, such as mapping the soft building edges.

The relevant cities' metro map (available online), in conjunction with Google maps, was used to identify the different public transit routes and locations.

\section{Method of Square Selection}

It was important from the outset to apply parameters in the selection of contemporary squares. There were two tiers to the selection process. First an extensive list was compiled which included squares from books and journals (see appendix one). The next step was to go through this list selecting only 15 to make the detailed analysis more achievable for this thesis.

The squares were selected based on:

\section{Relationship to central city}

This was mainly based on the proximity of the square to the city centre. Malvern Square, for example, was omitted due to its relatively poor proximity to central Melbourne city.

\section{The date of completion}

In order to gather a list of contemporary precedents all of those selected were completed within the last 20 years. Of course this meant that many of the world's greatest and most popular squares were omitted from this study, in search of more contemporary precedents.

\section{Hard landscaping}

Selecting squares that were primarily hard landscaped helped to avoid the inclusion of parks, which fell outside the scope of the study.

The squares are located in a number of cities internationally and they are centrally located within their greater urban contexts. The 15 squares selected are:

Barking Town Square, Barking, Greater London, England

Bonn Square, Oxford, England

Federal Plaza, San Francisco, California, United States

Federation Square, Melbourne, Australia

Grand Canal Square, Dublin, Ireland

Meeting House Square, Dublin, Ireland

New Amsterdam Plein, New York, United States

Plaza de Santo Domingo, Madrid, Spain

Square Four, Beirut, Lebanon

St. Patrick's Square, Auckland

The City Dune, Copenhagen, Denmark

Theatre Square, Rotterdam, Netherlands

Town Hall Square, Toronto, Canada

Union Square, San Francisco, California, United States

Urban Lounge, St. Gallen, Switzerland

Cathedral Square, Christchurch has also been included in this analysis for comparison with the other 15 squares. The analysis was completed on the pre-earthquake form of the square.

\section{Sources for Precedents}

Journals were the most effective way of gathering precedents, as it was easy to omit articles and publications that fell outside of the timeframe. In addition, only the most successful square designs reached publication. 
The range of journals included urban design, landscape architecture and architecture. A comprehensive list of these journals is below:

\author{
Architecture and Urbanism $(\mathrm{a}+\mathrm{u})$ \\ Journal of Landscape Architecture \\ Journal of Urban Design \\ Kerb \\ Landscape Architecture New Zealand \\ Landscape Australia \\ Landscape Design \\ Landscape Journal \\ Paisea \\ Places \\ Urban Design Quarterly \\ Urbis Landscapes
}

The squares were selected by methodically by reviewing these journals and applying the criteria above to the process. This ensured only the most relevant squares were selected for this study.

\section{Analytical Attributes}

The attributes with which the town squares were evaluated are as follows.

\section{Figure Scale and Spatial Identity}

Redrawing each square as figure ground plans is an important technique in establishing the squares spatial identity amongst the urban context. A clear sense of spatial identity is reliant on the shape of the square, density of surrounding building and the scale of open space.

Each square is drawn to the same scale to make comparisons between the ratio of built and open space; density and continuity of the buildings; and patterns of building.
The simple figure ground is important in terms of integration as it clearly establishes the squares spatial identity in plan amongst the built environment.

\section{Street Pattern}

This establishes the relationship between the square and the street pattern or city grid. In terms of integration it is intended that mapping this attribute will reveal how well connected the square is with the surrounding city.

The red lines illustrate the way in which the square is integrated with the street pattern. The illustration also identifies a hierarchy to the street pattern, with the three different line weights. The thicker lines are representative of the dominant street pattern and the thinner lines represent smaller connections within the main grid or pattern. Although these lines show a hierarchy in the grid pattern, they are somewhat abstract as they do not necessarily indicate street widths, good streets or street use, such as pedestrian only lanes and service lanes.

\section{Public Transport Routes}

This is to investigate the relationship between public transport and the city square, and illustrate the proximity of public transit routes and corridors to the square. The different routes are indicated with various colours, and the broken line styles indicate the different types of transport included in the study. It is hoped this will reveal how well integrated the square is with the cities public transit systems. This is particularly important as the large size of the contemporary city means we are reliant on motorised transport, especially when integrating and connecting the central city to the outer suburbs

\section{Landscape and Natural Features}

Identifying the proximity and integration of surrounding environmental features to the square. In addition to rivers, seafronts 
and grassed areas, this study includes major planting. This will indicate the density and level of integration the natural landscape has with each square.

\section{Soft Building Edges}

It is expected that this analysis will reveal how buildings are integrated with the edges of each square. This will be done by mapping the soft building edges that are in close proximity to the square.

The assessment and mapping of hard and soft edges draws from the work of Jan Gehl. In his book Cities for People he describes a method of assessment developed during a 1990 urban renewal project in Stockholm (Gehl 240). This method is fairly complex, with five classifications in which the quality of the built edges could be categorised.

For this thesis only two criteria will be used to assess the quality of the built edge: hard and soft.

These two categories subsume a number of different criteria such as building front and back, active and inactive uses as well as architectural gestures and details.

For example a Cathedral has a clear front and back, the front being the soft edge. The same can be said of many other traditional urban building types.

Use is as equally as important. Whether it is an inviting shop window display or cafe seating that spills out into the street or square. Both are considered soft edges, in some cases regardless of architectural detail or whether or not they are located at the front of a building.

Architectural gestures and detail may refer to a situation where an edge has no active use, and is not the front, but is articulated in such a way that it softens an otherwise blank wall. This is particularly important for more contemporary buildings, where all edges (at least in theory) are considered to be the building front. An example would be a modernist tower building, where an entrance canopy can soften an otherwise monotonous facade. An- other would be a surface or skin that creates exceptional visual delight to an otherwise blank built edge.

It is worth noting that this last property is not included in the method described by Gehl, who would appear to favour more historic European building types when assessing the quality of the built edge.

\section{Hierarchy of Space}

This illustrates a hierarchy of spaces within each square. This is based off the enclosure of space, orientation and arrangement of buildings and changes in ground level. Also included are prominent areas of notable ground materiality, areas shared with vehicles and areas that suggest movement over rest and vice versa.

Hierarchy of space also takes into account three dimensional information such as the articulation and continuity of the built edges. These include prominent and historical building facades, arcaded edges and canopies. The information for these diagrams was gathered using Google Maps and Streetview.

A gradient scale is used to illustrate the hierarchy of space. The lightest shades often illustrate vehicular roads and pedestrian paths designed primarily for movement and darker shades illustrate more enclosed spaces that hold prominence over others. It is intended that mapping the hierarchy of space will reveal zones of prominence within the square. For example by showing how well these squares can be distinguished as urban rooms or "experience spaces" (Gehl 32). Additionally it is hoped that it will reveal how pedestrian and vehicular movement paths are integrated with the square. 


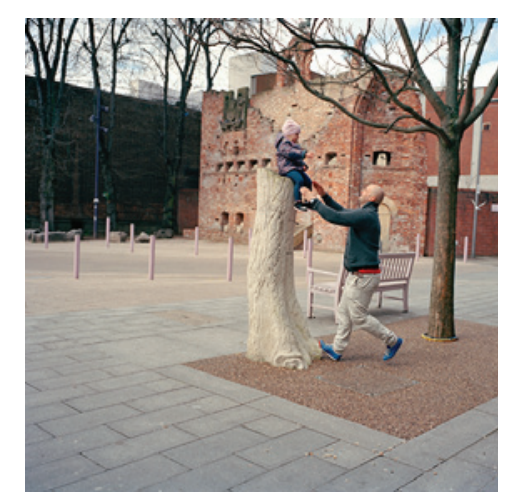

Barking Town Square

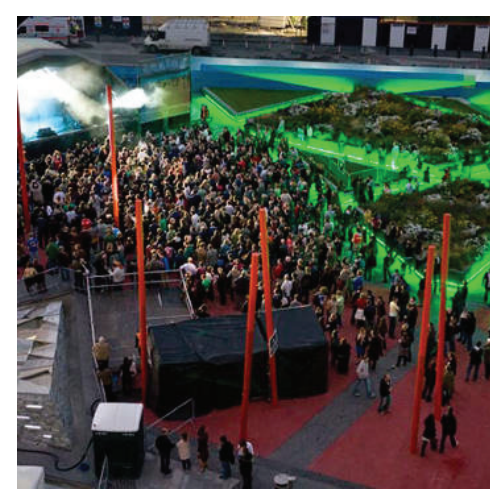

Grand Canal Square

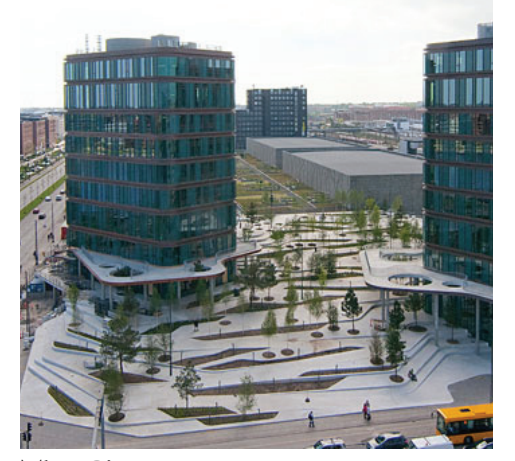

The City Dune

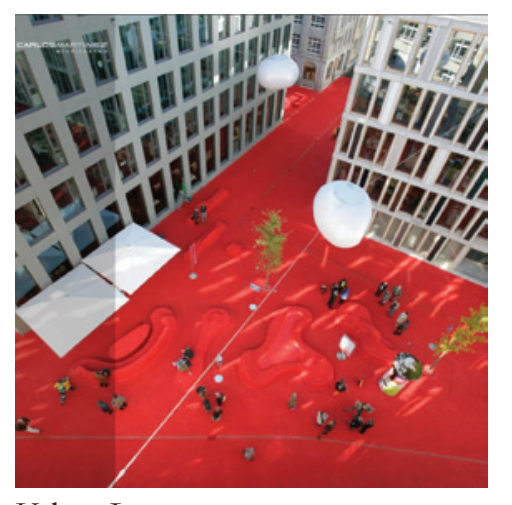

Urban Lounge

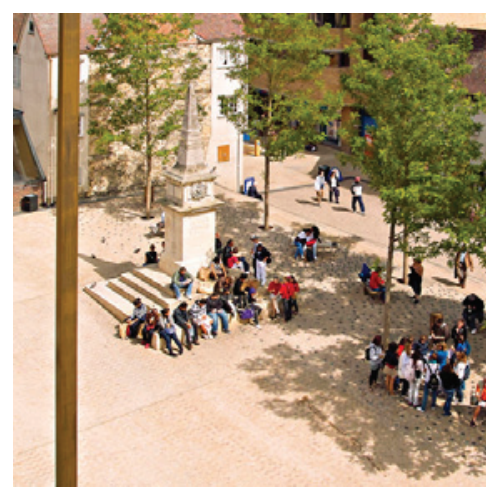

Bonn Square

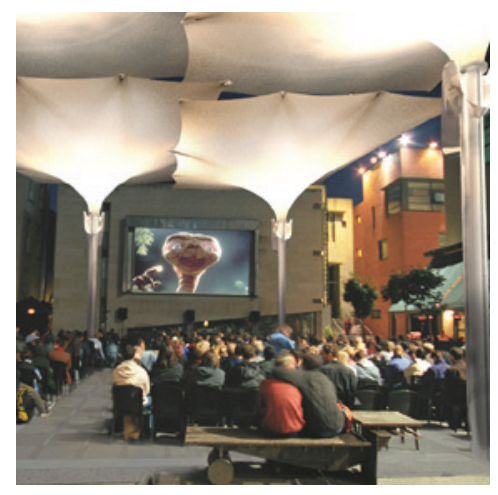

Meeting House Square

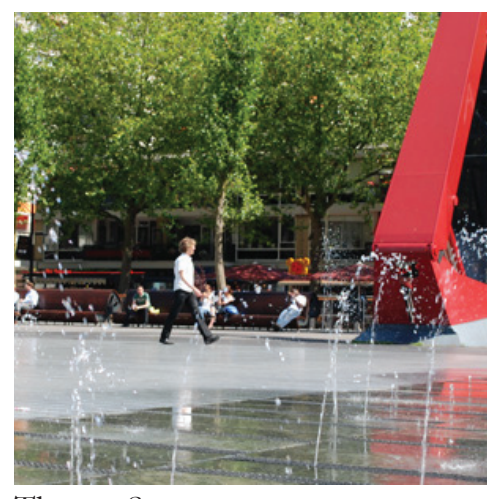

Theatre Square

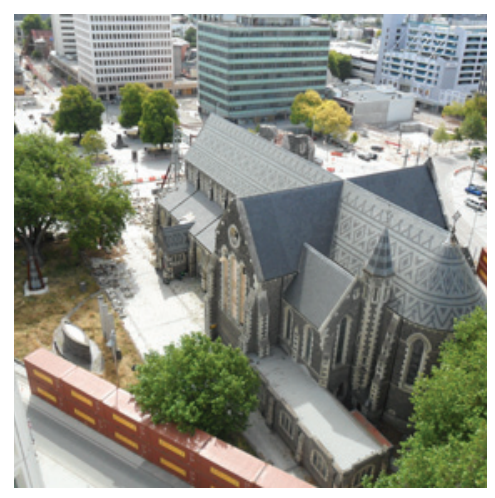

Cathedral Square

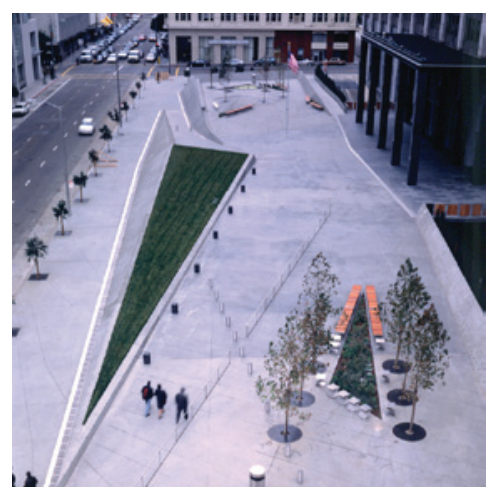

Philip Burton Federal Plaza

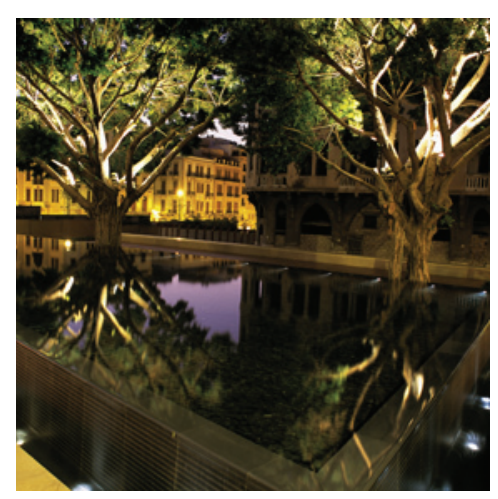

Square Four

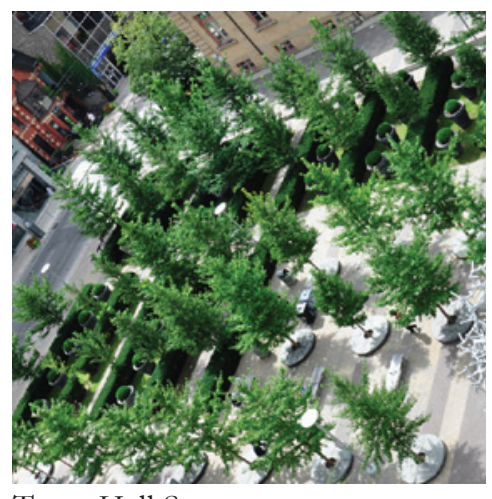

Town Hall Square

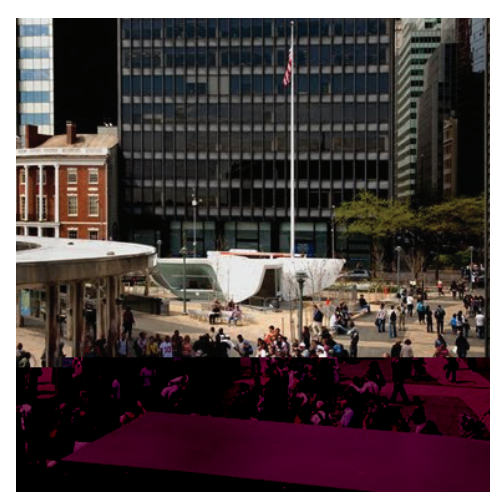

New Amsterdam Plein

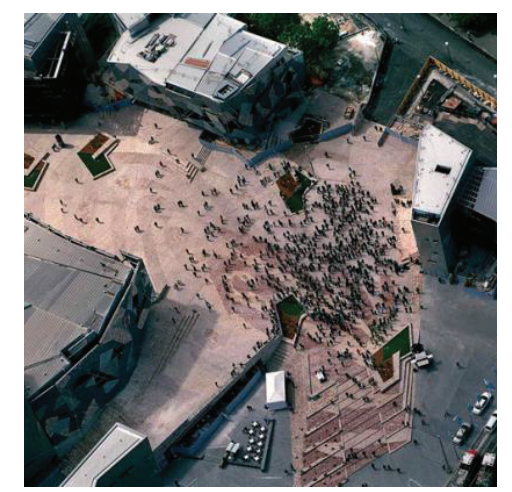

Federation Square

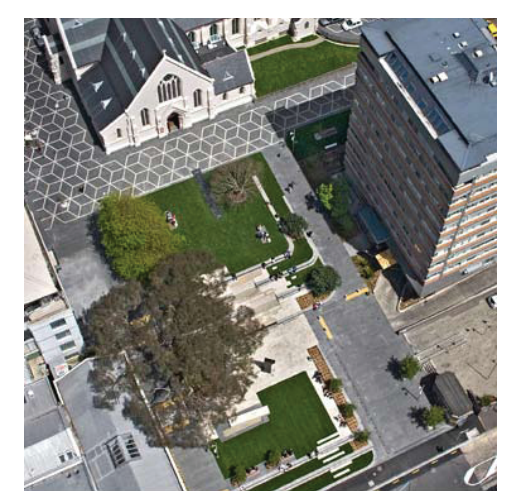

St Patrick's Square

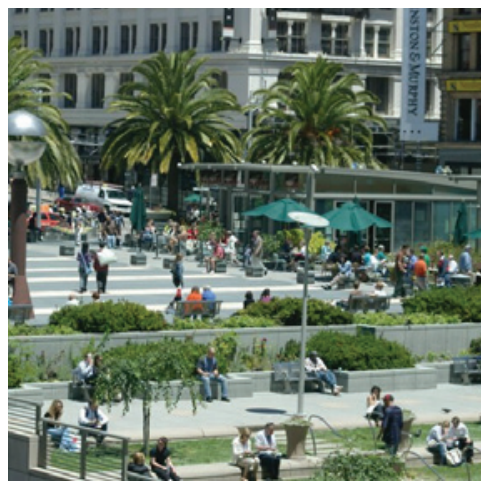

Union Square

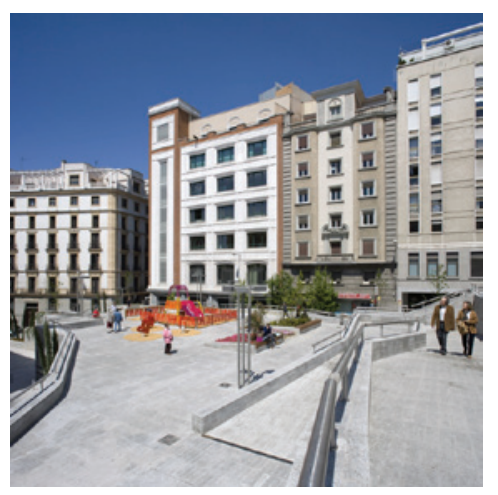

Plaza de Santo Domingo 


\section{Graphic Analysis}

On the following pages each precedent is presented in figure ground plan to a scale of 1:2500 with the five attributes presented alongside. While they were all originally drawn to scale, the diagrammatic nature of these drawings means they are reproduced here in no particular scale, however the drawings retain their original proportion.

The following section, entitled Findings, is where the individual attributes have been collated on a single page for comparison. Summary diagrams on the opposite page graphically illustrate some preliminary findings. These are then discussed in depth in the associated paragraphs. 


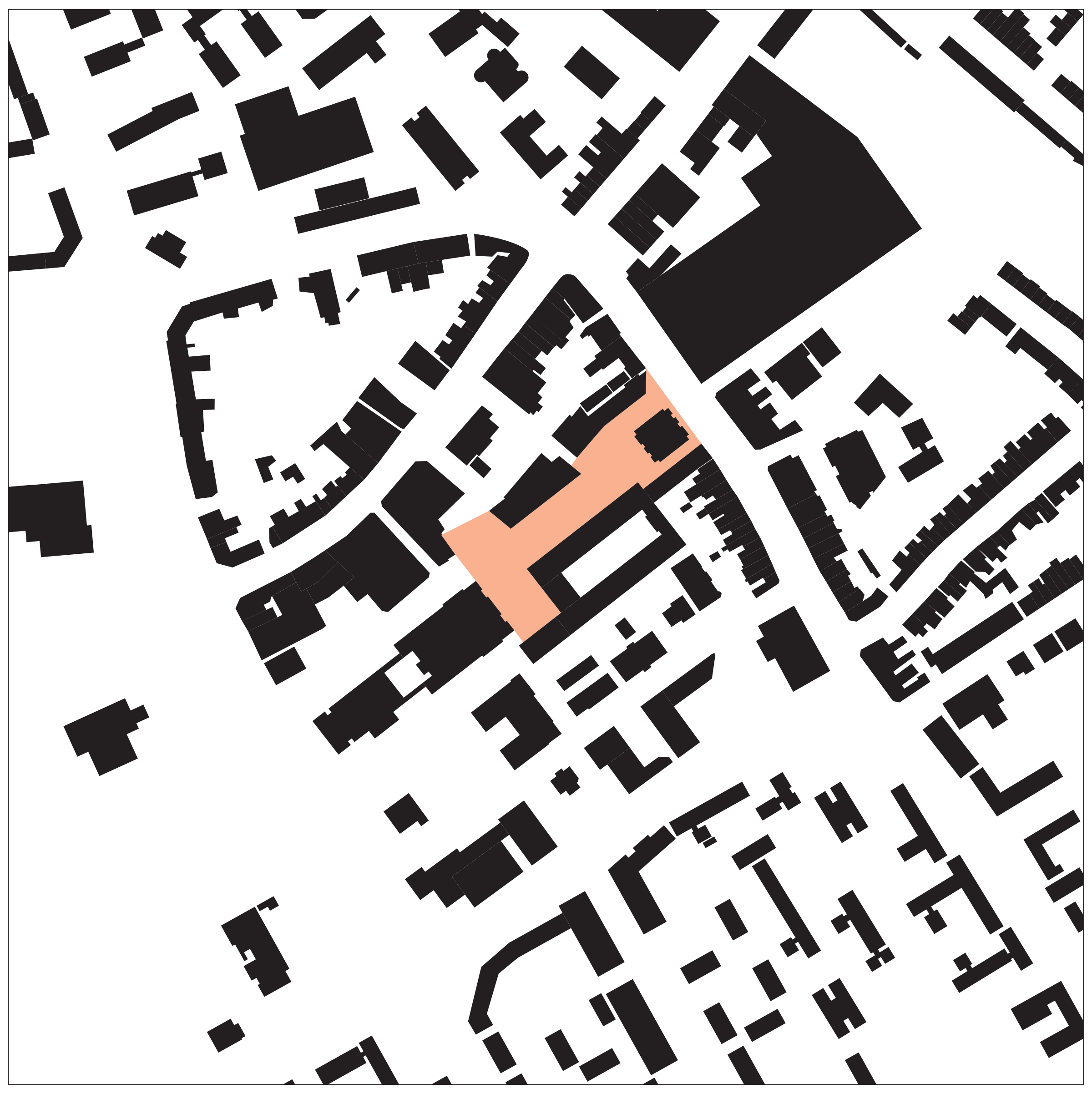


Figure 27.

(opposite page)

Barking Town

Square figure

ground plan. Scale

1:2500

Figure 28. Analyti-

cal overlays.

\section{Barking Town Square}

Barking, Greater London, England

muf Architecture/Art

2010

Hierarchy of Space More Prominent

Less Prominent

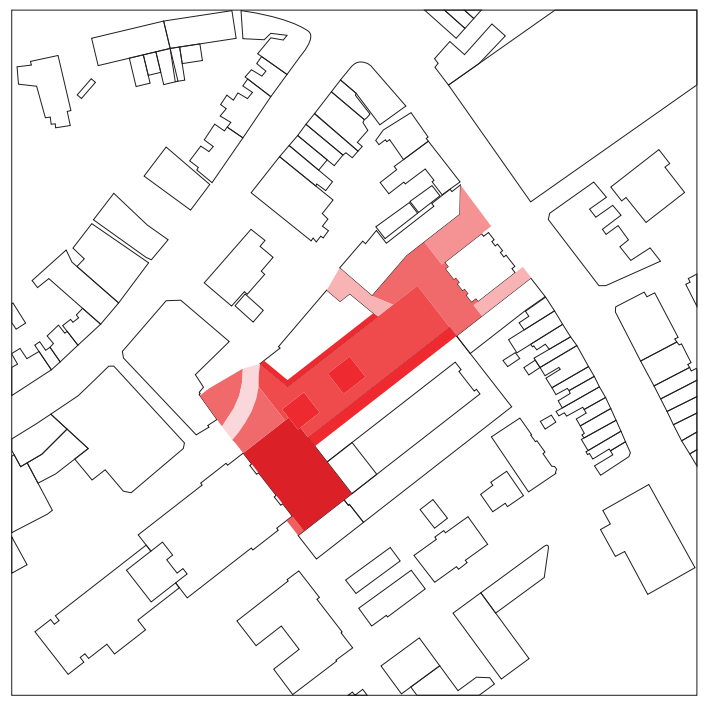

Soft Built Edges Soft Built Edge

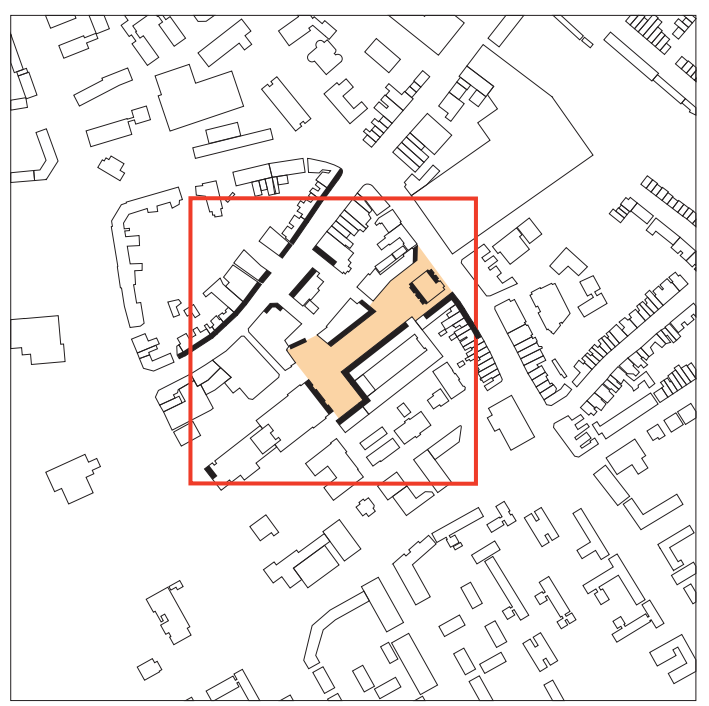

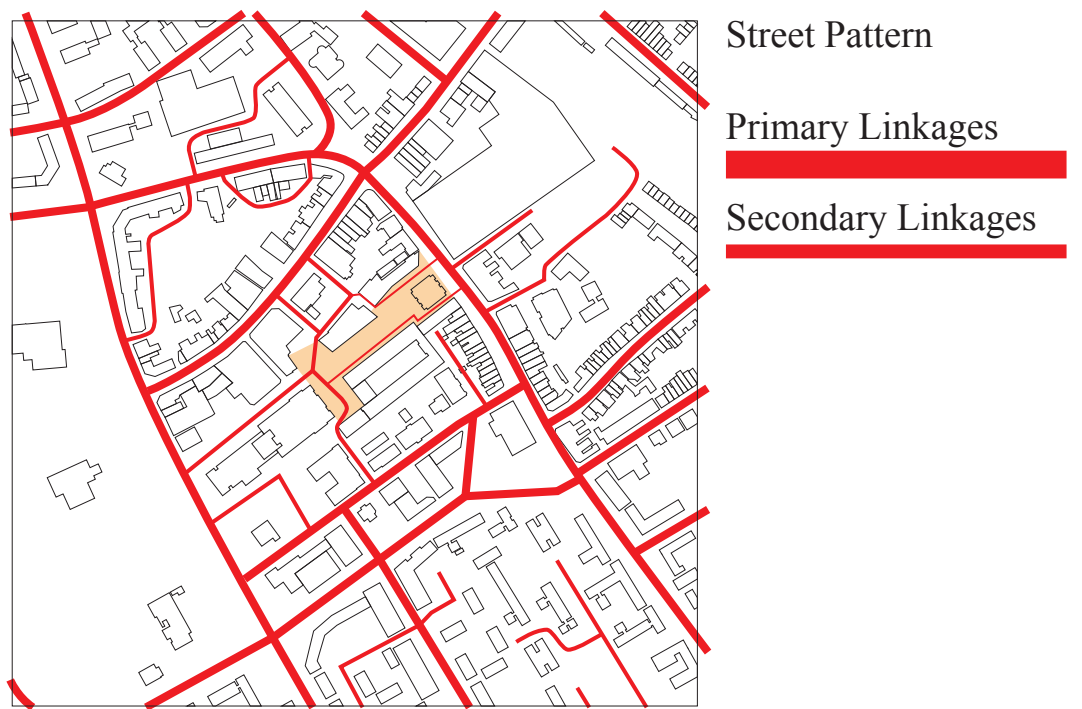

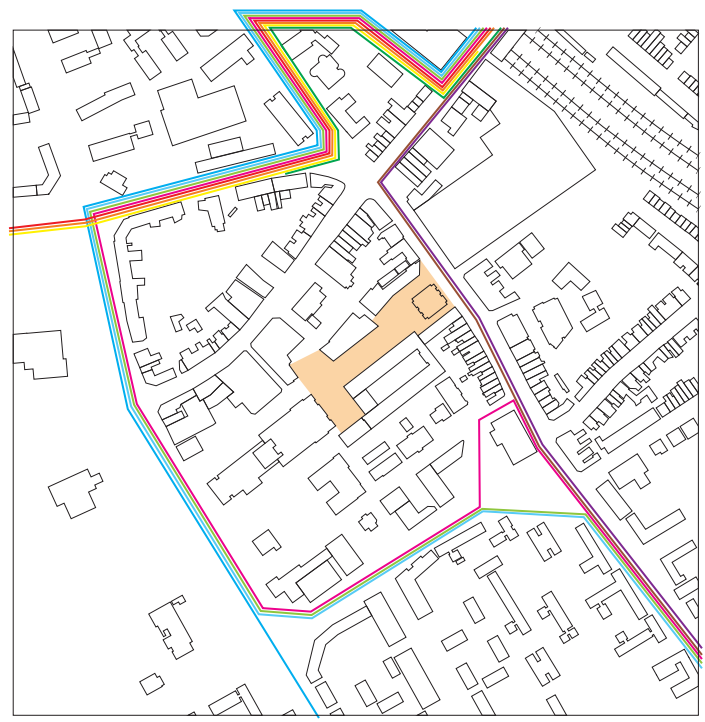

Public Transit Routes

Bus

\section{Rail}

$+1+1+1+1$

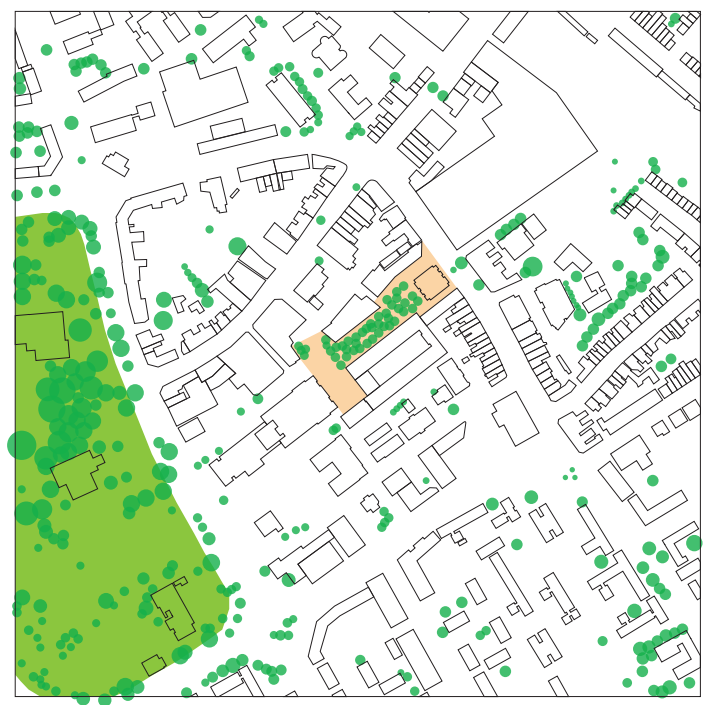

Landscape Features

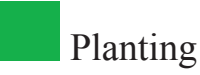

Green Space 


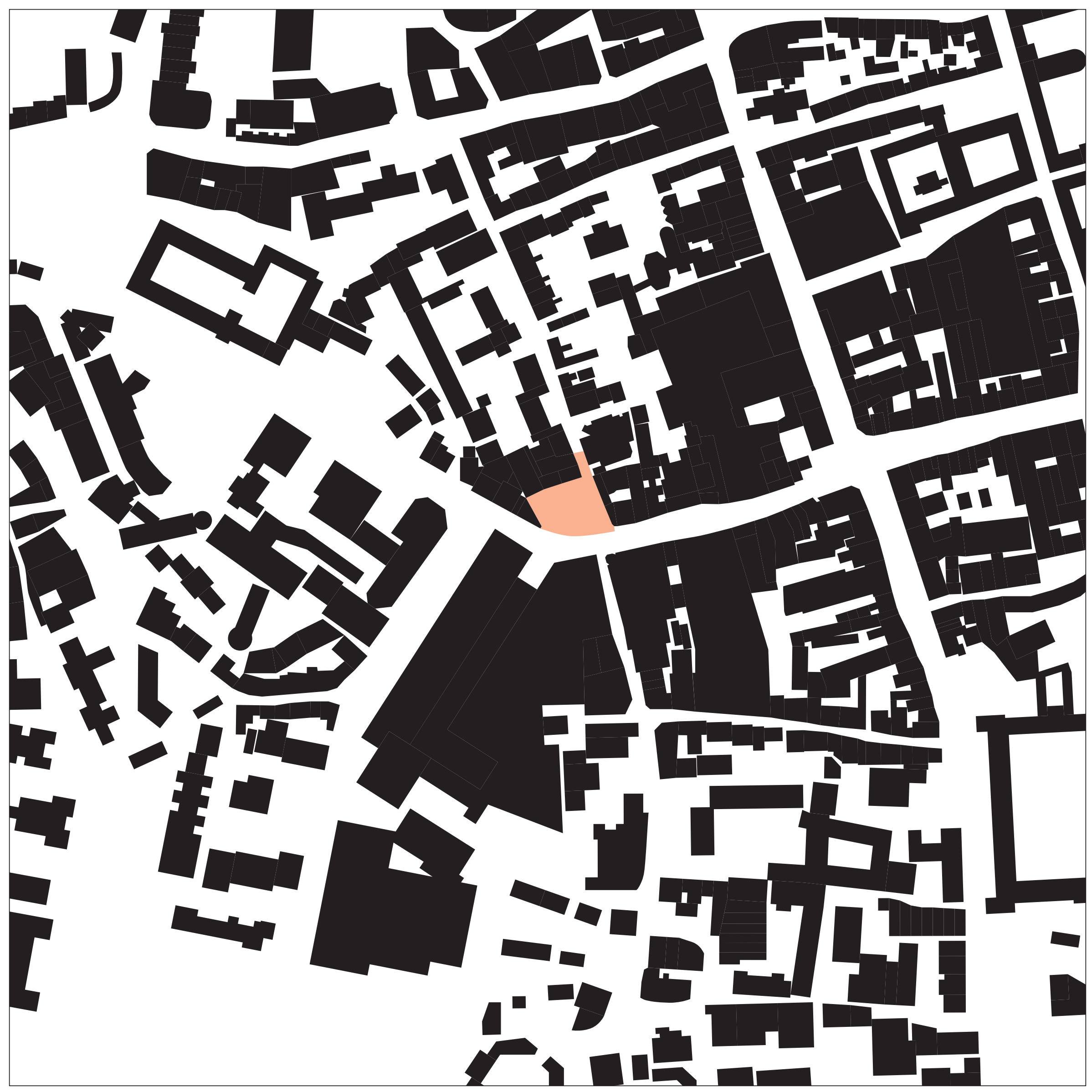


Figure 29.

(opposite page)

Bonn Square figure

ground plan. Scale

1:2500

Figure 30. Analyti-

cal overlays.

\section{Bonn Square}

Oxford, England

Greame Massie Architects

2008
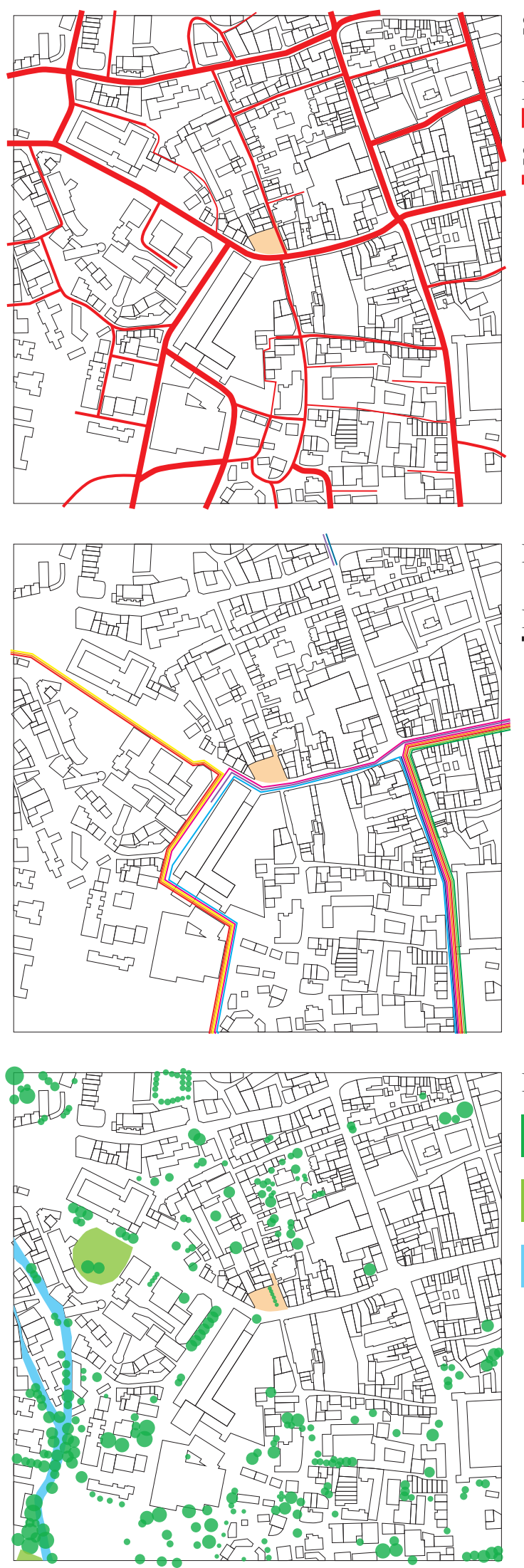

Street Pattern

Primary Linkages

Secondary Linkages

Public Transit Routes

Bus

Landscape Features

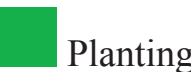

Green Space

River 


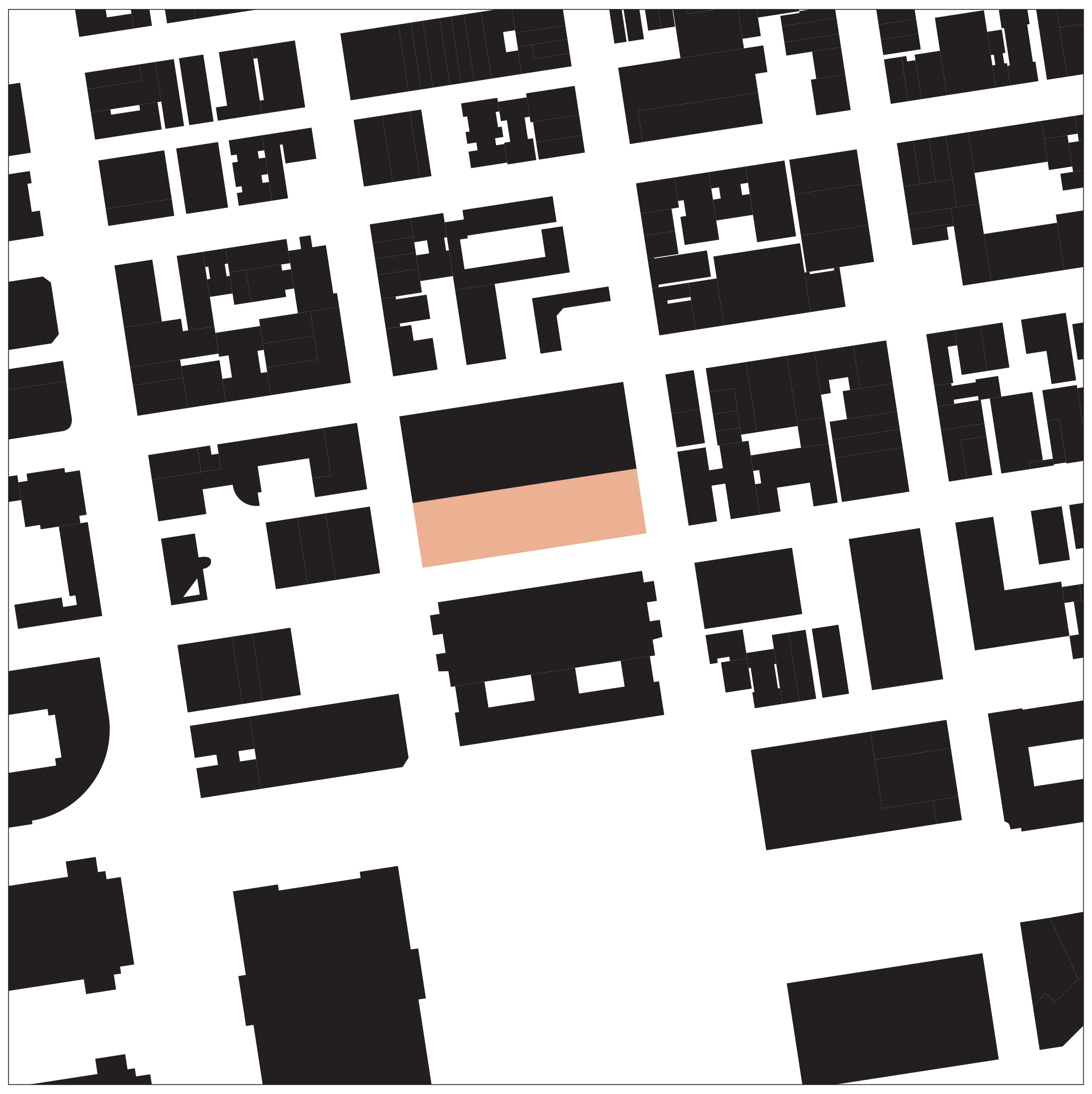


Figure 31.

(opposite page)

Philip Burton

Federal Plaza

figure ground plan.

Scale 1:2500

Figure 32. Analyti-

cal overlays.

\section{Philip Burton Federal Plaza}

San Francisco, California

Della Valle and Bernheimer Design 2000

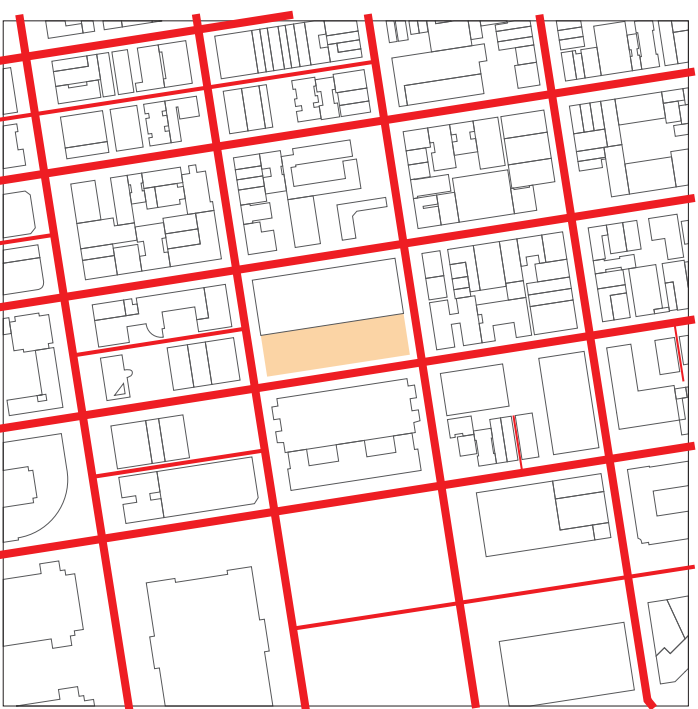

Hierarchy of Space More Prominent

Less Prominent

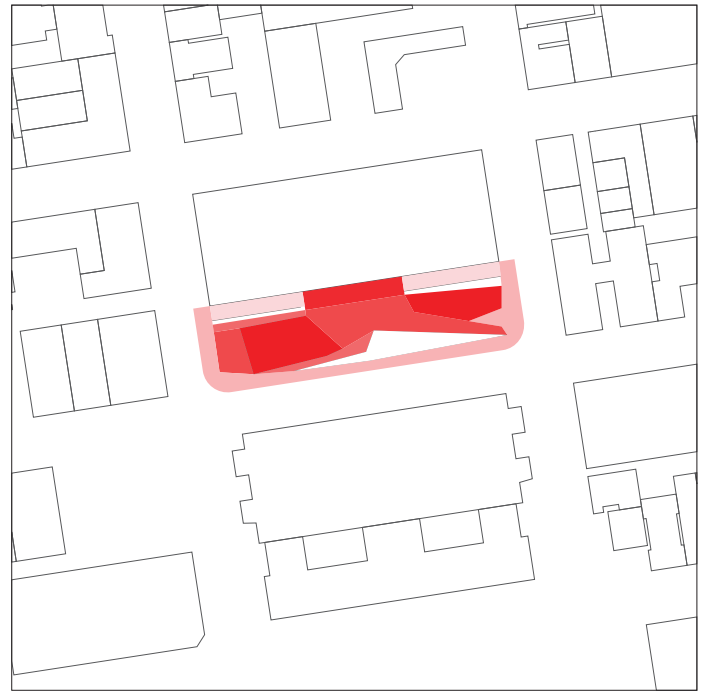

Soft Built Edges Soft Built Edge

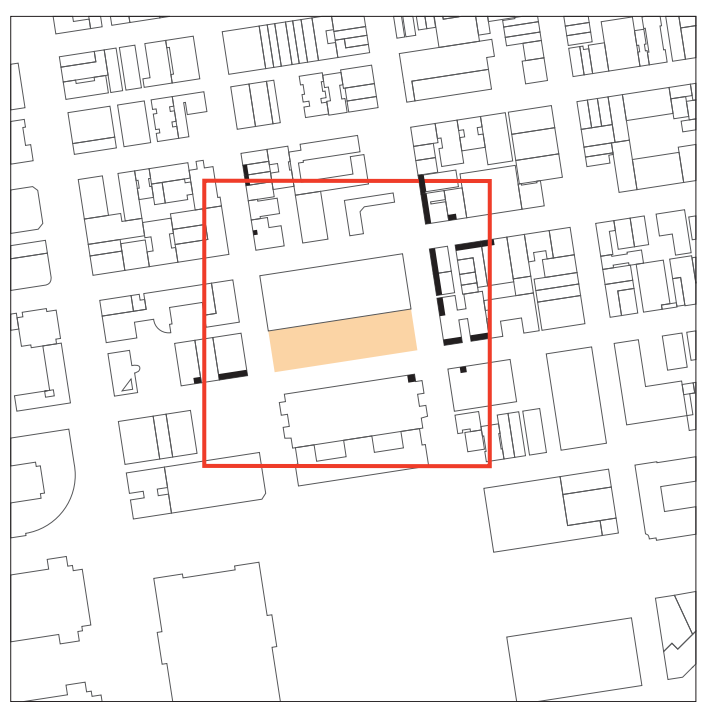

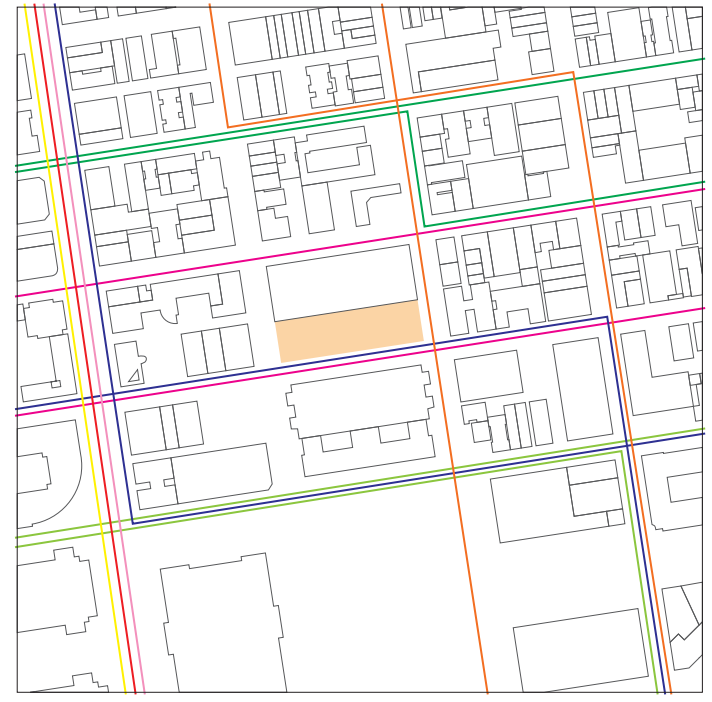

Public Transit Routes

Bus

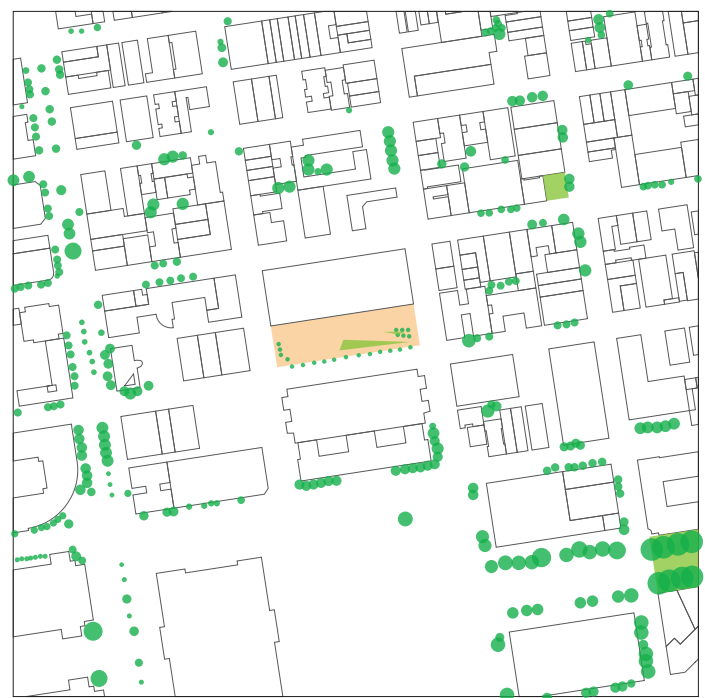

Landscape Features

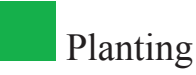

Green Space 


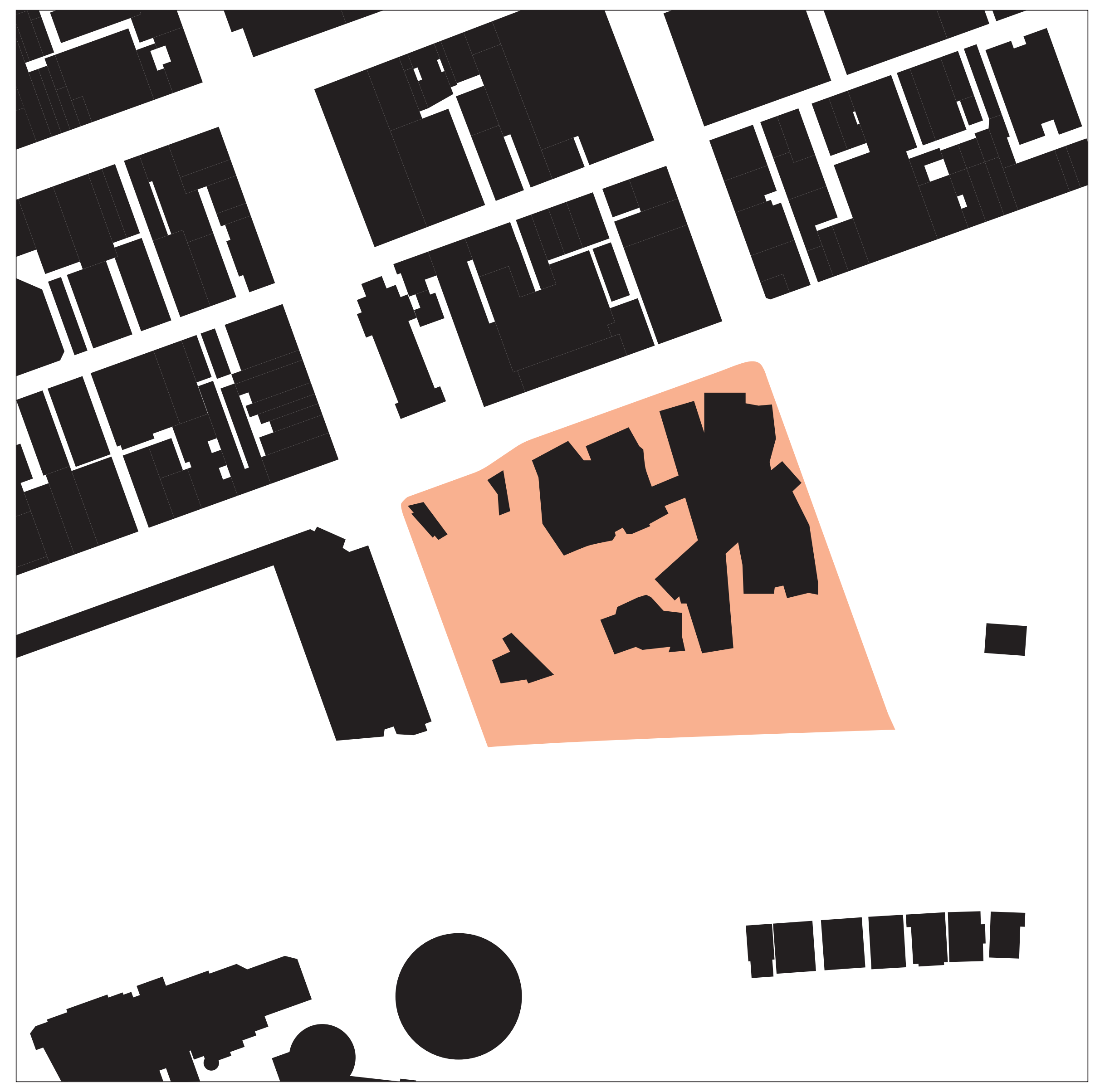


Figure 33.

(opposite page)

Federation Square

figure ground plan.

Scale 1:2500

Figure 34. Analyti-

cal overlays.
Federation Square

Melbourne, Australia

LAB Architecture and Bates Smart 2002

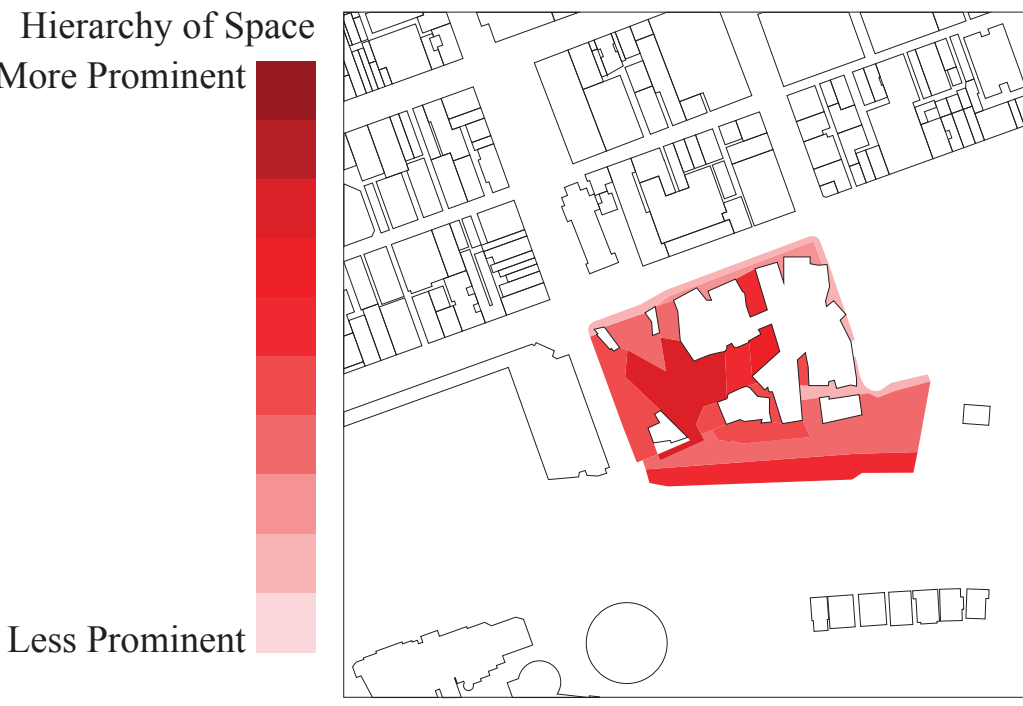

Soft Built Edges
Soft Built Edge

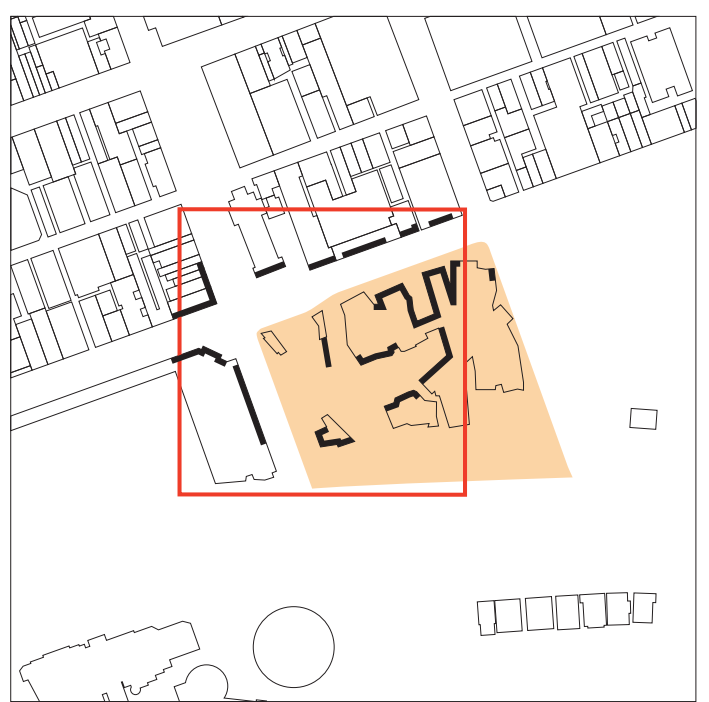

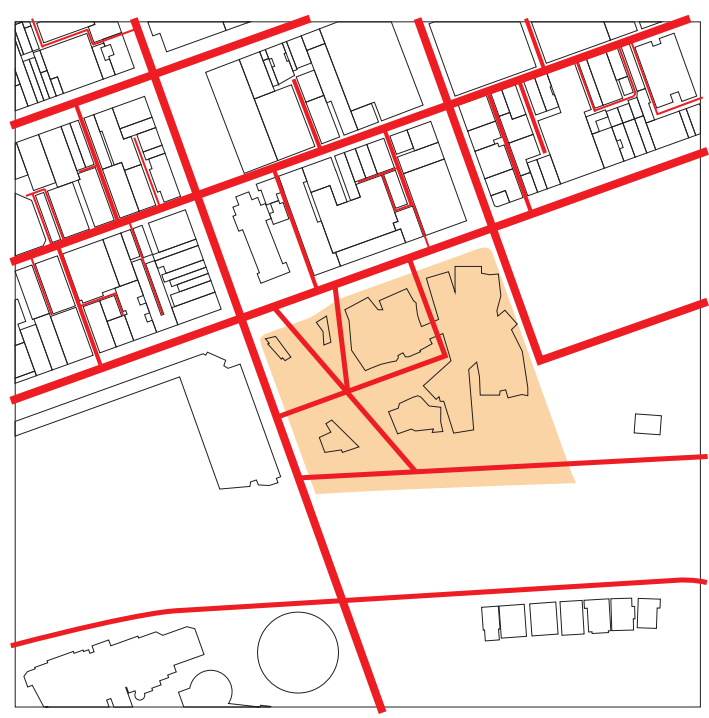

Street Pattern

Primary Linkages

Secondary Linkages

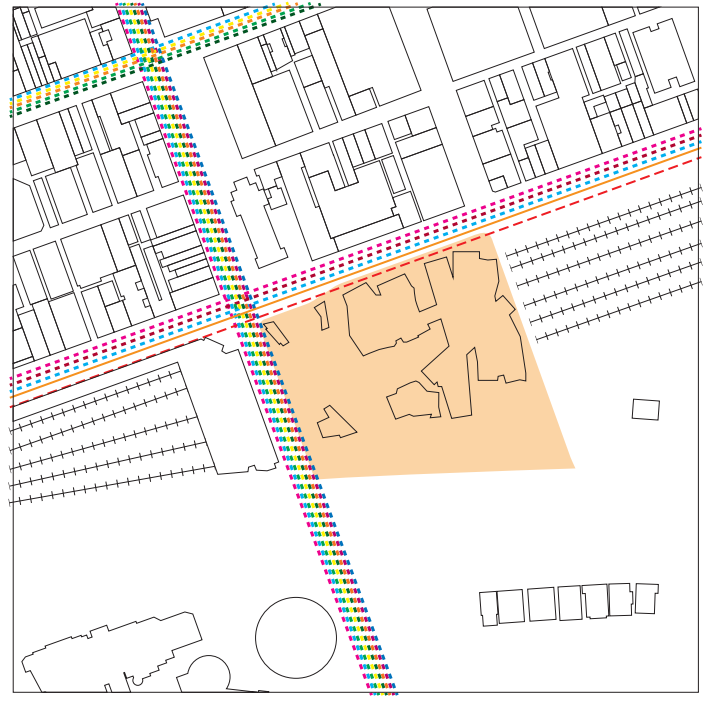

Public Transit Routes

Bus

\section{Light Rail}

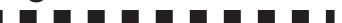

Rail

$\mathrm{H}+1+1+1+1$

Underground

- - - - - -

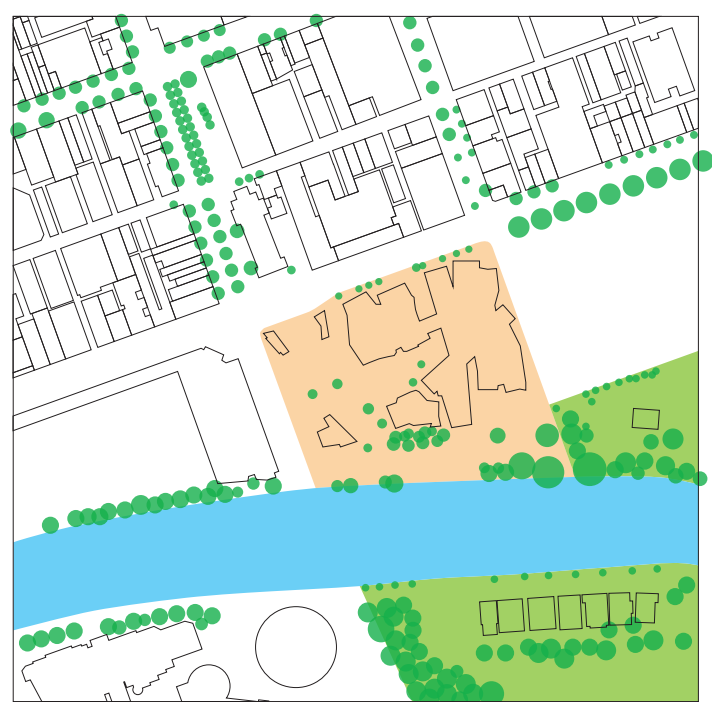

Landscape Features

Planting

Green Space

River 


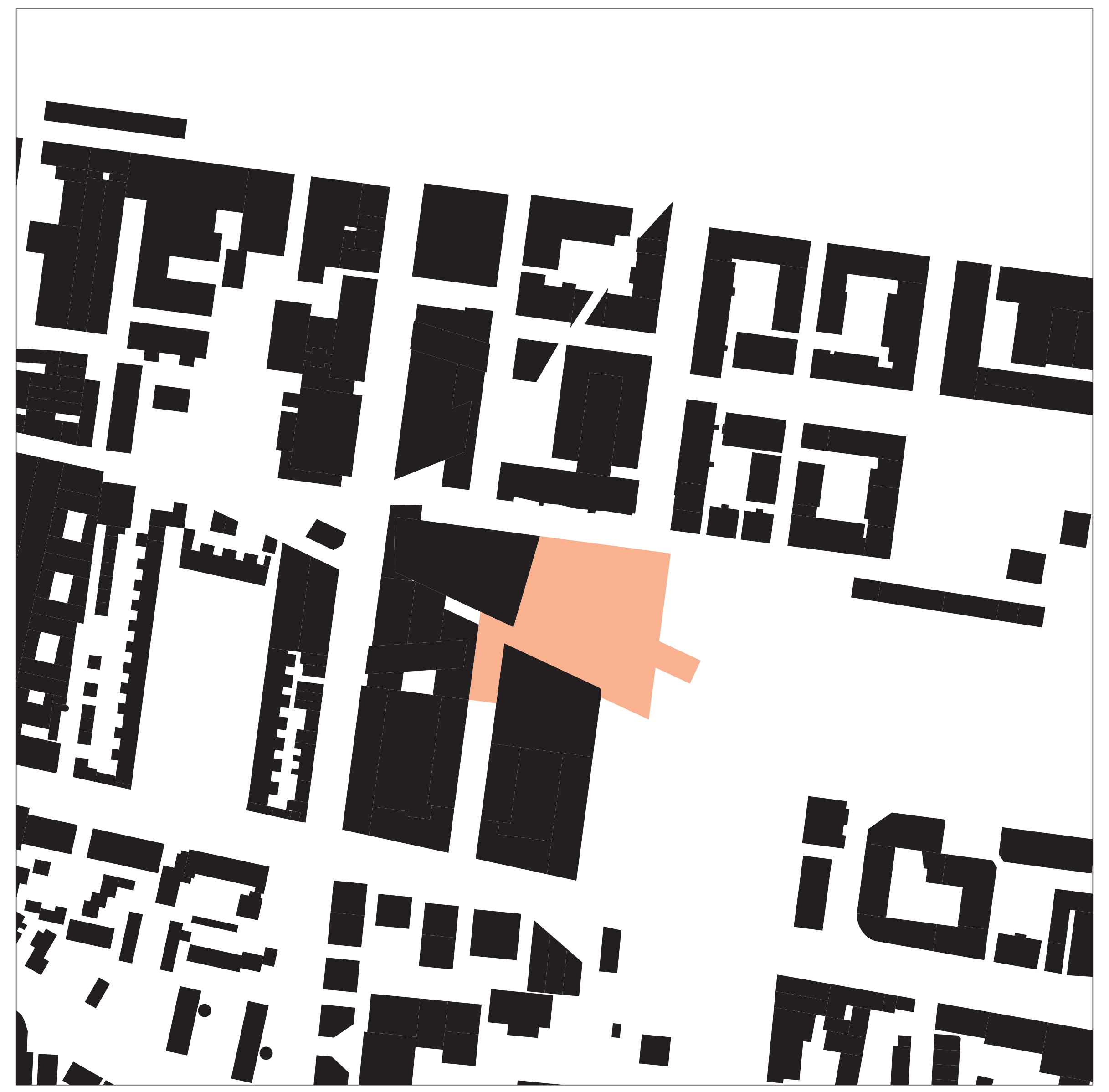


Figure 35.

(opposite page)

Grand Canal Square

figure ground plan.

Scale 1:2500

Figure 36. Analyti-

cal overlays.
Grand Canal Square

Dublin, Ireland

Martha Schwartz Partners

2007

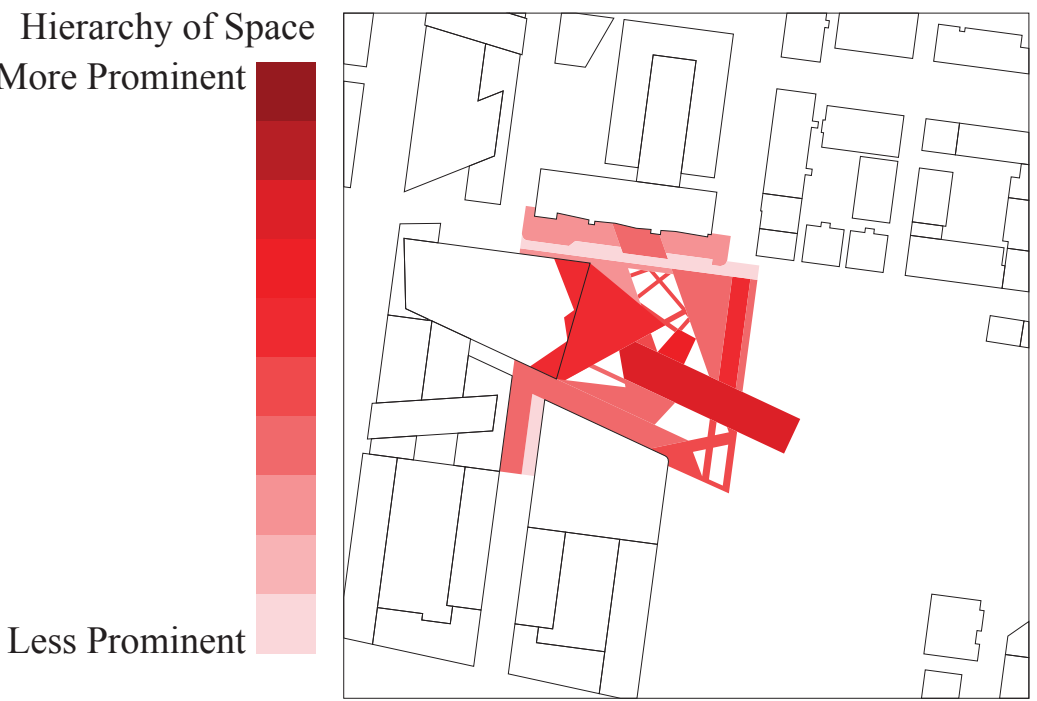

Soft Built Edges Soft Built Edge

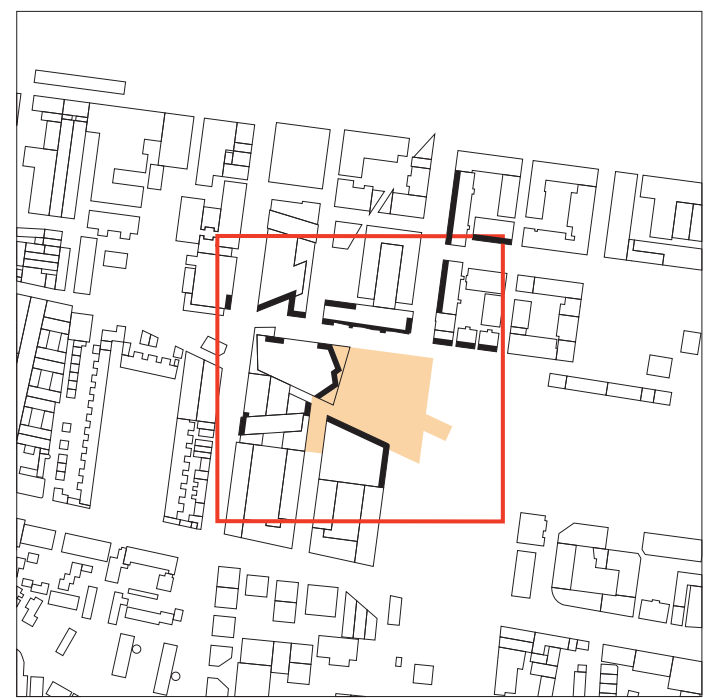

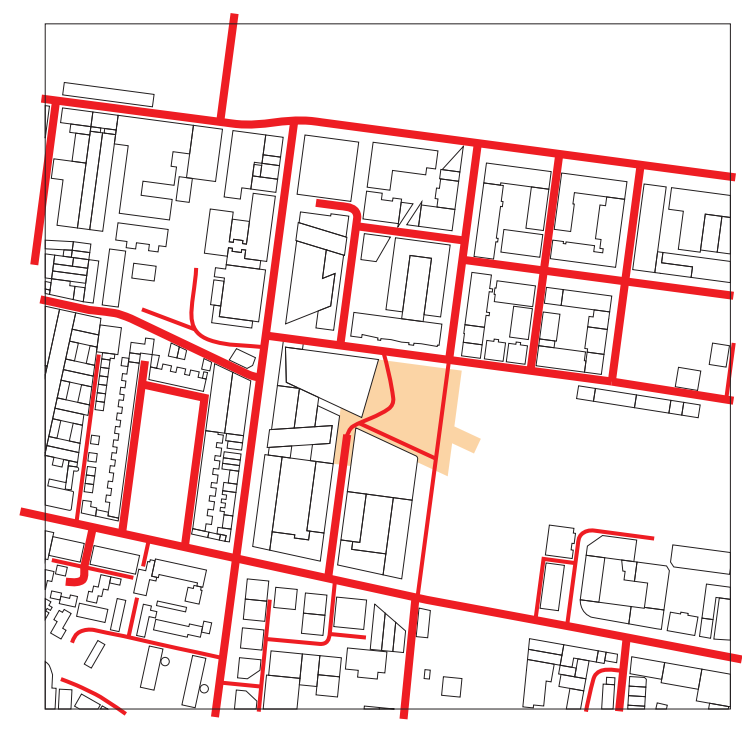

Street Pattern

Primary Linkages

Secondary Linkages

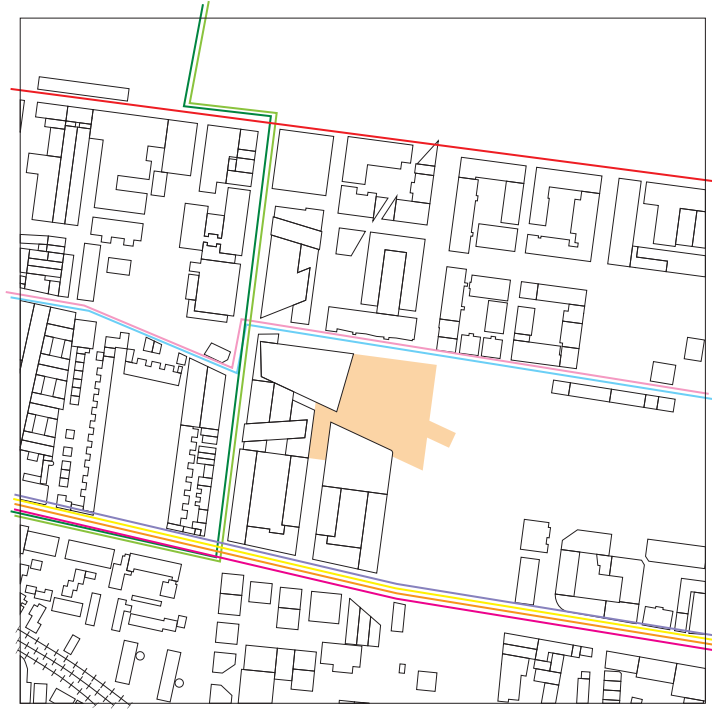

Public Transit Routes

Bus

Rail

$+1+1+1+1$

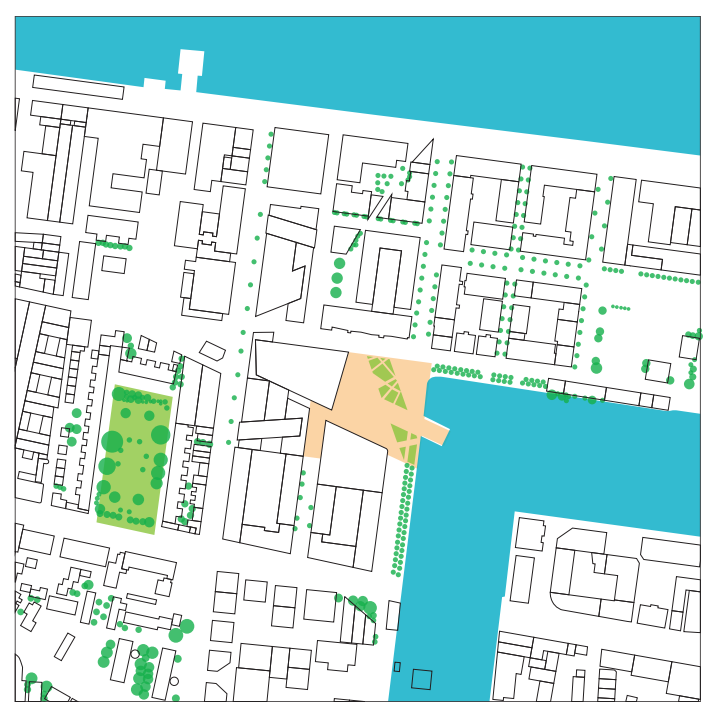

Landscape Features

Planting

Green Space

Ocean 


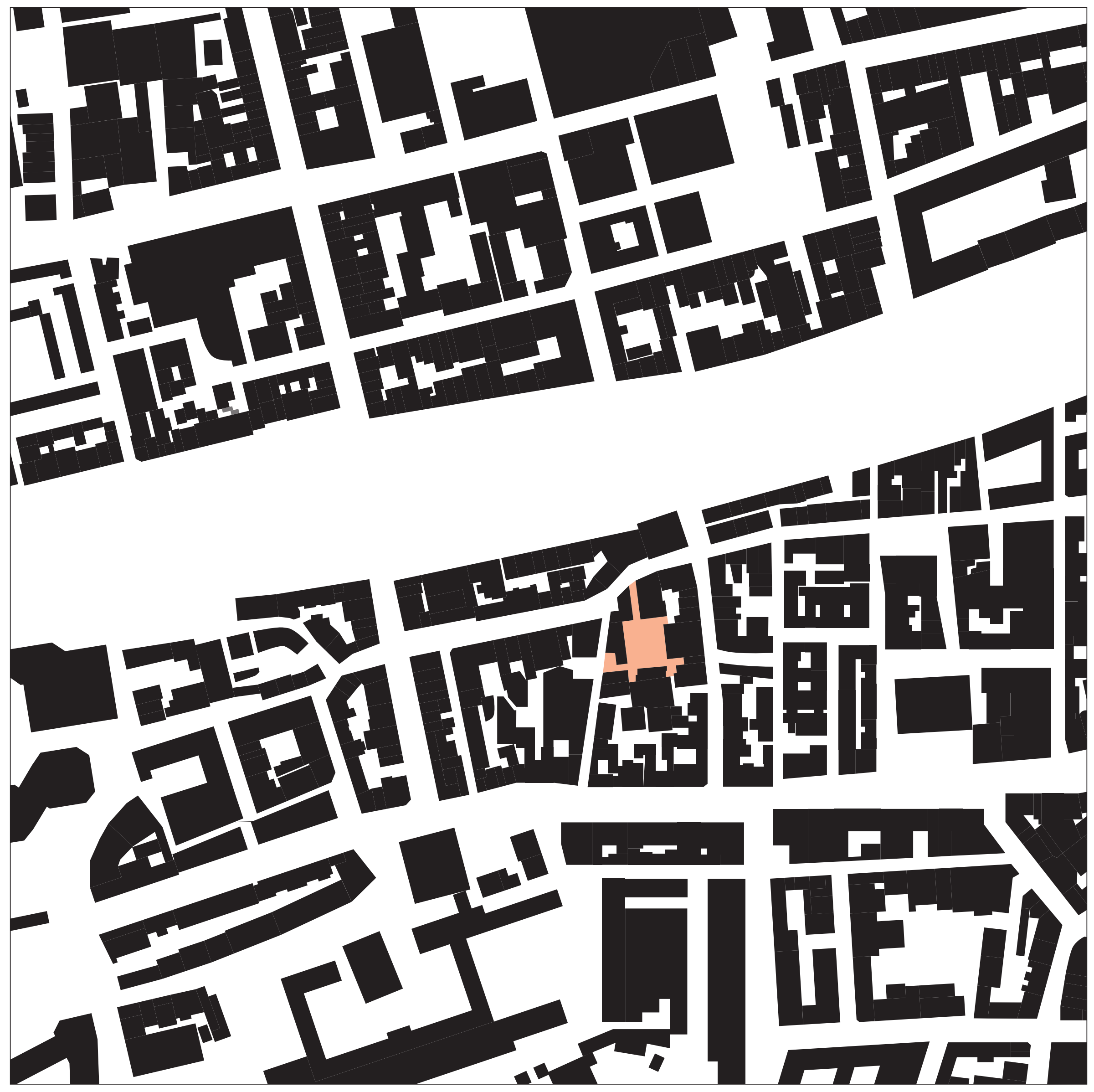


Figure 37.

(opposite page)

Meeting House

Square figure

ground plan. Scale

1:2500

Figure 38. Analyti-

cal overlays.
Meeting House Square

Dublin, Ireland

Sean Harrington Architects. 2002

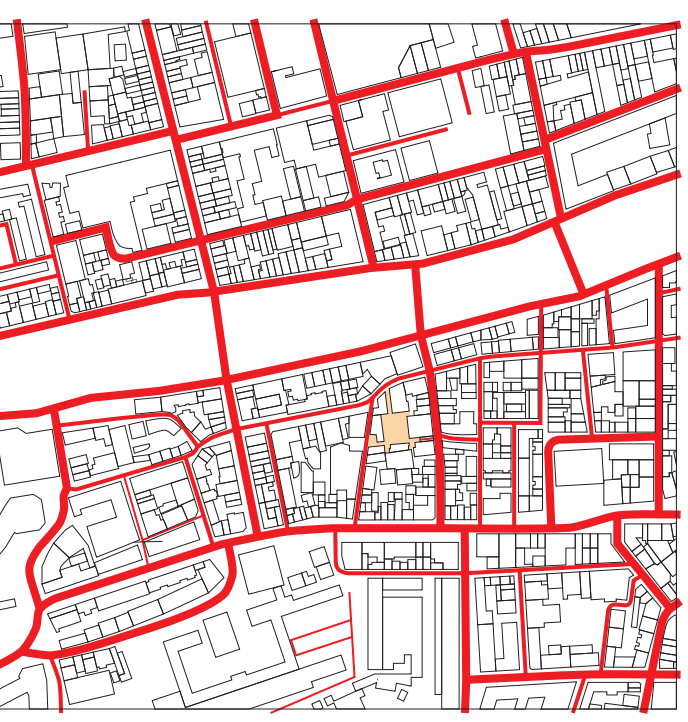

Hierarchy of Space More Prominent

Less Prominent

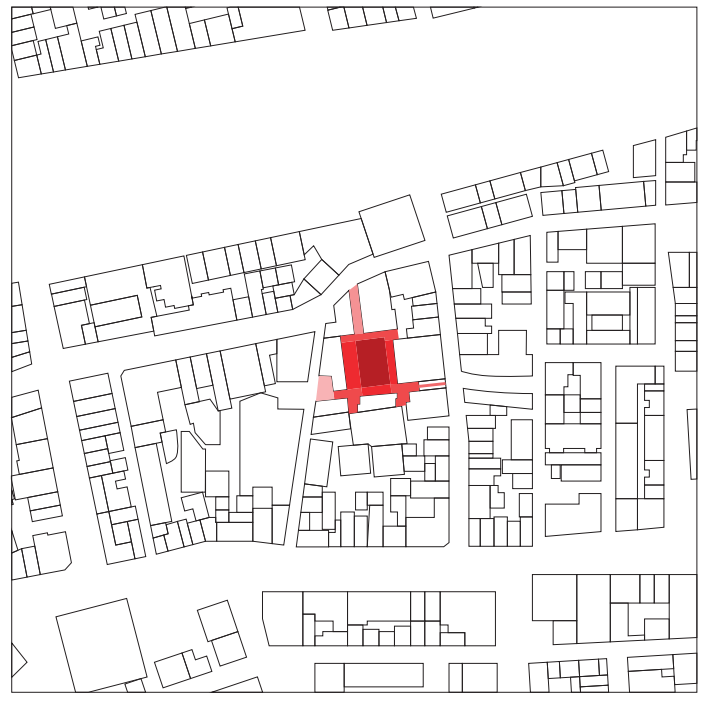

Soft Built Edges Soft Built Edge

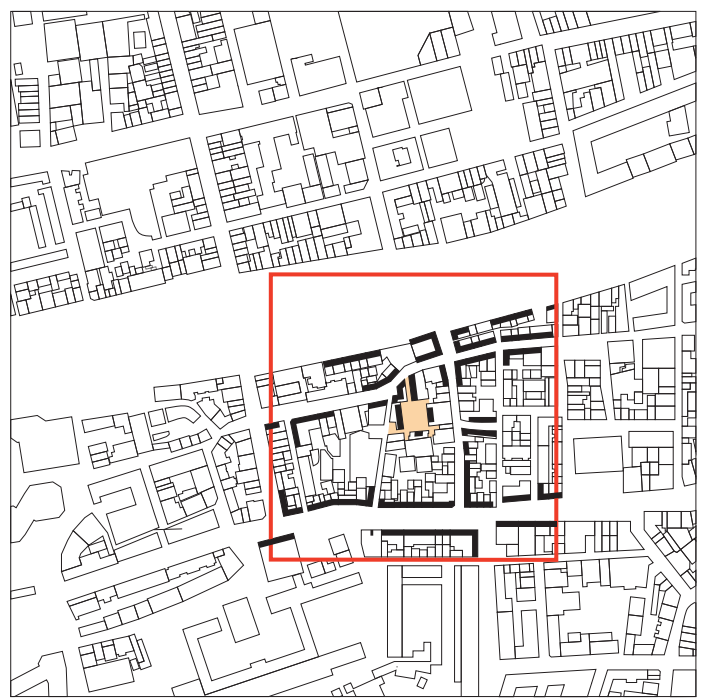

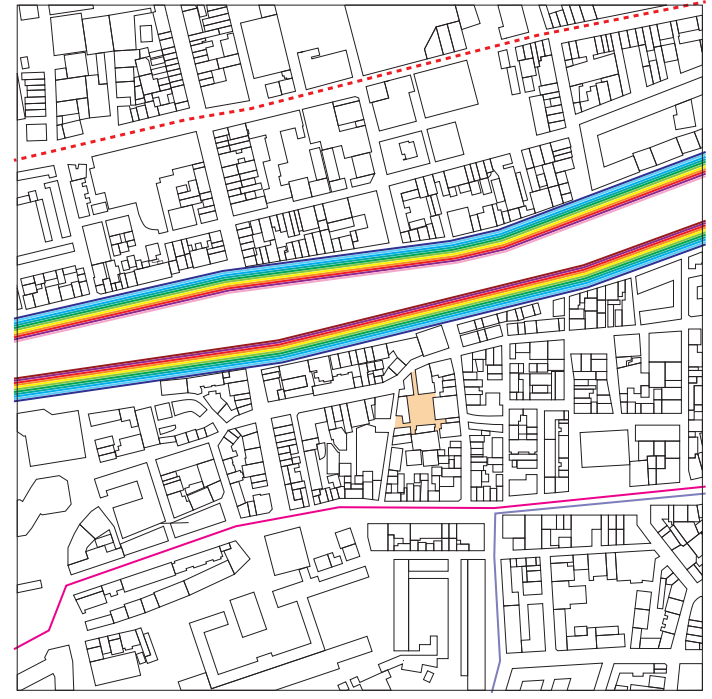

Public Transit Routes

Bus

Light Rail

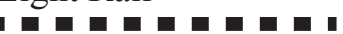

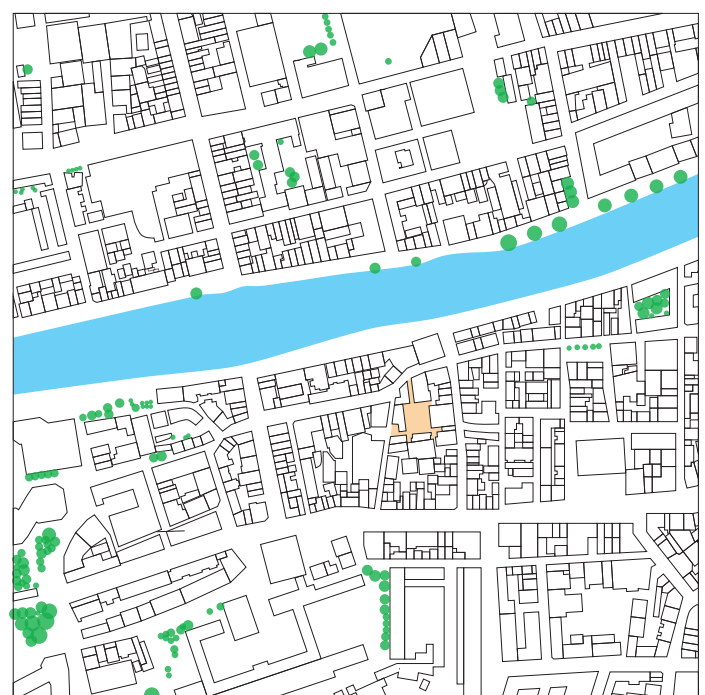

Landscape Features

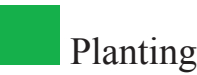

River 


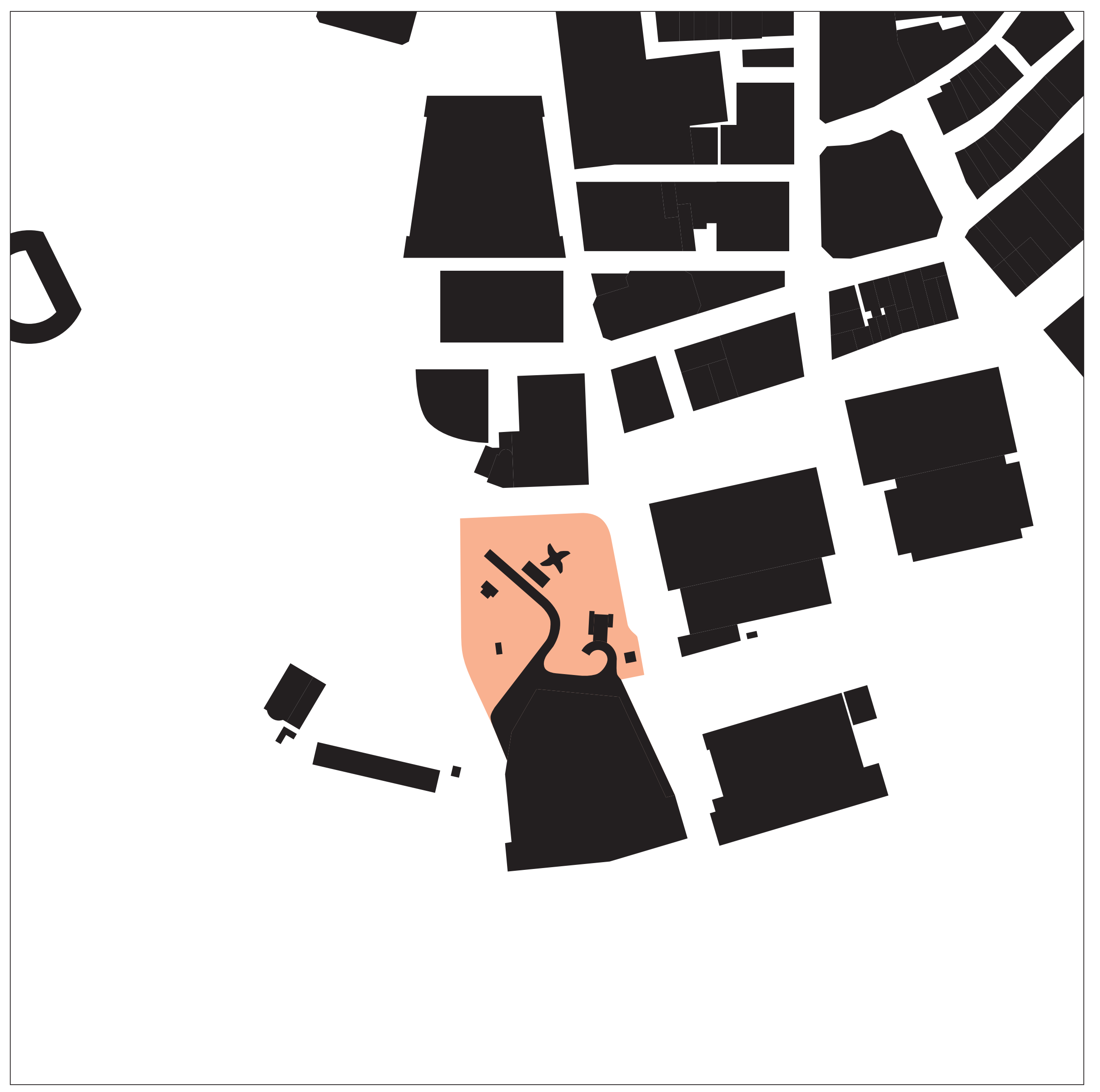


Figure 39.

(opposite page)

New Amsterdam

Plein figure ground

plan. Scale 1:2500

Figure 40. Analyti-

cal overlays.
New Amsterdam Plein

Manhattan Island, New York

UN Studio

2008

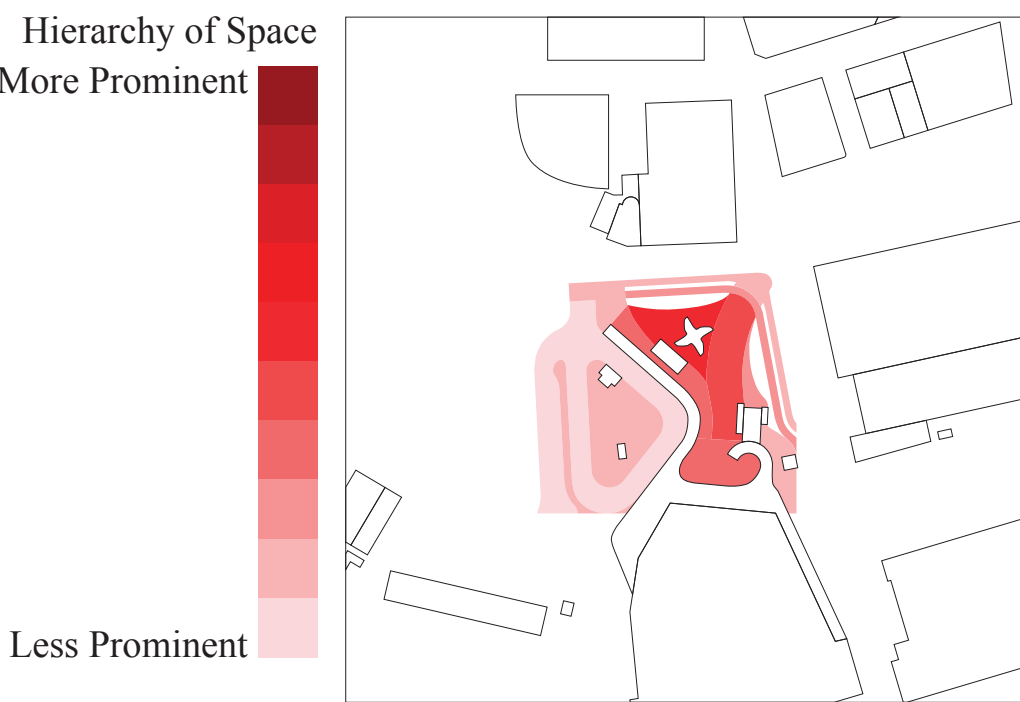

Soft Built Edges
Soft Built Edge

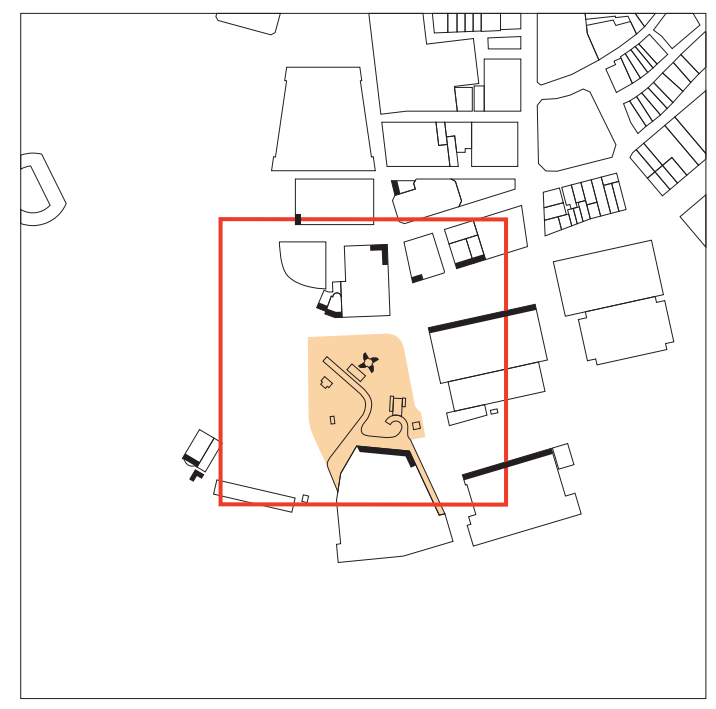

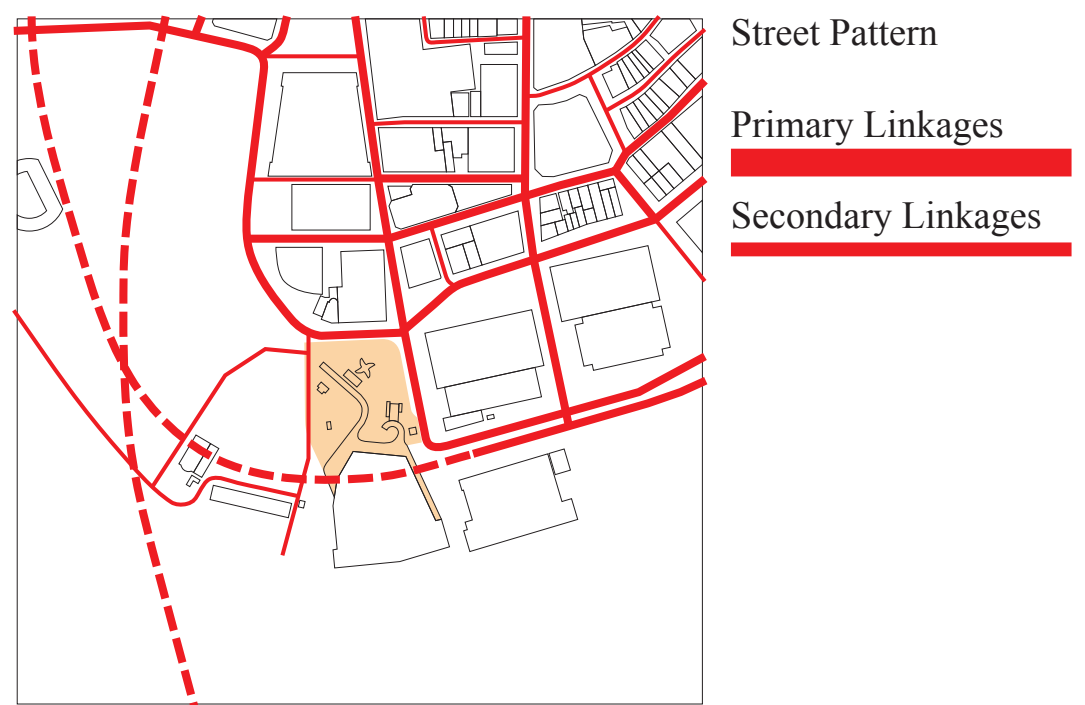

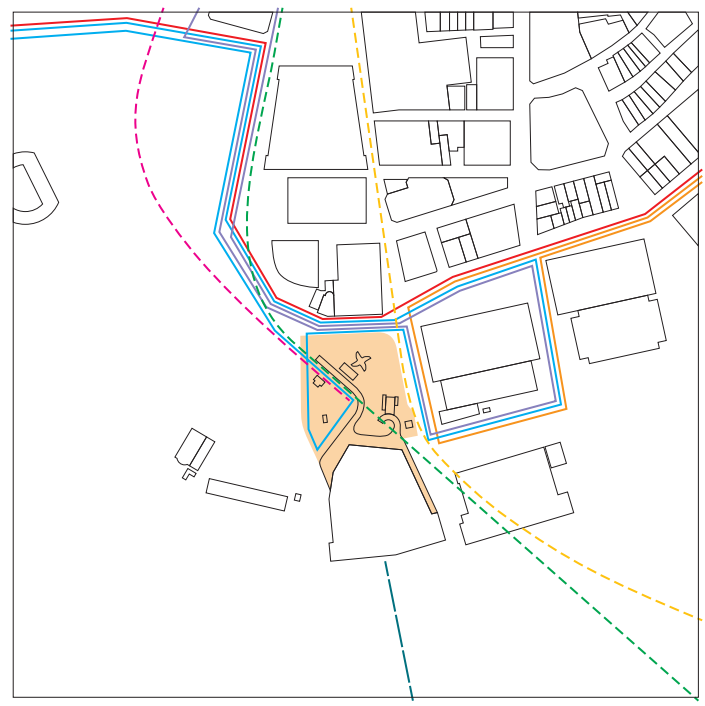

Public Transit Routes

Bus

Underground

Ferry

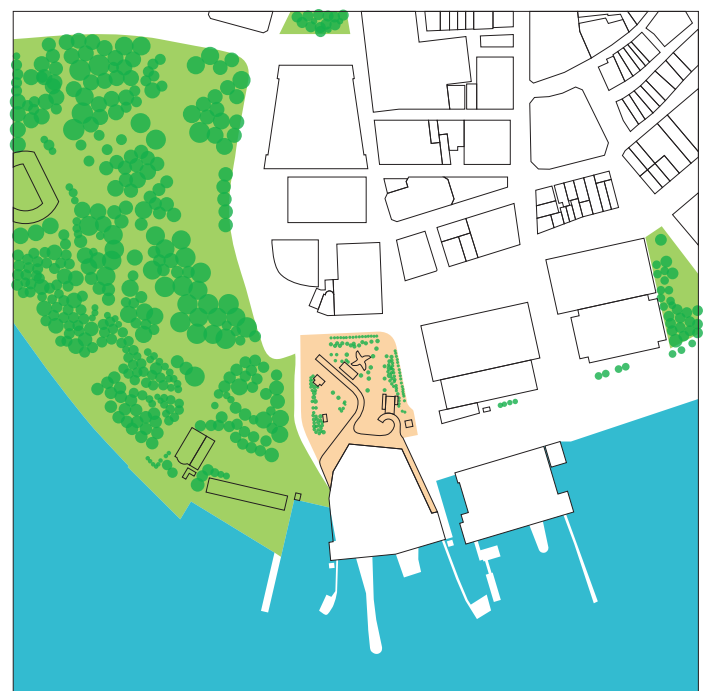

Landscape Features

Planting

Green Space

Ocean 


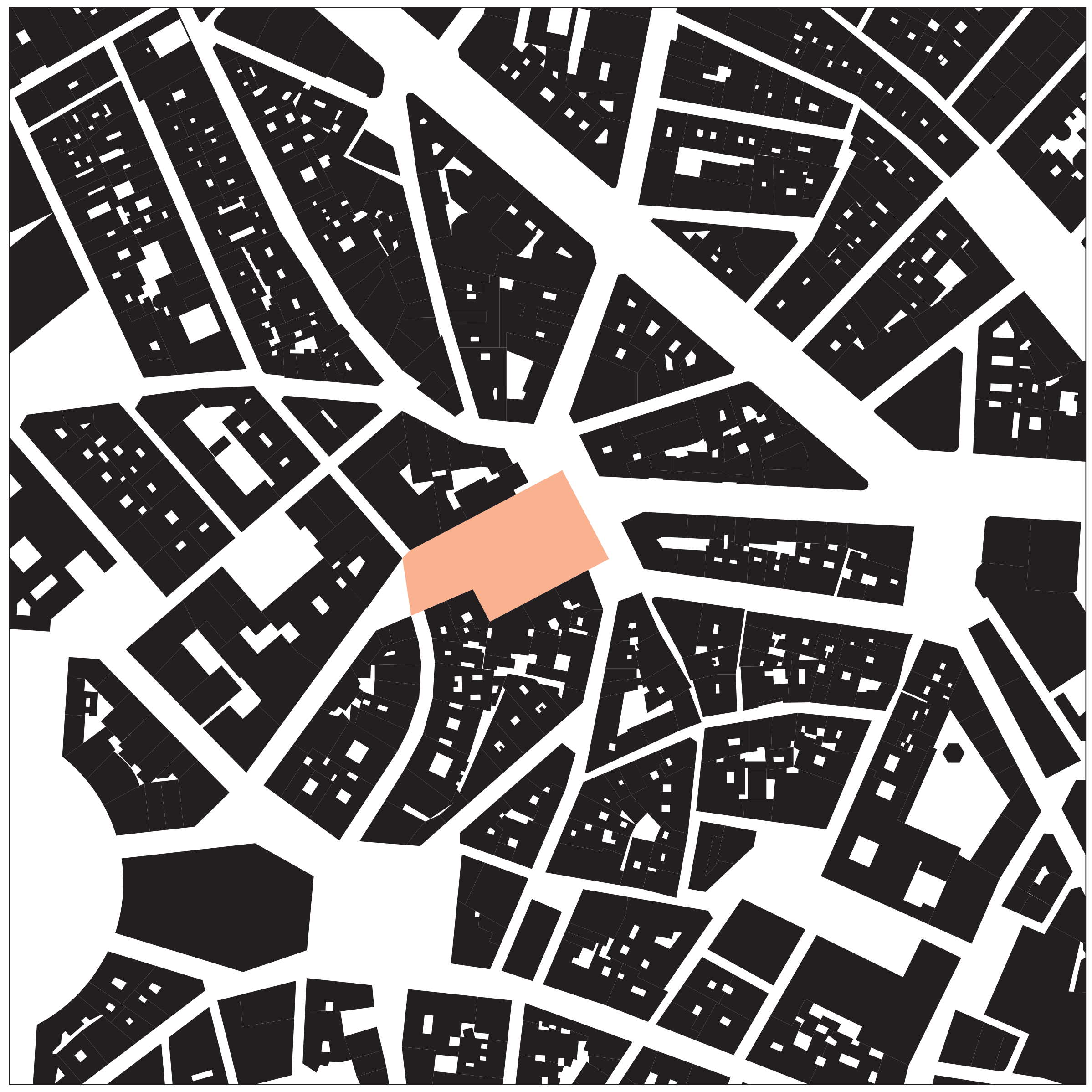


Figure 41.

(opposite page)

Plaza de Santo

Domingo figure

ground plan.

Scale 1:2500

Figure 42. Analyti-

cal overlays.

\section{Plaza de Santo Domingo}

Madrid, Spain

Marinas Arquitectos Asociados 2007

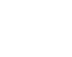
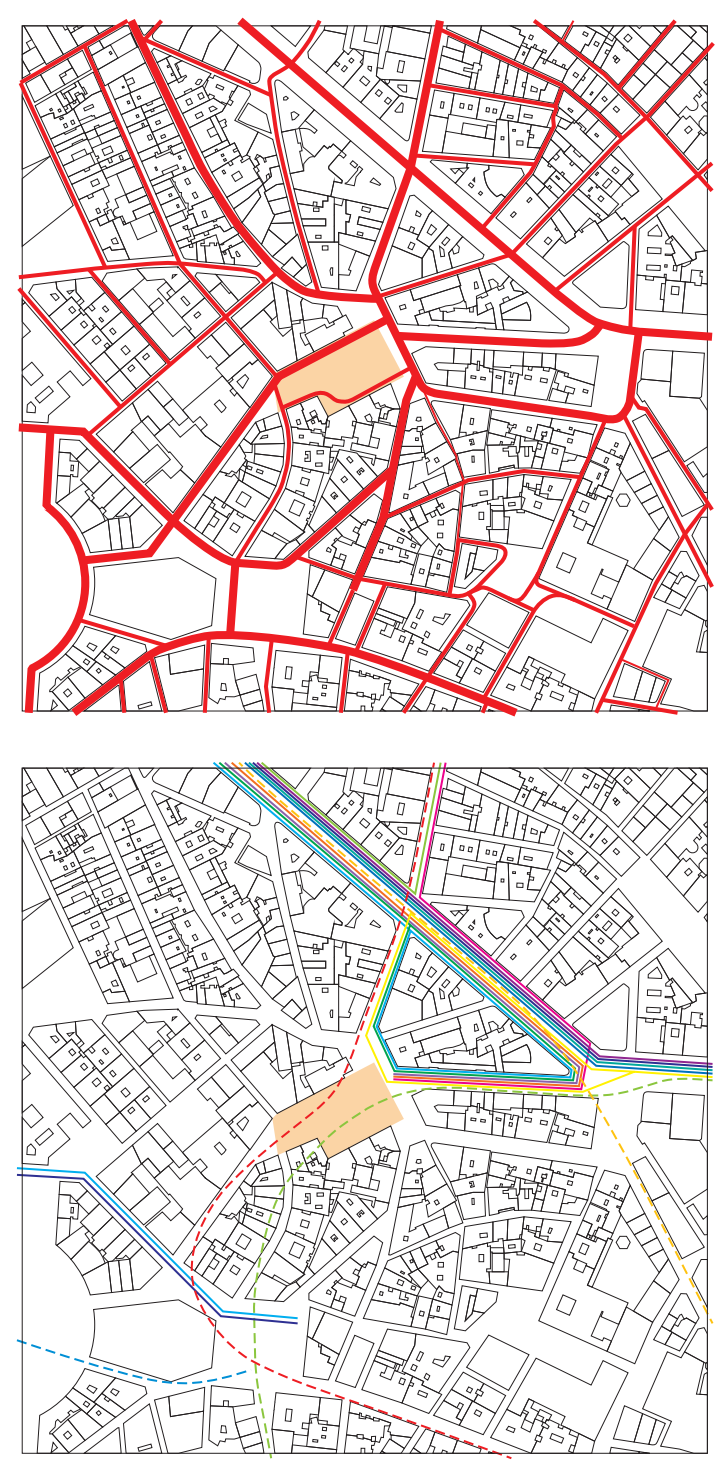

Public Transit Routes Bus

Underground

- - - - - -

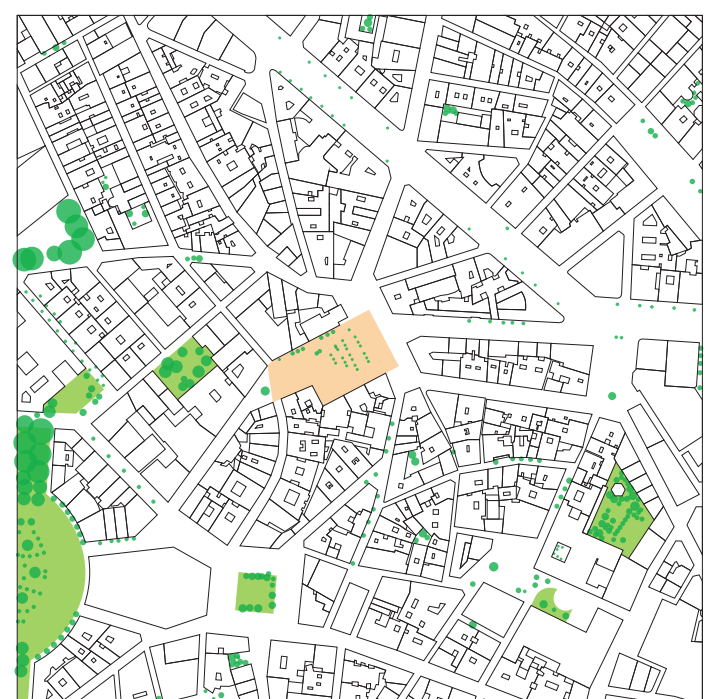

Primary Linkages

Secondary Linkages
Landscape Features

Planting
Green Space Hierarchy of S
More Prominent

Less Prominent

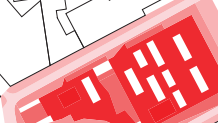

Soft Built Edges Soft Built Edge

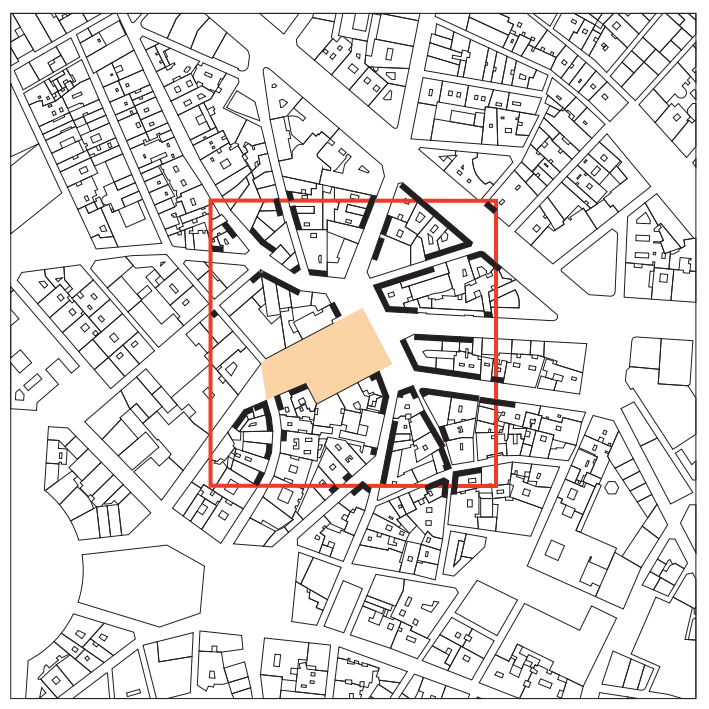




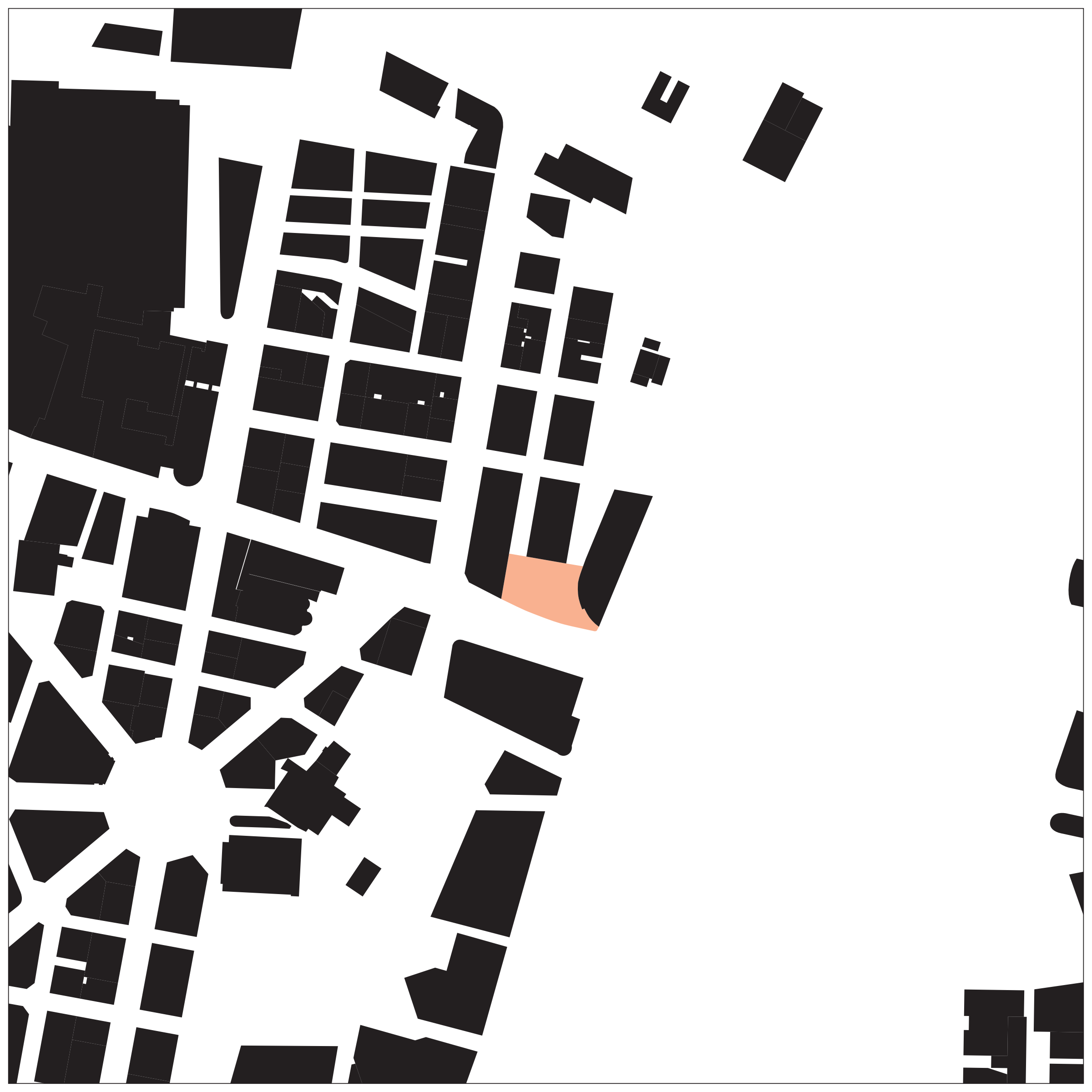


Figure 43.

(opposite page)

Square Four figure

ground plan.

Scale 1:2500

Figure 44. Analyti-

cal overlays.

\section{Square Four}

Beirut, Lebanon

Vladimir Djurovic Landscape Architects 2004

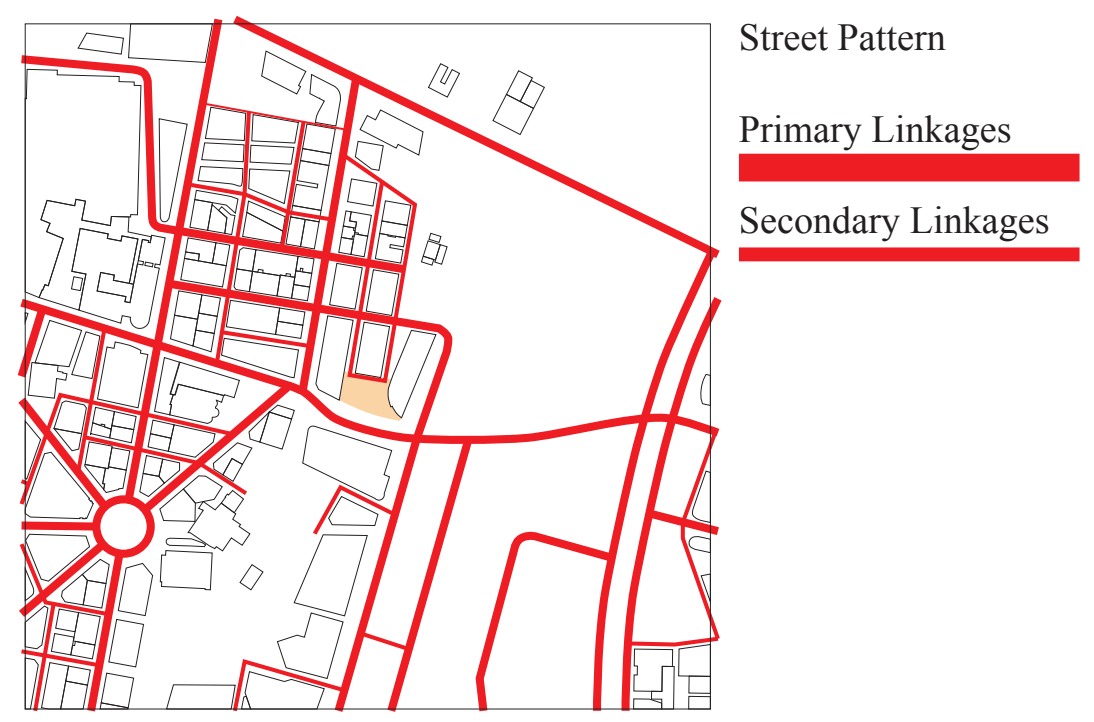

Hierarchy of Space More Prominent

Less Prominent

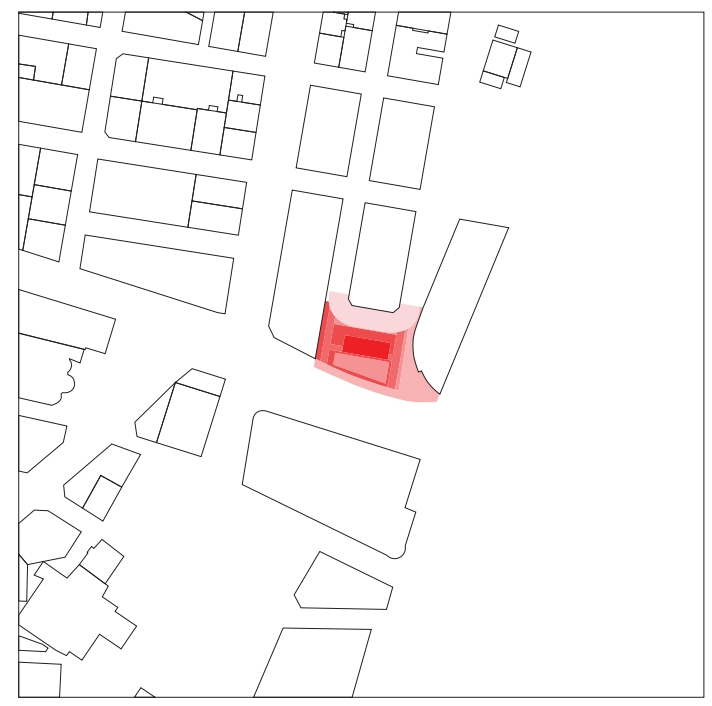

Soft Built Edges
Soft Built Edge

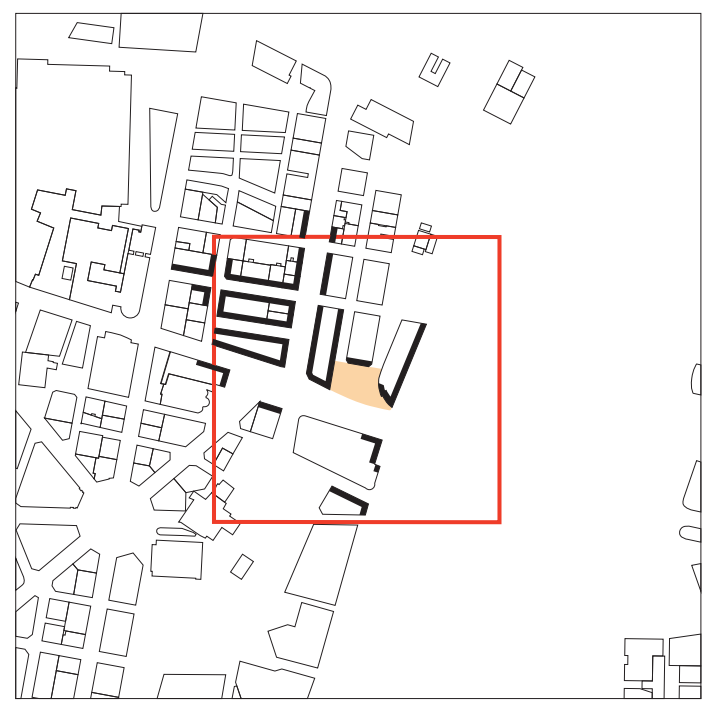

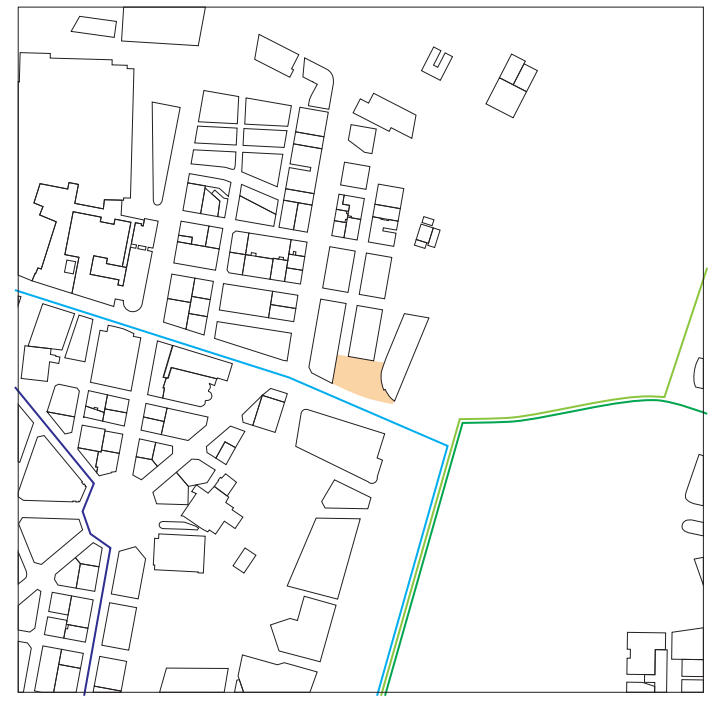

Public Transit Routes

Bus

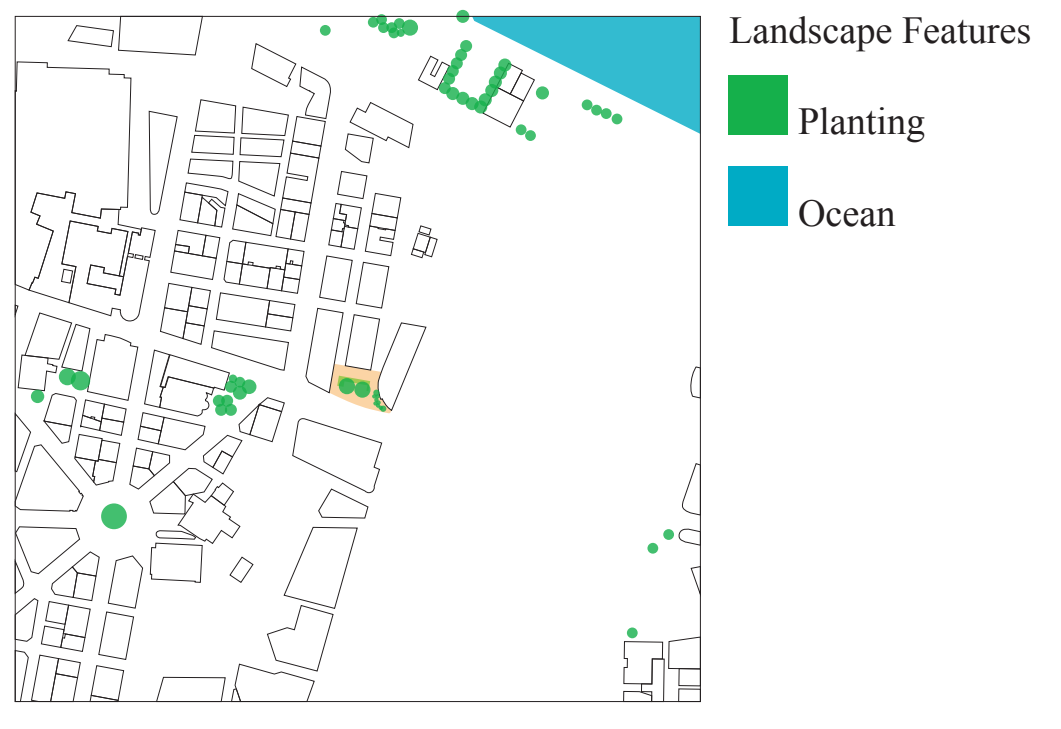




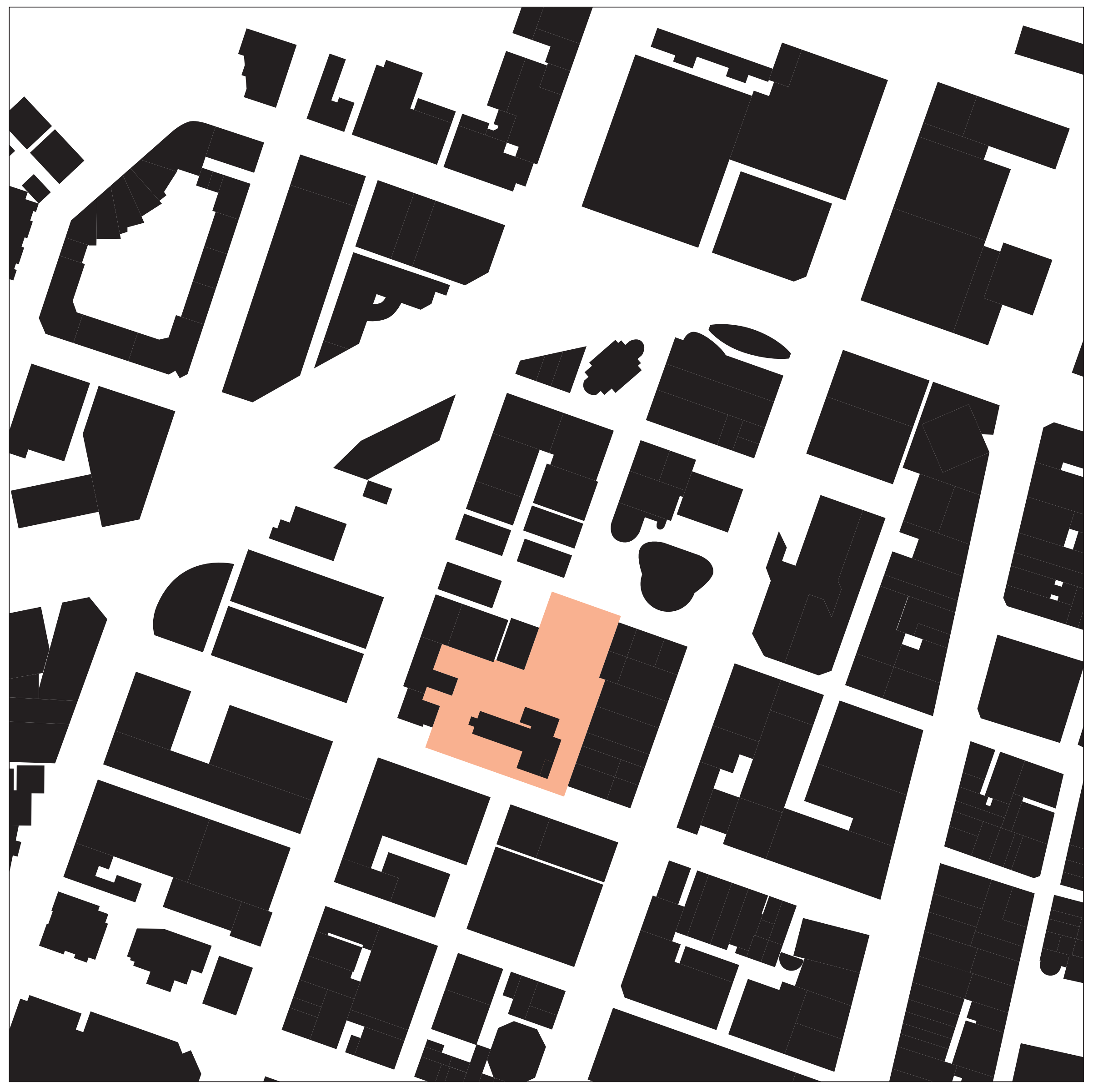


Figure 45.

(opposite page) St.

Patrick's Square

figure ground plan.

Scale 1:2500

Figure 46. Analyti-

cal overlays.
St. Patrick's Square

Auckland, New Zealand

Boffa Miskell

2007

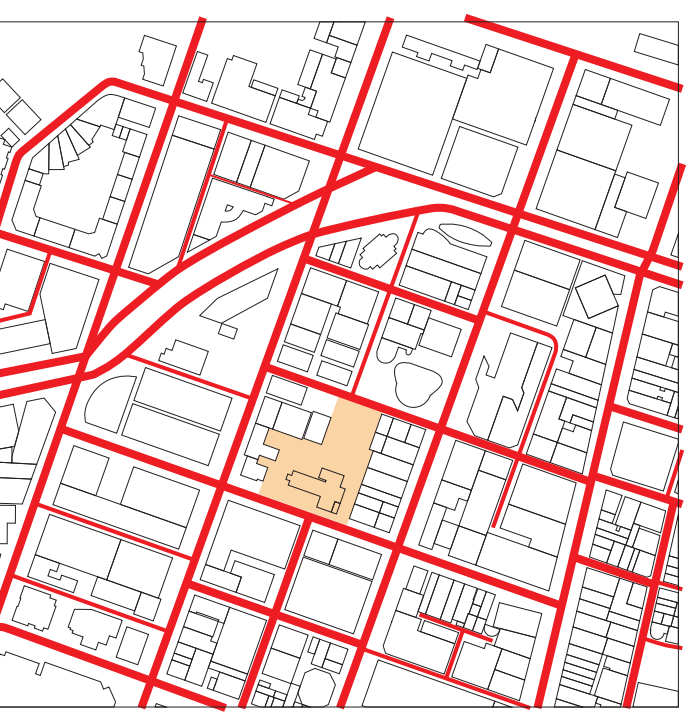

Street Pattern

Primary Linkages

Secondary Linkages

Hierarchy of Space More Prominent
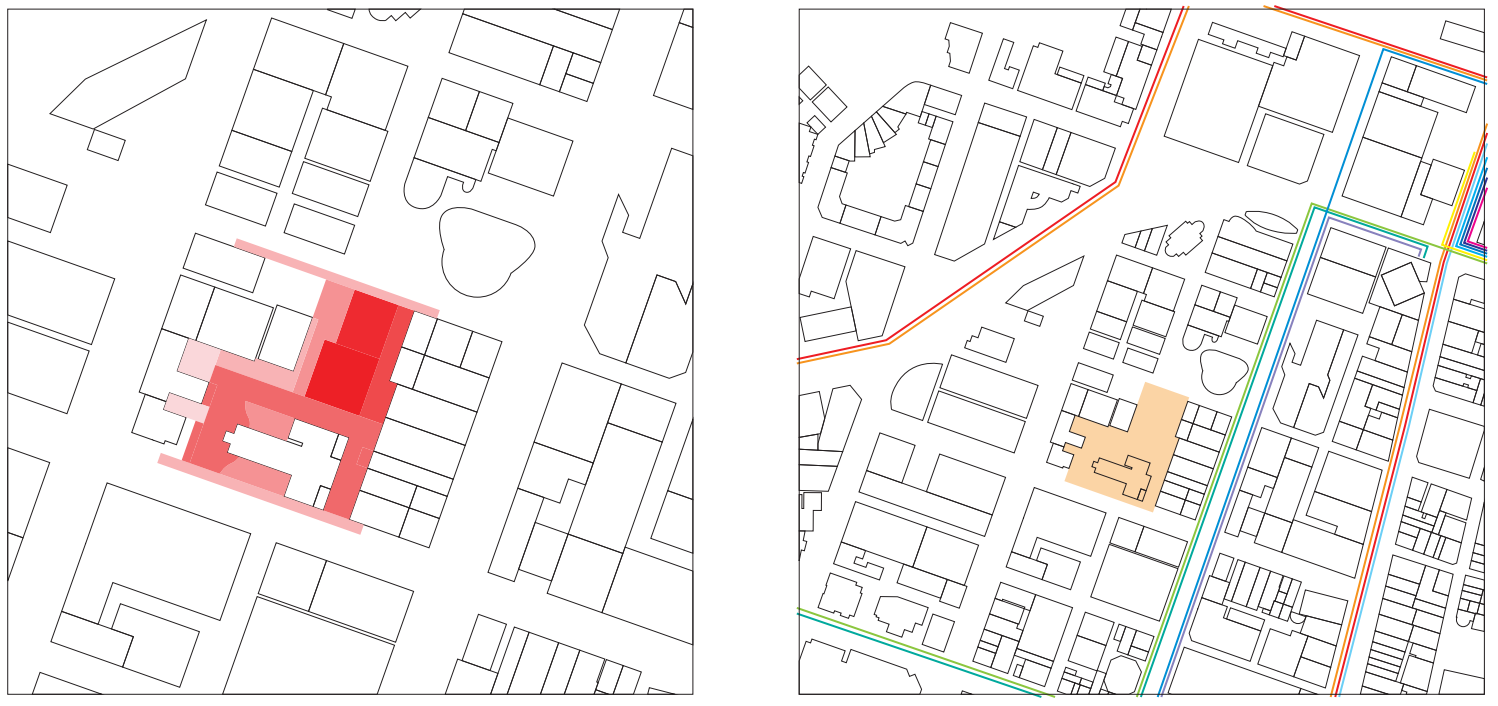

Public Transit Routes

Bus

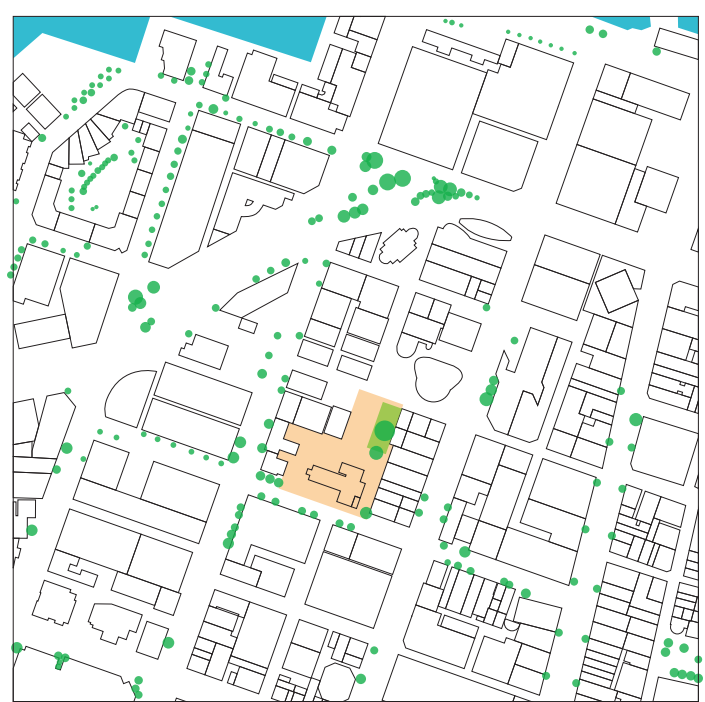

Landscape Features

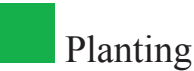

Green Space

Ocean

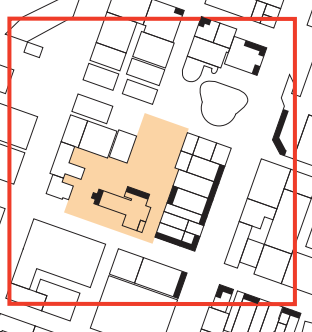




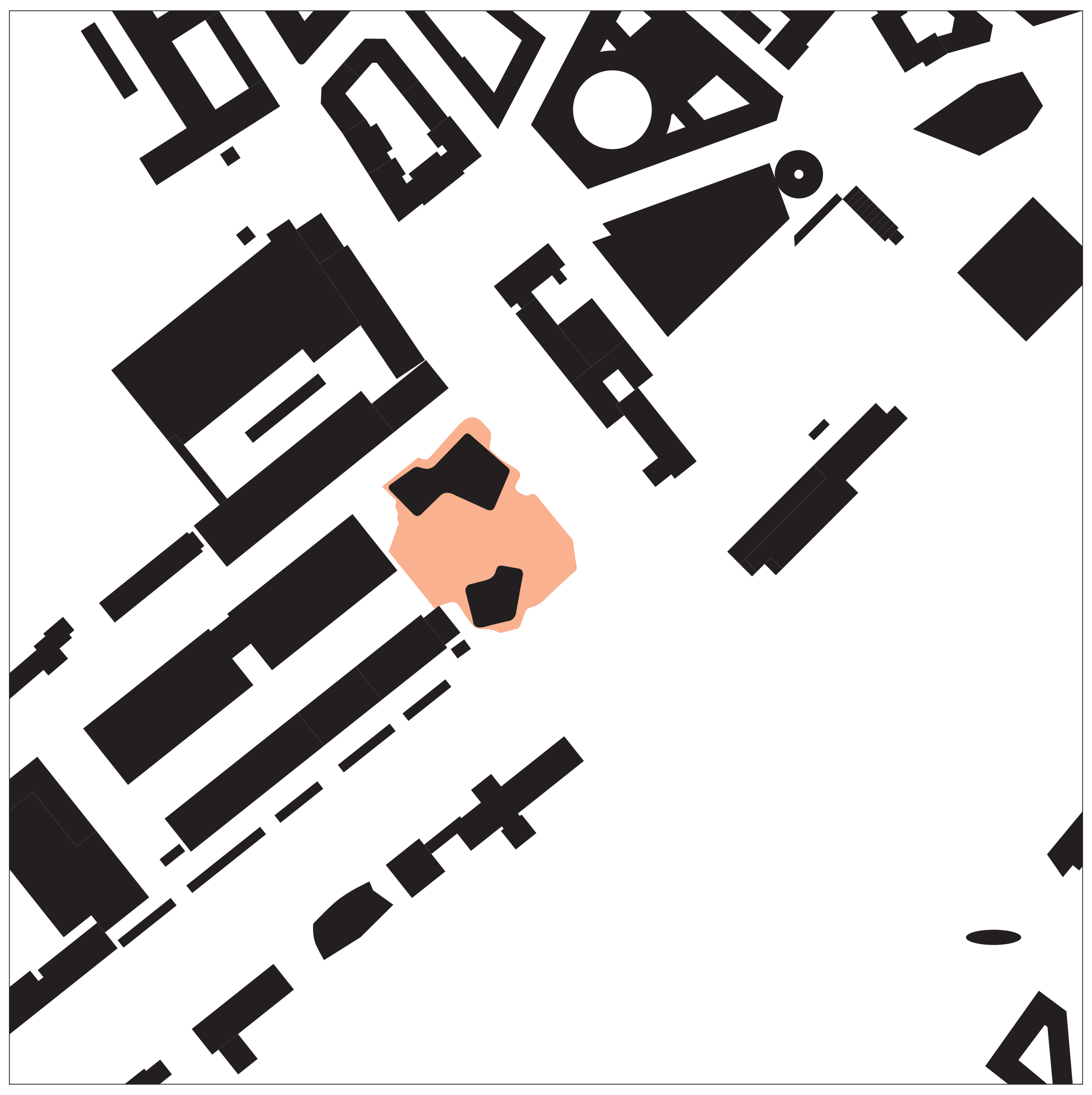


Figure 47.

(opposite page)

The City Dune

figure ground plan.

Scale 1:2500

Figure 48. Analyti-

cal overlays.
The City Dune

Copenhagen, Denmark

Stig L. Andersson (SLA)

2010

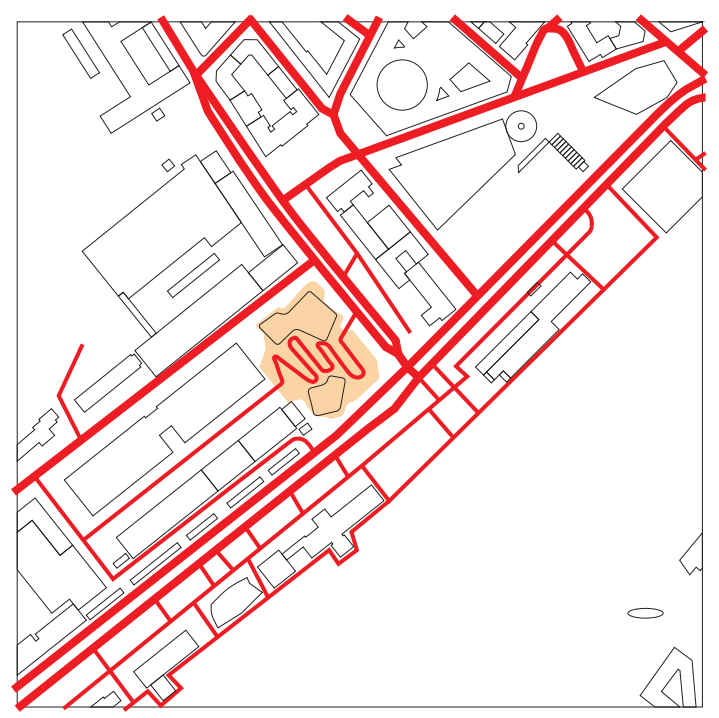

Street Pattern

Primary Linkages

Secondary Linkages

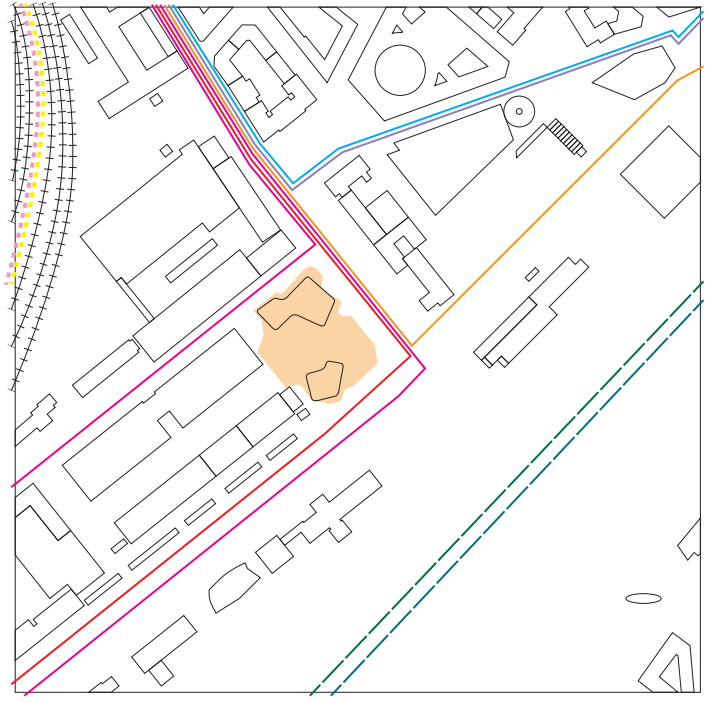

Public Transit Routes

Bus

Light Rail

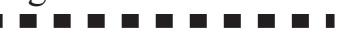

Rail

$+1+1+1+1$

Ferry

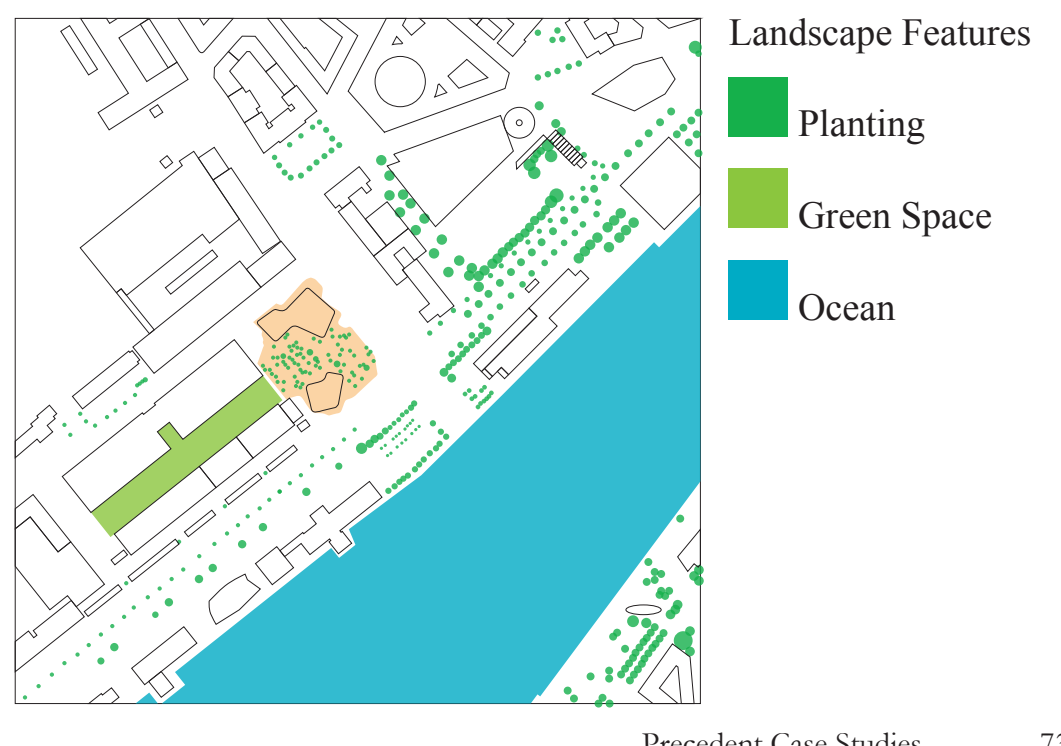

Soft Built Edges
Soft Built Edge

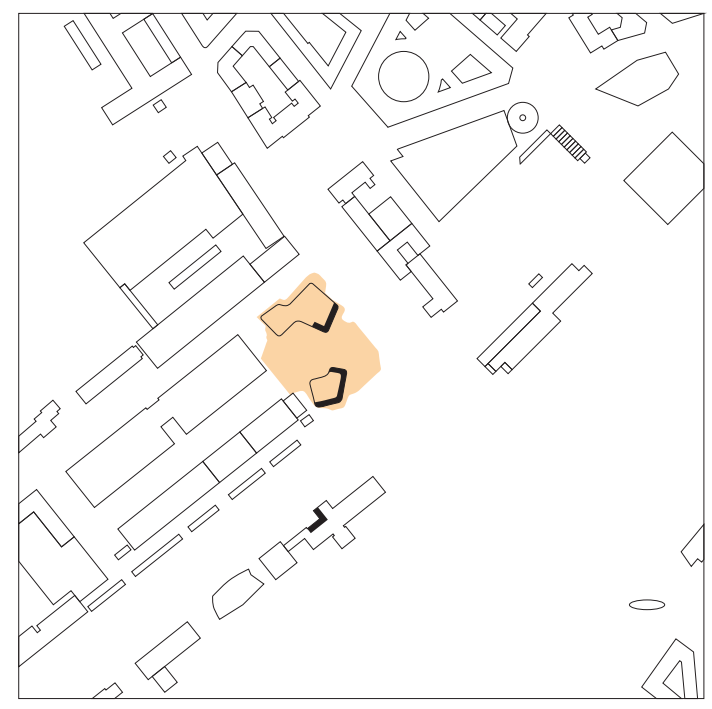




$$
\text { J }
$$


Figure 49.

(opposite page)

Theatre Square

figure ground plan.

Scale 1:2500

Figure 50. Analyti-

cal overlays.

\section{Theatre Square}

Rotterdam, The Netherlands

Adriaan Geuze and West 8 Architects 1996

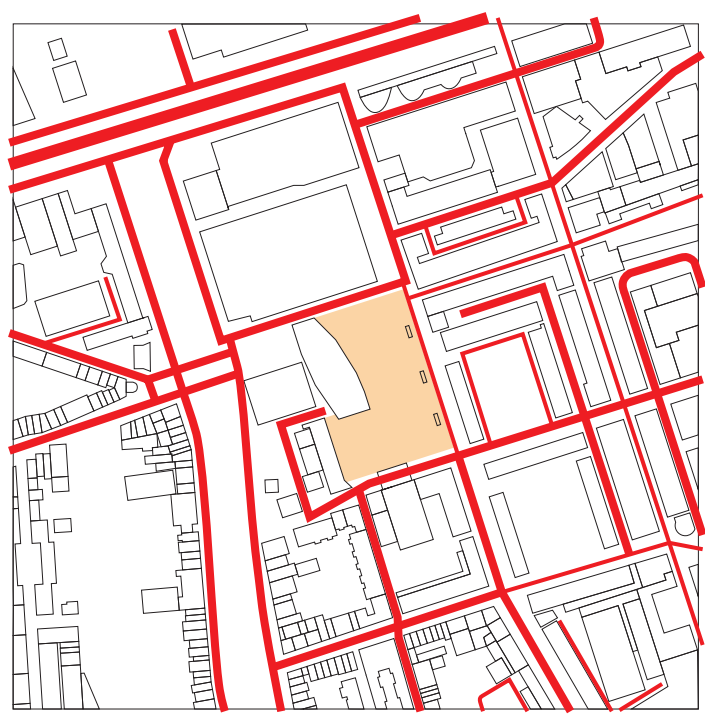

Street Pattern

Primary Linkages

Secondary Linkages

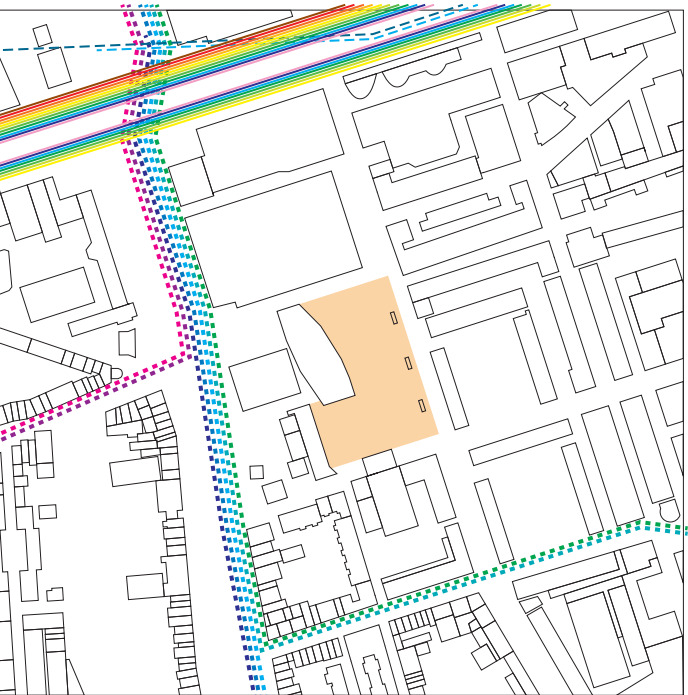

Public Transit Routes

Bus

Light Rail

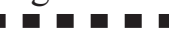

Underground

- - - - -

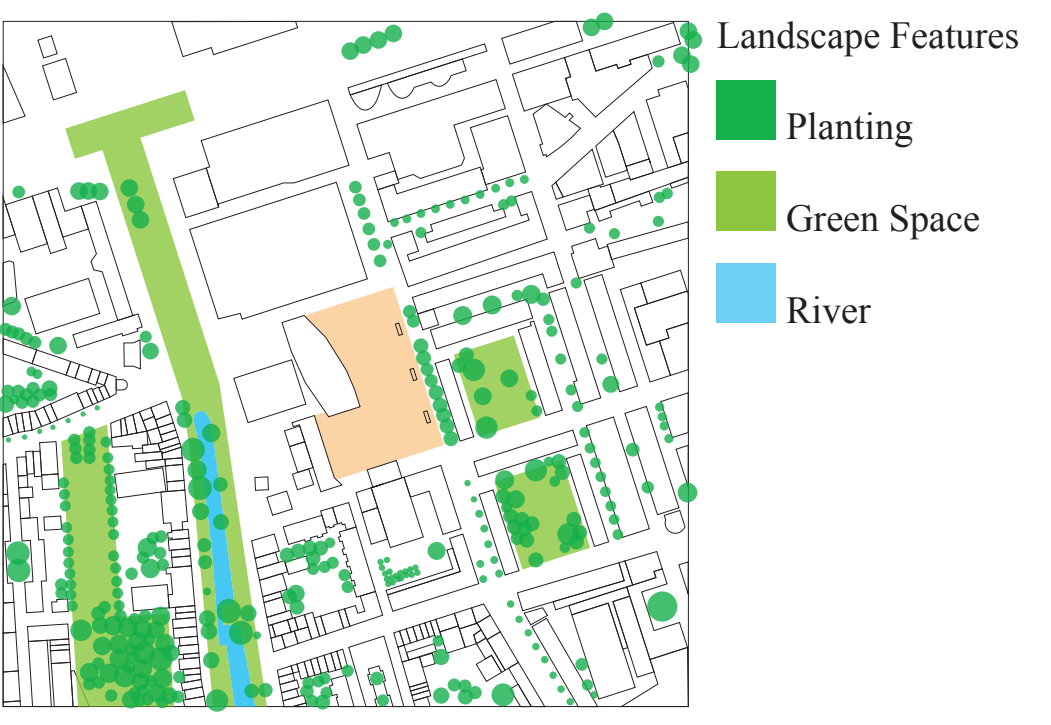

Precedent Case Studies 


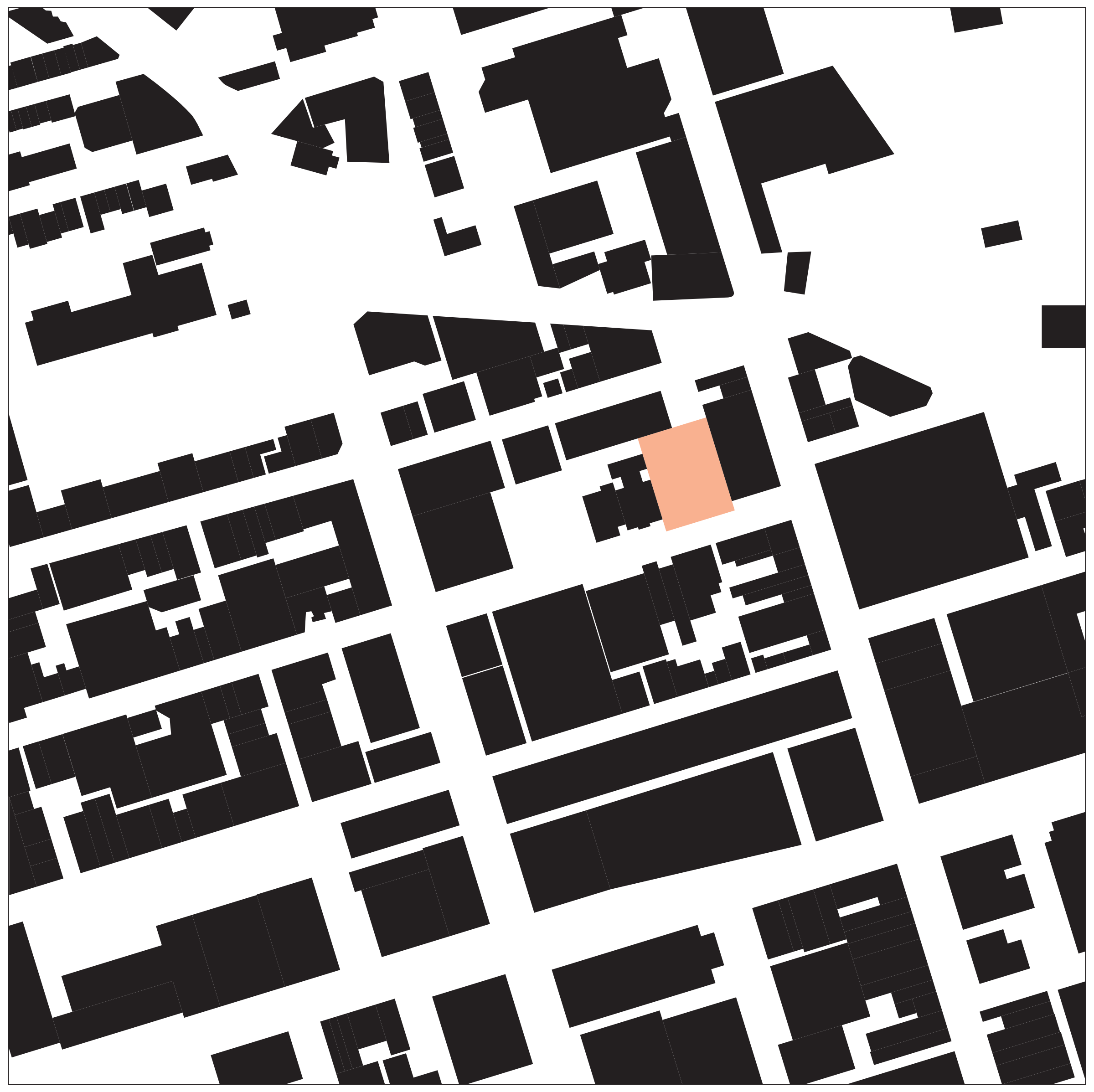


Figure 51.

(opposite page)

Town Hall Square

figure ground plan.

Scale 1:2500

Figure 52. Analyti-

cal overlays.

\section{Town Hall Square}

Toronto, Canada

Janet Rosenberg and Associates 2005
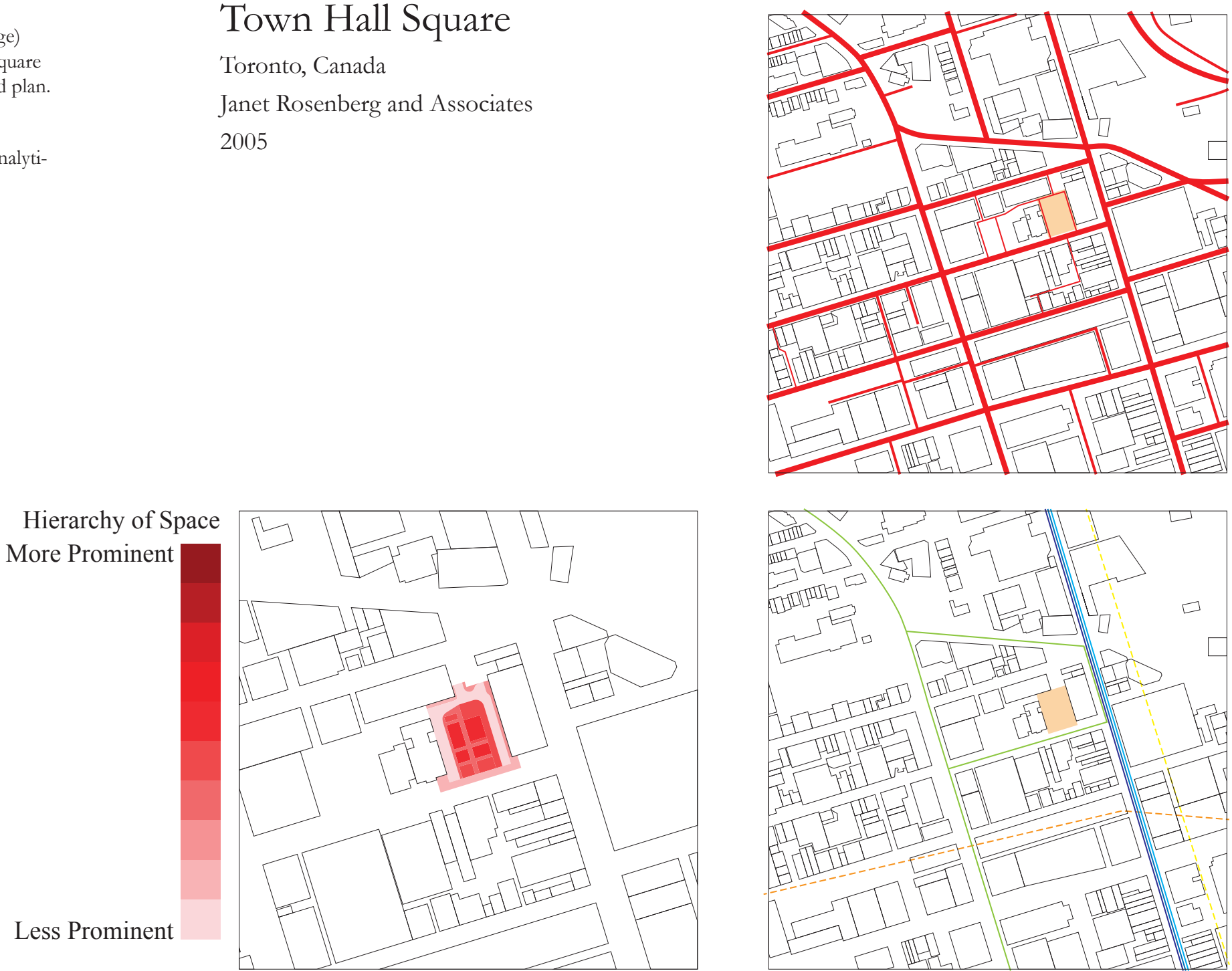

Soft Built Edges
Soft Built Edge

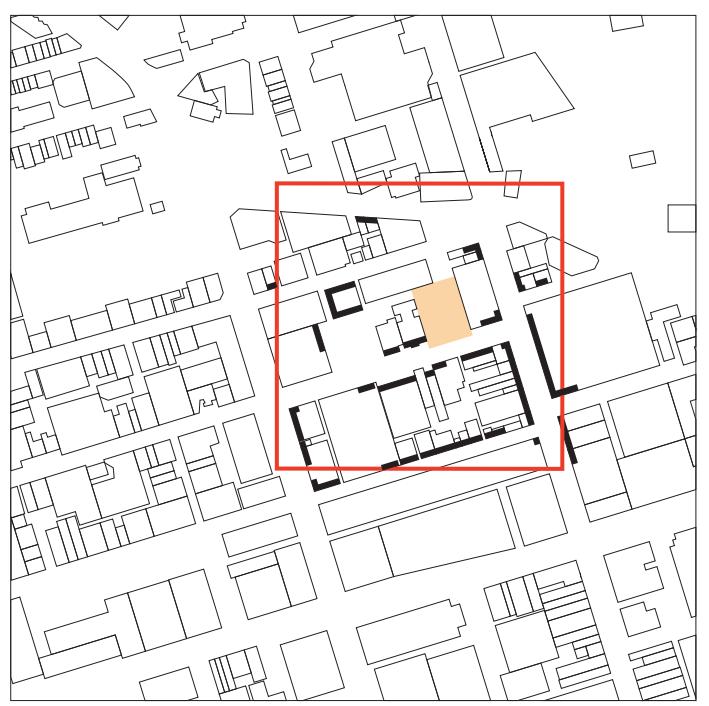

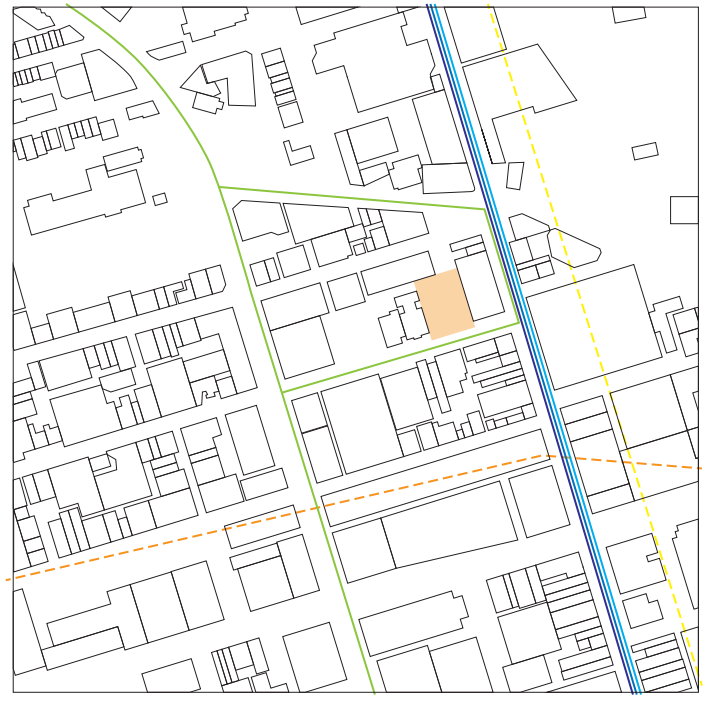

Public Transit Routes

Bus

Underground

- - - - - -

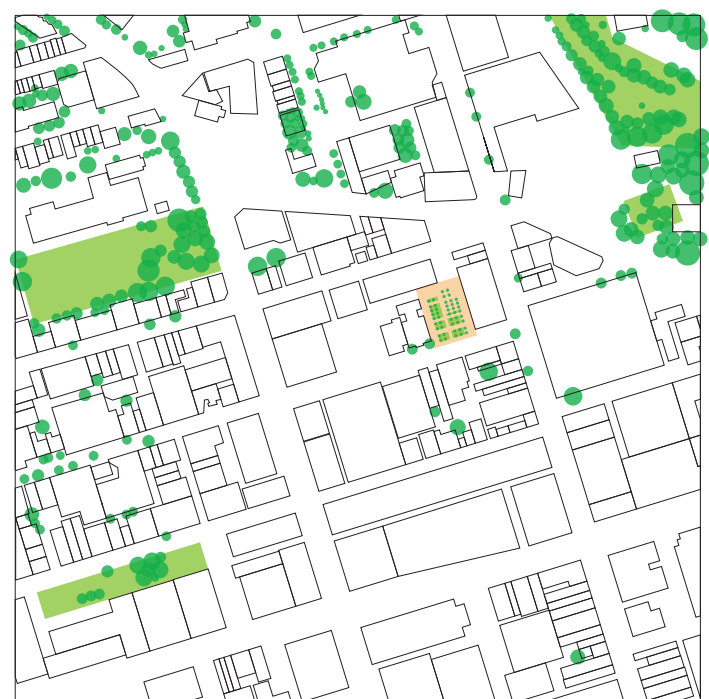

Landscape Features

Planting

Green Space 


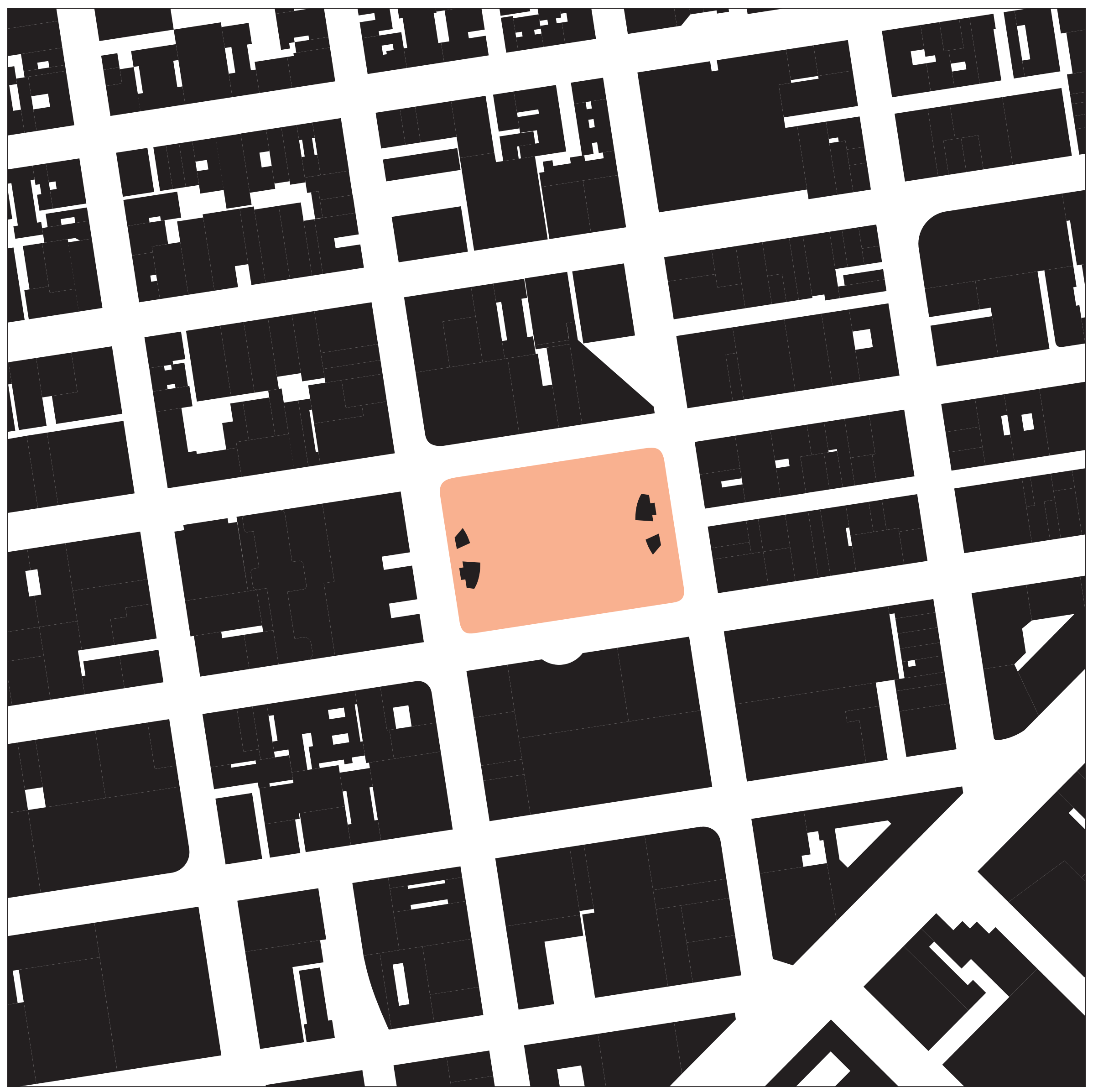


Figure 53.

(opposite page)

Union Square

figure ground plan.

Scale 1:2500

Figure 54. Analytical overlays.

\section{Union Square}

San Francisco, California

April Phillips Design Works

and Forthingham Landscape Architects 2002
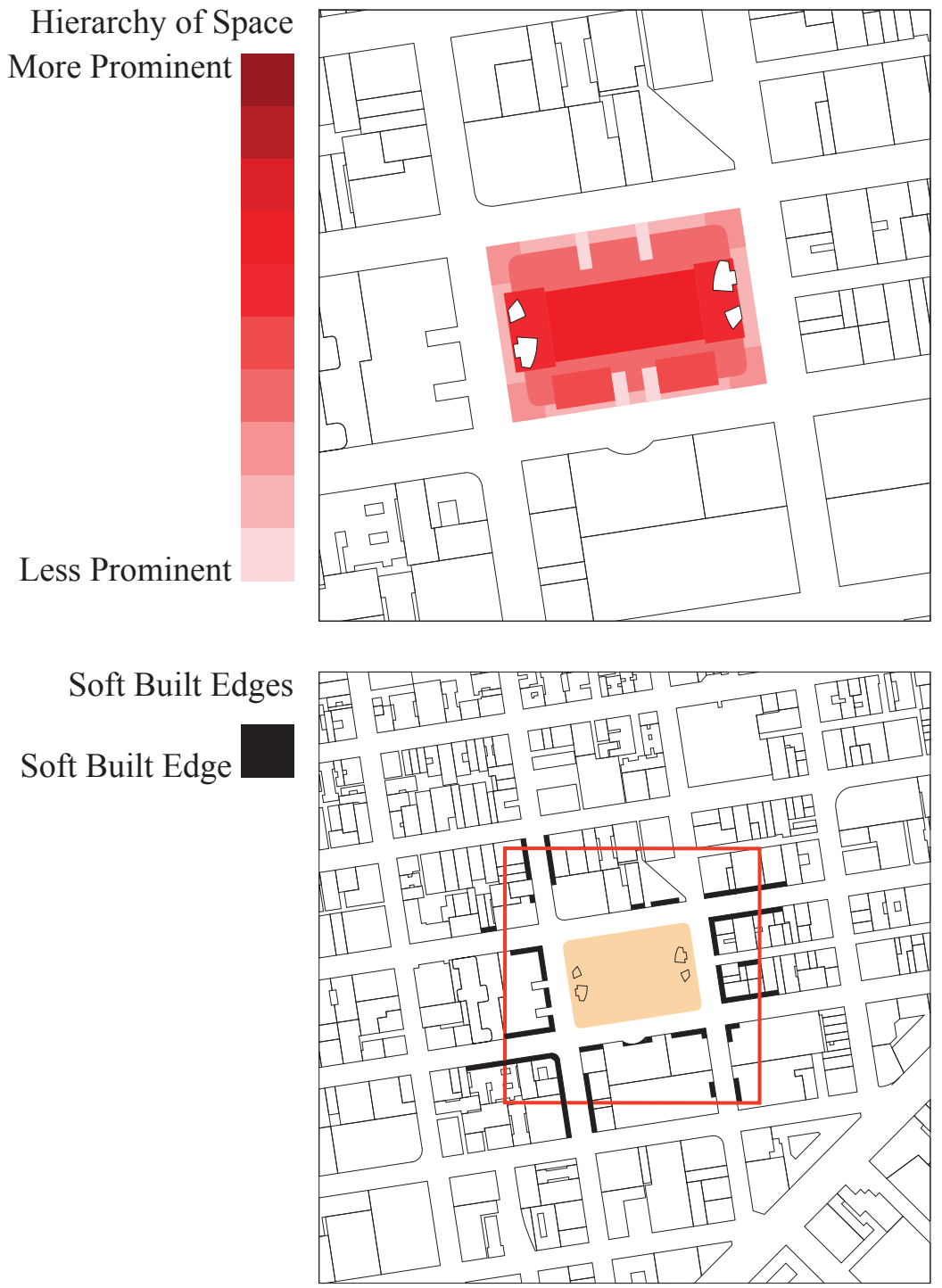

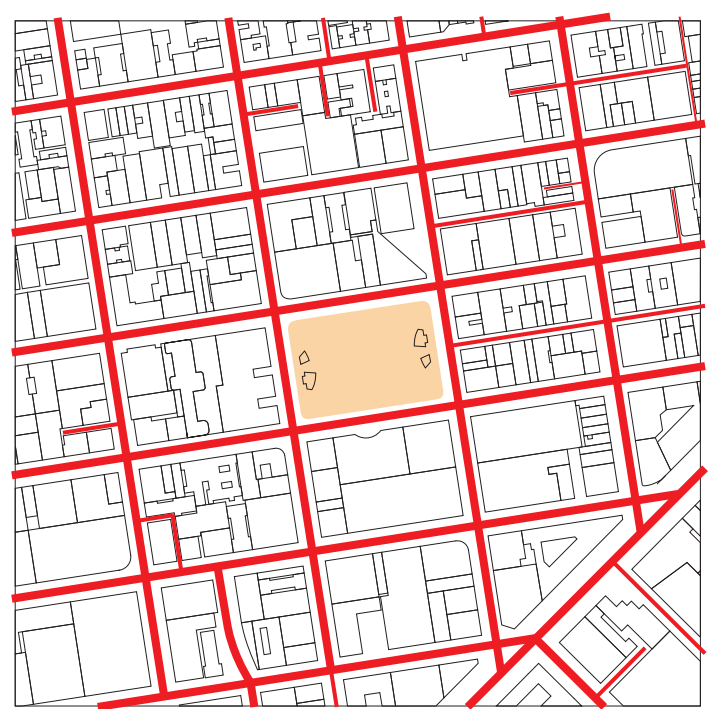

Street Pattern

Primary Linkages

Secondary Linkages

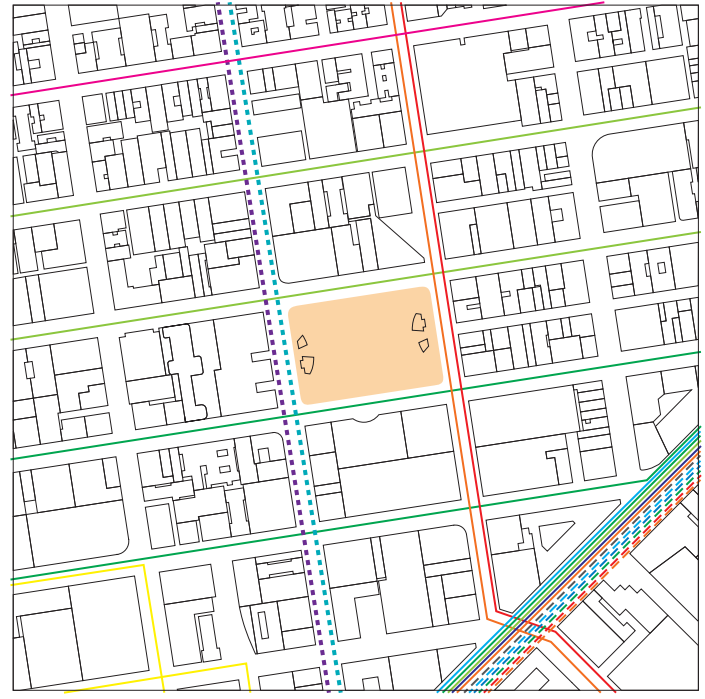

Public Transit Routes

Bus

Light Rail

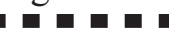

Underground

$------$

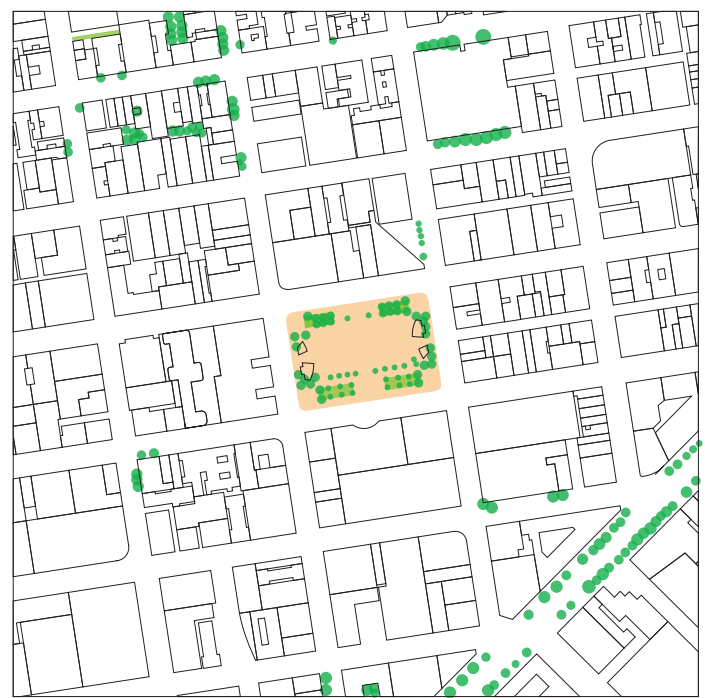

Landscape Features

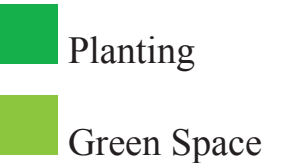




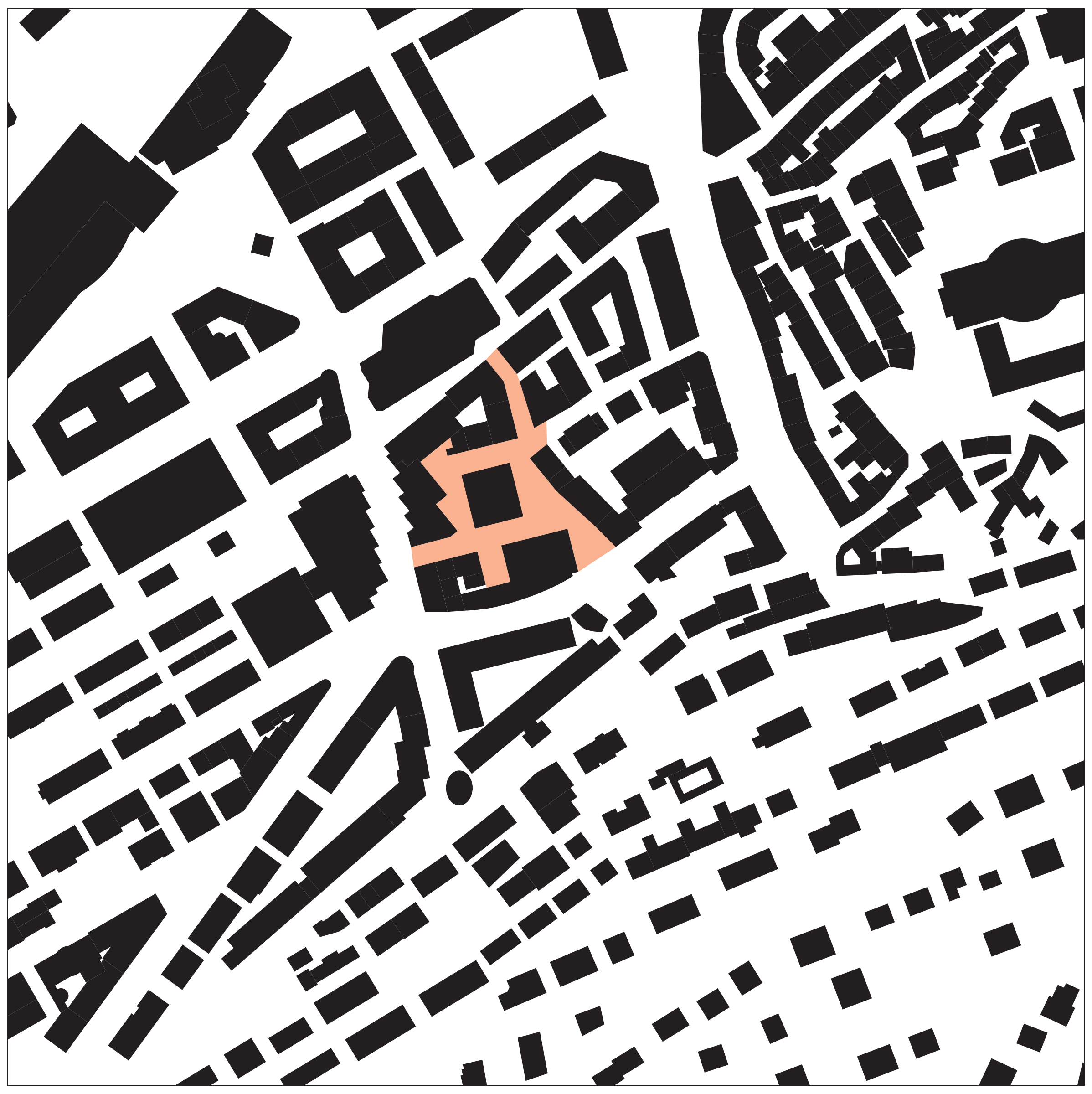


Figure 55.

(opposite page)

Urban Lounge

figure ground plan.

Scale 1:2500

Figure 56. Analyti-

cal overlays.

\section{Urban Lounge}

St. Gallen, Switzerland

Carlos Martinez with Pipilotti Rist 2006
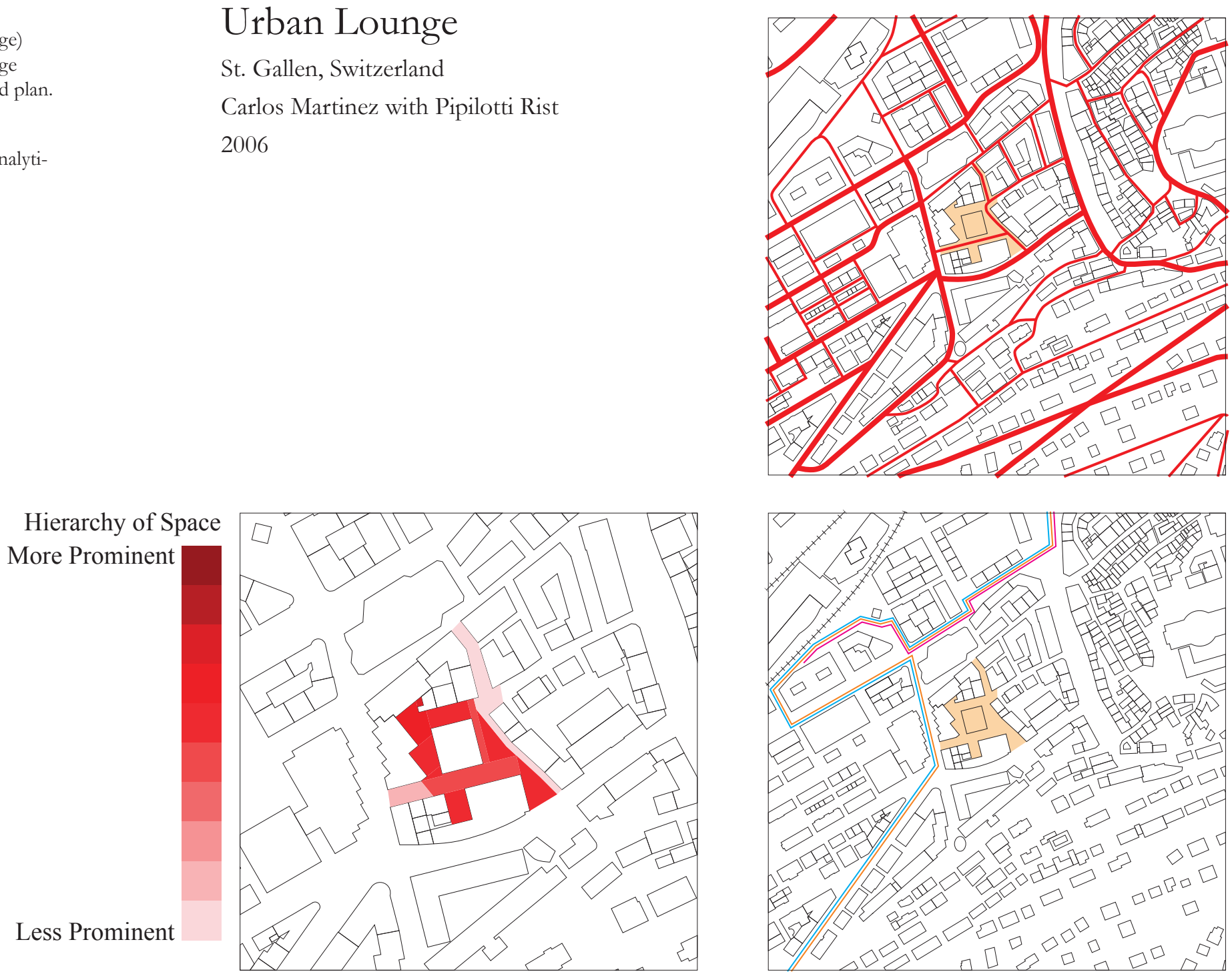

Public Transit Routes

Bus

Rail

$+1+1+1+H$

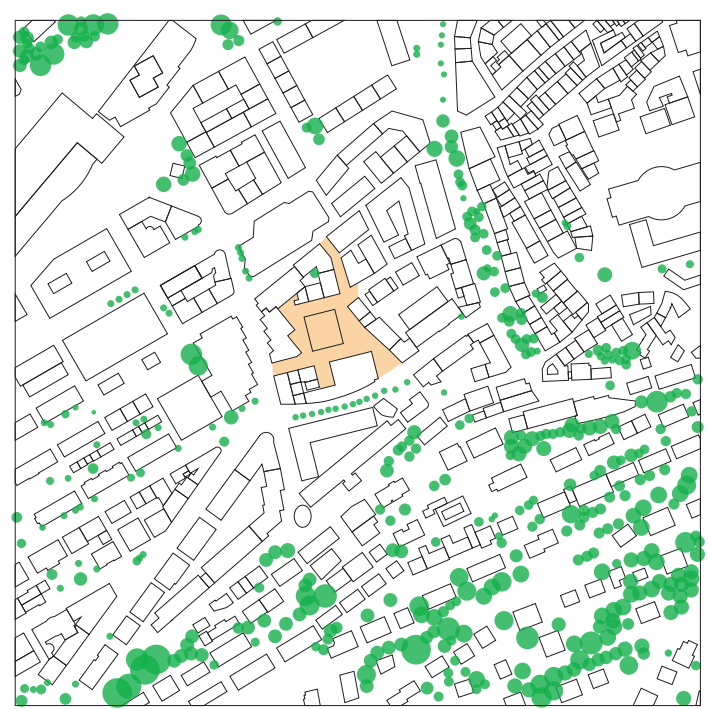

Landscape Features

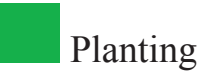

Soft Built Edge

$\mathrm{NA}$ 


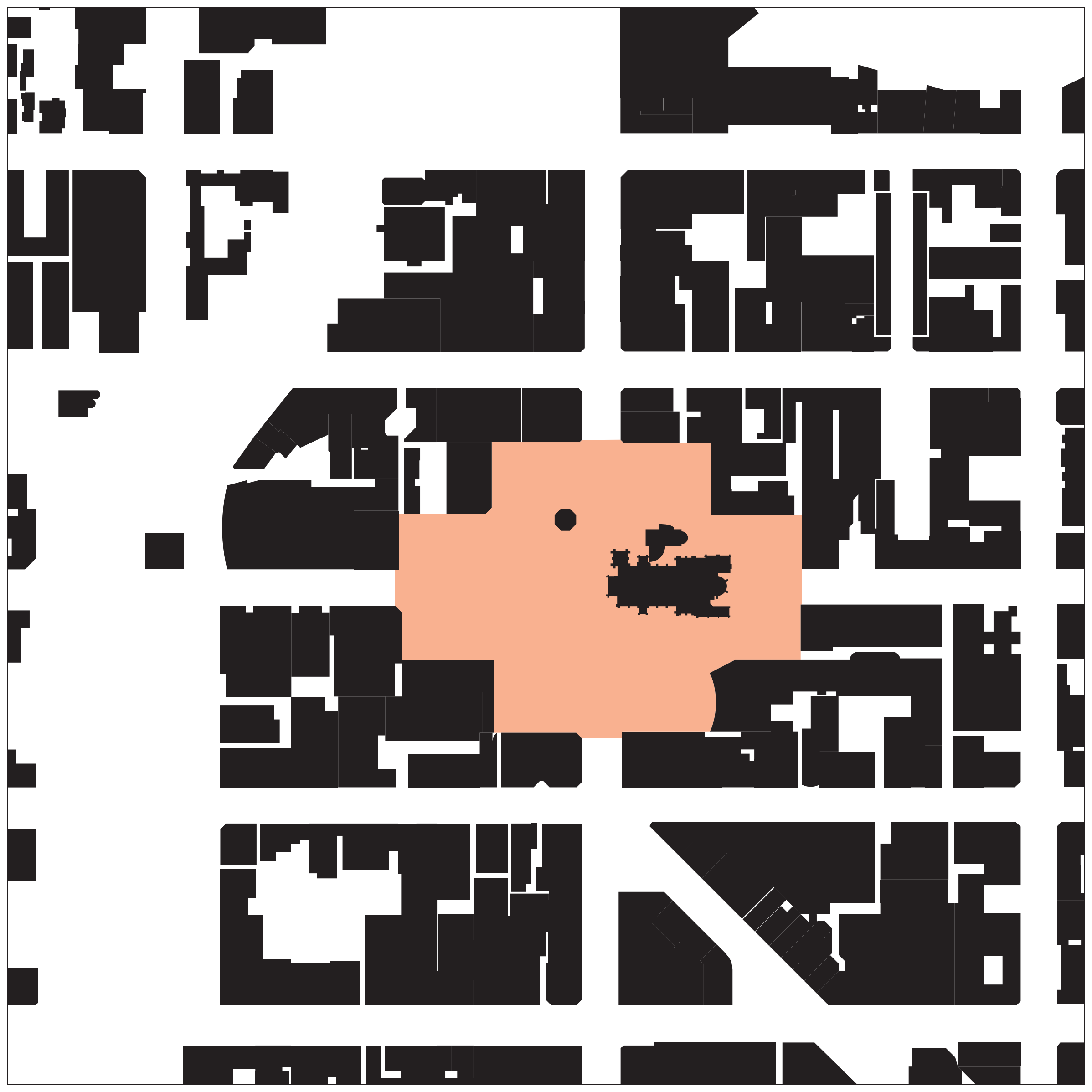


Figure 57.

(opposite page)

Cathedral Square

figure ground plan.

Scale 1:2500

Figure 58. Analyti-

cal overlays.
Cathedral Square

Christchurch, New Zealand

Edward Jollie

1850
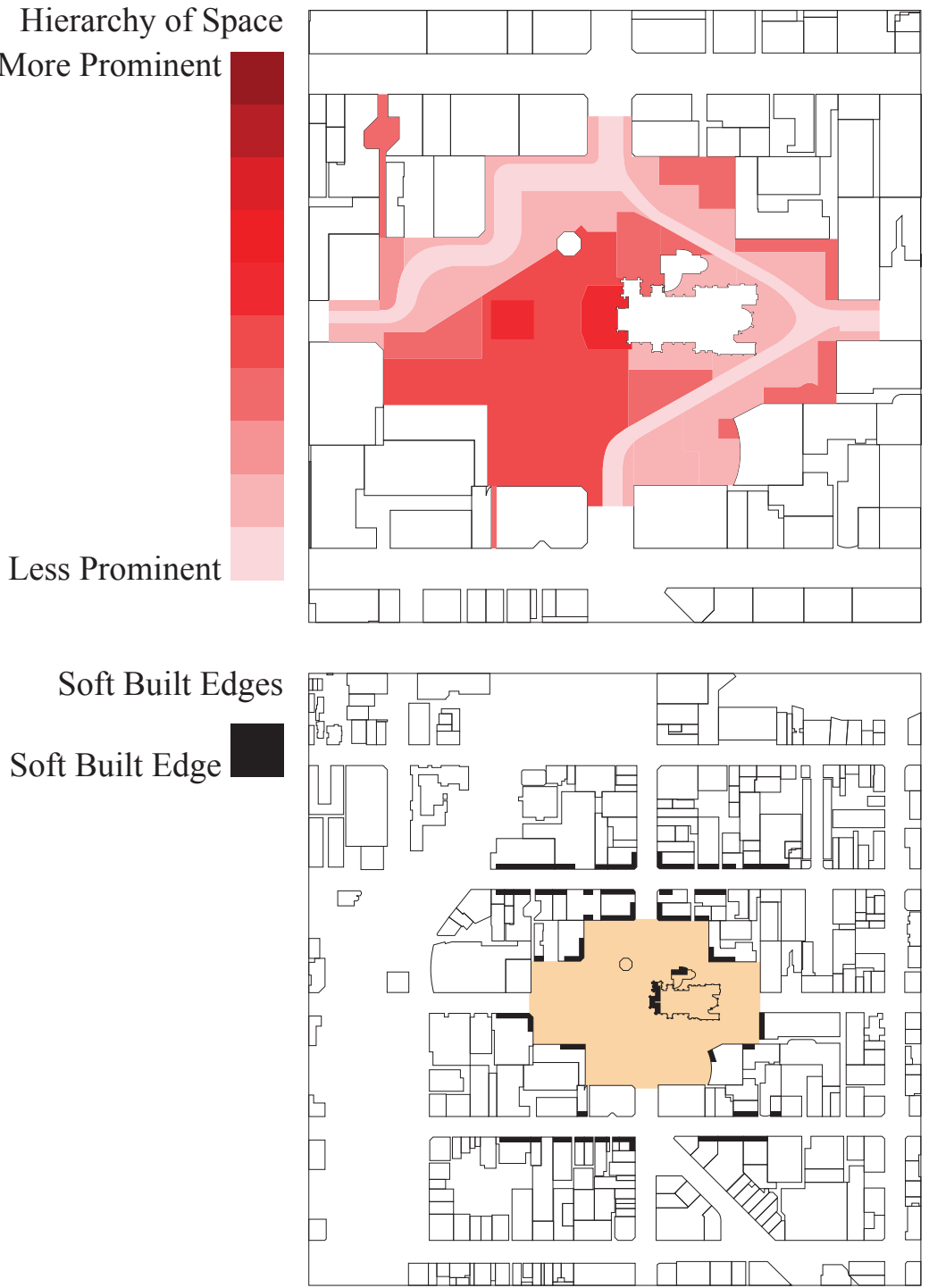
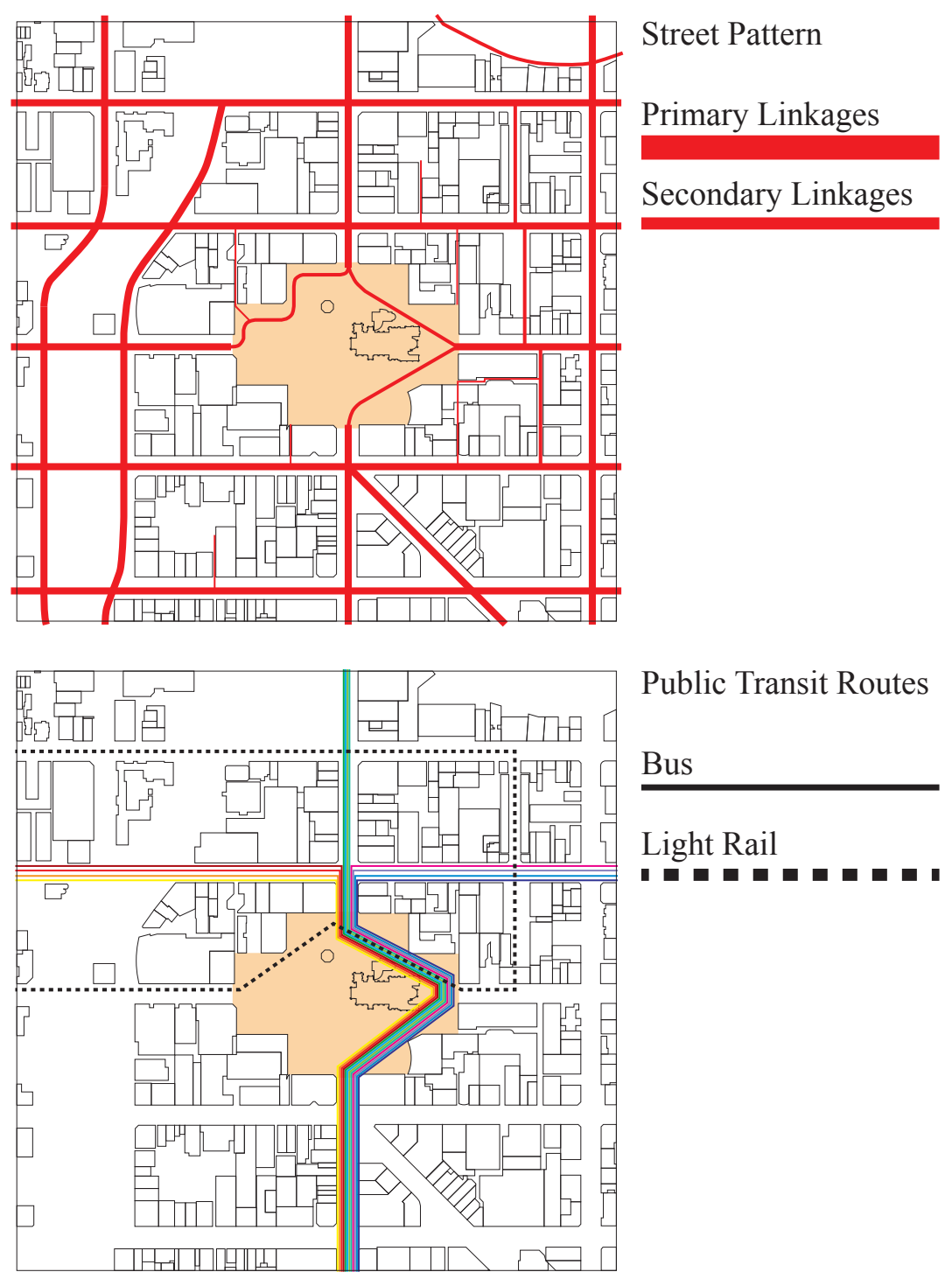

Public Transit Routes

Bus

Light Rail

- - = -

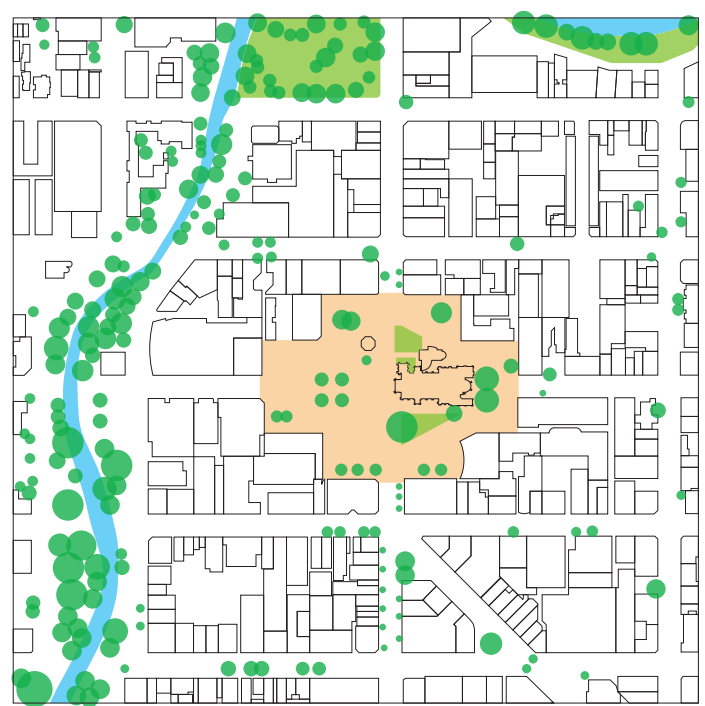

Landscape Features

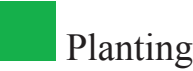

Green Space

River 
84 U.thon Traum 


\section{Findings}

The graphical analysis generally proved to be useful. However, some attributes proved to be more so than others.

For example, the investigation of public transit routes affirmed the presumption that there would be a strong connection with the square, while the mapping of planting and natural landscape features revealed less than expected. These maps disclosed more about the proximity of landscape features to the square, rather than revealing how the attribute was integrated, or contributed to the integration of the square. This is mostly due to the fact that the process of mapping these attributes prioritises plan based information.

Nevertheless the summary diagrams present a number of different situations gathered from the precedent studies. Some are more indicative of integrated design solutions than others. 


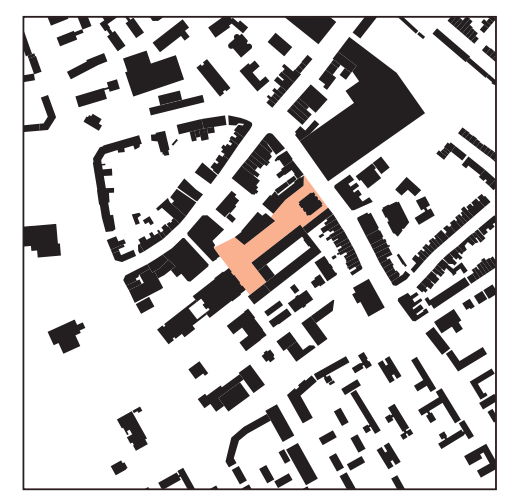

Barking Town Square
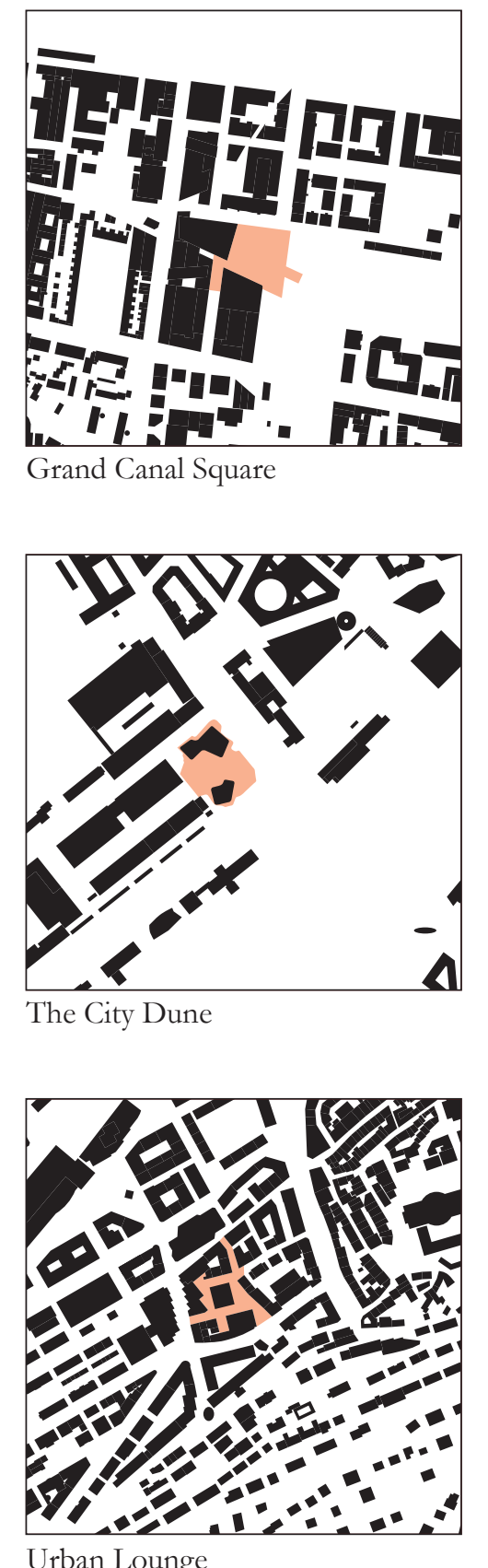

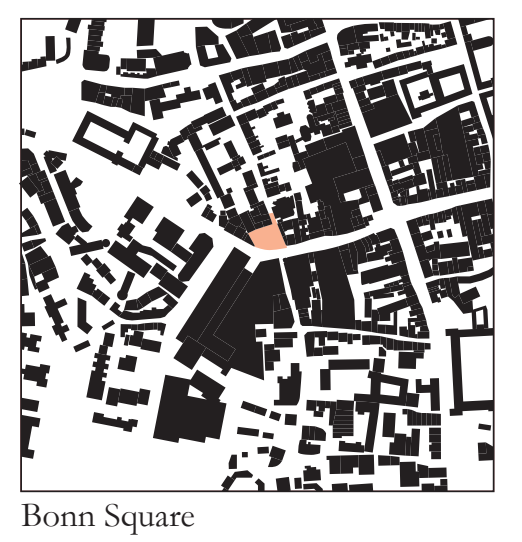

1.

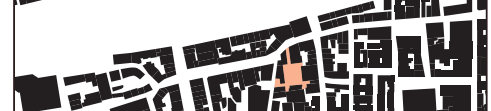

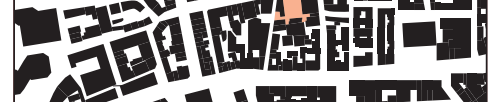
-

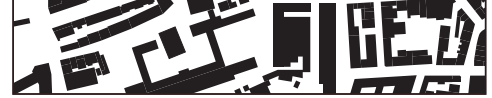

Meeting House Square
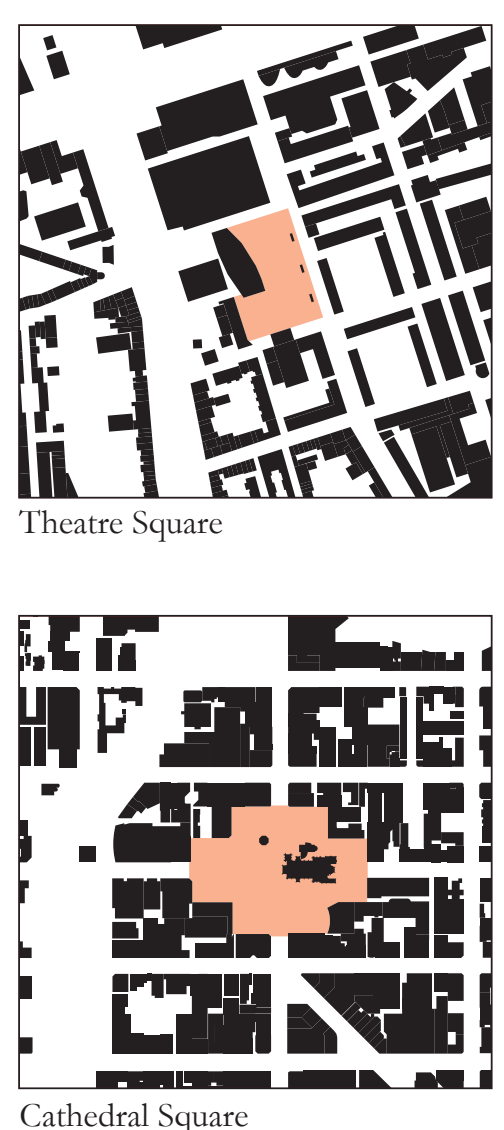

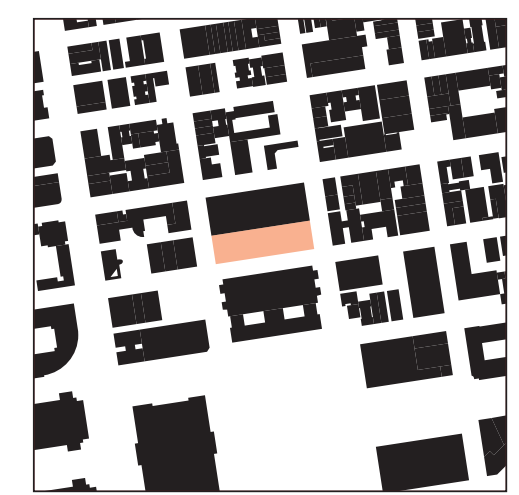

Philip Burton Federal Plaza
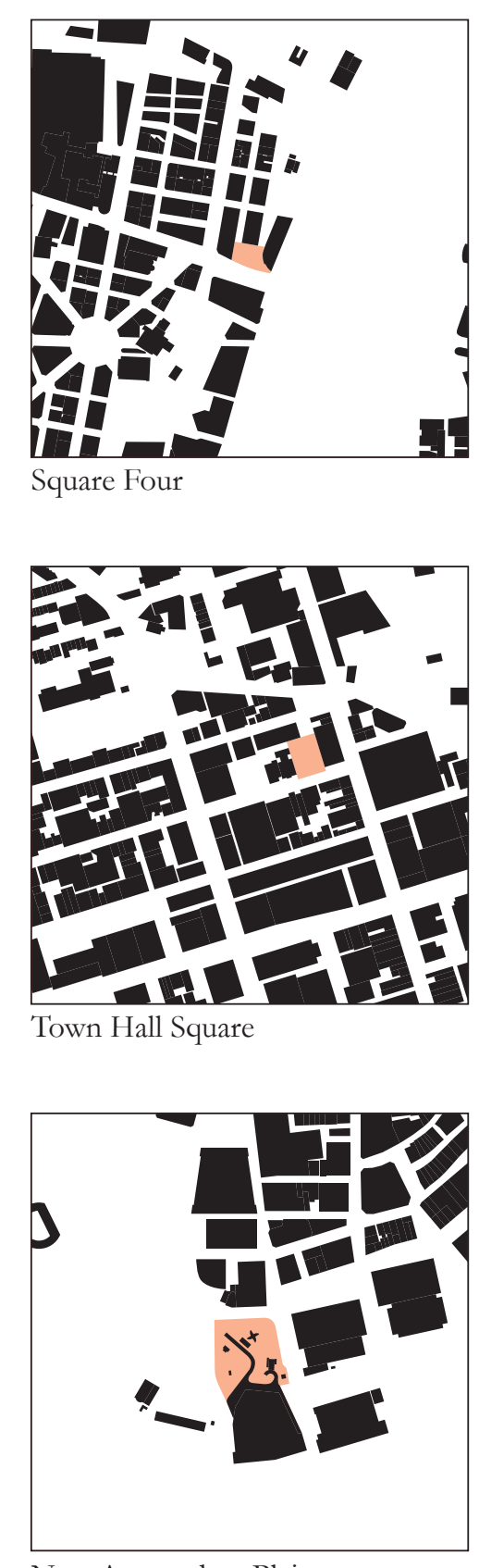

New Amsterdam Plein
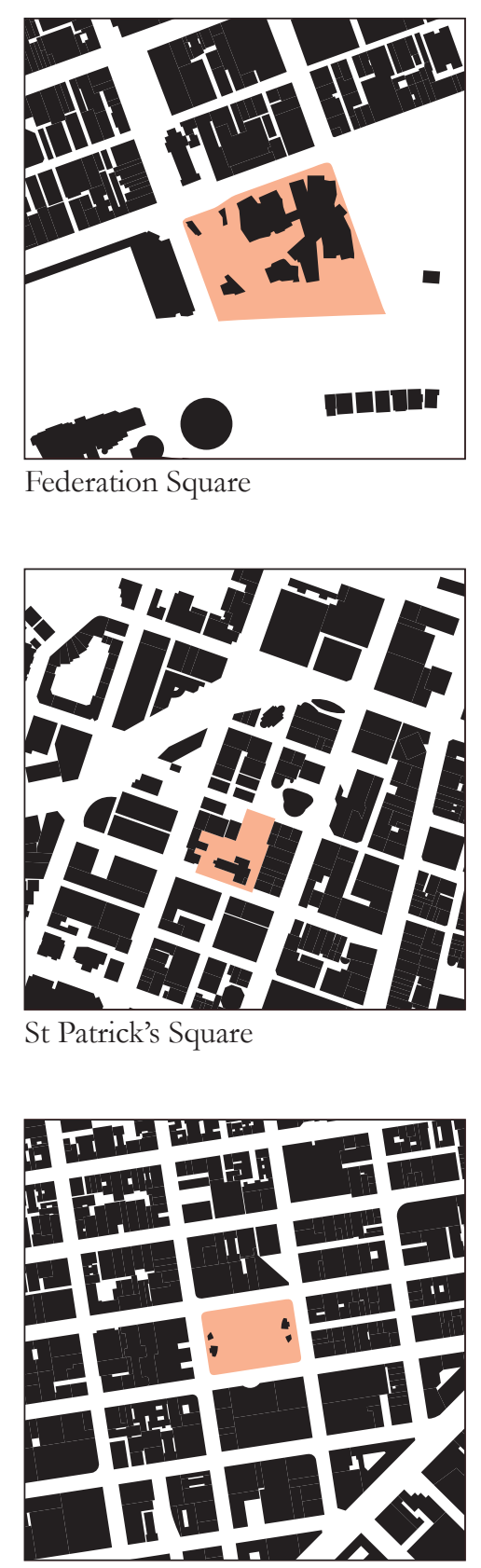

Union Square

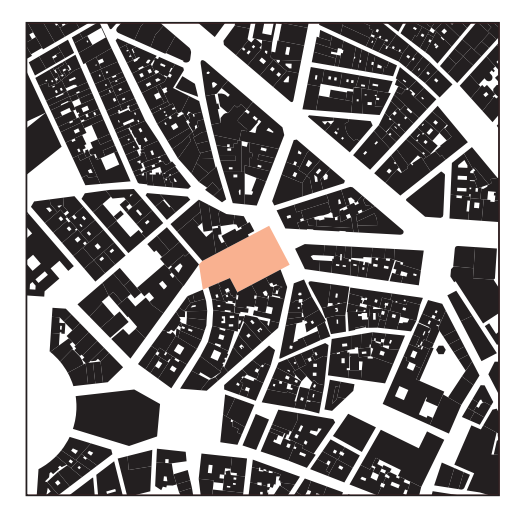

Plaza de Santo Domingo 
Figure 59. (opposite page) Figure ground plan comparisons. Figure 60. Figure ground findings.

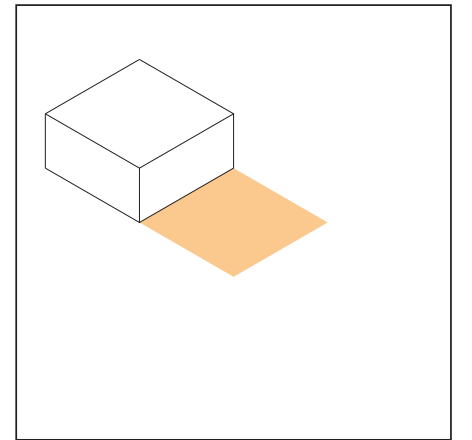

Interacts on one edge

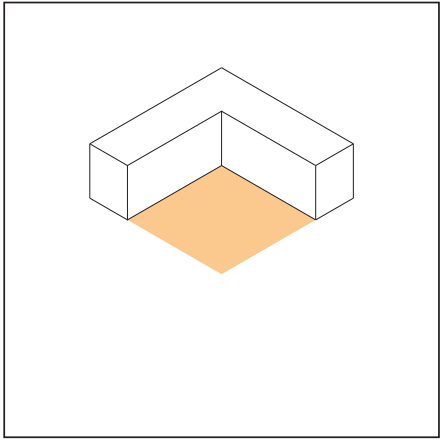

Wraps around on two sides

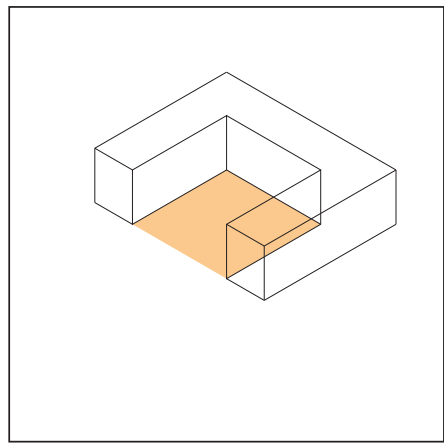

Wraps around on three sides

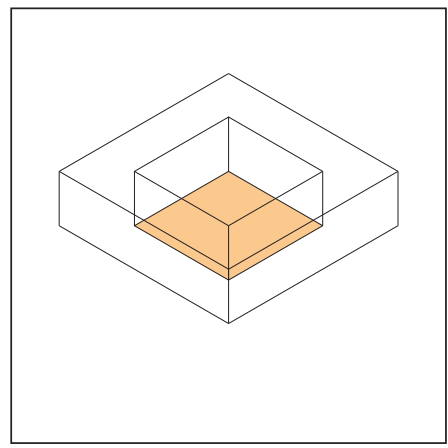

Total enclosure on all sides

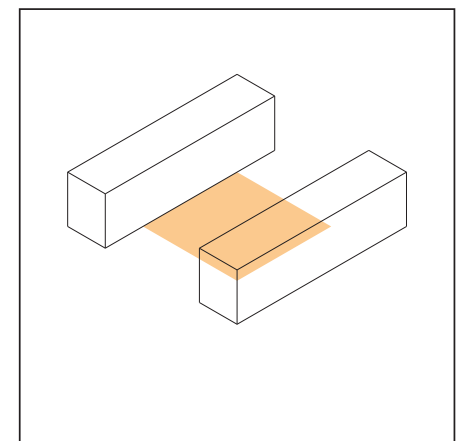

Framed between buildings

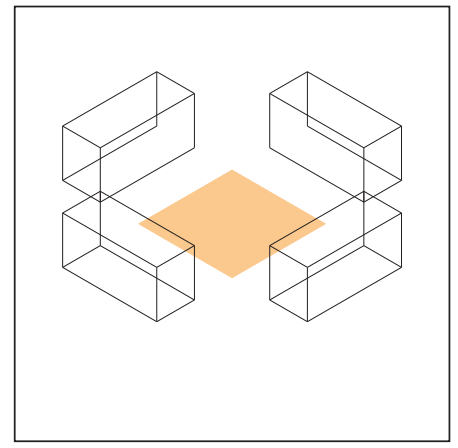

Separate from built form

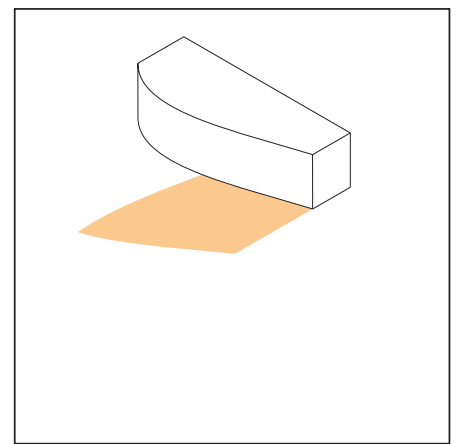

Built form moulds to space

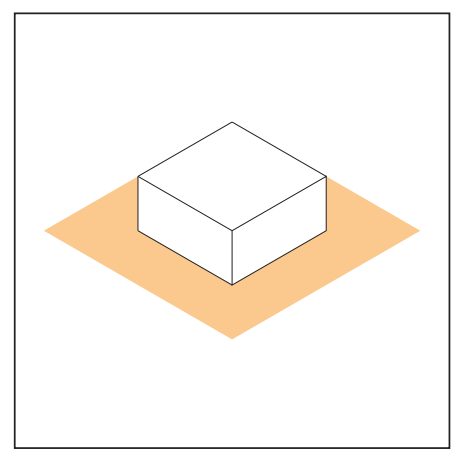

Space surrounds built form

\section{Figure Scale and Spatial Identity}

The scaled figure ground studies generally proved to be helpful, particularly in demonstrating the variance in the scale of the city squares studied. For example, the scale of the colonial city squares, particularly Cathedral Square, in comparison with the European precedents is worthy of note.

Cathedral Square proved to be the largest scale space of all the precedents studied. Federation Square covers a similar area, but the building complex within the square is articulated to enclose a smaller amount of open space. This lessens the perceived lack of enclosure that overly large open spaces fall victim to.

In terms of integration, the scale of open space has a strong relationship to the surrounding buildings. Proportionally integrating the two is vital to the perception of enclosure and spatial identity.

The surrounding built form was generally found to not entirely encompass the edges of the square. A majority of squares studied had an open edge on one or more sides. Some were completely open such as Union Square. Only Meeting House Square exhibited total enclosure through built form. 


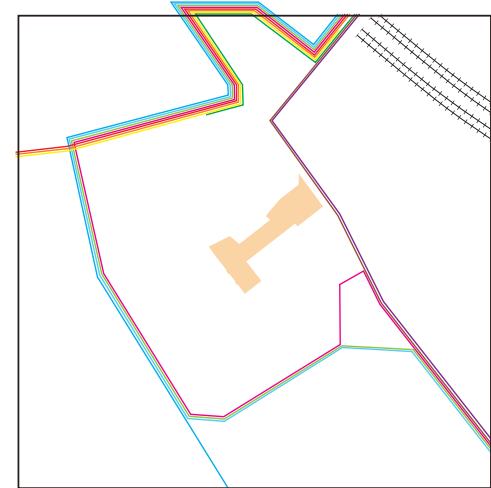

Barking Town Square

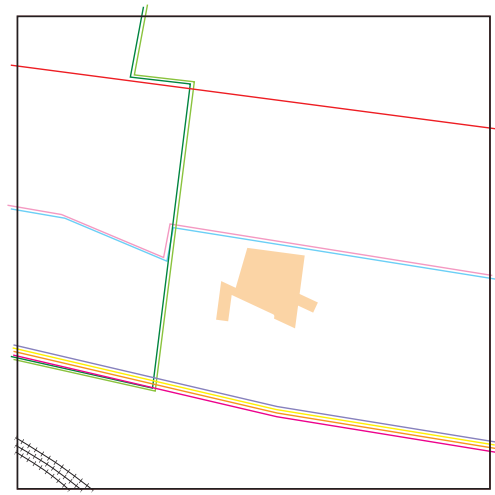

Grand Canal Square

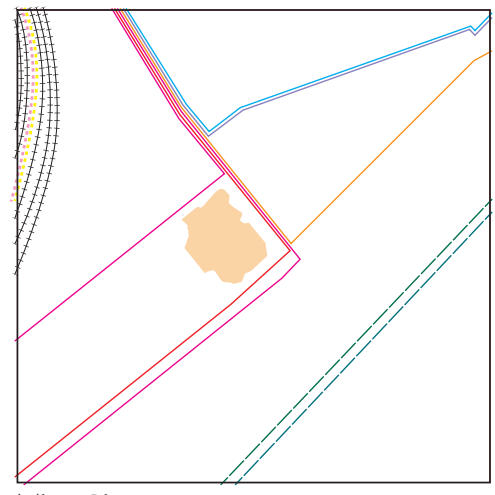

The City Dune

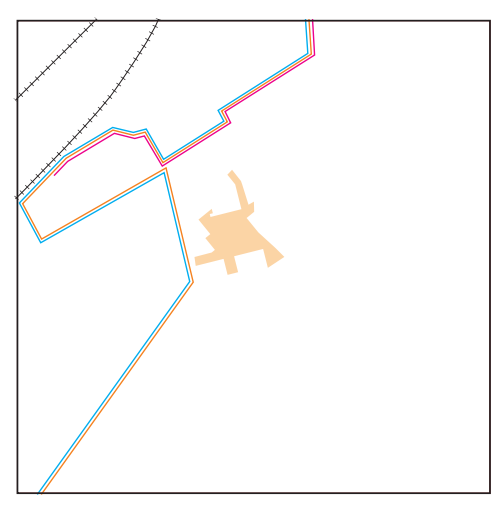

Urban Lounge

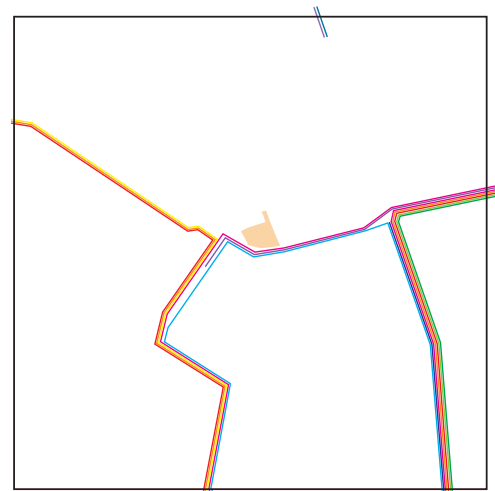

Bonn Square

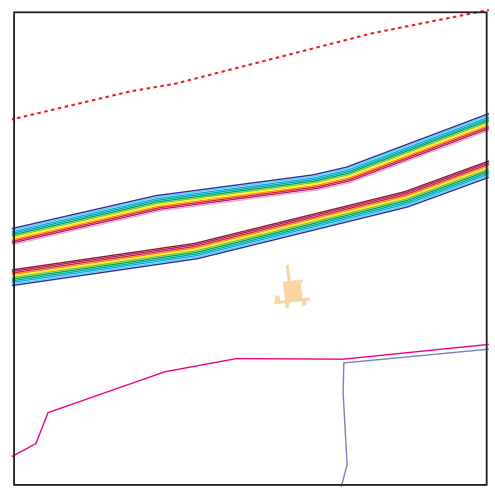

Meeting House Square

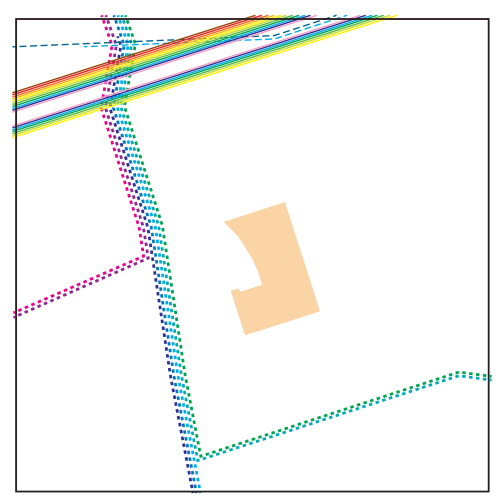

Theatre Square

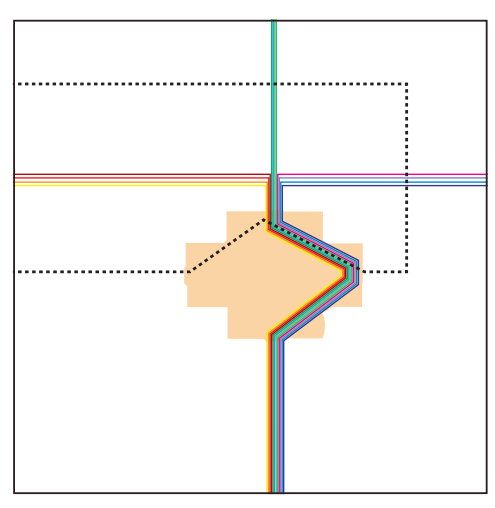

Cathedral Square

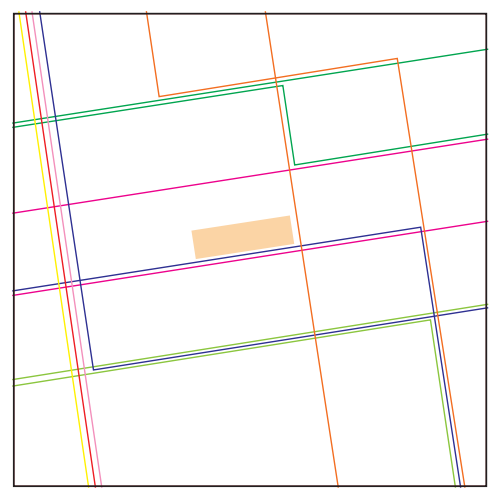

Philip Burton Federal Plaza

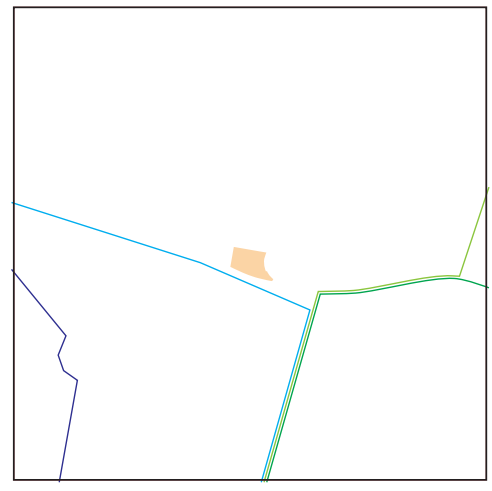

Square Four

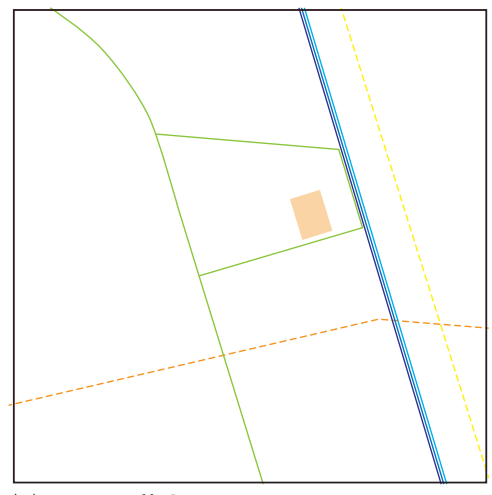

Town Hall Square

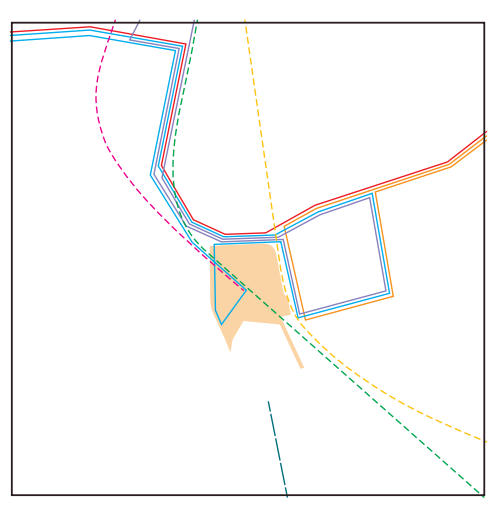

New Amsterdam Plein

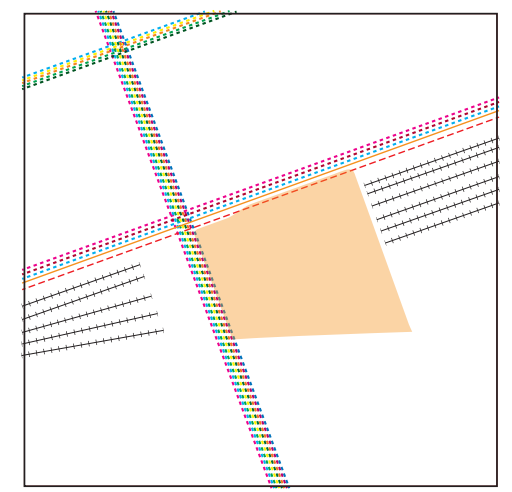

Federation Square

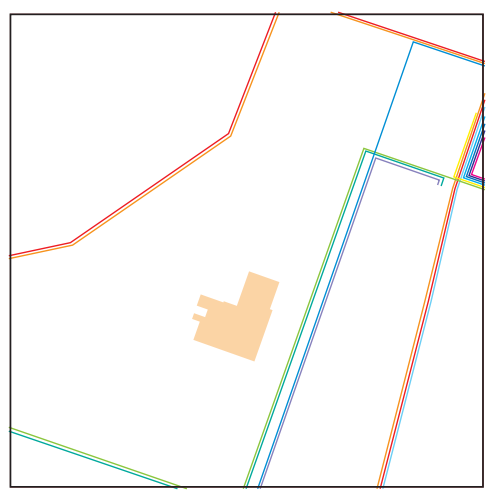

St Patrick's Square

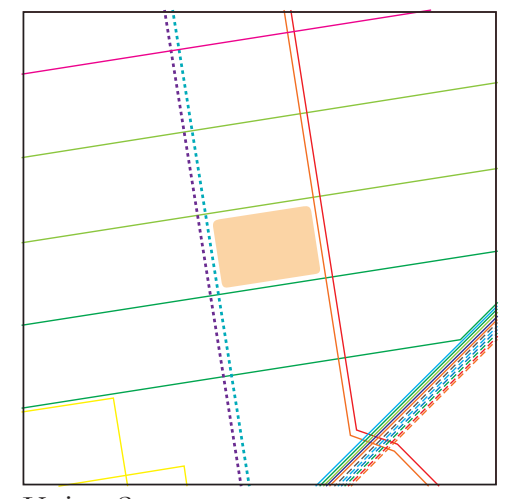

Union Square

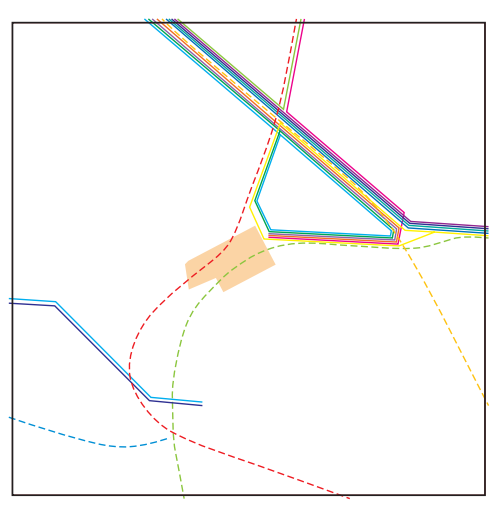

Plaza de Santo Domingo 
Figure 61. (opposite page) Comparison of public transit plans. Figure 62. Public transit findings.

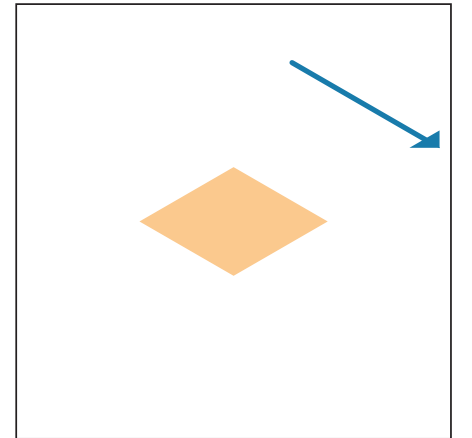

Within 5 min walking distance

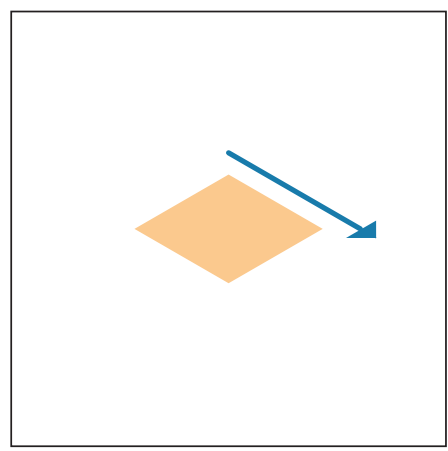

Passes on one edge

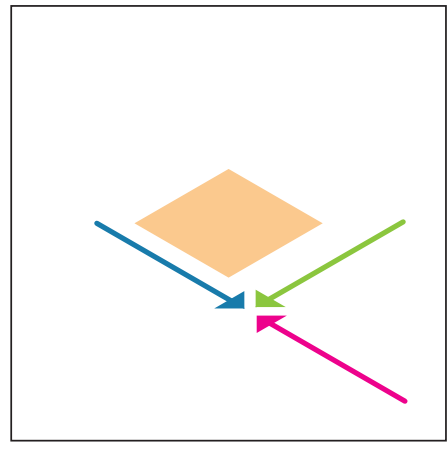

Different modes converge next to

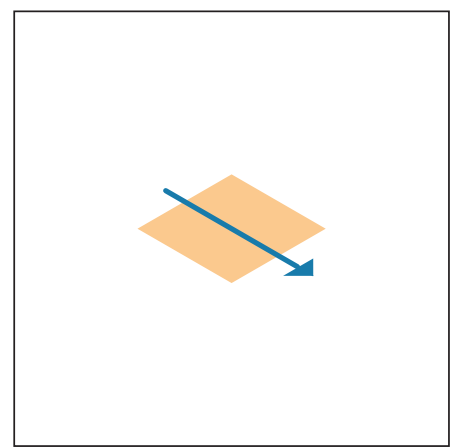

Passes through

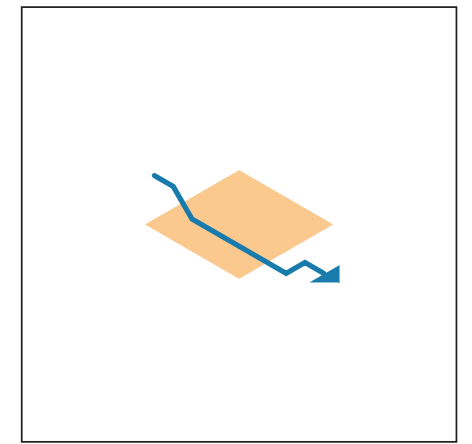

Passes underneath

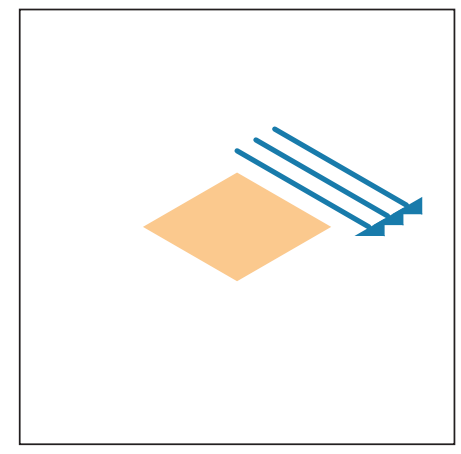

Transit corridor passes on one edge

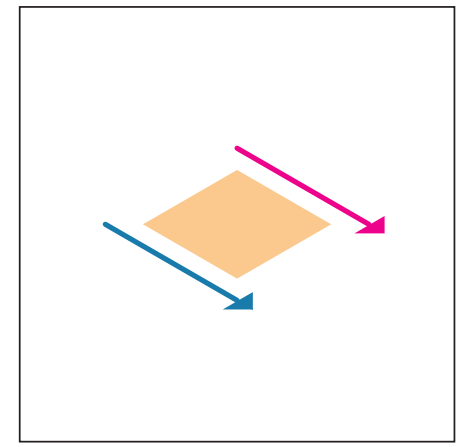

Different modes of transit pass next to

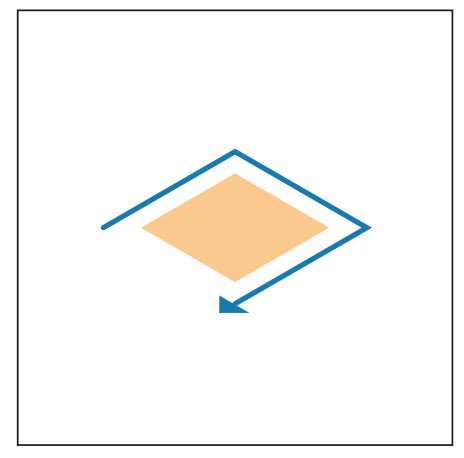

Circulates around

\section{Public Transit Routes}

All of the squares were proximate to public transit routes, with all having at least one route alongside the square. Most had a major public transit corridor within the 300 metre study radius surrounding the square. This trend would suggest that public transit is integral to the design of contemporary city squares. Federation Square, for example, is located at the junction of two light rail transit corridors with a third, Melbourne's main railway, running underneath the square.

Theatre Square is an example of mixed modes of transit running proximate to the square. Light rail, buses and an underground all converge just north of the square.

Cathedral Square is the only example to have a major public transit corridor run through the square itself. This presents a unique situation where public transit is perhaps overly integrated with the square. As the roads begin to isolate spaces within the square, reducing the overall quality of public space. 


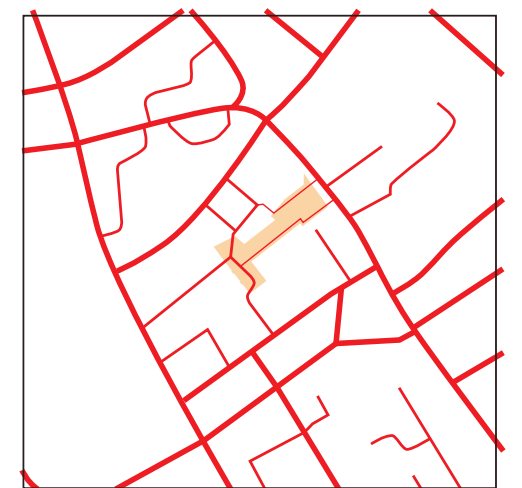

Barking Town Square

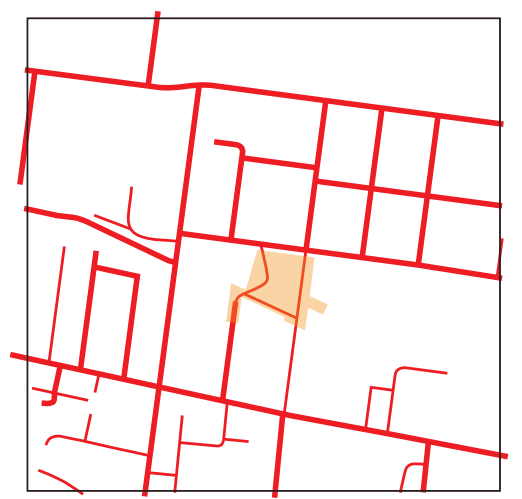

Grand Canal Square

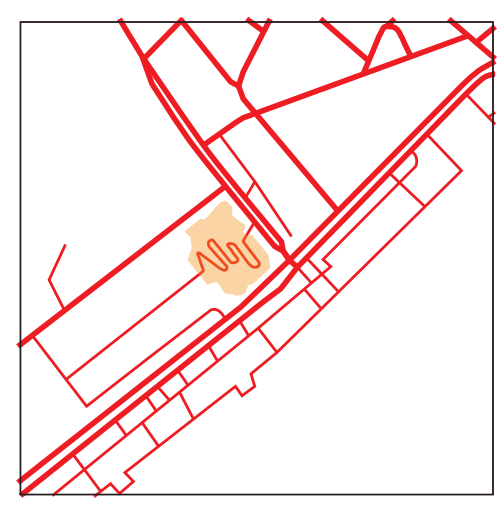

The City Dune

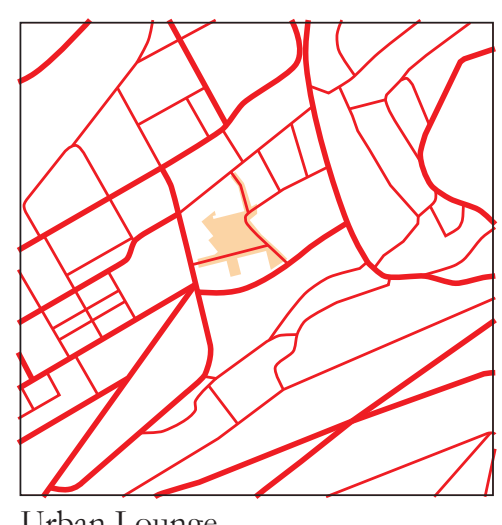

Urban Lounge

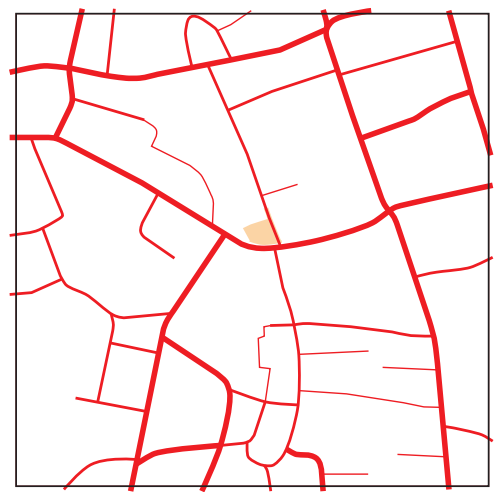

Bonn Square

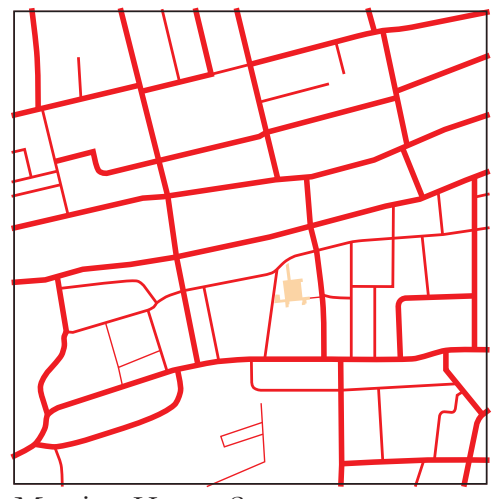

Meeting House Square

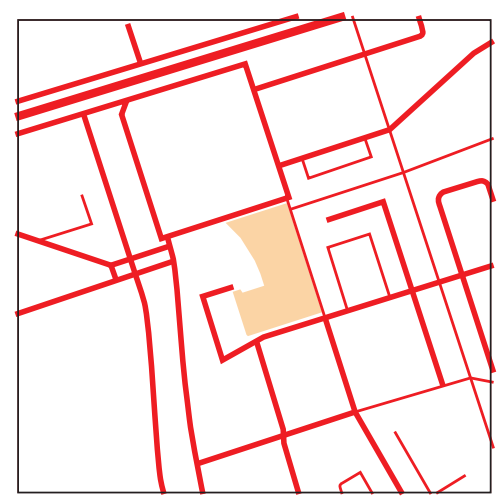

Theatre Square

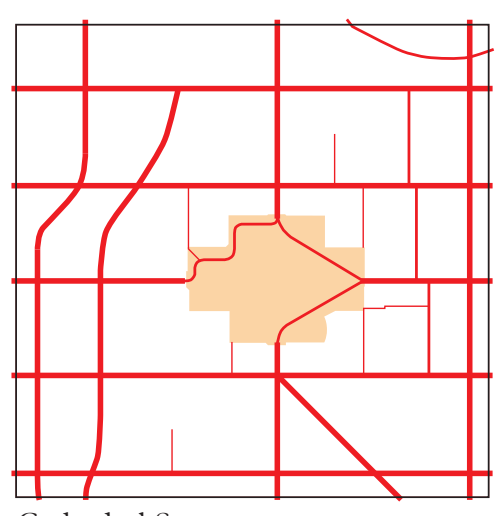

Cathedral Square

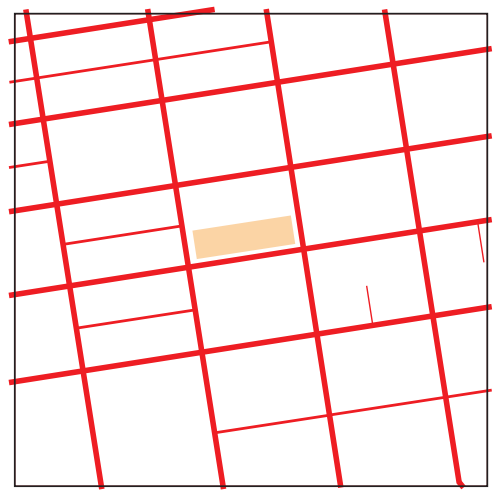

Philip Burton Federal Plaza

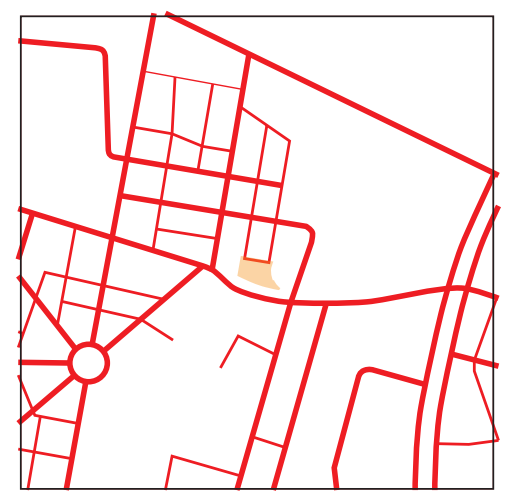

Square Four

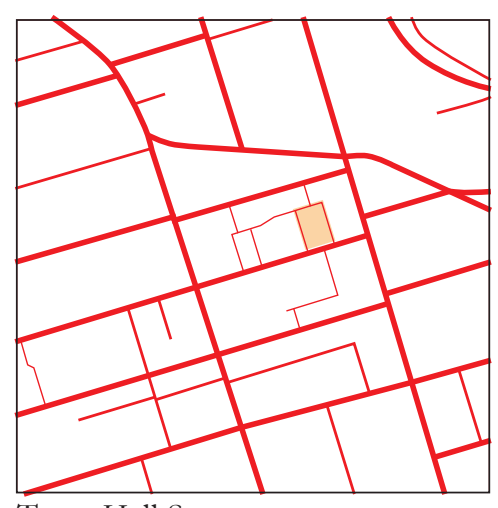

Town Hall Square

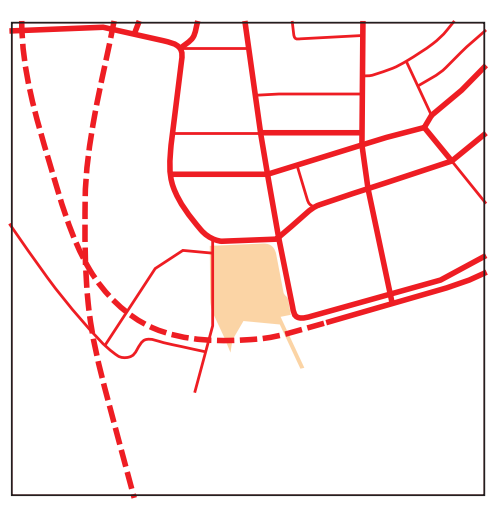

New Amsterdam Plein

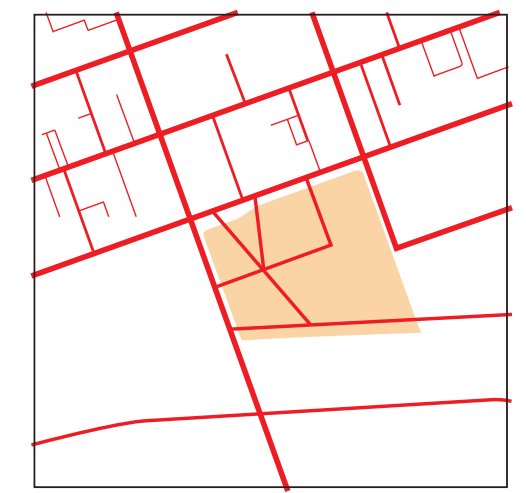

Federation Square

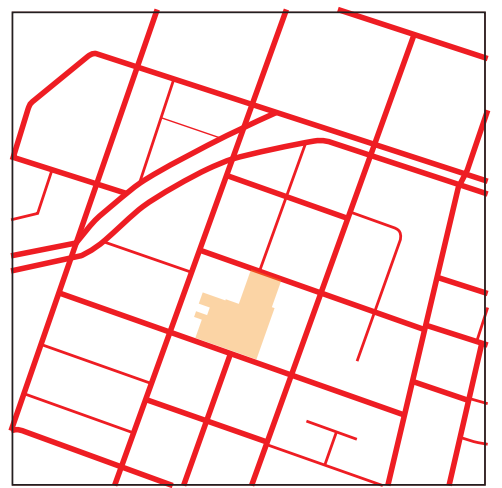

St Patrick's Square

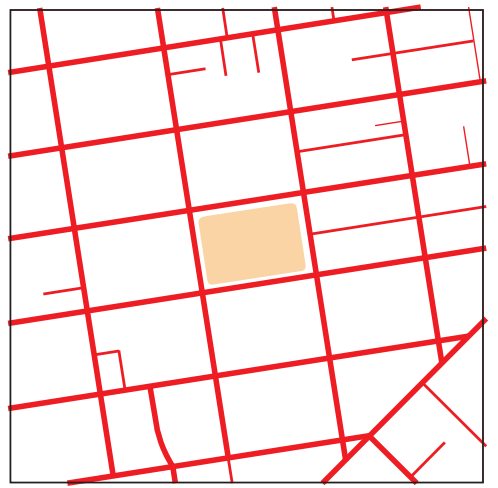

Union Square

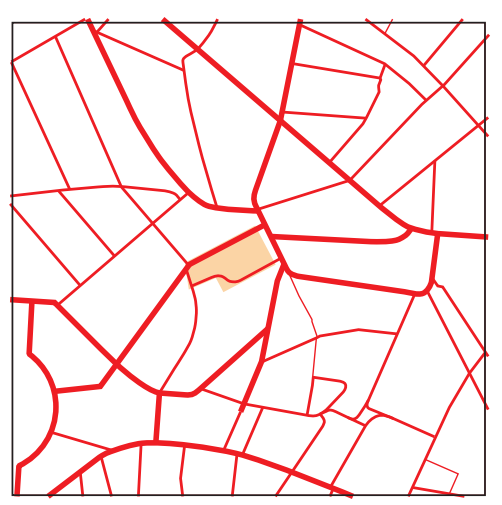

Plaza de Santo Domingo 
Figure 63. (opposite page) Comparison of city grid plans. Figure 64. City grid findings.

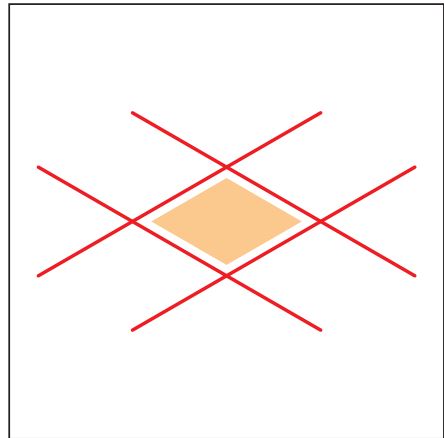

Within city grid

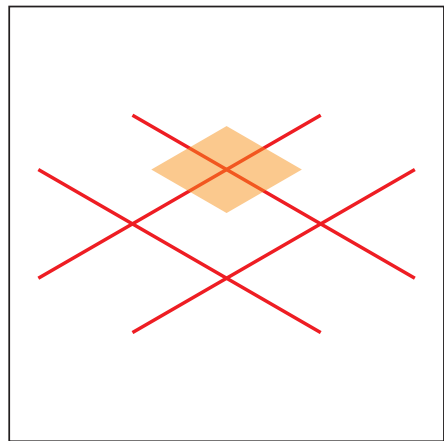

On intersection of grid

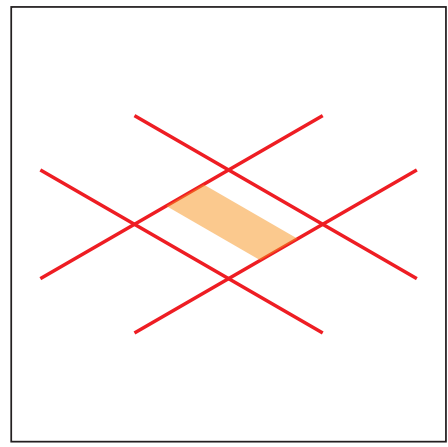

Stretches between grid lines

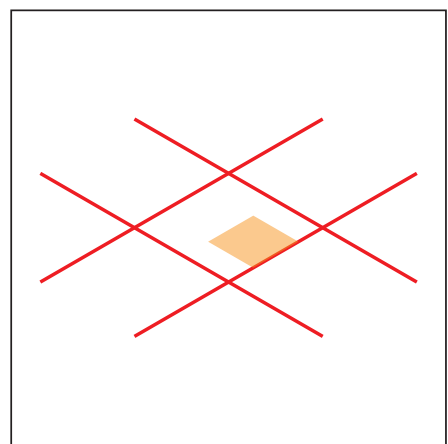

Set into grid

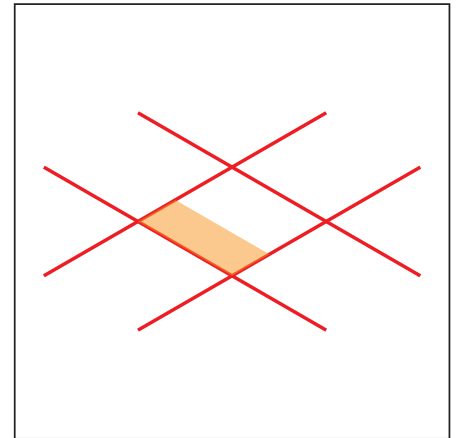

Set into grid interacts on $2-3$ sides

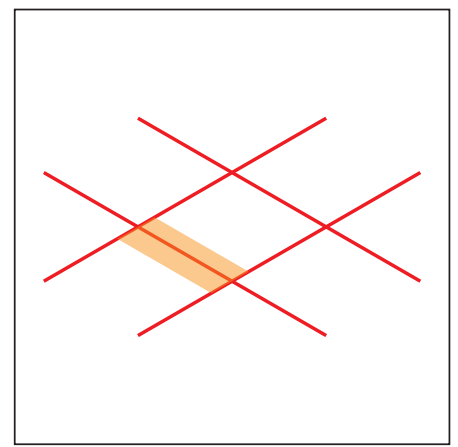

Stretches along grid lines

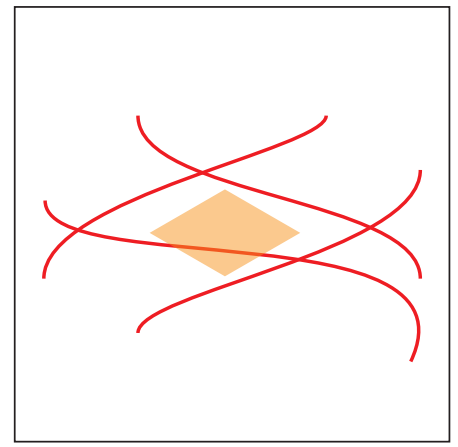

Indifferent to street pattern

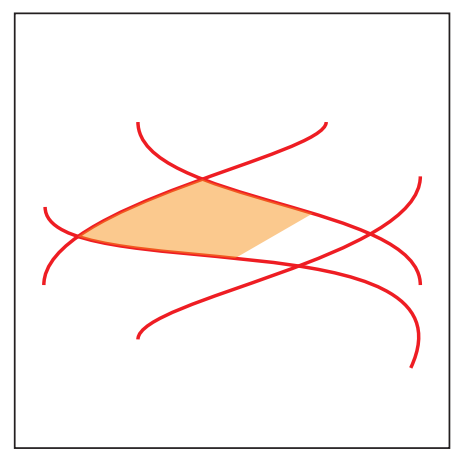

Moulds to street pattern

\section{Street Pattern}

The analysis of the city grid revealed that most squares were located within major grid lines and are often defined by the street pattern. For example, Union Square takes up one city block within San Francisco's rigorous gridiron plan, separated from the surrounded building edges. This can be harmful to other integrative attributes such as, hierarchy, and scale of open space and the benefits that soft building edges can have on the square. The same can be said of Cathedral Square, however the roads have been rerouted irrespective to the orthogonal geometry of the square.

Federation Square, City Dune and Grand Canal Square are other examples where the street pattern is altered within the square. Within Federation Square the orthogonal grid lines are altered and redirected by the composition of the non-orthogonal building forms. The City Dune does the same, in addition to redirecting the path along the rising contours of the ground plane to a raised park on the southwest edge.

In some cases the squares are set into the grid, or incorporate minor grid lines into the design. For example, Barking Town Square integrates paths through the square, both pedestrian and vehicular in places.

In terms of integration, these studies reveal that while squares often conform and integrate the street pattern, in some cases this can be overdone to the detriment of spatial identity and enclosure.

Most integrate a street on one or more edges. While most squares conformed to the surrounding street pattern, some deformed the pattern within the square. Doing this however requires that the shape of the square, and buildings, support such an alteration. 


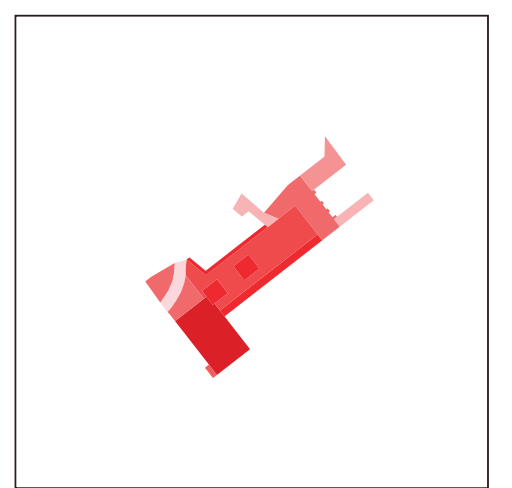

Barking Town Square

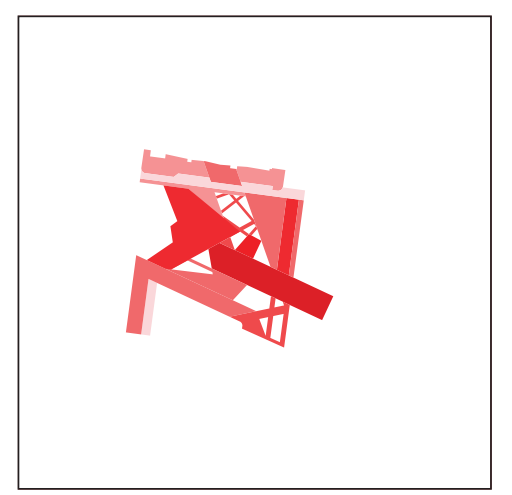

Grand Canal Square

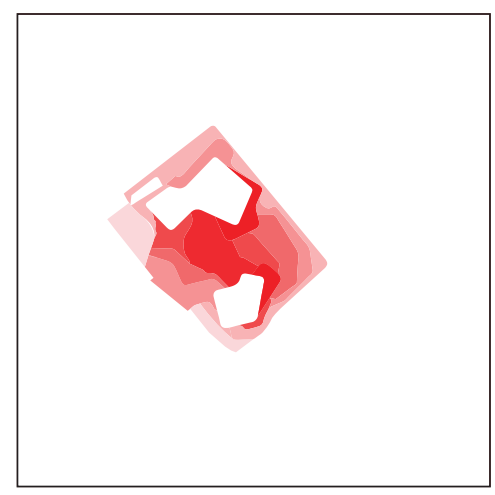

The City Dune

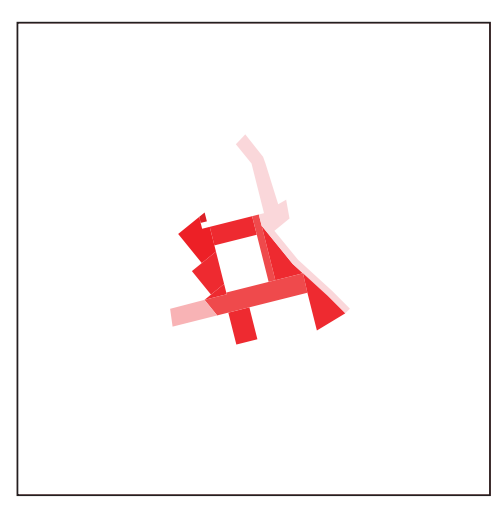

Urban Lounge

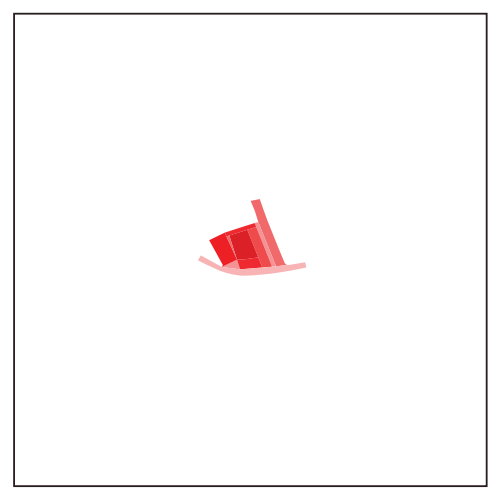

Bonn Square

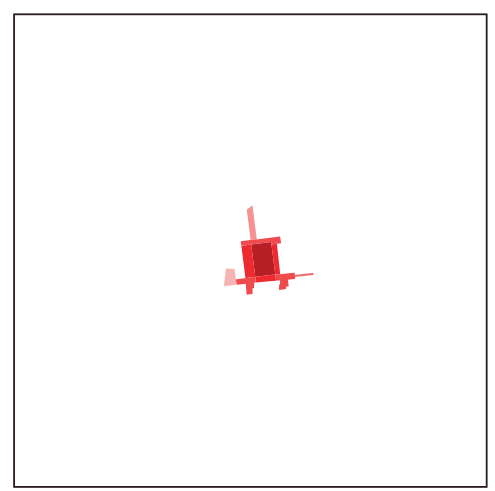

Meeting House Square

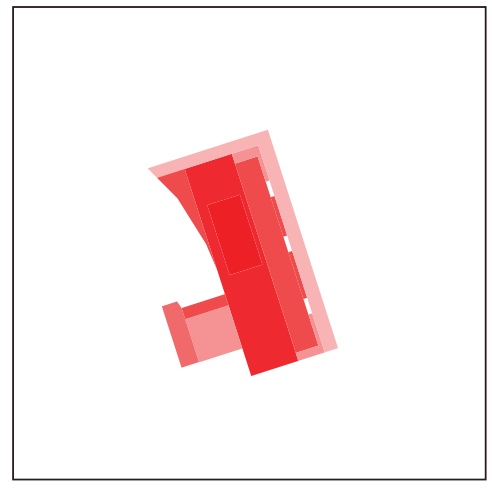

Theatre Square

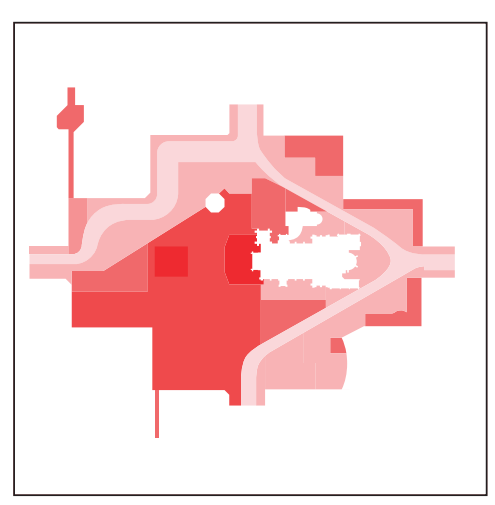

Cathedral Square

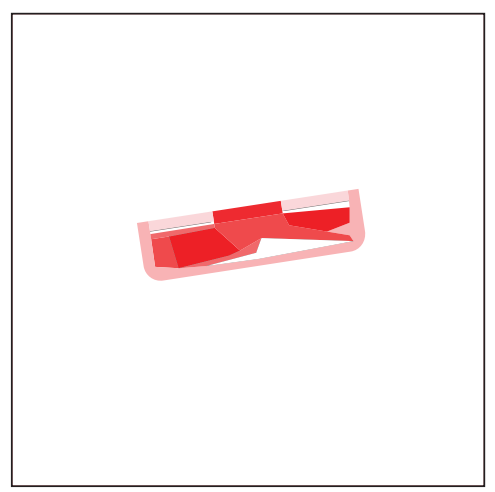

Philip Burton Federal Plaza

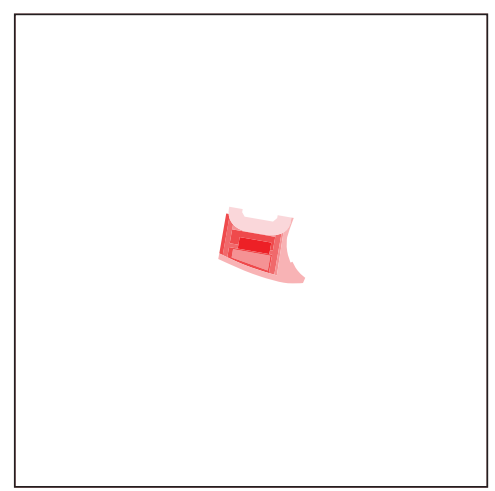

Square Four

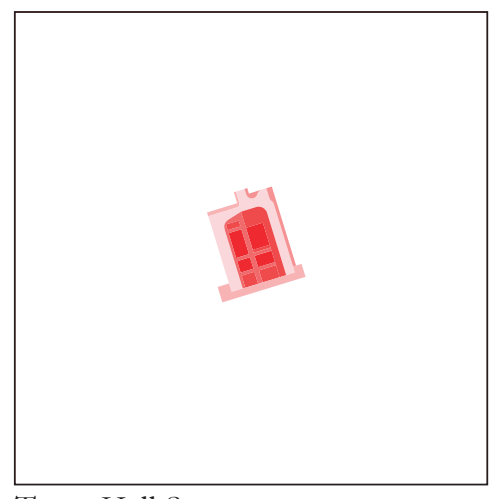

Town Hall Square

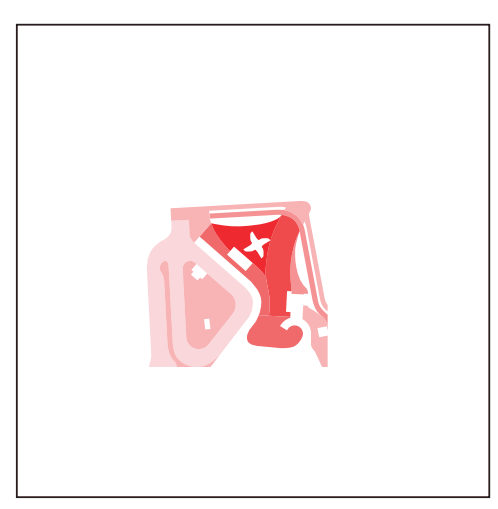

New Amsterdam Plein

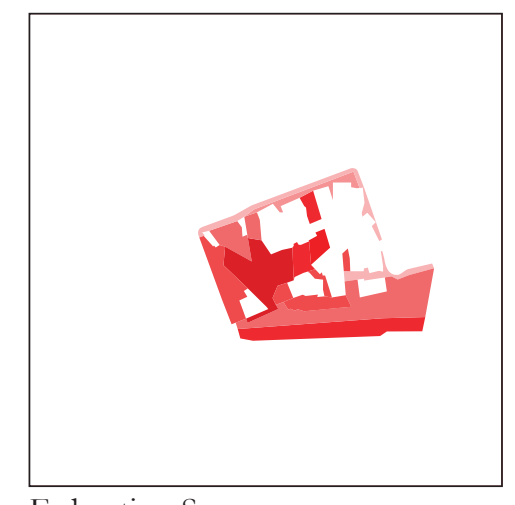

Federation Square

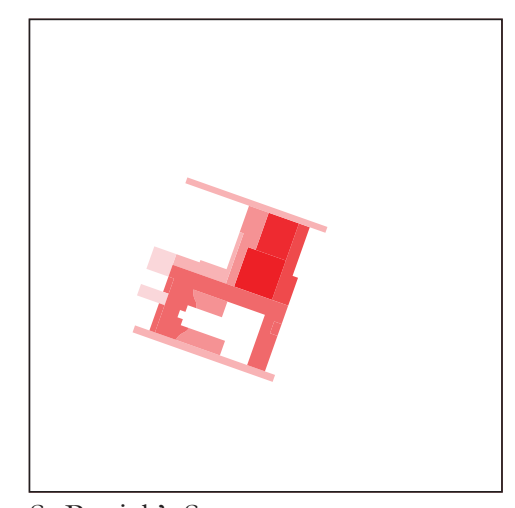

St Patrick's Square

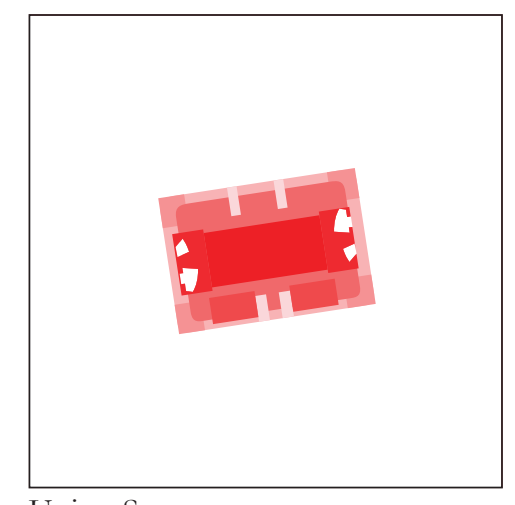

Union Square

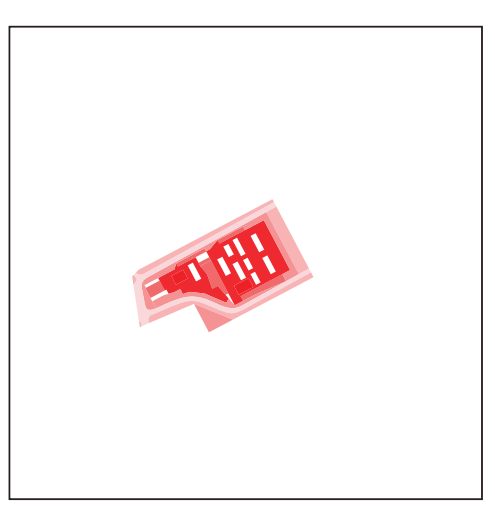

Plaza de Santo Domingo 
Figure 65. (opposite page) Comparison of space hierarchy plans.

Figure 66. Space hierarchy findings.

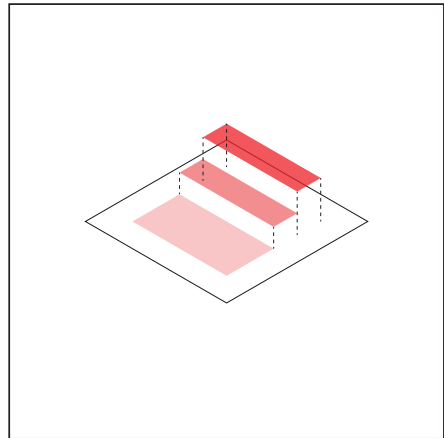

Linear progression

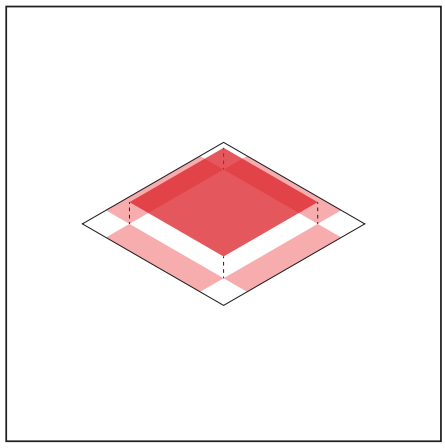

Prominant centre

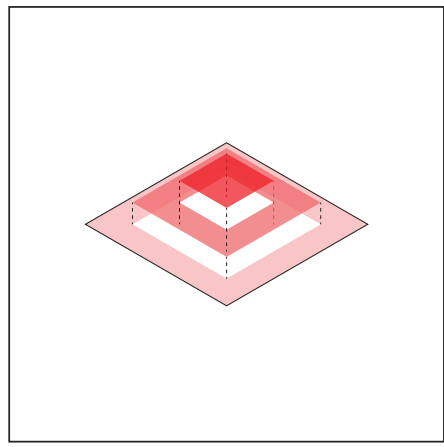

Progression to central promi-

nance

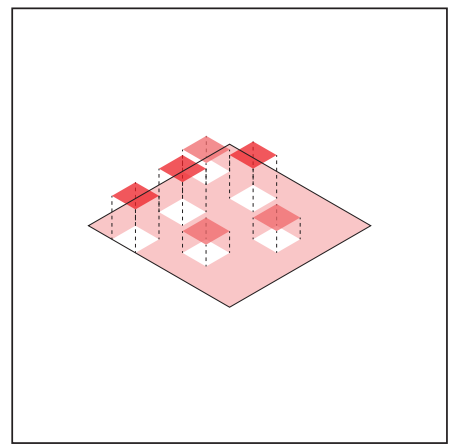

Dispersed hierarchies

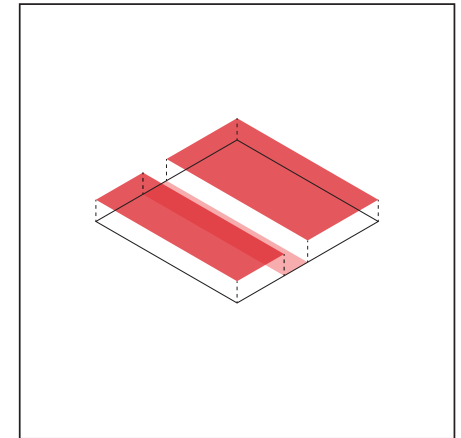

Dividing path

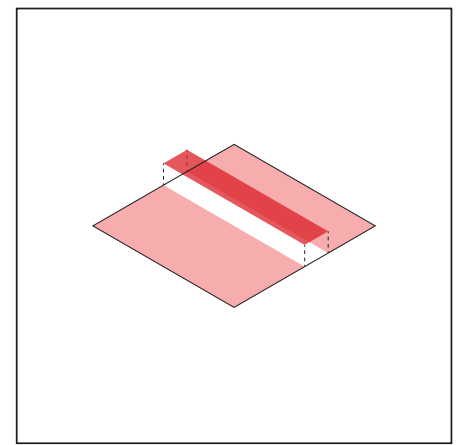

Prominant path

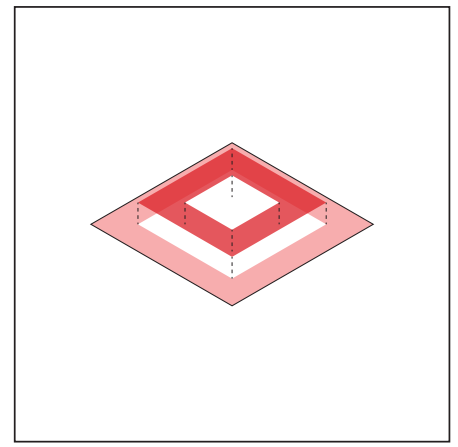

Hierarchies surrounding building

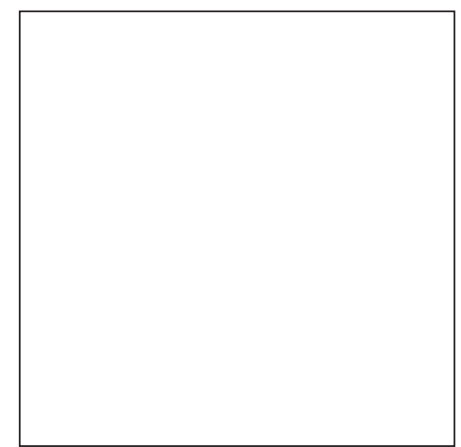

\section{Hierarchy of Space}

Mapping the hierarchy of space revealed that, generally, most squares had at least one space that was more prominent than any other. Meeting House Square, Union Square and St Patrick's Square are amongst those with a clear hierarchy to the space, with one prominent central location dominating the square.

Other examples, such as the Urban Lounge in Switzerland, Grand Canal Square and Federation Square have more than one prominent location, creating ambiguity in the hierarchy of space. In terms of integration this part of the research was inconclusive as to which is preferable.

The Irish examples show the two sides. Meeting House Square has a clear hierarchy of space with definite enclosure, a clear spatial identity and a somewhat cosy scale and proportion.

Grand Canal Square, on the other hand, is much more ambiguous in its spatial hierarchy and identity. This is perhaps due to it being far superior in terms of connectivity with the surrounding streets, soft building edges and landscape features.

This dichotomy in relation to the hierarchy of space shows that this attribute is dependant on the other attributes, including soft building edges, street pattern and the composition of surrounding buildings. Barking Town Square has a more prominent location to the south, due to the articulation of soft built edges particularly at the internal corners. Other examples of spatial hierarchy that are dependent on other attributes include The City Dune, Bonn Square and parts of Cathedral Square. 


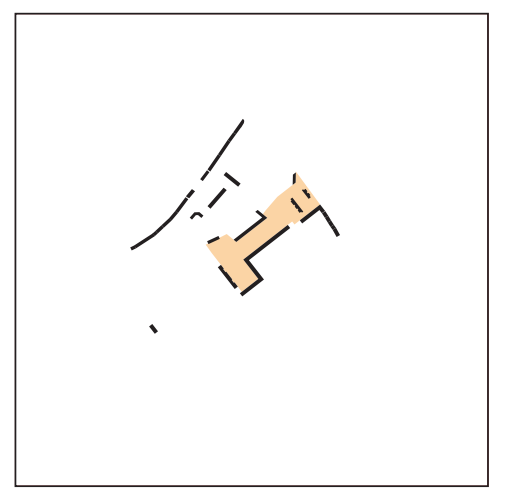

Barking Town Square

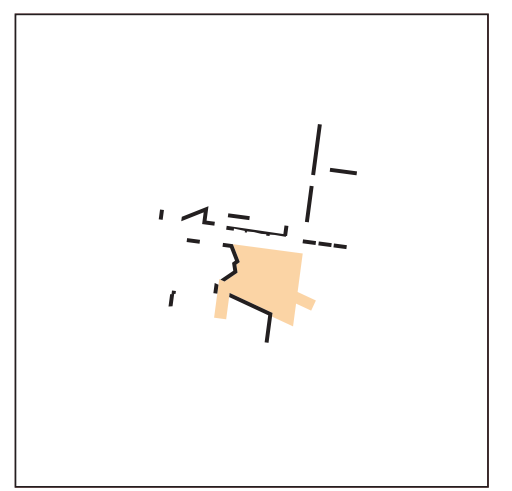

Grand Canal Square

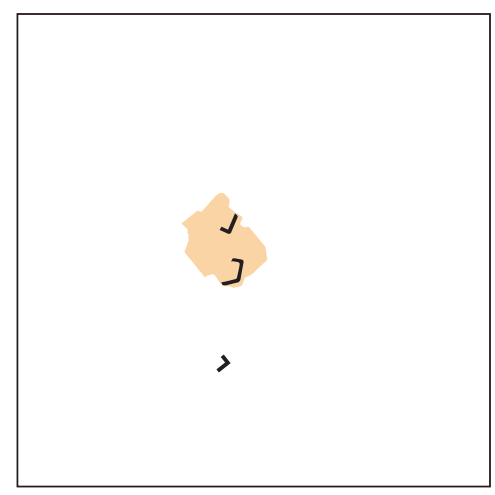

The City Dune

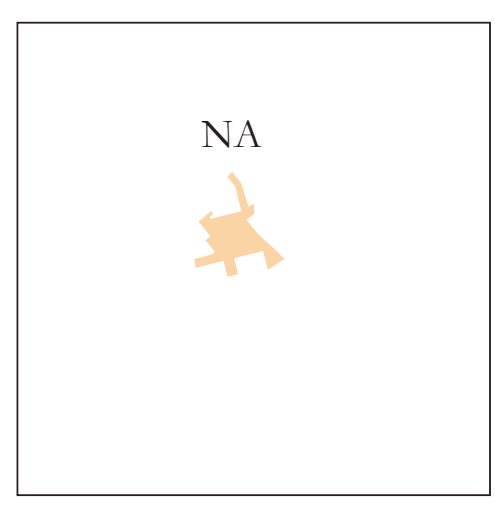

Urban Lounge

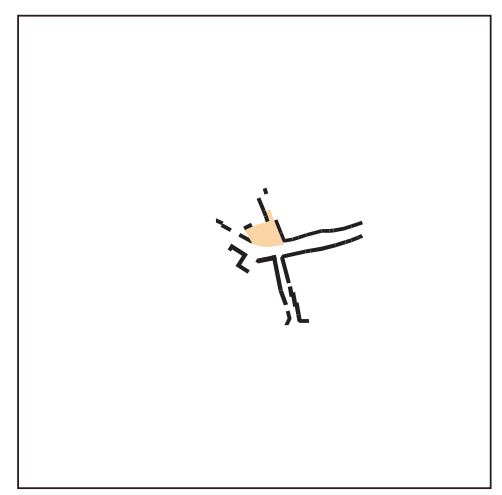

Bonn Square

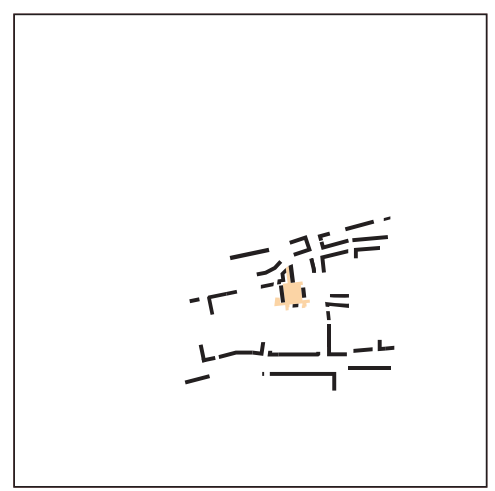

Meeting House Square

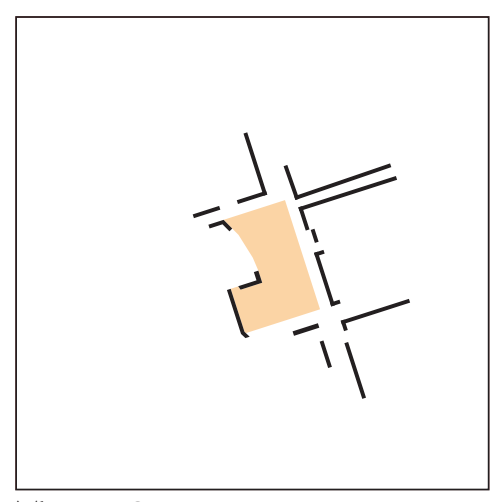

Theatre Square

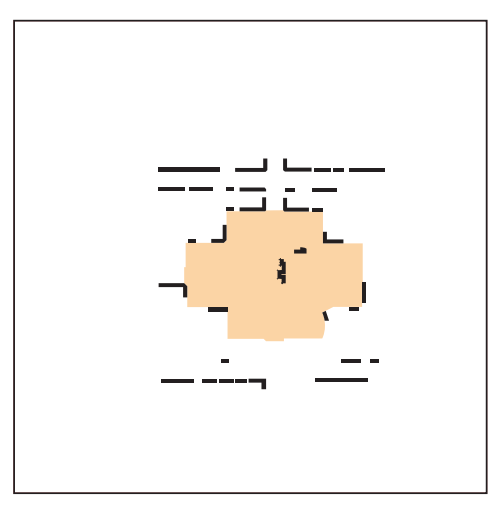

Cathedral Square

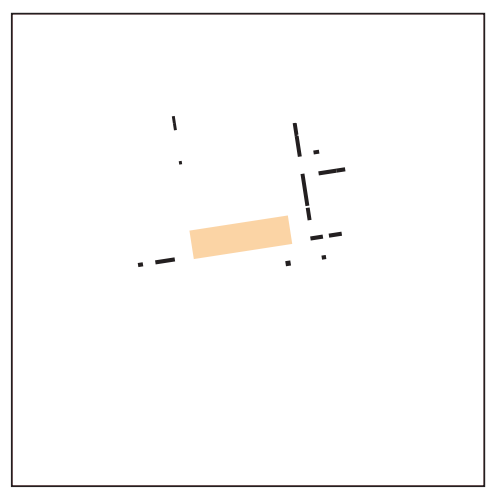

Philip Burton Federal Plaza

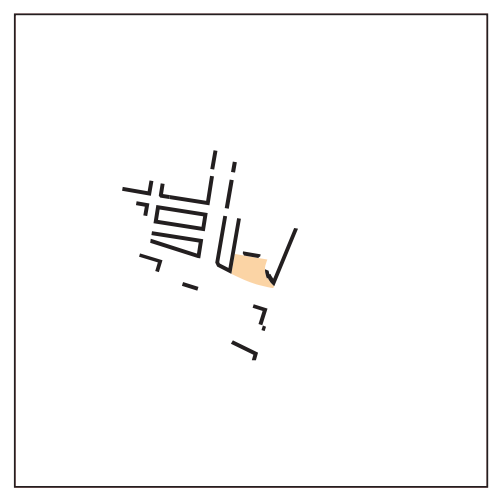

Square Four

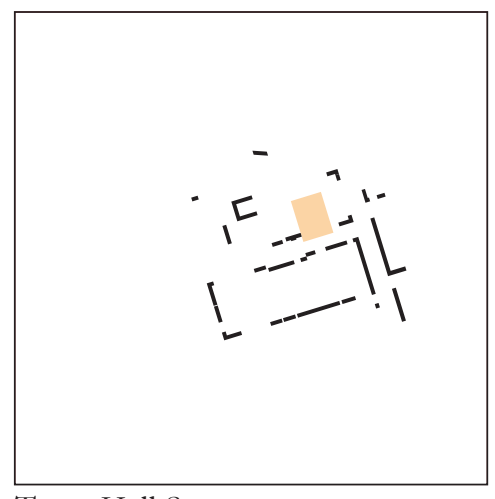

Town Hall Square

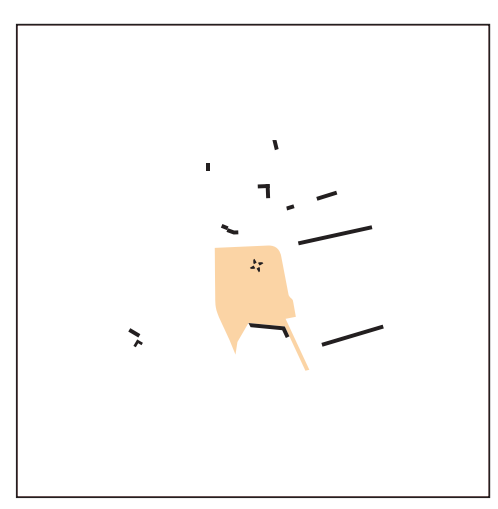

New Amsterdam Plein

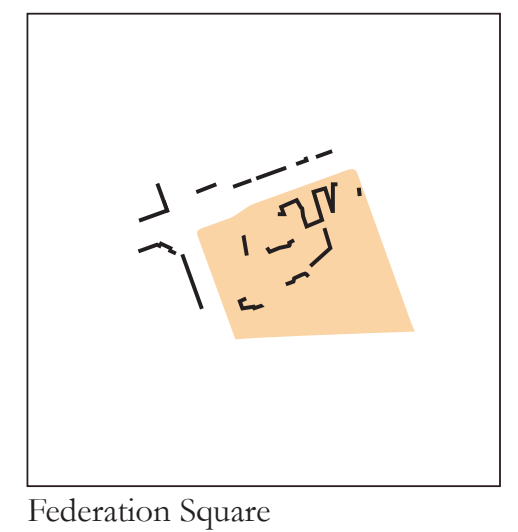

Federation Square

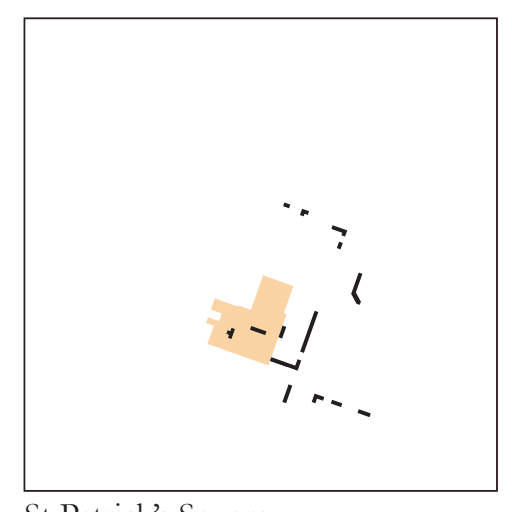

St Patrick's Square

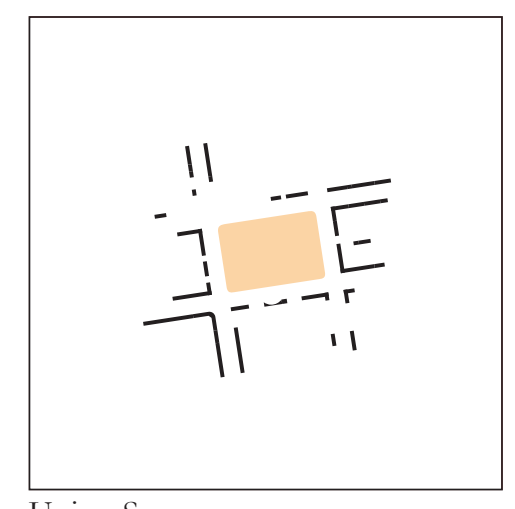

Union Square

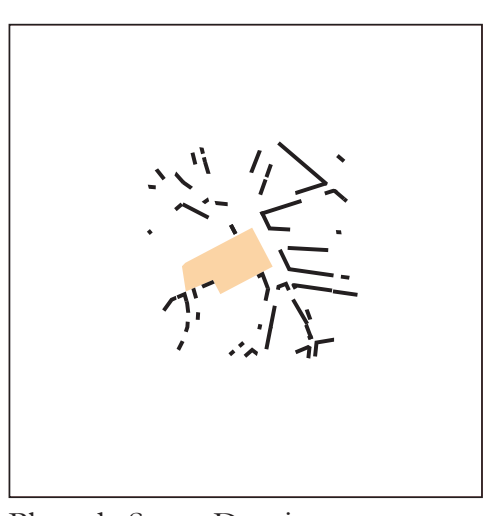

Plaza de Santo Domingo 
Figure 67. (opposite page) Comparison of active edge plans Figure 68. Active edge findings.

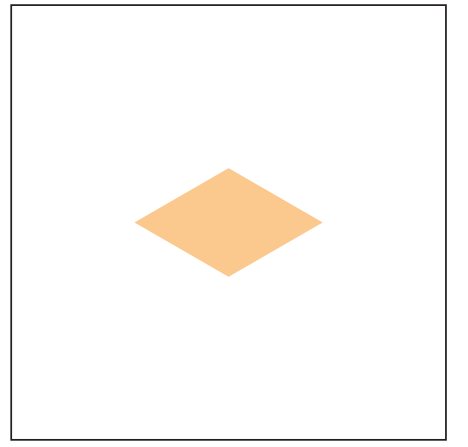

No soft edges

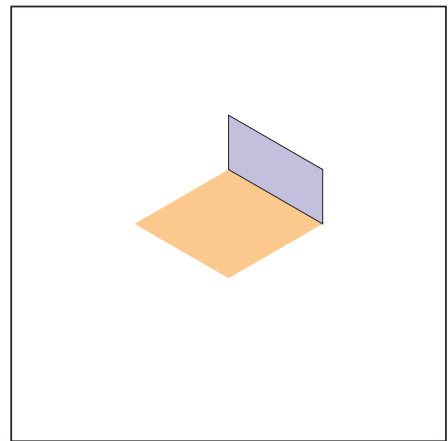

Soft edge facing into square

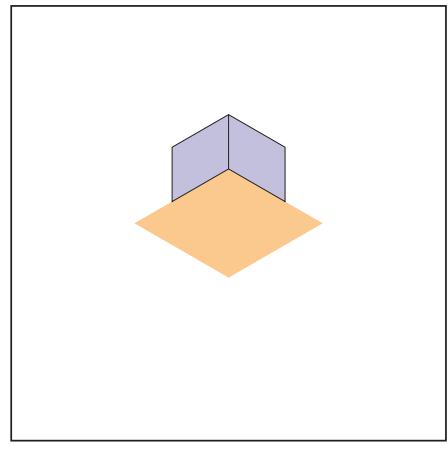

Sof edges in corner

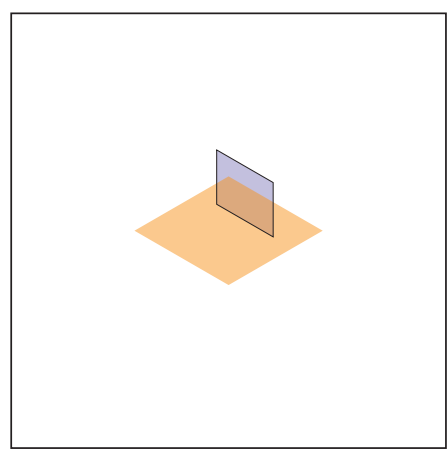

Projects into square

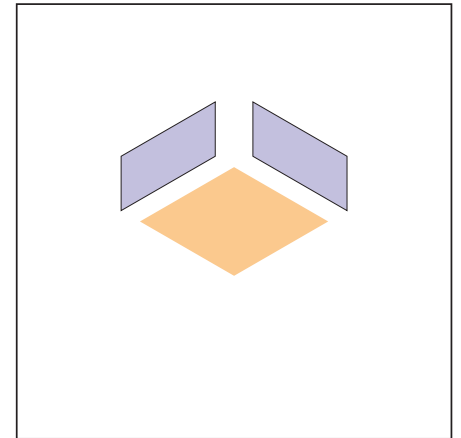

Disengaged from square

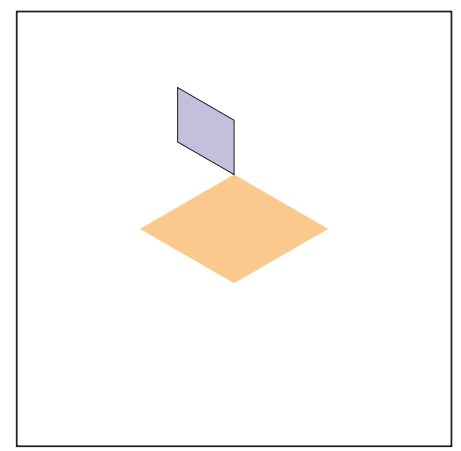

Adjacent to square

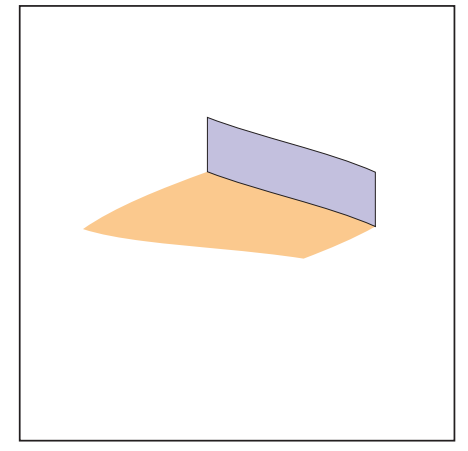

Moulds to edge of square

\section{Soft Building Edges}

The soft built edge of a building is most successfully integrated when faced directly onto the square. Barking Town Square has a number of soft building edges and arcades that frame the square to generate activity. This example is noteworthy as it incorporates a folly wall on the western edge to hide the supermarket that backs onto the square. Perhaps the biggest insight from mapping this attribute was that many of the squares were not surrounded by continuous soft built edges, suggesting that these buildings are not integral elements to the square.

It is worth noting that there are precedents with an abundance of continuous soft building edges that do not directly frame the square. Oxford's Bonn Square has soft building edges on the southern edge that are separated by a road. Theatre Square and Town Hall Square exhibit the same characteristics, while Union Square is completely separated on all sides from the continuous soft edges that surround it.

While these examples do not have soft built edges directly influencing the activity within the square they sacrifice this attribute in favour of connectivity with the wider urban context, the integration of public transit, and the cities street pattern. Suggesting that soft building edges can be combined with other attributes to better integrate the square overall. 


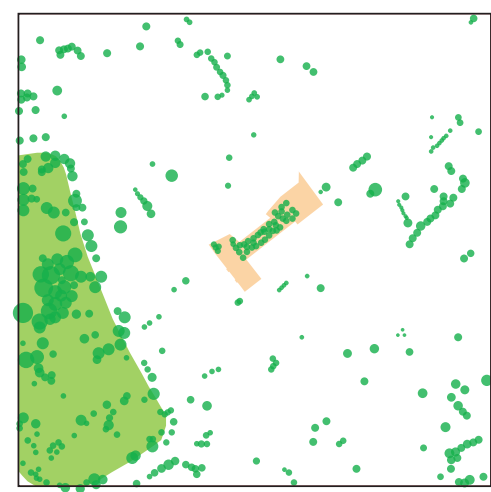

Barking Town Square

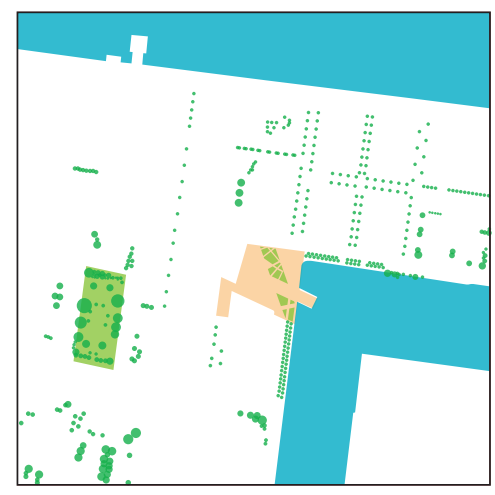

Grand Canal Square

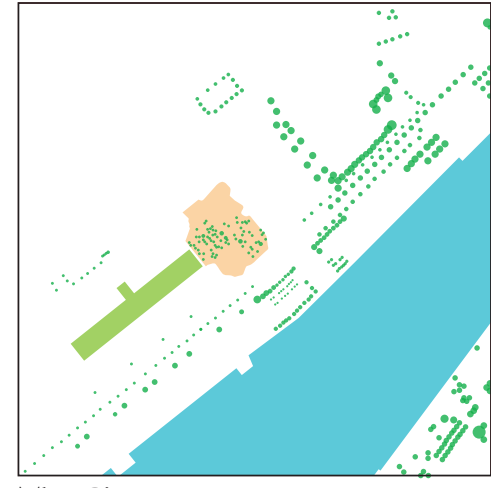

The City Dune

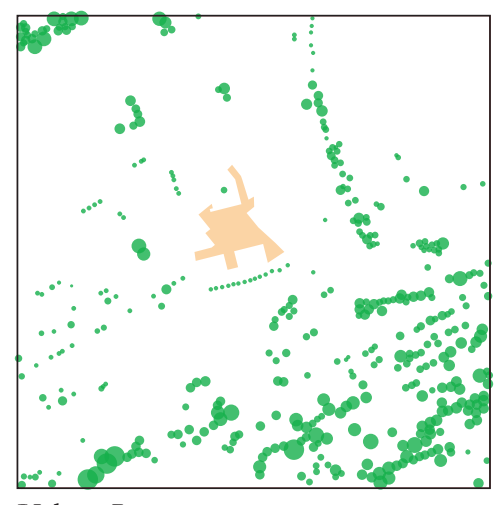

Urban Lounge

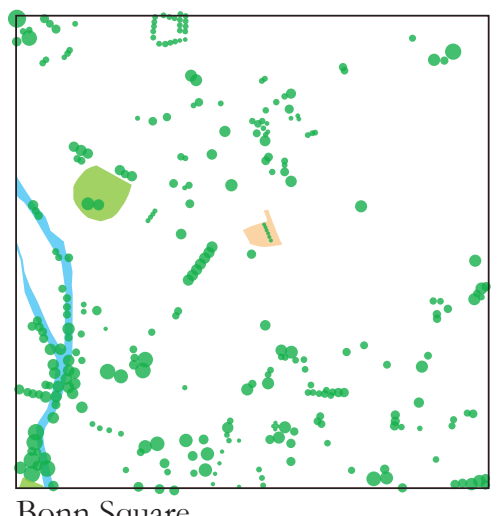

Bonn Square

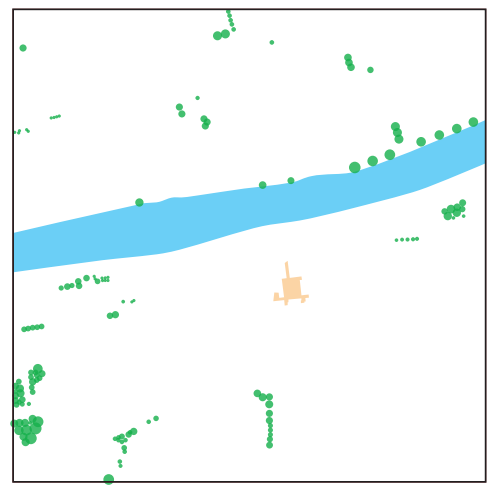

Meeting House Square

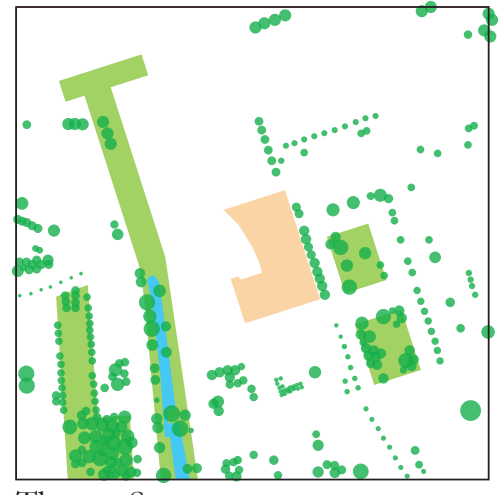

Theatre Square

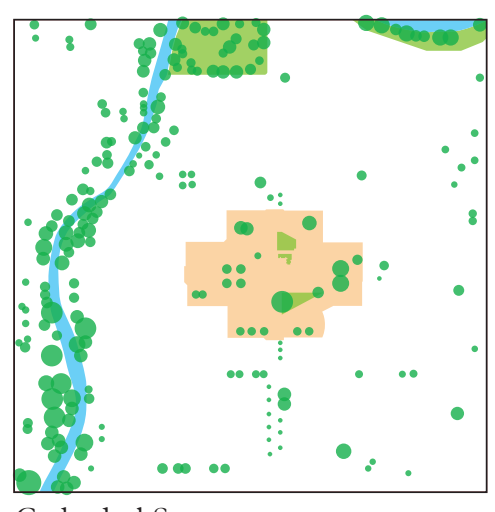

Cathedral Square

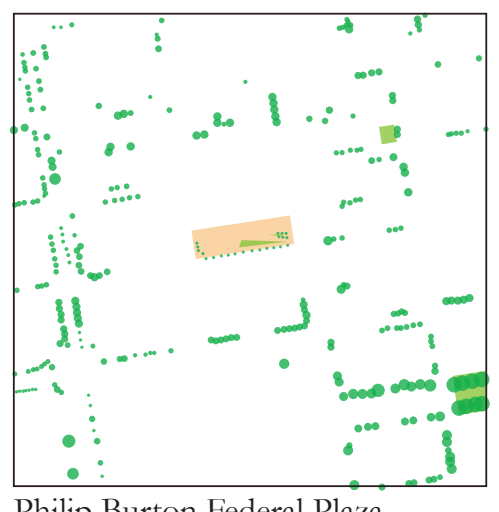

Philip Burton Federal Plaza

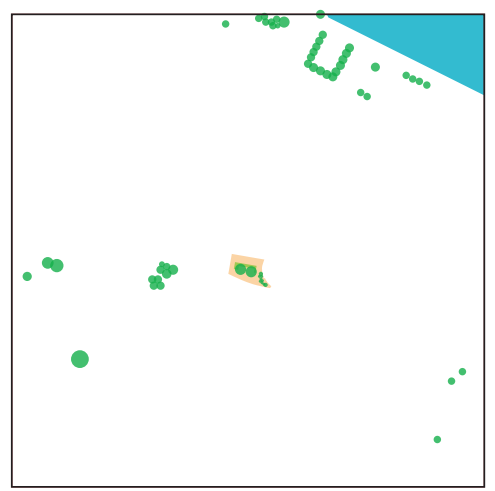

Square Four

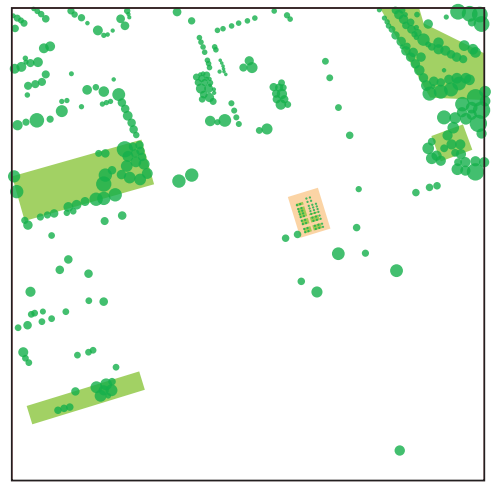

Town Hall Square

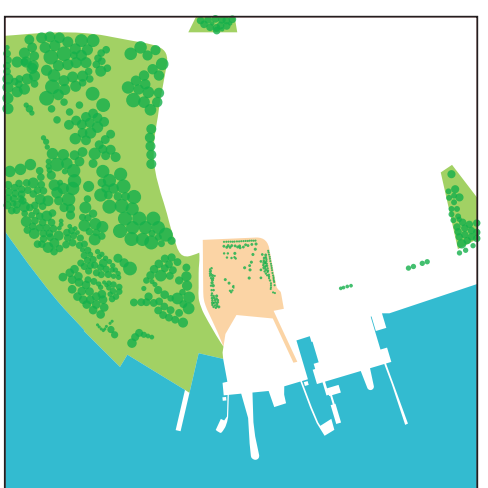

New Amsterdam Plein

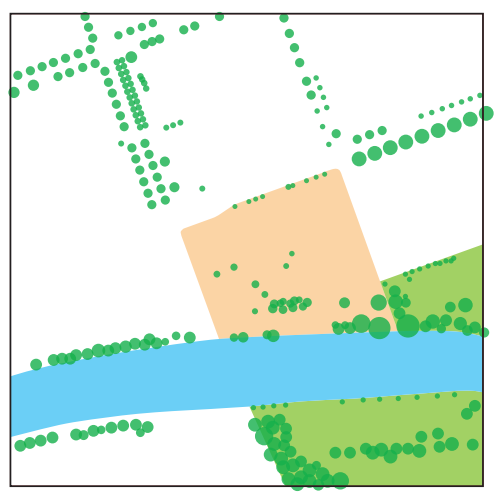

Federation Square

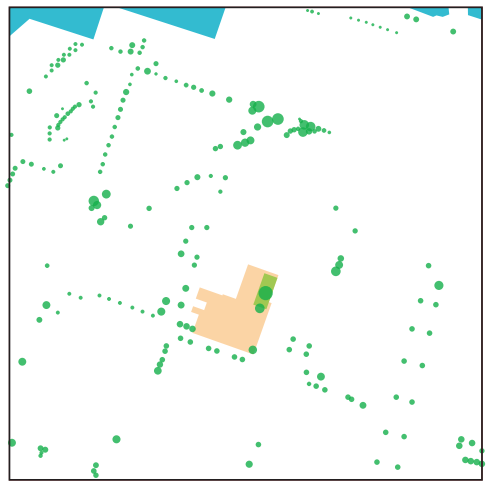

St Patrick's Square

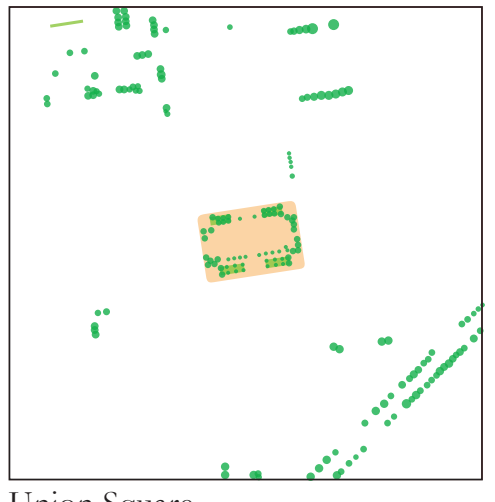

Union Square

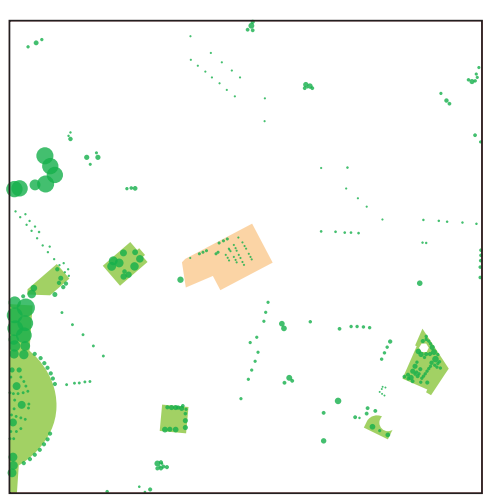

Plaza de Santo Domingo 
Figure 69. (opposite page) Comparison of green space plans Figure 70. Green space findings.

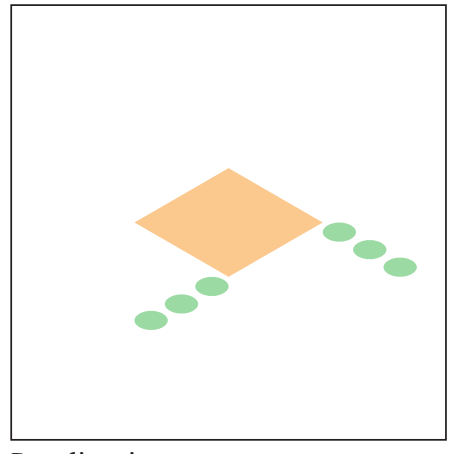

Leading into

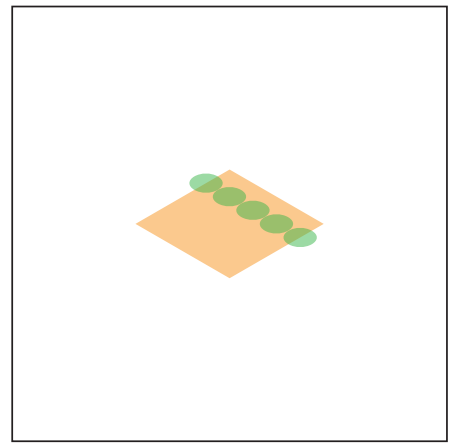

Organising within square

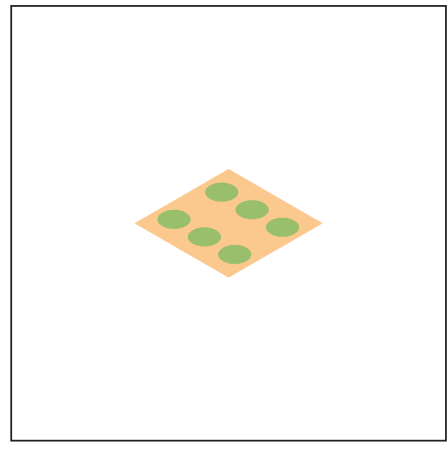

Integrated within square

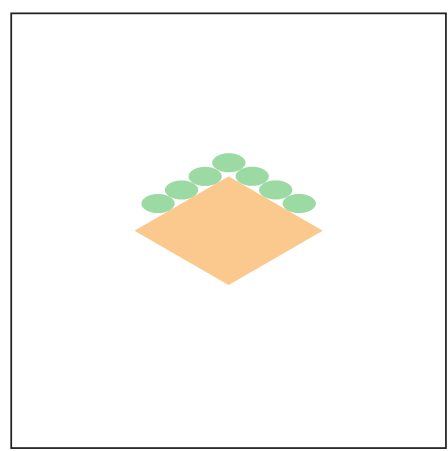

Framing around edges

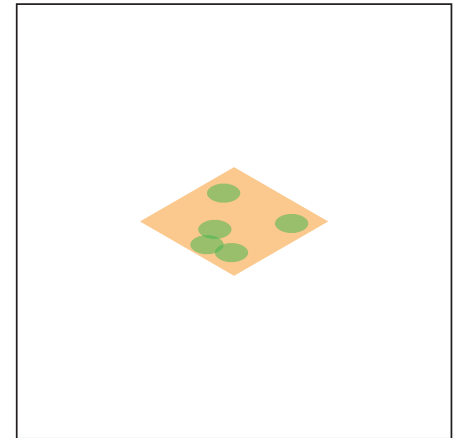

Natural layout within square

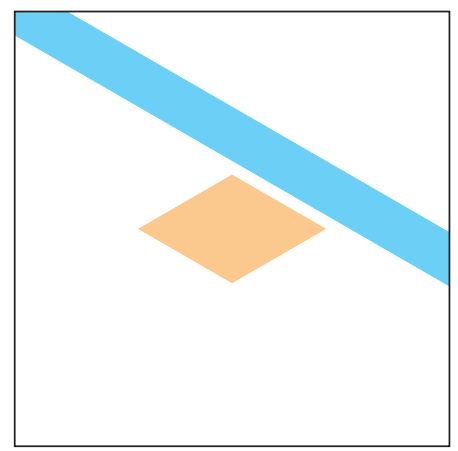

Natural water body frames one edge

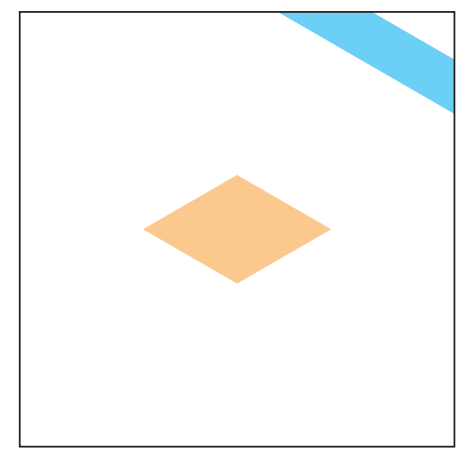

Natural water body within 5 min walking distance

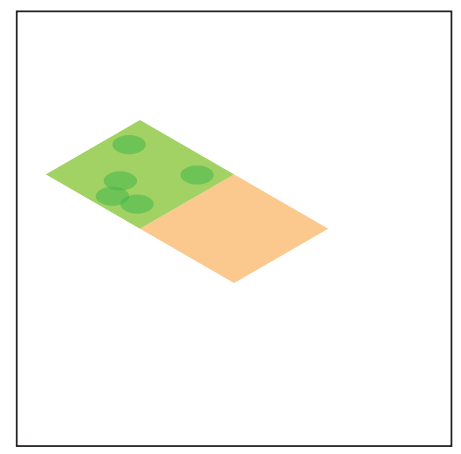

Connected to green space

\section{Landscape and Natural Features}

The mapping of landscape features was not as useful as expected. This can be put down to the study excluding many of the more park-like designs in favour of hard landscaped city squares. Additionally the exclusion of three dimensional information meant that some of the topographical features of these case studies are not presented here.

The study did reveal, however, that there were cases where planting became an integral part of the square. Such as Square Four in Beirut where two large trees are a major element in the design. The arbitrarium in Barking Town Square, and rows of planting in Town Hall Square are other examples.

Additionally a pattern did emerge where plantings often became organising elements, either within or around the square. This pattern often revealed that plantings were used to highlight connections better integrating the square with surrounding context. Grand Canal Square, Theatre Square and to some extent Federation Square exhibit this attribute.

The City Dune is a unique example because, as the name suggests, the ground imitates a sand or snow dune. This rises up integrating the square with a raised grassed area nearby. This demonstrates how landform can be integral to creating connections on different levels. The hierarchy of space diagram illustrates some of the contours, but unfortunately the exclusion of three dimensional information means this feature is barely apparent in the plan based illustrations.

Federation Square and Grand Canal Square integrate the surrounding water bodies with the design. Grand canal square expresses this with a gestural path (illustrated in the hierarchy of space diagram) connecting the principle building with the canal water. The whole of Federation square is effectively a bridge over an array of railway lines which integrates the Yarra River with the square as well as Melbourne's central city. 


\section{Summary of Findings}

In summary, the mapping of these five attributes revealed that over all integration is reliant on multiple properties working together. While all five attributes revealed insights in themselves, it is important to note that some attributes are dependant on one another.

For example, a clear hierarchy of space is dependant on the proximity of soft building edges, the enclosure afforded by the surrounding buildings and to some extent the location of planting and landscape features.

Alternatively, too much of one attribute can be harmful to others. For example, while a square may be well integrated with the cities street pattern and public transit system, it may in turn be disconnected from the surrounding soft building edges. This can also create an ambiguous hierarchy of space and a vague spatial identity.

Finding the right balance to create a well integrated square remains an issue to be properly addressed in the design case study chapter.

Additionally it has to be noted that the process of drawing and collating this chapter proved helpful toward the background and the design case study chapters. In particular the attributes of soft built edges and hierarchy of space required the case study squares and surroundings to be examined in three dimensions. The subsequent process of collation, categorisation, and illustration (if only in plan) proved inspirational toward to the design phase.

\section{Improvements}

Possible improvements for this portion follow:

Widening the definition of the square to include more contemporary hybrid urban landscapes and public spaces.

More detailed ground plans that include curbs, ground material and possibly the ground floor plans of buildings that front onto the square.

Larger sample size to determine trends more definitively.

Map the use of the surrounding buildings. This could be limited to ground floor uses for plan-based mapping, or include more three dimensional representations of use across different floors.

The biggest improvement that could be made to this study would be to include three dimensional information. This would have given much clearer results in assessing integrative properties of these squares, compared with just the plan-based mapping. Attributes that could have benefitted from three dimensional drawings include: the assessment of the square's enclosure in terms of building height and vertical proportions, topographical landscape features, and more detailed information in regard to the vertical separation of connections above and below ground level. This last section would also have benefitted again by distinguishing between pedestrian and vehicular connections. All of this information can be articulated with a few cross sections through these squares, or possibly an isomeric diagram. Regrettably these drawings were omitted from the study as in the context of this thesis it would not have been feasible to add this level of detail. Fortunately however many of the issues this omission raises can be addressed in the design case study chapter. 
$\stackrel{4}{\text { Chapter }} \underset{\text { Cathedral Square Christchurch }}{4}$ 


\section{B.M. 273}

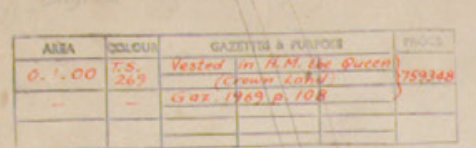

For this portion

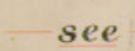

sheet 1

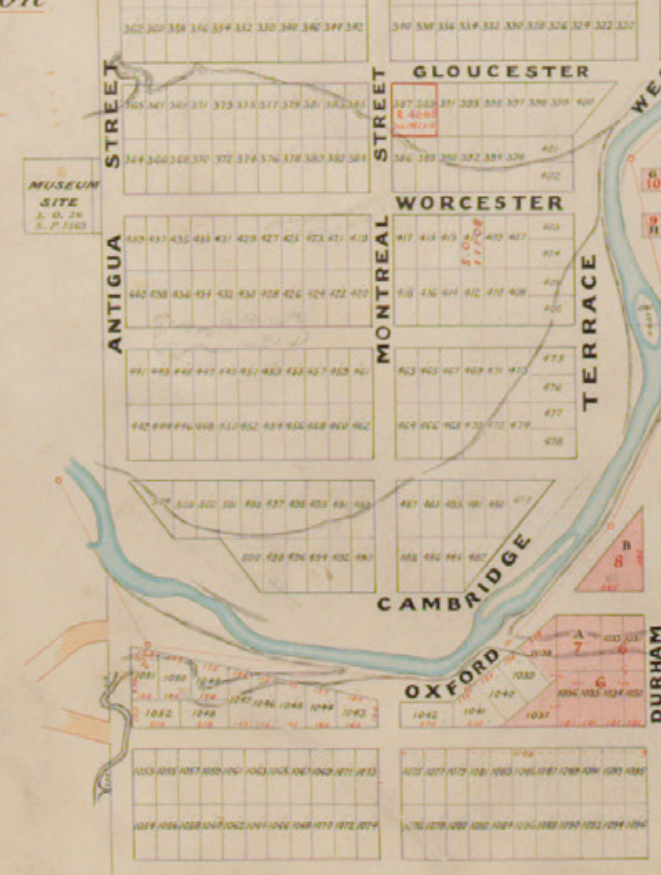

CHRISTCHURCH 
Source: Jollie,

Edward. Black Map

of Christchurch.

1850. Archives New

Zealand, Christch-

urch. Archives New

Zealand. Web. 25

Apr. 2013.
This chapter offers a brief introduction to the site chosen for the design case study part of this thesis.

The focus is on setting the scene, introducing Christchurch City, Cathedral Square, and establishing site specific design criteria.

Christchurch's Cathedral Square exhibits many of the issues indicative of a disintegrated square as identified in the background and precedent case study chapters. This condition preceded the events of 2010 and 2011 when a series of major earthquakes caused widespread damage to Christchurch and destroyed much of the central city.

The focus now is on rebuilding Christchurch City.

\section{Introduction}

The first part of the chapter consists of a series of maps that introduce the city at three scales. The different scales include city-wide maps, central city maps and then more detailed plans of the square. These drawings are based on the pre-earthquake square. They are followed by a series of drawings illustrating the marred form of the post-earthquake square. Central Christchurch was still in a state of flux at the time this thesis was undertaken. This means that the identification of buildings to be retained may not be accurate given that the fate of many buildings is still undecided or not known. In any case, every effort was made to ensure that the drawings are as accurate as possible at the time of publication.

The final part of the chapter introduces the Canterbury Earthquake Recovery Authority (CERA) and the Christchurch Central Development Unit's 100 day plan for rebuilding central Christchurch. This section consists of a short overview of the proposal for the rebuilding of Cathedral Square. It also comments on the inherently New Urbanist plan and makes note of those propositions contained within the plan that the design case study will seek to integrate.

The chapter then concludes by summarising the physical and qualitative properties unique to Cathedral Square that will further inform the design case studies. 



\section{Pre - earthquake Site - Analysis}




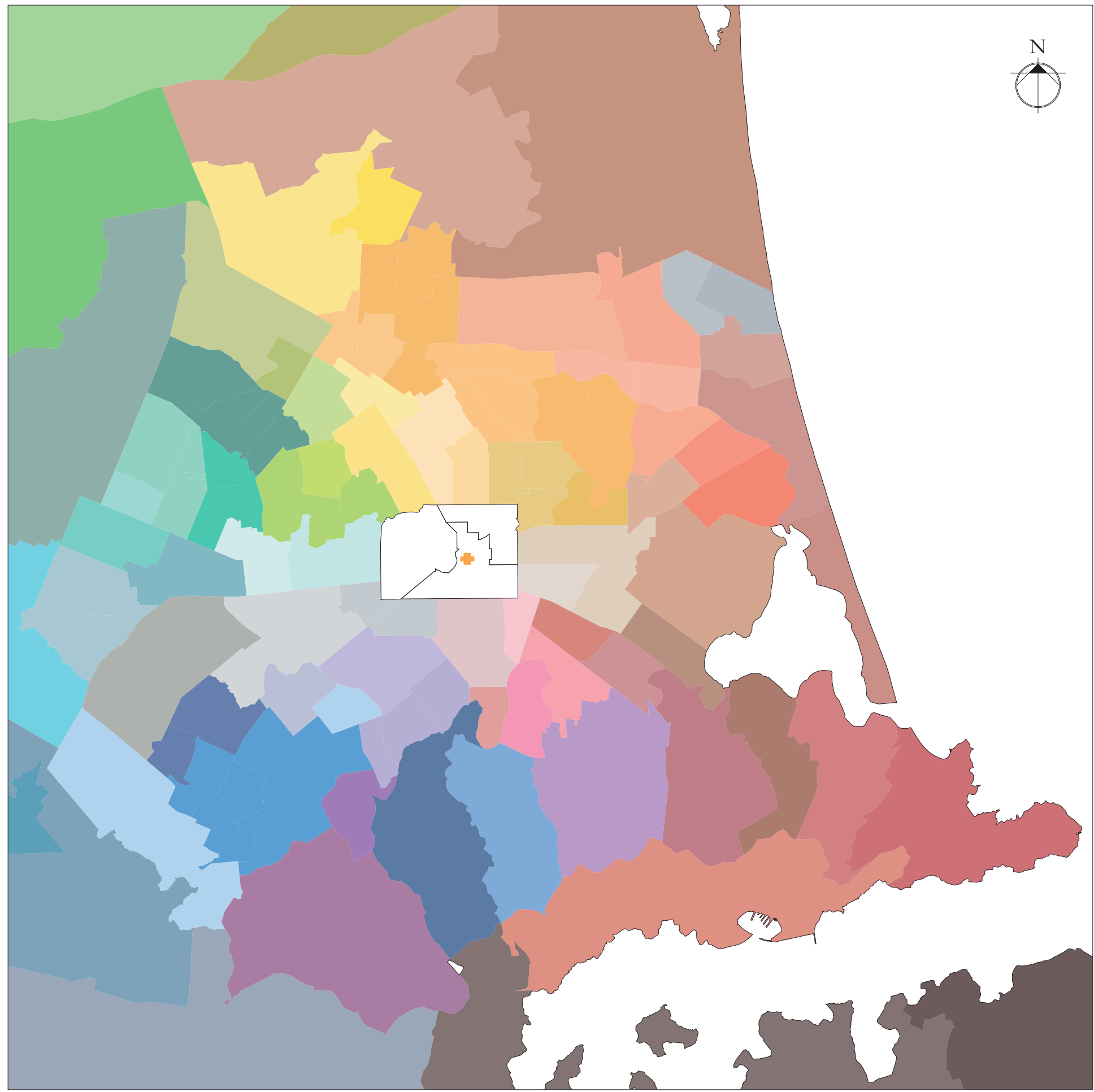

Figure 72. Map of Christchurch suburbs. Draw-

ing adapted from: Koordinates.com

Central Christchurch is dwarfed by the suburban periphery. The colours are indicative of Christchurch's sprawling suburbs. 
Figure 73. Map of Christchurch's road network.

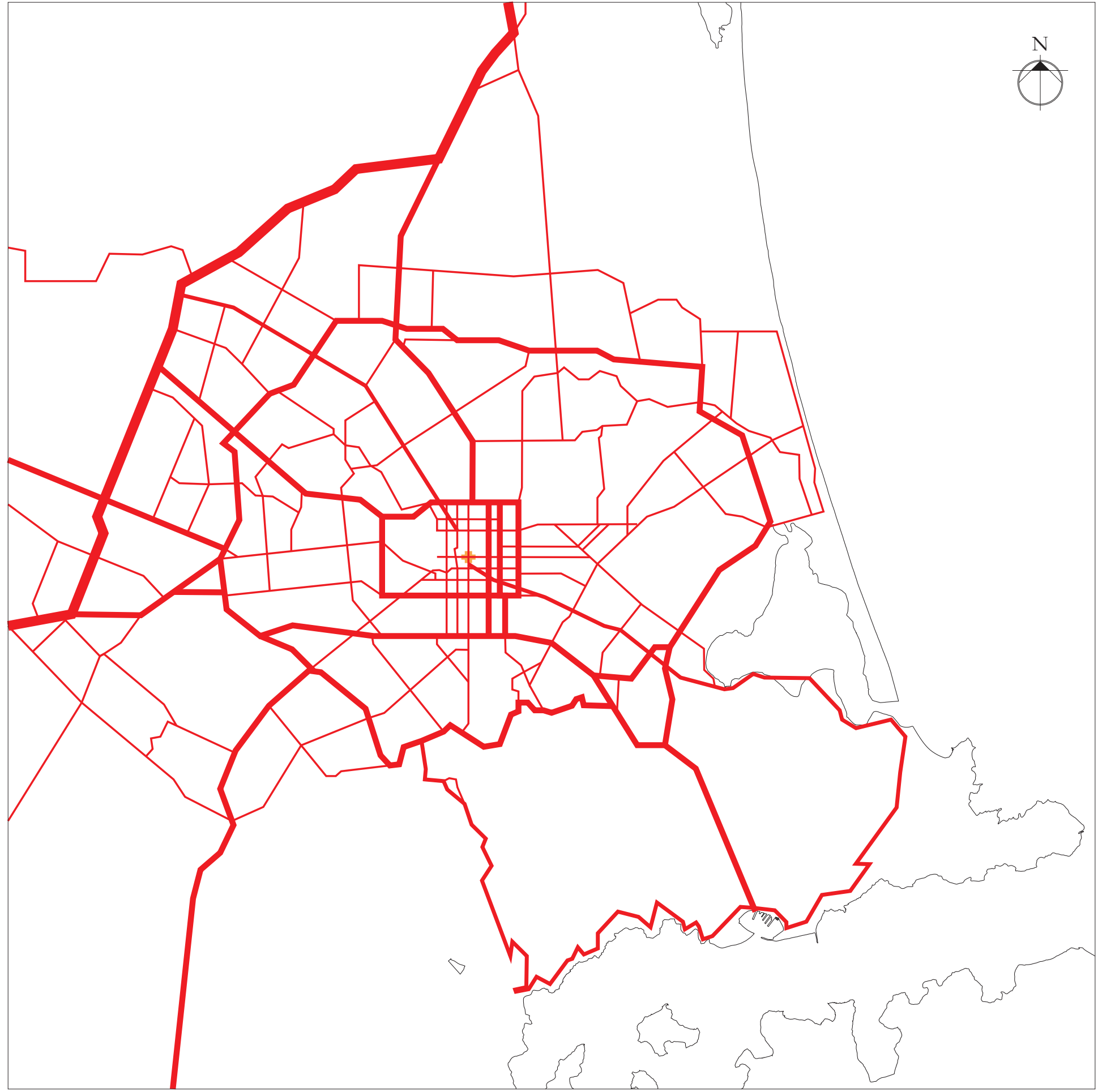

Christchurch's street pattern shows a succession of rings with various cross routes splaying out from the centre.

In sharp contrast is the rigorous gridiron street pattern within the central city, enclosed by the four avenues. High Street, from the south east, is the only non-orthogonal street to penetrate the grid to the city centre - Cathedral Square. 

Figure 75. Map of Christchurch green space and reserves.

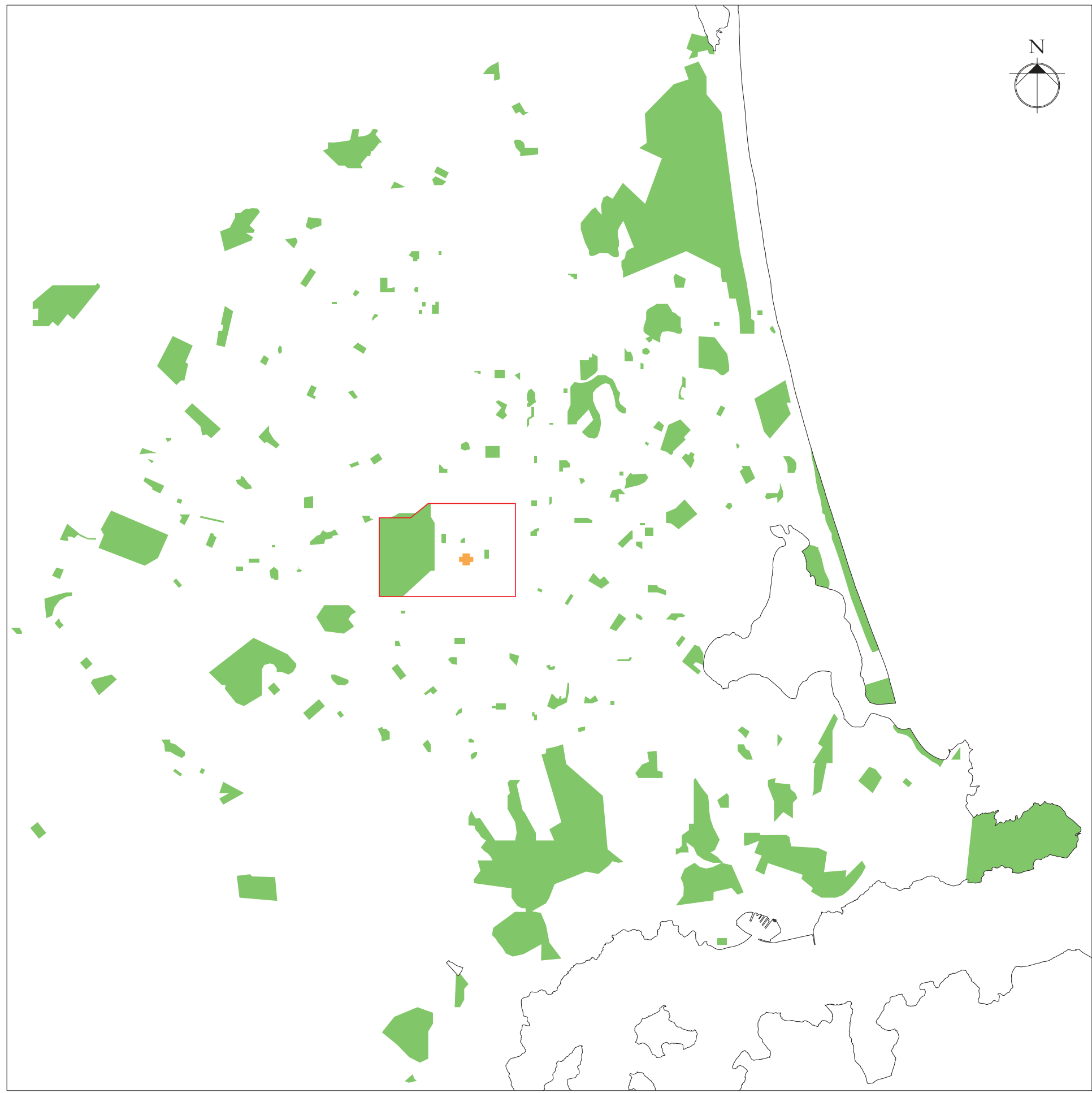

Green space is a major feature of Christchurch's urban landscape. Alongside the numerous suburban parks are large areas of reserve land to the north and south of the central city.

Hagley Park takes up the whole western portion of the central city. Cranmer, Latimer and Victoria Squares are also green spaces. 


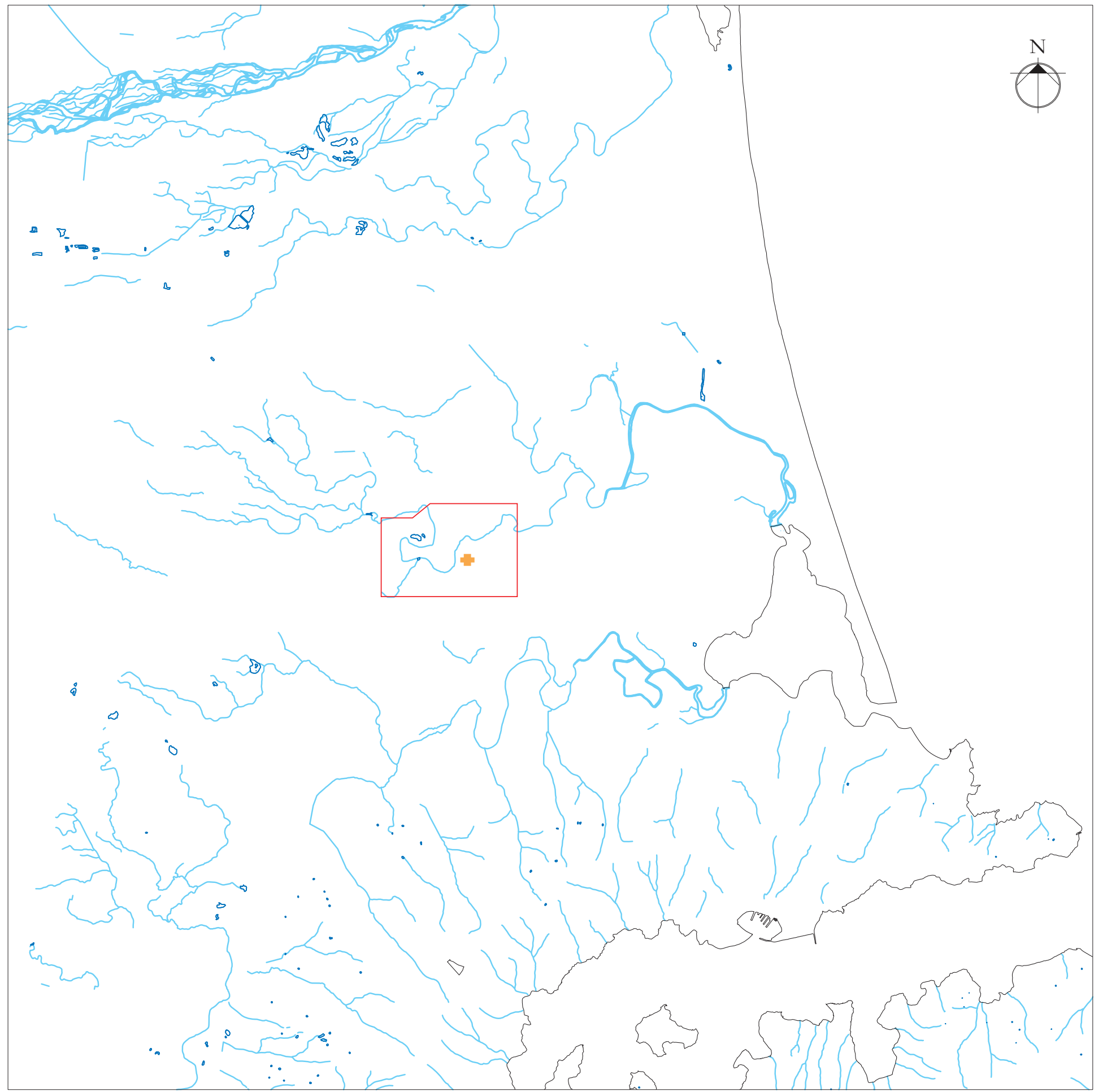

Figure 76. Map of Christchurch rivers, streams and lakes.

Drawing adapted from: Koordinates. com

Map showing the waterways in and around Christchurch city.

The Avon River meanders through the central city, passing the square, to the west eventually draining into the estuary to the far east. 
Figure 77. Map showing Christchurch's red zoned

land.

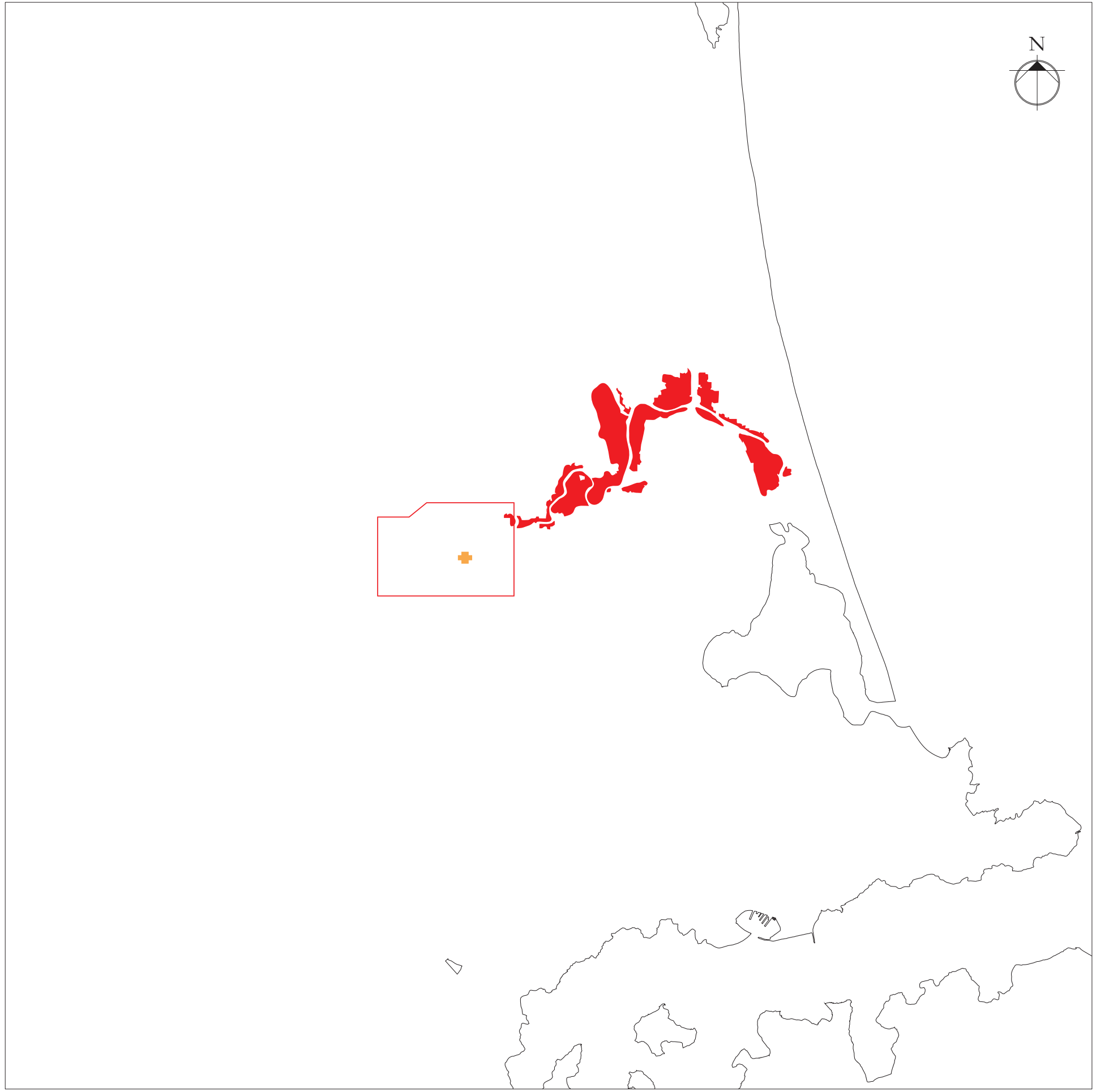

Map showing the land deemed to be unsuitable for development.

This land follows the Avon river and only affects a small portion of the cental city, but has a significant impact on the eastern suburbs.

It is proposed much of this land will become a public wetland. 


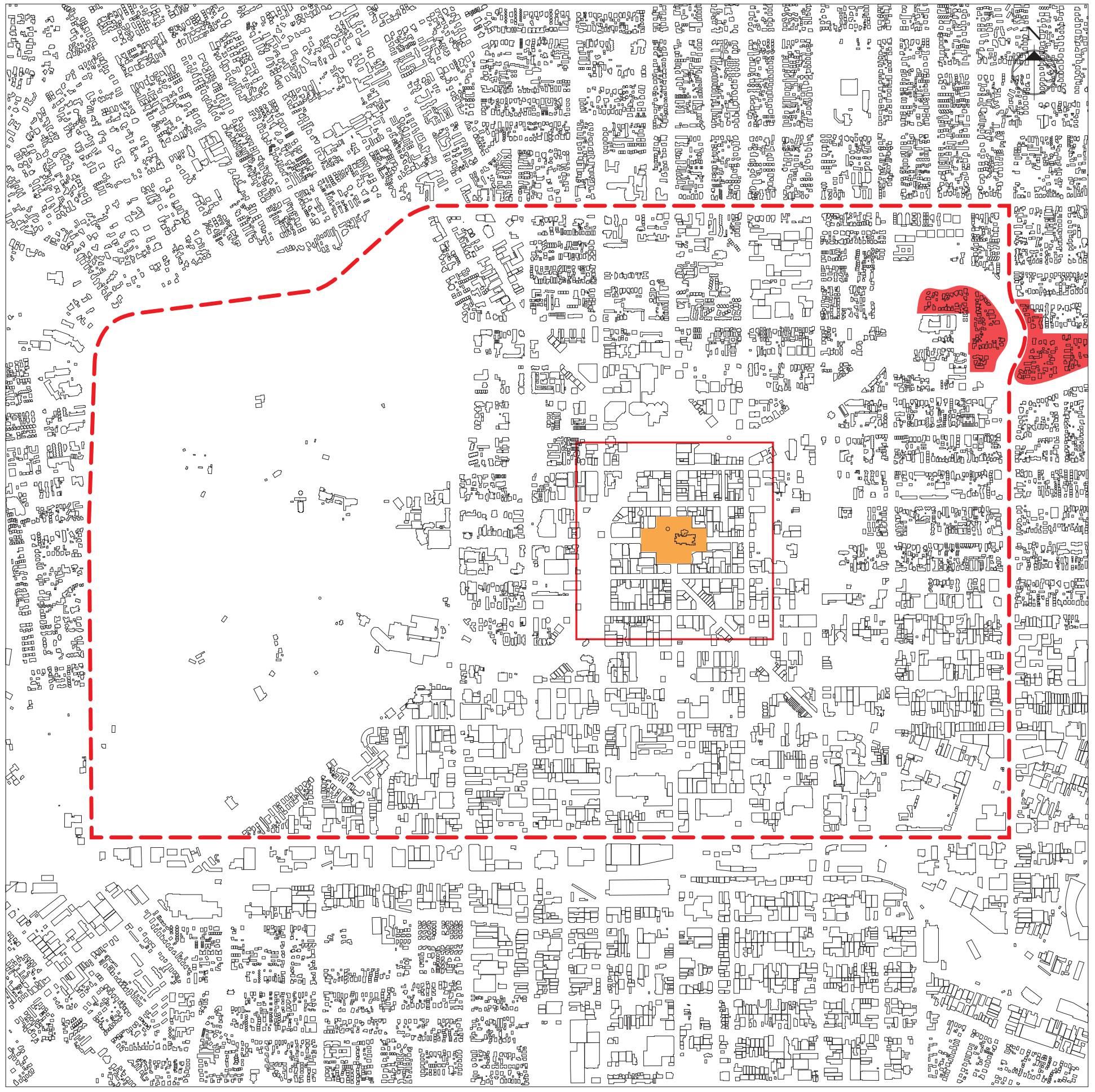

Figure 78. Detailed map of Christchurch central and Square.

Detailed map of central Christchurch showing the four avenues that define the greater central city area. 
Figure 79. Map showing walking distances from Cathedral Square.

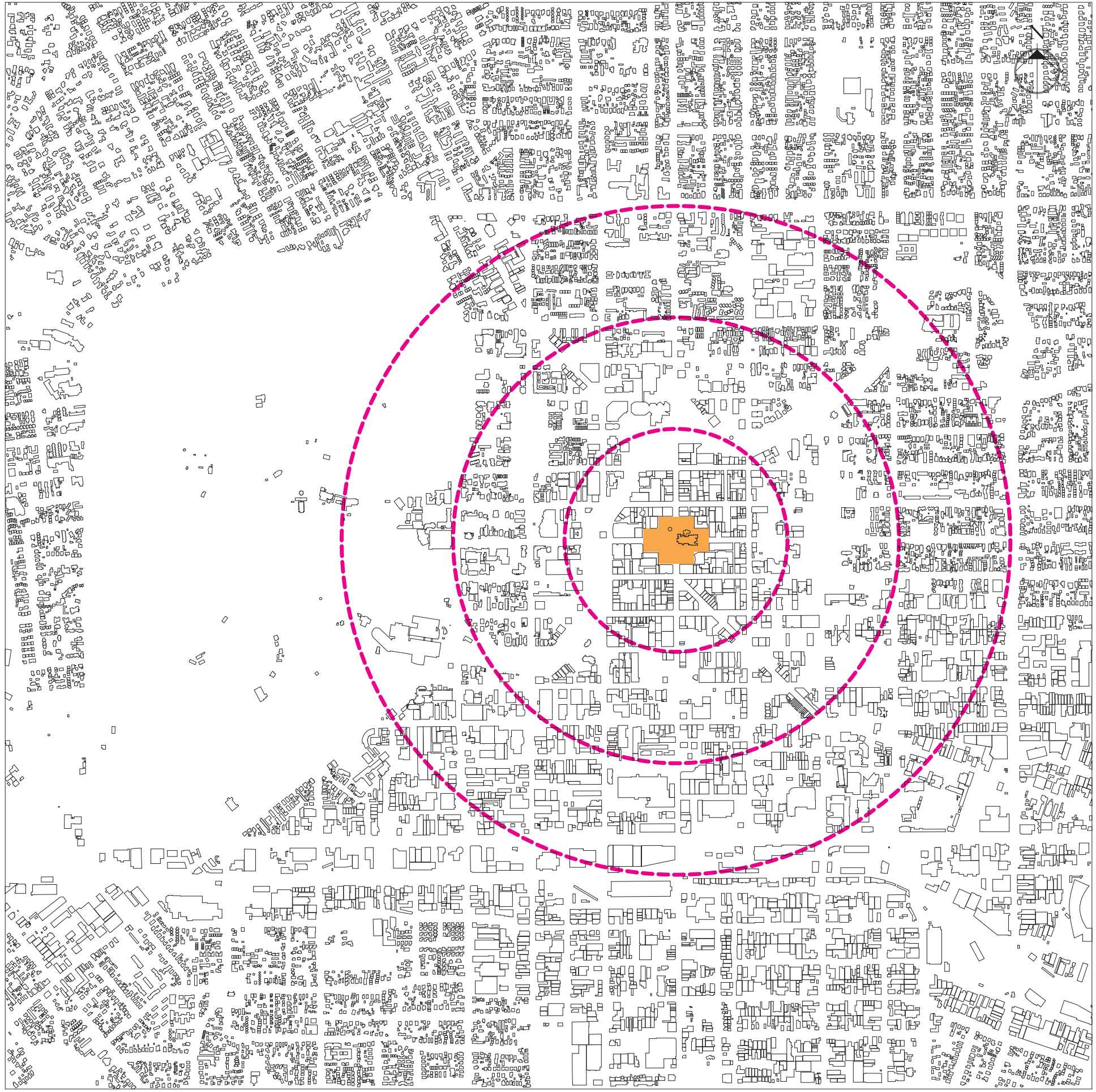

The three concentric circles represent five, ten and fifteen minute walks from Cathedral Square. The five minute distance captures significant stretches of the Avon River, as well as Victoria Square. Other significant places include: High Street, Cashel Mall, New Regent Street and Worcester Boulevard. 


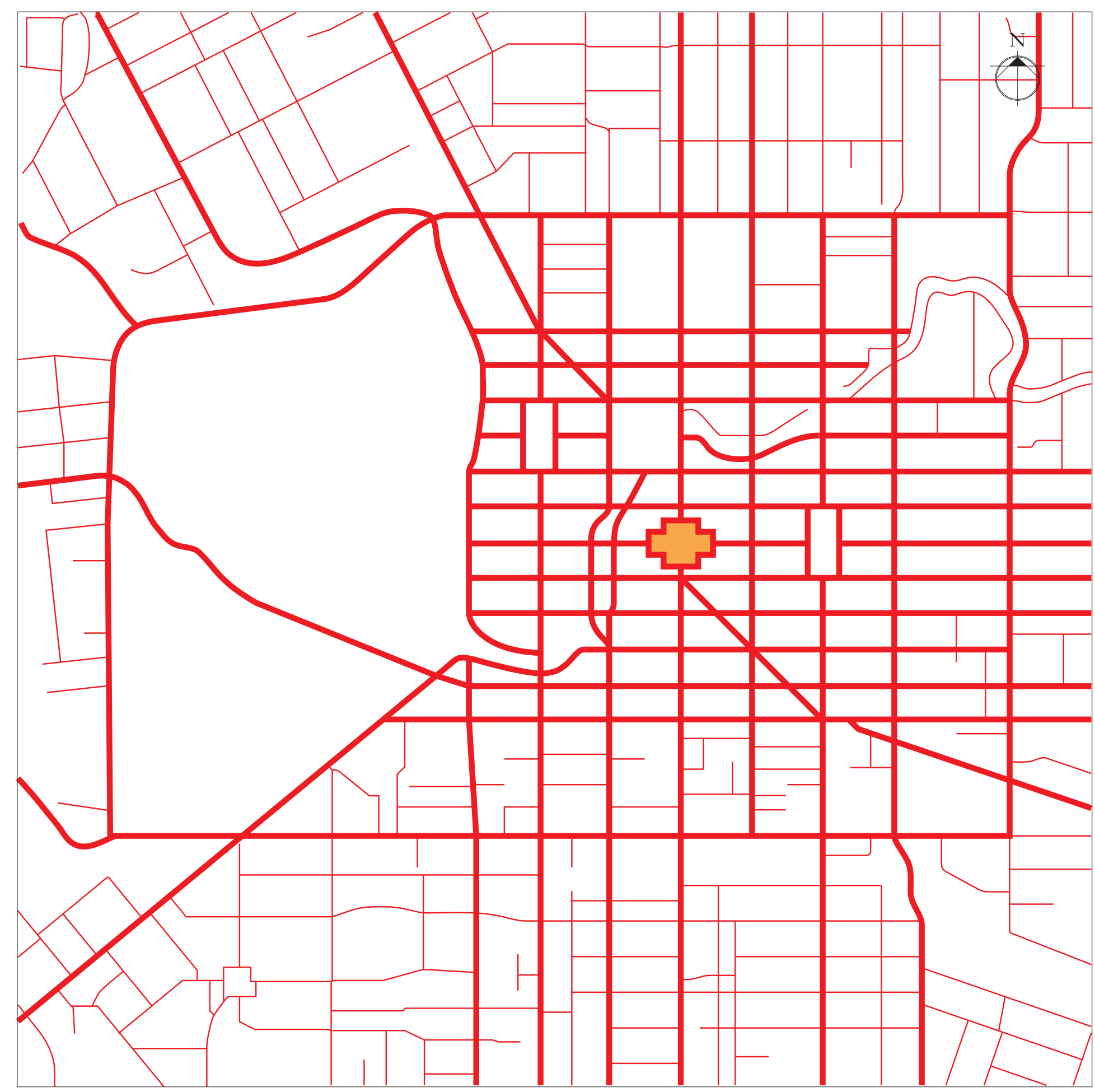

Figure 80. Map of central Christchurch gridiron street pattern.

A closer view of Central Christchurch's street pattern reveals it retains the original grid pattern as laid out by Edward Jollie in 1850. 
Figure 81. Map of main streets that intersect the square.

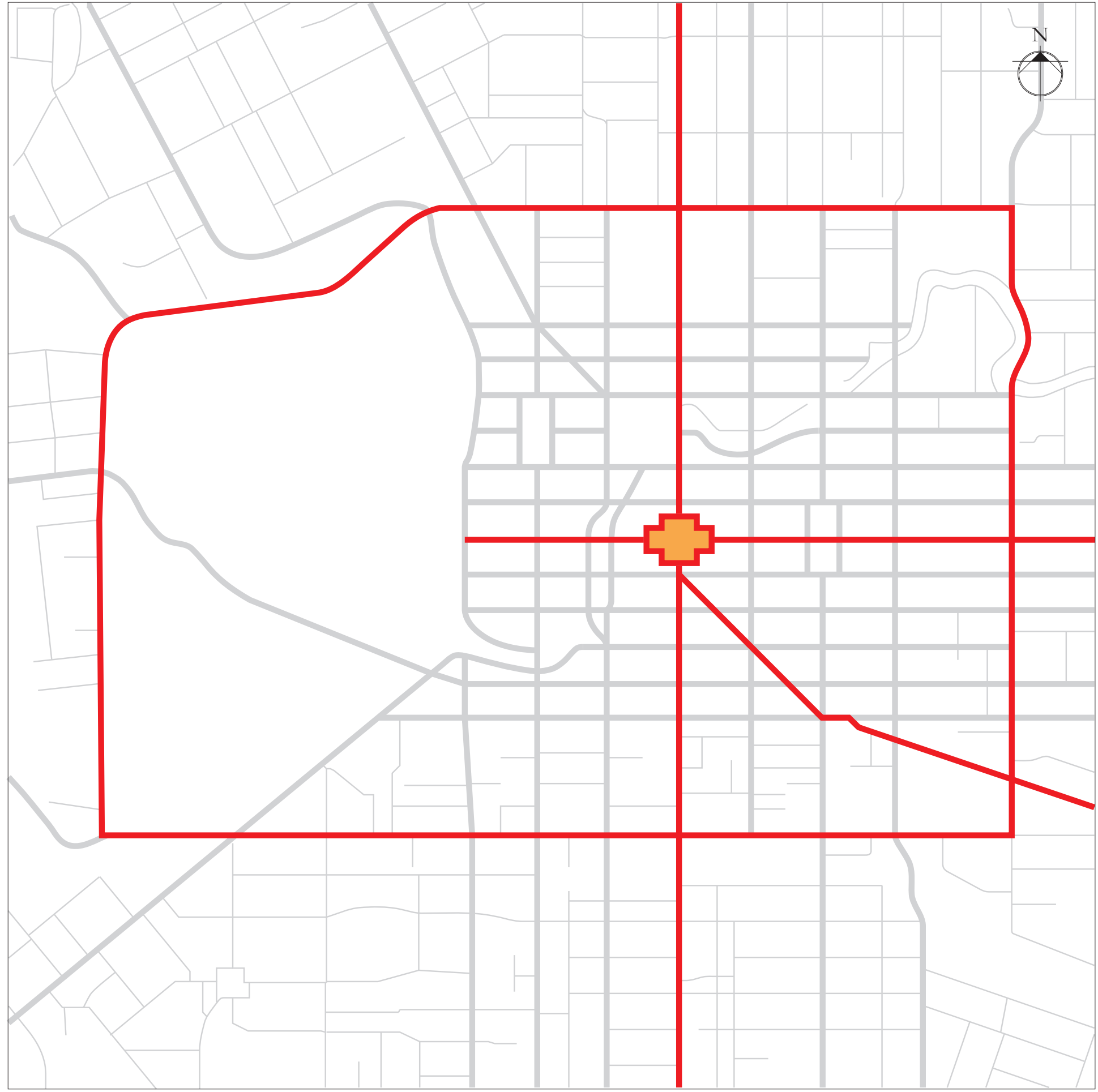

Cathedral Square is bisected north - south and east - west by two streets. Colombo Street and Worcester Street/Boulevard. High Street terminates at the southern entrance to Cathedral Square.

The four avenues of Moorhouse, Fitzgerald, Bealey and Deans define the central city district. 


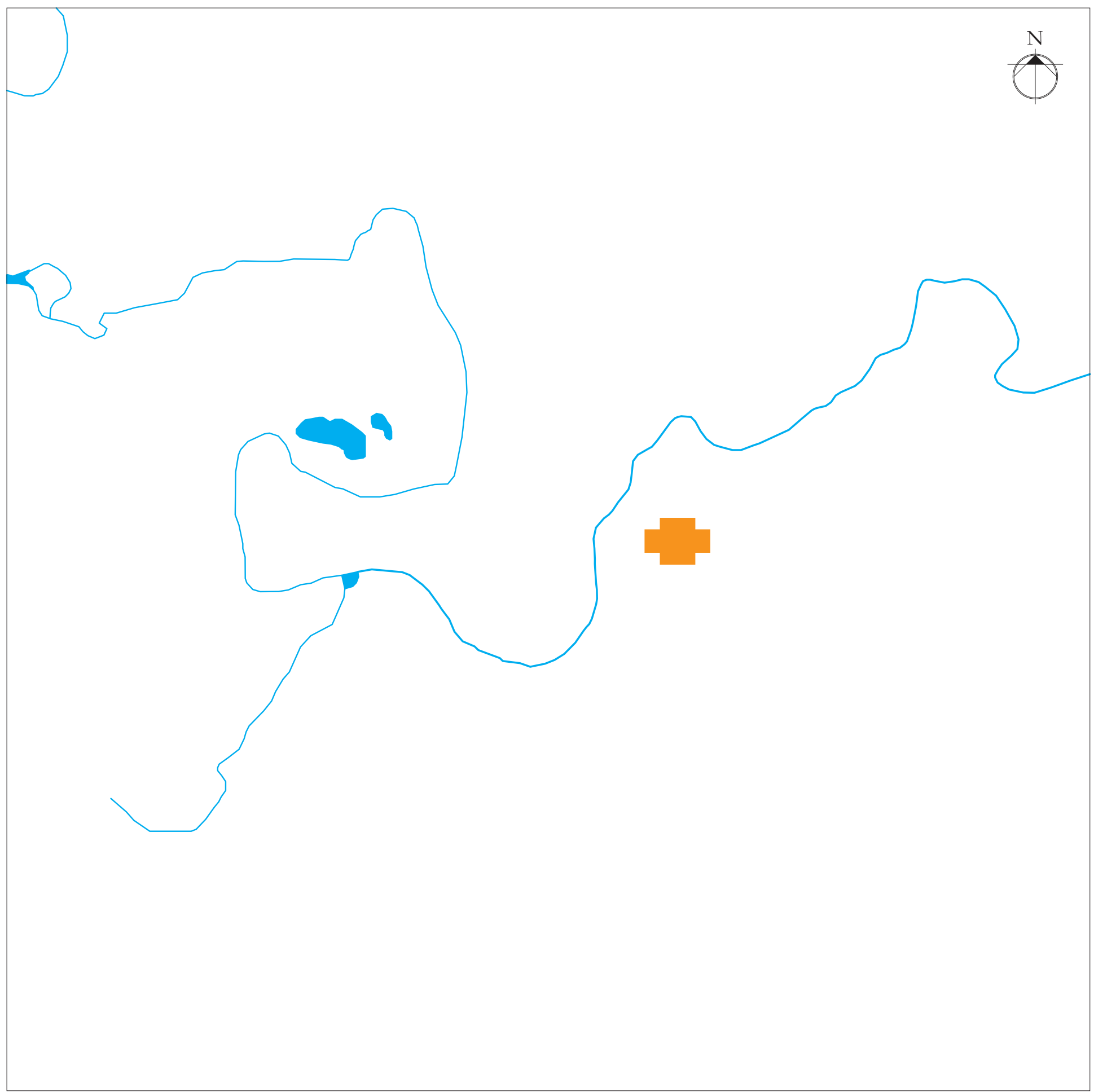

Figure 82. Map Avon River proximate to Cathedral Square.

Map showing the close proximity of the Avon River to Cathedral Square. 
Figure 83. Map of green space proximate to Cathedral

Square.

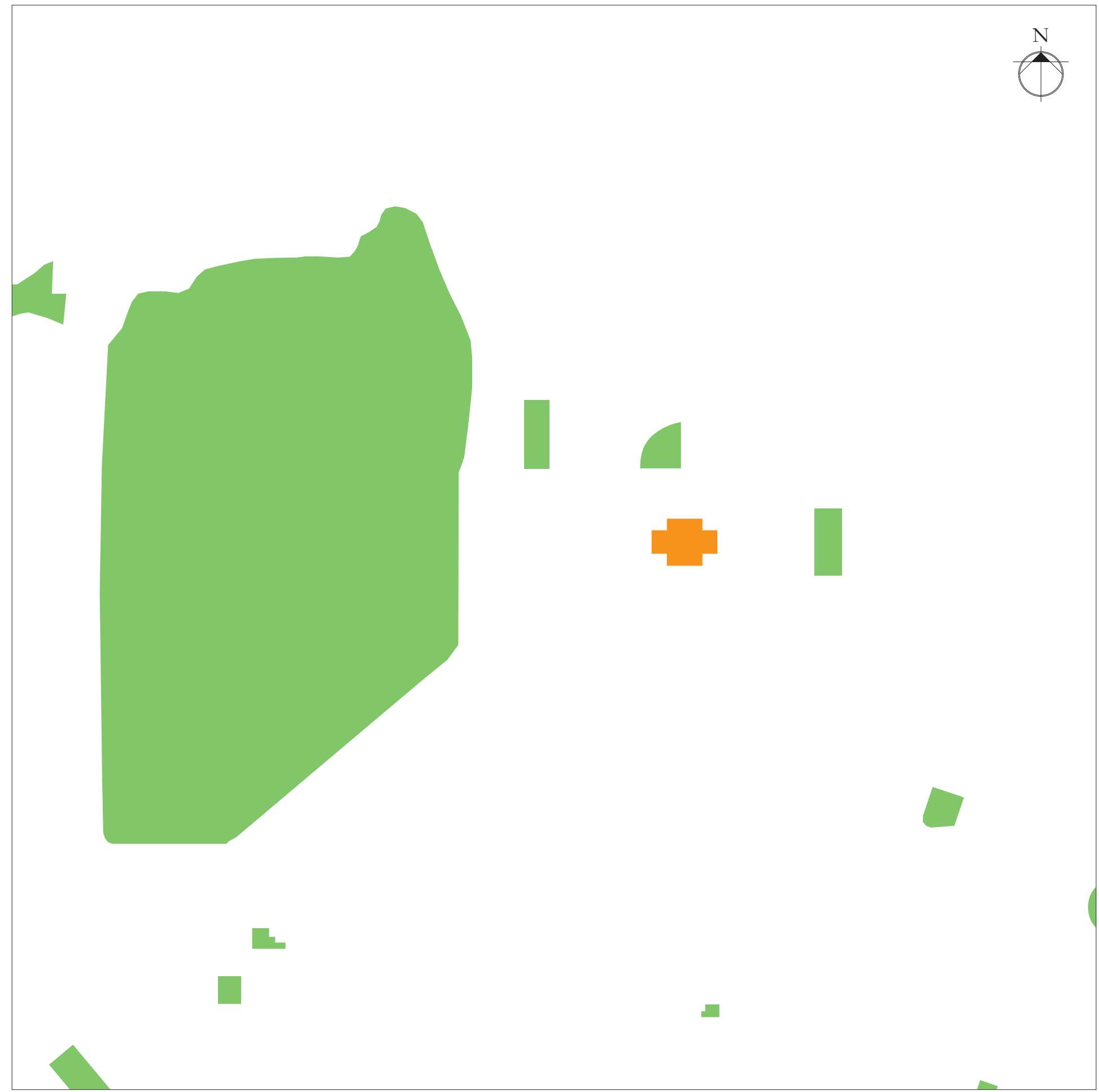

Map showing the green space proximate to the square.

Cathedral Square has a direct westward connection to Hagley Park, via Worcester Boulevard, crossing the Avon River en route. 


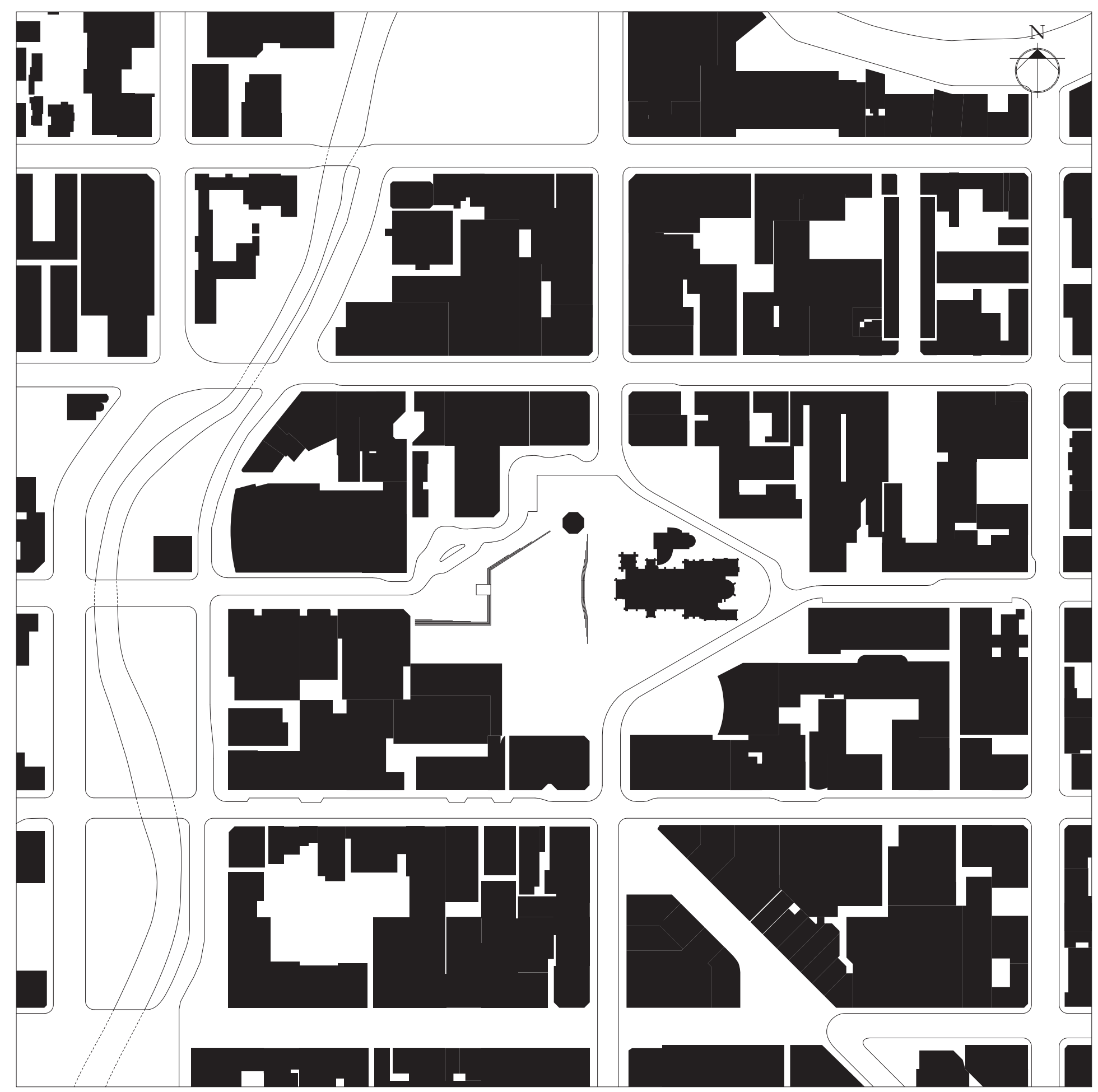

The plan of the existing pre-earthquake Cathedral Square shows the large scale of open space.

The cathedral, although an inseparable piece of the squares identity, is independent from the surrounding forms and isolates large portions of the square, particularly on the eastern side. 
Figure 85. Plan of Cathedral Square showing pre-earthquake pedestrian areas and lanes.

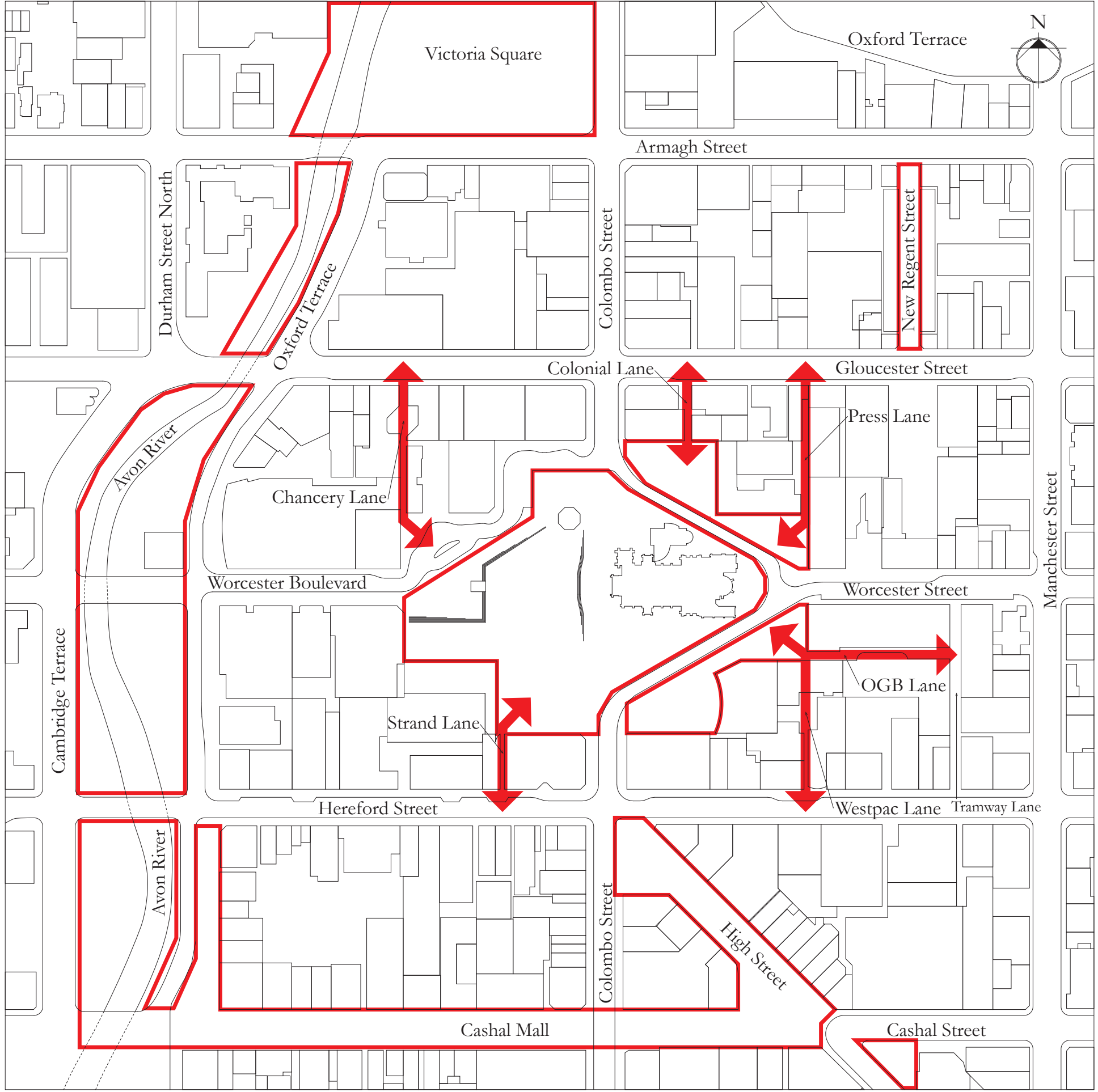

Existing Pedestrian lanes and precincts.

The pedestrian only precincts are separated from the square. The placement of roads around three edges of the square act as barriers to pedestrian connectivity between the square and the surrounding buildings. 


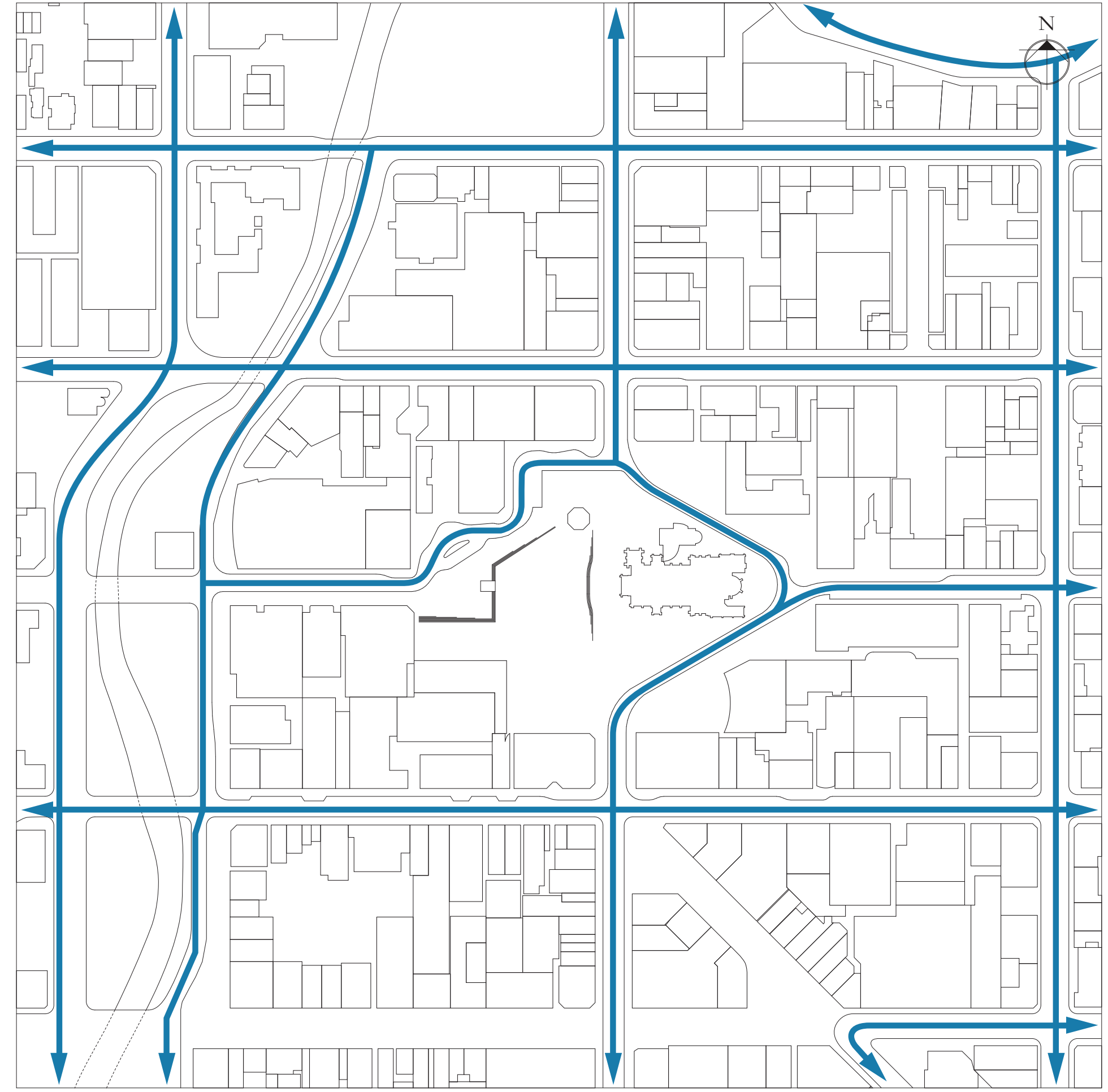

Existing vehicular network.

Almost all roads proximate to the square with the exceptions of Cashel Mall and parts of High Street are accessible by car.
Figure 86. Plan of Cathedral Square showing pre-earthquake vehicular connections. 
Figure 87. Plan of Cathedral Square showing pre-earthquake public transit routes through the square.

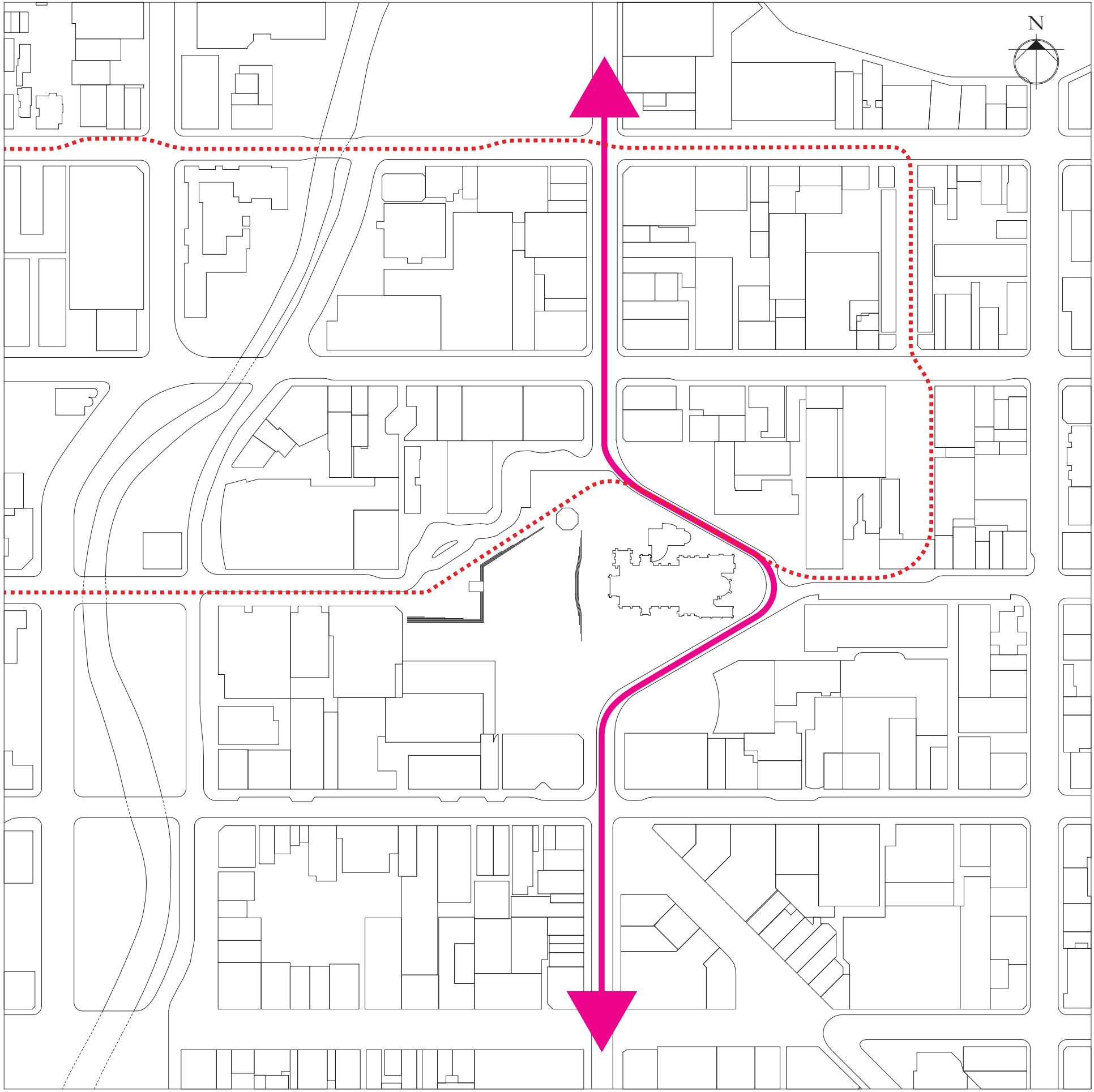

Public transit routes that pass through the Cathedral Square.

Cathedral square has a history of integrating public transit, but the existing routes became a pedestrian barrier and segregated large areas of the square. 


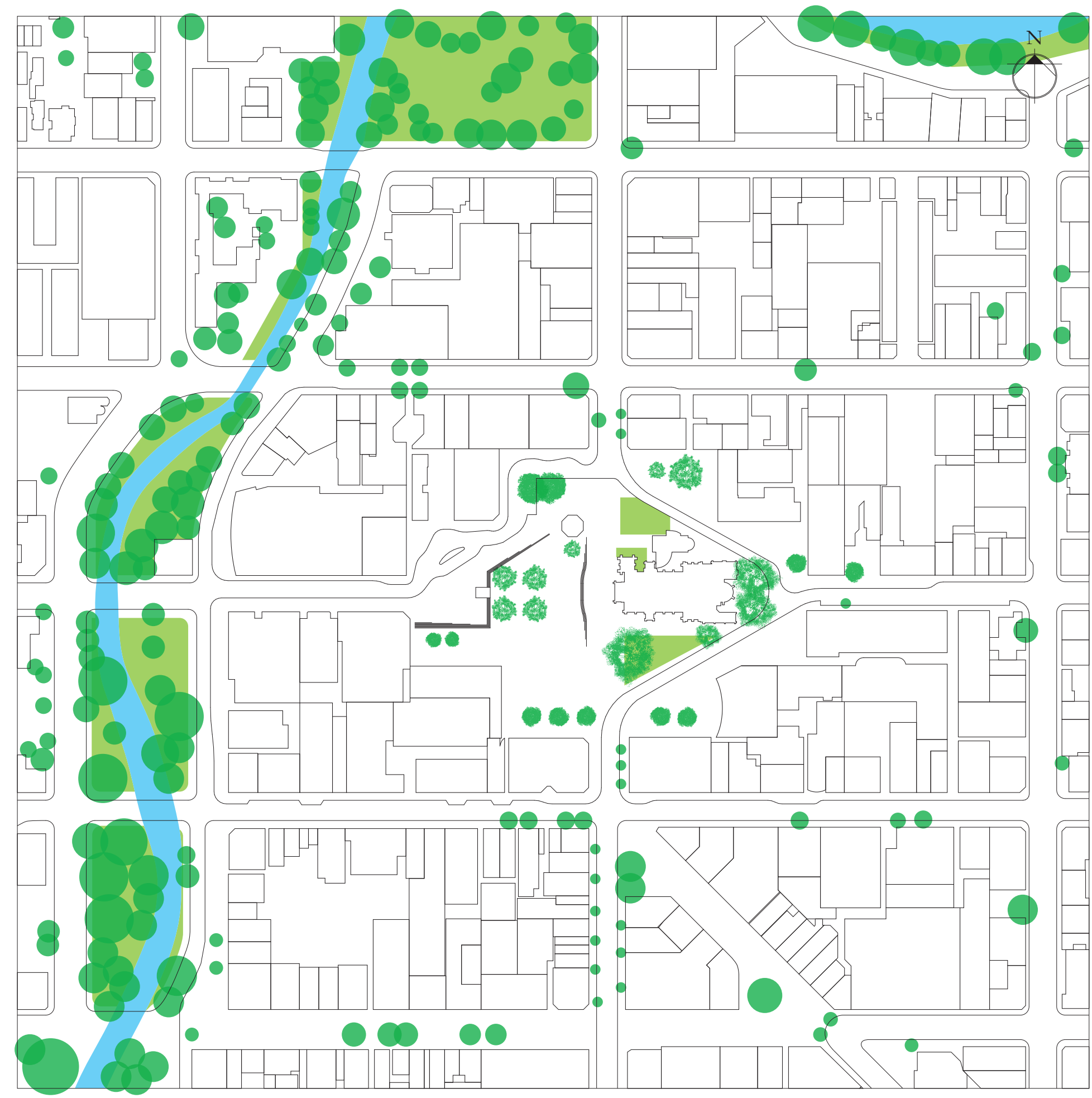

Figure 88. Plan of Cathedral Square showing significant areas of green space and significant planting within the pre-earthquake square.

\section{Cathedral Square contains a number of significant plantings.}

The most significant being the four trees in front of the Cathedral and the large oaks around this building. The Avon River is the most significant area of natural landscaping proximate to the square. 
Figure 89. Plan of Cathedral Square showing hierarchy of space within the pre-earthquake square.

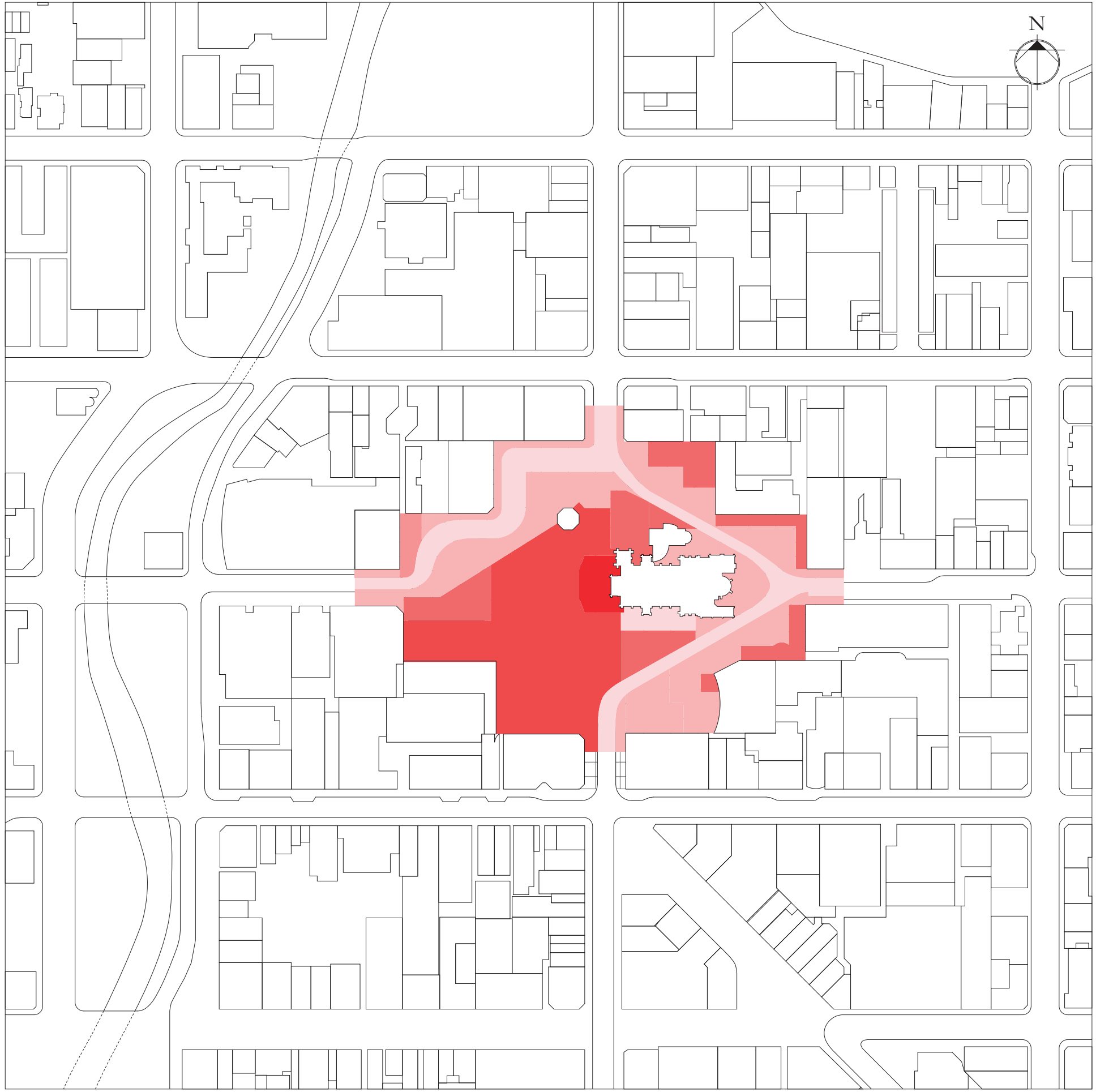

Mapping the hierarchy of space shows the dispersal of spaces within the square caused by the roads and the location of the Cathedral. The spaces at the back of the Cathedral clearly have less prominence than the space in front of the Cathedral. The large scale of the square means there is little overall cohesion to the space. The only space of real prominence is the south-west quadrant and the area directly in front of the Cathedral. 
Figure 90. Pre-

earthquake Cathe-

dral Square.

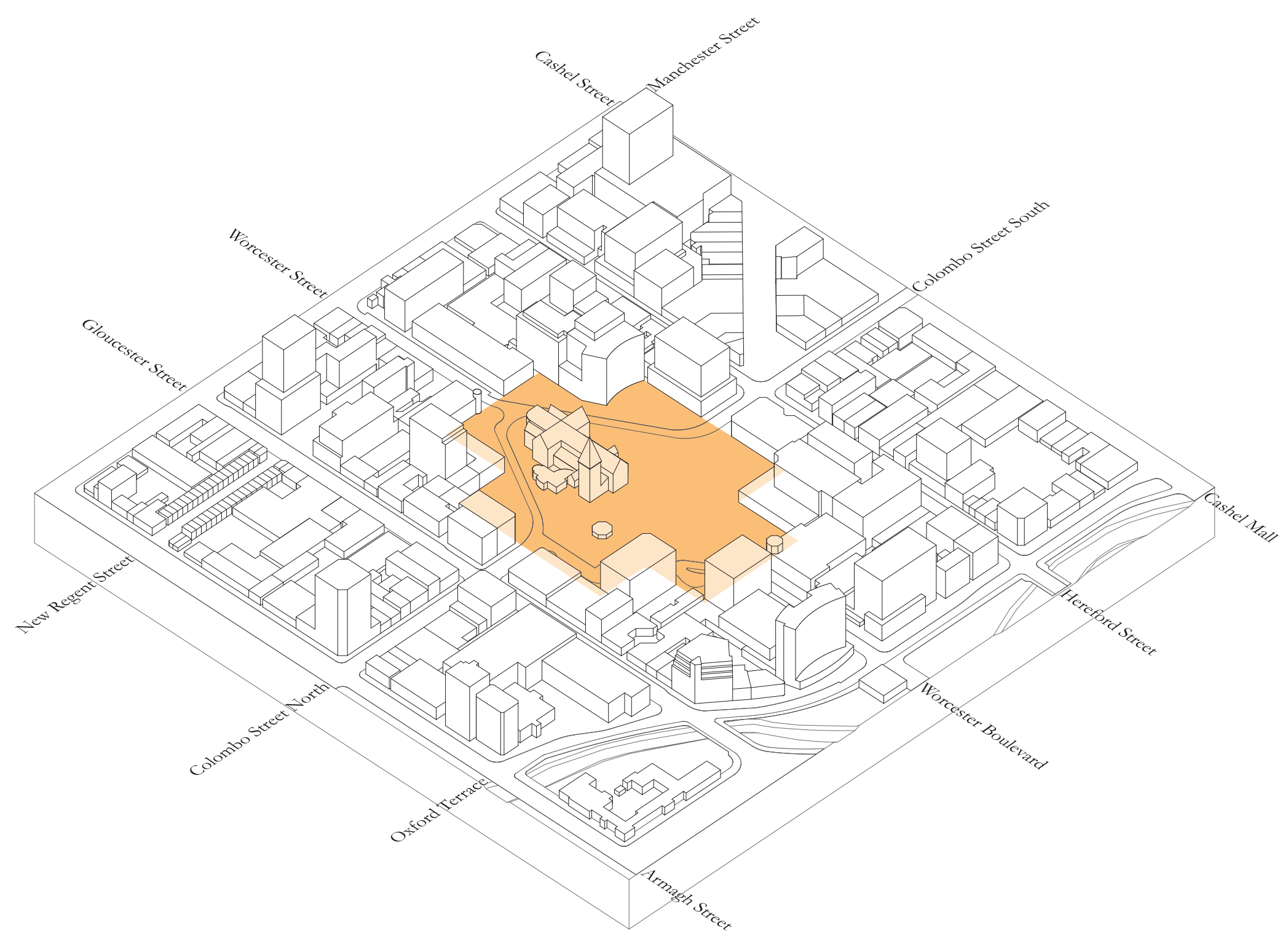

Isometric drawing looking south-east across Cathedral Square prior to the September 2010 and February 2011 earthquakes. 
Figure 91. Isometric

drawing showing

condemned build-

ings to be demol-

ished.

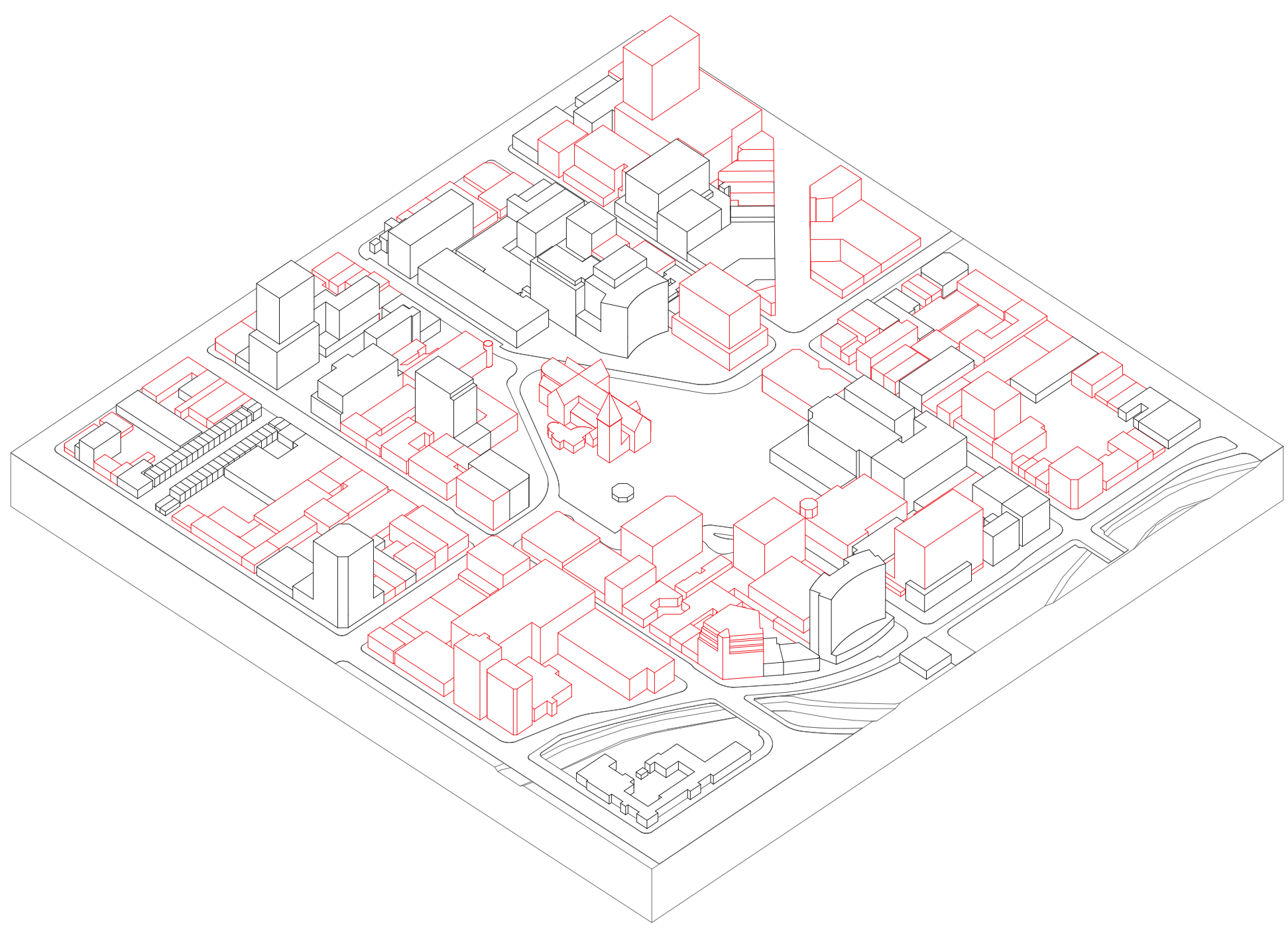

Highlighted are the buildings about the square that have been outlined for demolition. 
Figure 92. Draw-

ing showing the

pre-earthquake

buildings that front

onto the square and

significant planting.

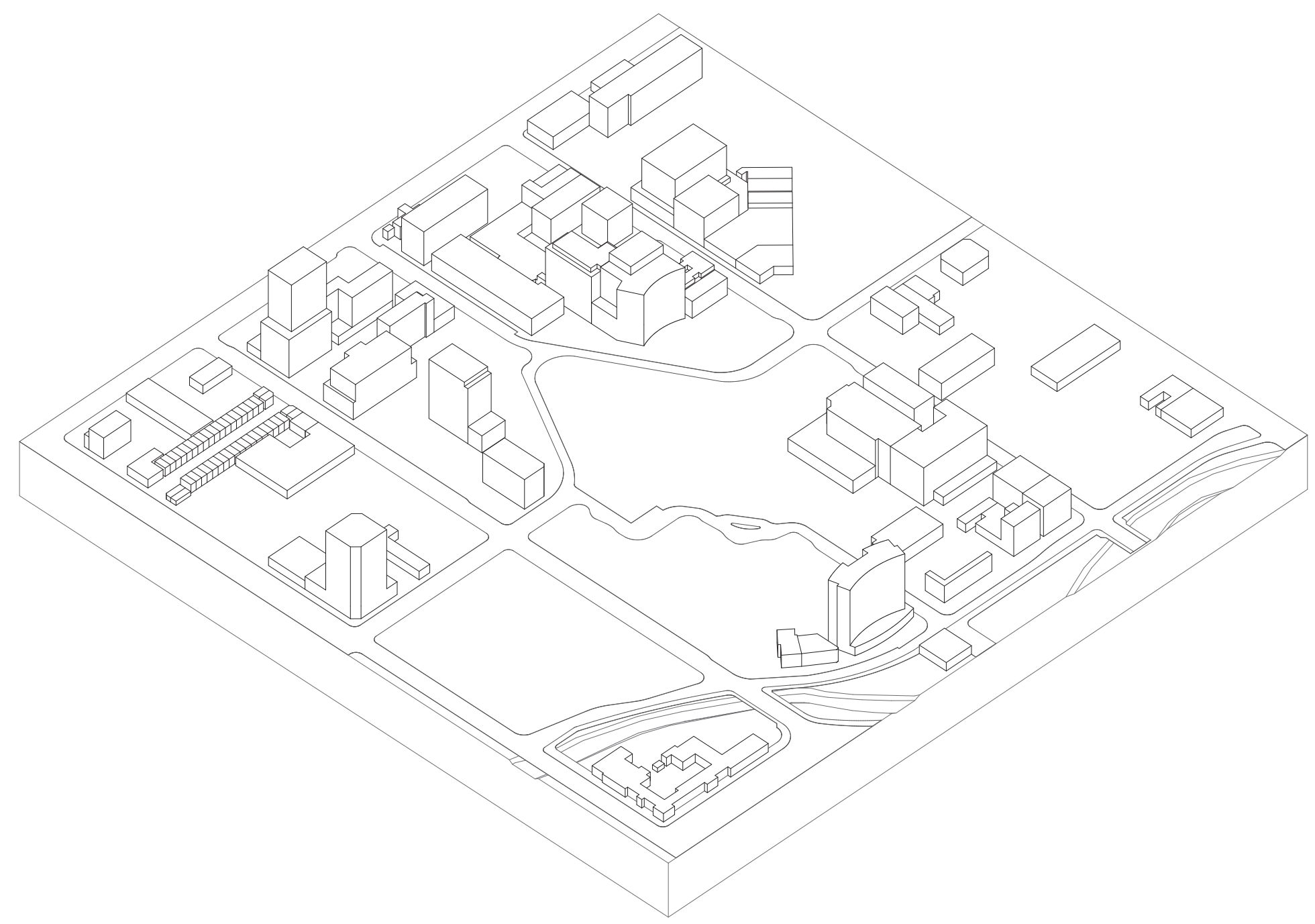

View across Cathedral Square after the removal of all condemned buildings. 


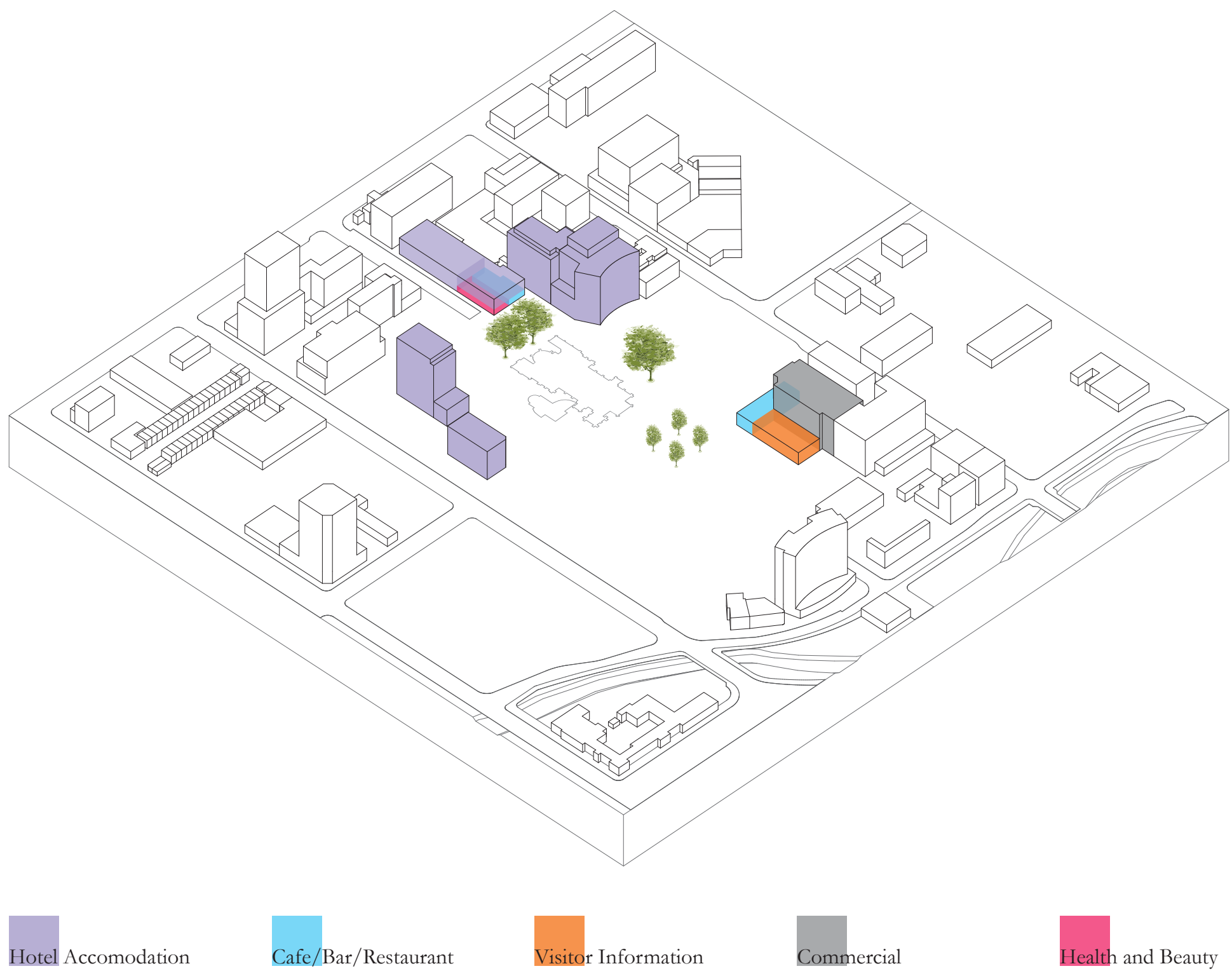

Illustration showing pre-earthquake uses in the remaining buildings about the square. Also shown are significant and historical plantings and Cathedral building footprint. 


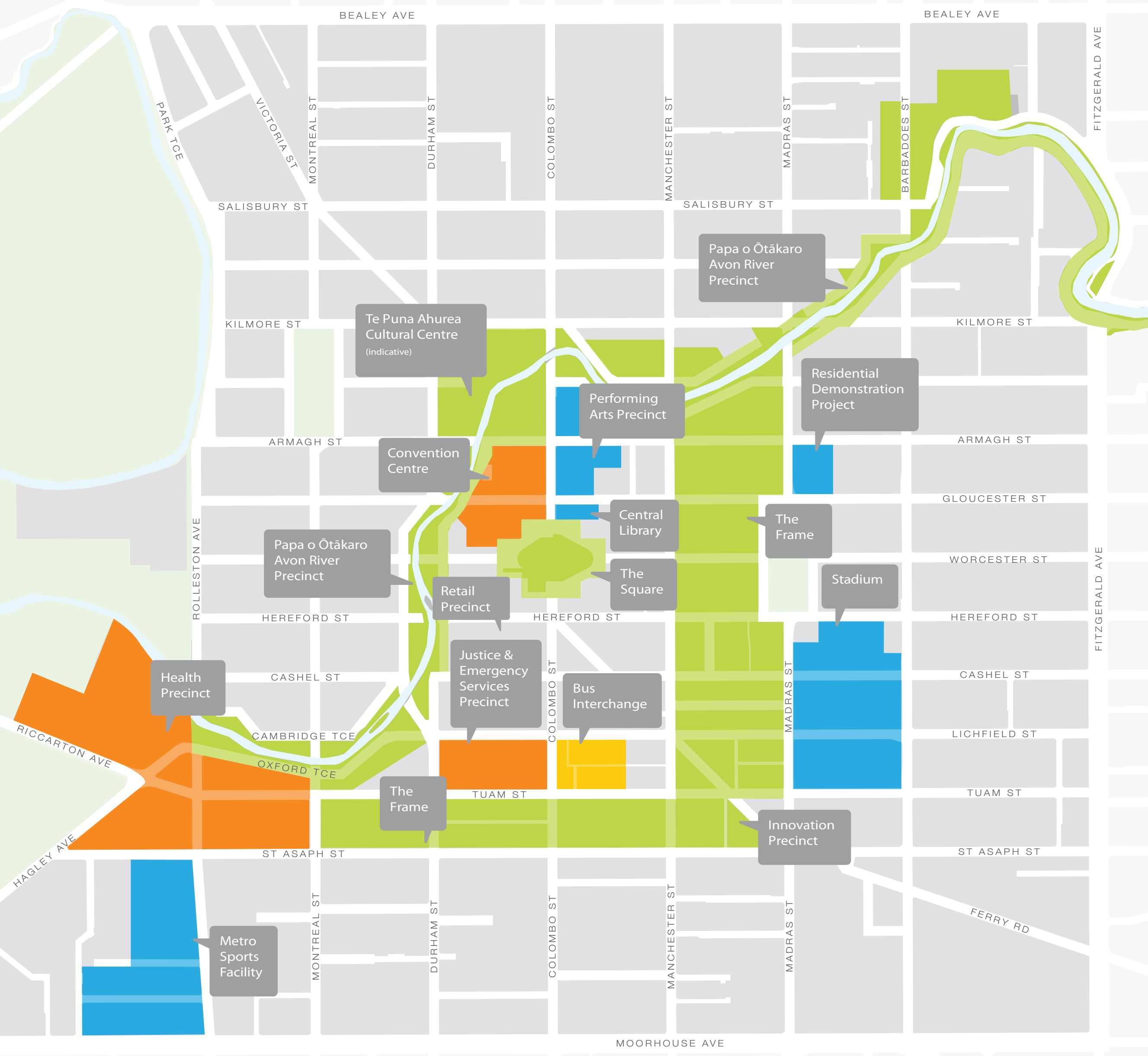




\section{CERA and the 100 day Blueprint}

Figure 94. (opposite page) Map of the central city plan proposed by the CCDU. Source: Canterbury Earthquake Recovery Authority. Central Christchurch Development Unit. Christchurch Central Recovery Plan. July 2012. Web. 16 March 2013.
During the undertaking of this thesis the Canterbury Earthquake Recovery Authority (CERA) formed the Christchurch Central Development Unit (CCDU). Building on the earlier draft Central City Plan by the Christchurch City Council, the CCDU compiled an urban recovery plan for central Christchurch that included Cathedral Square.

This thesis adopts the CCDU's blueprint as a basis for the design case study. However, the following analysis of the blueprint revealed some aspects in relation to Cathedral Square that this thesis seeks to challenge.

The plan is inherently New Urbanist promoting principles such as enhanced connectivity, walkability, mixed use buildings and diversity as well as an increased density and low rise/neo-traditional building types.

There is also a commitment to sustainable practices, such as constructing more energy efficient buildings, "greening the city" and integrating alternative transport options, such as cycling and robust public transit, all of which are clearly based on contemporary New Urbanist theory (Canterbury Earthquake Recovery Authority 41).

There are parts of the plan that stray from the New Urbanist approach, such as segregating use into precincts. While the intention is to cement several central city "anchor" projects and generate further urban growth, mono-functional planning has, in the past, proven to have a negative effect on public space. Additionally the scale of some of these precincts is also of concern, particularly the size of the proposed Convention Centre. Of the anchor projects outlined in the CCDU's Blueprint Plan, several have been identified as major considerations to the design case studies. These are:

The Convention Centre

The New Central City Library

The Green Frame

The Avon River Precinct 
The Convention Centre is by far the most remarkable of the proposed precincts, but also one of the most troublesome in terms of physical integration. This multi-use complex is a truly contemporary building, which reflects the contemporary city's need to be able to attract and connect on an international scale. It is a huge complex, taking up more than one city block, and faces onto Cathedral Square, the Avon River, Colombo Street and Victoria Square, swallowing Gloucester Street in between. The proposed Convention Centre fits right into Koolhaas' category of "XL architecture" (Koolhaas and Mau 827). Such a large scale building can be problematic in terms of integrating at an appropriate scale and proportion to Cathedral Square as well as in relation to human scale.

The introverted use of the Convention Centre means that it may not contribute much in the way of vitality to Cathedral Square, especially within its own plaza. It also primarily caters for international visitors to the city more so than the local population of Christchurch.

The new Central City Library is another program that should be well integrated with the square. Many urban design guides and groups such as the Commission for Architecture and the Built Environment (CABE) promote the integration of popular public buildings such as the Central Library with city squares. Corbett is an advocate for integrating the public library as an activity generator for the square, claiming that it is "an integral part of the civic identity of a city" (Corbett 97). Corbett goes on to say that contemporary libraries offer many more public services than just storing books and have much to offer the contemporary city square (97).

Other than its location on the northern edge of the square next to the Convention Centre, the Library is perhaps the least defined of the square's public buildings to date. Nevertheless a well integrated Central City Library within the square will help activate the space and compliment Christchurch's healthy network of contemporary suburban libraries (Canterbury Earth- quake Recovery Authority 79).

The CCDU's plan also suggests other uses that could be integrated with the square to fulfil the vision of it becoming a 24 hour contemporary public space. These include the integration of cafes, restaurants, bars and entertainment venues, such as cinemas.

Other uses that could contribute to the vitality of the square include the several hotels that still stand proximate to the square. More permanent accommodation in the form of high quality residential apartments can also be integrated to bestow 24 hour occupation and passive surveillance of the square.

Of course the CCDU also mentions the most iconic building of Christchurch, the Cathedral. However the unknown fate of the Cathedral makes it hard to determine the rest of the squares design. The CCDU plan does reserve the original site in the middle of the square for a Cathedral. (Figures 96, 97 and 98 show options released to the media). However, given the problematic

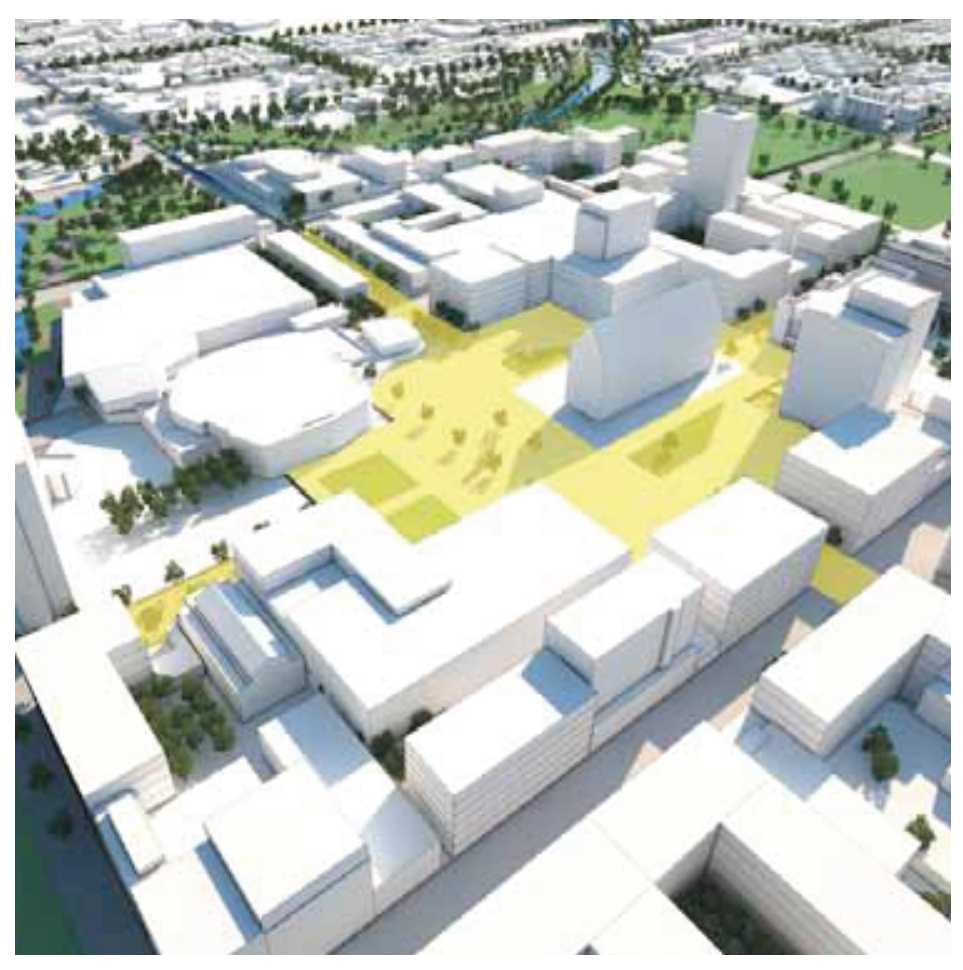

Figure 95. Illustration from the Blueprint plan of the proposed square design. Note the Convention centre in the top left corner of the image.

Source: Canterbury Earthquake Recovery Authority. Central Christchurch Development Unit. Christchurch Central Recovery Plan. July 2012. Web. 16 March 2013. 
Figure 96. Source: "Christchurch Cathedral restoration design option." Illustration. One News. Television New Zealand, 4 Apr. 2013. Web. 16 May 2013.

Figure 97. Source: "Christchurch Cathedral traditional option." Illustration. One News. Television New Zealand, 4 Apr. 2013. Web. 16 May 2013.

Figure 98. Source: "Christchurch Cathedral contemporary option." Illustration. One News. Television New Zealand, 4 Apr. 2013. Web. 16 May 2013.
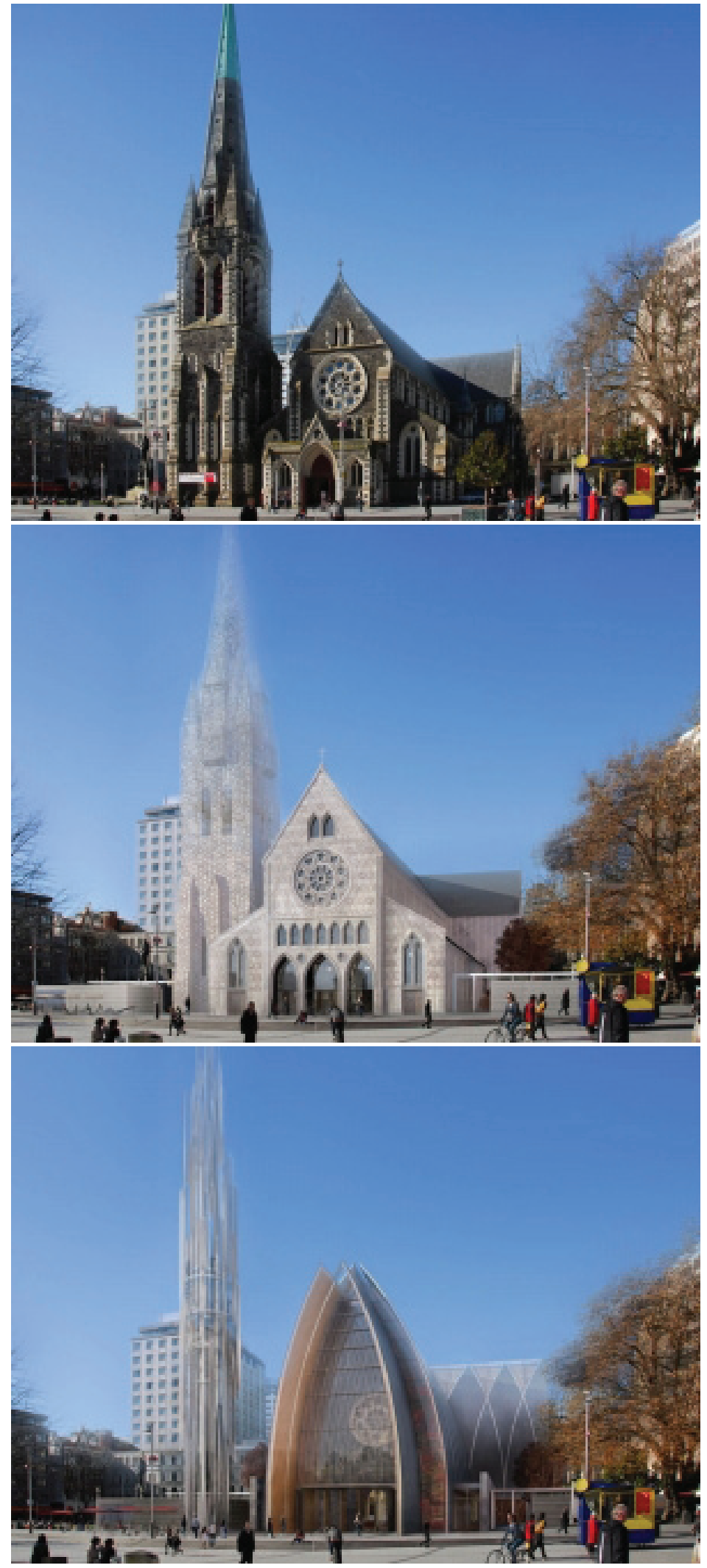

location of the old Cathedral, this thesis challenges the idea of rebuilding the Cathedral on the original site and suggests that a new cathedral should be integrated with the square, but not necessarily in its original location, or form.

Apart from the Convention Centre, Central City Library and space for a Cathedral, the CCDU plan is somewhat ambiguous as to the design of the rest of the square. The illustrations do suggest that the new design will retain the cruciform shape of the square covering just under 28,000 metres square.

The building heights of the surrounding buildings have been restricted to 28 metres or seven storeys (Canterbury Earthquake Recovery Authority 105). The urban benefits include a more palatable scale for people, more sunlight access and a common and continuous building height around the edge of the square. The downside, as discussed earlier, is a square surrounded by historically derivative perimeter block development that may not necessarily fit with the more contemporary building proposals within the square. The Convention Centre and New Central City Library are two examples.

The lowered building height is also disproportionate to the large amounts of open space, particularly in the area at the front of the Cathedral.

The CCDU plan has also made the square into a pedestrian only area. For the first time ever public transit has been excluded from the square. While this increases pedestrian connectivity, it also decreases vehicular connectivity, especially public transport, which is important for a contemporary city of such sprawling proportions. In addition to the fact public transport has always been an integral part of Cathedral Square (NZ Federation of University Women, Canterbury Branch). While the revised bus routes are unclear what is clear is that a new bus interchange has been included one block south of the old bus exchange. This indicates that there is a commitment to integrating public transit with the whole central Christchurch precinct. 
The plan also incorporates more green space within the central city, especially around the square, such as at the nearby Avon River precinct and the Green Frame to the east.

The original plan of Christchurch incorporated a Green Belt around the perimeter of the city. If retained, the belt would have enclosed Christchurch in green space in a similar way to what the CCDU have proposed. Unfortunately most colonial green belts in New Zealand were eventually engulfed by development (Home 15). The CCDU is proposing to reinstate this reserve land around the edge of the central city, albeit on a significantly more modest scale. It also integrates the Avon River precinct as the western edge to the frame and connects to Hagley Park via the health precinct in the south west corner. The frame is intended to encourage more high-density development in the central city. It also seems to encourage low-density campus style development within this frame, which may sentence it to a fate not unlike the original Green Frame.

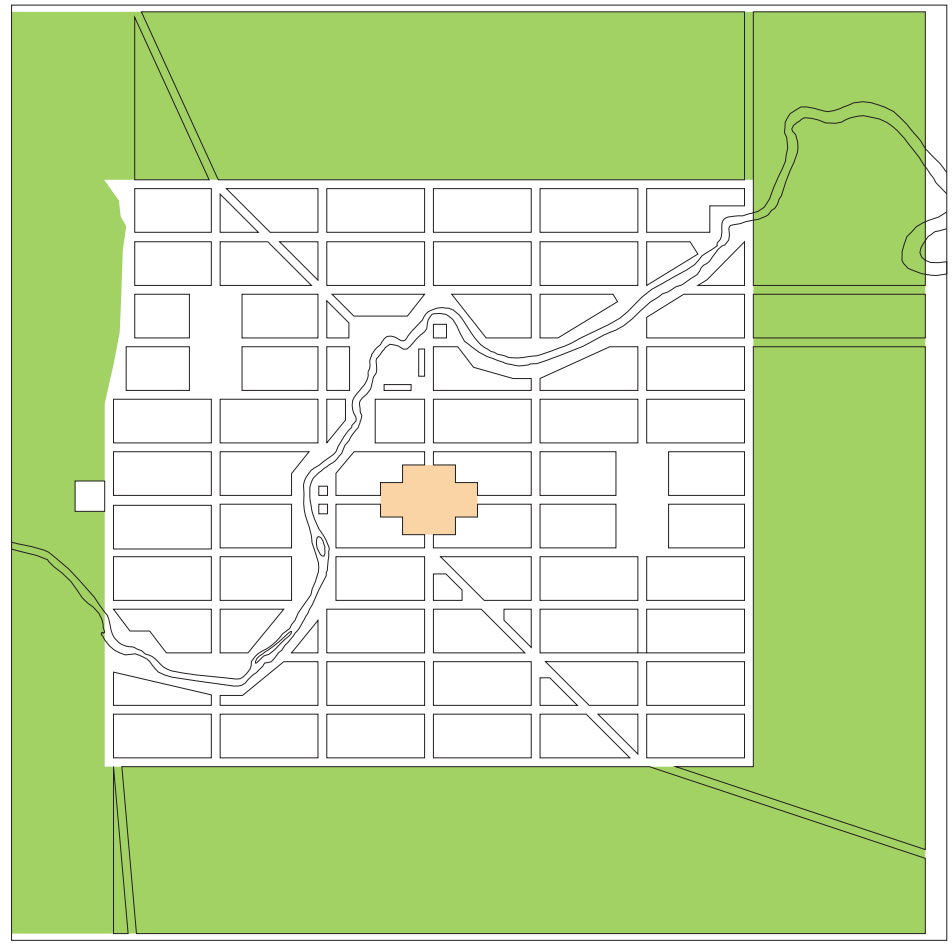

Figure 99. Diagrammatic map showing the original green belt around Christchurch city.

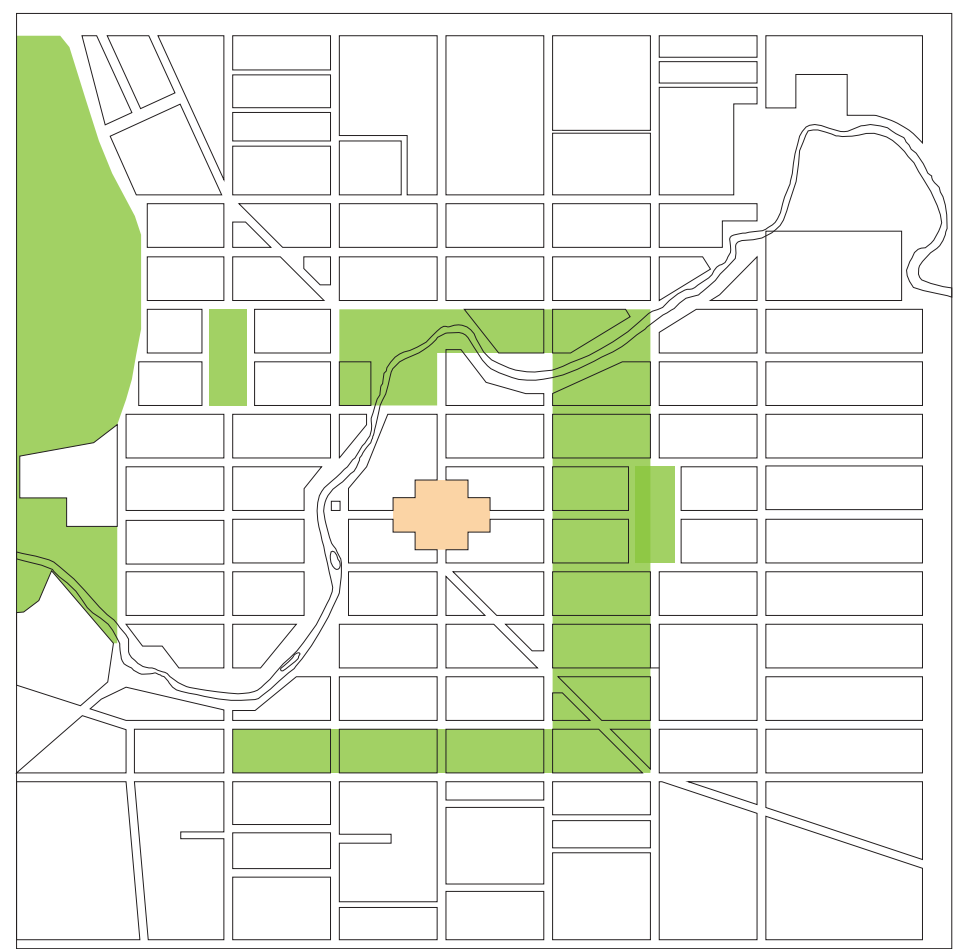

Figure 100. Diagrammatic map showing the proposed green frame around central Christchurch. 


\section{Toward a Design Case Study}

This chapter has found that there are a number of site-specific criteria that need to be considered in the design case study. One consideration is reducing the overall size of the square from its original 27,000 square meterage. A smaller central city should proportionally require a smaller city square. This is in addition to the lower CBD building heights that require reconsideration of the amount of open space in the square. This is especially so, as perceived spatial enclosure and identity has been particularly poor in the existing square.

Another important factor is the integration of public transport. Public transit has always been integral to the square, largely due to the fact it has two main streets, Colombo and Worcester, running though it north south and east west respectively. The blueprint has a commitment to integrating a bus interchange within the central city and the challenge for this thesis is developing ways of integrating the routes with the square. Of course improved pedestrian connectivity in and around the square must be considered alongside the integration of any vehicular traffic.

The integration of existing buildings, in particular the heritage facades of the Old Government Building and the Chief Post Office Building and a number of other buildings around the square need to have their amenity retained as the city is reconstructed around them.

There are also a number of prepositions by the CCDU that align with the goals of this thesis, and are to be integrated with the design case study. These are:

\section{International Convention Centre}

There is approximately 5,000 square metres worth of Convention Centre occupying the North West corner of the square. This is to be included in the design case studies on this site as the remainder of the complex holds a significant and integrated location between Victoria and Cathedral Squares. The form and relationship of this structure to the square and surrounding 
buildings will be reviewed by the design case studies.

\section{New Central City Library}

The CCDU plan outlines a rough size of twice that of the old Central Library, which the Christchurch City Library website states as being approximately 6,000 square metres. This 12,000 square metre library roughly coincides with some early estimated figures of 11,000 square metres. This is calculated using the metric handbook's rule of thumb of 30 metres square per 1,000 of the population. This figure caters to the needs of the contemporary Central City Library and all the additional services they now offer (Edwards and Khan).

\section{The Cathedral}

The historic Cathedral covered an area of approximately 1,870 metres squared over one level. This is in addition to a 290 metre square visitors centre to the side. No other building is more ingrained to the Square's, or indeed Christchurch's, identity than the Cathedral. This creates quite a tumultuous situation on what to do, as on one hand this is an incredibly iconic building, and on the other it has been established as problematic in terms of integration, the theme of this thesis. This is addition to the ongoing debate on whether to restore what is left, or not.

This thesis takes the position that a new cathedral must be integrated with the square, but is not limited to the restoration of the existing structure. The benefits of developing multiple schemes help in resolving this issue through design.

\section{The Green Frame Avon River Precinct}

The square has always had a relatively strong link to the Avon River down Worcester Boulevard. However there is an opportunity to improve this connection and the buildings that frame the boulevard.

The Green Frame to the east is a new proposal that needs to be considered in the design of the square. Improving connectivity between the square and the Green Frame is another key factor to consider in the design case study.

There are also some significant trees within the square, mostly large oak trees, which were part of the existing design. The four trees in front of the Cathedral, for example, are symbolic of the first four ships to arrive at Banks Peninsula carrying colonists. 


\section{Chapter \\ Design Case Studies}




$$
\varpi+\square \backslash
$$




\section{Introduction}

This chapter introduces and presents the three design case studies for rebuilding and reintegrating Christchurch Cathedral Square.

The design component of this thesis is made of three phases of design (see figure 5.1). The first phase is composed of the development of three unique design concepts. The second phase is involves a discussion of the three design concepts, and the final phase is the design development of the third scheme, as it is the most revealing design in terms of answering the research question.

Each design concept proposes to reintegrate the square with Christchurch city based on the five integrative properties drawn from chapter two. These are: Scale and Proportion, Identity, Use, Connectivity and Natural Landscape. These properties set a common benchmark upon which each design concept can be equally compared.

Establishing three separate schemes sets up a more robust design investigation, particularly in relation to the second part of the research question, the extent as to which New Urbanism can contribute to the integration of the square. It also meant that the relationship between each of the five integrative properties could be studied in greater depth.

This chapter is composed in three parts. The first presents the three design concepts individually. Each concept is introduced with a brief explanation and a series of plan-based diagrams that show the principal moves in forming each design.

The design is then presented in a series of more detailed isometric drawings. These isometric drawings show more detailed information about the design, specifically in relation to the five integrative properties. This is followed by a series of photographs of the physical scale model used to compose and develop each design. This pattern of presentation is repeated for each of the three design case studies.

Part two consists of a written discussion and comparison of each design scheme. 
The third and final section is an additional design development section that further explores the third concept. This section presents this scheme in more detail and further explores the integrative possibilities of this most contemporary and contentious scheme.

The urban scale of the three designs mean they are limited in their architectural resolution. They are designed to respond to the urban properties of integration and are assessed against these.

The more site-specific elements of the brief are only developed based on the square metre figures from the previous chapter. Architectural details are avoided in order to keep the focus on the integration of the square at an urban scale. 
Figure 101. Design research process.
Part One

\section{Part Two}

Design Dicussion and Comparison

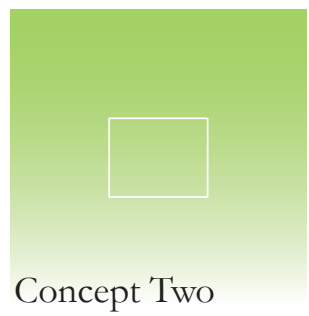

Concept Two

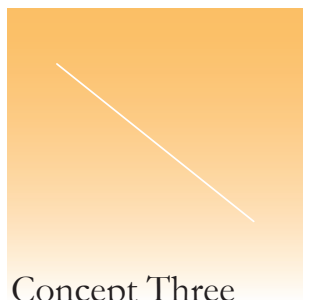

Concept Three

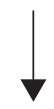

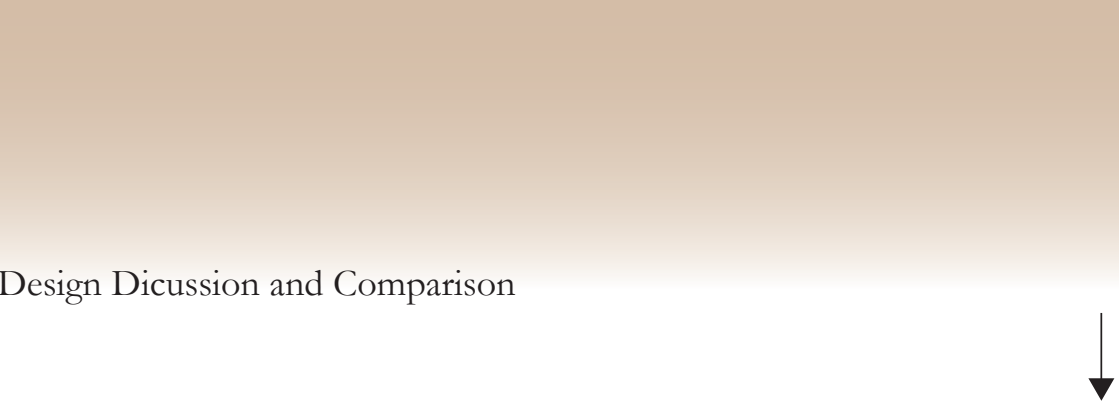

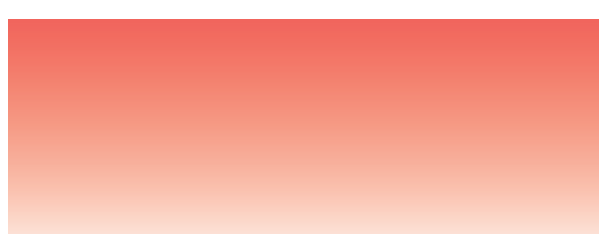

Concept Three Development

Part Three 



\section{Design Concept 1}




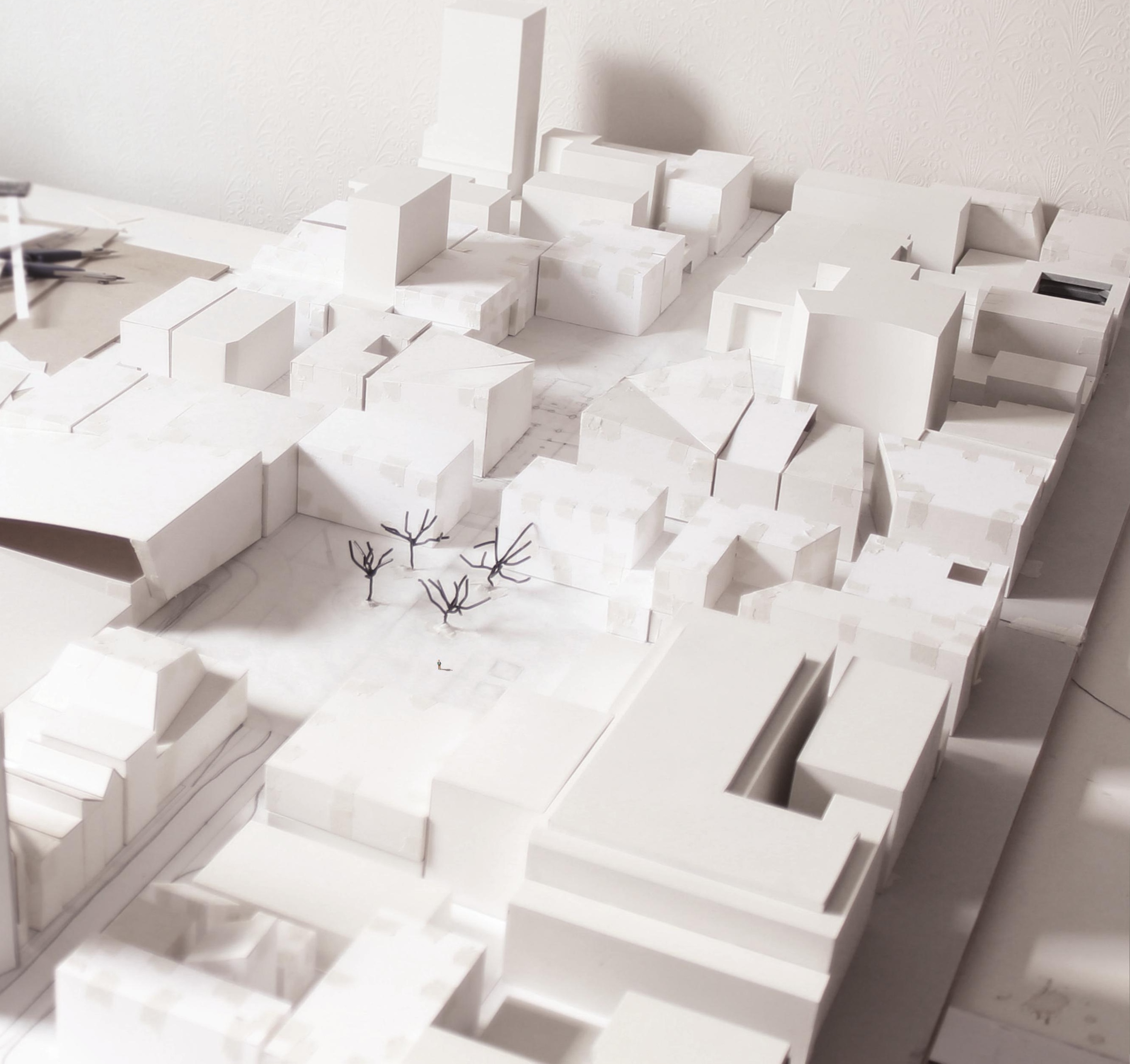




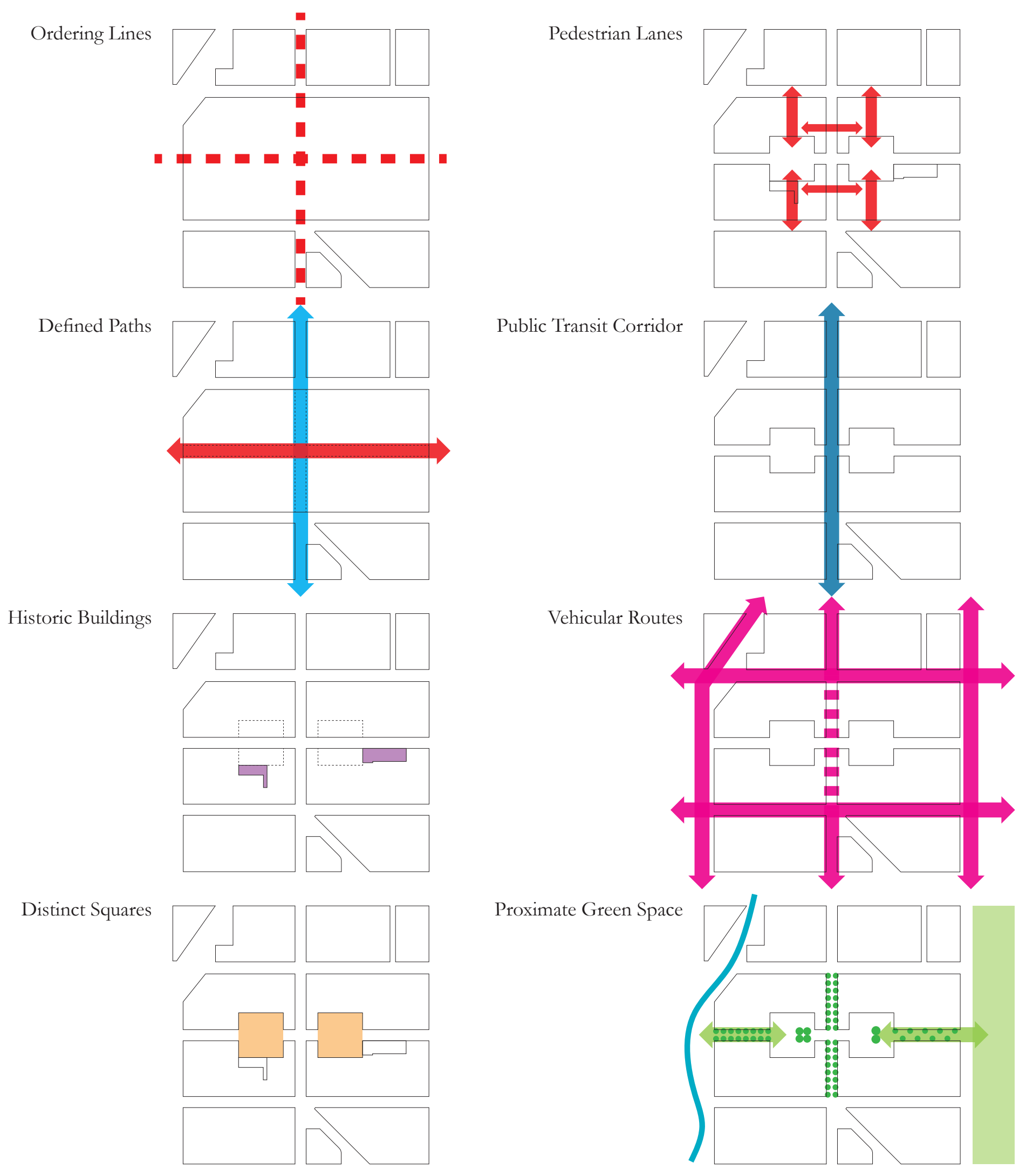


This concept focuses on integrating public transport networks with the city's gridiron street pattern.

Colombo and Worcester Streets act as principal ordering lines defining the spatial form of this proposal. The absence of the Cathedral has allowed for the extension of Colombo Street through what was the centre of the original square, the intention being that the street will be used for Christchurch's public transit system.

This transit corridor will carry the major bus routes from the new central city bus exchange at Lichfield Street, between the two squares and out to suburban destinations. Additionally, during off peak transit times, the street will be accessible to service vehicles and private cars.

Colombo Street will feature wide footpaths, with an integrated cycle lane, to serve pedestrians and cyclists alongside public transit commuters.

A canopy of deciduous trees and building awnings will protect occupants from the elements. The trees also serve as a buffer zone between the steady flow of lumbering buses and the bustle of pedestrians. This encloses the footpath between trees and a street wall of active building fronts including cafes and shops.

Perpendicular to the Colombo Street transit corridor is the eastwest path from Worcester Street to Worcester Boulevard. This path is to be sanctioned a pedestrian precinct to connect the two squares and create an intense focus of activity where it crosses Colombo Street. The flows of vehicular and pedestrian traffic are combined create a space filled with people, coming, going, crossing, waiting, watching, meeting, shopping, eating.

East west permeability between the squares is important in order for them not to become isolated from one another. Clear pedestrian crossings and active and porous ground floors in the buildings between the squares will ensure a high level of pedestrian connectivity.

Neither the public transit corridor, nor the pedestrian path, would be able to achieve such spatial clarity if the Cathedral remained in its pre-earthquake location. Aside from the removal of the Cathedral from its historical site, the concept is unique as the square is divided into two separate spaces. Each is roughly the same size and shares the same proportions, combined covering an area of 11,500 metres squared.

The smaller scale of the two squares helps to create a stronger sense of spatial identity and enclosure. Both squares are surrounded by a composition of new buildings that are of a suitable proportion to the smaller dimensions of the square and to that of the human occupants.

The buildings are also composed to distance the squares from the transit corridor. These buildings help each square to attain their own spatial identity and enclosure while simultaneously framing the transit corridor and the Worcester Boulevard pedestrian path. These pivotal buildings must integrate multiple frontages, and create a high level of pedestrian connectivity between the two squares and the transit corridor.

The buildings around each square also integrate a number of public uses. These include a new Central City Library facing into the eastern square and the Convention Centre facing into the western square.

These public buildings are the main activity generators in their respective square. It is expected that other buildings around the square will be adopted with a mixture of uses that complement these principal buildings.

Ultimately it is intended that each square will adopt its own unique identity. The eastern square with the new Library and Cathedral has more of a relaxed local character about it, while the western square with the international Convention Centre will adopt a more formal, or civic, character.

The controversial decision to remove the original Cathedral from the square was done in the interests of a more integrated square. The two-part building creates a gateway space in between that integrates the Worcester Street pedestrian path. This 
in-between space is based on the width of the old Cathedral nave, and could potentially integrate other architectural remnants of the badly damaged Cathedral.

The Worcester pedestrian path also connects the squares with the Avon River to the west, and the proposed Green Frame to the east. The integration of these two natural landscapes creates a unique sequence of spaces from natural to artificial, as one travels from east to west and vice versa. 


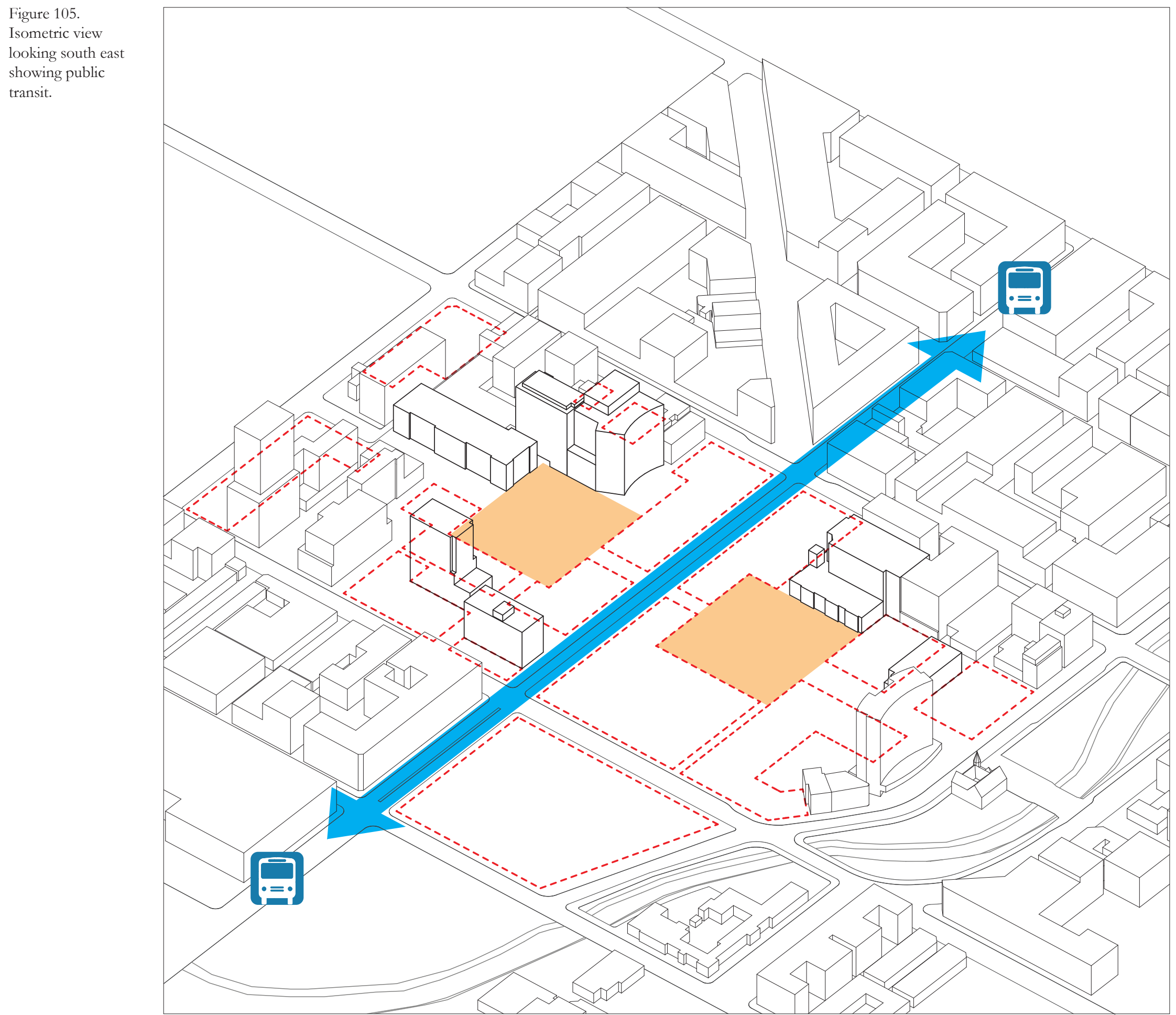

Retaining the continuity of Colombo Street as a vehicular path, Cathedral Square is divided into two smaller squares. 


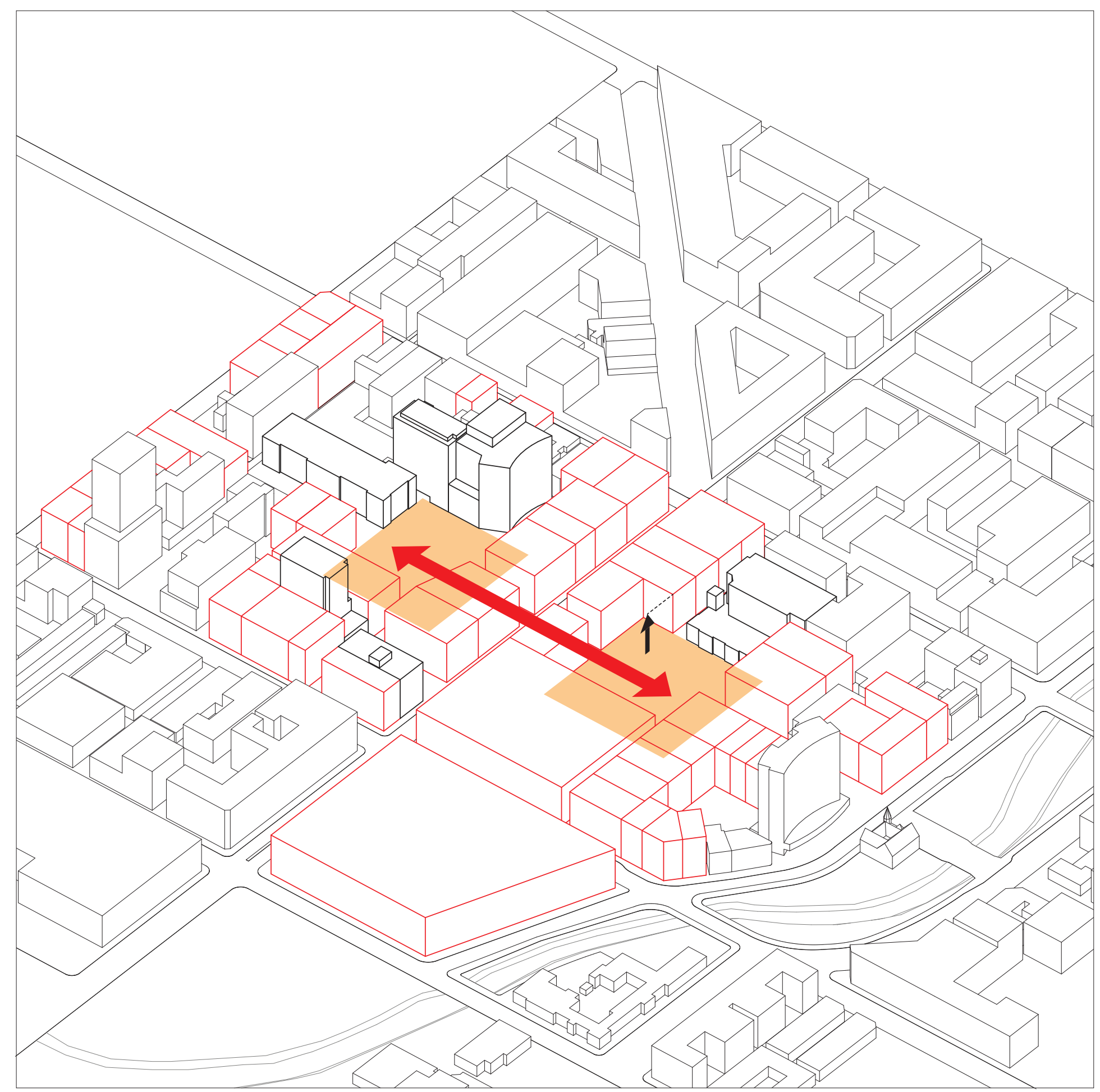

Basic building footprints are projected up to the maximum permissible building height of 28 metres or seven storeys. These buildings spatially define the two squares, which are connected via an east west pedestrian path perpendicular to the transit corridor.

Figure 106.

Isometric view

looking south east

showing pedestrian

path. 
Figure 107.

Isometric view

looking south east

showing spatial

enclosure.

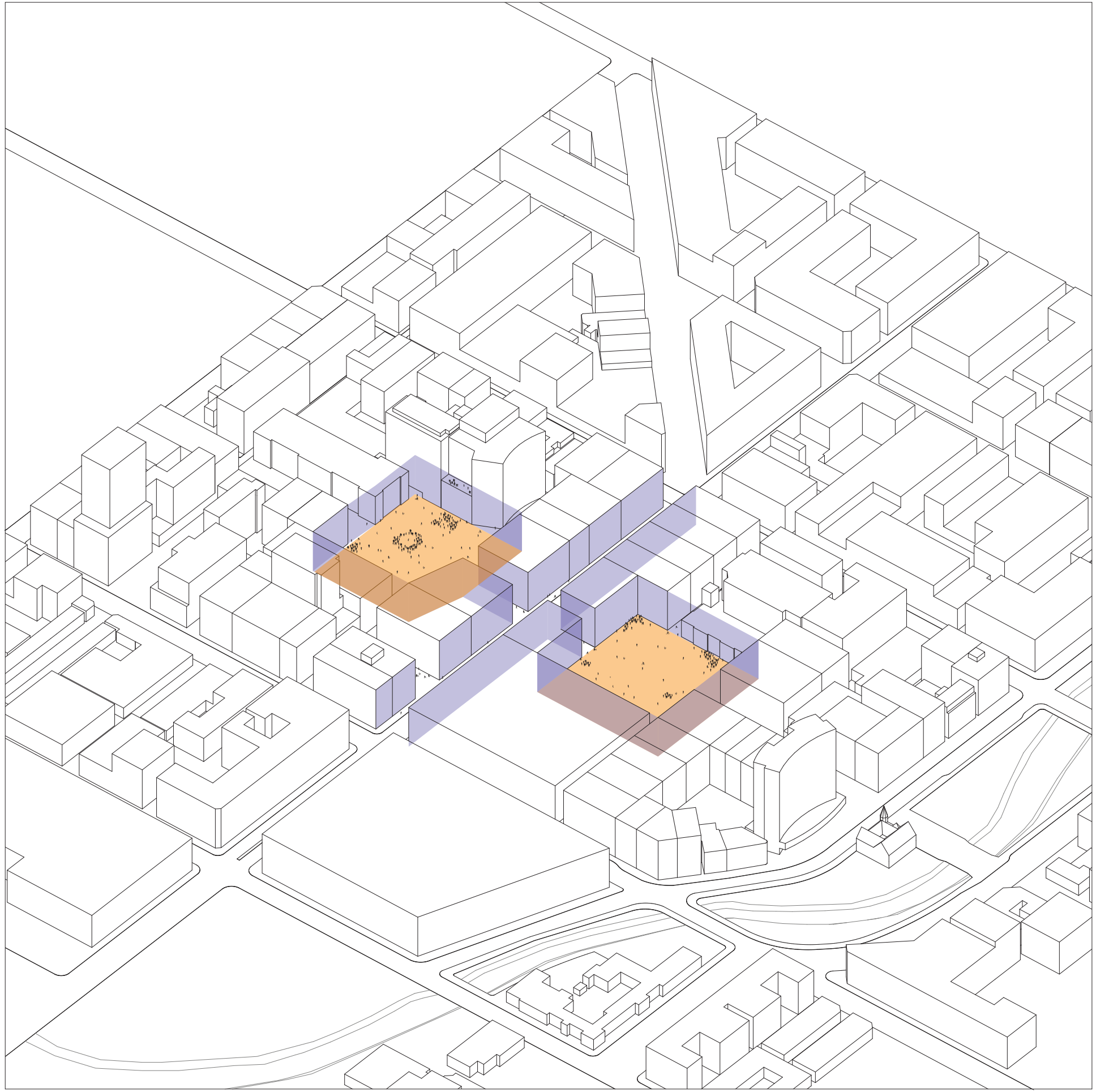

Continuous building edges enclose each square and define the edges of the Colombo Street transit corridor. Active ground floor facades will feed life and vitality into the squares and compliment the bustle of public transit on Colombo Street. 


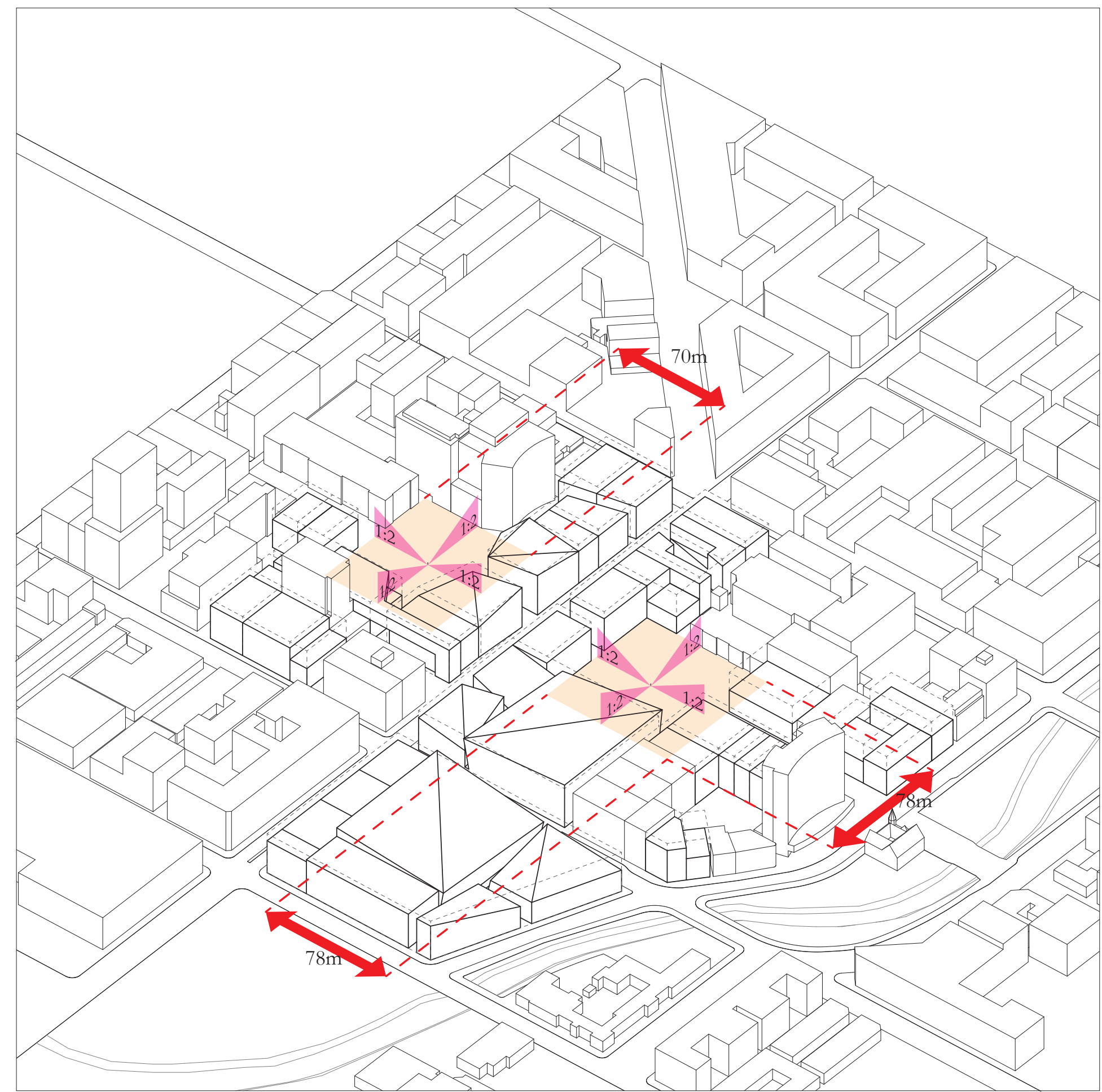

Figure 108.

Isometric view

looking south east

showing scale and

proportion.

Building heights are adjusted and composed to better match the smaller scale of open space within each square. Buildings heights are also adjusted to better fit with the existing building heights. 
Figure 109.

Isometric view

looking south east

showing green

space.

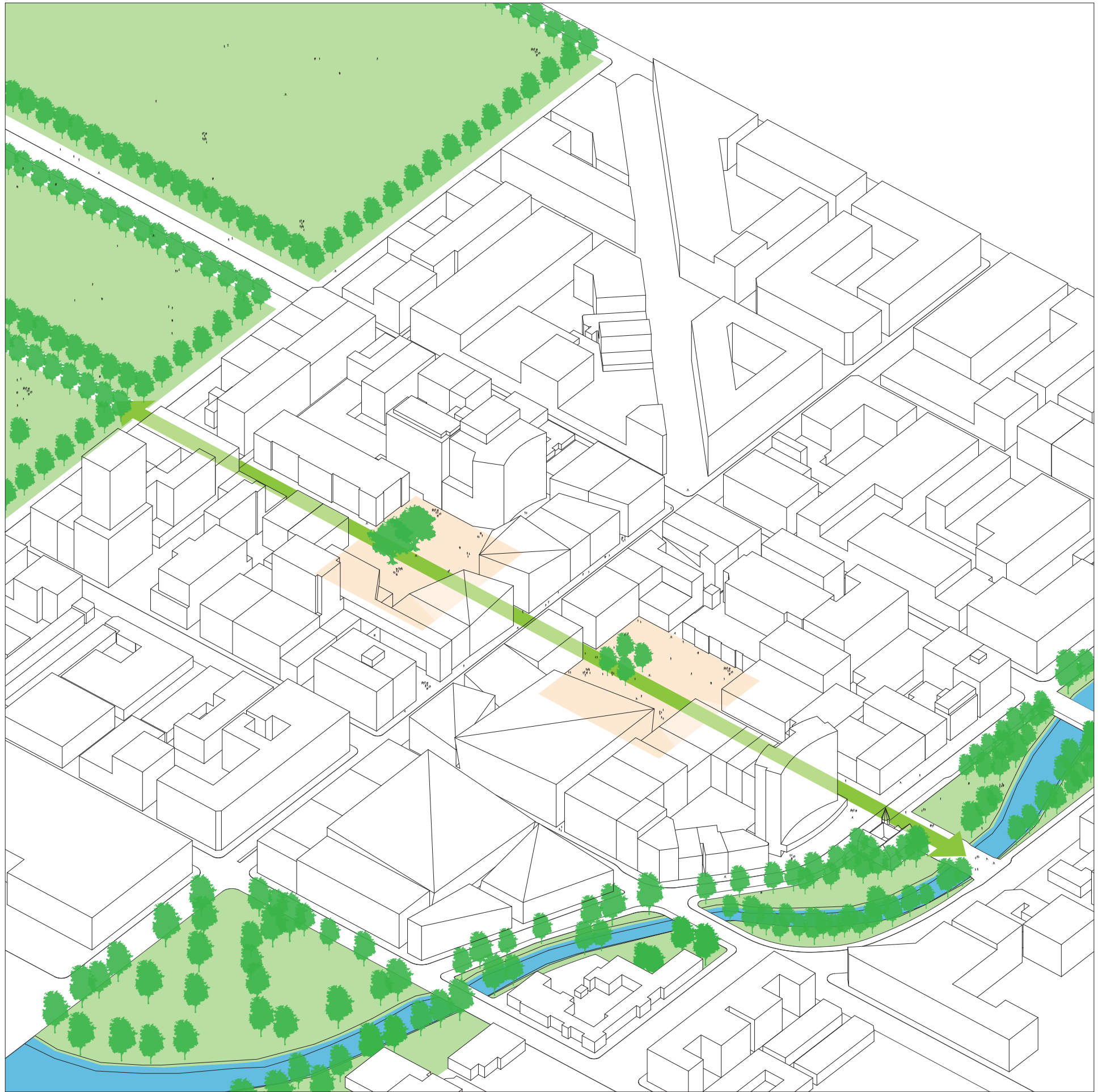

A continuous pedestrian path from the eastern Green Frame through to the Avon River integrates both squares in this sequence of public spaces and crosses the Colombo Street public transit corridor. 


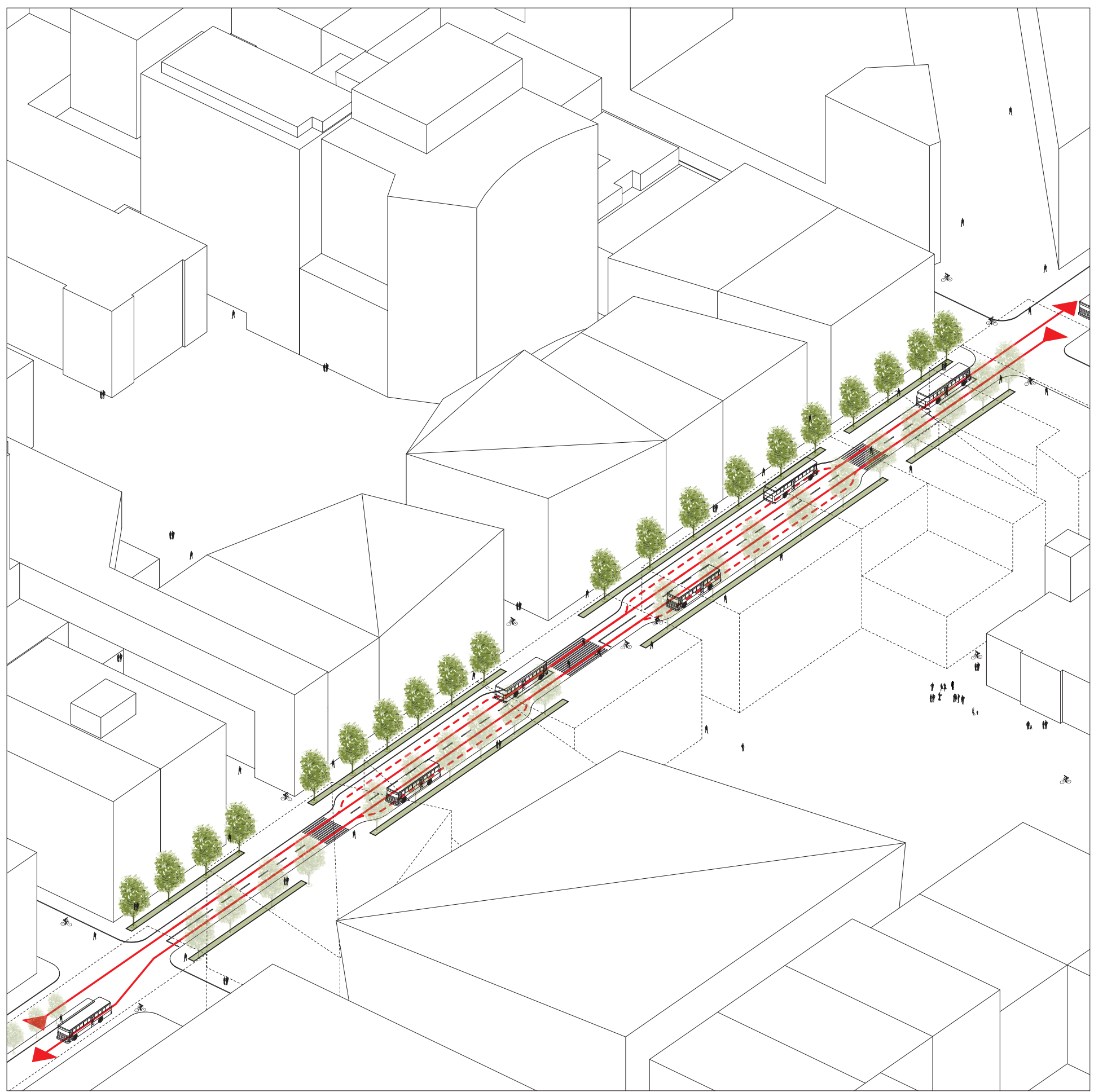

Figure 110.

Isometric view

looking south east

showing public

transit detail.

The proposed Colombo Street transit corridor is designed to carry all of Christchurch's bus routes through the heart of the city, integrating public transit between the squares. 
Figure 111

Isometric view

looking south east showing pedestrian connectivity.

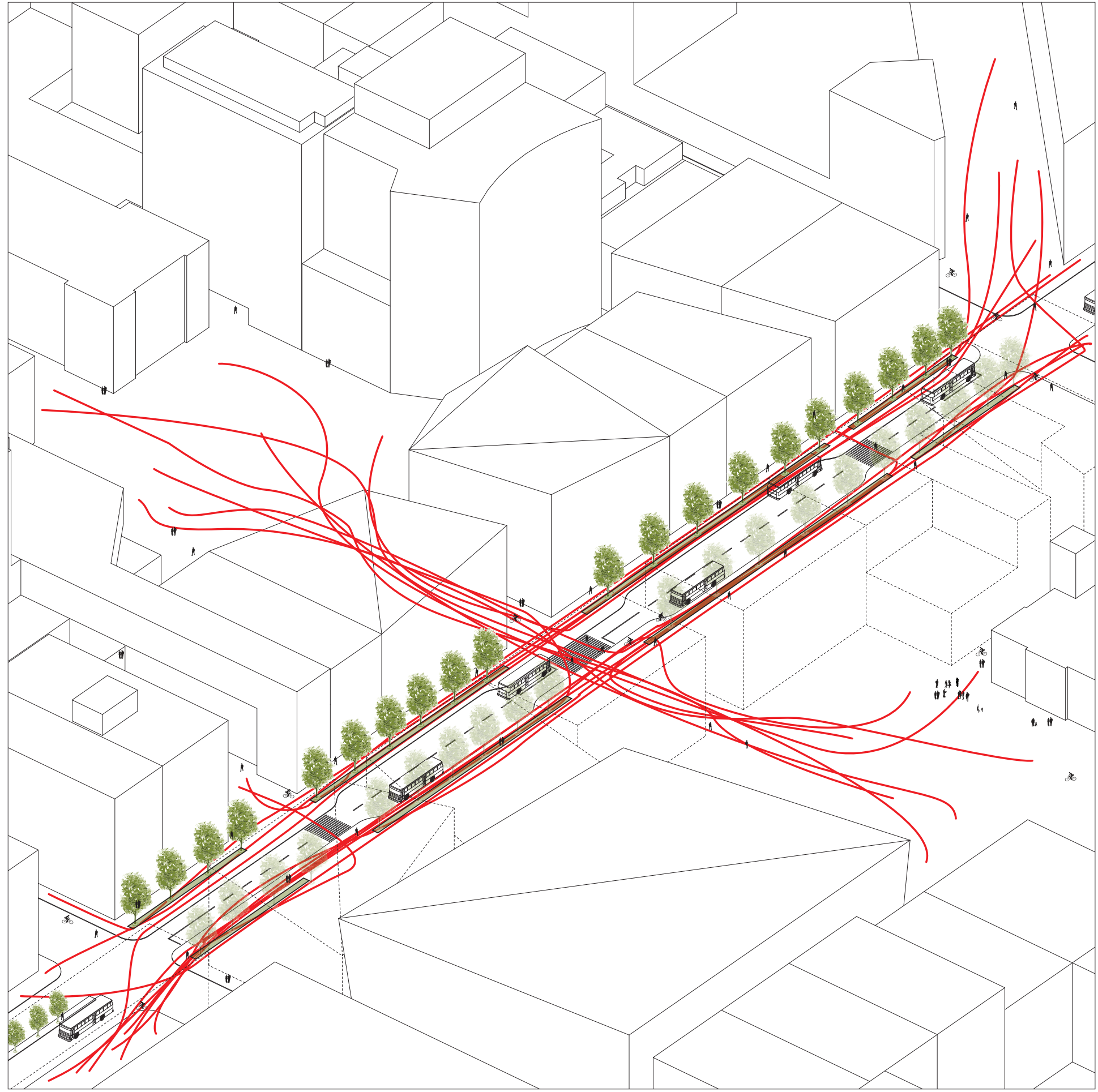

Alongside busses are generous footpaths shaded by trees, to divide cyclists and pedestrians from the flow of vehicles. The Worcester Street crossing ensures a high level of pedestrian connectivity across the transit corridor. 


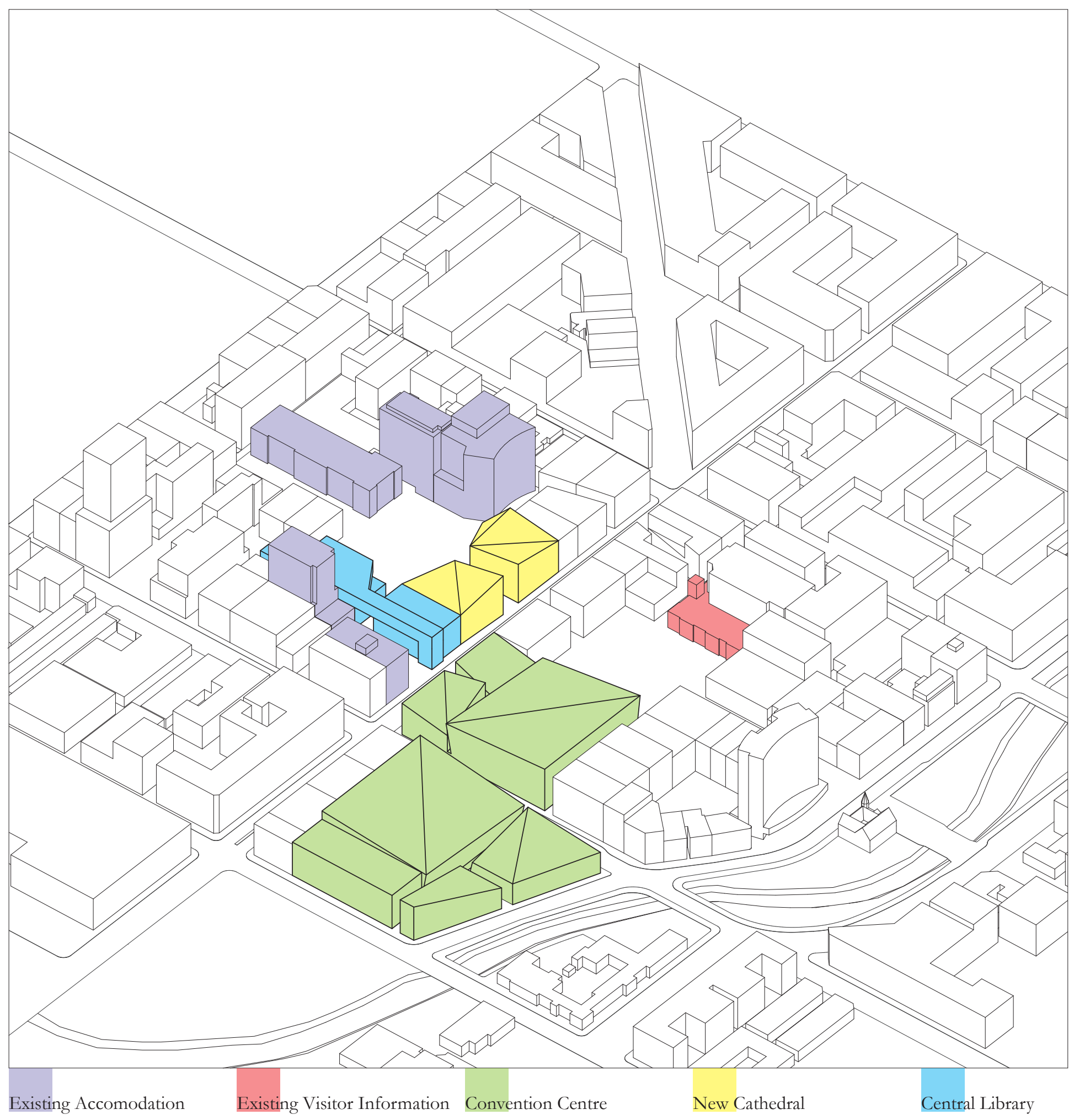

Figure 112.

Isometric view

looking south east

showing building

use.

The new Central City Library and two-part Cathedral generate more informal activity in the eastern square, while the Convention Centre around the western square creates a more formal public space 
Figure 113. Isometric view of a typical mixed use building.

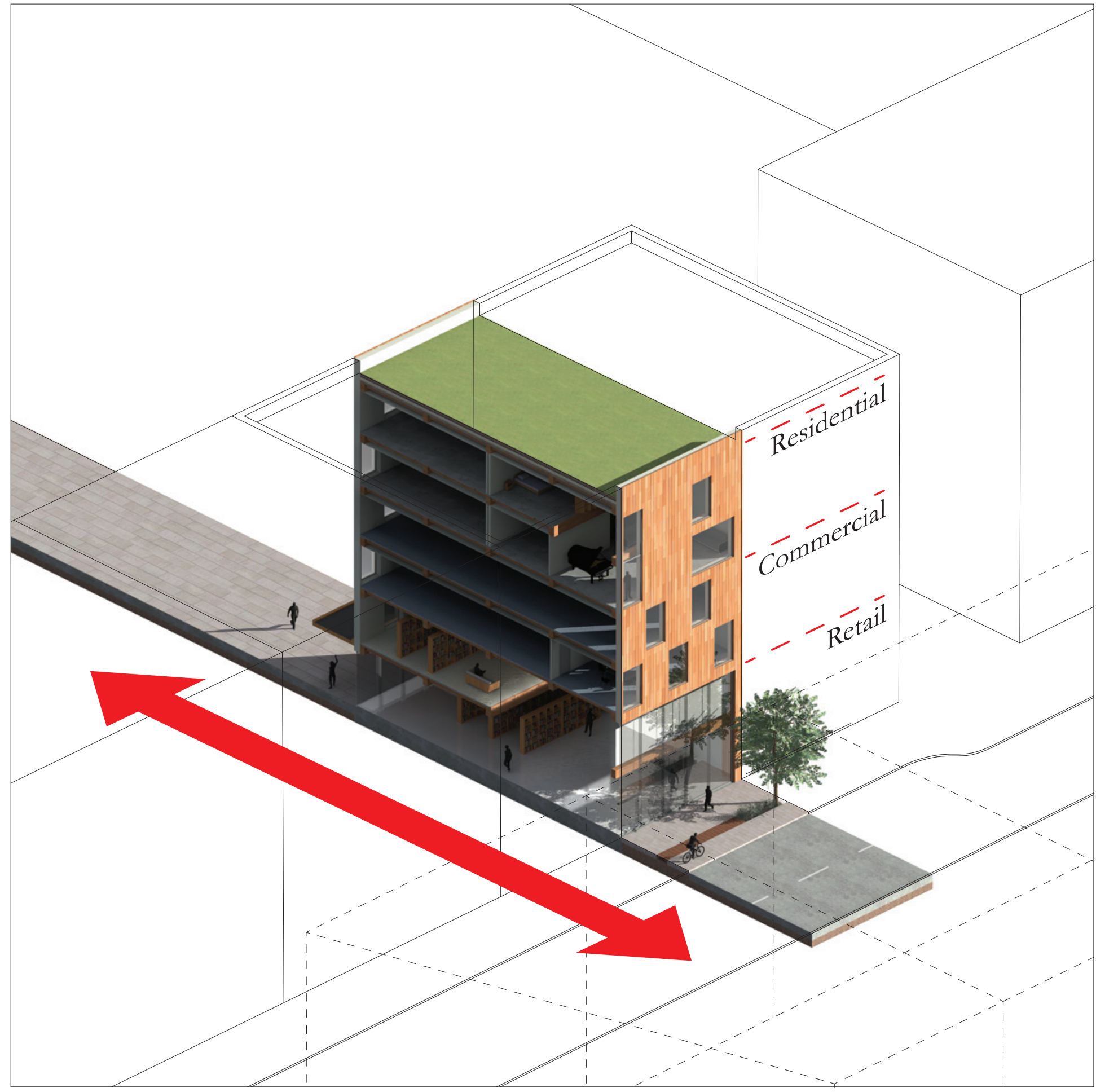

The drawing above illustrates a typical mixed building located between the transit corridor and the squares. These buildings are composed to spatially define the transit corridor and squares. The visually and spatially permeable ground floors retain a high level of pedestrian connectivity between the two. 


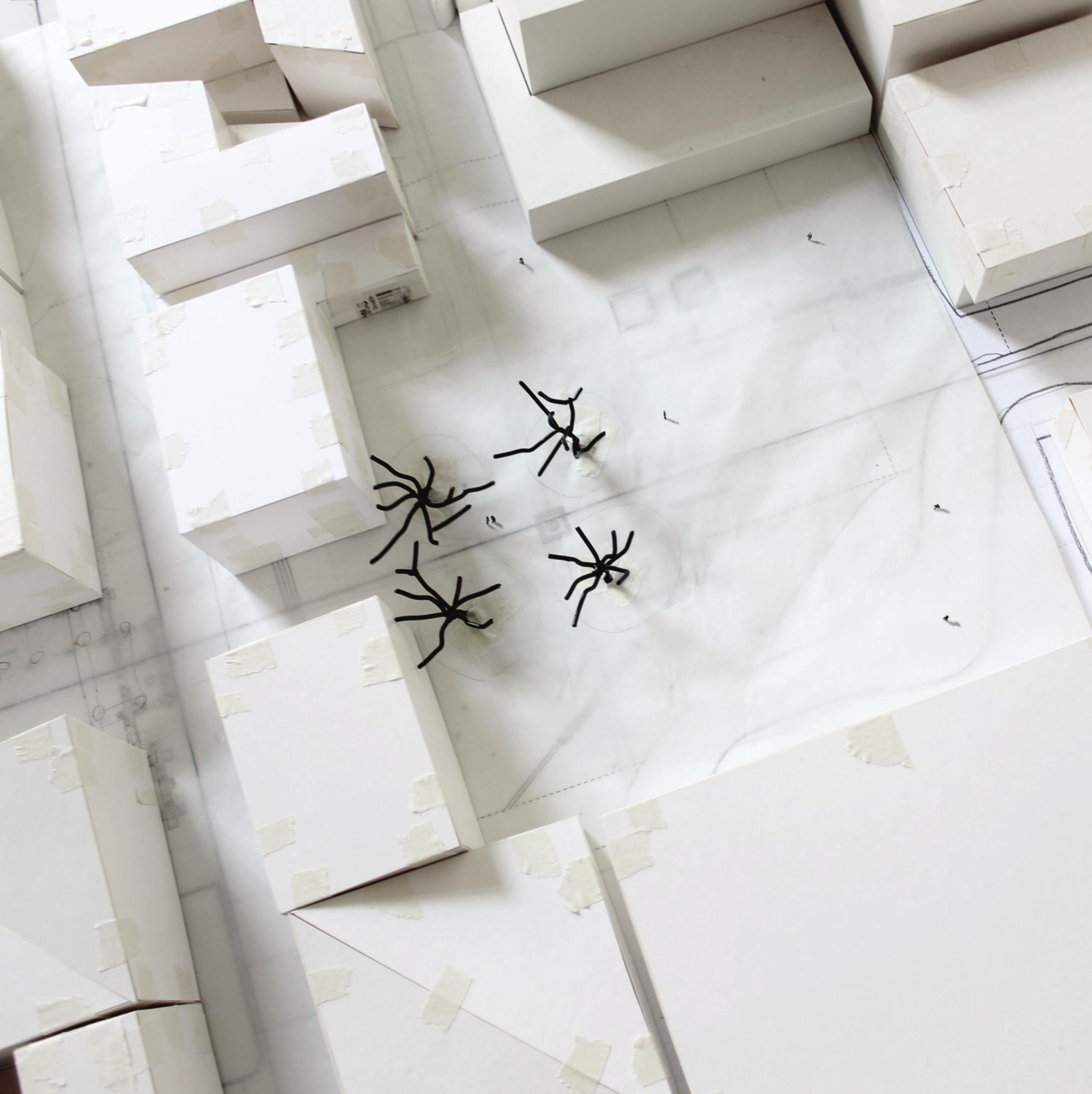


Figure 114.

(opposite page)

Aerial view of the western square.

Figure 115. View looking across the western square.
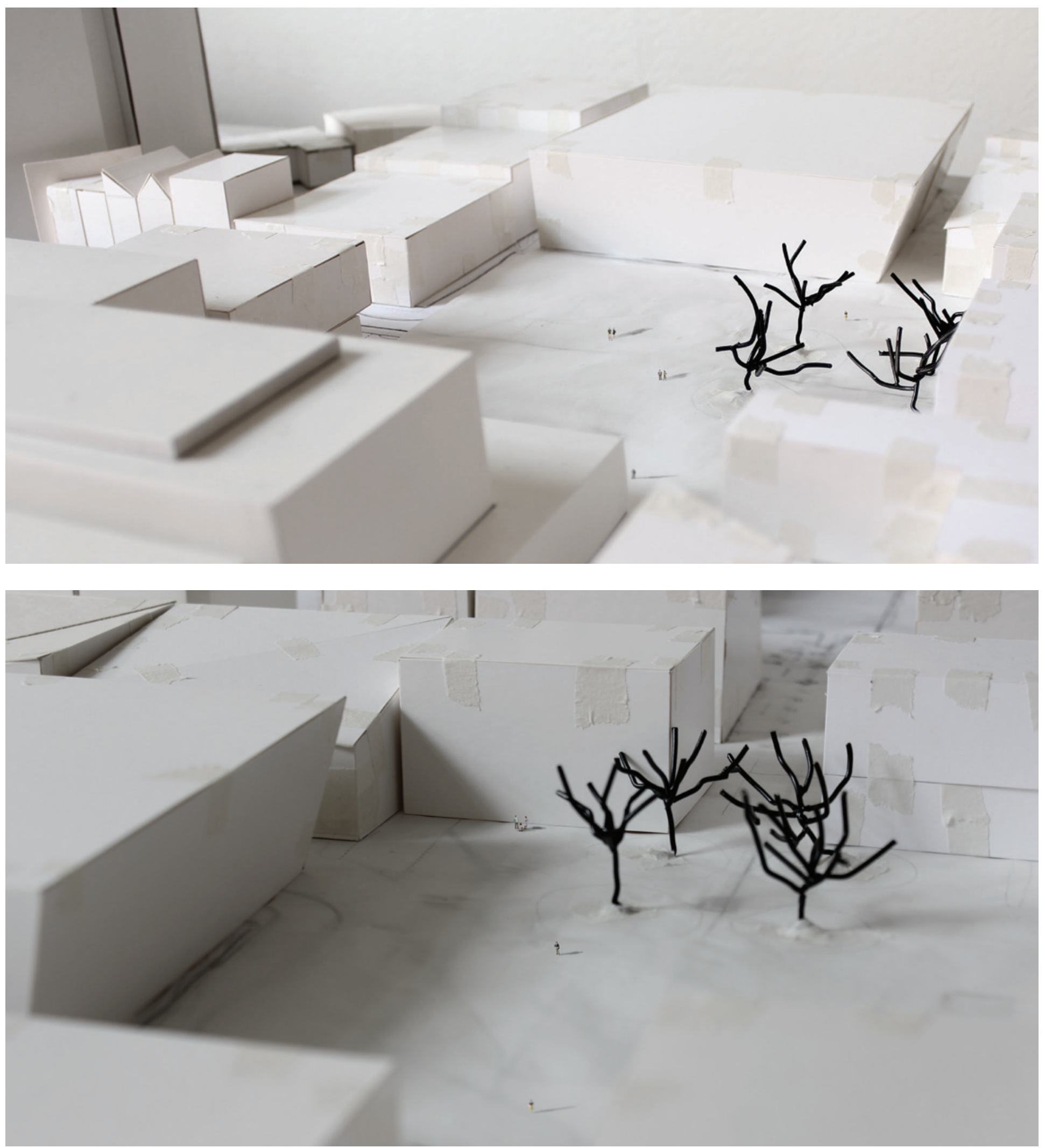

Design Case Studies

155 

Figure 117. (opposite page) Aerial view of the eastern square.

Figure 118. View looking across the eastern square at the Millennium hotel and new $\mathrm{Ca}$ thedral.

Figure 119. Aerial view of Millennium hotel lane and connection to Colombo Street transit corridor.
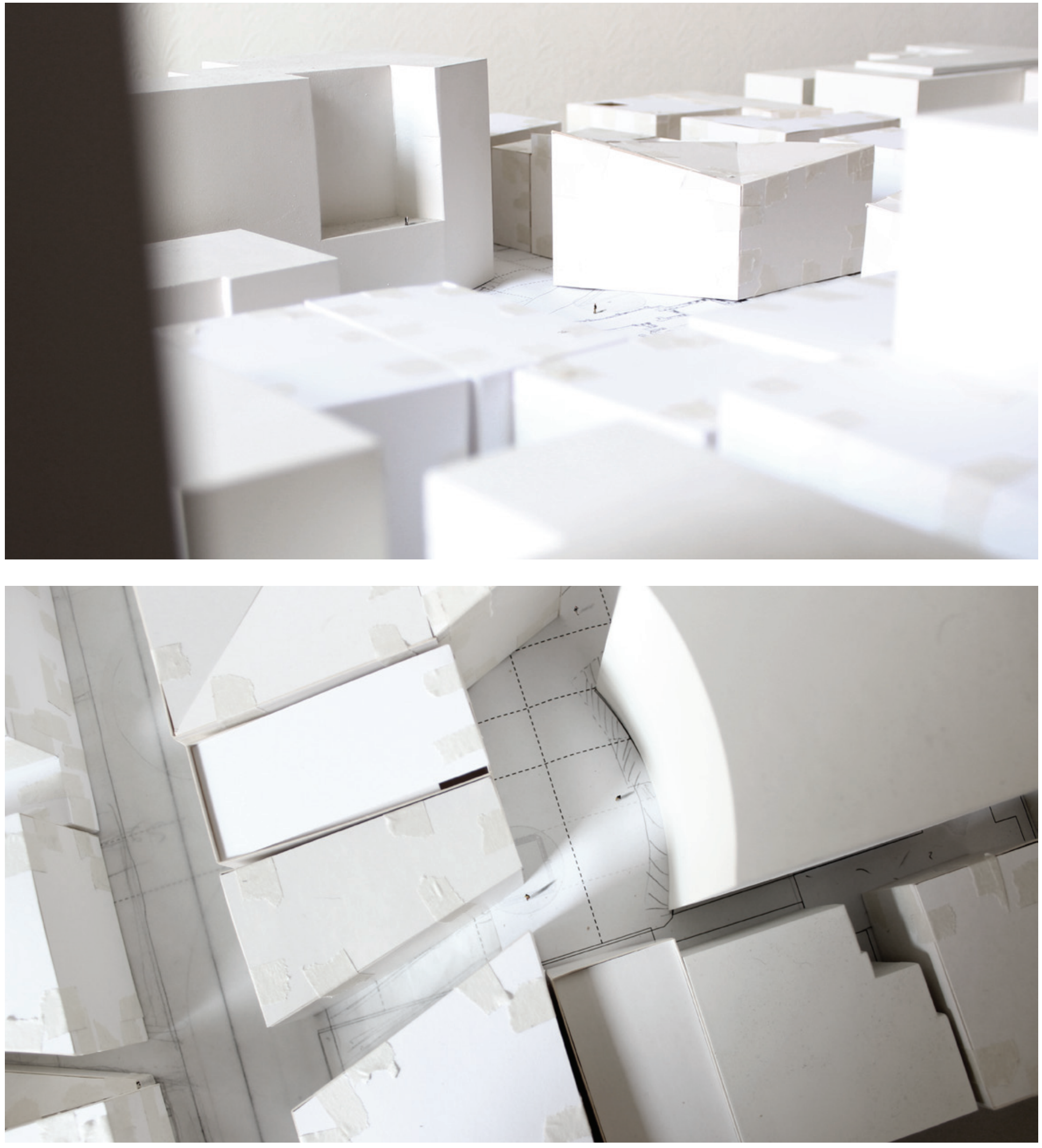

Figure 120.

(opposite page)

Aerial view of

Colonial Lane con-

necting the eastern

square to Glouces-

ter Street.

Figure 121. View

of Colonial Lane and Library sky

bridge.

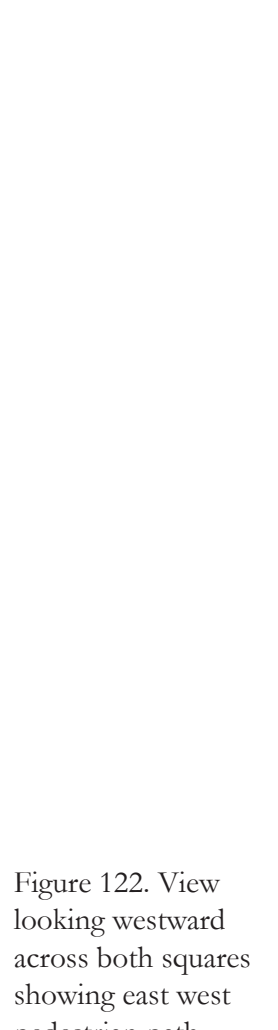

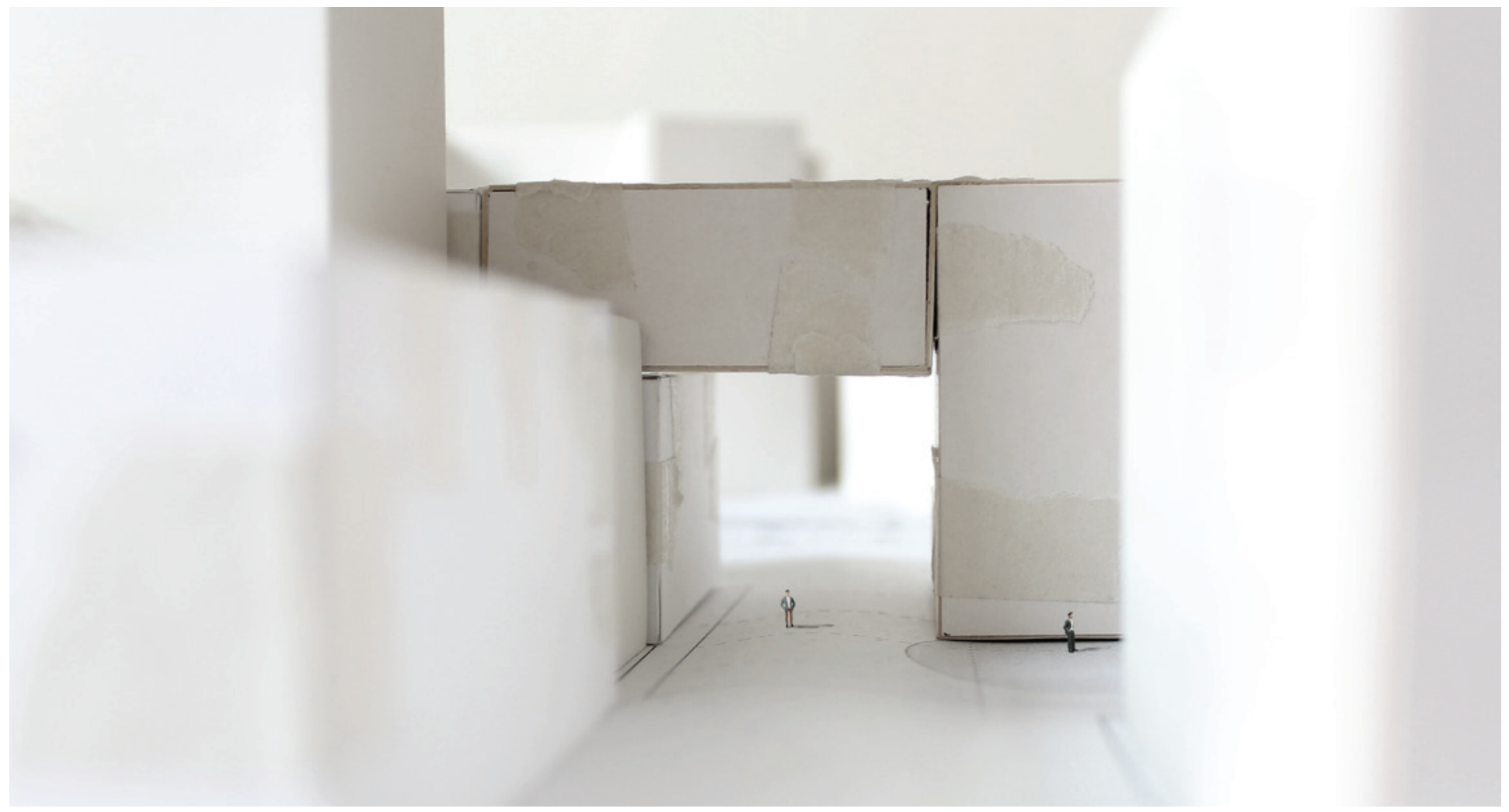

pedestrian path.

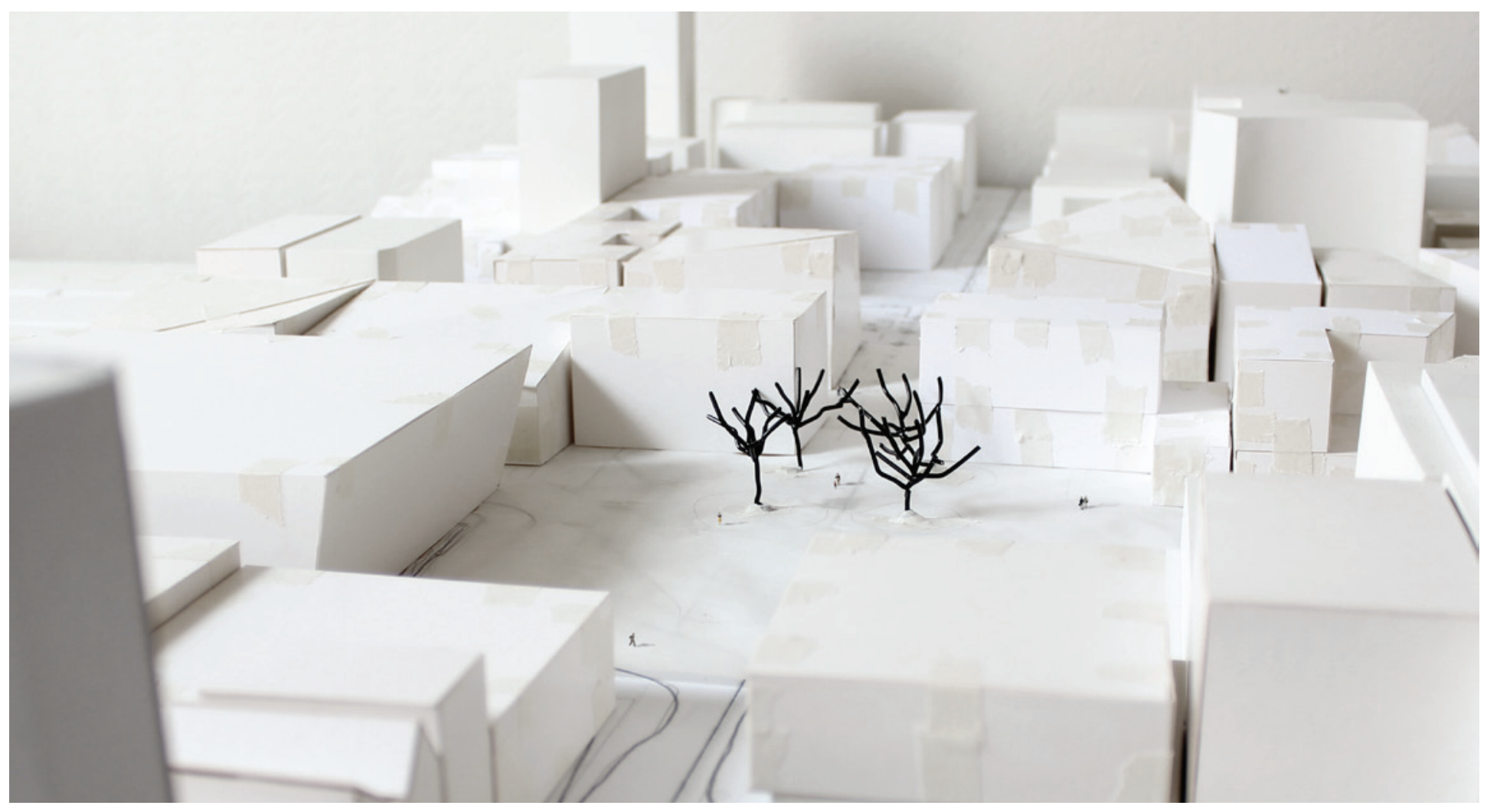




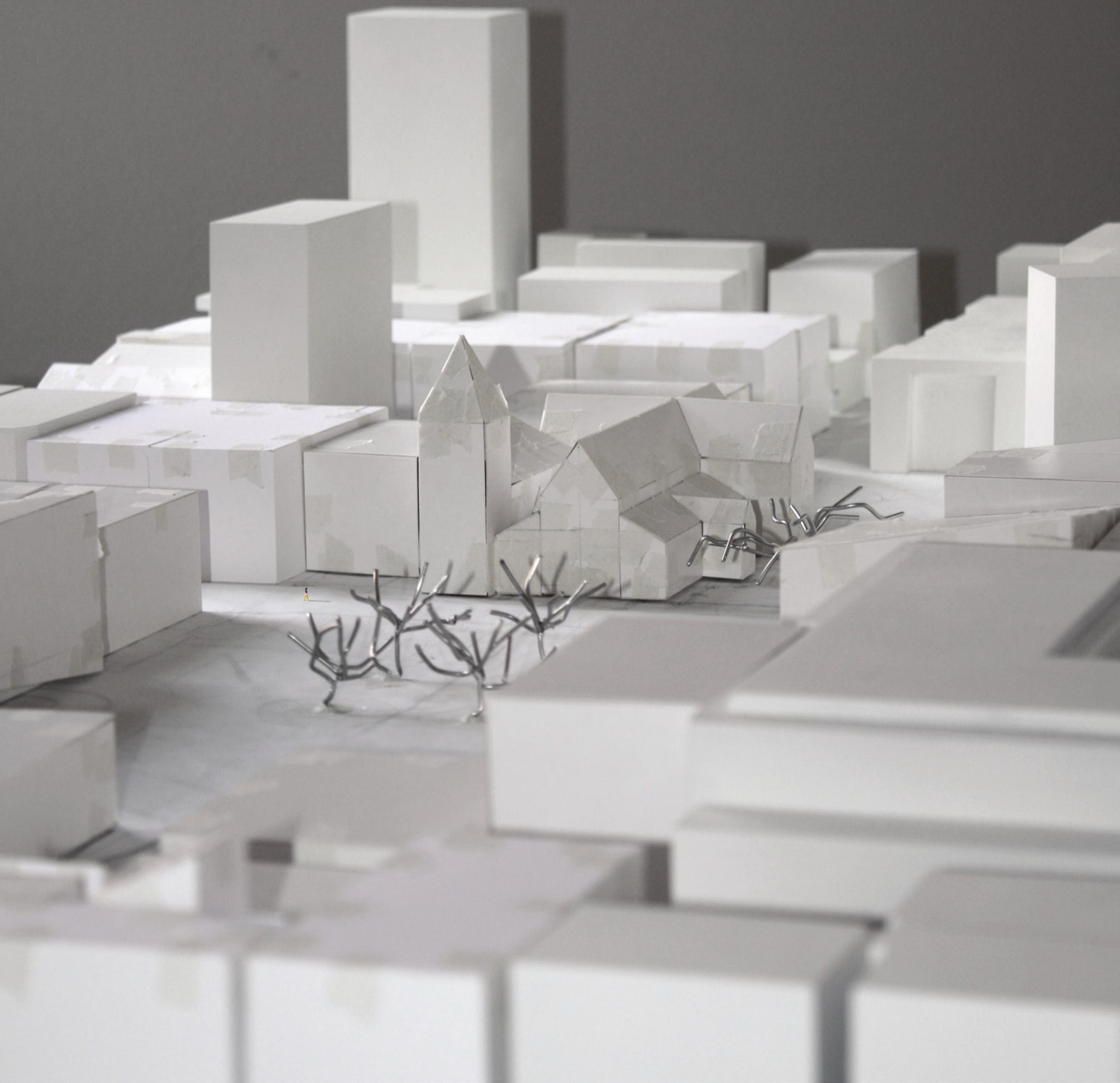


Design Concept 2 



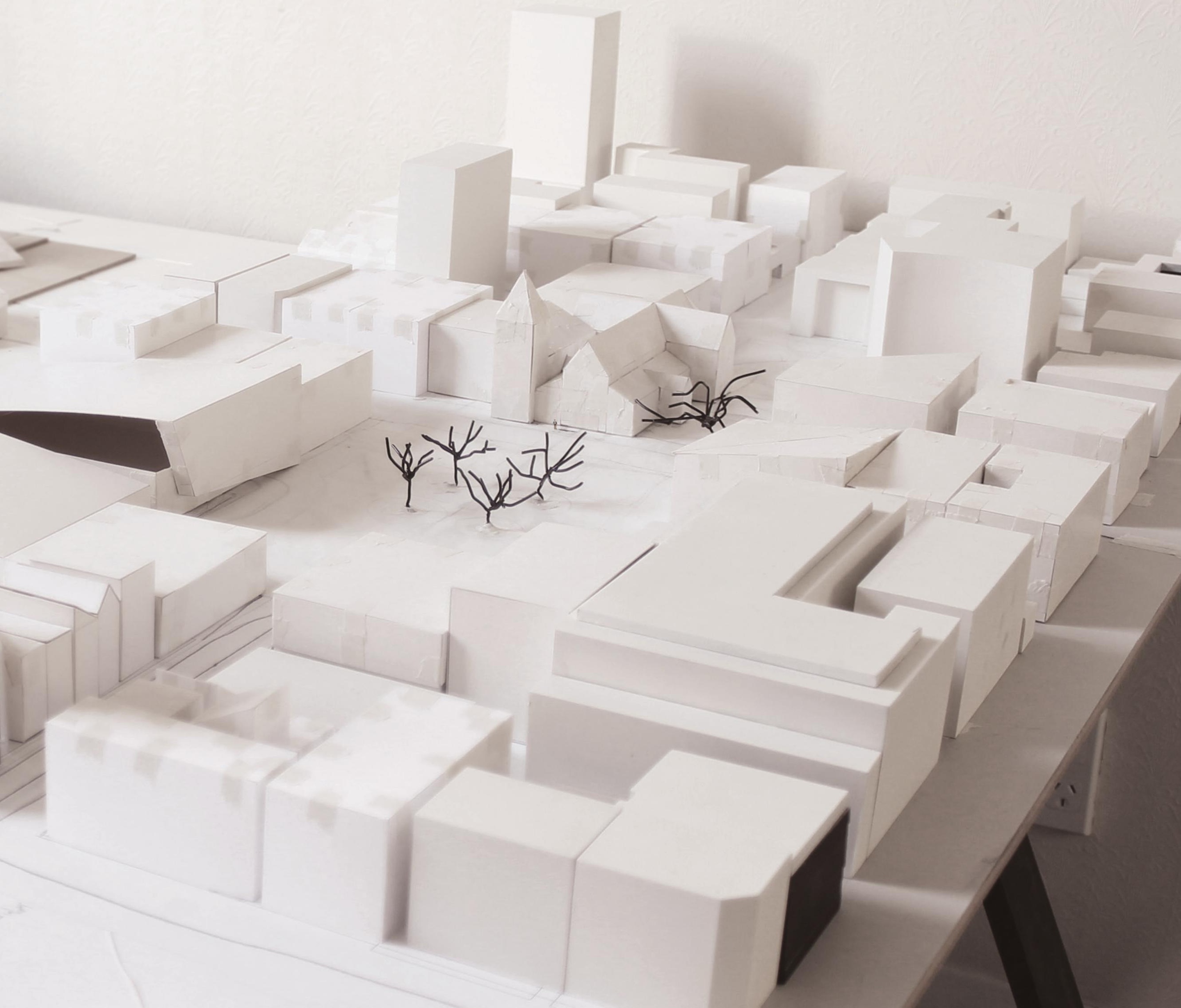


Reformed Square
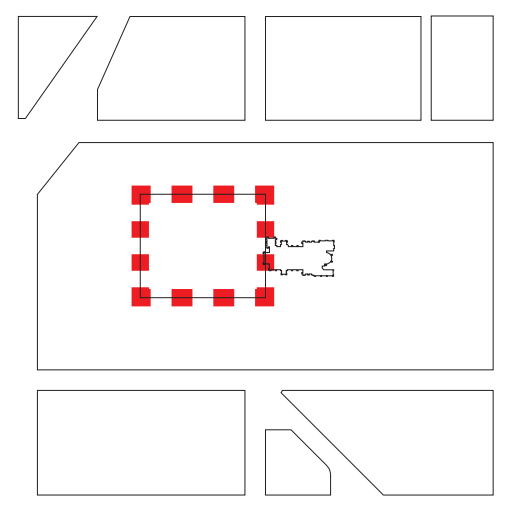

Main Entries

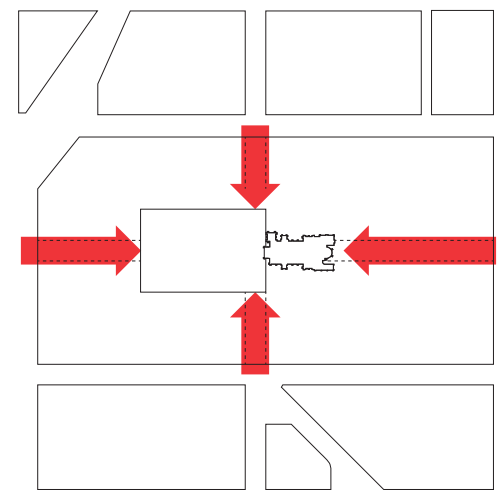

Existing Buildings

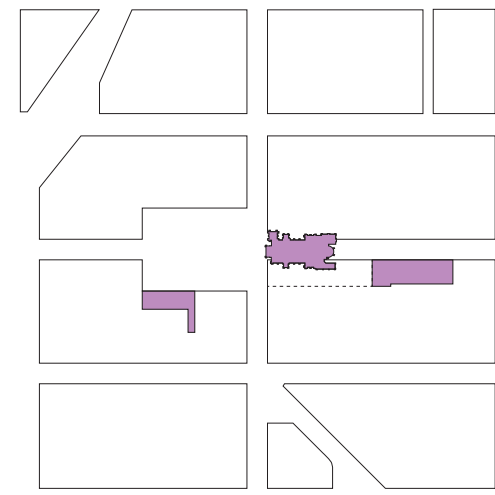

Unitary Square

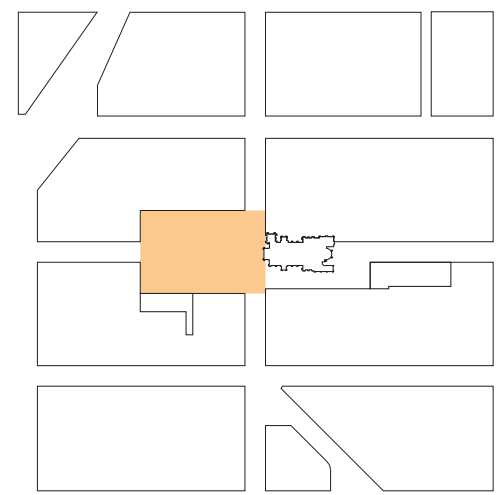

Pedestrian Lanes

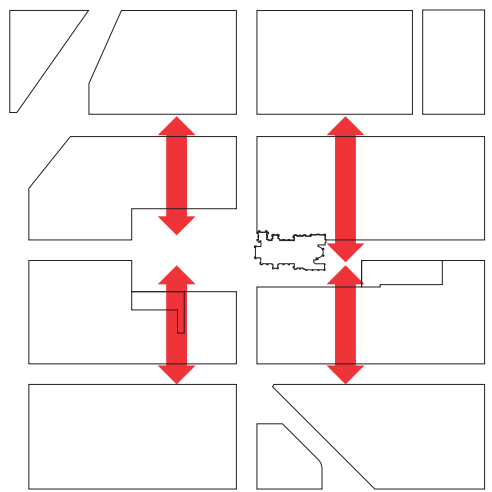

Circulating Public Transit

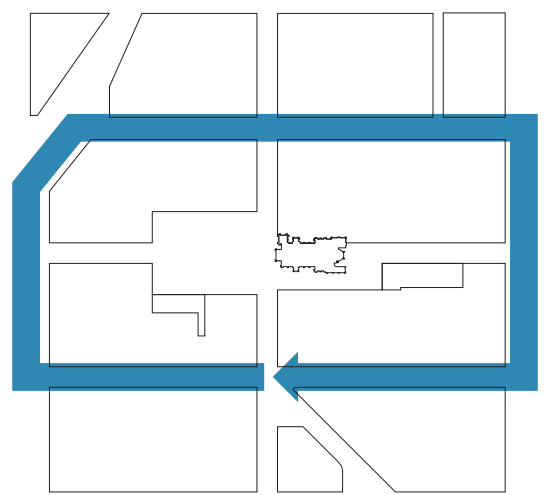

Vehicular Routes

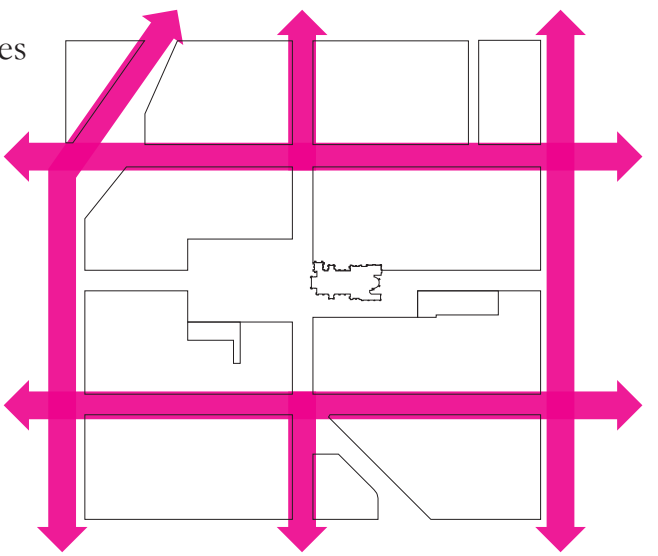

Proximate Green Space

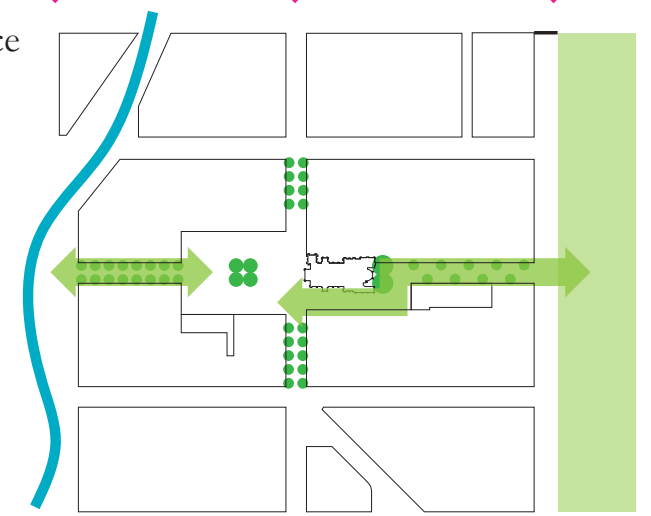


Figure 124. (previous pages) Concept two design

model.

Figure 125 . (opposite page)

Concept two planning diagrams.
Concept two is the most conservative of the three proposals. Like the first scheme the shape of the new square follows the orthogonal geometry of central Christchurch's street layout.

The square is significantly smaller than the original, covering an area of just over 9,300 metres squared. The smaller scale creates a much clearer sense of enclosure for the occupants. The shape of the square is based on the creation of a unitary space with a clear spatial hierarchy and enclosure.

The width of the square is the same as the narrowest part of the existing square (78 metres). The length has essentially been halved and the front facade of the Cathedral is now part of the eastern edge to the square.

Unlike the other two designs, the proposal integrates the Cathe$\mathrm{dral}$, in historic form, on its original site. However it is proposed that it be an attached, or integrated, building rather than freestanding. New buildings will be built adjacent to the Cathedral in order to enclose the new square. These buildings will be sensitive to the scale and restoration of the Cathedral, ensuring that it remains the principal building about the square.

The more integrated Cathedral combats the spatial fragmentation that plagued the old square. The concealed northern elevation also reduces the extent of restoration works needed on the Cathedral. This means that more time, effort and material can be used on restoring the front facade and tower.

The southern elevation of the Cathedral remains freestanding and frames a subsidiary space connected to the main square. This annexed space is intended to retain pedestrian connectivity between the square and Worcester Street without compromising the unified form of the square. This space also creates an enticing glimpse through the existing oak trees to the Old Government Building (OGB) behind the Cathedral.

The Chief Post Office building (CPO), fronts directly onto the new square. This ' $L$ ' shaped building simultaneously folds round to form one side of the lengthened Strand Lane.
Opposite this is the Convention Centre, which frames the northern edge of the square. The Convention Centre buildings are separated in order to integrate a public laneway that creates an alternative connection to Gloucester Street. This laneway also connects the rest of the Convention Centre complex to the square.

The whole of the square is to become a pedestrian precinct, including the subsidiary space east of the main square. Colombo Street enters and exits the square from the north and south and is closed to vehicular traffic. This includes public transit vehicles that circulate around the square and stop where laneways enter and exit the block. Worcester Boulevard is also closed to vehicular traffic to strengthen pedestrian connectivity with the Avon River. Worcester Street is partially accessible by car, primarily for service vehicle access. 


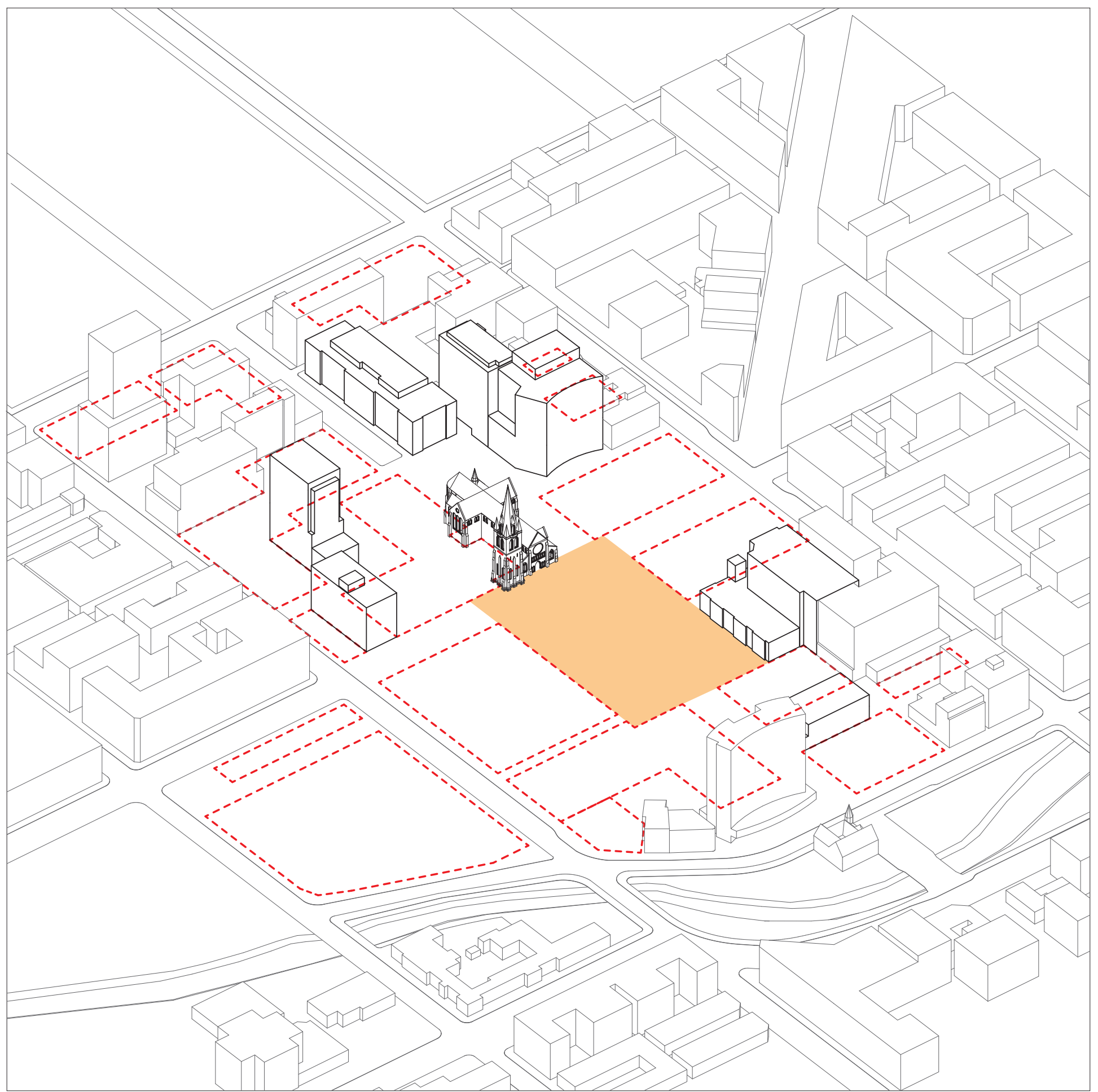

Figure 126.

Isometric view

looking south east

showing the square.

The proposed square is to a smaller scale and reformed to accentuate the Cathedral as the principal building. 



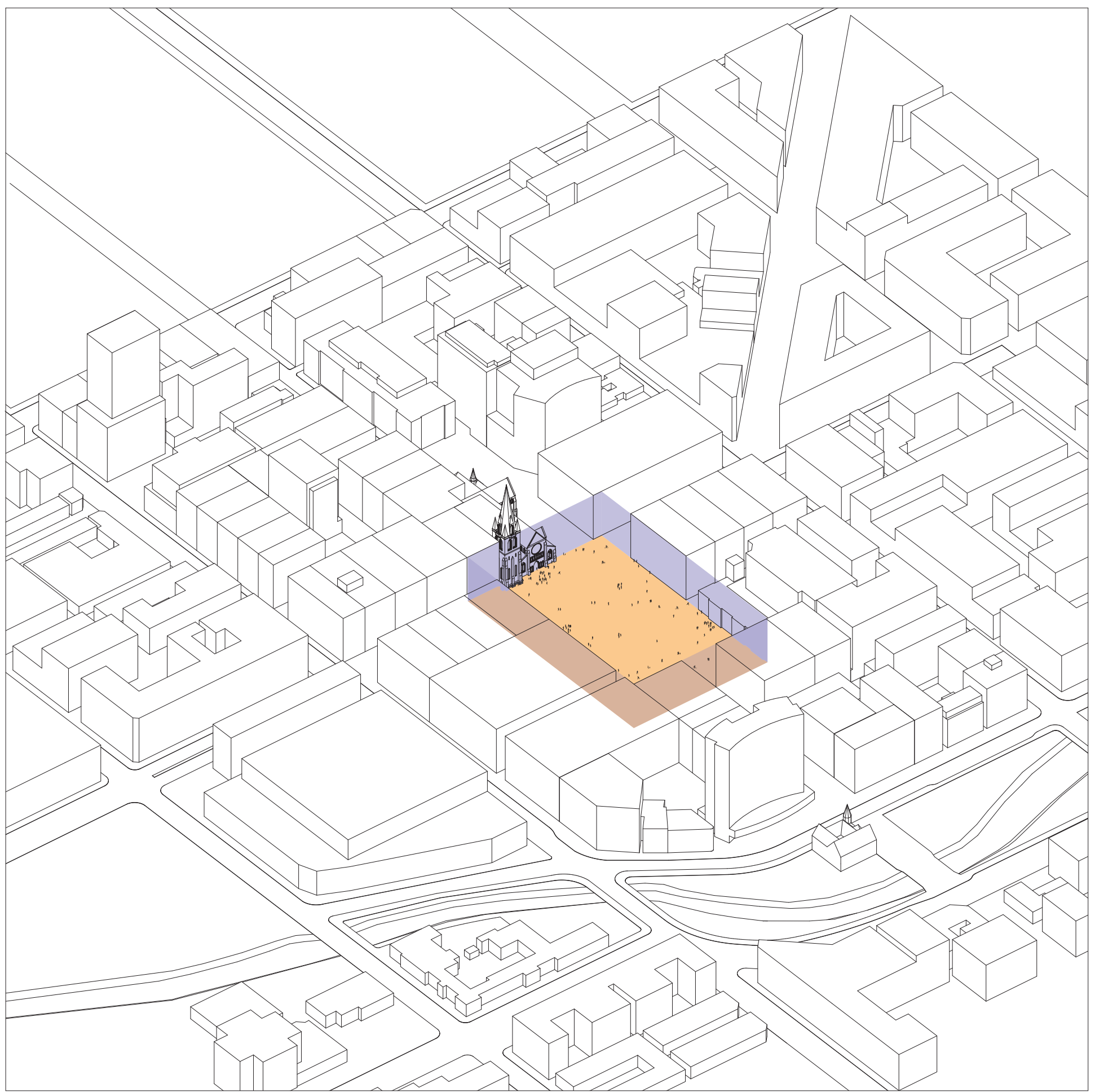

Figure 128.

Isometric view

looking south east

showing spatial

identity.

The composition of buildings surrounding the square is designed to enclose and create a clear spatial identity. Continuous building heights and active building edges front onto the square to add vitality and generate activity. 



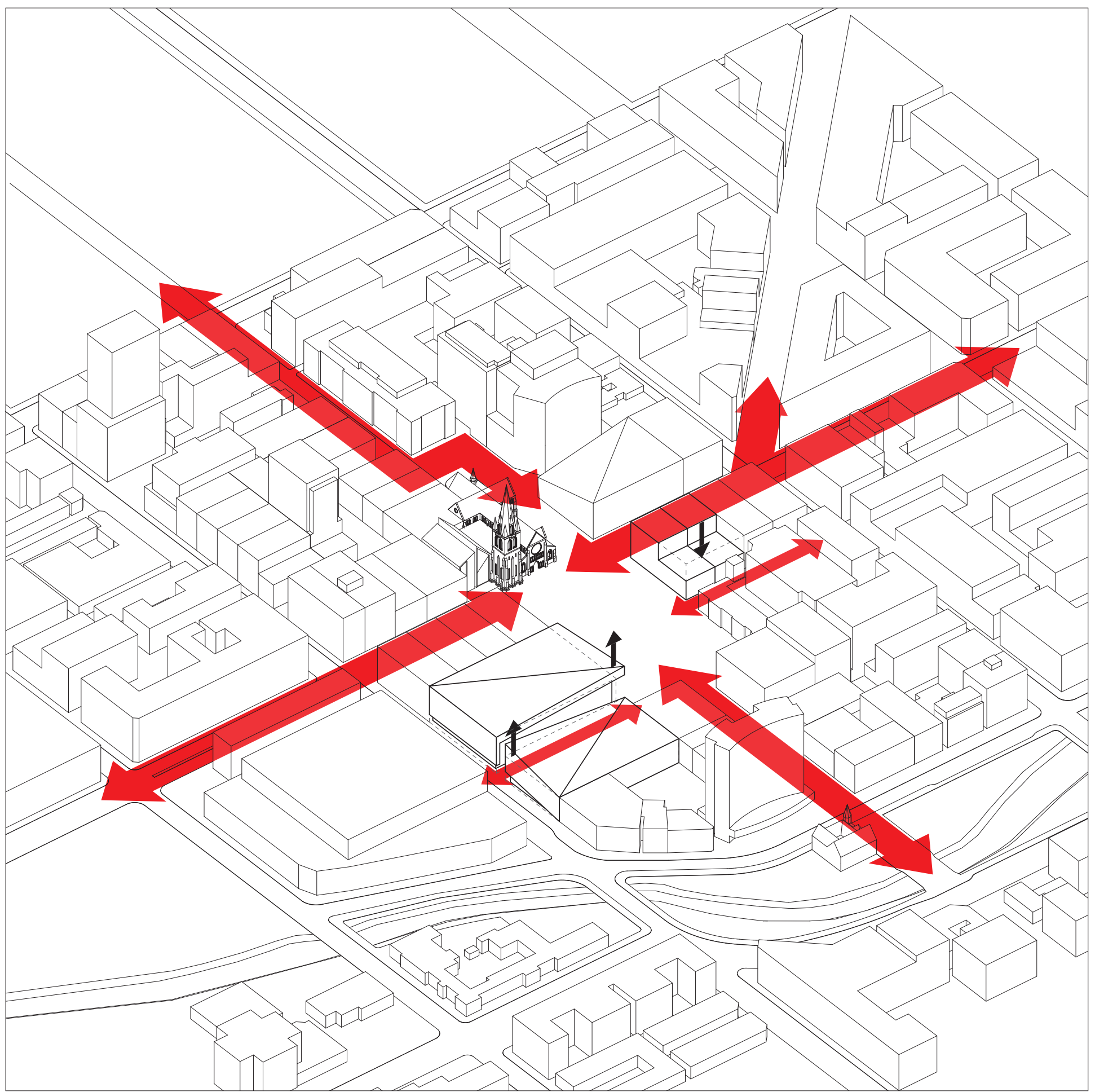

Figure 130.

Isometric view

looking south east

showing pedestrian

connections.

The square retains Colombo Street, Worcester Street and Worcester Boulevard as main entries. Two subsidiary lane ways also provide additional access to the square. Vehicles are excluded from the square. 
Figure 131.

Isometric view

looking south east

showing public

transit.

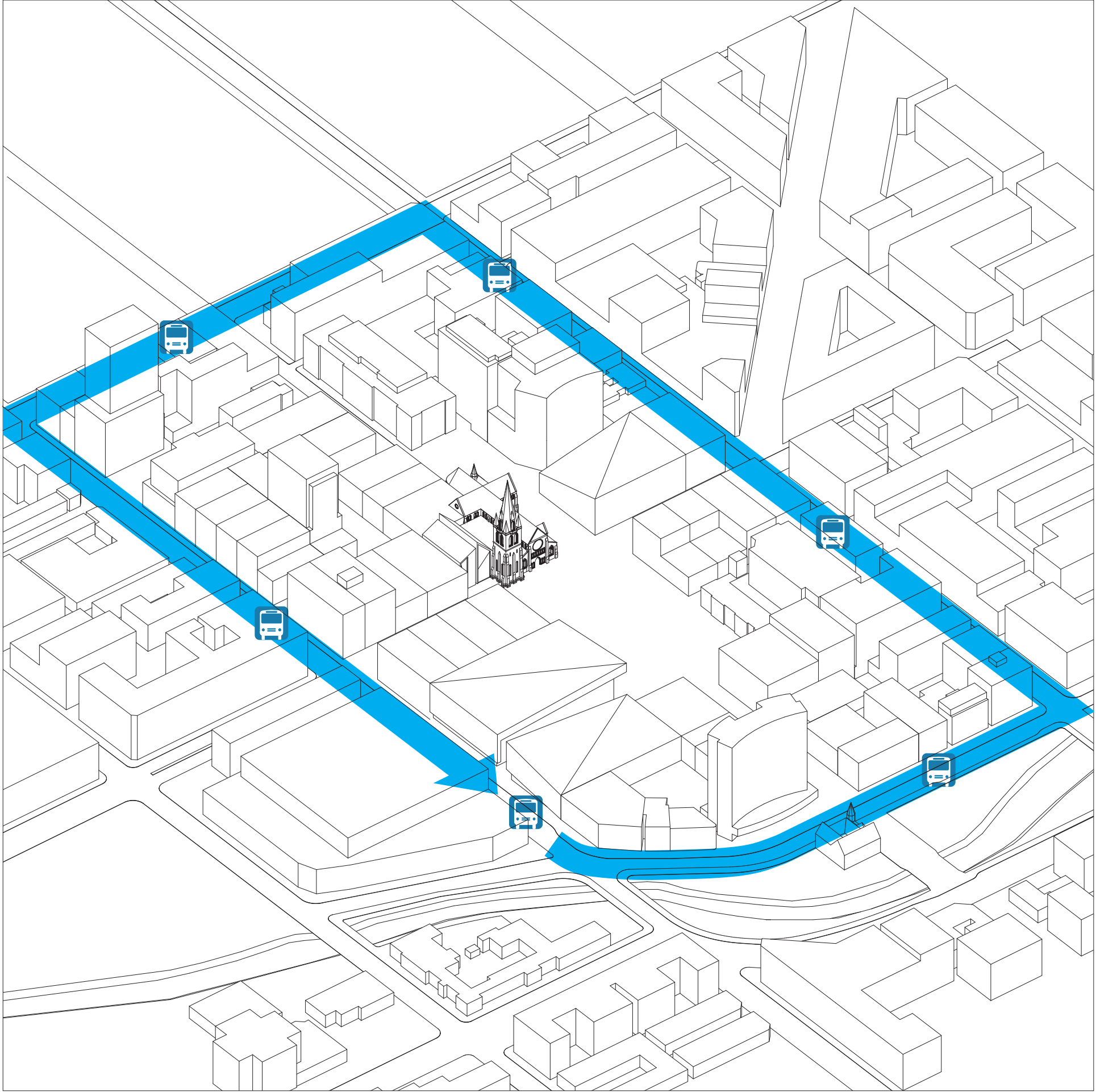

Public transit circulates the central city square with bus stops on Hereford, Manchester and Gloucester Streets as well as Oxford Terrace. The stops coincide with the pedestrianised streets and lanes entering the square. This integrates the two without compromising the spatial integrity and hierarchy of the square. 


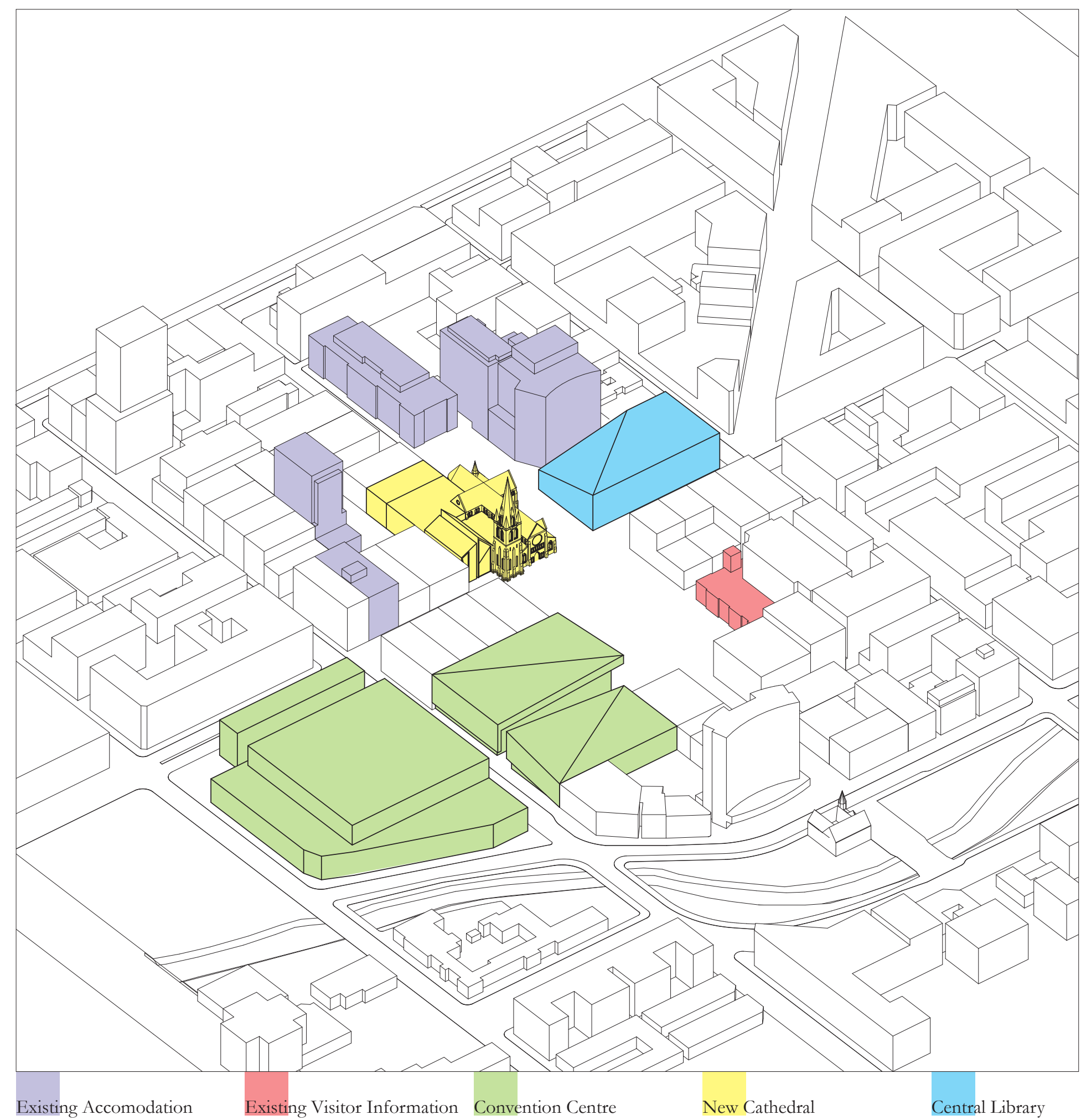

Figure 132.

Isometric view

looking south east

showing building

use.

The Cathedral is retained as the principal building about the square. A new Library forms the south east corner of the square. The Convention Centre forms the north west corner of the square. All have a presence within the unitary square. 
Figure 133.

Isometric view

looking south east

showing green

space.

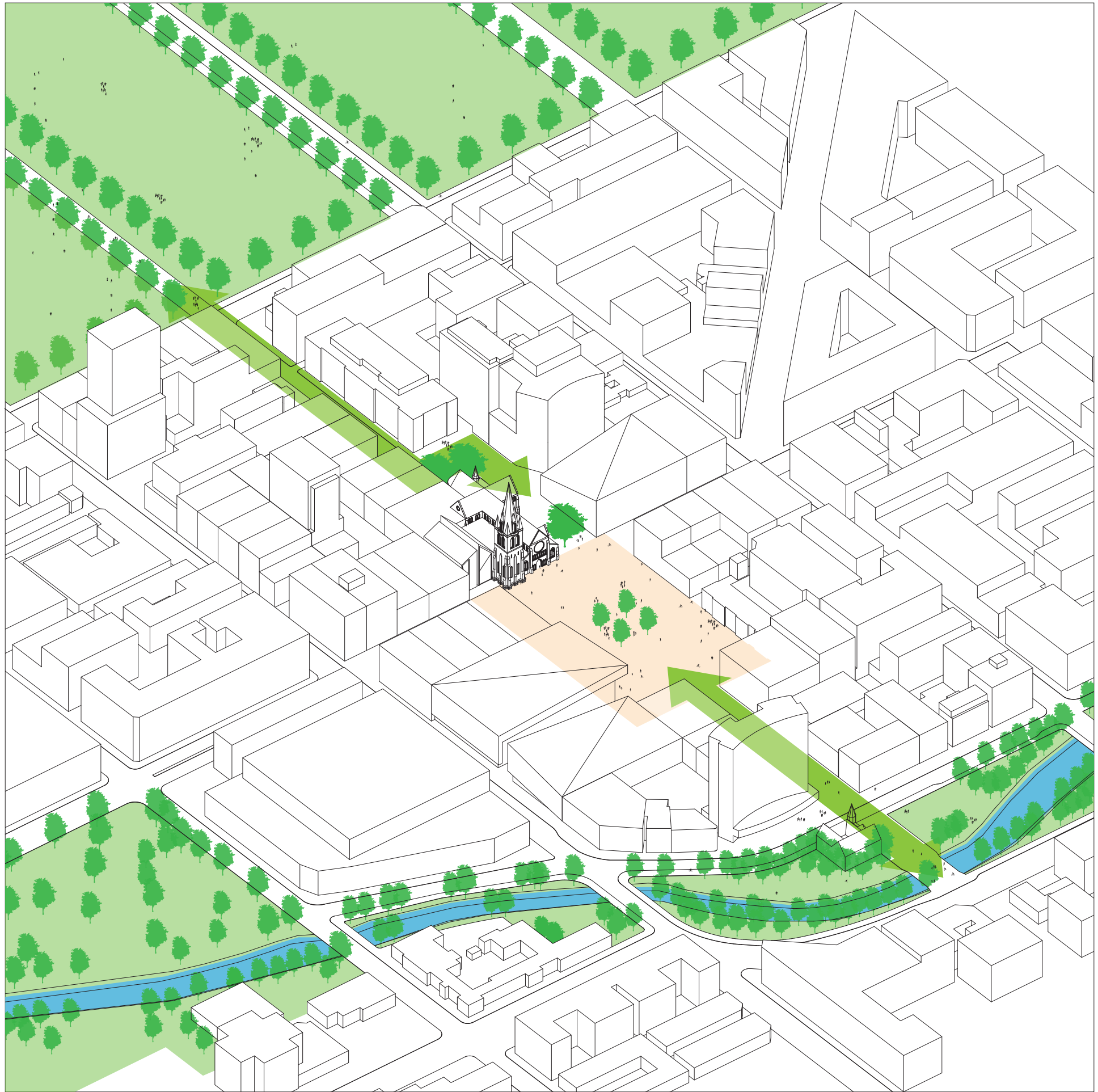

The proposed square retains some of the existing oak trees around the Cathedral. Also retained are the four trees in front of the Cathedral. A high level of connectivity between the square the Avon river front and the proposed Green Frame to the east create a unique precession of public spaces both natural and man made. 
Figure 134.

(opposite page)

Aerial view of the

square.

Figure 135. View looking north east across square.

Figure 136. View looking south west across the square.
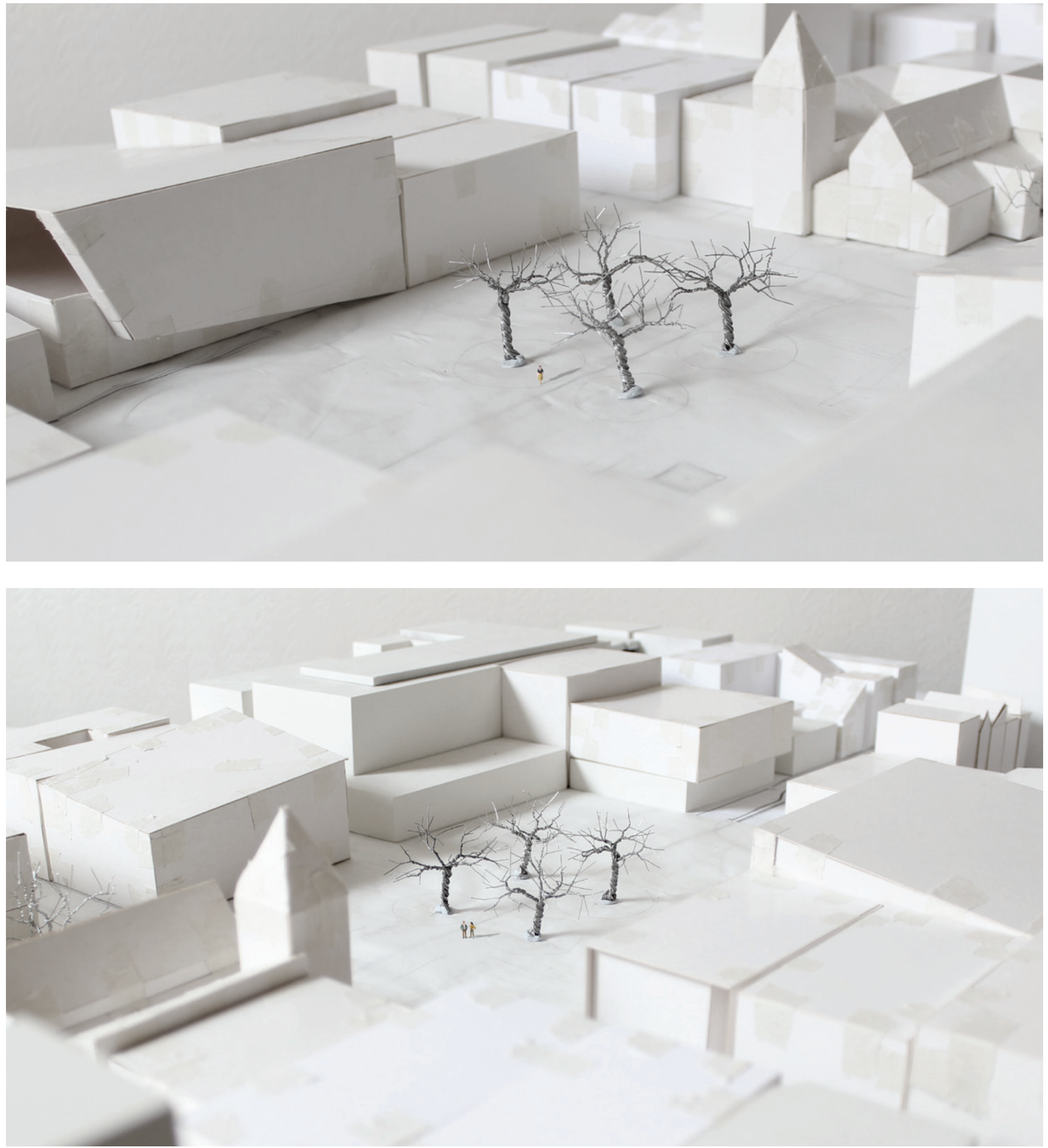


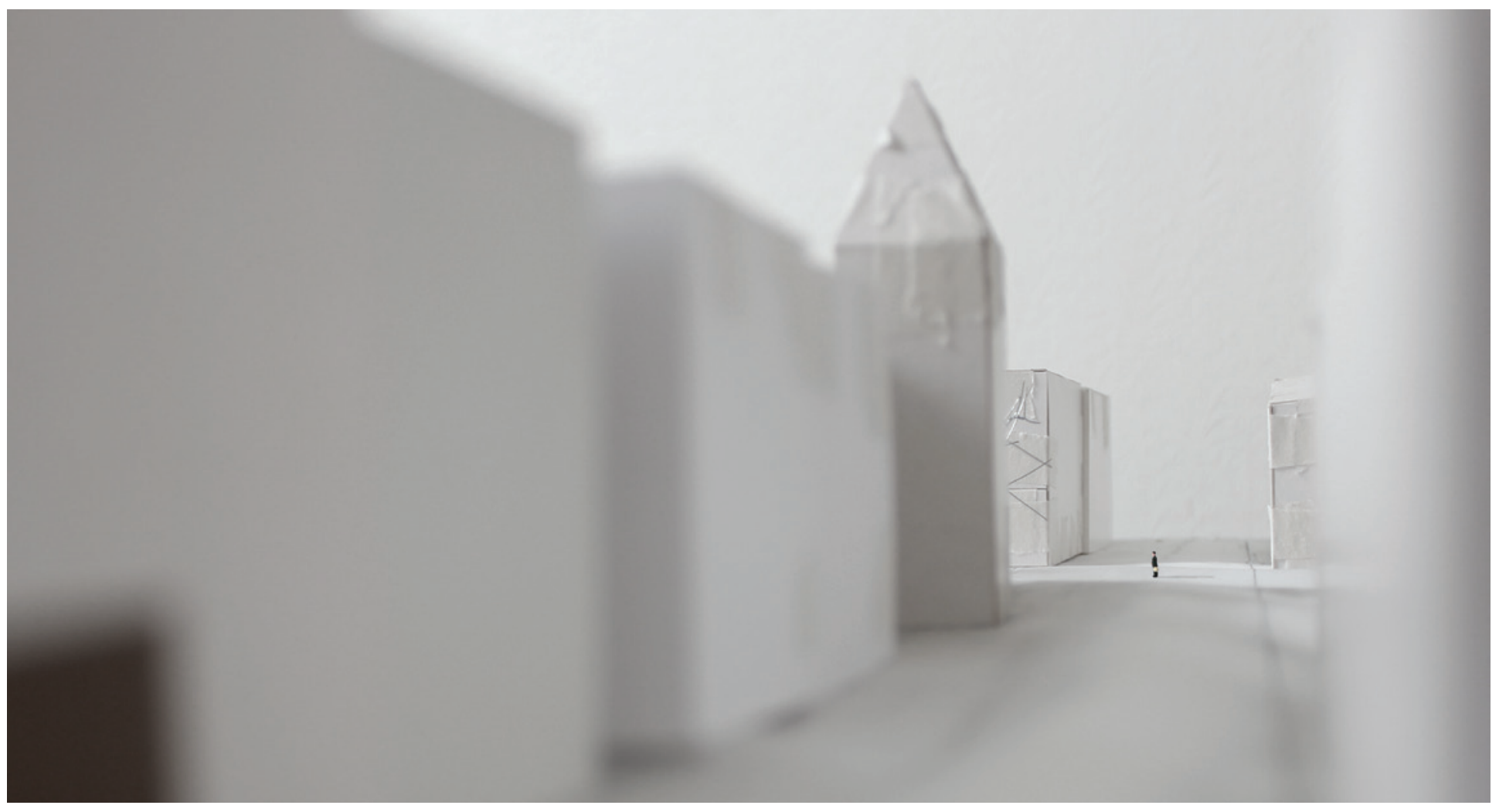

Figure 137. View

looking south down

Colombo street

with protruding

Cathedral tower.

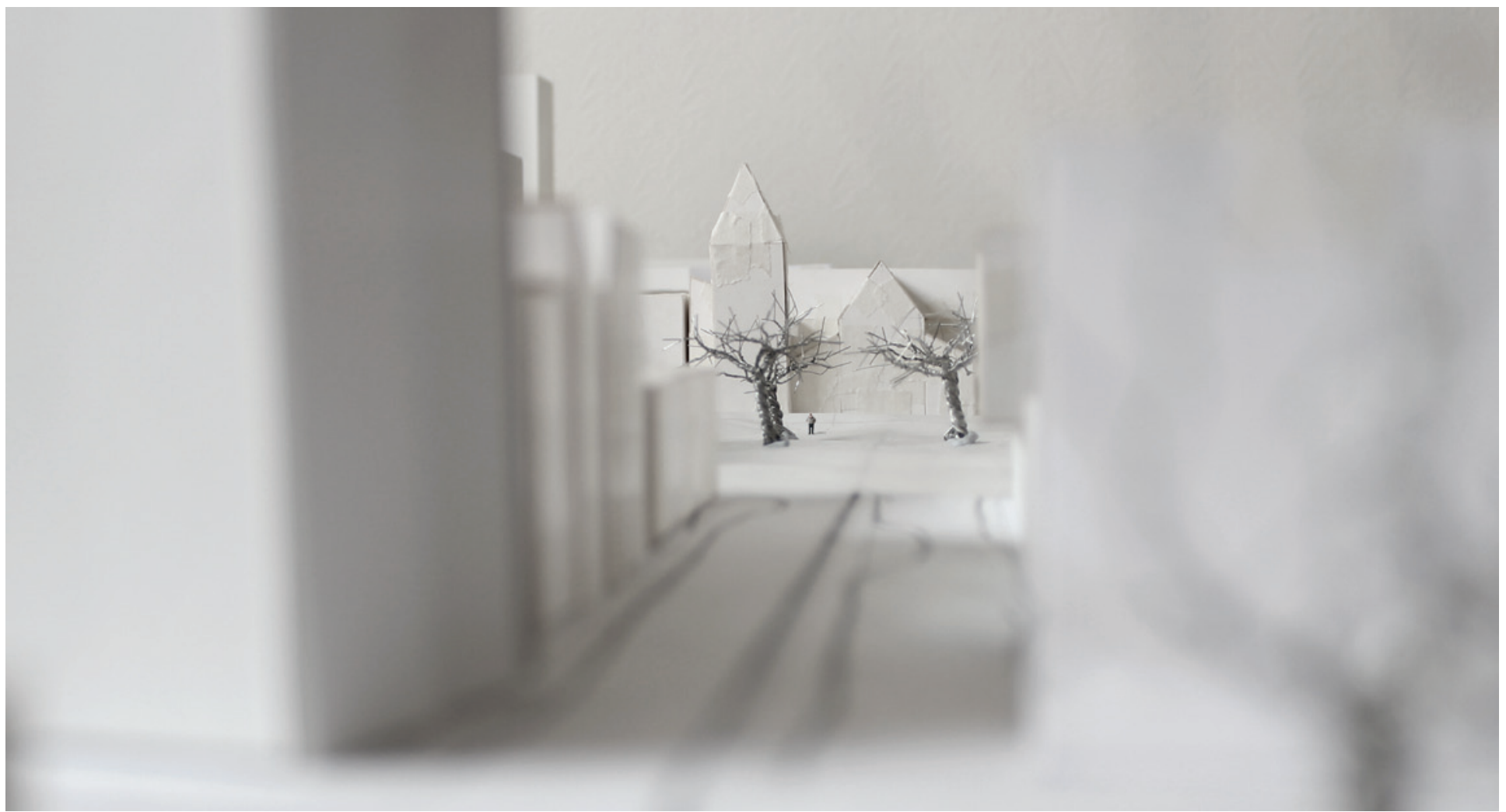

Figure 138. View down Worcester

Boulevard of $\mathrm{Ca}$ -

thedral from Avon River.

Figure 139.

(opposite page)

Aerial view of $\mathrm{Ca}$ thedral and tower. 



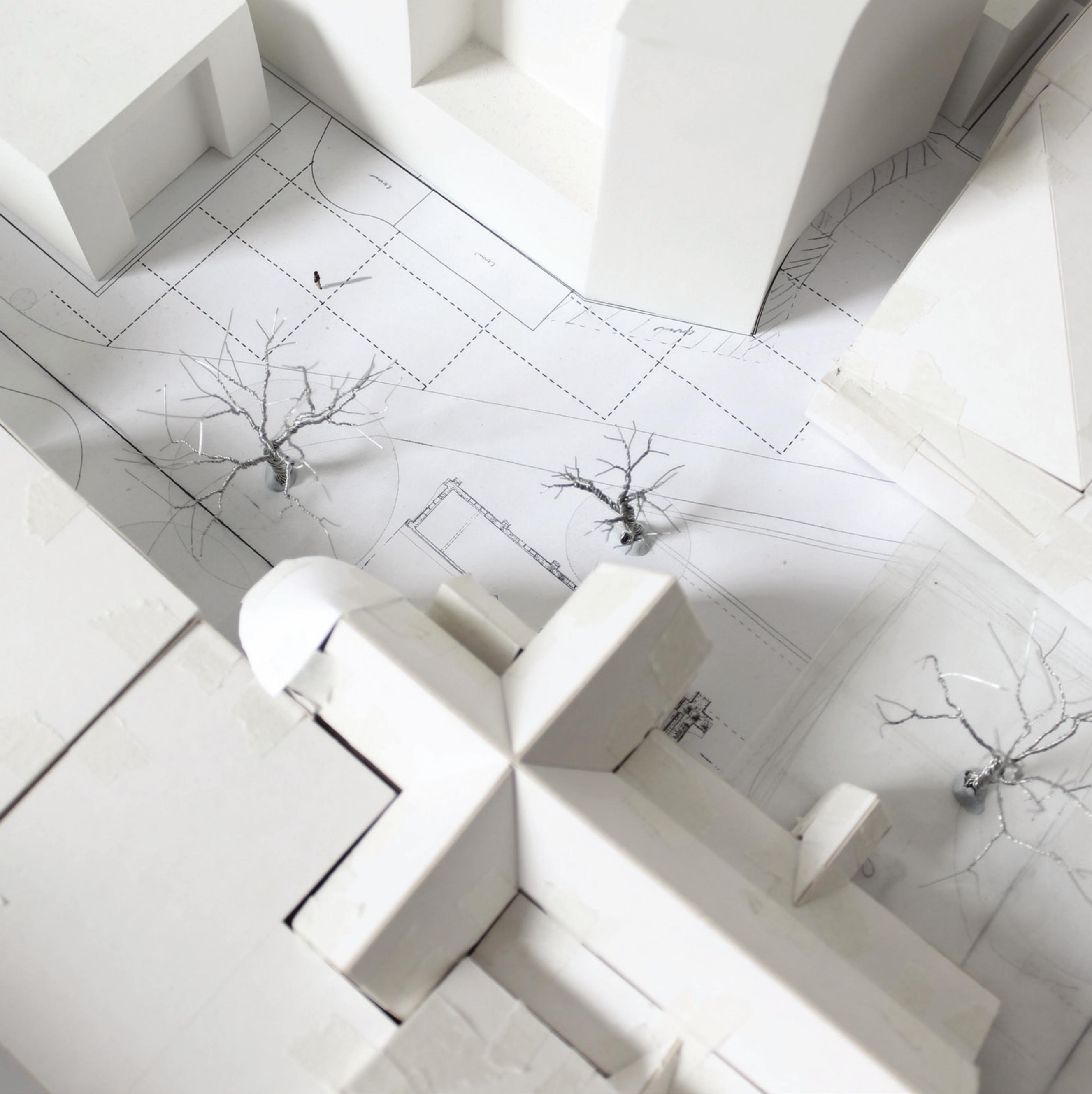


Figure 141 (opposite page) Aerial view of the square annex.

Figure 140. View looking westward across the whole scheme.

Figure 142. View looking east into

the square annex with OGB in the background.
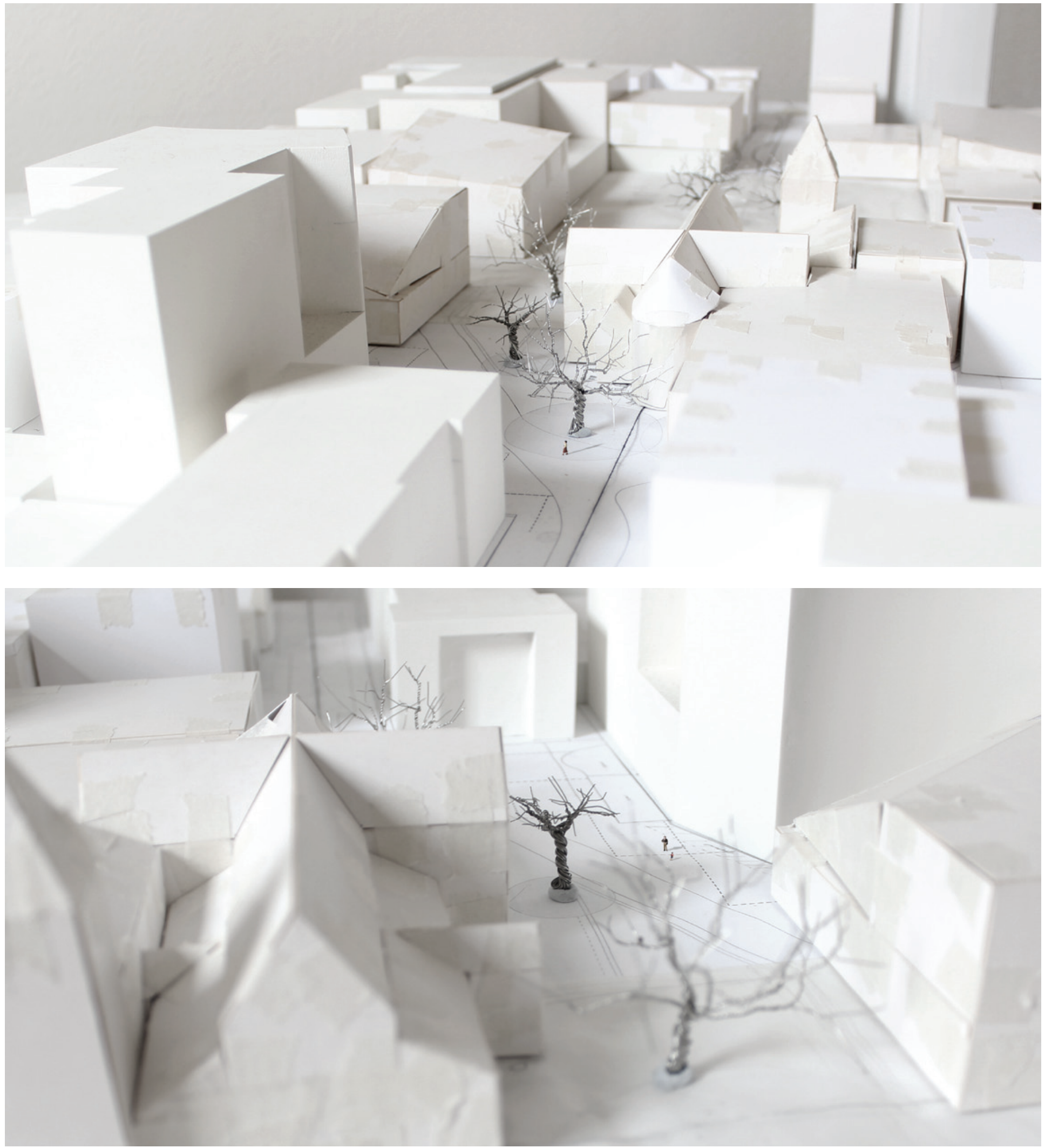



\section{Design Concept 3}




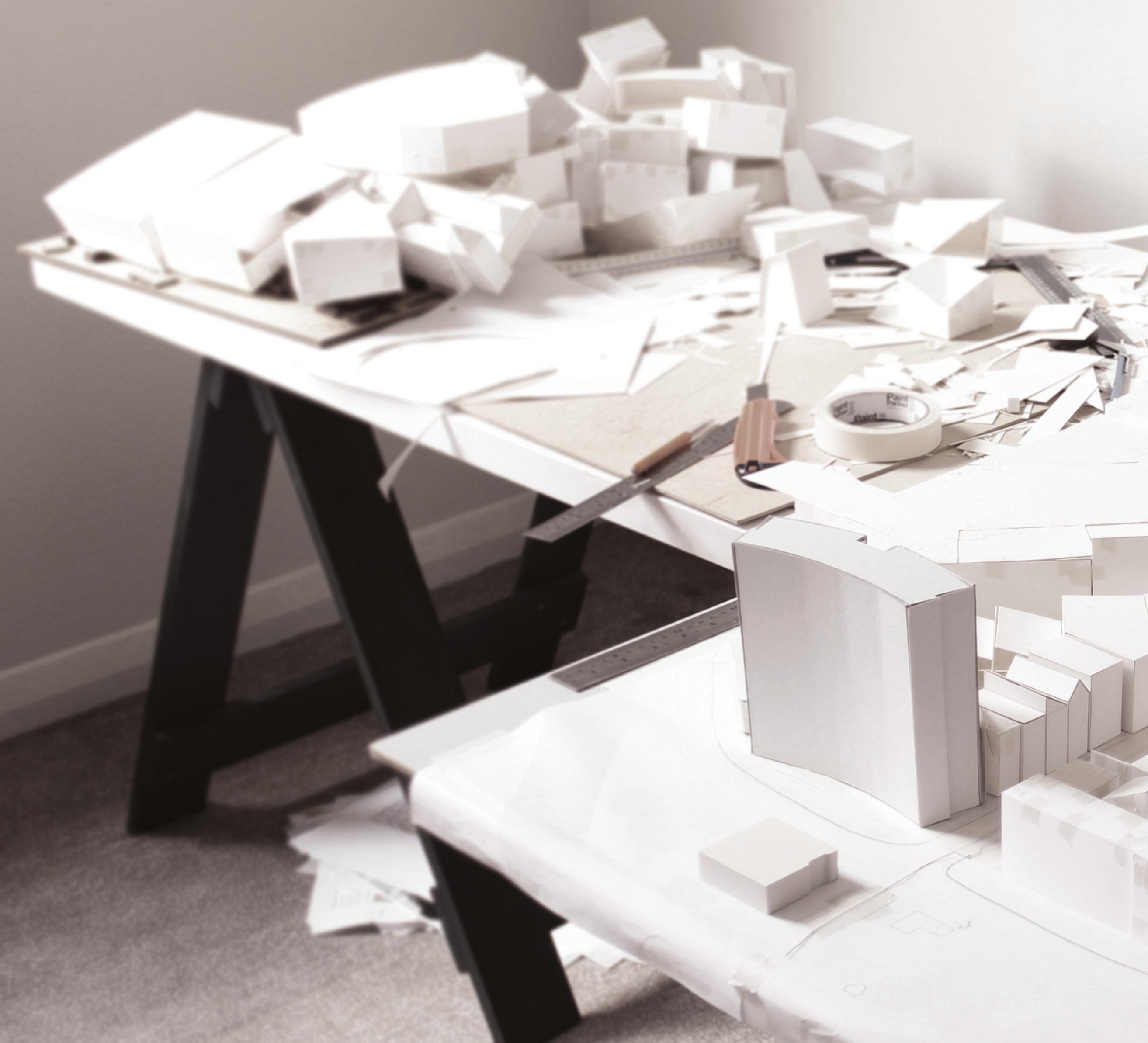




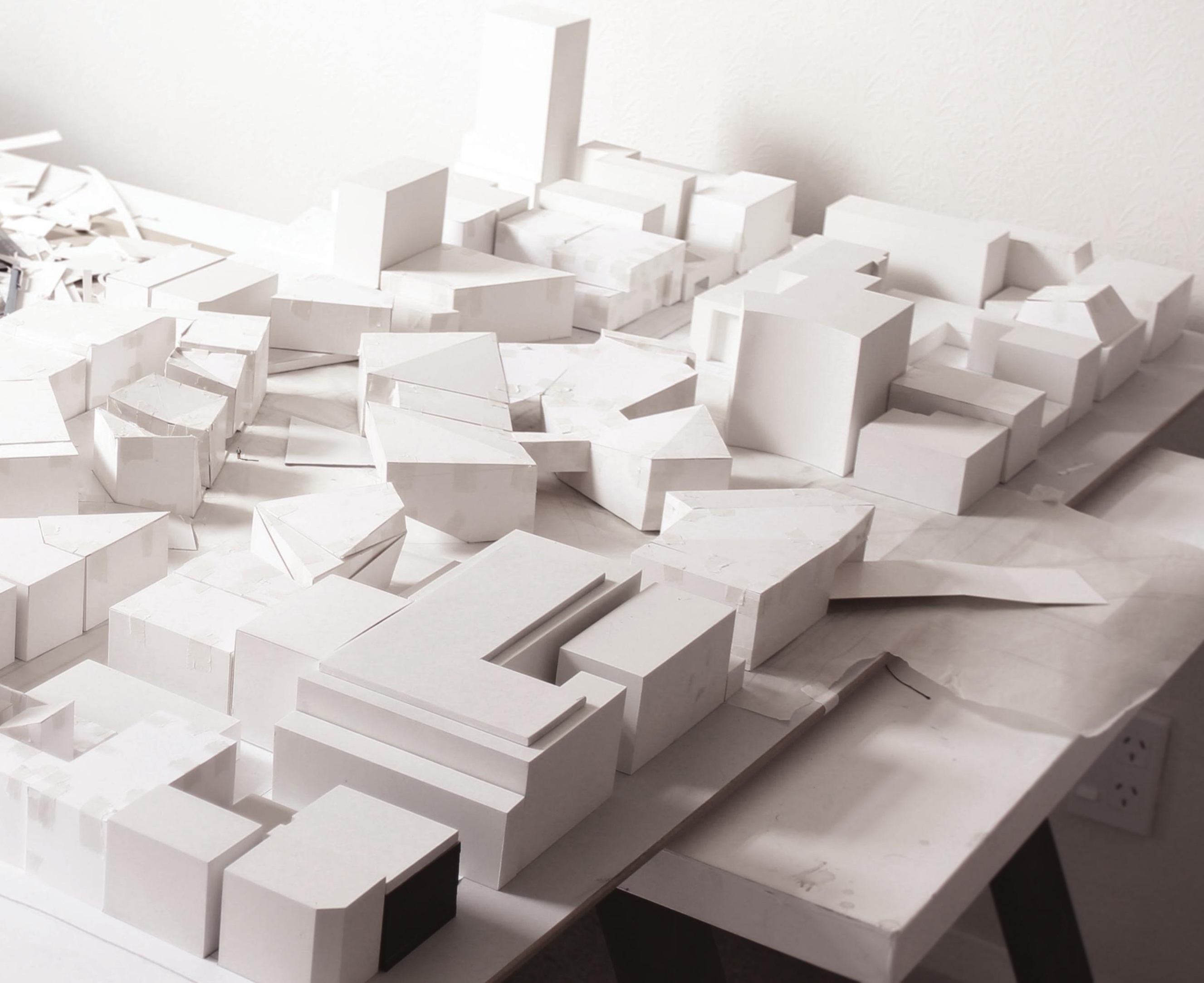




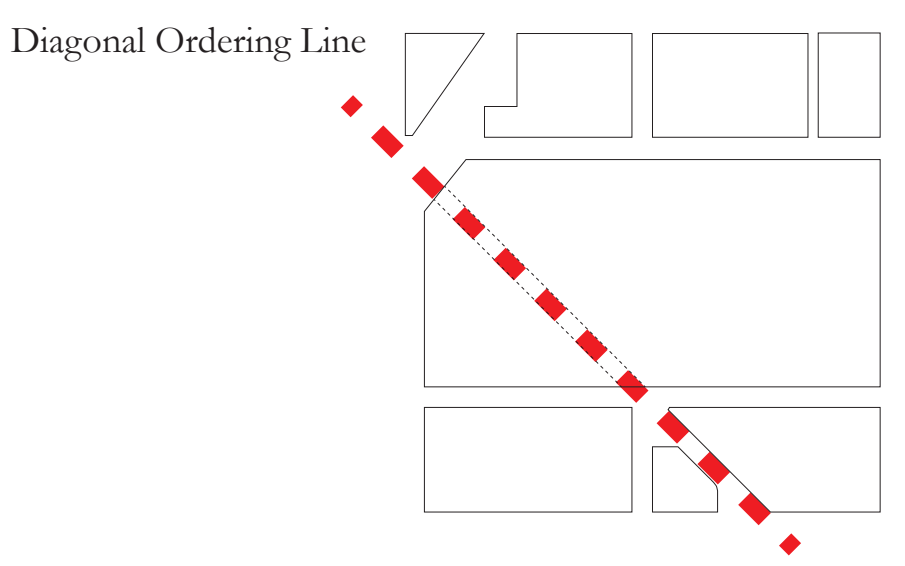

Main Entries

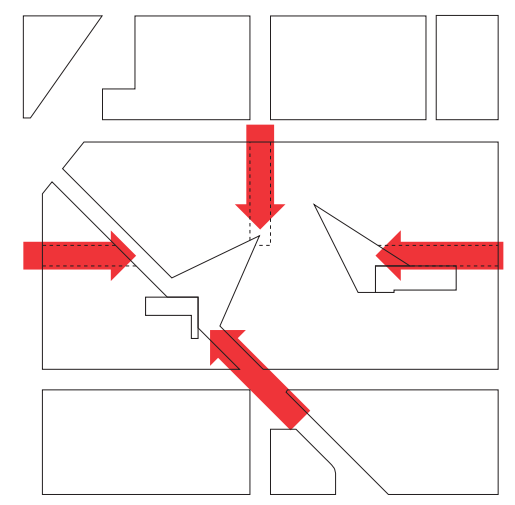

Terminal Views
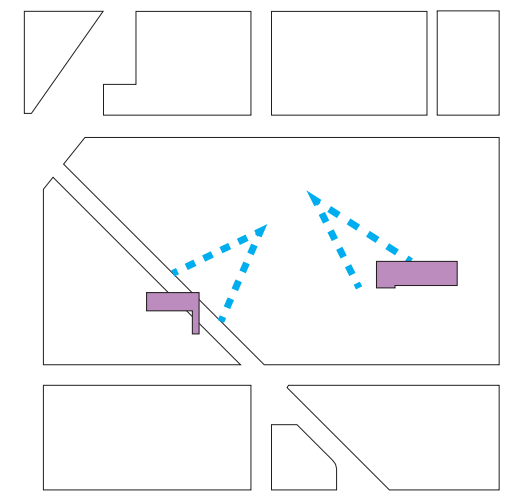

Amorphous Spaces

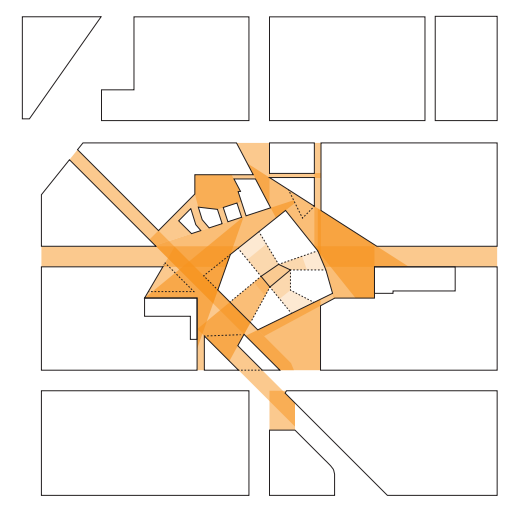

Circular Pedestrian Path
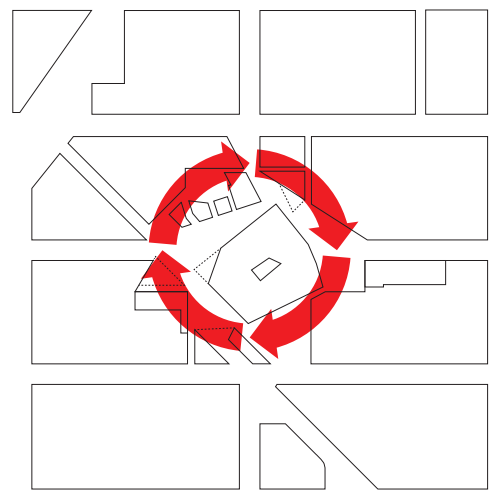

Public Transit Routes

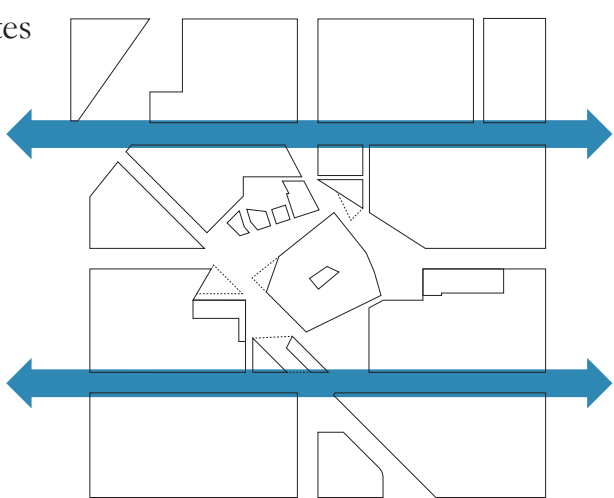

Vehicular Routes

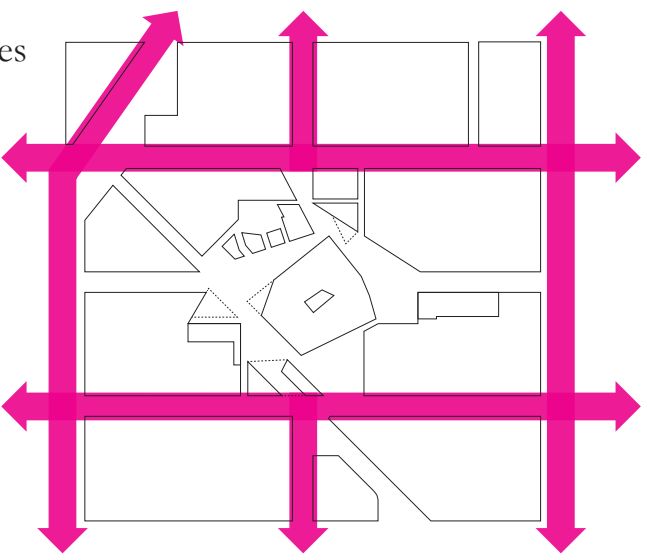

Proximate Green Space

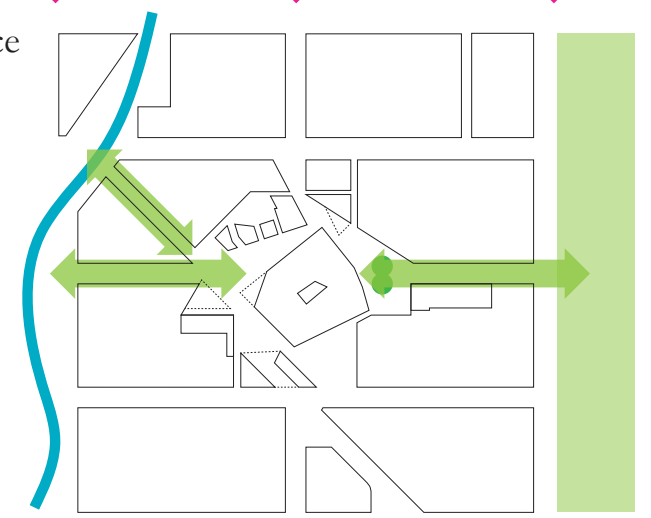


Concept three is the most contemporary of the three proposals in that it is the most removed from New Urbanism. Drawing from the avant-garde Post Urbanist projects discussed in the background chapter, this design breaks away from historical urban form to more thoroughly investigate, through design, the extent to which New Urbanism can contribute to the integration of the square.

This concept proposes to transform Cathedral Square into a multitude of spaces or squares. This radical spatial outcome is the result of a much more empirical, or artistic, composition of buildings, based around more experiential qualities such as: scale, proportion, spatial identity and enclosure. The design also has another level of complexity in that many of the spaces and buildings are refined through infinite design alterations and iterations. These artistic alterations privilege the less tangible aspects of the design such as enticing views between different spaces or picturesque partial views of particular buildings. The non-orthogonal geometry employed in a majority of the spaces and buildings allows for a much more rigorous design exploration of these possibilities, and challenges the more rational design decisions made in the first two schemes.

The first move in forming this concept is to extend the anomalous High Street through the square. This diagonal ordering line begins to break up the orthogonal geometry and is the main gateway into this scheme. The two blocks are connected by a bridge that rises out of the ground on High Street and creates an unobstructed pedestrian path over top of the Colombo and Hereford Street junction. The separation of pedestrian and vehicular flows allows for the integration of public transport on Hereford Street without obstructing pedestrian connectivity between High Street, the square and the river beyond. The raised path passes through a mixed use building on a sort of internal plateau, with views of the historic CPO, proposed Convention Centre and the new Central City Library.
Public transport has been routed down Hereford Street and Gloucester Street. The Southern Square opens up onto Hereford Street to visually and spatially integrate vehicular traffic. The fact that this square opens out onto the street means the buildings on the other side of Hereford Street make up the southern edge to the square. This integrates Hereford Street for greater accessibility to the square by public transport and private car.

Celebrating the two historical buildings that remain in Cathedral Square, the OGB and the CPO, informed much of this design. Beginning at a common starting point, two oblique view angles were mapped and the surrounding buildings composed to create an urban viewing cone of these historic buildings. These spaces have become two of the more significant squares within the whole scheme. The diagonal ordering line and subsequent freedom from the orthogonal street geometry helps to integrate these two historic facades and privilege these unique views.

Three existing entrances to the square from Colombo Street North, Worcester Street and Worcester Boulevard connect the surrounding gridiron street pattern with the altered forms of the square. The openness of the south square negates the need for a ground level entrance on this side.

The other spaces are largely based on a circular movement path resulting in a large central structure as well as interconnecting all the spaces around this building.

For example, the OGB Square is connected to the southern square via a tight gap between the central building complex and the existing Millennium Hotel tower. This path connects these two spaces, but also creates partial views from either side of the path, most notably of the OGB. Additionally, the oblique angles employed in the composition of paths means they connect without adversely affecting the sense of enclosure. It must be noted here that the simple gesture of a circular movement path is only part of a more complex set of three dimensional 
design alterations and iterations. However for the purposes of comparison and consistency between the concepts this process has been retrospectively summarised in diagram form.

The large freestanding building in the centre of the new scheme is the principal building in this concept. This building faces outwards onto each of the surrounding squares. Porous building edges and integrated paths through the building connect the surrounding squares to one another and break up the huge scale of the building. The public pathways through the building also combat the isolation and spatial fragmentation that standalone buildings create, such as the existing Cathedral.

All four of these paths meet at a central open air atrium where escalators, lifts and stairs assist people to different levels of this central building complex. These paths are framed by active building edges occupied by a multitude of uses including retail outlets and cafes.

The main purpose of the complex is to house a new Central City Library and a replacement Cathedral.

Three pavilions create a scale buffer zone between the main plenum of the Convention Centre and the north square. Fractured by pedestrian paths that connect the two spaces, these pavilions are morphed and composed to integrate the large scale and proportion of the Convention Centre.

Their location creates a smaller square behind on a raised platform that acts as a public pre-function area or outdoor foyer for the Convention Centre.

The stepped paths that link these two open spaces also allow shafts of afternoon sun to enter the North Square and the roofs are sloped to improve overall natural day lighting.

The North Square between the Library/Cathedral complex and the Convention Centre complex was initially formed around the view cone of the CPO. This square is also a space where local meets global. The space is framed on one side by the Convention Centre, which caters primarily for people visiting Christchurch, and on the other by the Central City Library, which is geared toward the local population. This distinction in users helps to bring vitality and continuous occupation to the square.

Colombo Street North is still the main northern entry to the square. From this location one can see onto the North Square and into OGB Square. Similar to the North Square, OGB square is composed primarily around the oblique view angle of the OGB. This view cone is framed on one side by the Central City Library/Cathedral complex, and on the other by new mixed use buildings that fold around into Worcester Street to create a continuous urban wall. These buildings (like most around the fringes of this scheme) serve a dual purpose, mediating between the new non-orthogonal and existing orthogonal urban geometries. Opposite the OGB, still on an east-west axis, is the Cathedral quarter of the central building complex. This part of the building is composed and scaled to enclose the space between the two buildings. It is possibly the only part of the complex that subtly retains parts of the original orthogonal urban geometry. Partial views through the crevice like gap between the Cathedral and Millennium Hotel leads one back to the South Square and the Hereford Street entrance. 
Figure 146. Isometric view looking south east showing new buildings.

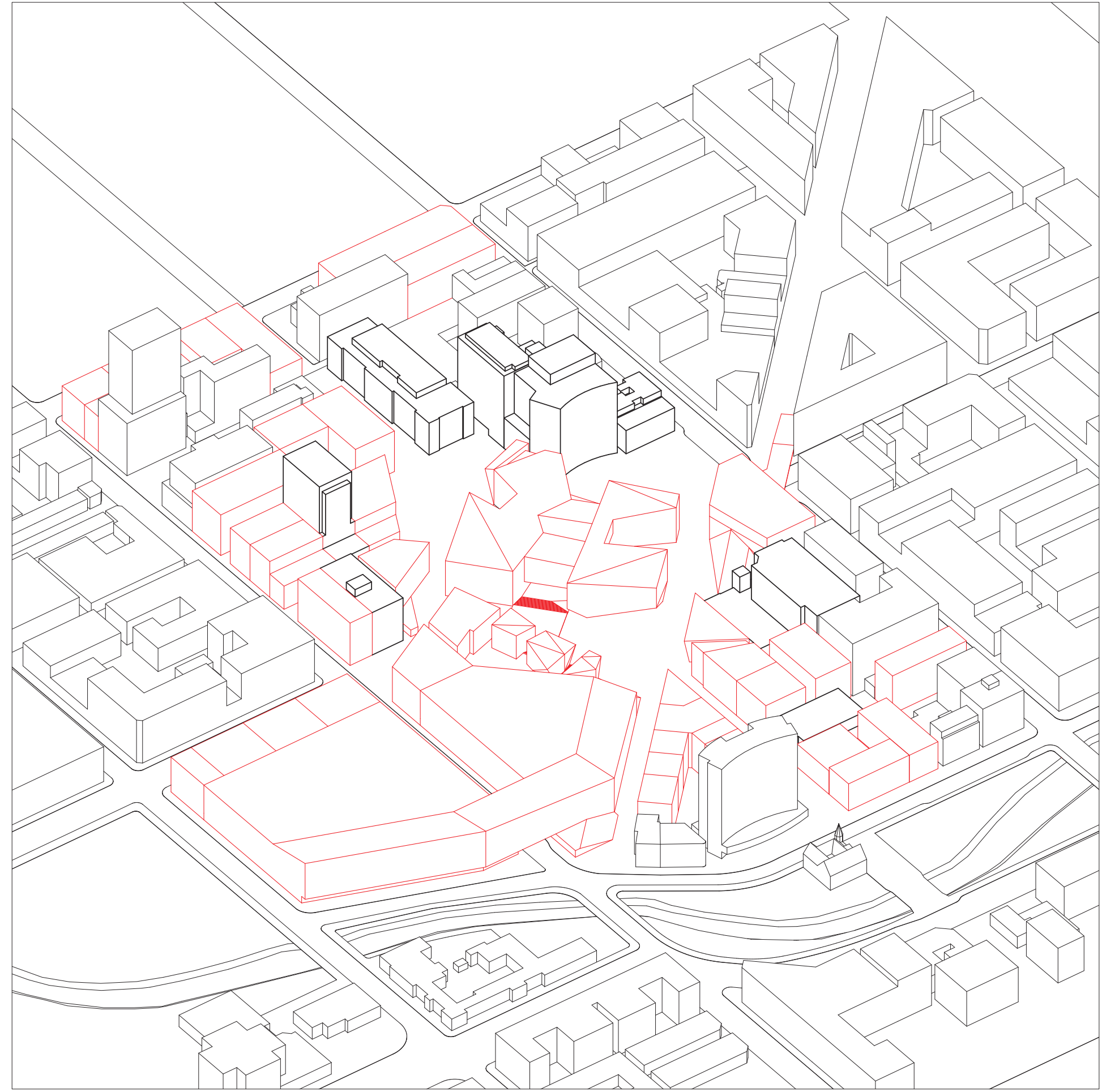

The almost infinite number of corrective adjustments mean the three dimensional formation of this concept cannot be as easily expressed as the first two concepts. The formation of these buildings is sensitive to both scale, proportion, enclosure, identity and existing context. 


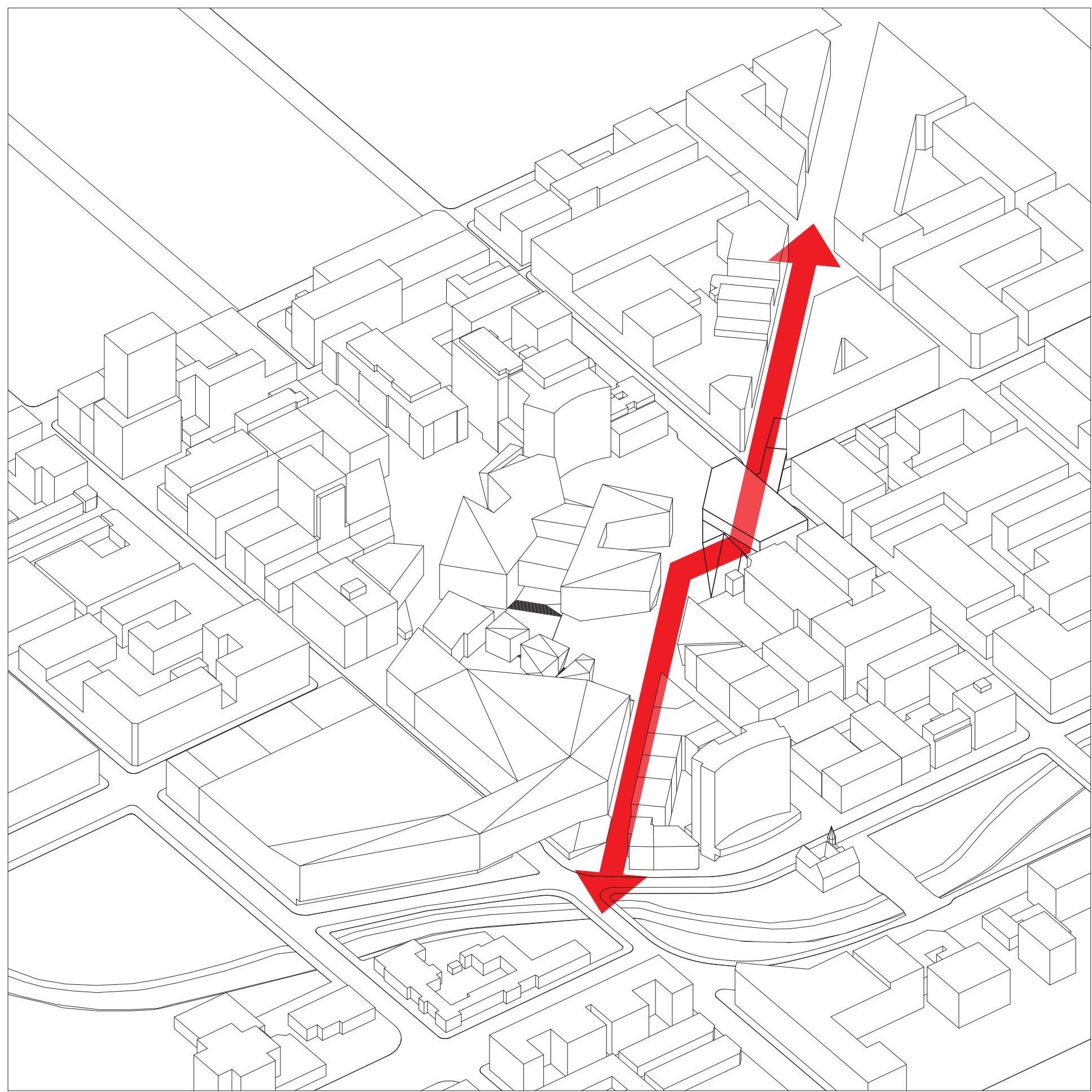

Figure 147.

Isometric view

looking south east

showing High Street

pedestrian path.

Extending the anomalous High Street through the square is the principal move in the formation of this scheme and creates an extended pedestrian path and dramatic main entry to the square from the south. 
Figure 148.

Isometric view

looking south east

showing public

transit.

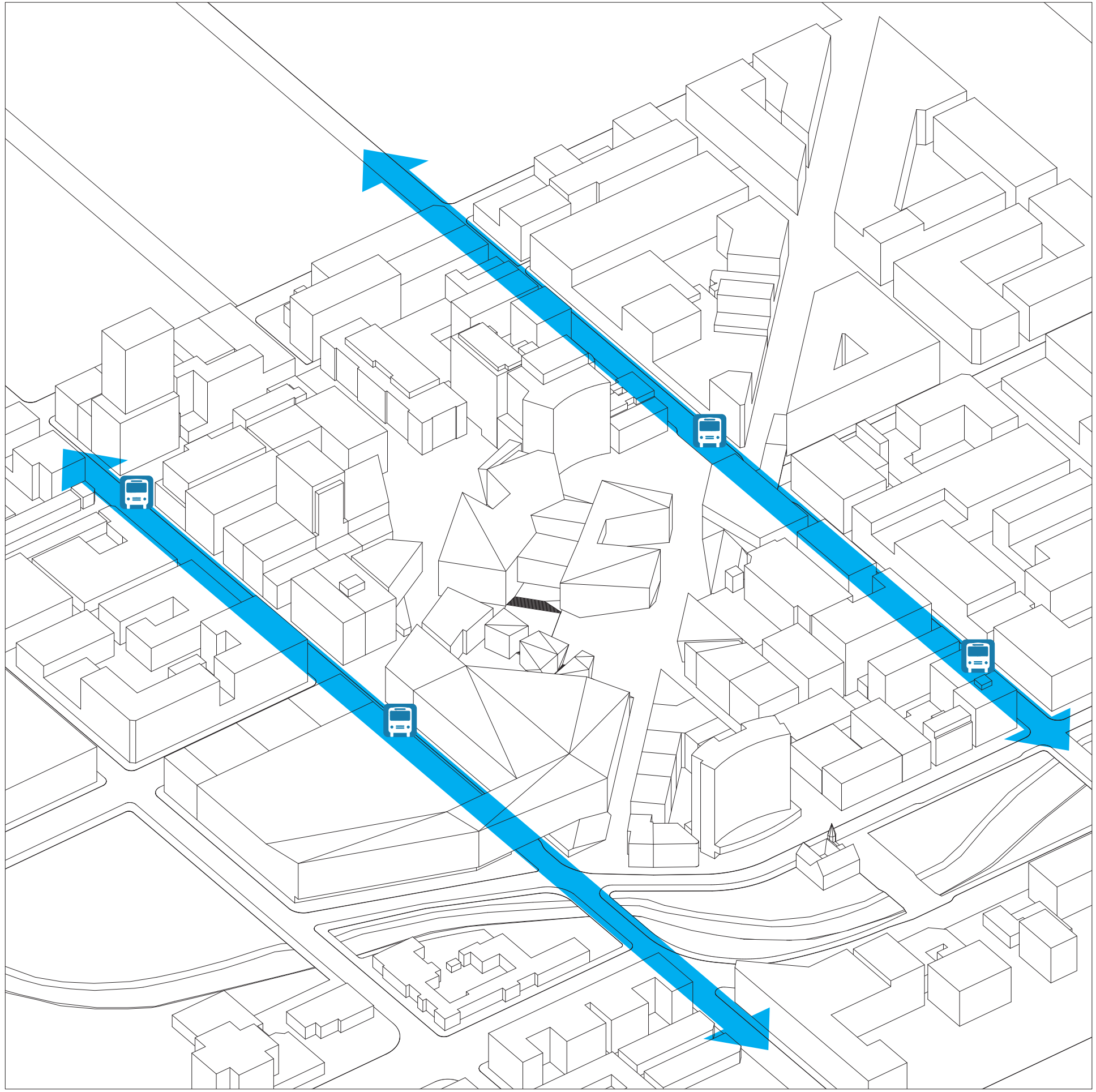

Public transit runs both north and south of the square with stops strategically located around the entries and exits to the square. 


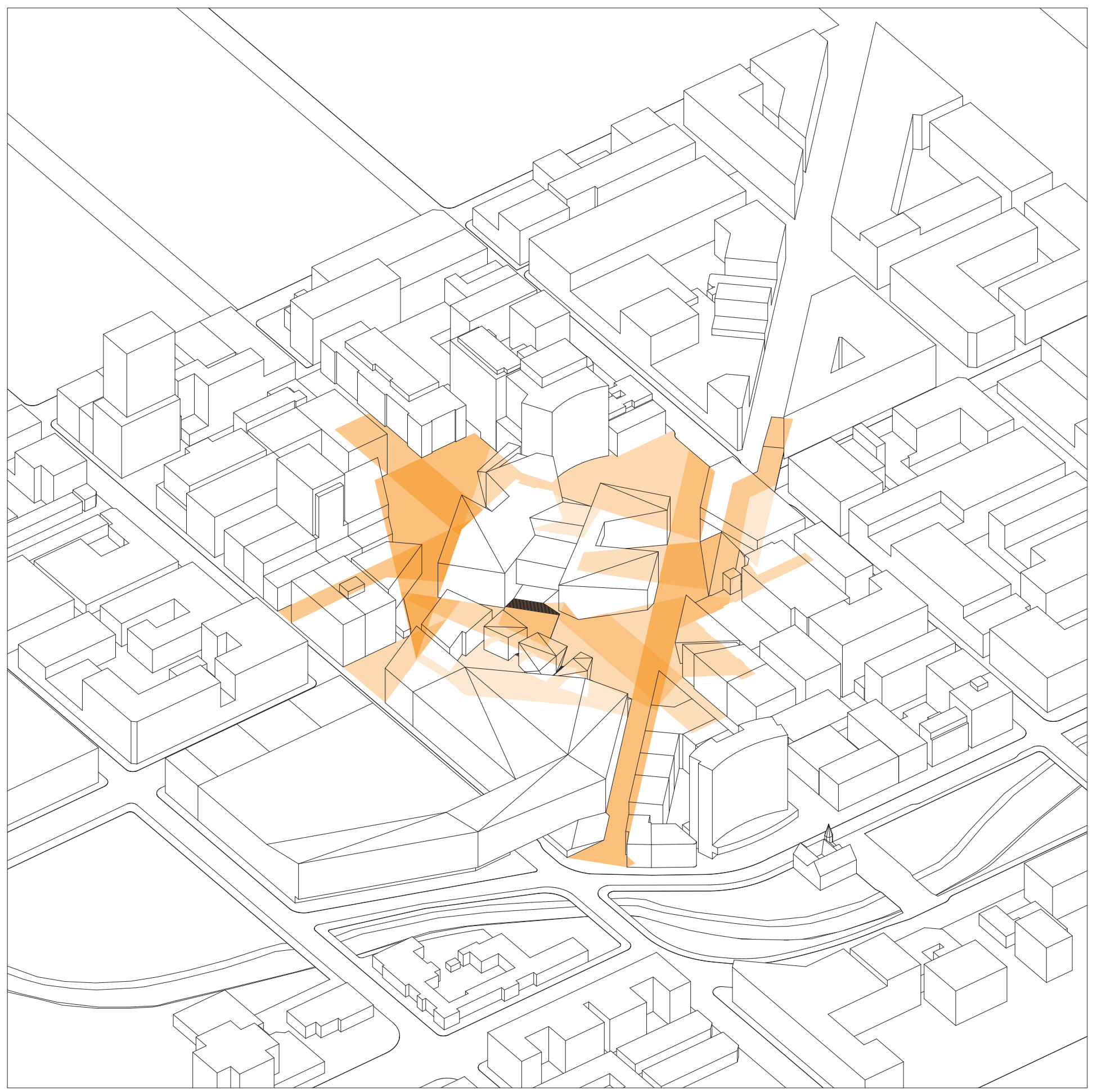

Figure 149.

Isometric view looking south east showing multiple spaces.

The square is made up of a variety of spaces of varying proportion, scale, associated use and degrees of enclosure. There is no clear hierarchical separation between the spaces.

190

Urban Trauma 
Figure 150.

Isometric view

looking south east

showing building

use.

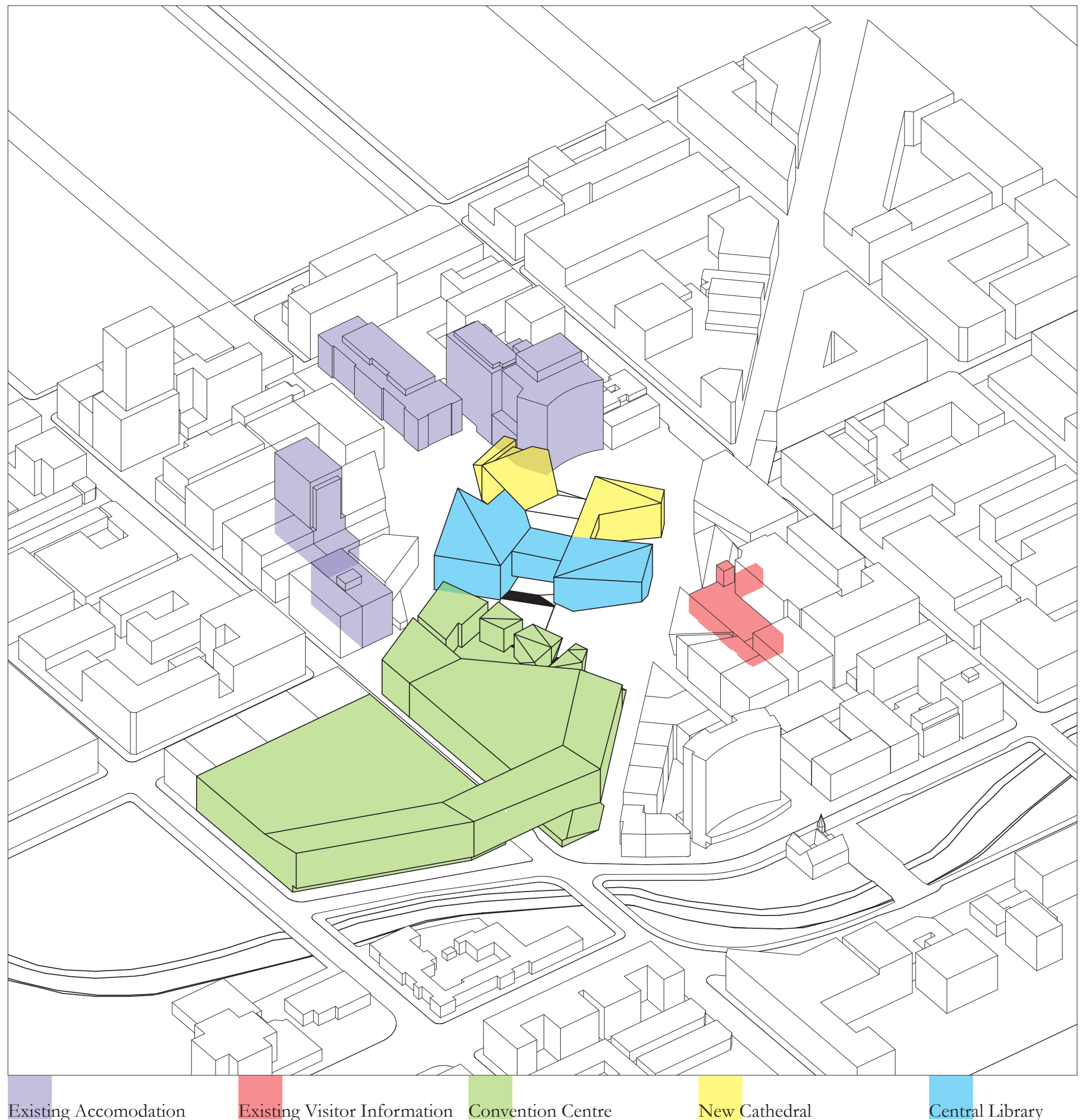

The Central Building Complex houses a New Central Library and Cathedral. This hybrid building intentionally upsets traditional assumptions about these institutions in favour of a more contemporary integration of building uses. 


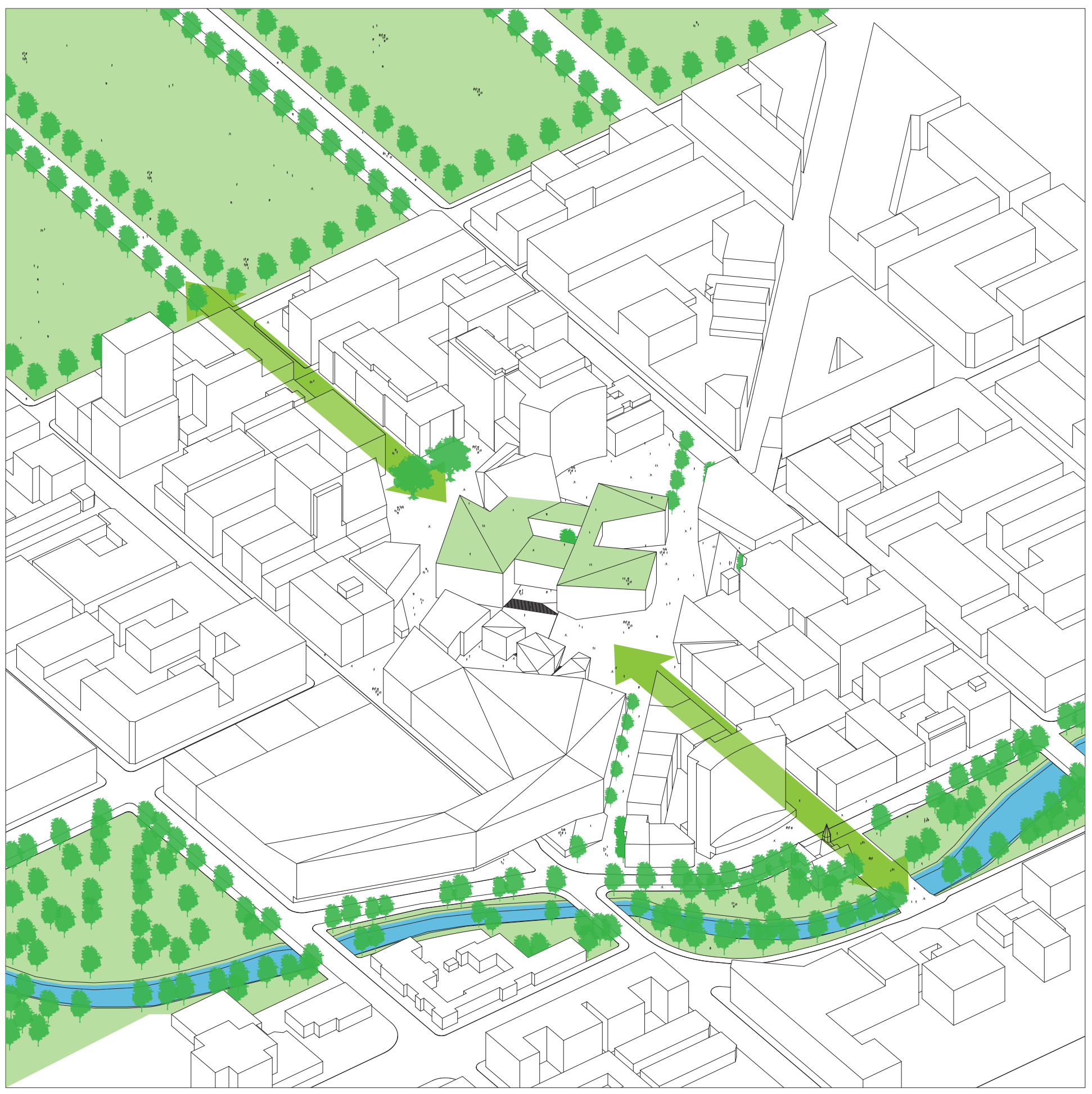

Figure 151.

Isometric view

looking south east

showing green

space.

Like the first two concepts this design seeks to strengthen connections with the Avon River and proposed Green Frame. The topological forms also integrate planted areas on the ramped and folded surfaces, the Library roof in particular. This vast area of park-like space, integrates greenery without compromising the squares identity as a hard landscaped space. 
Figure 152.

Isometric view

showing pedestrian and vehicular flows.

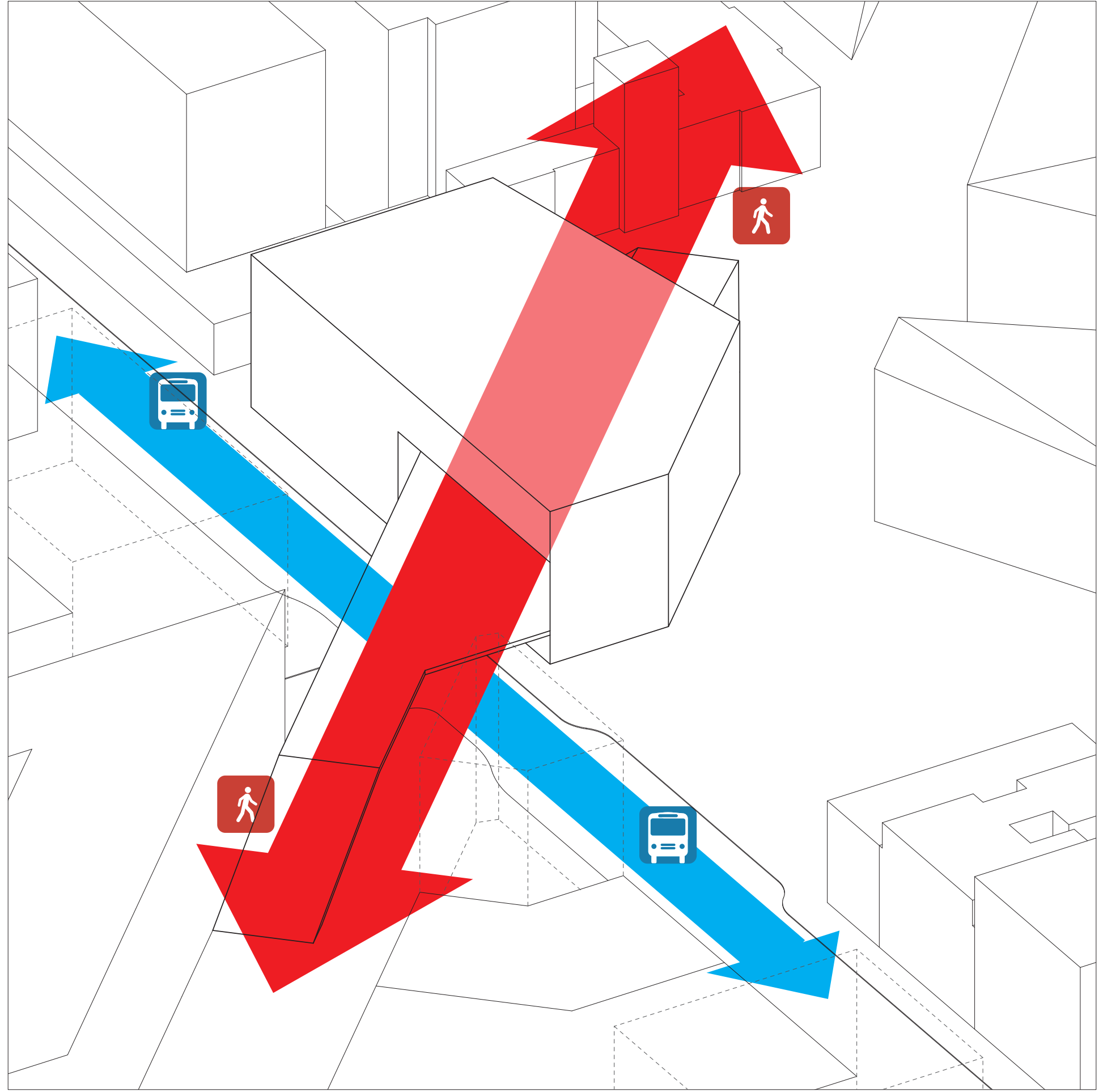

The continuity of High Street is preserved with a raised path through a mixed use building. A transit corridor below flows under this path, with bus stops along the edge of the South Square. 


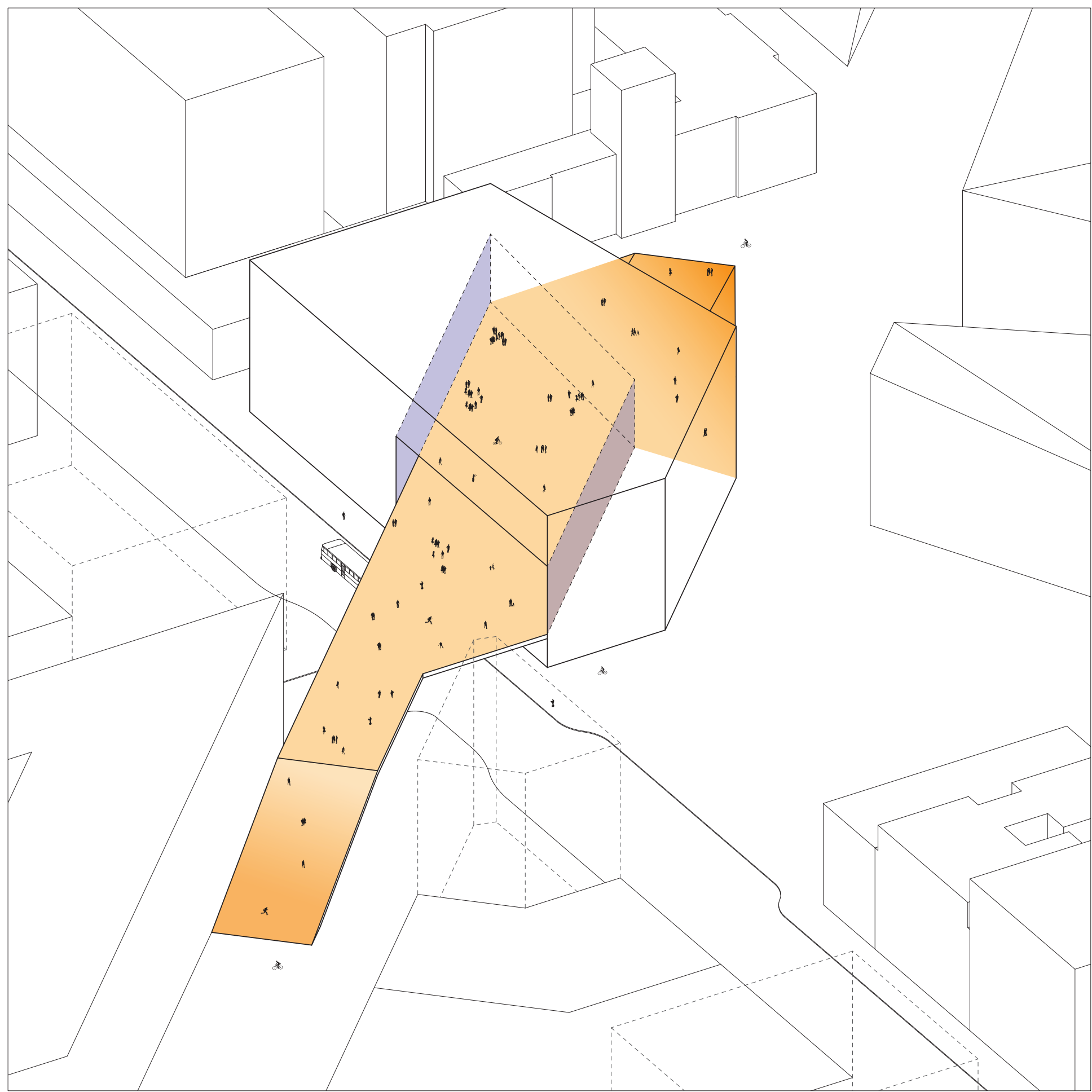

Figure 153.

Isometric view

showing porous

enclosure.

The raised path passes through a tunnel in a mixed use building - the main gateway from the south linking High Street with the square. Active edges add vitality and life to this arresting main entrance to the square. 
Figure 154.

Isometric view

showing South

Square enclosure.

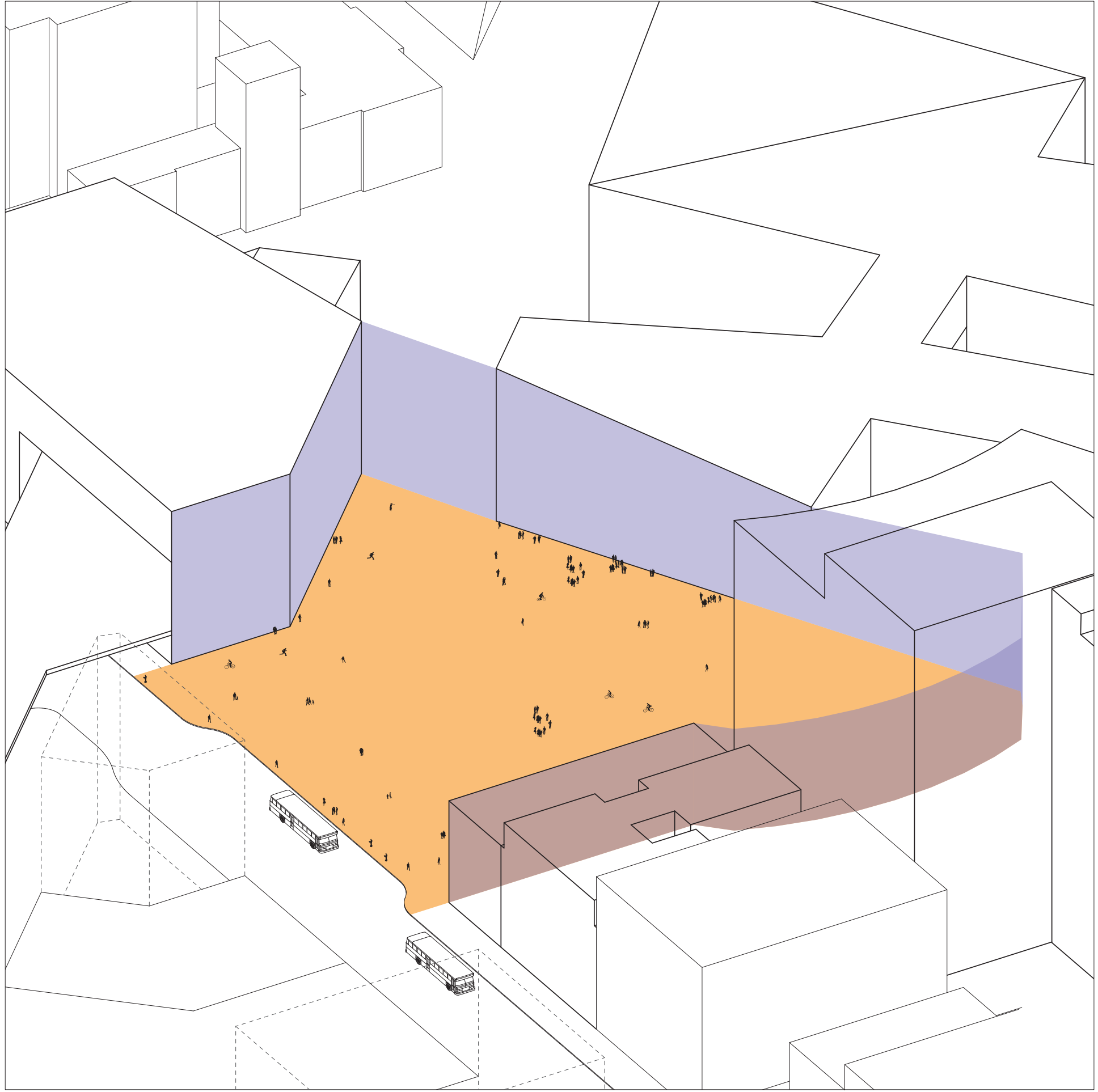

The South Square opens out onto the Hereford Street transit corridor. Busses stop along this edge of the square integrating public transport and vehicular accessibility to the square. 


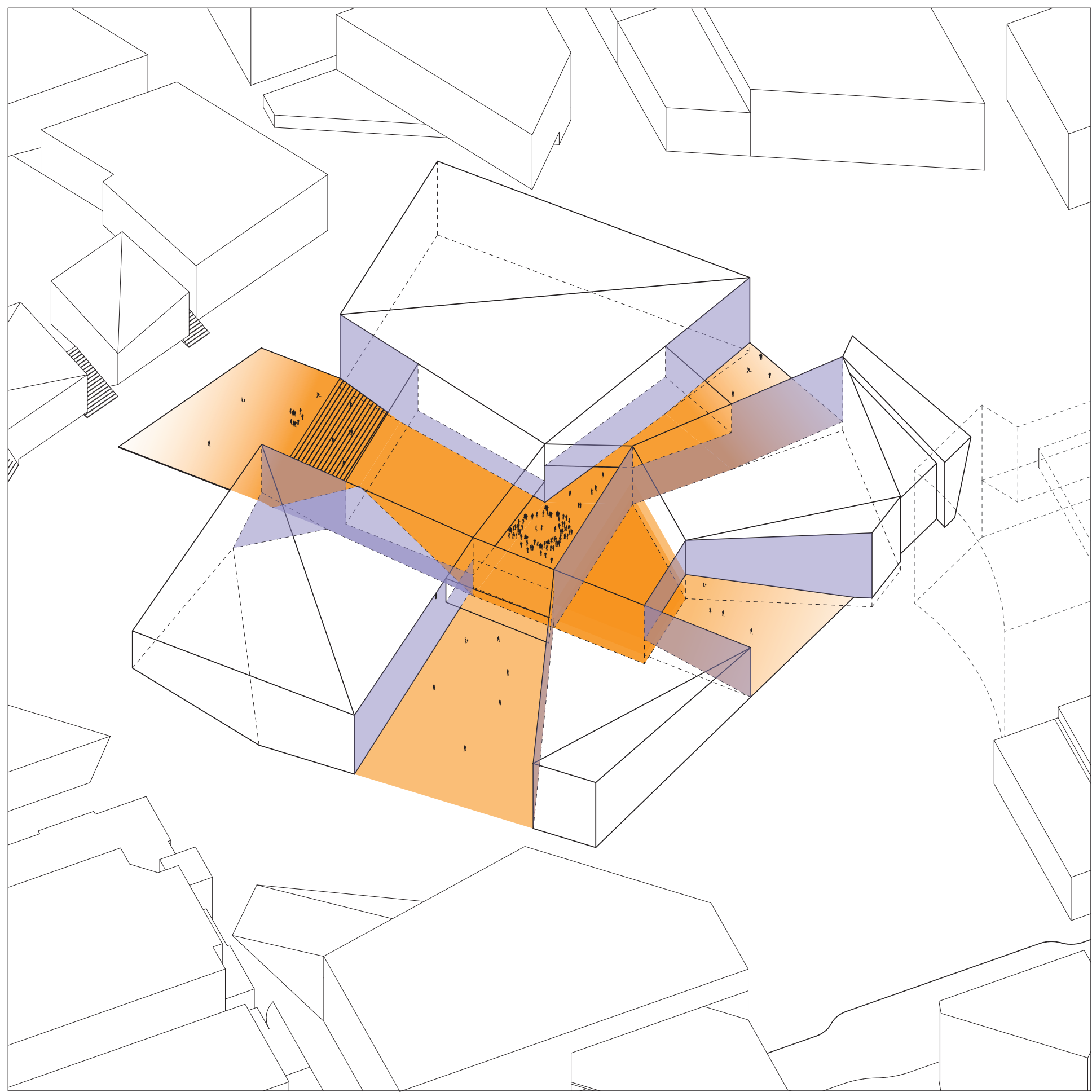

Figure 155.

Isometric view

showing porosity of

the Central Building Complex.

Four 'cuts' into the Central Building Complex allow for a high level of permeability through this structure. Three surfaces fold down into a subterranean space that all meet under an open air atrium. Next to this is a vertical circulation block that the fourth path ramps up into. These folded surfaces create a continuity of public space that flows into and through this principal building in the square. 
Figure 156. Isometric view showing pedestrian flows.

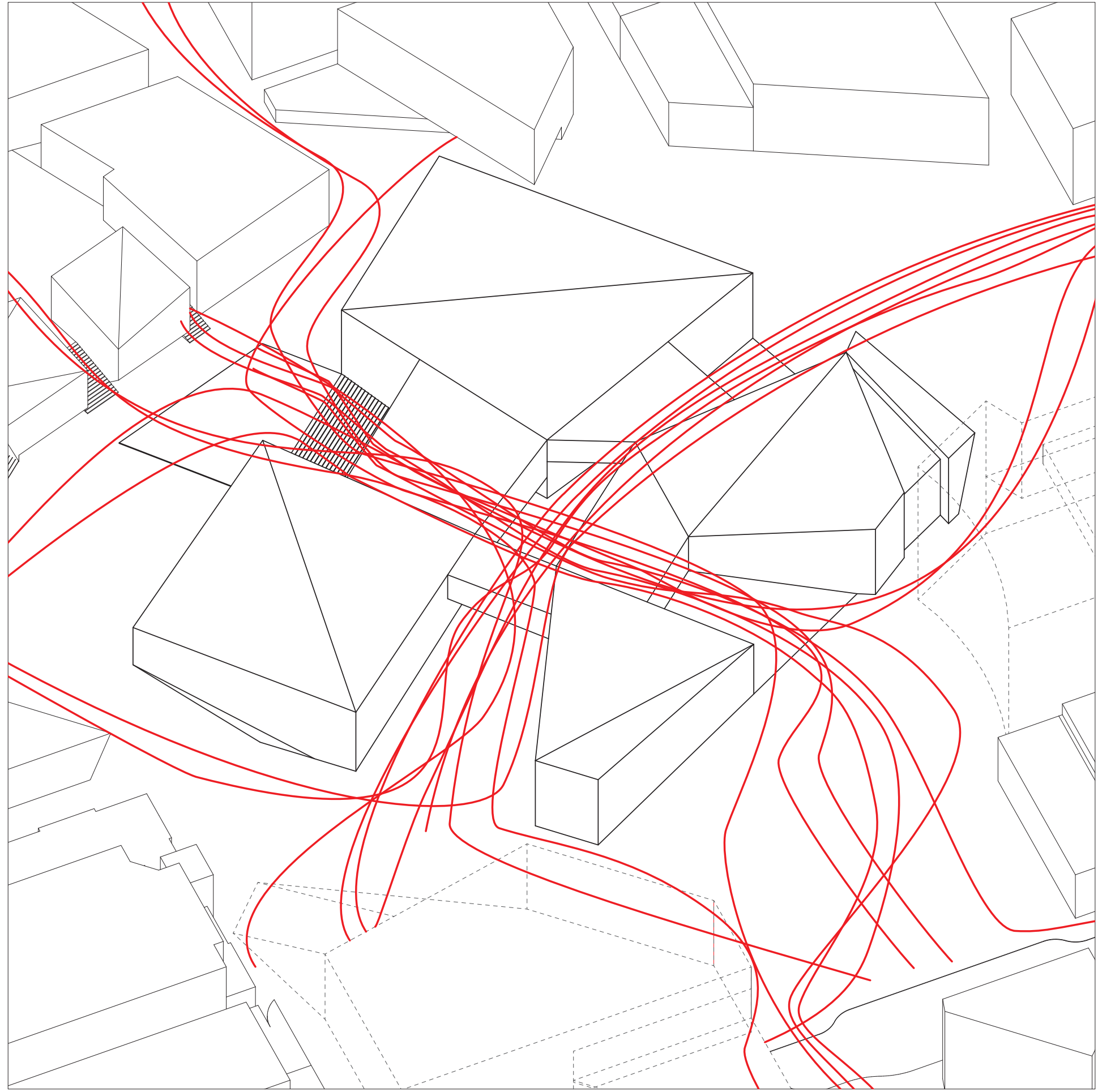

The porous Central Building Complex mean that there is a high level of connectivity between the surrounding open public spaces. Four access points converge in a open air atrium alongside an indoor circulation block where a network of escalators, elevators stairs and ramps create a sort of departure space where one can get anywhere within the building complex. 


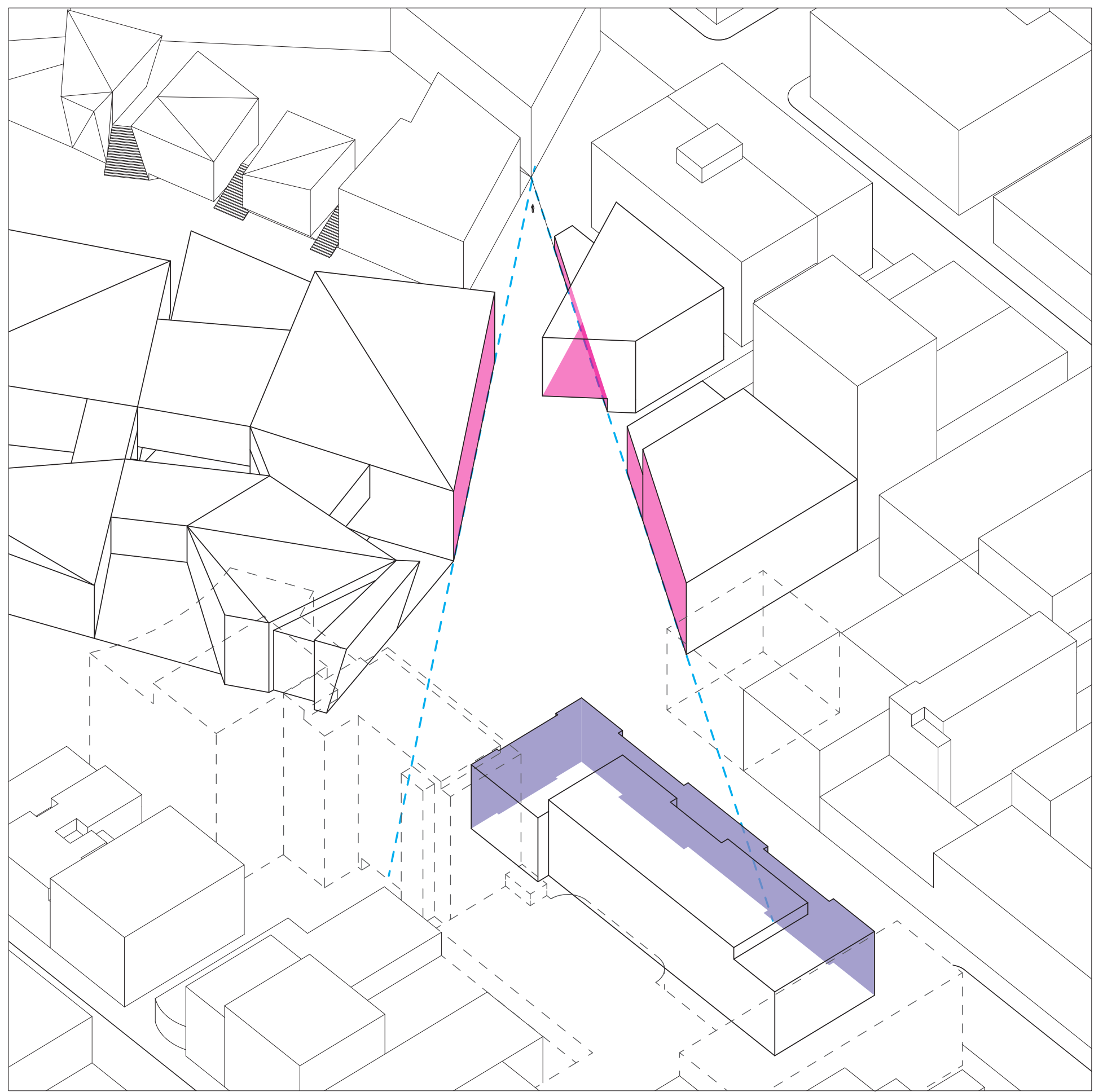

Figure 157.

Isometric view

showing terminal

view of OGB.

The eastern space of OGB Square is formed based off of an oblique approach angle to the Historic Old Government Building. The faces of the enclosing buildings are composed and shaped around this view and approach from the northern entrance. 
Figure 158

Isometric view

showing OGB

Square enclosure.

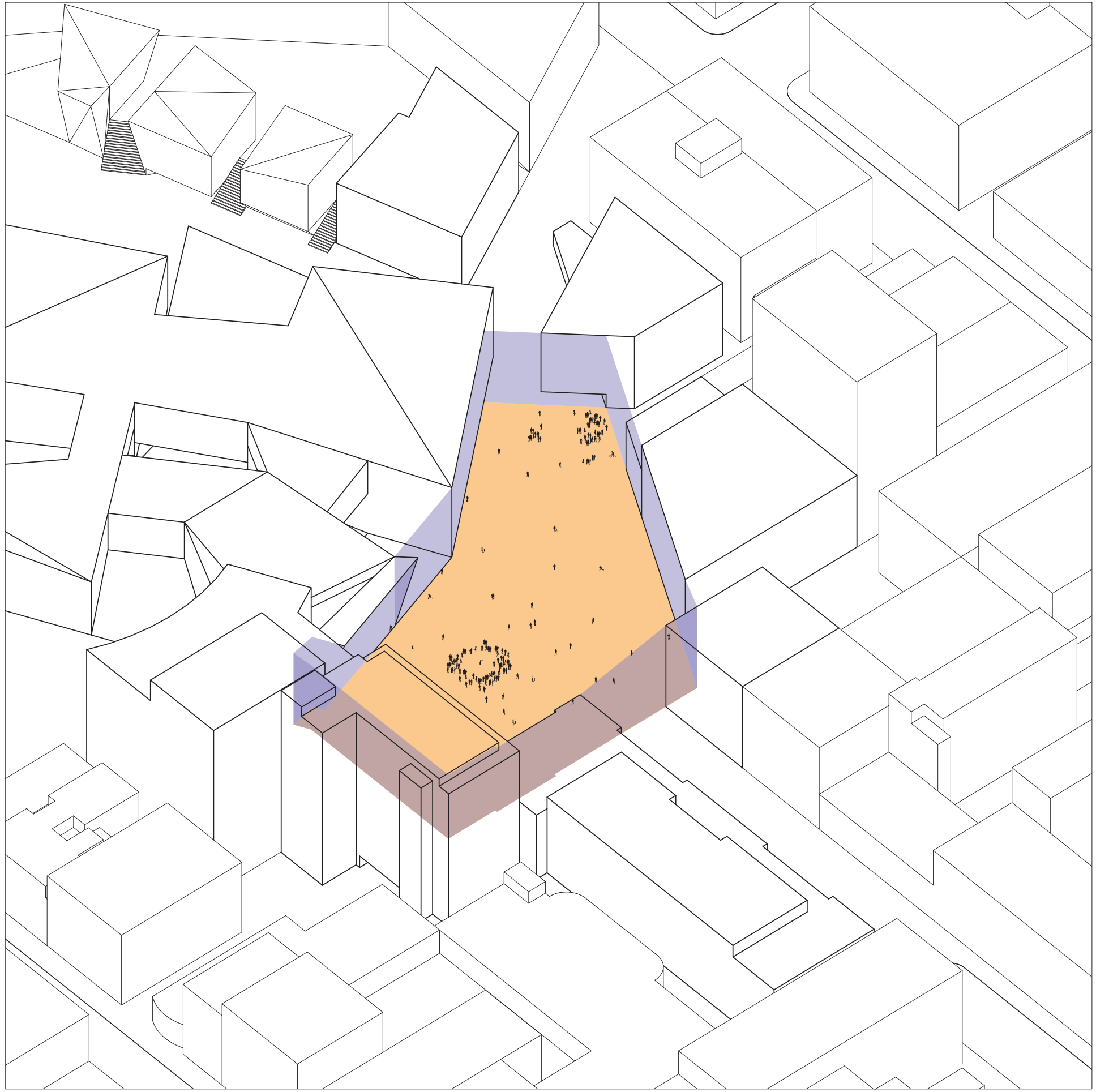

The buildings are also composed to retain a certain level of continuity in the roof lines enclosing the space. The heights of the new buildings are sensitive to the proportion open space with shorter buildings either side of the space and the taller existing tower facing down the longer length of the space. 


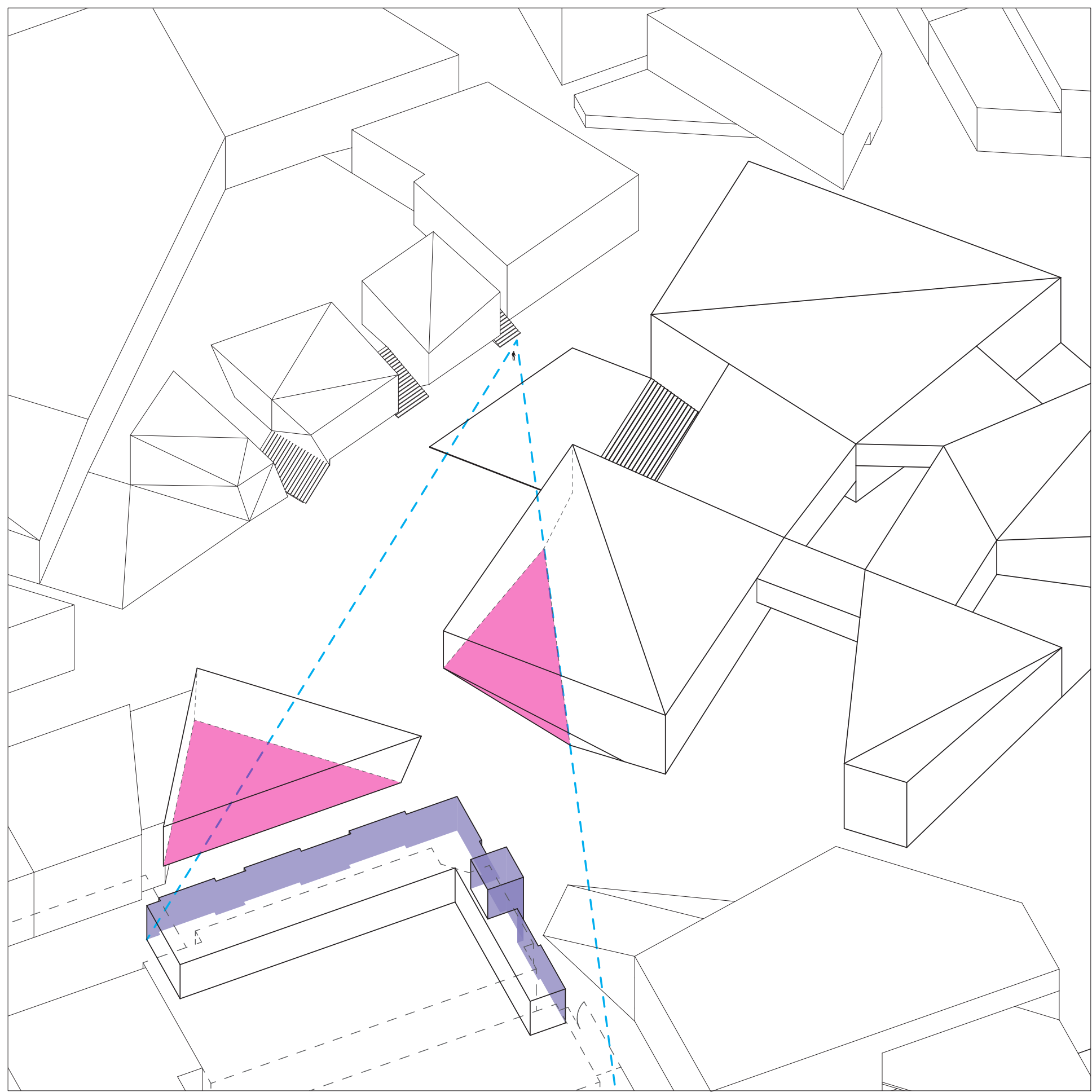

Figure 159.

Isometric view

showing terminal

view of $\mathrm{CPO}$

building.

Similar to OGB Square, the North Square between the Convention Centre and Library is composed based on oblique approach and view angles of the Chief Post Office building. The corner of the Library has been folded under to gradually reveal more of the historic facade from the square. Another building has been raised on 'pilotis' in order to preserve the view of the facade and the continuity of open space at ground level. 
Figure 160.

Isometric view

showing North

Square enclosure.

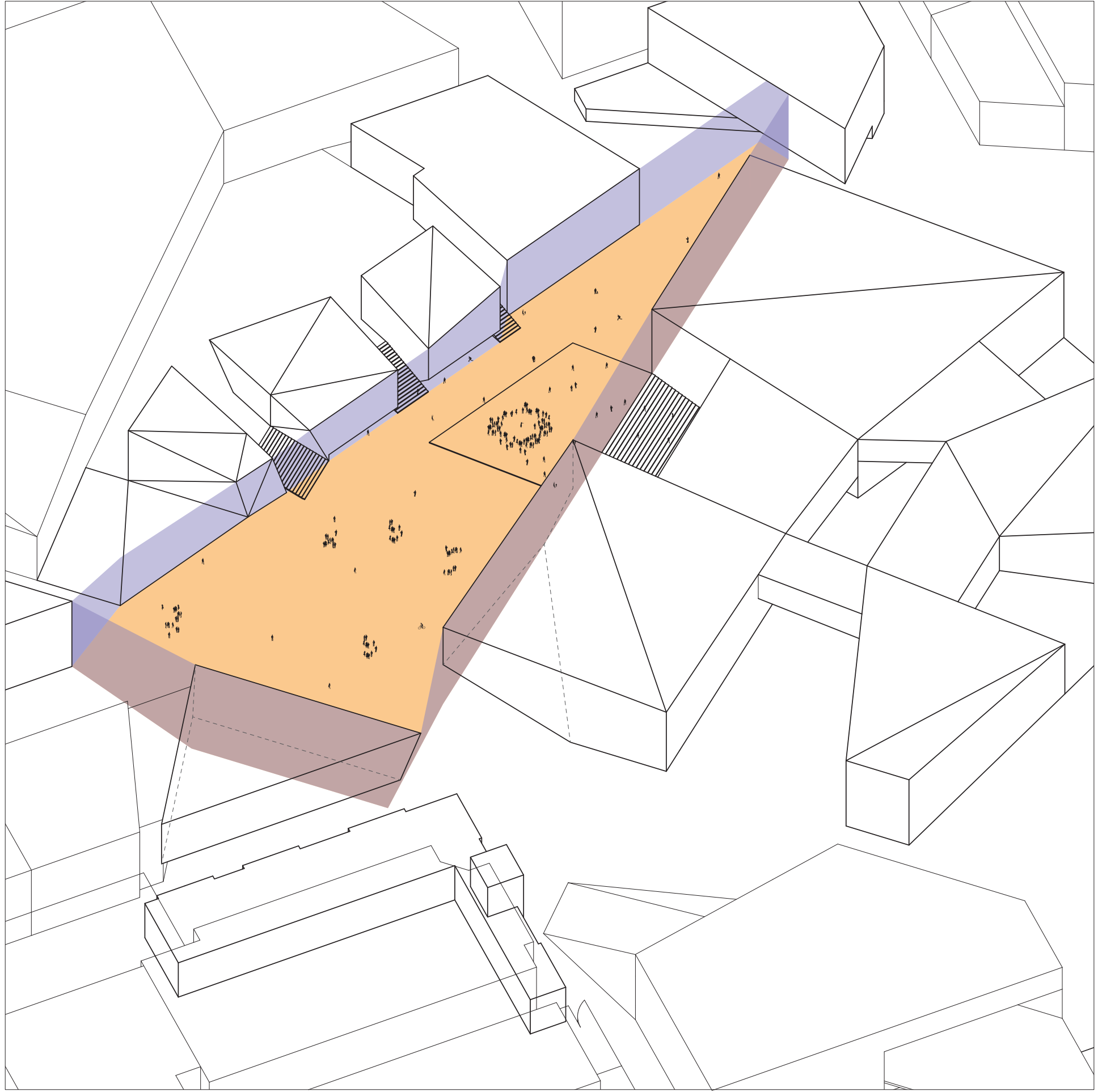

Enclosure of open space has been retained with a continuity of building height lines and raised facades. These porous structures retain physical and visual permeability at ground level while enclosing this open space. The freedom to manipulate these structures also means the can be morphed to a scale sensitive to the human inhabitants. 


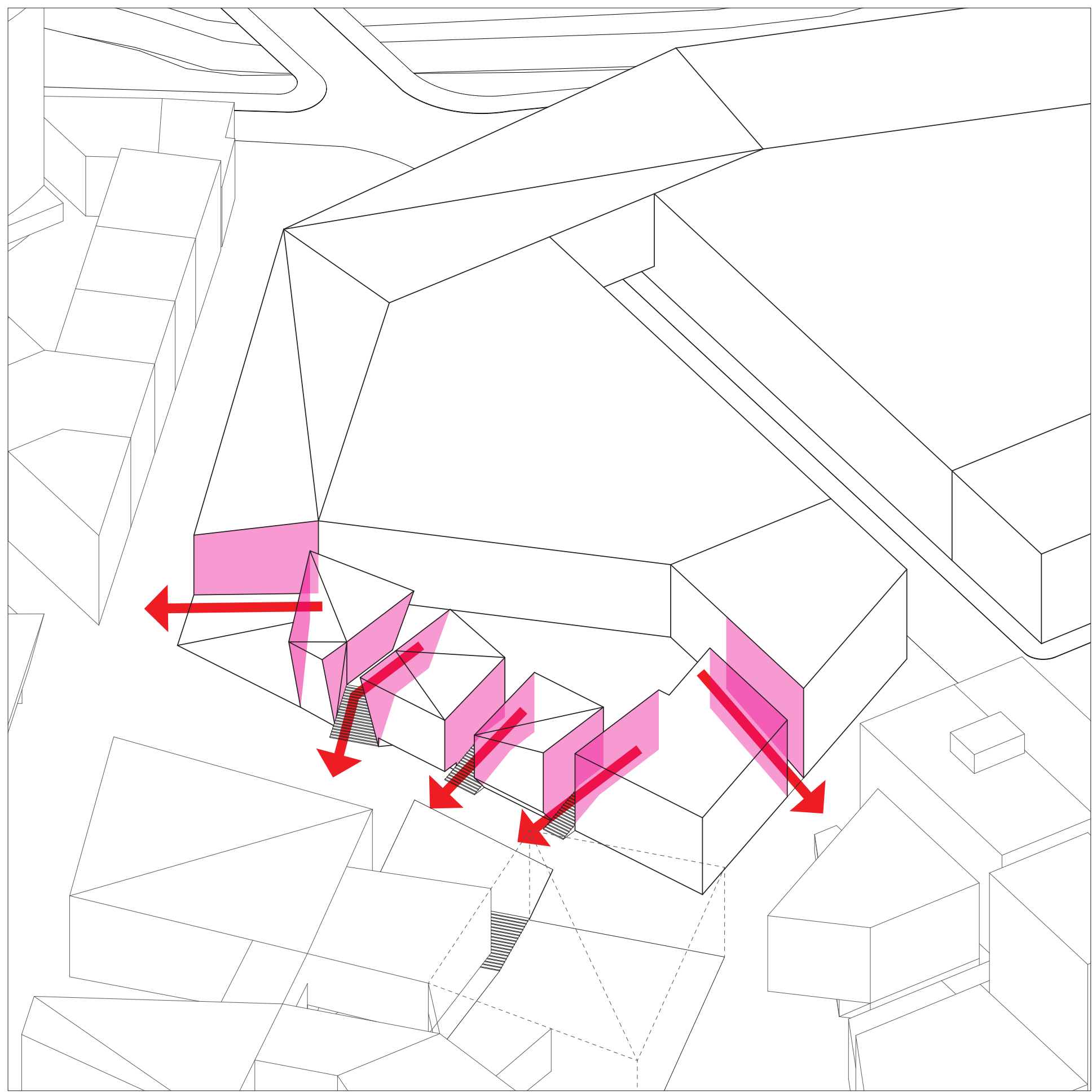

Figure 161.

Isometric view

showing porosity

of the Convention

Centre pavilions.

The Convention Centre fronts onto the North Square opposite the new Central Library. A series of porous pavilions have been manipulated to integrate the large scale Convention Centre complex with the square. Several paths retain a high level of connectivity to the Convention Centre. 
Figure 162. Isometric view showing Convention Centre Square enclosure.

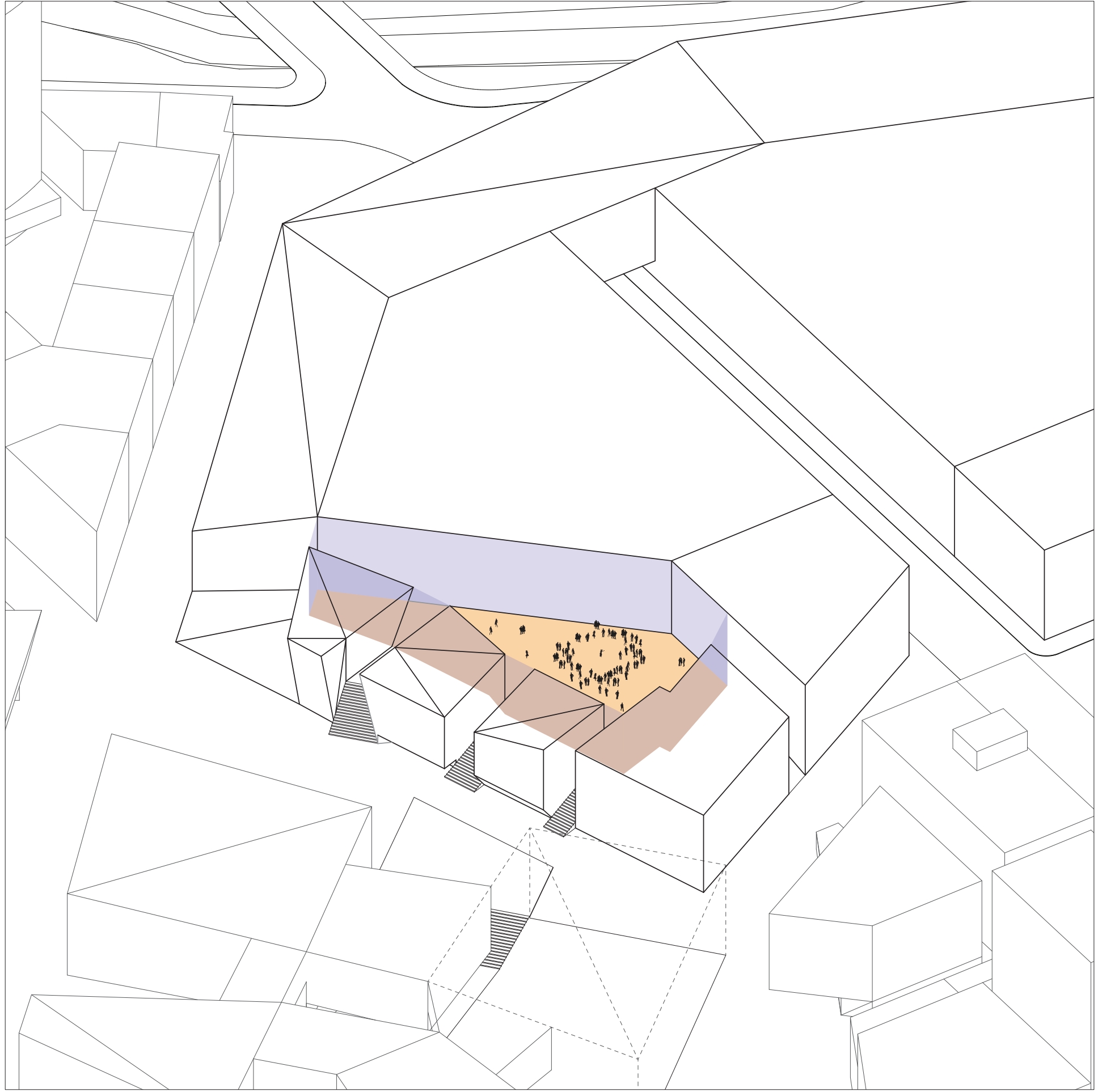

The pavilions also create a smaller space behind that is strongly associated to the Convention Centre. This spooling area can be thought of as a public atrium or pre-function space, for Convention Centre activities. 


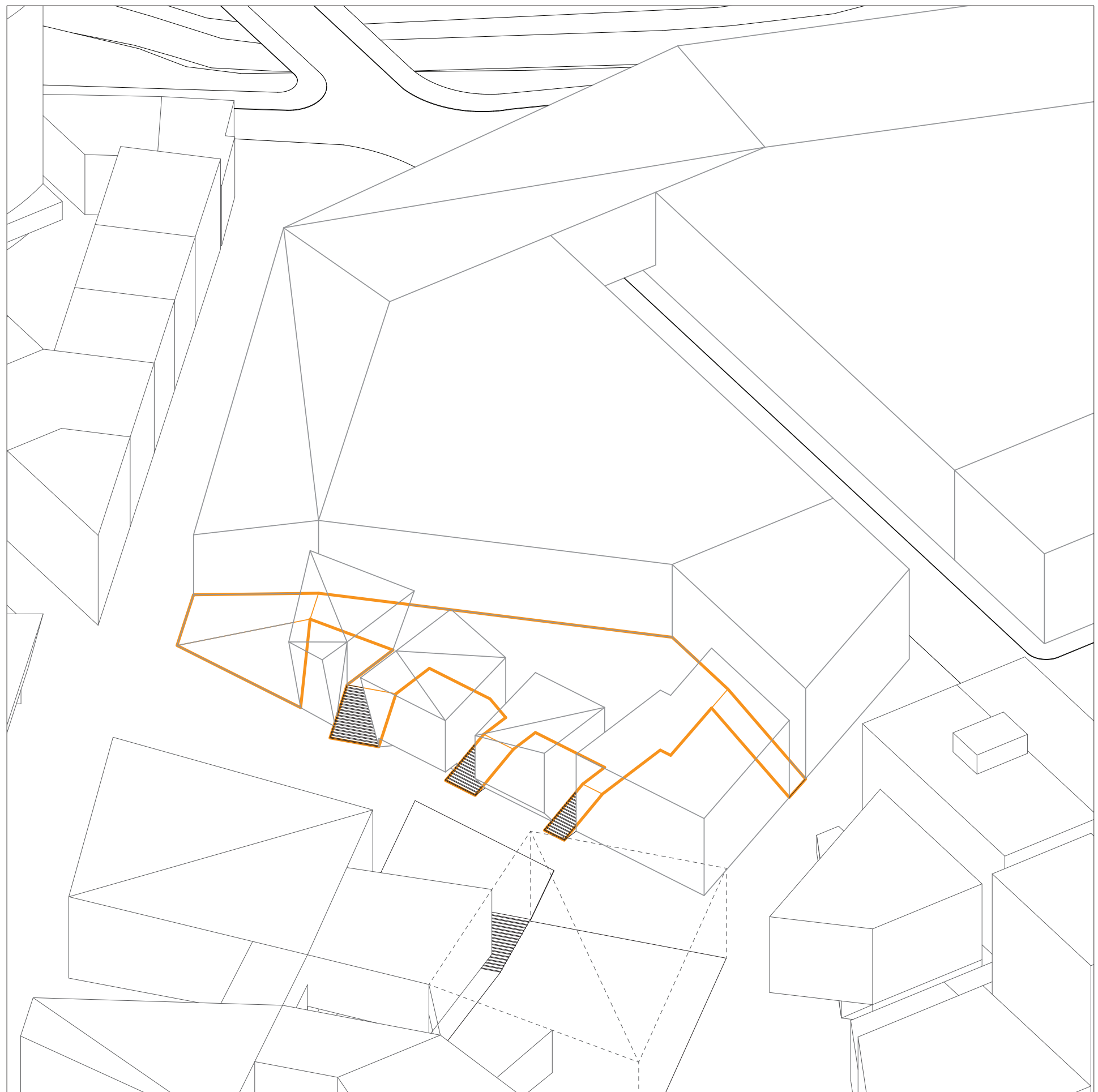

Figure 163.

Isometric view

showing raised floor

of the Convention

Centre Square.

This space is also raised one level to help enclose the North Square create a concealed space below to integrate the more intrusive activities associated with the Convention Centre, serves, car parking, etc. 
Figure 164.

Isometric view

showing sub-floor

parking and inte-

grated public transit path.

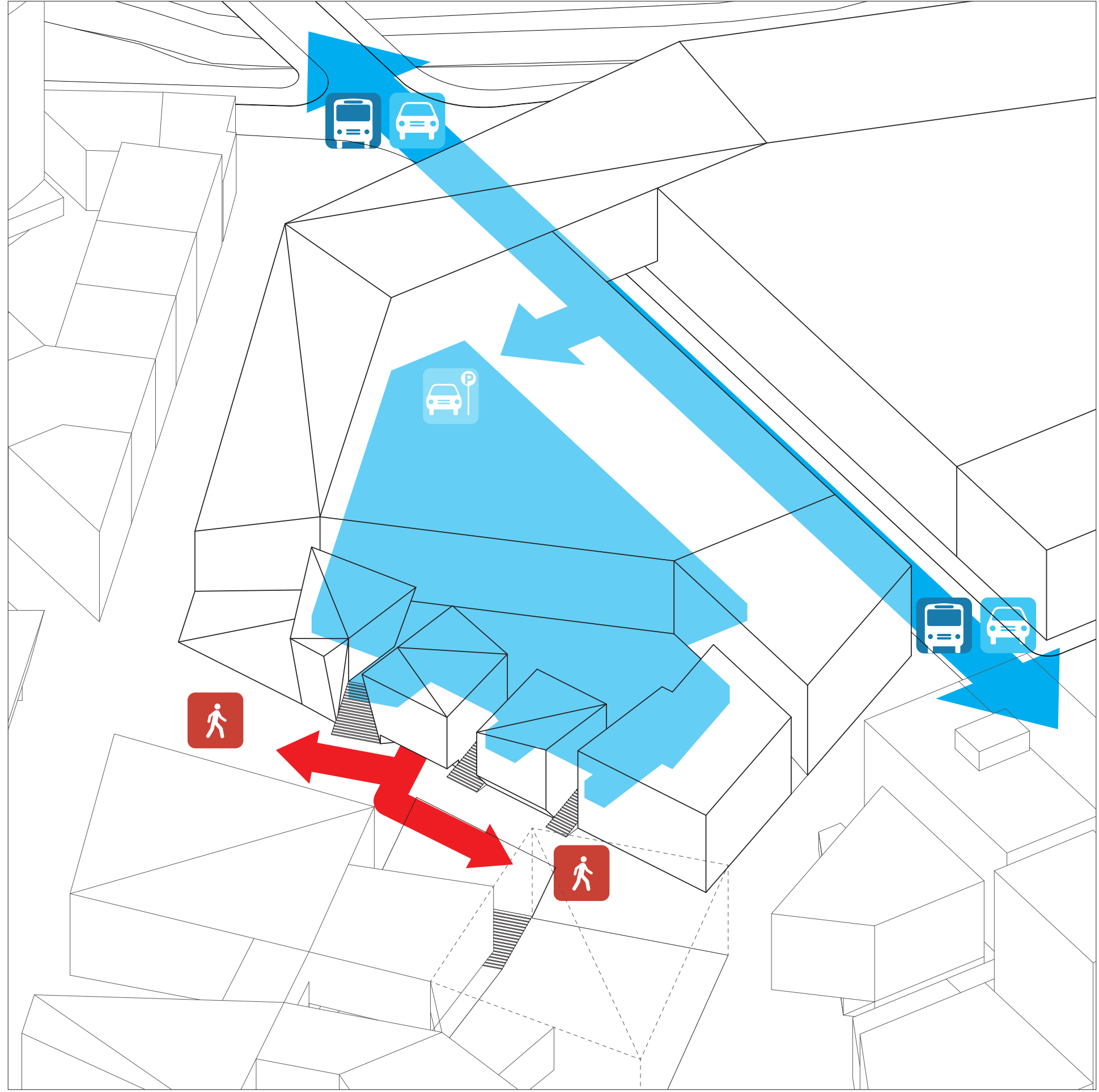

The concealed space below the raised Convention Centre integrates a subterranean car park, with access from Gloucester Street. The pavilions then become a gateway from this carpark to the pedestrianised square. 


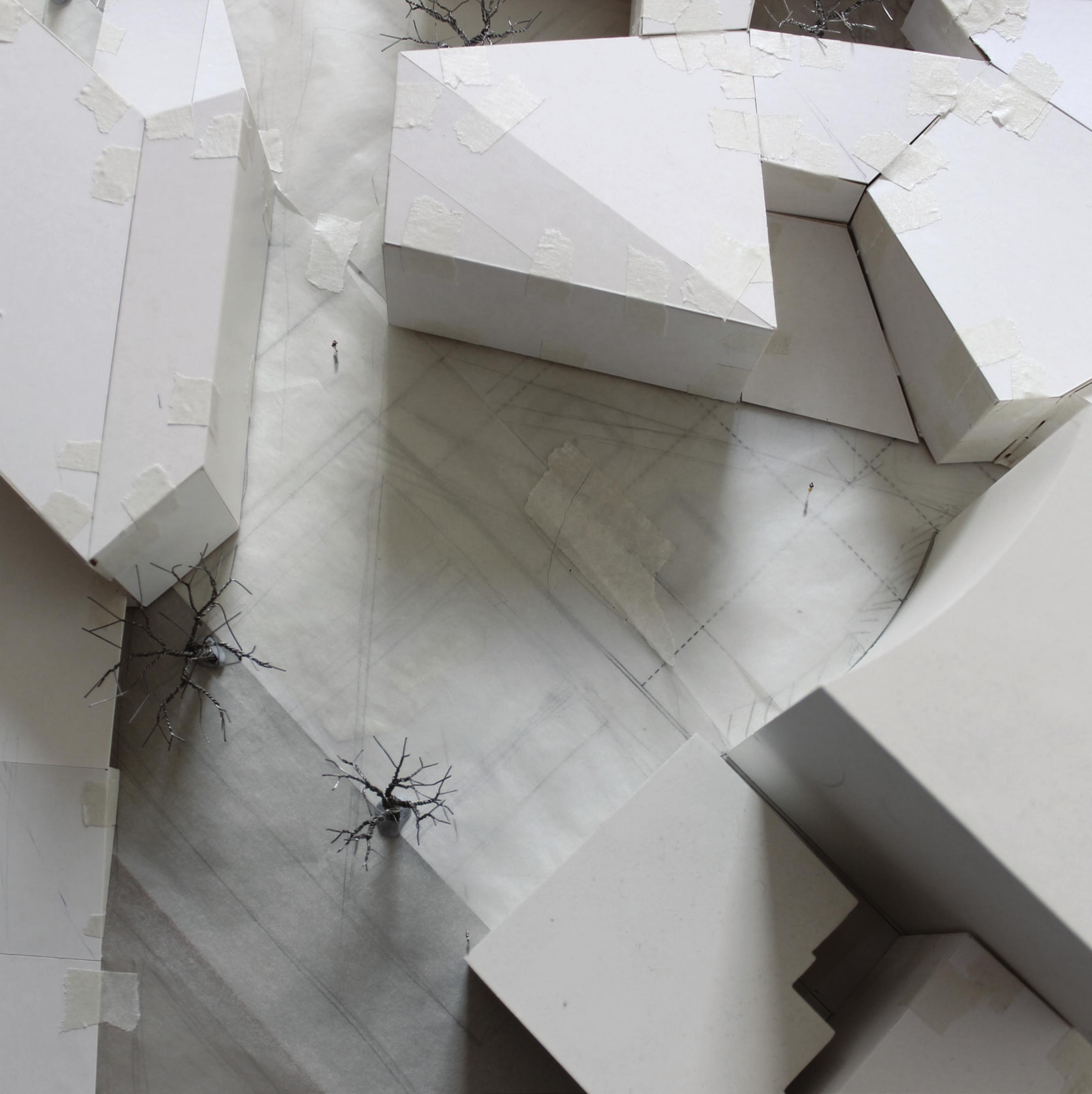


Figure 165 (opposite page)

Aerial view of

South Square.

Figure 166. View looking due north into the South

Square.

Figure 167. View through High Street bridge building

showing the partial views of the $\mathrm{CPO}$

building.
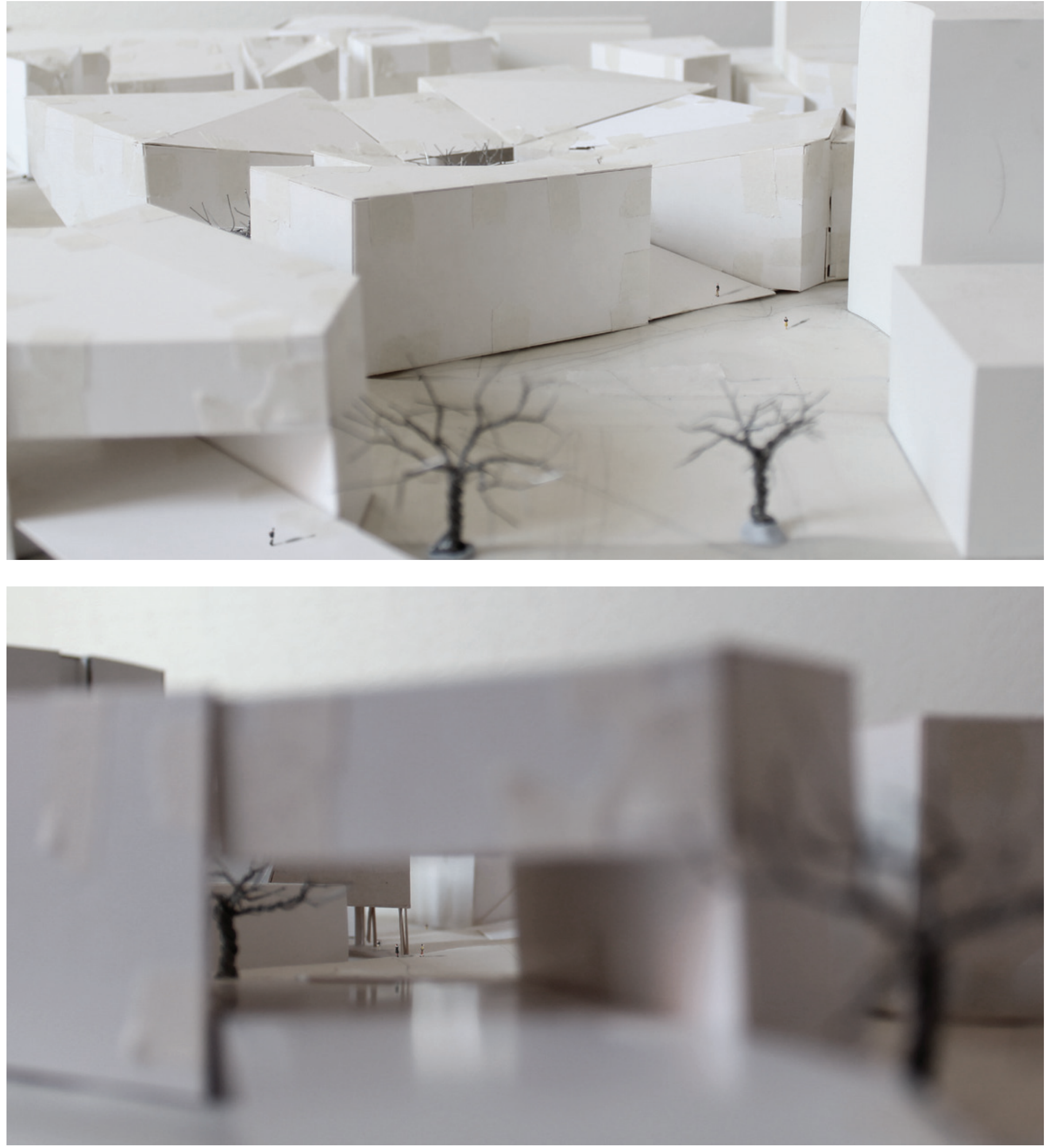


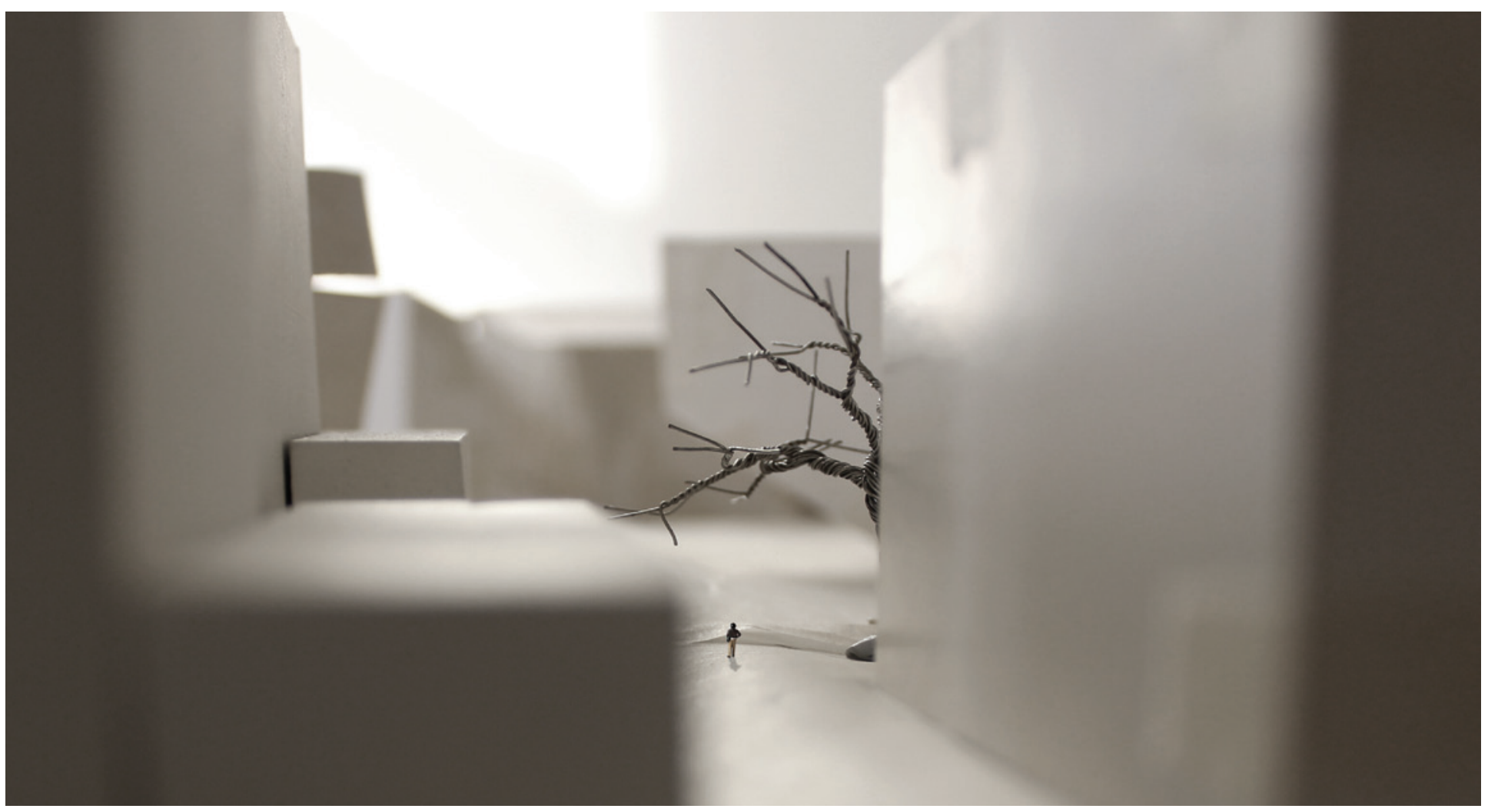

Figure 168. View down Strand Lane.

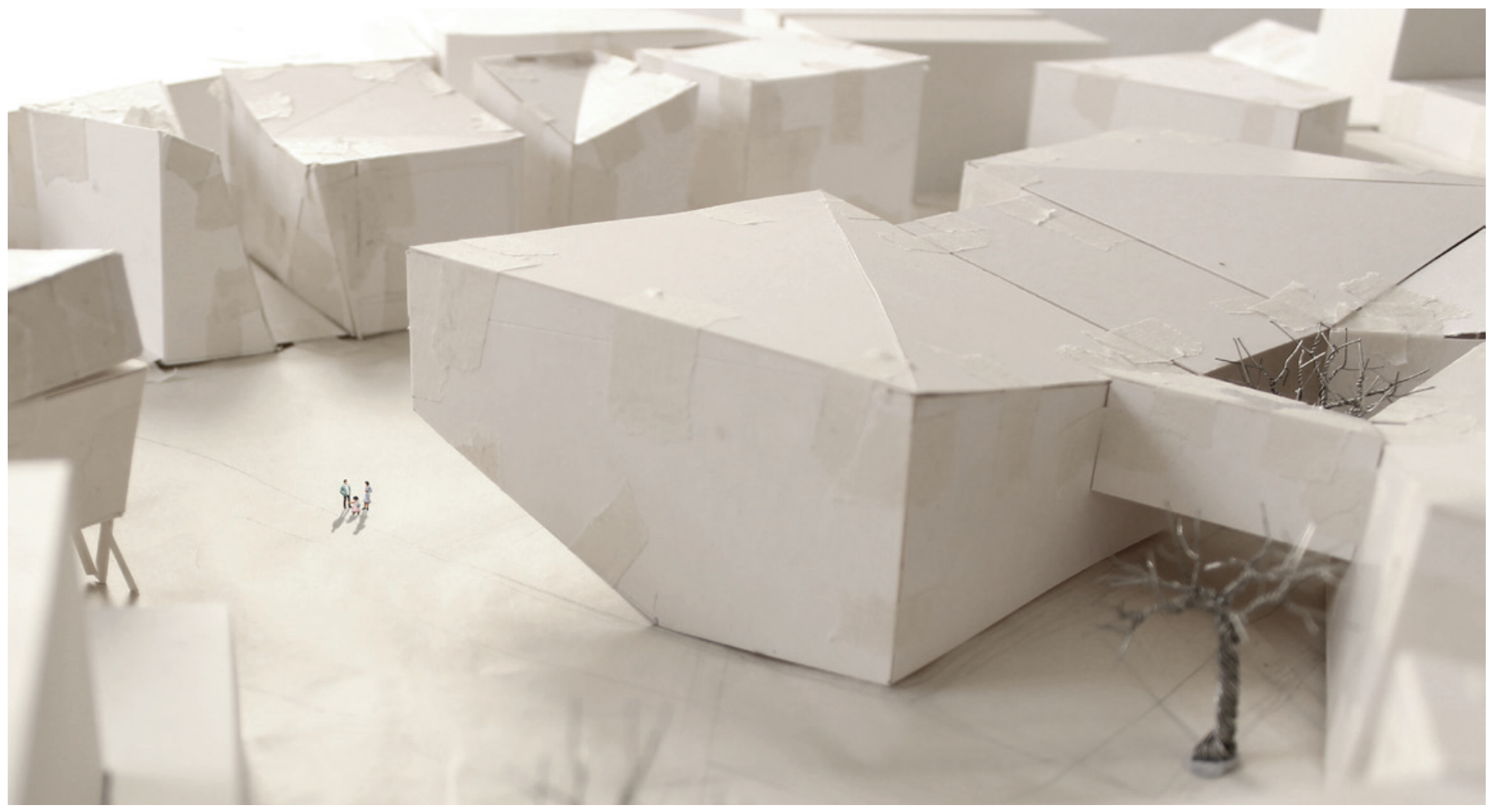

Figure 169. View looking north showing the library quarter of the central complex and the Convention Centre pavilions behind.

Figure 170. (opposite page)

Aerial view of the western entrance to the central complex. 


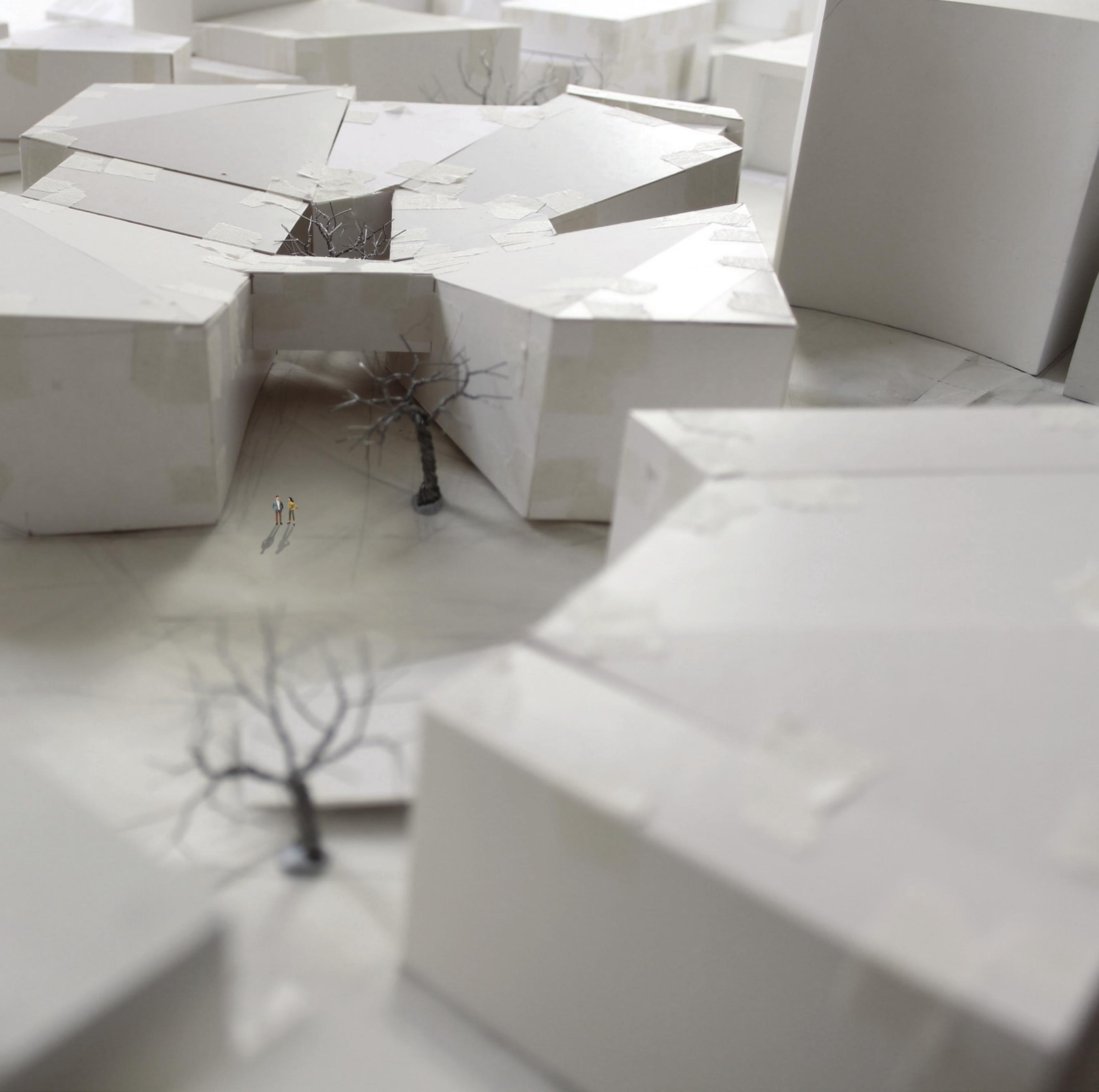




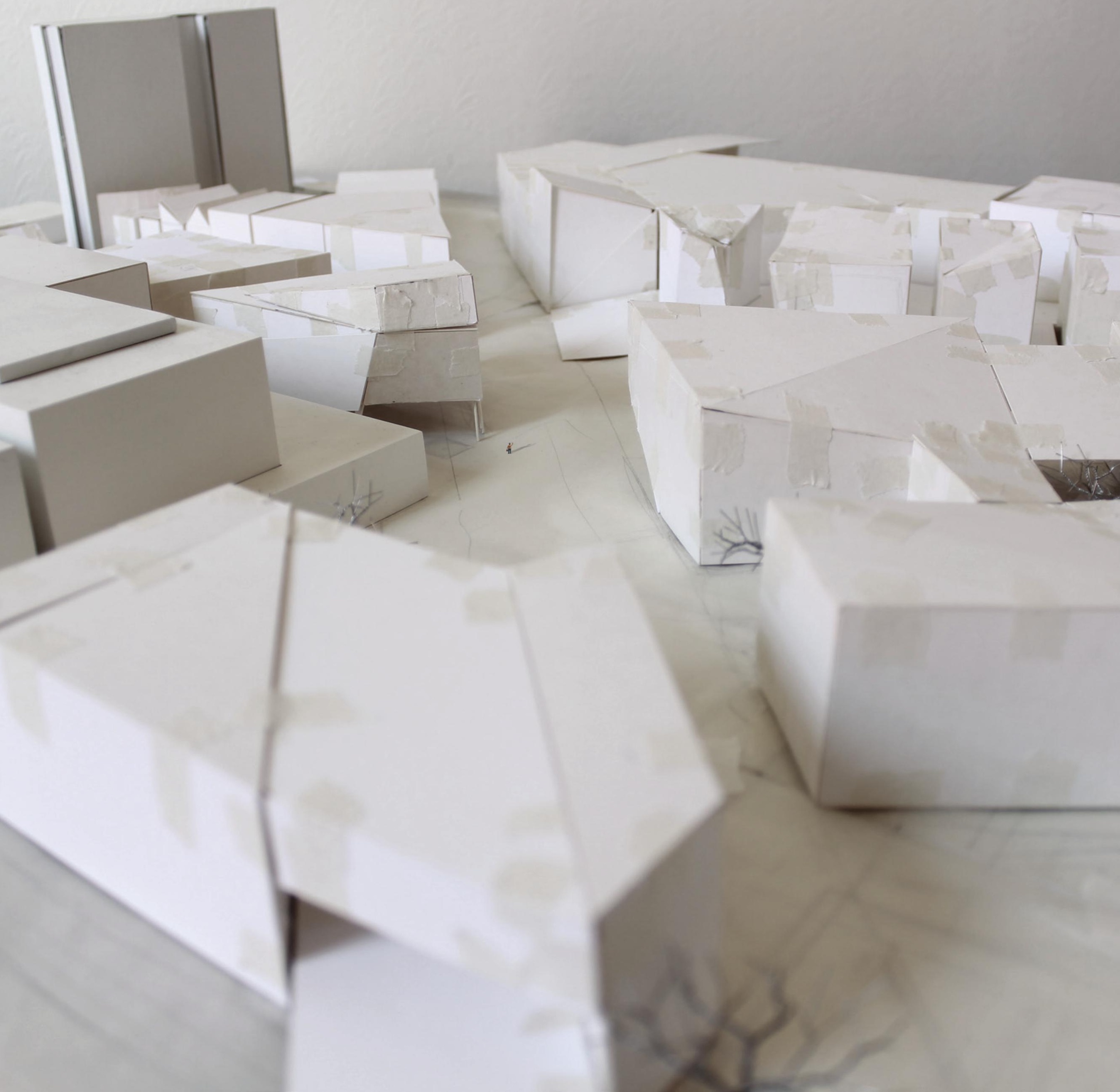


Figure 171 .

(opposite page)

View looking north-

ward of the High

Street extension.

Figure 172. View

looking eastward

across the square of

the Central Building

Complex.

Figure 173. View of library quarter from Worcester

Boulevard.
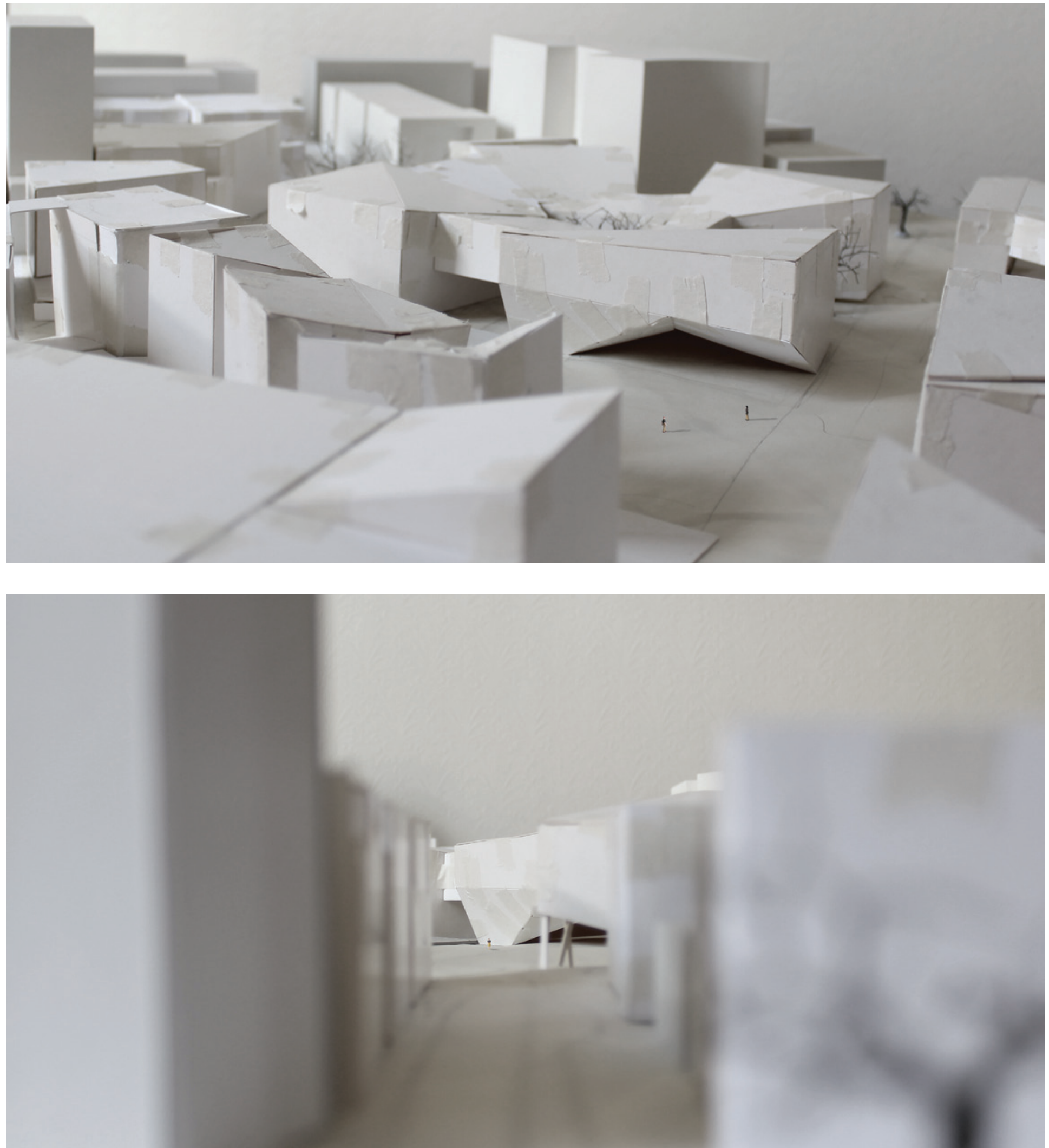


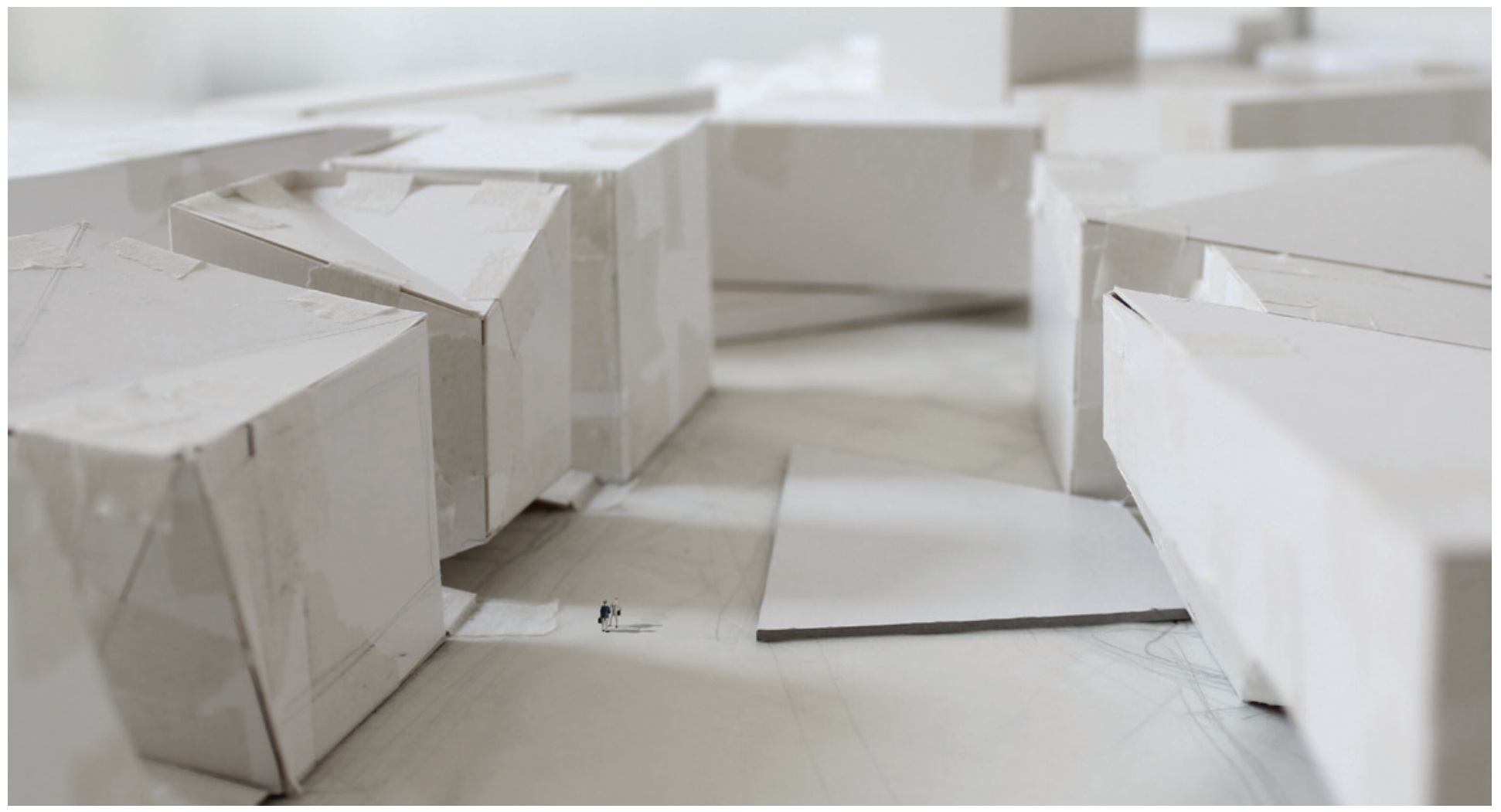

Figure 174. View into North Square, to the right the new

Library, to the left Convention Centre pavilions.

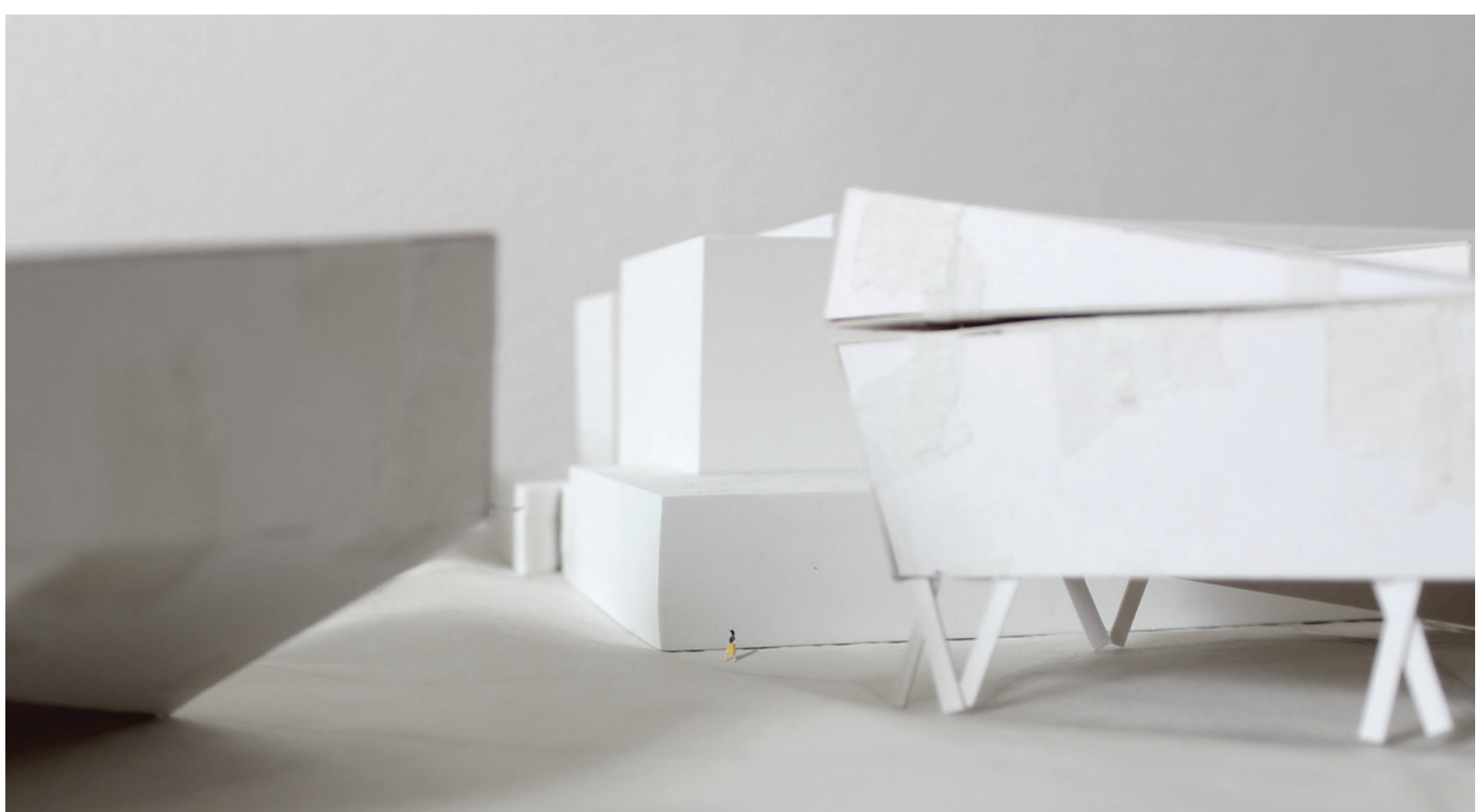

Figure 175. View of CPO building inside North Square. 


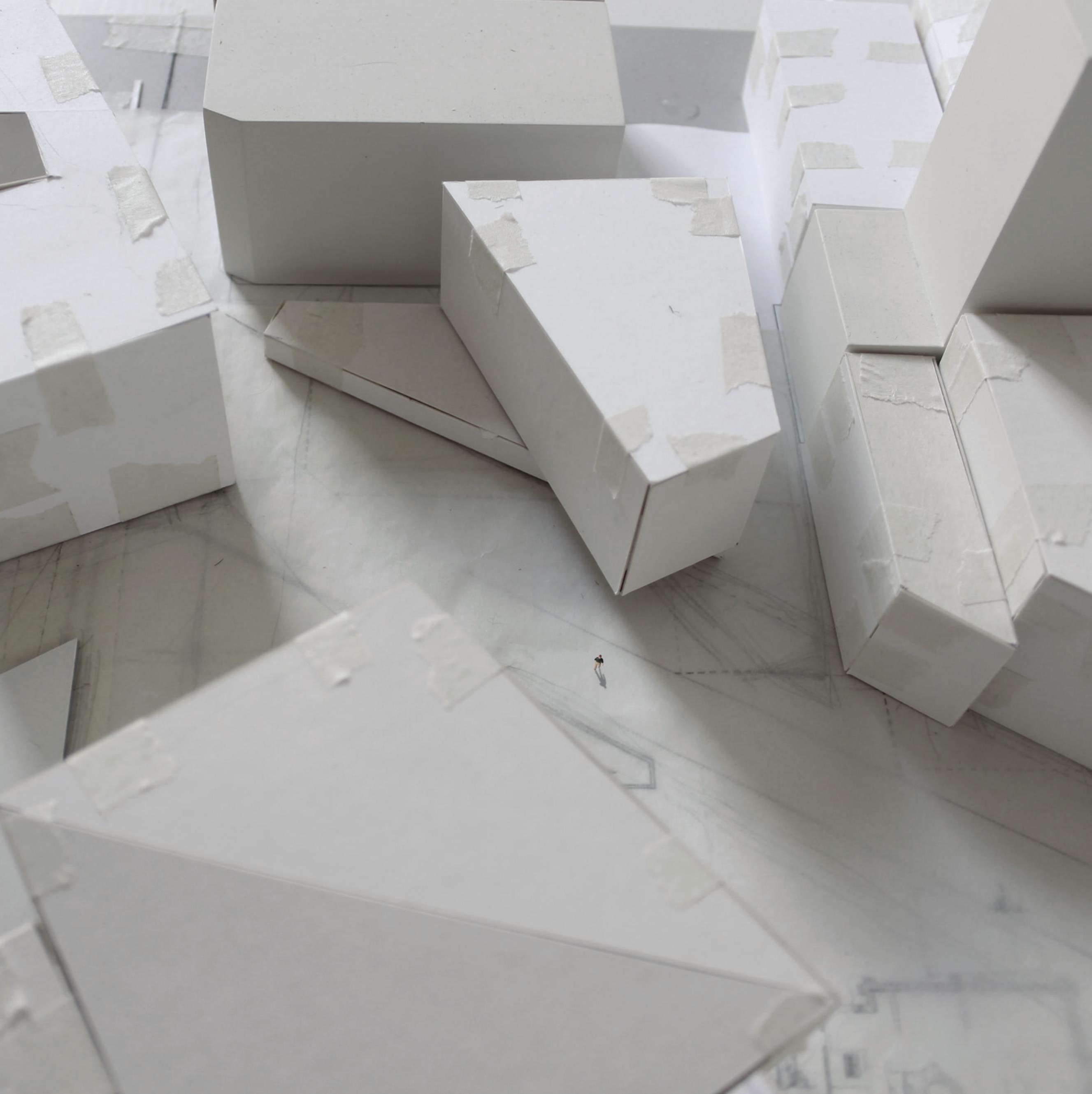




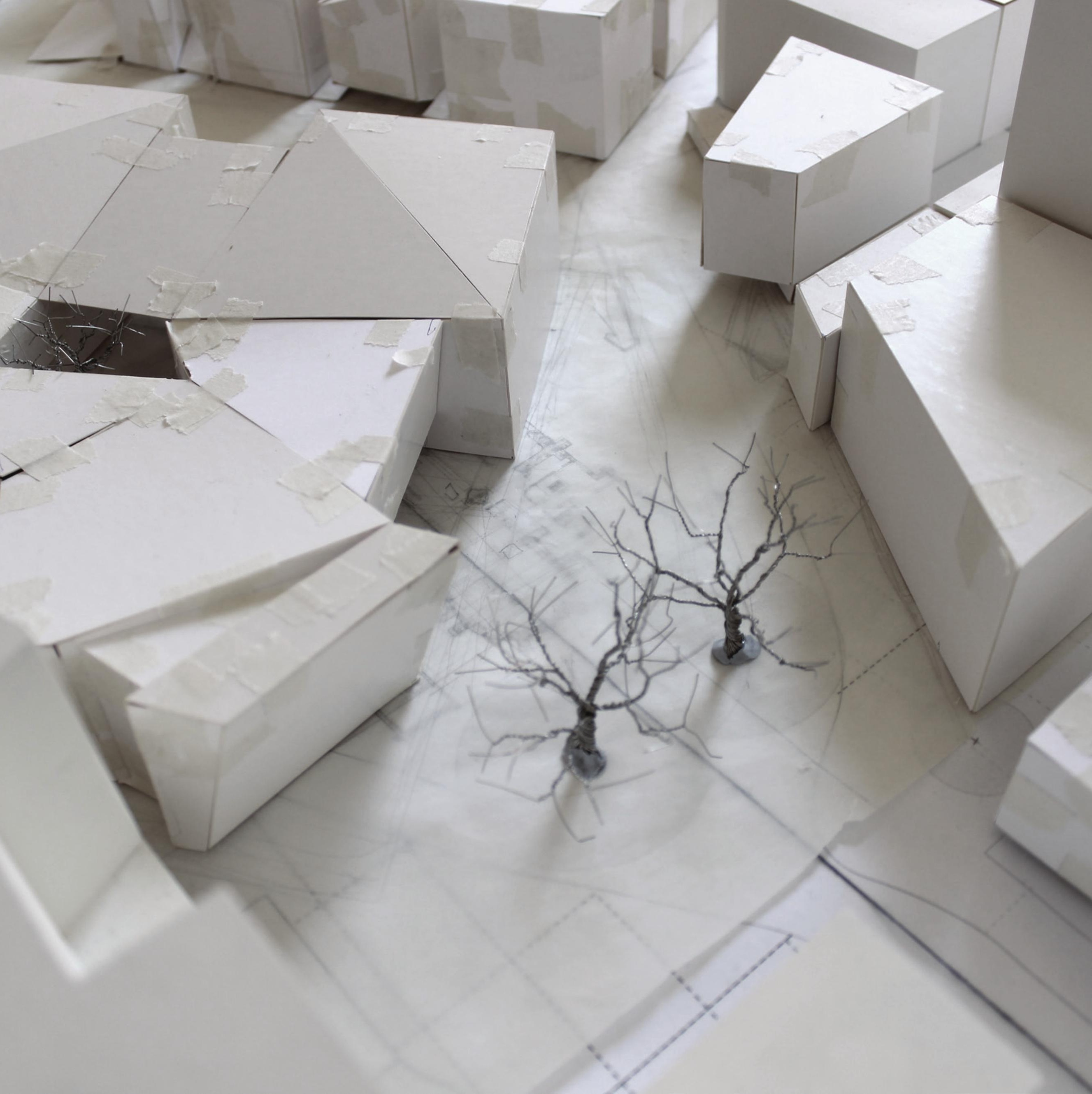


Figure 177.

(opposite page)

Aerial view of

OGB Square.

Figure 178. View

looking south

toward OGB

Square.

Figure 179. View

looking due south

across the Centra

Building Complex

with Colonial Lane

in the foreground.
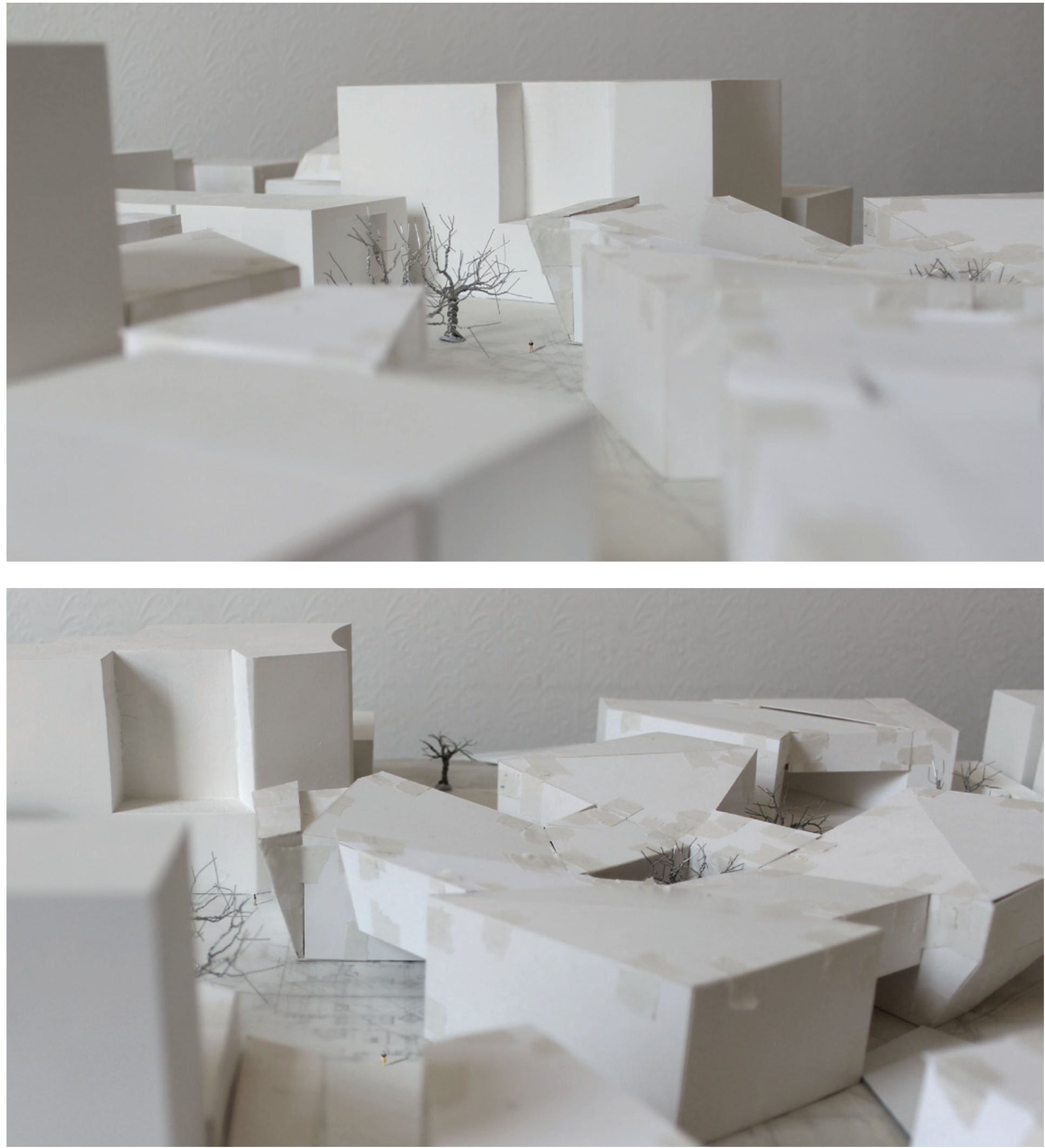


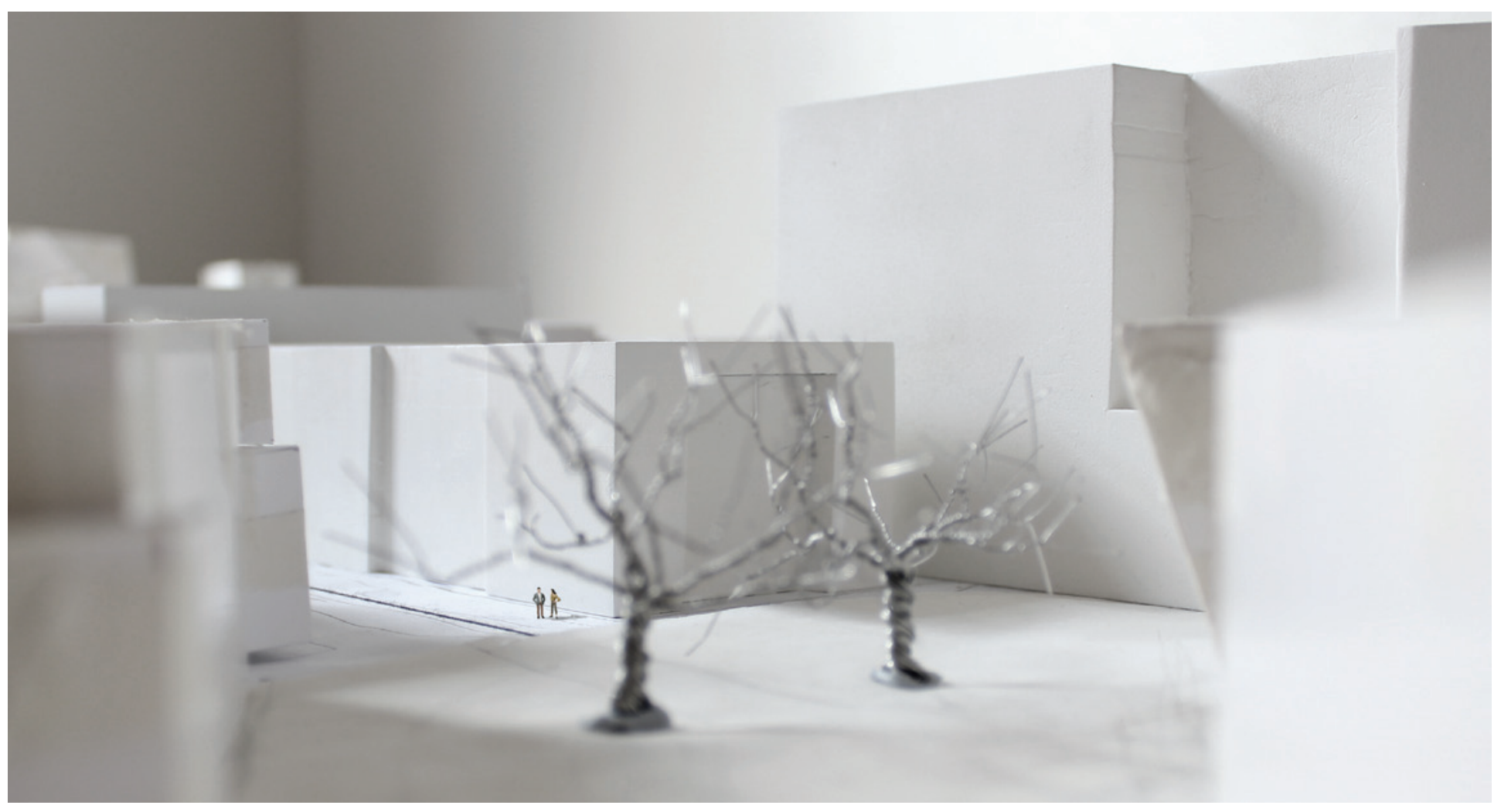

Figure 180. View of OGB.

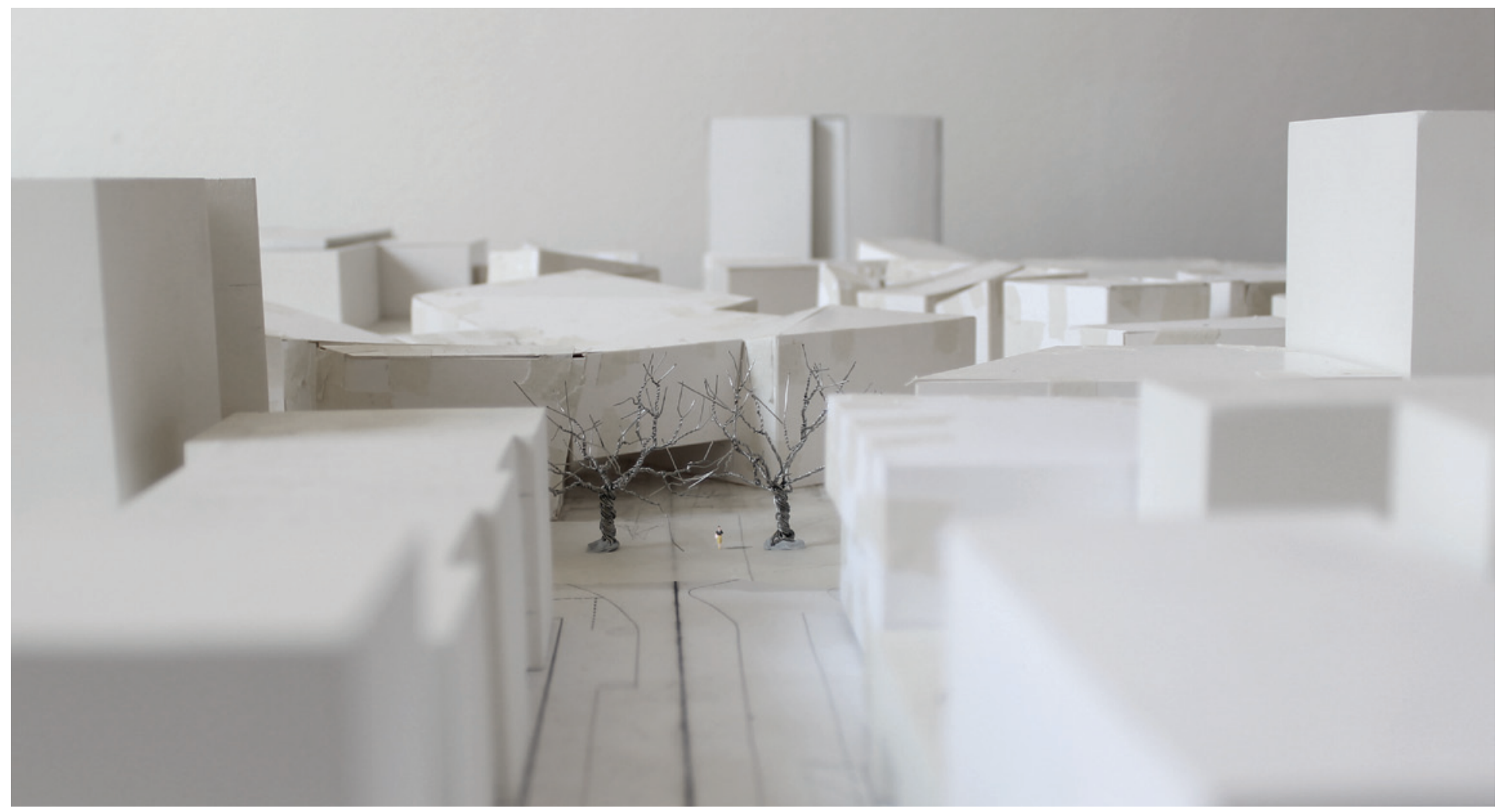

Figure 181. View looking down Worcester Boulevard toward the Central Building Complex.

Figure 182.

(opposite page) Aerial view of

OGB Square and the narrow link back to South Square. 



\section{Concept One}

Concept One is based around creating a high level of connectivity between the square and the rest of the city. Following the city's rigorous orthogonal street geometry, the design integrates a public transit corridor through the centre of what was the existing square. The result of this transit-orientated scheme is a somewhat unique dual square design. Each square is smaller than the pre-earthquake square and the CCDU proposal, and the surrounding buildings are lowered to create intimate proportions. The emphasis on connectivity within this Concept One has meant that in comparison with the other two case stud-

\section{Design Discussion} ies some properties of integration were limited in their development.

The proposal for a new Cathedral, to take up two sites either side of the old Cathedral, is a somewhat contentious move. It is justified on the basis that this more contemporary design is able to integrate the pedestrian pathway between the two parts creating an urban gateway that is dimensionally based on the existing Cathedral nave and aisles. The two part Cathedral also divides the use of the building. One part houses ritualistic and ceremonial programmes and the other houses community based initiatives offered by the church in addition to clergy offices and administration.

The success of this contentious proposal relies on a high quality of architectural design and detail - especially in how the two new Cathedral buildings articulate the space between them.

The pedestrian path is a key element of this Concept One. It is part of a long east west pedestrian precinct that connects the two squares, as well as the Green Frame and the Avon River. Despite the fact that both squares have a high level of connectivity with the two green spaces, the squares themselves integrate very little green space. The outcome being a somewhat historically derivative hard landscaped square with little green space, beyond the reintegration of existing plantings. 
Integrating the central public transit corridor has resulted in two distinct squares. The spatial identity of each square is reasonably well defined with continuous building edges, proportionate and continuous building heights and defined internal corners.

But the fact that there are two squares means that the public buildings are separated from one another. The eastern square incorporates the new Central City Library, and new Cathedral, and the western square integrates the new Convention Centre. While this may mean that each square takes on a unique identity of its own, it also prevents these uses from mixing and potentially stimulating more vitality. Concept Two, for example, integrates these new public buildings in a way that means users will mix in the unitary public space between. And in Concept Three the Convention Centre and Library are directly opposite one another, turning the square into a hybrid space activated by both Library and Convention Centre users.

The fact that these main activity generators are divided in the Concept One is due to prioritisation being given to the integration of a transit corridor.

The decreased size of the squares means that integrating large public buildings such as the Library and Convention Centre can be problematic, in terms of scale and proportion.

Although the heights of these buildings are proportionate to the open space, the widths and amount of land required to fit everything means that they dominate entire edges of their respective squares.

This design showcases the disparity in the need to create smaller better-proportioned public spaces and the need to integrate large contemporary public buildings. Concept Two suffers the same issue, as the Convention Centre dominates the entire southern edge of the square including the reinstated Chancery Lane.

It is also worth noting that two large existing hotel towers frame the eastern square. The disproportion between these towers and smaller square may result in the western square becoming the less desirable of the two. This is in addition to the fact that the international Convention Centre is expected to bring more visitors to Christchurch and presumably large-scale buildings for accommodation will be in demand. The point being made here is that if the additional sites in this concept are filled with large single use buildings that aren't scale sensitive, these spaces may quickly become subservient to the buildings.

The introduction of a public transport corridor and a perpendicular pedestrian corridor through the square are the defining features of Concept One. The integration of Colombo Street along its axis has dictated the resultant dual square design. The adherence to the existing city grid and the integration of both proposed and existing buildings, however, has been achieved more successfully in Concepts Two and Three. 


\section{Concept Two}

The square in Concept Two is to a much smaller scale and the new buildings that enclose it are better proportioned to the amount of open space. The unitary square has created a clearer hierarchy than the dispersal and isolation of spaces the pre-earthquake square suffered from, or indeed the other two concepts exhibit.

Conserving the Cathedral and retaining the unitary square are the driving properties for Concept Two however this has created some issues in terms of connectivity and the integration of natural landscape and new buildings.

Concept Two seeks to re-establish the strong historical identity of the square by integrating a restored Christchurch Cathedral. However, it has been noted that the existing layout of the square, and the central location of the Cathedral, isolated and fragmented the pre-earthquake square. Therefore the Cathedral has been altered in this concept and is restored in a way that is more responsive to the surrounding context.

The north elevation of the Cathedral is attached as part of a row of new buildings. These new buildings fill the void created by the demolition of existing buildings and reframe the new square, where the Cathedral once again stands as the principal building.

Other benefits of attaching the Cathedral include: reducing the extent of restoration, mitigating costs involved in restoring and strengthening historic buildings and concentrating restoration on the front of the Cathedral that faces the new square. Furthermore the attached buildings create more space for a new Visitor's Centre, contemporary church uses as well as additional strength for the seismically vulnerable Cathedral.

Although the most conservative of the three concepts, its controversy lies in the attachment of the Cathedral a building that has always been detached. It is undesirable to retain the Cathe$\mathrm{dral}$ as a freestanding building in the middle of the square due to the negative impact on the hierarchy, identity and articulation of public space.

The southern elevation of the Cathedral remains detached and forms the edge of a subsidiary space to the main square. This space ensures that the two hotel towers and the OGB are annexed to the main square while also retaining connectivity to Worcester Street and the proposed Green Frame beyond.

There is a risk that this adjunct space, alongside the main square, may become under-utilised. The back of the Cathedral contributes little to the space and the large scale of the two hotel towers are out of proportion in relation to the small amount of open space. The OGB is the real feature and, as one of two historic buildings left in the square, it is not given much prominence in comparison with Concept One and Three.

The integration of green space in Concept Two is very much reliant on strong connections to the Avon River and Green Frame. However, unlike the other concepts, the location of the Cathedral upon the east west axis interferes with a clear connection between the main square and the Green Frame.

The existing oak trees on this side of the Cathedral have been retained in this concept as part of an effort to integrate more green space. The main square is retained as a traditional hard landscaped surface with the exception of the four oaks in the centre. There is little integration of green spaces beyond the retention of these existing trees and connections to the Avon River and Green Frame.

The subsidiary space connects at the south east corner of the main square and creates an excessively large opening in the "urban wall' that encloses it. The main entrance to the square from Colombo Street (pedestrianised) also enters on this corner and only compounds the problem.

As a result the rectangular shape of the main square is less clearly defined. The integration of the new Central City Library will still help activate this corner, but the omission of an internal 
corner may mean the space becomes more of an intersection, diffusing activity rather than enclosing and fostering it.

Concept Two proposes to expel all vehicular traffic, both public and private, from the square. All paths that lead into the square are pedestrian only, transforming the area into a pedestrian precinct. There is a risk that the square may become too isolated from the surrounding vehicular streets. It is proposed that public transit would circulate the square on the outskirts of the block, but in the interests of spatial identity, enclosure, scale and proportion there is a lack of integrated public transit connections and vehicular accessibility to the square.

Similar to the Concept One, the Convention Centre dominates the whole southern edge of the proposed square. The intimate proportions of this square mean that despite the low height of the Convention Centre the large horizontal proportions of the building make it difficult to integrate into a square of this size.

Concept Two attempts to integrate what remains of the existing square and compound it into a smaller, better-proportioned, unitary space.

However, in trying to integrate these existing buildings, the OGB, the Heritage and Millennium hotel towers, and the already problematic Cathedral, has meant Concept Two inherits some of these existing issues.

None of these features offer anything new or anything particularly exciting, particularly in comparison with Concepts One and Three, or even the pre-earthquake square. For example, the cruciform shaped square, despite being over-scaled and illproportioned in places, may in fact offer more opportunities for creating a more exciting space, especially when one considers the improvements outlined in the CCDU 100 day plan.

This is in addition to the fact that the rectangular square offers nothing new to the city, and lacks a certain contemporariness when compared to the other concepts, Concept Three in particular.

This is the most conservative of the designs, but nonetheless produces a more integrated city square that can justly retain the name Cathedral Square. 


\section{Concept Three}

Design Concept Three is the most contemporary of the three case studies in that it adopts more of a Post Urbanist approach to the integration of the square. It was identified in the background chapter that there is an emerging side to the Post Urbanist project that is much more concerned with integrating public space into the contemporary city. Integrative principals such as porosity, topology, hybridity and connectivity all promote the integration of open public space and architecture.

Concept Three employs these principles alongside the fractal and free flowing architectural forms, typical of these projects, in an effort to further interrogate the extent to which New Urbanism can contribute to the integration of the square.

This concept is unique in that it is made out of a multitude of open public spaces. The formation is based on the diagonal ordering lines of the High Street extension and views of the existing heritage facades.

All the open spaces have their own sense of enclosure and identity. The buildings around them are composed and morphed in order to create continuous building edges, and heights. The scale and proportion of these spaces are intimate in some places and generous in others. These are dependant on the desired experiential qualities and on integrating existing and heritage buildings. This concept does, however, lack a clear spatial hierarchy and the definition of open spaces can be overly complex when compared with Concepts One and Two, which both have a much more robust spatial hierarchy and identity.

The porous nature of the new buildings means that these spaces take on their own spatial identity and retain a high level of physical and visual connectivity.

The Central building complex, for example, preserves pedestrian flows through the building and is the primary building that frames these spaces and views.

There are folded ground surfaces that ramp up into the building and down onto a subterranean level. This approach of using topological forms to merge building and public space creates a porous and integrated architecture that is able to preserve pedestrian flows as well as other more New Urbanist properties such as scale, proportion and spatial identity.

The contentious decision to almost completely ignore Christchurch's orthogonal street geometry means there is some discontinuity in a city known for its long straight streets and vistas.

Concepts One and Two work within the rigorous street geometry, integrating long and straight paths through the square or between the squares. Concept Three intentionally imposes a discontinuity in these paths in an effort to arrest movement and encourage people to linger and experience what this anomalous square has to offer.

This is not to suggest that there is a lack of connectivity in Concept Three, as stated there are numerous paths to take - but the choice that has to be made means people have to engage with the square in more depth.

The placement of the large-scale Convention Centre in the north west corner is more skilfully integrated into Concept Three. A series of porous pavilions have been manipulated to create more agreeable proportions between the Convention Centre building and the North Square. Concepts One and Two suffered as the Convention Centre dominated entire edges of the square. The pavilions are composed in a way that separates the square from the Convention Centre, and creates a separate public space behind. Several stepped paths maintain a high level of connectivity between the two open spaces and ensuring the Convention Centre is accessible from rest of the square.

Topological interventions are important in the integration of traffic and pedestrian flows, as the High Street Bridge building shows. This building integrates a raised pedestrian path above the traffic on ground level that moves up and down Hereford Street. This raised path preserves both pedestrian flows and vehicular flows, by separating them. 
This spatial separation produces an 'exclusive integration' of these two incompatible flows of movement. The vertical separation of the paths means they are inaccessible to one another, yet they occupy the same space.

This is in comparison to Concept One, which has an 'inclusive' approach to integrating vehicular traffic. The two are combined on the same level celebrating the fact that where they intersect, activity can be generated as well as benefits such as passive surveillance, social interaction and an increased level of accessibility between pedestrians and vehicles. The separation in pedestrian and vehicular flows preserves their respective flows, but the social benefits are lost.

The increased flow of traffic down Hereford Street means that this can be used as a public transport route. Buses pass under the High Street Bridge and stop where the South Square opens out onto Hereford Street, integrating public transport by making a clear connection between this square and bus route. The spatial issues of integrating streets with squares have been discussed in previous chapters, such as the loss in spatial definition. In Concept Three the southern edge of the square ground folds up slightly to create a sheltered bus stop. Along with the plantings this small topological gesture helps enclose the South Square and soften the impact of Hereford Street traffic.

One of the defining features of the Post Urbanist project is the merging of the natural landscape and architecture to create a more integrated urban environment. Concept Three embraces this idea by landscaping the undulating roof of the Central Building Complex. This elevated park-like space is accessible to the public via the circulation atrium inside the central building complex. The topological surfaces on the roof of this structure create more cohesive integration of building and natural landscape features such as grassed surfaces and plantings. It is entirely possible that Concepts One and Two could be endowed with green roofs. However, the orthogonal building geometry means the green roofs may appear as additions to the building rather than integrated into the building design.

This rooftop park is quite removed from the open public space on the ground level. Getting people there is aided by mechanical transport, but even so there is a risk that this space may become isolated from the rest of the square. Similar to Concepts One and Two a high level of connectivity to the Avon River precinct and Green Frame is retained.

Compared with the more distinguished proposals that typify the Post Urbanist project, Concept Three is relatively reserved. Mostly because there is an implicit problem with this sort of design, in that ramped surfaces often produce large areas of unusable facade where they slope down to meet the ground. These buildings can also be inefficient in terms of the cost of structural engineering involved in constructing slanted surfaces, cantilevers and exotic folds.

Add to this the realities of constructing a ramp that is accessible for all users, and the designs can quickly become unpractical. Many theorists, including Gehl, have written about the disadvantages of changes in level in public spaces and peoples reluctance to traverse them. This increases the risk that the spaces they lead to may become underutilised due to substantial changes in level. The High Street Bridge, Convention Centre Square and subterranean levels of the central building complex face this issue.

The interior of the central building complex, with its multi-level library, is able to avoid this issue by adopting tactics usually seen in shopping malls, which include escalators and lifts in an interior circulation atrium next to the open air atrium. 


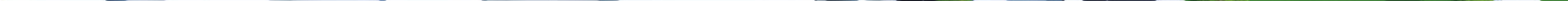




\section{Design Development}

Figure 183

(opposite page)

Aerial view of

concept three.
Overall, the hybrid design methodologies used in Concept Three optimise both integration and contemporary urbanism. This is achieved by combining New Urbanism's inherently integrative agenda with that of the Post Urbanist's contemporary design approach.

Traditional integrative properties of spatial identity, mixed use, human scale and proportion, combined with emerging integrative trends of porosity, topology, and hybridity create a more integrated and contemporary city square. Connectivity is also included, but this property in general is upheld in both streams of thought.

The input from the more contemporary Post Urbanist approach meant that the extent to which New Urbanism can contribute to the integration of the square could also be more robustly examined.

Concept Three has received an extra level of development because the design is less persuasive on a conceptual level, especially in comparison with the other case studies. In addition, the complexity of this design meant it almost naturally called for an extra level of development.

The following section presents a series of rendered images illustrating the development of this investigative design process. Extensive computer modelling, alongside physical modelling, helped to develop this concept. This iterative design process revealed more findings from the design process as the more experiential qualities, on which this design is based, could be developed.

Following the presentation of these images is a brief discussion outlining the insights gained from this development.

While this development showcases another level of complexity in the design, this is limited to the architectural and spatial concepts that this thesis is primarily concerned with. The design would benefit from an additional level of landscape development, however this field of design falls outside the author's expertise. 


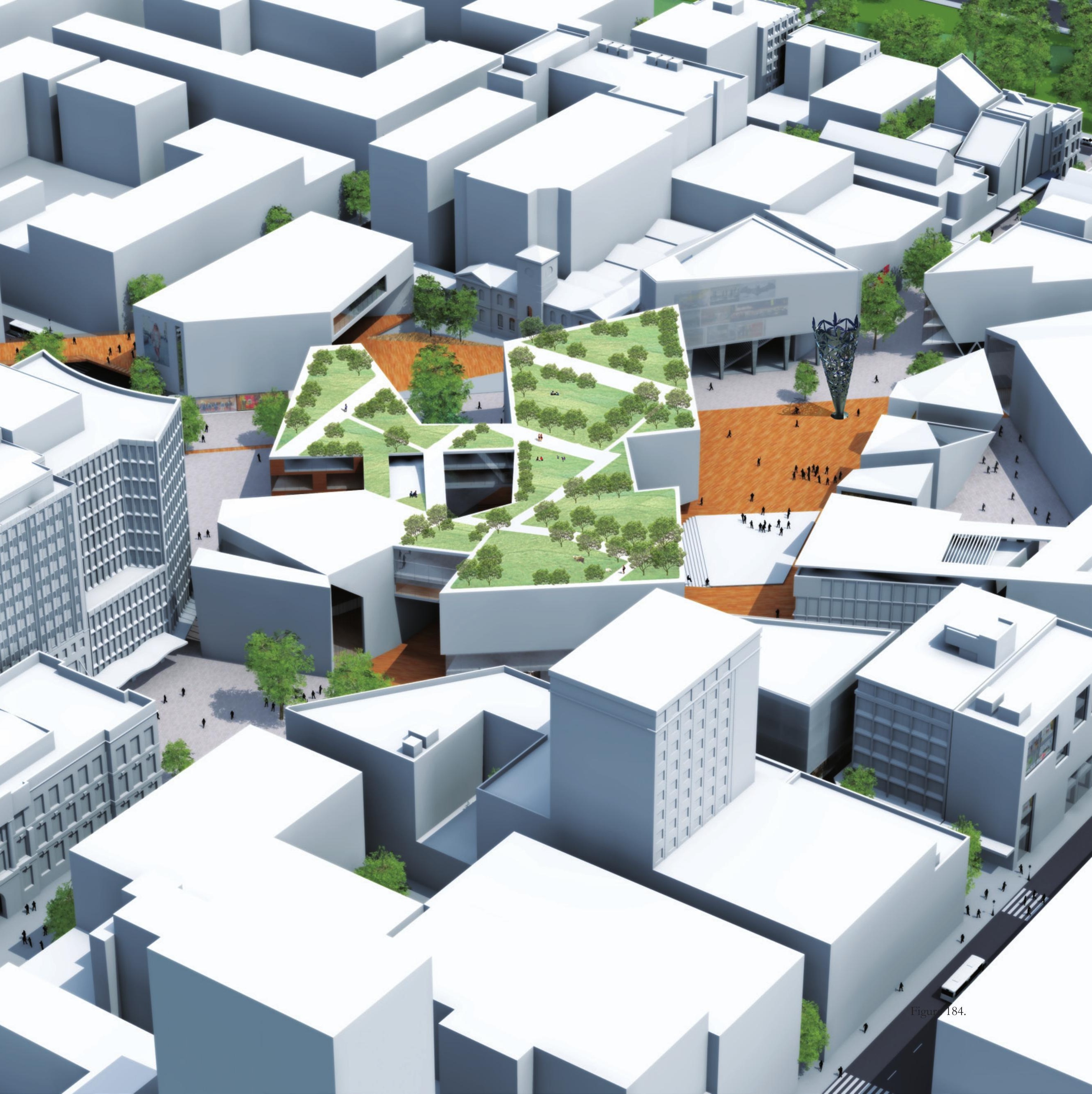




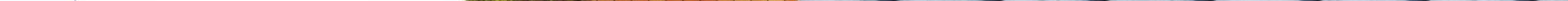




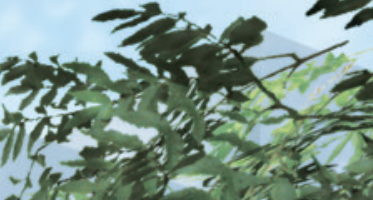

$l_{1}=x^{2}-2$ Ple 2 (9)

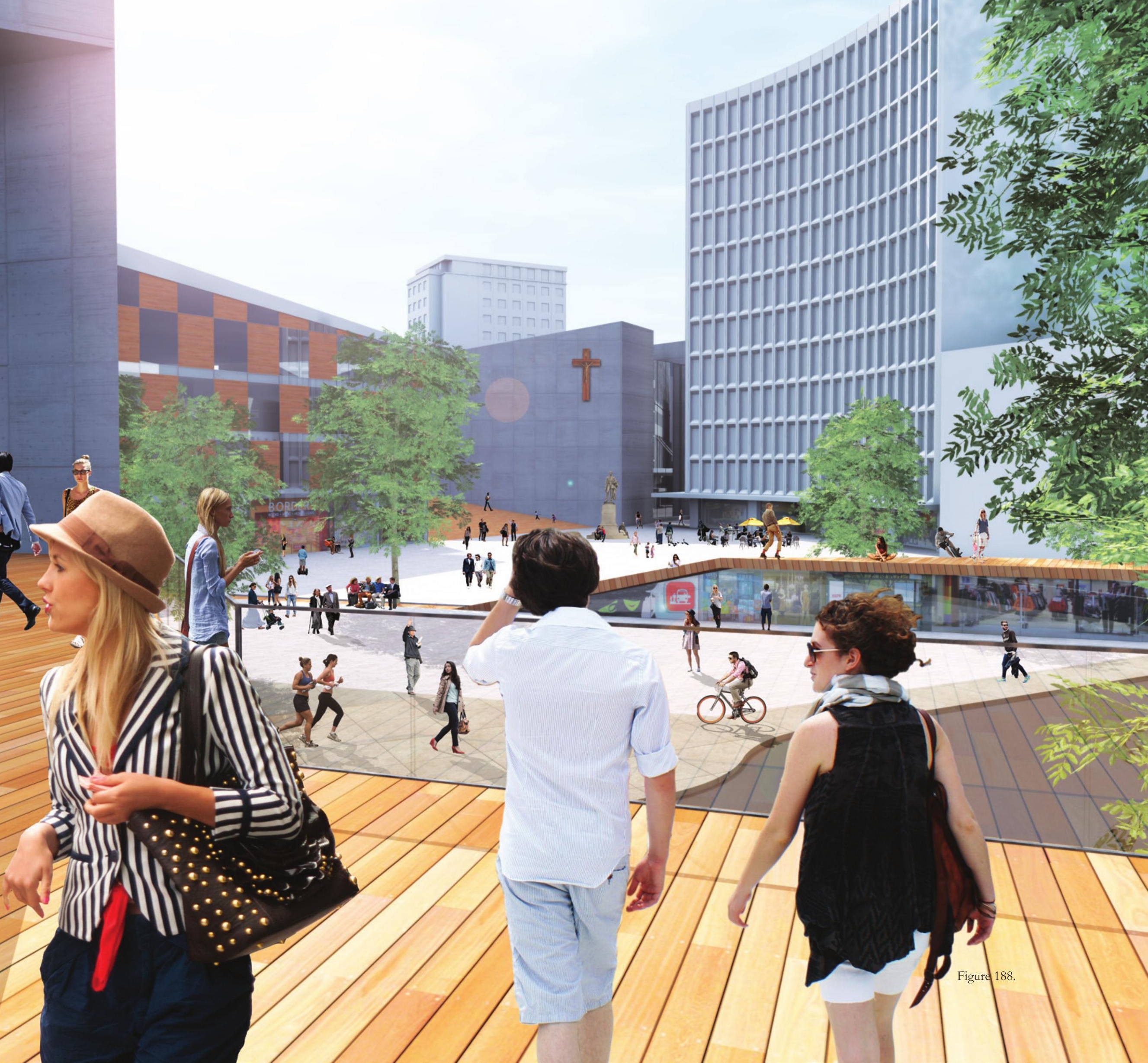




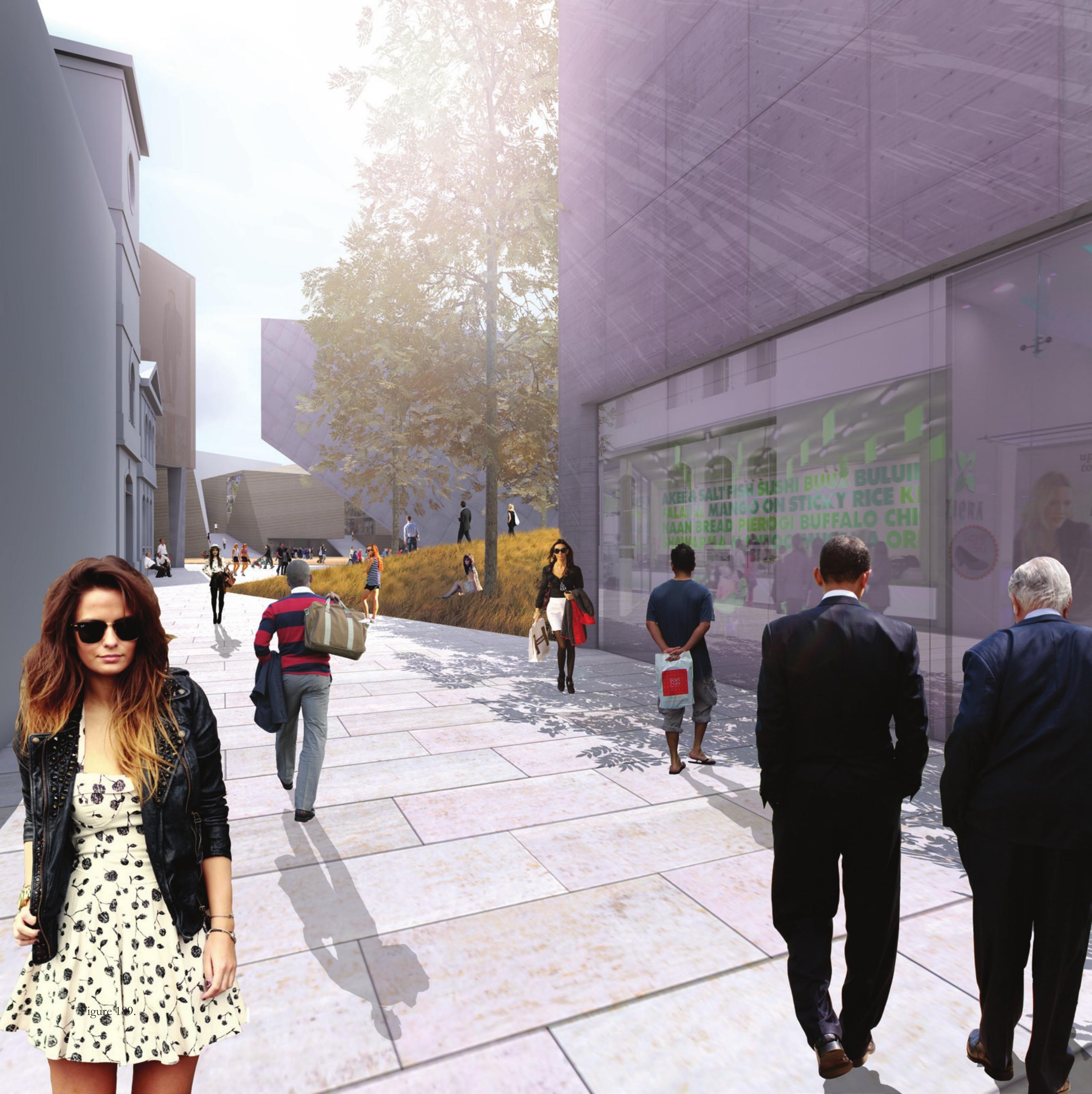




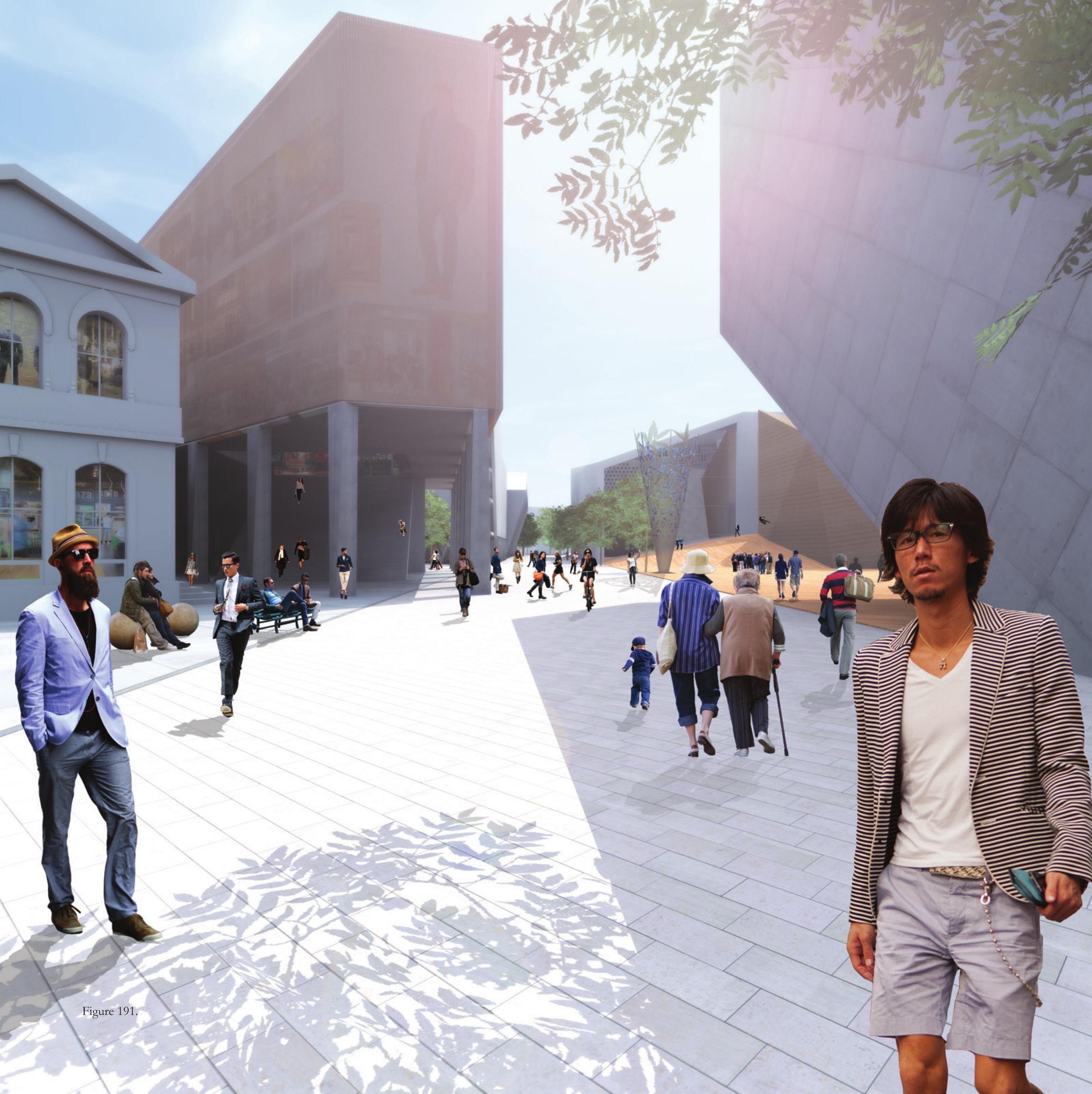




$$
{ }^{2}=\frac{n}{n}=n^{2}=
$$

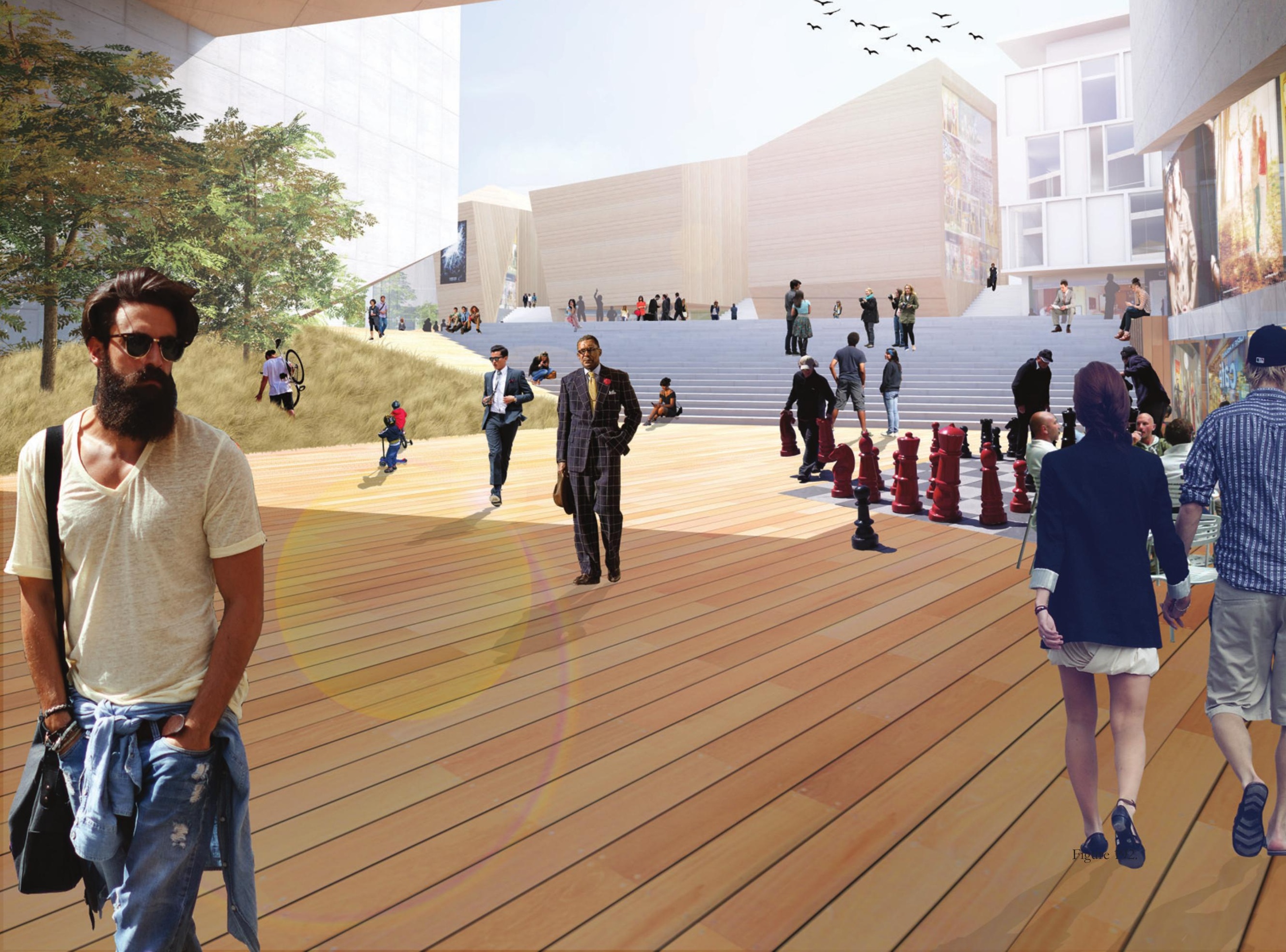




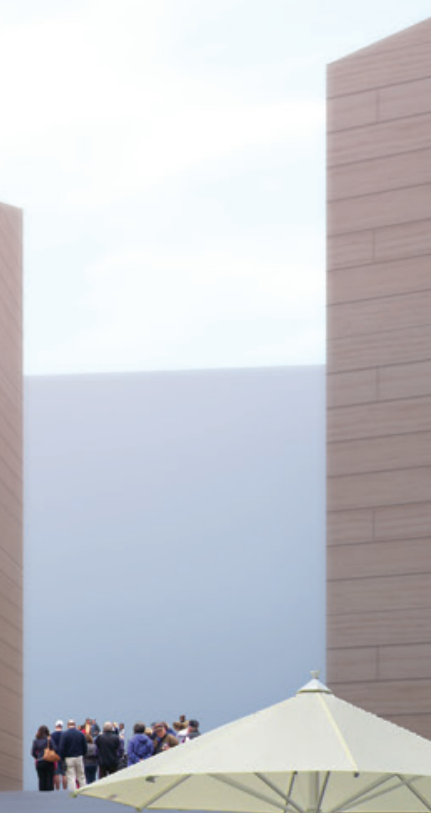

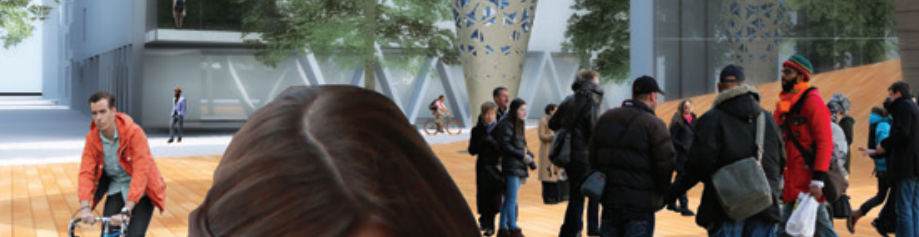

(2)

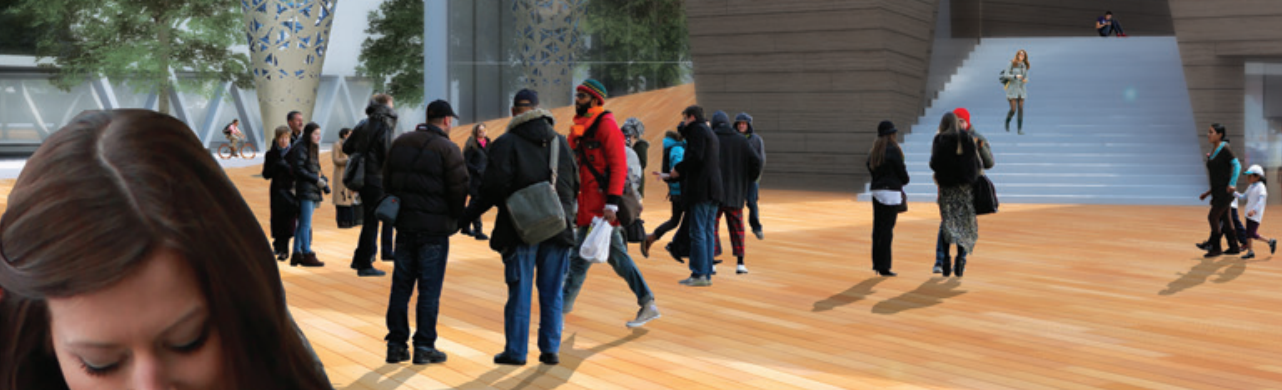
1 ,
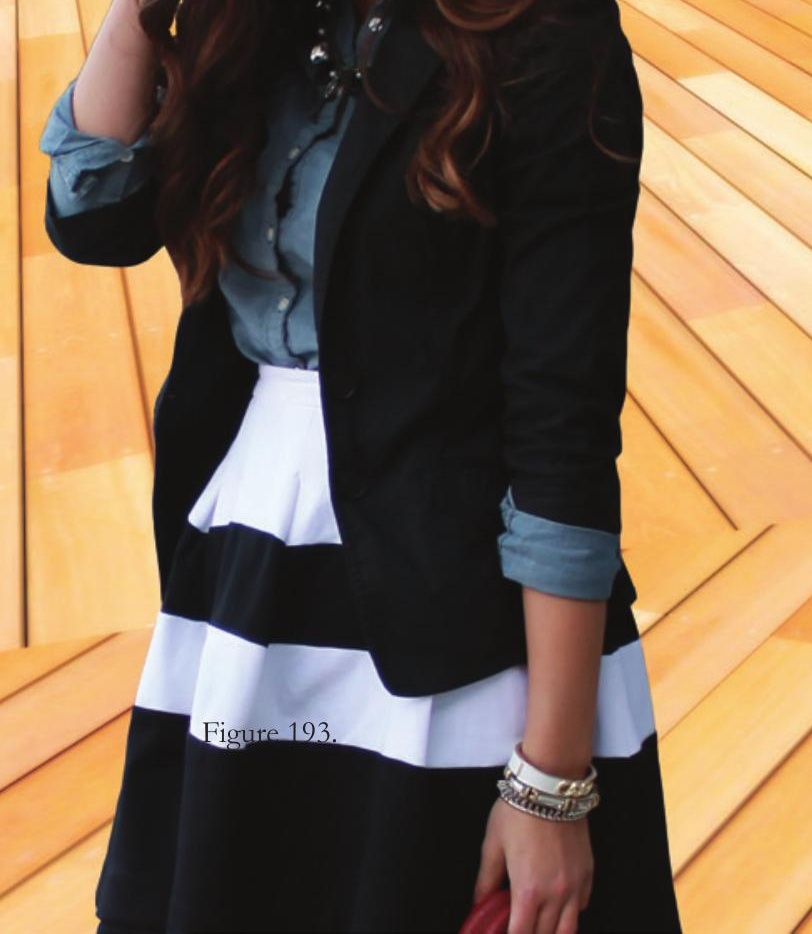


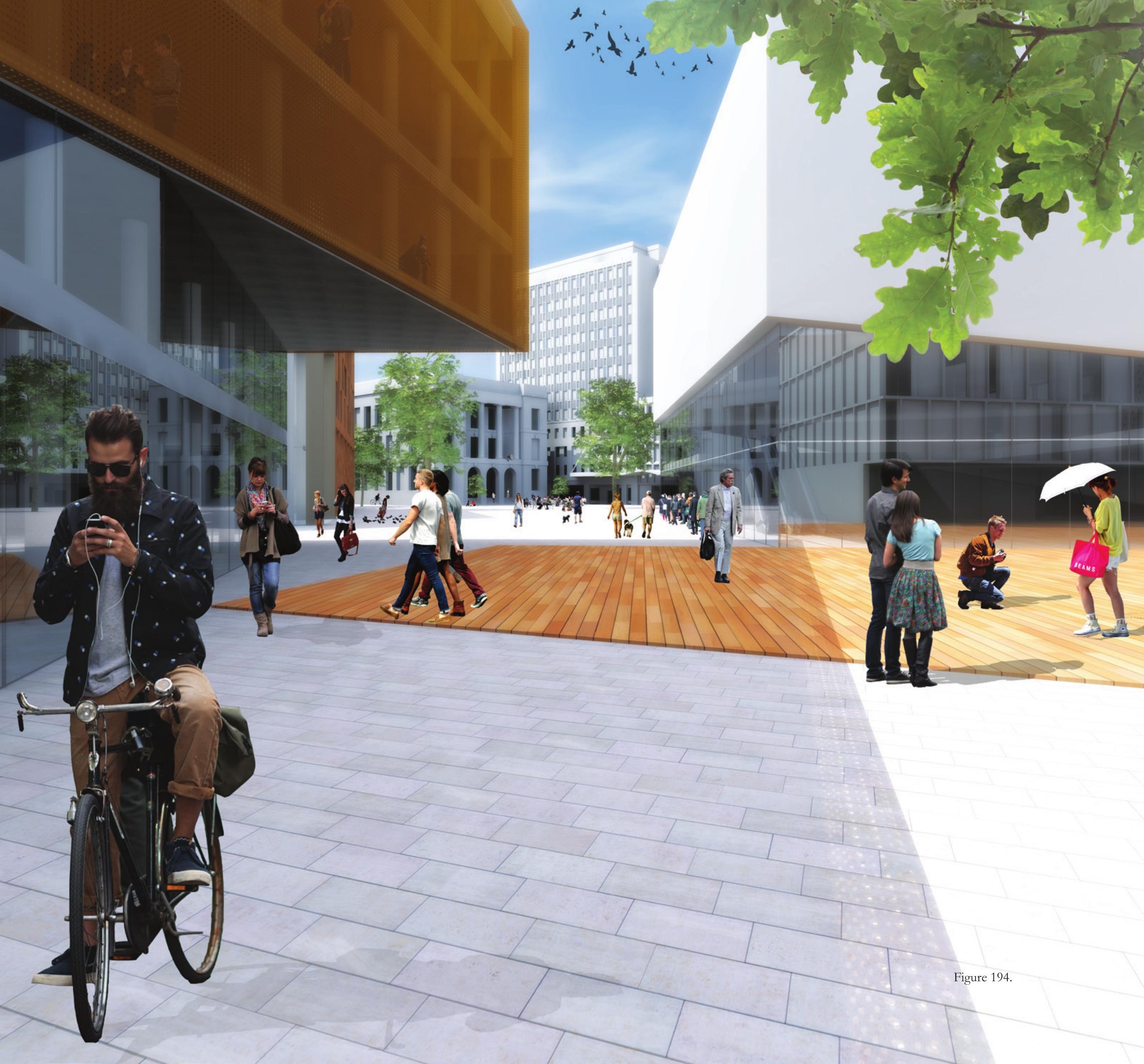




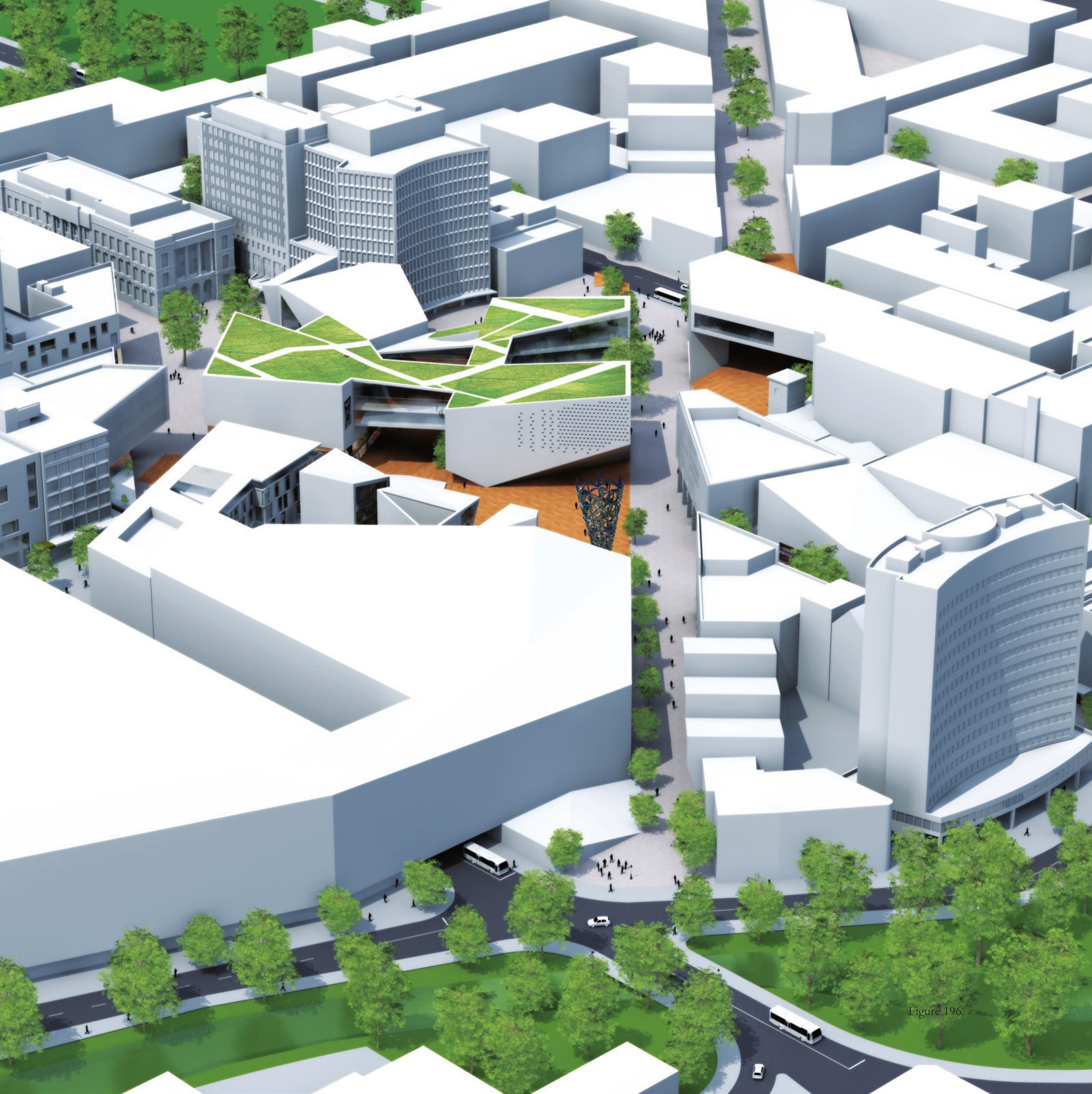




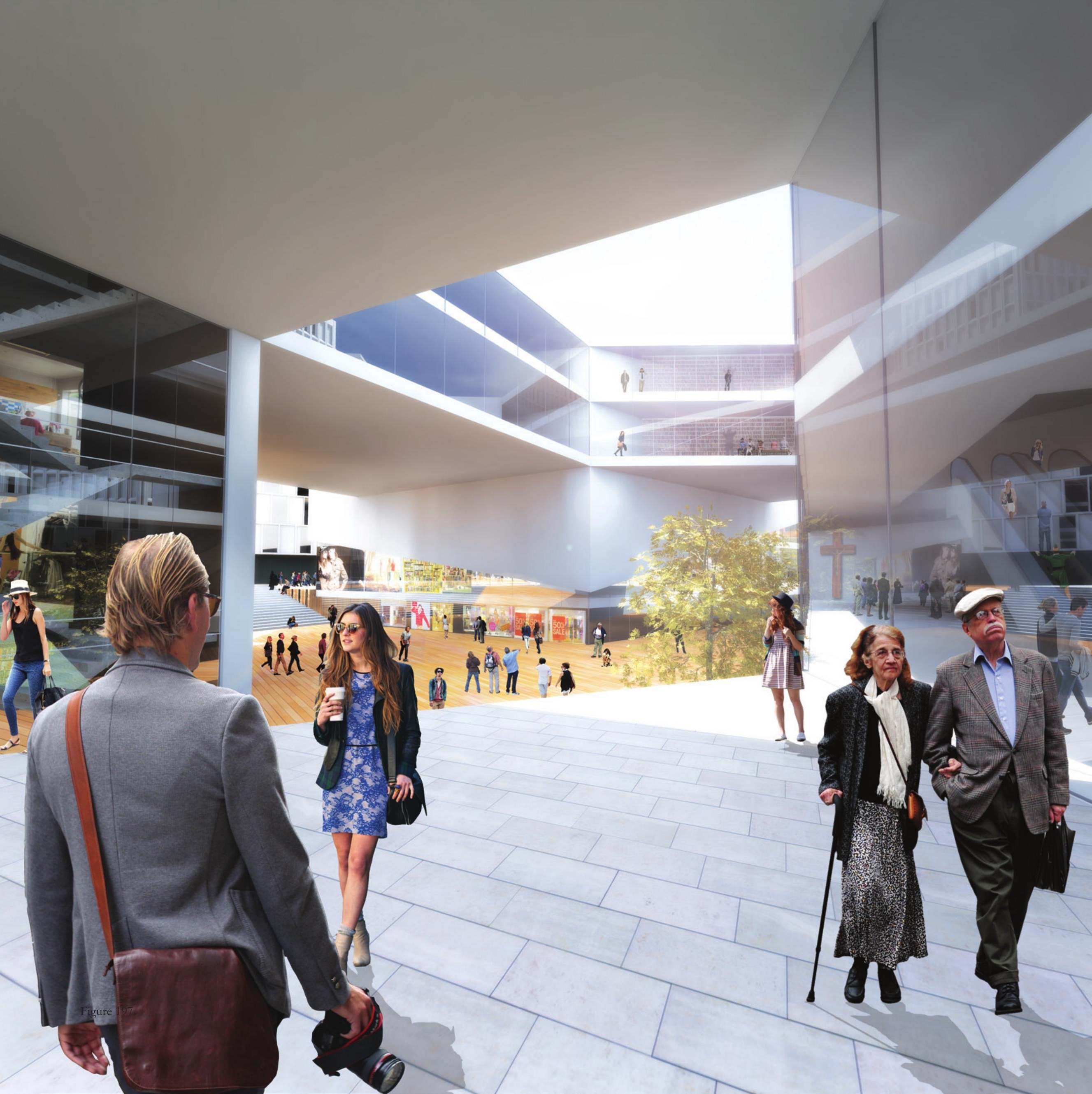




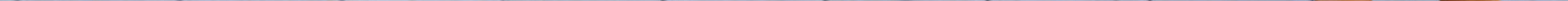




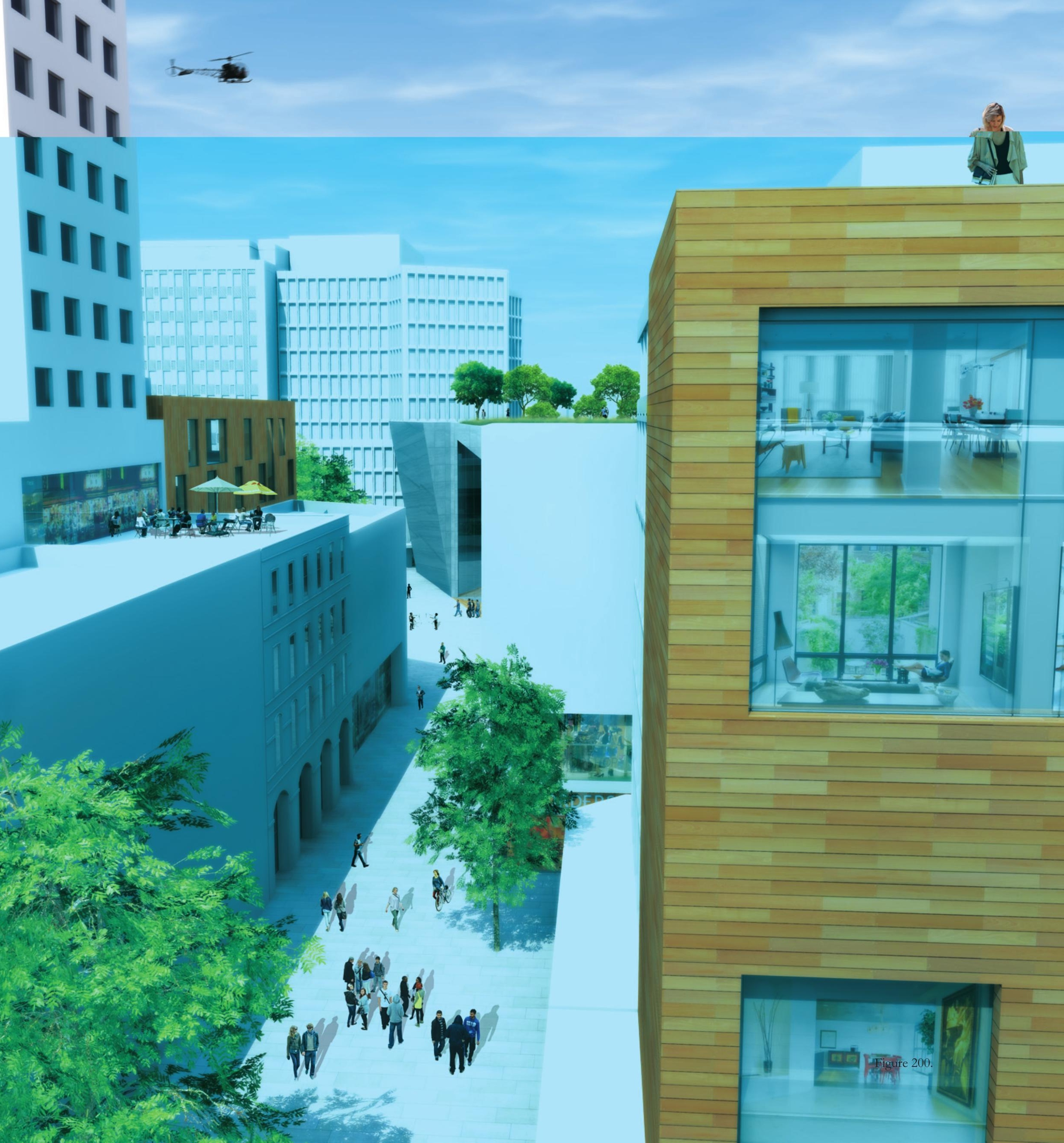




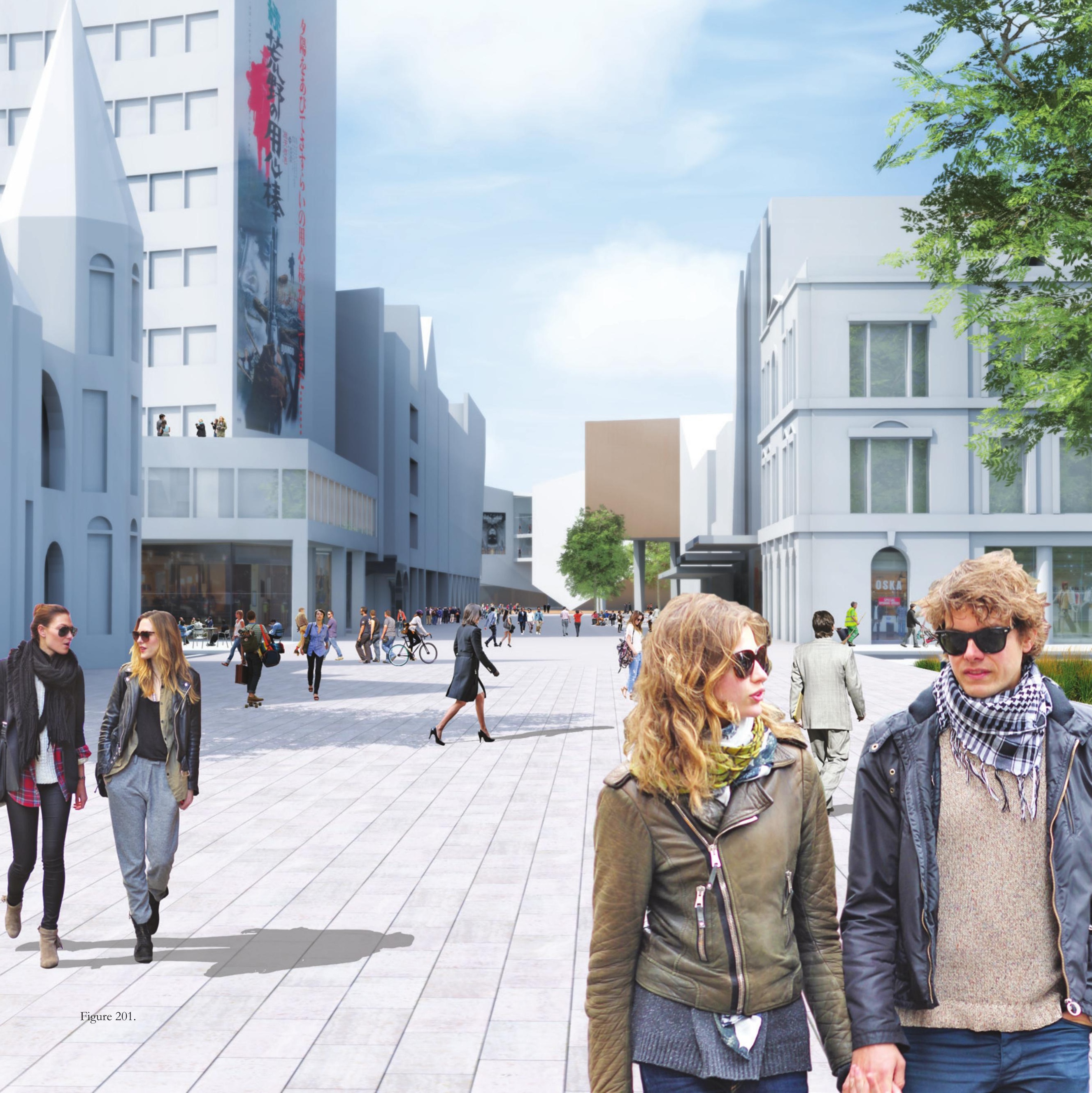




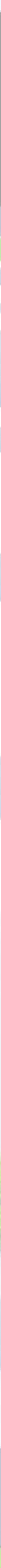




\section{List of Preceding Figures}
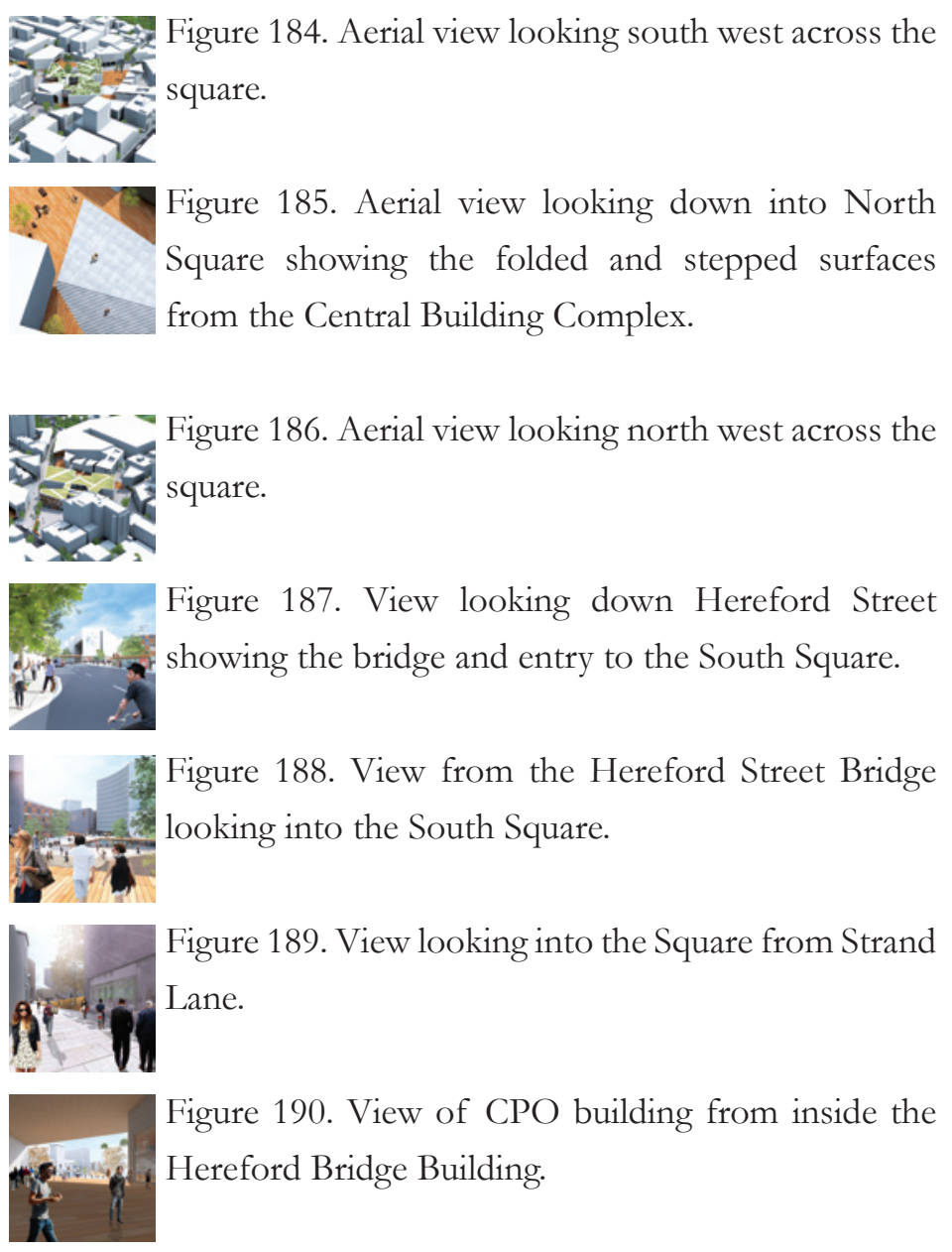

Figure 190. View of CPO building from inside the Hereford Bridge Building.

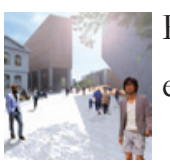

Figure 191. View looking north down High Street extension.

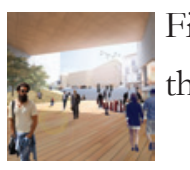

Figure 192. View out to North Square from inside the Central Building Complex.

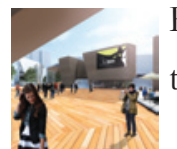

Figure 193. View of North Square looking toward the Convention Centre pavilions.

Figure 202. (opposite page)

View looking north east across the square. Figure 194. Terminal view looking toward the OGB.

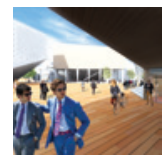

Figure 195. Terminal view looking toward the CPO.

If Figure 196. Aerial view looking south east across the square showing the High Street extension.

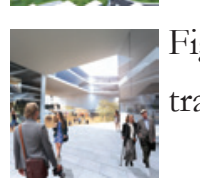

Figure 197. View of open air atrium inside the Cen-

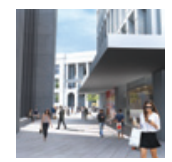

잘. Figure 199. Aerial view looking into OGB Square.
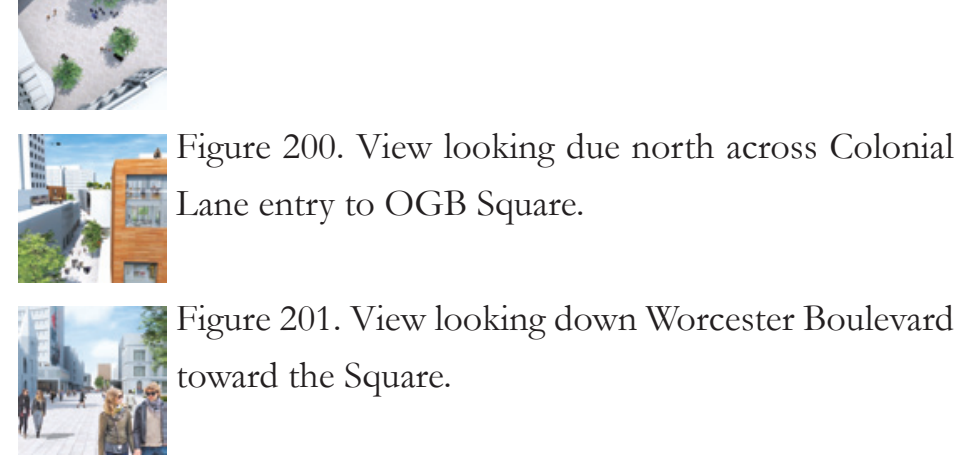
This extra level development was done because much of Concept Three is based on the more experiential qualities of urban design. For example, the proportions of many of the buildings do not conform to a standard ratio as Concepts One and Two do. This showed that the manipulation of building heights and forms could be done successfully without needing to adhere to such rigorous proportions or geometries. This revealed that the freedom of form-making afforded through a Post Urbanist approach can be integrated with the square, and more importantly, it can better integrate the surrounding buildings.

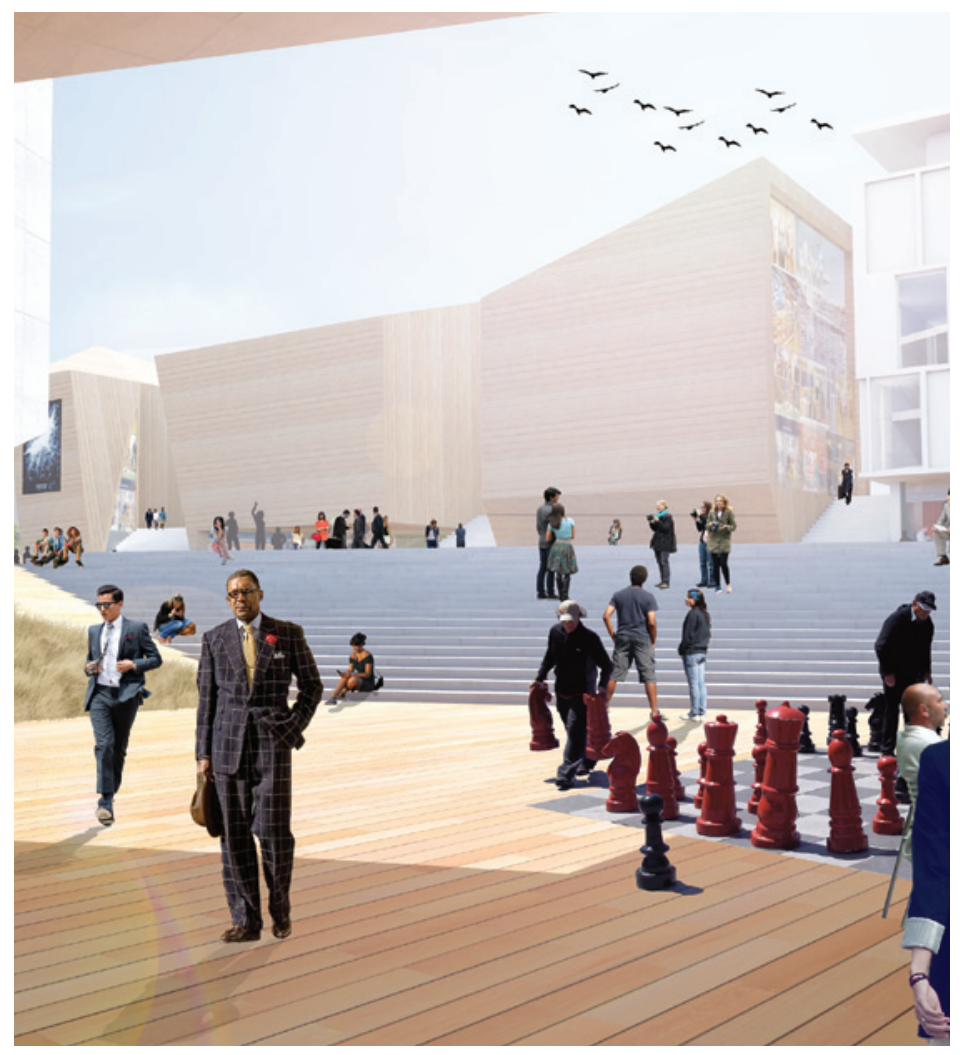

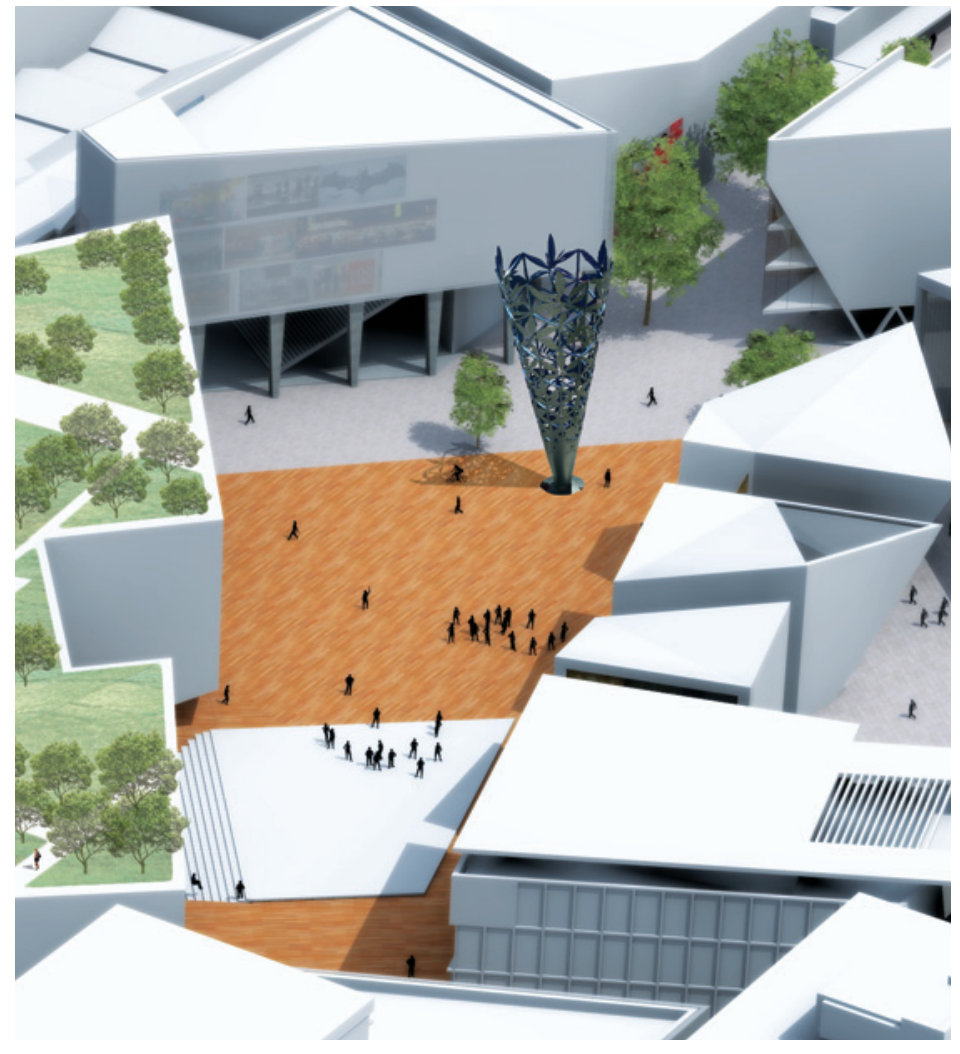

Figure 203. Close up of North Square showing manipulated building shapes.

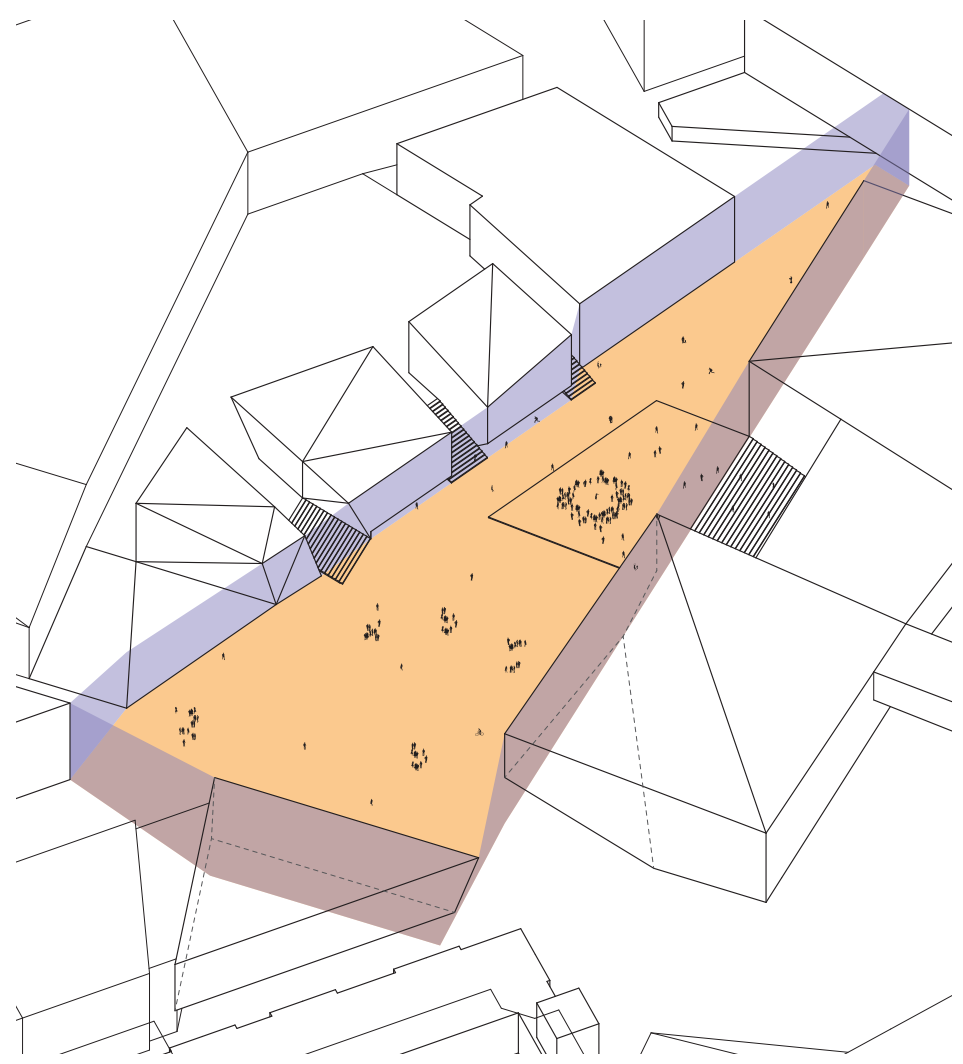

Figure 204.

Diagram showing the enclosing buildings about the North Square.

Figure 205. (far left) View of Convention Centre pavilions. 
Figure 206.

Terminal view of

OGB framed by

new buildings.

Figure 207. (far

right) Terminal view

of CPO framed by

new buildings.
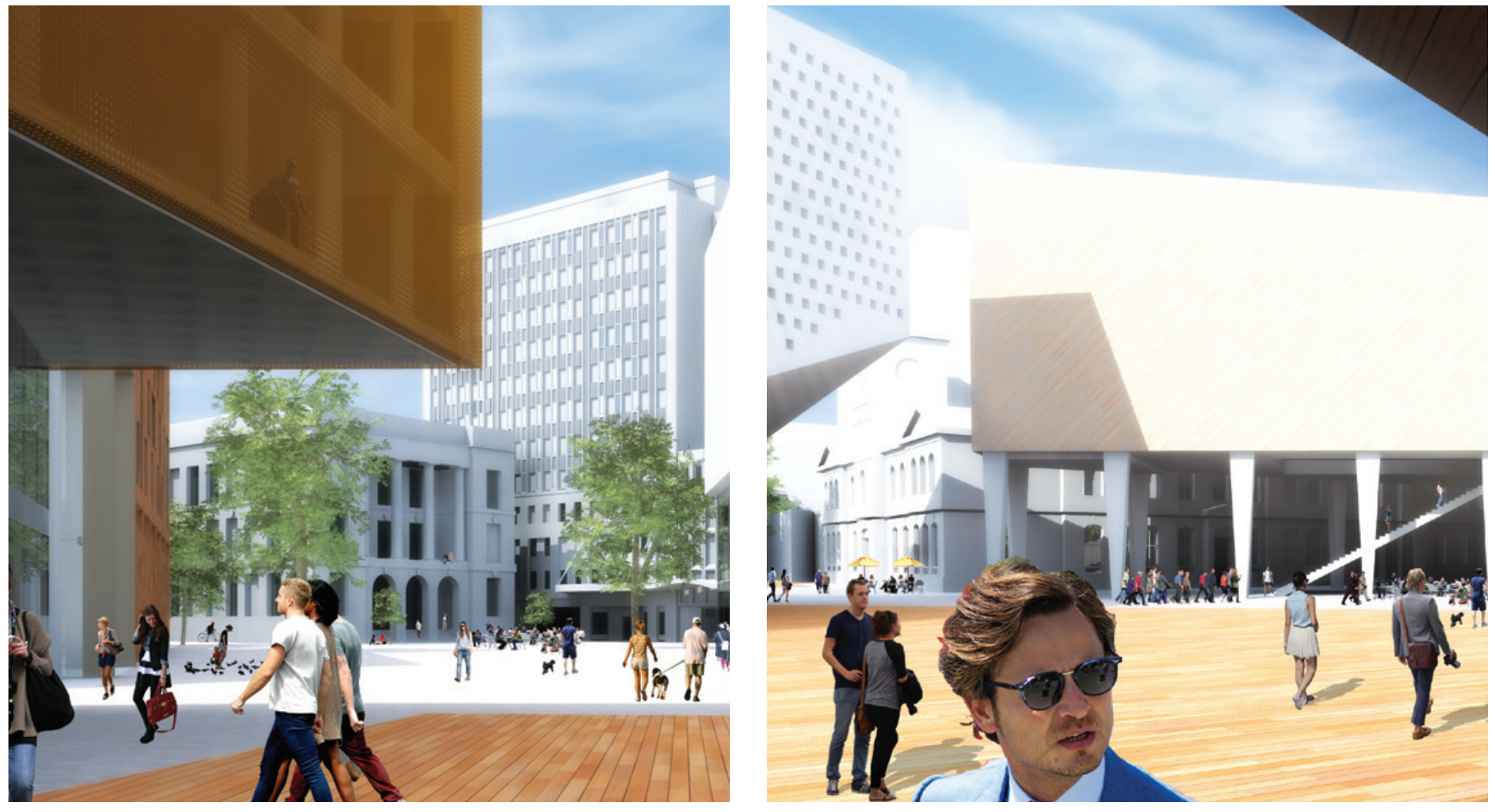

Figure 208

Diagram showing the framed terminal view of the OGB.

Figure 209. (far right) Diagram showing terminal view of CPO.

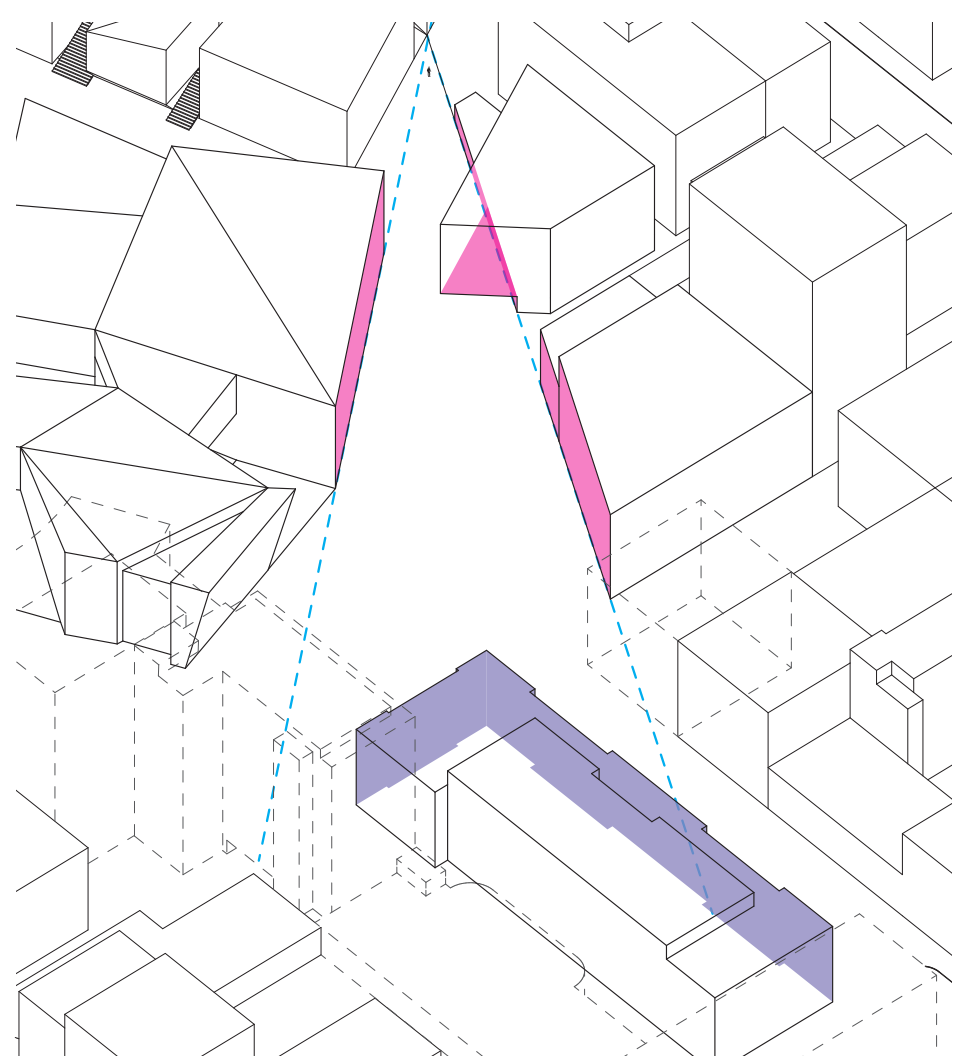

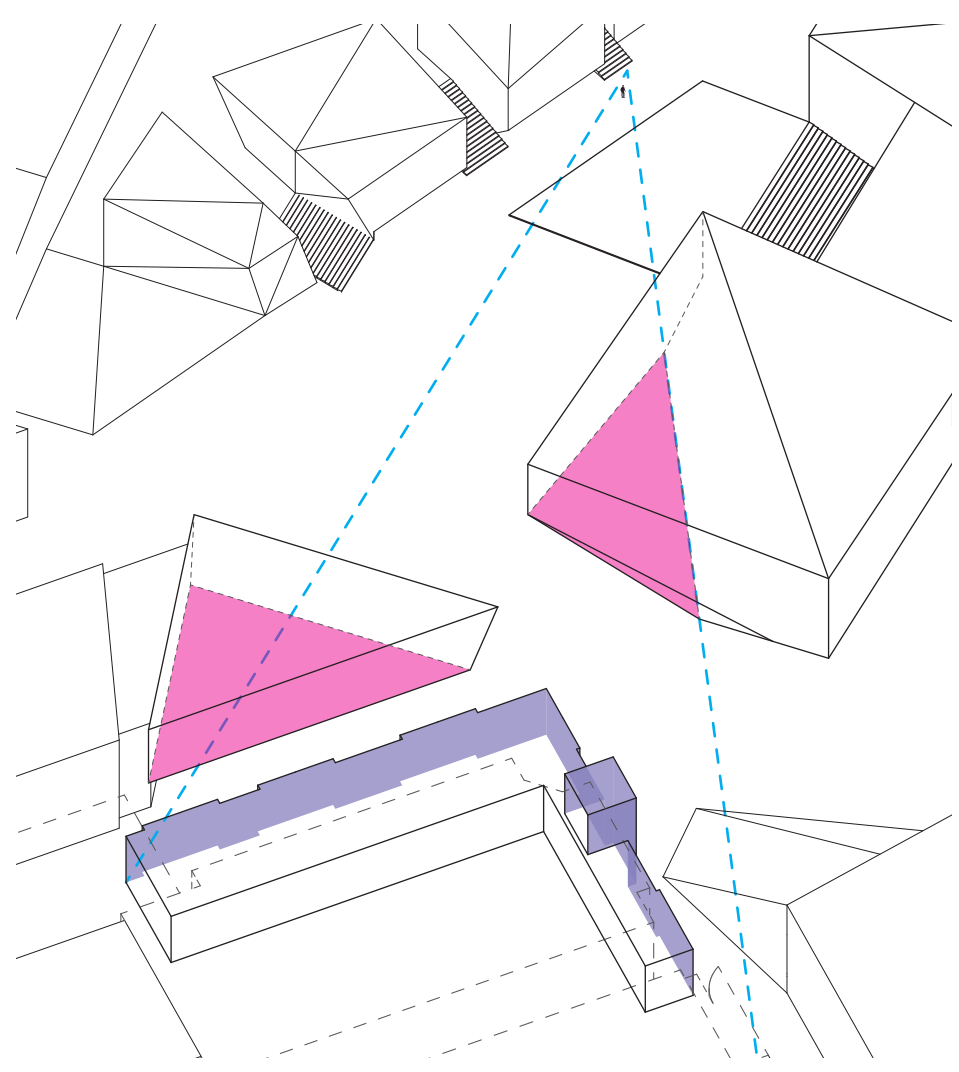


Further insights were gained into the identity of the city square with Concept Three. All three concepts work on the New Urbanist derived premise that part of the squares identity is that it be a hard landscaped open space enclosed with buildings. Despite the Post Urbanist influence, and the tendency of these projects to be somewhat anti-contextual, Concept Three has been formed to create cohesive built edges and continuous building height lines (see figure 212).

New buildings proposed at the edges of the square moderate the non-orthogonal geometry of the square with the orthogonal streets and lanes that connect with the square (see figure 210). This proves that the combination of these methodologies has been beneficial in terms of creating a spatial identity for each of the open spaces within Concept Three.

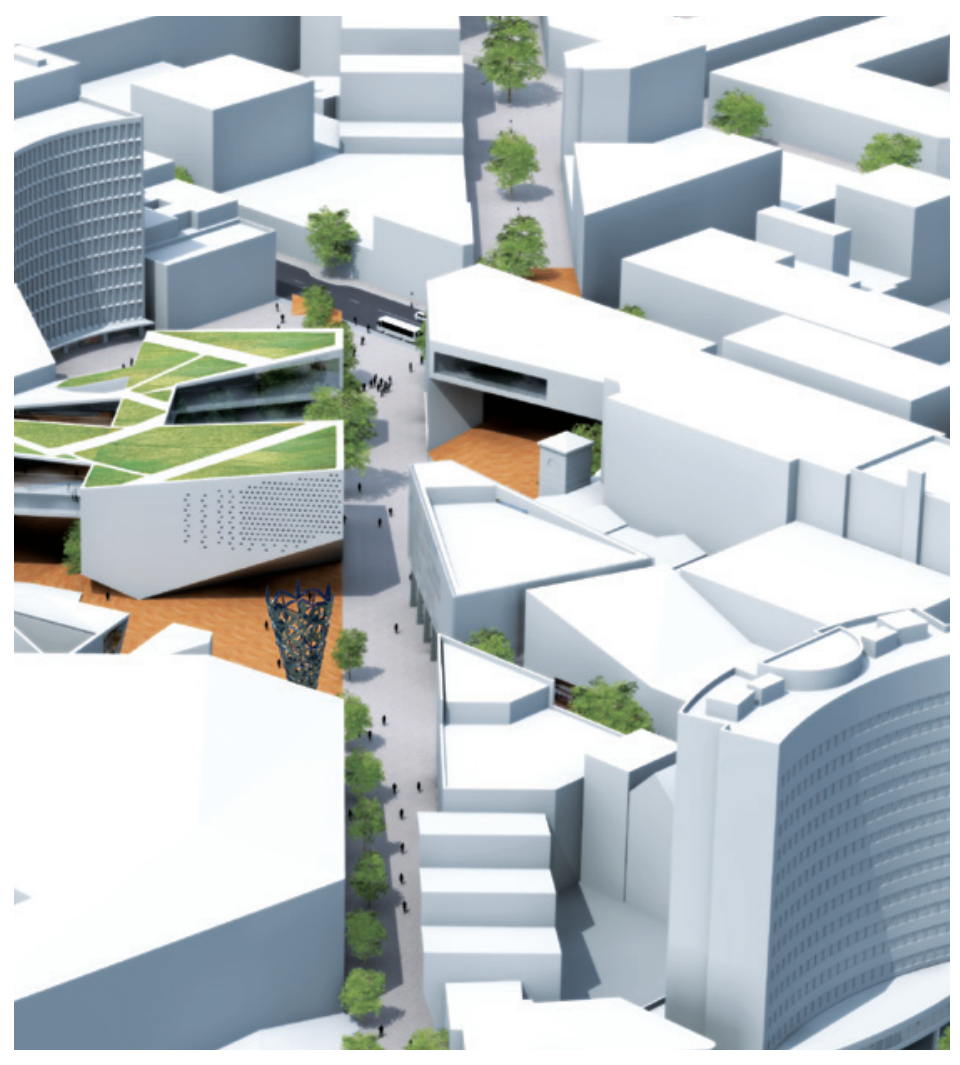

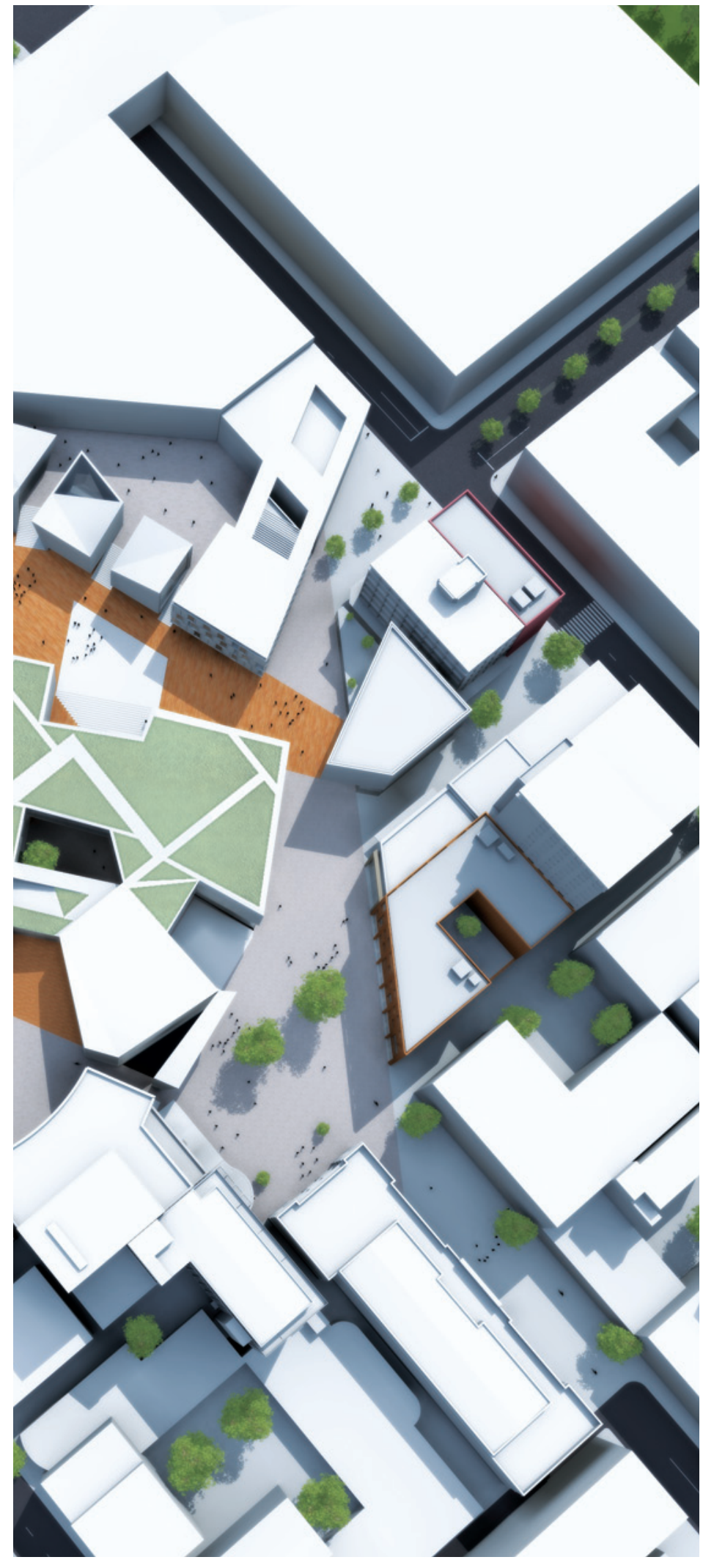

Figure 210. Aerial view showing the buildings that moderate the nonorthogonal and orthogonal urban geometry.
Figure 211. (far left) Aerial view showing the integration of the anomalous High Street.

Figure 212. (opposite page) View of North Square in the evening showing the contextual building forms and continuous building heights. 


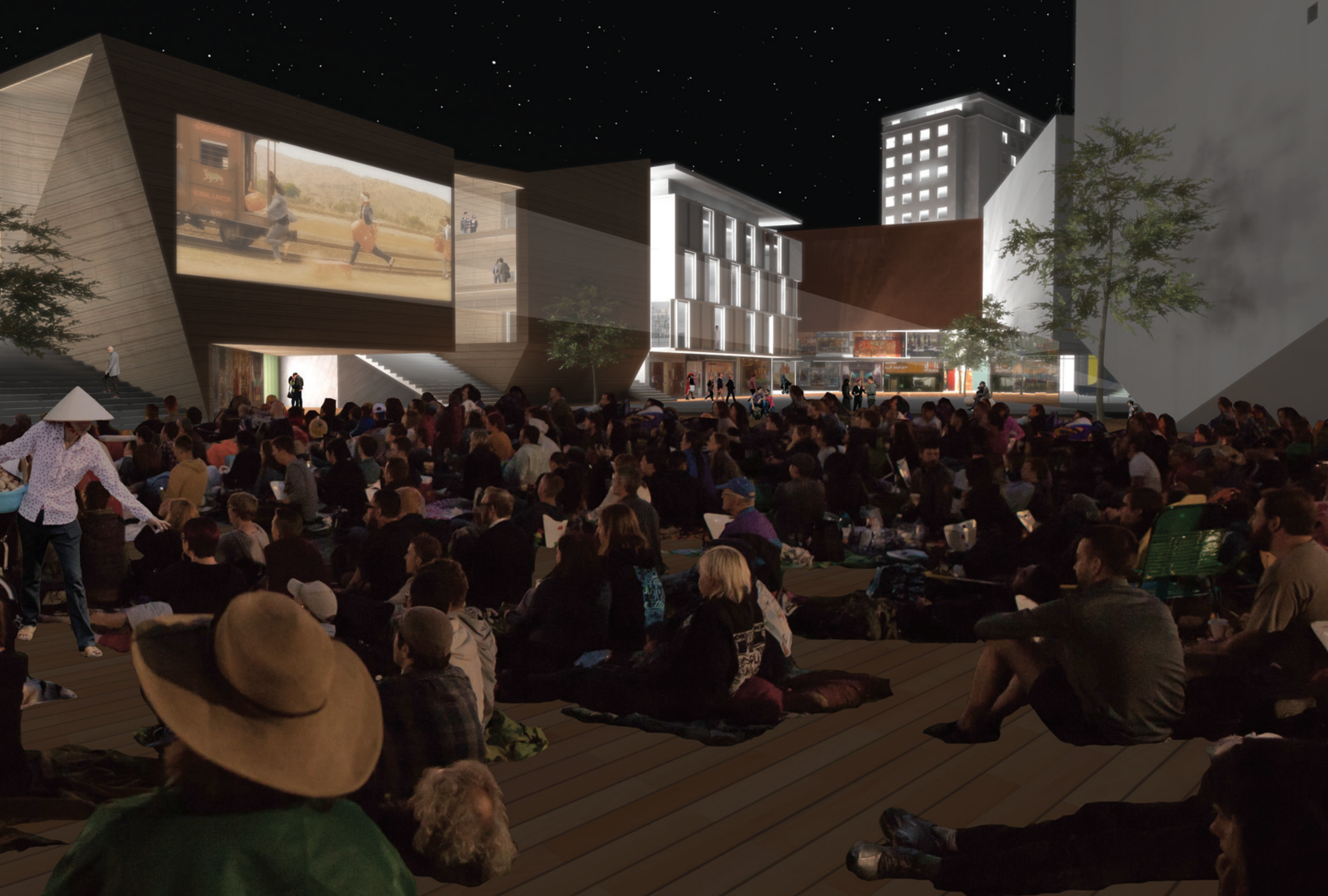


In designing and developing Concept Three, the integration of natural landscape produced an unexpected insight. The adoption of topological, urban and architectural forms proved more helpful toward the overall integration of the square. The actual physical integration of grassed areas and plantings were beneficial to the square, but did not actually contribute much in terms of integration.

The manipulated ground surfaces that fold down under the library, to create pathways through the building, proved more helpful toward the integration of the square and enclosing buildings (see figure 215).

The same is true of the stepped paths that lead to the main entry of the Convention Centre (see figure 214).

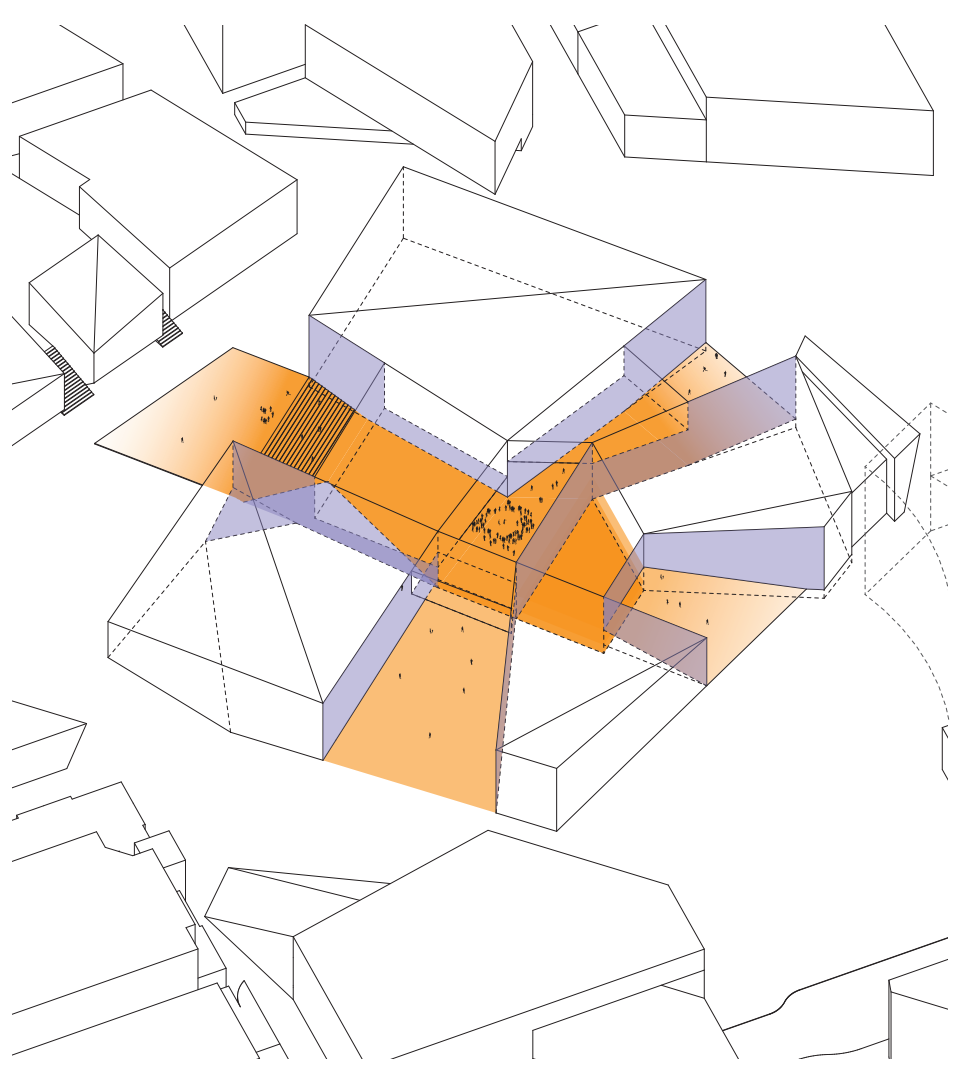

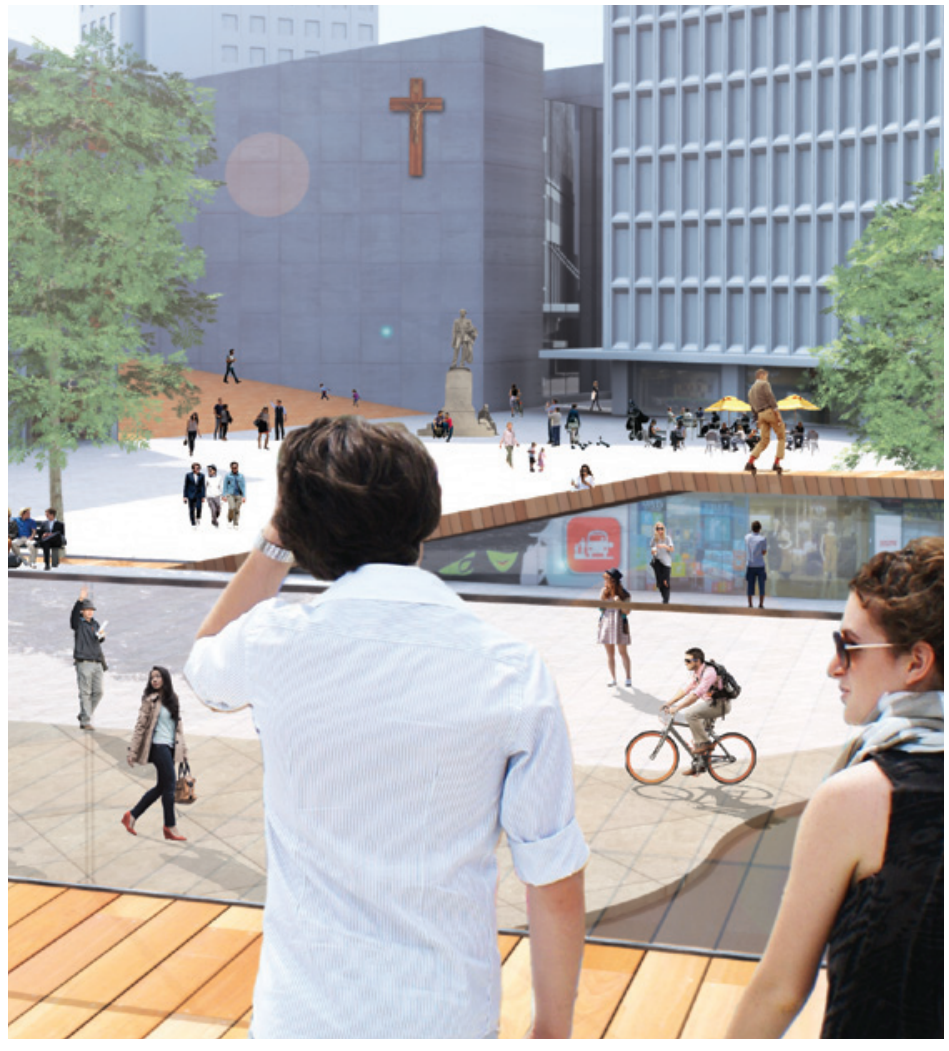

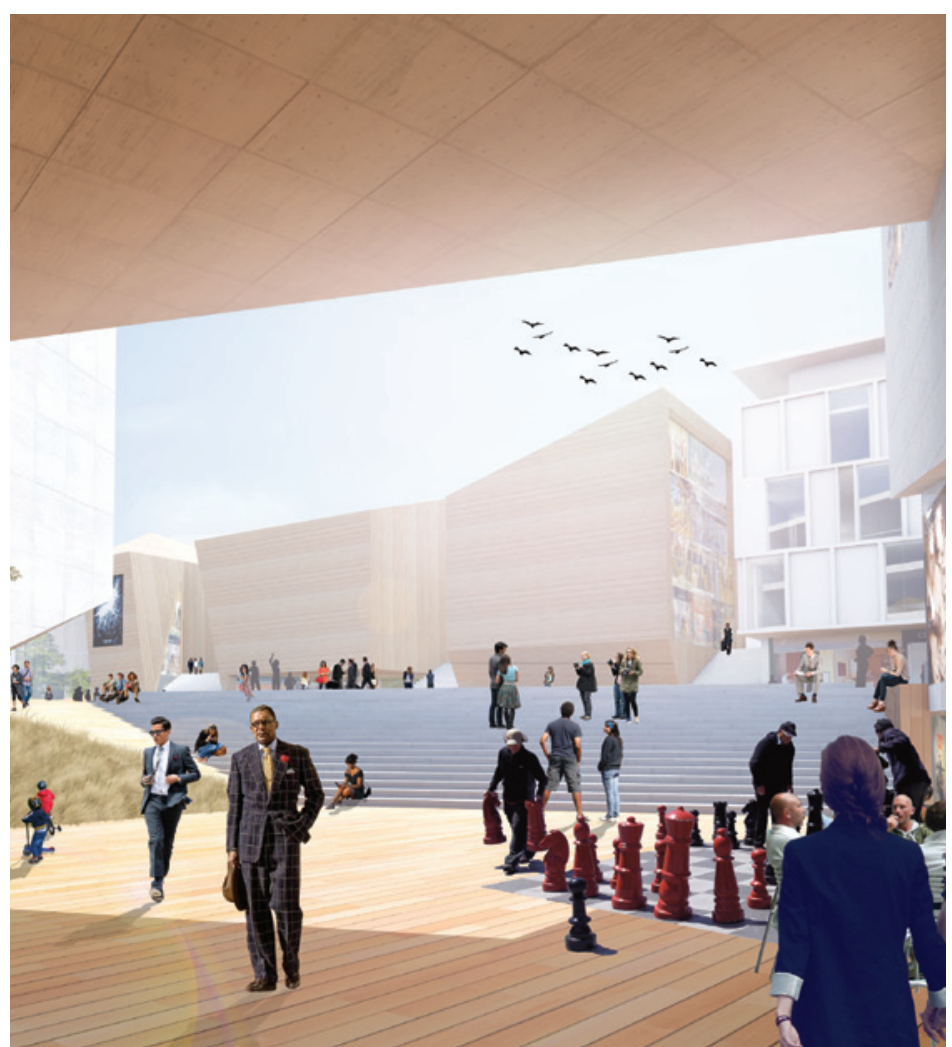

Figure 213. Close up of South Square from High Street

Bridge, note the timber surface that rises out of the ground to enclose the square from High Street.

Figure 214. View showing ramped surfaces that fold down into the Central Building Complex.

Figure 215. (far left) Diagram showing ramped surfaces that enter the Central Building Complex. 
Figure 216. View looking east of the green roof atop the Central Building Complex.

Figure 217.

Isometric diagram showing the green space relative to the square.

Figure 218. (far right) Aerial view of Central Building Complex green roof.

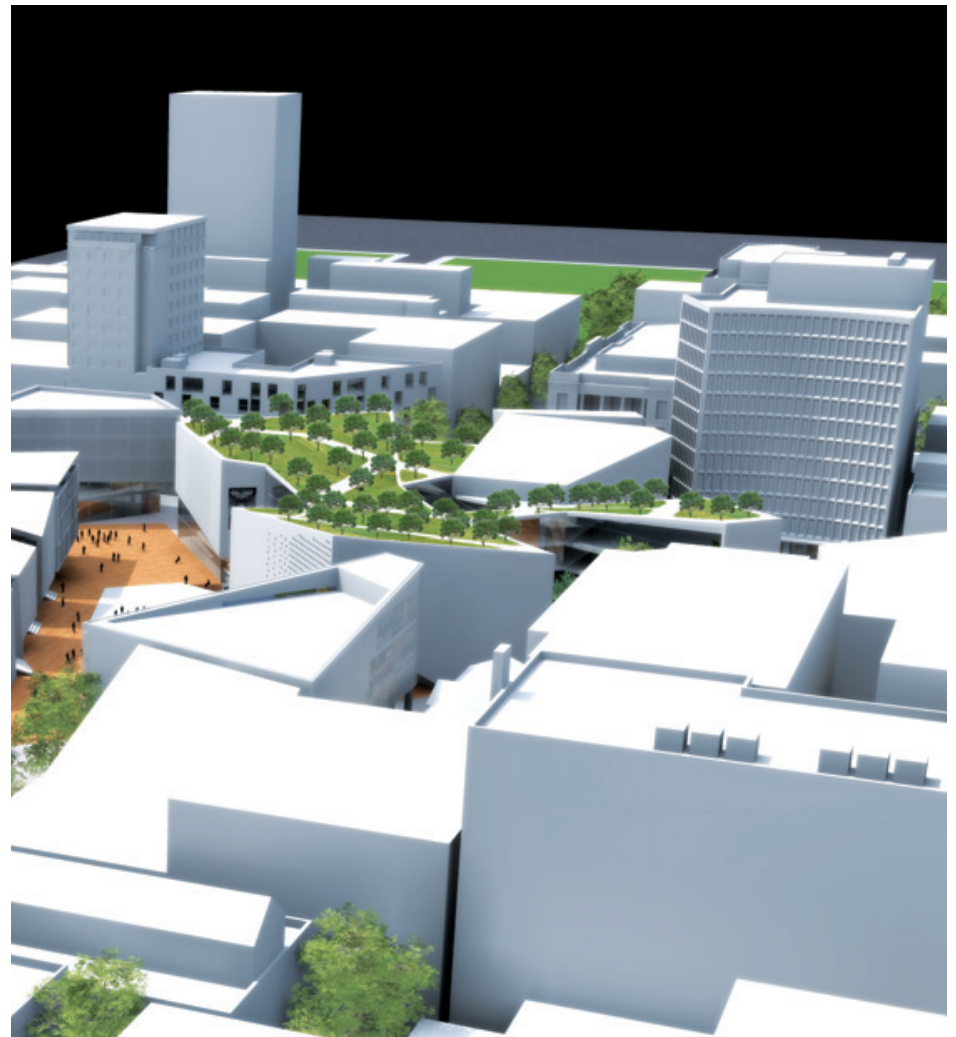

The folded and ramped surfaces atop of the Central Building Complex mimic natural grassy hill forms (see figure $216 \& 218$ ). In this respect, Concept Three fuses natural and artificial landscape features better. But it is equally as possible to integrate green roofs with more traditional buildings, such as those in Concept One and Two.

The development of Concept Three shows that integrating green space directly with the square is less important than the overall benefits to integration that topological landscape in itself has to offer. This does discount the importance that plantings and green space can have in the square. However, like Concepts One and Two, green space can be enjoyed through increasing connectivity with the Green Frame and Avon River Precinct, integrating the square as a unique piece of a larger urban framework (see figure 217).

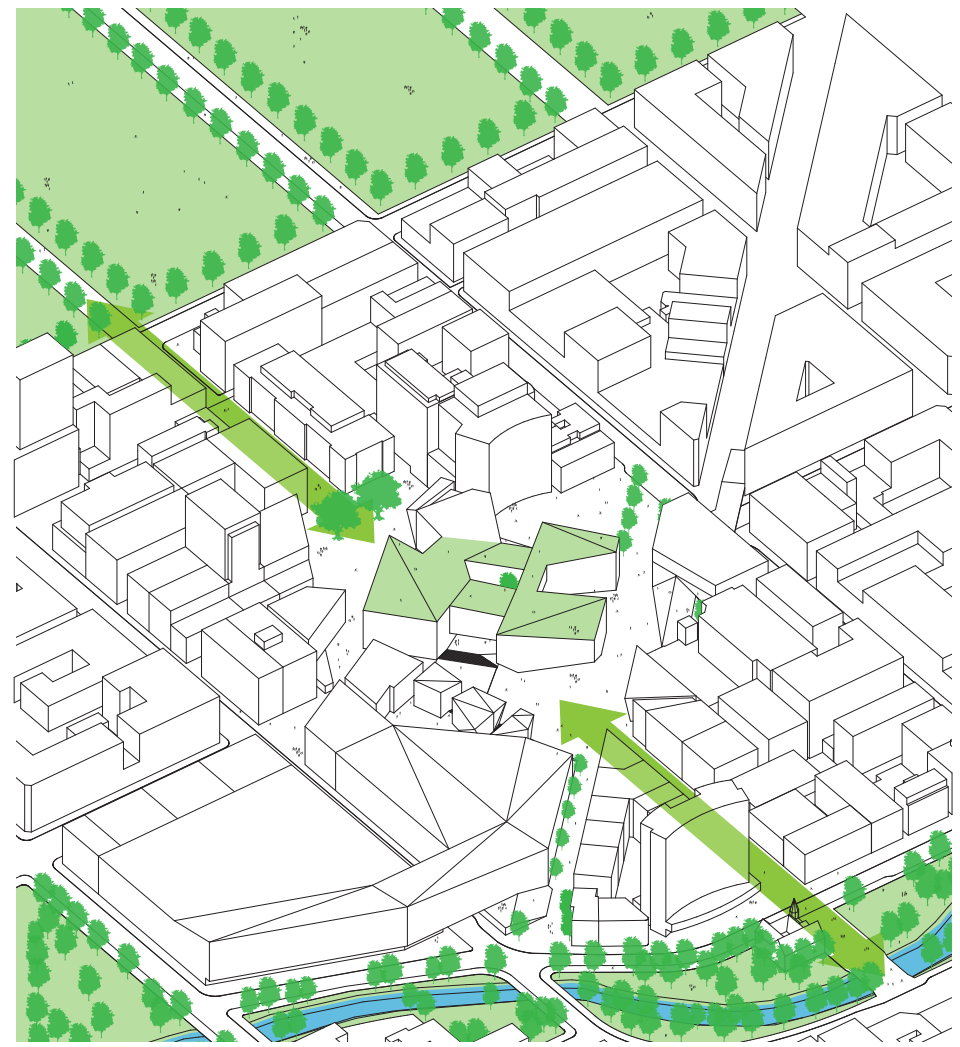


The development also produced more insights into the integration of contemporary buildings, particularly in terms of urban porosity. The folded edges of the buildings allow for the further development of more experiential qualities on which Concept Three is based, including the partial views (see figures 204 - 209). Many of these qualities are difficult to express at a conceptual or diagrammatic level and the rendered views at eye level help in the development of these and in the development of how all these spaces interrelate in this concept. For example, even though the spaces retain a high level of spatial identity and separating them from one another. The there are certain points as one moves through the spaces that create visual connections between them, revealing physical connections as well. Proving this idea that these porous building formations can retain more traditional concepts of spatial identity and enclosure, while simultaneously retaining visual and physical connectivity between the multitude of spaces (see figures 219 \& 220).

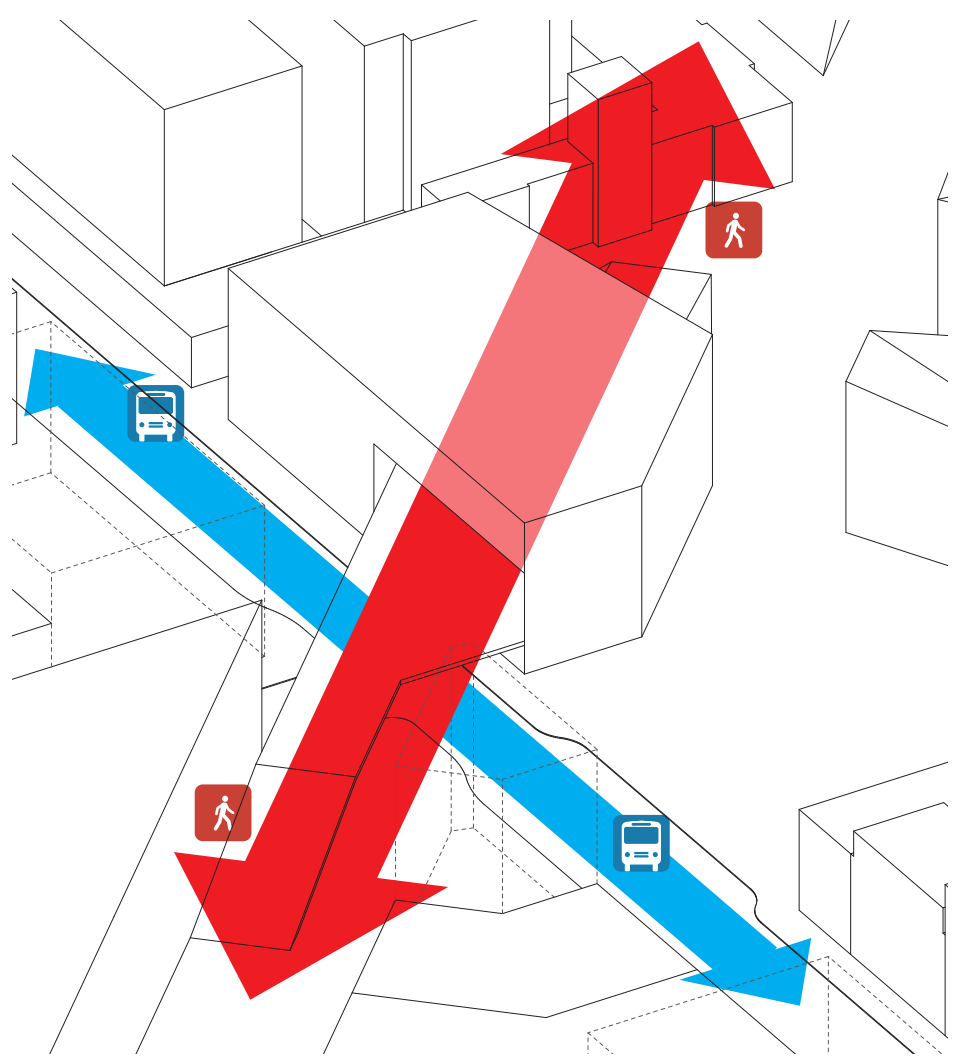

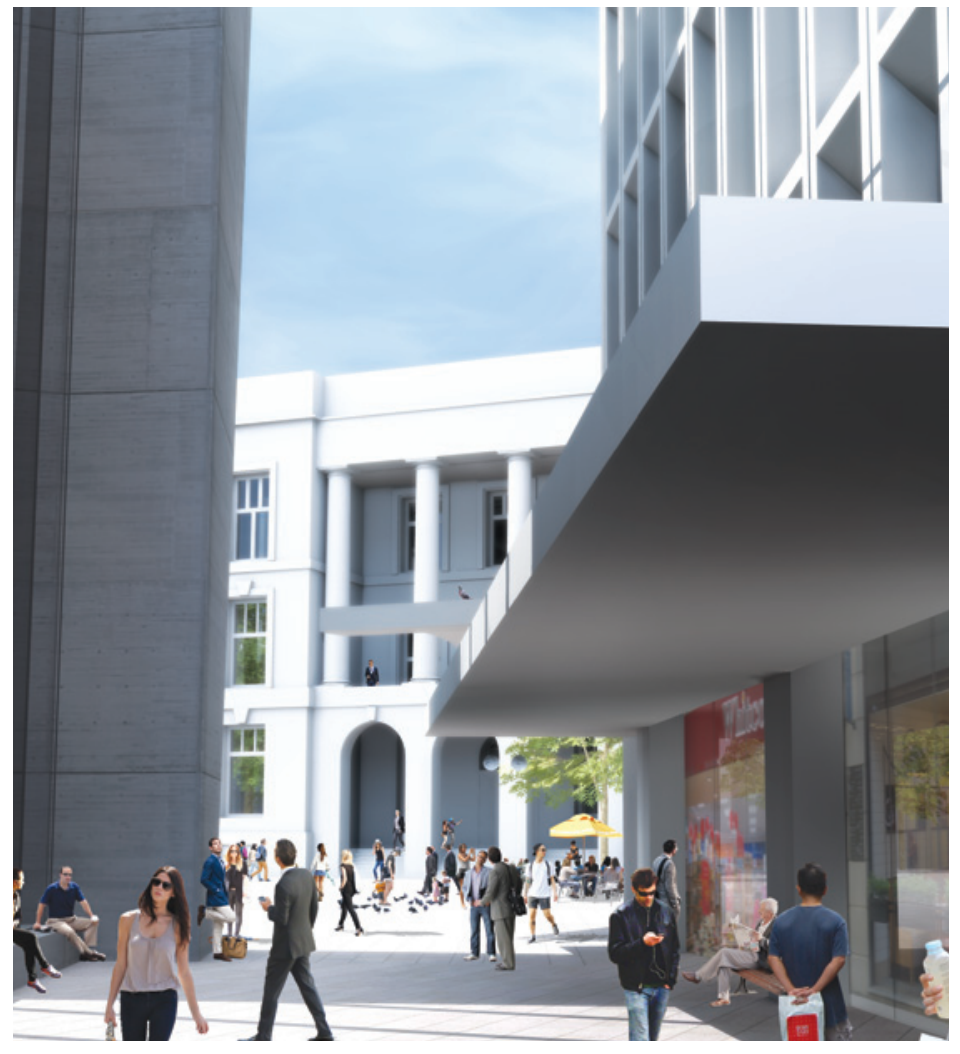

Figure 219. Partial view of OGB from South Square.

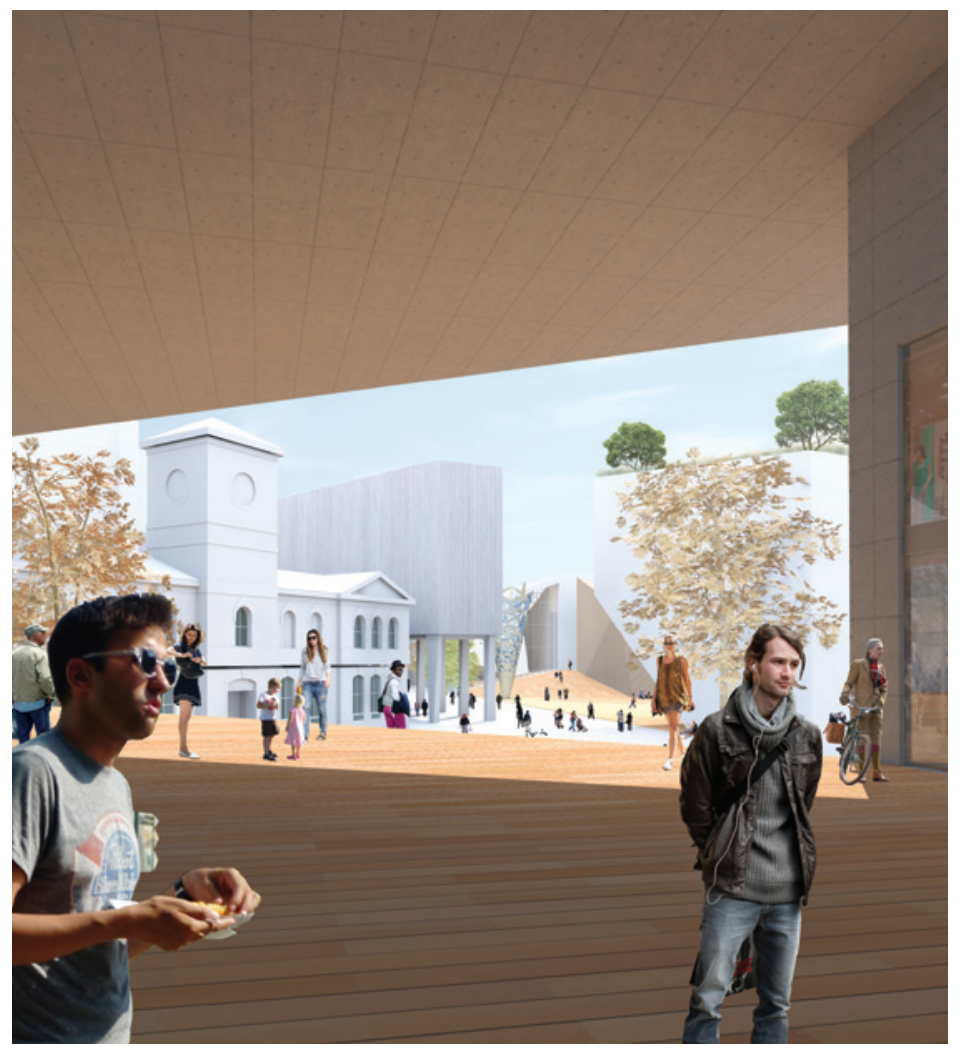

Figure 220. View from inside the porous High Street Bridge building.

Figure 221. (far left) Diagram showing the separation of flows with porous urbanism. 


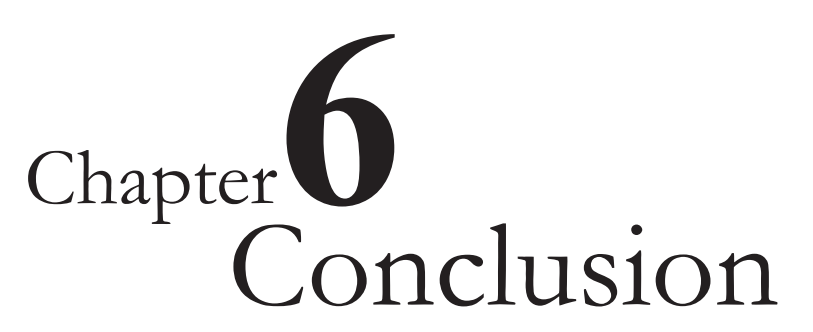


This section seeks to consolidate the findings of this thesis in order to answer the research question:

'How can the square be better integrated with the contemporary city, and to what extent do New Urbanist Design principles contribute to this union?'

\section{Introduction}

Like the research question, this chapter is divided into two parts. The first, Integrating the Square, addresses how the square can be better integrated with the contemporary city. This section summarises the findings from the design case studies and relates these findings back to presumptions made in the preceding chapters.

Ultimately the three Christchurch-based design case studies show that there are strategies to better integrate the square with the city. The development of the third concept also indicates that, in a few specific areas, New Urbanism has a limited capacity to integrate, but can benefit from the inclusion of Post Urbanist principles.

The second part, entitled The Role of New Urbanism, presents specific findings about the contribution New Urbanism makes to integration.

There are five main findings: Urban Topology and the Natural Landscape, Extra Large Architecture and Traditional Urbanism, Manipulating Scale, Proportion and Identity and Inclusive Connectivity and Excusive Connectivity.

Once again, the third design concept, (with a combination of New Urbanist and Post Urbanist design principles) provided the greatest integration and the most significant findings. Design Concept Three supports the thesis that there are specific areas of New Urbanism which limit its capacity to integrate the square with the contemporary city. Concept Three also showed that joint application of New Urbanist and Post Urbanist principles is possible and beneficial for integration.

The chapter is concluded with a Summary of Findings followed by Thoughts for Further Research. 


\section{Integrating the Square}

Integration is based on a multitude of properties working together. This insight was identified in the initial precedent study and has been verified within the design case studies.

Each design case study had a unique approach to integrating the square and each concept privileged specific integrative properties in order to achieve this.

The first two concepts had a much narrower, New Urbanist approach to integration. For example, the first concept prioritised the integration of public transit and pedestrian connectivity over other properties.

As a result the square was divided into two spatially distinct spaces. Each square is smaller and better proportioned than the pre-earthquake square and the CCDU proposal. However, the individual spaces fail to accommodate the large spatial footprint of proposed buildings such as the Convention Centre and Central City Library. Also the proposed "splitting" of the Cathedral into two equal volumes is less resolved and less convincing than the treatments in Concepts Two and Three.

These outcomes suggest that an emphasis on connectivity can become problematic if other aspects of integration are compromised. In Concept One, difficulties were encountered with spatial identity, the integration of contemporary building uses and related issues with scale and proportion.

Design Concept Two looked much more closely at integrating the existing fabric of Cathedral Square. Form was derived from the existing orthogonal street pattern and the Cathedral was retained on its original site, albeit as an attached building. The resultant square is once again of a smaller scale and better proportioned. The space is pedestrianised and celebrates what remain of Christchurch's heritage buildings.

While better able to accommodate the large footprint of the proposed Convention Centre and Library, this design does not offer the city a new and updated identity. The conservative, "European" design lacks the up to date imagery offered by the third design and, to a lesser extent, the first design. Because con- 
cept two fails to suitably update the square it becomes detached from the surrounding contemporary city.

Design Concept Three achieves the best overall integration and offers unique ways to integrate the site-specific design criteria. Including a Post Urbanist approach within the integration project means that the resulting design has more to offer the contemporary city. Concept three challenges the intrinsically conservative approaches of Concept One and Two. It also offers a critique of the pre-earthquake layout of the square and the CCDU proposal.

During the development of concept three it becomes clear that the New Urbanist principles of Scale, Proportion, Identity and Mixed Use can be combined with Post Urbanist principles of Hybridity, Porosity and Landscape Topology. The result is a more integrated and contemporary square. The remaining integration principle - Connectivity - is common to both design approaches. However, Post Urbanism is more concerned with the 'flow' of connections.

The third design embraces this inclusive approach to design and shows that the integrative properties were able to be included in a mutually beneficial way. The freedom in form making that is afforded through a Post Urbanist approach proved that the site specific deign criteria could also be successfully integrated. The design benefits of adopting a Post Urbanist as well as New Urbanist approach to designing the square have proved the presumption made at the end of Chapter Two that a more integrated square required a more inclusive approach toward design methodologies. 


\section{The Role of New Urbanism}

The design case studies of Christchurch Cathedral Square prove that squares can be better integrated with the contemporary city. However this research has found that the extent to which New Urbanism can contribute to this integration is limited.

Design Concept Three is the most contemporary of the three case studies and is used at length in the discussion as it interrogates the extent as to which New Urbanism can contribute to the integration of the square.

New Urbanism has an inherently integrative agenda but, in the context of the contemporary city, there are a few specific areas where this historically derived movement was found to be lacking.

These findings relate specifically to the integrative properties identified in Chapter Two: Scale and Proportion, Identity, Connectivity, Use and Natural Landscape.

\section{Urban Topology and the Natural Landscape}

The first two design concepts are limited in their integration of the natural landscape. They are mostly concerned with strengthening connections to the surrounding natural features, in this case the Avon River precinct and Green Frame. This way the square retains the traditional identity of being a hard landscaped space rather than becoming overly park like. As was found in the precedent study chapter, tress and other plantings can be integrated as ordering or feature elements. For example, the existing oak tree in concept two divides the main square from the subsidiary space beside the Cathedral.

Design Concept Three is unique in that it takes the integration with the natural landscape a step further by introducing topological forms to the square. These forms often imitate undulating natural landscapes and can be employed to merge public space and buildings into a single entity.

In this approach ramped surfaces are easily endowed with grass and various plantings to create an artificial landscape. The roof of the Central Building Complex in the third concept is reflective of this type of landscape integration. However the design 
was limited in its capacity to explore this relationship because specialist landscape advice was not available within the Design Case Study.

The main finding was that topological landforms create more opportunity to integrate the natural landscape without compromising the spatial identity of the square, whereas the more traditional design principals that favour horizontal and vertical distinctions are less receptive to this total integration or fusion of landscape, architecture and urbanism.

\section{Extra Large Architecture and Traditional Urbanism}

Integrating large public buildings such as the Convention Centre and the New Central City Library became an issue in Concepts One and Two. These large complexes often dominated whole edges or corners of the smaller scale squares.

The architecture of New Urbanism is often historically derived with a preference for continuous and orthogonal facades that favour vertical articulation and geometry.

However, the huge length of the Convention Centre and Library facades raises doubts about the effectiveness of such detail and creates the prospect of excessive repetition. While these New Urbanist strategies can be effective the introduction of Post Urbanist principles expands the repertoire of design strategies and offers new ways to manage excessive balk.

The third concept, however, uses the more contemporary tactics of manipulating the ground plane, fractured façades, and sloped wall surfaces in an effort to blur the distinction between building and public space.

For example, the manipulation of ground and building surfaces and the fracturing of building form means the imposing Convention Centre can be broken down into more manageable and pleasantly scaled pavilions. Lessening the impact that such a grandiose façade would have on the smaller square.

The same can be said of the Central Building Complex where the single central building has gone through an almost innumerable series of manipulations, cuts and folds in order to preserve pedestrian flows through the building, and break down the scale of the large building façades.

It is the finding of this research that traditional or New Urbanist building types struggle to integrate the extra large contemporary building complexes with the square. Contemporary design approaches, such as that of Post Urbanism, provides further opportunity to integrate large public buildings with the square.

\section{Manipulating Scale, Proportion and Identity}

Using manipulated ground and building geometries creates a unique identity for the square. Post Urbanist projects often merge figure and ground to a point where there is complete ambiguity about what is building and what is public space. This approach differs from the more figural qualities of traditional spatial identity.

This thesis finds that these buildings can be manipulated to allow for continuity between open space and the buildings. But this same freedom in form-making also allows for the preservation of more traditional properties, such as proportionality and spatial identity. The most notable example is the manipulation of the ground plane down into, and through, the Central Building Complex. This arrangement integrates an extra subterranean level, while preserving the building height so that it matches the height of surrounding buildings.

This is one aspect in which Post Urbanism can be combined with new urbanism to achieve better overall integration between building and square, and simultaneously retain a high level of spatial identity for the square

\section{Inclusive Connectivity and Exclusive Connectivity}

Connectivity is one property that is shared between New Ur- 
banism and Post Urbanism. Both streams of thought recognise the importance of integrating a high level of pedestrian, and public/private vehicular connectivity with the square. However this design thesis has found their approaches toward achieving an integrated solution differ.

Concept One has a much more inclusive approach to integrating public transport with the square. The New Urbanist principals of walkability and transit-orientated design have been used to integrate a public transit corridor between the two squares. This corridor strategically combines pedestrians, busses and cyclists into a single transit corridor on one level.

The third concept takes an alternative approach by introducing a pedestrian bridge over top of the Hereford Street transit corridor. This concept is much more focussed on preserving the flow of these different movement types, and can be termed exclusive connectivity.

This thesis is inconclusive as to which of these types of integration contributes more in terms of overall integration as there are pros and cons for both approaches and it has not been possible to accurately model pedestrian circulation.

\section{Summary of Findings}

City squares can be better integrated with the contemporary city. This thesis has found that in terms of overall integration, it is imperative to identify the right balance between multiple integrative strategies and design properties.

The development of Concept Three found that there are contemporary design approaches that can contribute to the integration of the square with the contemporary city.

The extent to which New Urbanism can contribute to the integration of the square with the contemporary city was found to be limited. There are features in the contemporary city for which New Urbanism simply does not have the design vocabulary to achieve a convincing level of integration. Examples include large contemporary buildings and natural landscapes.

However, the design case study found that these properties can be better integrated with a Post Urbanist approach. Properties such as porosity, hybridity and topological forms can offer more integrated solutions than New Urbanism can.

The last finding was that New Urbanism is limited in its ability to integrate the contemporary city square. As the last design case study showed, elements of New Urbanism and Post Urbanism can be combined in order to optimise integration. As suggested in Chapter Two, an inclusive approach to design is more likely to deliver a highly integrated square.

\section{Thoughts on Further Research}

This thesis has re-visited some specific aspects of the city square. Chapters such as the theoretical background only skimmed the surface of the subject and leave much room for expansion, particularly on the subjects of Post Urbanism and New Urbanism. The thesis was also limited to five integrative properties of Scale and Proportion, Identity, Use, Connectivity and Natural Landscape. Further study mite identify additional integrative properties. Equally further research could define these five properties in more detail.

The graphic analysis of the selected precedents, it has been noted, can easily be expanded upon. The comparative analytical technique and graphic representation leave plenty of room for refinement and could easily be employed in similar research projects.

Given the importance that Post Urbanism assumes in the design phase of the research, it would have been helpful if the precedent study had specifically included examples of Post Urbanist public space projects. An extensive study of Post Urbanist 
public spaces with a more suitable graphical analysis would be a worthwhile endeavour. More sectional and three-dimensional analytical techniques would help to expand understanding and correct over emphasis on plan based concepts and strategies.

The Design Case Study chapter could benefit from a multidisciplinary approach to the design. The design investigations privilege architectural responses to the research question. Collaboration with landscape architects would be particularly beneficial for all three concepts and would allow further investigation into the integration of the square. The third concept would benefit particularly from landscape design input, as the high level of integration between the landscape and architecture calls for a multidisciplinary design approach.

Furthermore it would have been interesting to interrogate the CCDU's plan for the redesign of the square. This proposal puts fourth a conservative plan for the square retaining the existing scale, shape and Cathedral location. While this thesis identified and adopted parts of the plan that aligned with the integrative goals of the design case studies, there is little comparison made. This is primarily because the 100 day plan was released part through the undertaking of this research, after significant portions of the research were underway.

Finally the design research would have benefitted had Post Urbanism assumed an equal role alongside New Urbanism in the research. In this research Post Urbanism was introduced as a secondary component of the thesis in order to better answer the research question. However, given the importance that Post Urbanism played in developing the findings for this thesis, it may have been better to structure the research with Post Urbanism assuming a more prominent role in the methodology. For example, with hindsight it may have been more informative to have had three design case studies, one based on New Urbanism, a hybrid New Urbanist / Post Urbanist design and a pure Post Urbanist design. 
Bibliography 
Canterbury Earthquake Recovery Authority. Central Christchurch Development Unit. Christchurch Central Recovery Plan. Christchurch: Central Christchurch Development Unit, 2012. Print.

Carmona, Matthew, et al. Public Places Urban Spaces: The Dimensions of Urban Design. Oxford: Architectural Press, 2003. Print.

"Central Library Building." Christchurch City Libraries. Christchurch City Council, n.d. Web. 19 Mar. 2013. <http:// christchurchcitylibraries.com/Heritage/places/buildings/centrallibrary/>.

Childs, Mark C. Squares: A Public Place Design Guide for Urbanists. Albuquerque: U of New Mexico P, 2004. Print.

Christchurch City Council. Draft Central City Plan. Christchurch: Christchurch City Council, 2011. Print.

Clark, Kelly. "Hidden Territories: Integrating New Zealand Secondary schools with their Suburban Contexts." MA thesis. Victoria University of Wellington, 2010. Print.

Collins, George Roseborough and Christiane Crasemann Collins. Camillo Sitte and the Birth of Modern City Planning. London: Phaidon, 1965. Print.

"Charter of the New Urbanism." Congress for the New Urbanism. Congress for the New Urbanism. Web. 19 Sept. 2012. $<$ http://www.cnu.org/charter>.

Corbett, Nick. Transforming Cities Revival in the Square. London: RIBA Enterprises, 2004. Print.

Corbusier, Le. Towards a New Architecture. Trans. Frederick Etchells. London: Architectural Press, 1946. Print.
Curtis, William J.R. Modern Architecture Since 1900. 3rd Edition. London: Phaidon, 2006. Print.

Edwards, Brian and Ayub Khan. "Libraries." Metric Handbook: Planning and Design Data. Ed. David Littlefield. 4th ed. Abingdon: Architectural Press, 2012. Print.

Ellin, Nan. Integral Urbanism. New York: Routledge, 2006. Print.

Favole, Paolo. Squares in Contemporary Architecture. Trans. Leslie A Ray. Amsterdam: Architectura \& Natura, 1995.

Print.

Feiss, Carl. "Early American Public Squares." Zucker, Paul. Town and Square. Cambridge: MIT, 1970. 237 - 255. Print.

French, Jere Stuart and Michael Doty. Urban Space: A Brief History of the City Square. 2nd ed. Dubuque: Kendall/ Hunt, 1983. Print.

Gatje, Robert F. Great Public Squares: An Architects Selection. New York: W. W. Norton \& Co, 2010. Print.

Gehl, Jan. Cities for People. Washington: Island Press, 2010. Print.

Holl, Steven. Urbanisms: Working with Doubt. New York: Princeton Architectural Press, 2009. Print.

Home, Robert. Of Planting and Planning: The making of British Colonial Cities. London: E \& FN Spon, 1997. Print.

Jacobs, Jane. The Death and Life of Great American Cities. 1965. New York: Modern Library, 2011. Print.

Jenkins, Eric J. To Scale: One Hundred Urban Plans. New York: 
Routledge, 2008. Print.

Kelbaugh, Douglas. "Three Urbanisms and the Public Realm." Space Syntax 3rd International Symposium, Atlanta, Georgia 7-11 May 2001. Michigan: A. Alfred Taubman College of Architecture and Urban Planning, 2001. Web. 11 Oct. 2012. <http://www.ucl.ac.uk/bartlett/3sss/proceedings.htm>.

—. "Toward an Integrated Paradigm: Further Thoughts on the three Urbanisms." Places 19.2 (2007) : 12-19. Print.

Koolhaas, Rem and Bruce Mau. Small, Medium, Large, Extralarge. 2 vols. Rotterdam: 010, 1995. Print.

Krier, Leon. The Architecture of Community. Ed. Dhiru A.

Thadani and Peter J. Hetzel. Washington: Island, 2009. Print.

Krier, Rob. Urban Space. New York: Rizzoli, 1979. Print.

Lynch, Kevin. The Image of the City. Massachusetts: MIT, 1960. Print.

Mallgrave, Harry Francis and David Goodman. Introduction to Architectural Theory: 1968 to the Present. Malden: WileyBlackwell, 2011. Print.

Marcus, Clair Cooper and Carolyn Francis, People Places. 2nd ed. John Wiley \& Sons, 1998. Print.

Moughtin, Cliff. Urban Design Street and Square. 3rd ed. Oxford: Architectural Press, 2003. Print.

NZ Federation of University Women, Canterbury Branch. Round The Square: A History of Christchurch's Cathedral Square. Christchurch: Clerestory, 1995. Print.
Reps, John W. The Making of Urban America. A History of City Planning in the United States. Meriden: Princeton UP, 1965. Print.

Rowe, Colin and Fred Koetter. Collage City. Cambridge: MIT, 1978. Print.

Shields, Fraser. "Diagrams in Architecture: An Examination of Diagram Based Design Methods in Contemporary Urban Architecture Projects.” MA thesis. Victoria University of Wellington, 2010. Print.

Sitte, Camillo. The Art of Building Cities: City Building According to its Artistic Fundamentals. Trans. Charles T Stewart. Westport: Hyperion, 1979. Print.

Tzonis, Alexander. Le Corbusier the Poetics of Macbine and Metaphor. New York: Universe, 2001. Print.

Zucker, Paul. Town and Square. Cambridge: MIT, 1970. Print. 


\section{List of Figures}


Figure 1. Diagram outlining the thesis field of enquiry.

Figure 2. Authors drawing of the Agora, Assos. Drawn from: Zucker, Paul. Town and Square. Cambridge: M.I.T. Press, 40.

Figure 3. Authors drawing of the Acropolis, Athens. Drawn from: Sitte, Camillo. The Art of Building Cities. Westport: Hyperion Press, 6.

Figure 4. Authors drawing of Piazza San Carlo, Turin, Italy.

Figure 5. Authors drawing of Freiburg Munster, Freiburg, Germany.

Figure 6. Authors drawing of Piazza del Santo, Padua, Italy.

Figure 7. Authors drawing of Torico Square, Teruel, Spain.

Figure 8. Diagram of Medieval Market Square Morphosis. Redrawn from: Jere French, Urban Space. Dubuque: Kendall/Hunt, 63-64.

Figure 9. Authors diagram showing some basic rules of proportion between building and square. Drawn From: Moughtin, Cliff. Urban Design Street and Square. Oxford: Architectural Press, 100.

Figure 10. Authors drawing of William Penn's 1682 Plan for Philadelphia, Pennsylvania. Drawn from: Reps, John. The Making of Urban America. Meriden: Princeton UP, 162.

Figure 11. Authors drawing of the 1856 Plan of Savannah, Georgia. Drawn from: Reps, John. The Making of Urban America. Meriden: Princeton UP, 200.

Figure 12. Le Corbusiers Ville Contemporaine. Source: Alexander Tzonis, Le Corbusier The Poetics of Machine and Metaphor. New York: Universe, 73.

Figure 14. Authors drawing of City National Plaza, Los Angeles showing the continuity of public space.

Figure 15. Authors drawing of City National Plaza, Los Angeles showing the barriers to the modern field of public space.

Figure 13. Le Corbusiers Plan Voisin, Paris, 1925. Source: Colin
Rowe \& Fred Koetter, Collage City. Cambridge: MIT Press, 74-75.

Figure 16. Authors drawing of City National Plaza, Los Angeles showing the integration of vehicular traffic with the square.

Figure 17. Authors drawing of Lever House, New York. The podium integrates the oppressive scale of the tower with the public space at ground level.

Figure 18. Piazza San Marco, Italy Source: Kevin Lynch, The Image of the City. Cambridge: MIT Press, 79.

Figure 19. Flowing Gardens and Exhibition Hall, Xi'an, China. Source: Palma, Cristobal. "Flowing Gardens.” Photograph. de Muynck, Bert. “The Xi'an Trident.” Domus. 949 (2011): 24.

Figure 20. Authors diagram showing the Post Urbanist integration of the natural landscape.

Figure 21. Time Square Redux. Source: Ingels, Bjarke et al. "Time Square Redux.” Illustration. BIG. n.p. Web. 18 Feb. 2013. $<$ http://www.big.dk/\#projects-nyt>

Figure 22. Steven Holl's World Design Park Complex, Seoul, Korea. Steven Holl, Urbanisms, Working with Doubt. New York: Princeton Architectural Press, 36.

Figure 23. Authors drawing of Rem Koolhaas' Casa de Musica, Portugal.

Figure 24. Diagram showing drawing conventions used.

Figure 25. Drawing showing international locations of case study squares.

Figure 26. Photographs of selected precedents. Full photo citations follow:

Barking Town Square: Ebeling, Philipp. "Barking Town Square." Photograph. muf architecture/art. n.d. Web. 19 Dec. 2012. <http://www.muf.co.uk/portfolio/barking-townsquare- $2>$

Bonn Square: Graeme Massie Architects. "Bonn Square.” Pho- 
tograph. Greame Massie Architects. n.d. Web. 19 Dec.

2012. <http://www.graememassie.com/projects.html>

Philip Burton Federal Plaza: Barnes, Richard. "Philip Burton

Federal Plaza.” Photograph. Bernheimer Architecture. n.d. Web. 19 Dec. 2012. <http://bernheimerarchitecture. com/\#/philip-burton-federal-plaza-san-francisco/>

Federation Square: “Federation Square.” Photograph. Bates Smart Architects. n.d. Web. 19 Dec. 2012. < http://www.batessmart.com.au/projects/mixed-use/federation-squaremelbourne>

Grand Canal Square: “Grand Canal Square.” Photograph. Martha Schwartz Partners. n.d. Web. 19 Dec. 2012. <http:// www.marthaschwartz.com/projects/civic_institutional_ dublin.php\#>

New Amsterdam Plein: D’Addio, James. "New Amsterdam Plein \& Pavilion." Photograph. Orange Alert, Dutch Art Events. Kingdom of the Netherlands, 11 May 2011. Web. 19 Dec. 2012. <http://www.dutchartevents.com/architecture/2011/05/11/announcement-new-amsterdamplein-pavilion-to-open-on-may-12-2011-the-battery-newyork-city/>

Plaza de Santo Domingo: "Plaza de Santo Domingo by Marinas Arquitectos Asociados.” Photograph. Landzine, Landscape Architecture Works. 1 Mar. 2012. Web. 8 Dec. 2012. <http://www.landezine.com/index.php/2012/03/ plaza-de-santo-domingo-landscape-architecture-madri/ plaza-de-santo-domingo-by-marinas-arquitectos-asociados-03/>

Theatre Square: Geuze, Adriaan et al. "Schouwburgplein." Photograph. West 8. n.d. Web. 19 Dec. 2012. < http://www. west8.nl/projects/all/schouwburgplein/>

Town Hall Square: “Town Hall Square.” Photograph. Janet Rosenberg Associates. n.d. Web. 19 Dec. 2012. <http://www. jrala.ca/site/\#>

Union Square: “Union Square.” Photograph. MD Fotheringham
Landscape Architects. n.d. Web. 19 Dec. 2012. <http:// www.mdfotheringham.com/mdfotheringham.com/ Parks_Public_Places/Pages/Union_Square.html\#15>

Urban Lounge: “Stadtlounge.” Photograph. Carlos Martinez Architekten. n.d. Web. 19 Dec. 2012. <http://www. carlosmartinez.ch/projekt.php?p=33>

The City Dune: Andersson, Stig L. et al. "The City Dune/ SEB Bank.” Photograph. SLA. n.d. Web. 19 Dec. 2012. <http://www.sla.dk/byrum/sebgb.htm>

St. Patrick's Square: “St Patricks's Square.” Photograph. Boffamiskell. 2010. Web. 19 Dec. 2012. <http://www.boffamiskell.co.nz/news/downloads/BoffaMiskell_webs_ news_NZILA_awards_100423_final_small.pdf $>$

Square Four: Bruneel, Geraldine, Matteo Piazza and Roger Moukarzel. "Square Four.” Photograph. General Design 2010 ASLA Professional Awards. American Society of Landscape Architects. 2010. Web. 19 Dec. 2012. < http://www. asla.org/2010awards/069.html>

Meeting House Square: “Meeting House Square.” Photograph. Temple Bar Cultural Trust. n.d. Web. 19 Dec. 2012. <http://www.meetinghousesquare.ie/ meetingh/images/uploads/feature-cinema.jpg>

Cathedral Square: Authors own photograph.

Figure 27. Barking Town Square figure ground plan. Scale 1:2500

Figure 28. Analytical overlays.

Figure 29. Bonn Square figure ground plan. Scale 1:2500

Figure 30. Analytical overlays.

Figure 31. Philip Burton Federal Plaza figure ground plan. Scale $1: 2500$

Figure 32. Analytical overlays.

Figure 33. Federation Square figure ground plan. Scale 1:2500

Figure 34. Analytical overlays.

Figure 35. Grand Canal Square figure ground plan. Scale 1:2500 
Figure 36. Analytical overlays.

Figure 37. Meeting House Square figure ground plan. Scale 1:2500

Figure 38. Analytical overlays.

Figure 39. New Amsterdam Plein figure ground plan. Scale 1:2500

Figure 40. Analytical overlays.

Figure 41. Plaza de Santo Domingo figure ground plan. Scale 1:2500

Figure 42. Analytical overlays.

Figure 43. Square Four figure ground plan. Scale 1:2500

Figure 44. Analytical overlays.

Figure 45. St. Patrick's Square figure ground plan. Scale 1:2500

Figure 46. Analytical overlays.

Figure 47. The City Dune figure ground plan. Scale 1:2500

Figure 48. Analytical overlays.

Figure 49. Theatre Square figure ground plan. Scale 1:2500

Figure 50. Analytical overlays.

Figure 51. Town Hall Square figure ground plan. Scale 1:2500

Figure 52. Analytical overlays.

Figure 53. Union Square figure ground plan. Scale 1:2500

Figure 54. Analytical overlays.

Figure 55. Urban Lounge figure ground plan. Scale 1:2500

Figure 56. Analytical overlays.

Figure 57. Cathedral Square figure ground plan. Scale 1:2500

Figure 58. Analytical overlays.

Figure 59. Figure ground plan comparisons.

Figure 60. Figure ground findings.

Figure 61. Comparison of public transit plans.

Figure 62. Public transit findings.

Figure 63. Comparison of city grid plans.
Figure 64. City grid findings.

Figure 65. Comparison of space hierarchy plans.

Figure 66. Space hierarchy findings.

Figure 67. Comparison of active edge plans.

Figure 68. Active edge findings.

Figure 69. Comparison of green space plans.

Figure 70. Green space findings.

Figure 71. Edward Jollie's 1850 plan of Christchurch. Source: Jollie, Edward. Black Map of Christchurch. 1850. Archives New Zealand, Christchurch. Archives New Zealand. Web. 25 Apr. 2013. <http://archives.govt.nz/gallery/v/

Online + Regional+Exhibitions/Chregionalofficegallery/sss/Black+Map+of+Christchurch/CH1031180_+273_+Black+Map+Christchurch $+1850+$ Copy+2_+_2_JPG.html?g2_imageViewsIndex =1>

Figure 72. Map of Christchurch suburbs.

Figure 73. Map of Christchurch's road network.

Figure 74. Topographical map of Christchurch city.

Figure 75. Map of Christchurch green space and reserves.

Figure 76. Map of Christchurch rivers, streams and lakes.

Figure 77. Map showing Christchurch's red zoned land.

Figure 78. Detailed map of Christchurch central and Square.

Figure 79. Map showing walking distances from Cathedral Square.

Figure 80. Map of central Christchurch gridiron street pattern.

Figure 81. Map of main streets that intersect the square.

Figure 82. Map Avon River proximate to Cathedral Square.

Figure 83. Map of green space proximate to Cathedral Square.

Figure 84. Pre-earthquake Plan of Cathedral Square and surrounding streets.

Figure 85. Plan of Cathedral Square showing pre-earthquake pedestrian areas and lanes. 
Figure 86. Plan of Cathedral Square showing pre-earthquake vehicular connections.

Figure 87. Plan of Cathedral Square showing pre-earthquake public transit routes through the square.

Figure 88. Plan of Cathedral Square showing significant areas of green space and significant planting within the pre-earthquake square.

Figure 89. Plan of Cathedral Square showing hierarchy of space within the pre-earthquake square.

Figure 90. Pre-earthquake Cathedral Square.

Figure 91. Isometric drawing showing condemned buildings to be demolished.

Figure 92. Drawing showing the pre-earthquake buildings that front onto the square and significant planting.

Figure 93. Isometric drawing showing remaining building stock proximate to Cathedral Square.

Figure 94. Map of the central city plan proposed by the CCDU. Source: Canterbury Earthquake Recovery Authority. Central Christchurch Development Unit. Christchurch Central Recovery Plan. July 2012. Web. 16 March 2013. $<$ http://ccdu.govt.nz/the-plan>

Figure 95. Illustration from the Blueprint plan of the proposed square design. Note the Convention centre in the top left corner of the image. Source: Canterbury Earthquake Recovery Authority. Central Christchurch Development Unit. Christchurch Central Recovery Plan. July 2012. Web. 16 March 2013. <http://ccdu.govt.nz/the-plan>

Figure 96. Source: "Christchurch Cathedral restoration design option." Illustration. One News. Television New Zealand, 4 Apr. 2013. Web. 16 May 2013. <http://tvnz.co.nz/national-news/design-options-new-christchurch-cathedralunveiled-5394153>

Figure 97. Source: "Christchurch Cathedral traditional option." Illustration. One News. Television New Zealand, 4 Apr.
2013. Web. 16 May 2013. <http://tvnz.co.nz/nationalnews/design-options-new-christchurch-cathedral-unveiled-5394153>

Figure 98. Source: “Christchurch Cathedral contemporary option." Illustration. One News. Television New Zealand, 4 Apr. 2013. Web. 16 May 2013. <http://tvnz.co.nz/national-news/design-options-new-christchurch-cathedralunveiled-5394153>

Figure 99. Diagrammatic map showing the original green belt around Christchurch city.

Figure 100. Diagrammatic map showing the proposed green frame around central Christchurch.

Figure 101. Design research process.

Figure 102. Intersecting transit and pedestrian paths, concept one.

Figure 103. Concept one design model.

Figure 104. Concept one planning diagrams.

Figure 105. Isometric view looking south east showing public transit.

Figure 106. Isometric view looking south east showing pedestrian path.

Figure 107. Isometric view looking south east showing spatial enclosure.

Figure 108. Isometric view looking south east showing scale and proportion.

Figure 109. Isometric view looking south east showing green space.

Figure 110. Isometric view looking south east showing public transit detail.

Figure 111. Isometric view looking south east showing pedestrian connectivity.

Figure 112. Isometric view looking south east showing building use. 
Figure 113. Isometric view of a typical mixed use building.

Figure 114. Aerial view of the western square.

Figure 115. View looking across the western square.

Figure 116. View looking into western square also showing the path to the eastern square.

Figure 117. Aerial view of the eastern square.

Figure 118. View looking across the eastern square at the Millennium hotel and new Cathedral.

Figure 119. Aerial view of Millennium hotel lane and connection to Colombo Street transit corridor.

Figure 120. Aerial view of Colonial Lane connecting the eastern square to Gloucester Street.

Figure 121. View of Colonial Lane and Library sky bridge.

Figure 122. View looking westward across both squares showing east west pedestrian path.

Figure 123. View of Cathedral in concept two.

Figure 124. Concept two design model.

Figure 125. Concept two planning diagrams.

Figure 126. Isometric view looking south east showing the square.

Figure 127. Isometric view looking south east showing raised buildings.

Figure 128. Isometric view looking south east showing spatial identity.

Figure 129. Isometric view looking south east showing scale and proportion.

Figure 130. Isometric view looking south east showing pedestrian connections.

Figure 131. Isometric view looking south east showing public transit.

Figure 132. Isometric view looking south east showing building use.
Figure 133. Isometric view looking south east showing green space.

Figure 134. Aerial view of the square.

Figure 135. View looking north east across square.

Figure 136. View looking south west across the square.

Figure 139. Aerial view of Cathedral and tower.

Figure 137. View looking south down Colombo street with protruding Cathedral tower.

Figure 138. View down Worcester Boulevard of Cathedral from Avon River.

Figure 141. Aerial view of the square annex.

Figure 140. View looking westward across the whole scheme.

Figure 142. View looking east into the square annex with OGB in the background.

Figure 143. View looking west across concept three.

Figure 144. Concept three design model.

Figure 145. Concept three planning diagrams.

Figure 146. Isometric view looking south east showing new buildings.

Figure 147. Isometric view looking south east showing High Street pedestrian path.

Figure 148. Isometric view looking south east showing public transit.

Figure 149. Isometric view looking south east showing multiple spaces.

Figure 150. Isometric view looking south east showing building use.

Figure 151. Isometric view looking south east showing green space.

Figure 152. Isometric view showing pedestrian and vehicular flows. 
Figure 153. Isometric view showing porous enclosure.

Figure 154. Isometric view showing South Square enclosure.

Figure 155. Isometric view showing porosity of the Central Building Complex.

Figure 156. Isometric view showing pedestrian flows.

Figure 157. Isometric view showing terminal view of OGB.

Figure 158. Isometric view showing OGB Square enclosure.

Figure 159. Isometric view showing terminal view of CPO building.

Figure 160. Isometric view showing North Square enclosure.

Figure 161. Isometric view showing porosity of the Convention Centre pavilions.

Figure 162. Isometric view showing Convention Centre Square enclosure.

Figure 163. Isometric view showing raised floor of the Convention Centre Square.

Figure 164. Isometric view showing sub-floor parking and integrated public transit path.

Figure 165. Aerial view of South Square.

Figure 166. View looking due north into the South Square.

Figure 167. View through High Street bridge building showing the partial views of the $\mathrm{CPO}$ building.

Figure 170. Aerial view of the western entrance to the central complex.

Figure 168. View down Strand Lane.

Figure 169. View looking north showing the library quarter of the central complex and the Convention Centre pavilions behind.

Figure 171. View looking northward of the High Street extension.

Figure 172. View looking eastward across the square of the Central Building Complex.
Figure 173. View of library quarter from Worcester Boulevard.

Figure 176. Aerial view where North Square and OGB Square overlap.

Figure 174. View into North Square, to the right the new Library, to the left Convention Centre pavilions.

Figure 175. View of CPO building inside North Square.

Figure 177. Aerial view of OGB Square.

Figure 178. View looking south toward OGB Square.

Figure 179. View looking due south across the Central Building Complex with Colonial Lane in the foreground.

Figure 182. Aerial view of OGB Square and the narrow link back to South Square.

Figure 180. View of OGB.

Figure 181. View looking down Worcester Boulevard toward the Central Building Complex.

Figure 183. Aerial view of concept three.

Figure 184. Aerial view looking south west across the square.

Figure 185. Aerial view looking down into North Square showing the folded and stepped surfaces from the Centra; Building Complex.

Figure 186. Aerial view looking north west across the square.

Figure 187. View looking down Hereford Street showing the bridge and entry to the South Square.

Figure 188. View from the Hereford Street Bridge looking into the South Square.

Figure 189. View looking into the Square from Strand Lane.

Figure 190. View of CPO building from inside the Hereford Bridge Building.

Figure 191. View looking north down High Street extension.

Figure 192. View out to North Square from inside the Central Building Complex. 
Figure 193. View of North Square looking toward the Convention Centre pavilions.

Figure 194. Terminal view looking toward the OGB.

Figure 195. Terminal view looking toward the CPO,

Figure 196. Aerial view looking south east across the square showing the High Street extension.

Figure 197. View of open air atrium inside the Central Building Complex.

Figure 198. View of OGB from South Square.

Figure 199. Aerial view looking into OGB Square.

Figure 200. View looking due north across Colonial Lane entry to OGB Square.

Figure 201. View looking down Worcester Boulevard toward the Square.

Figure 202. View looking north east across the square.

Figure 203. Close up of North Square showing manipulated building shapes.

Figure 204. Diagram showing the enclosing buildings about the North Square.

Figure 205. View of Convention Centre pavilions.

Figure 206. Terminal view of OGB framed by new buildings.

Figure 207. Terminal view of CPO framed by new buildings.

Figure 208. Diagram showing the framed terminal view of the OGB.

Figure 209. Diagram showing terminal view of CPO.

Figure 210. Aerial view showing the buildings that moderate the non-orthogonal and orthogonal urban geometry.

Figure 211. Aerial view showing the integration of the anomalous High Street.

Figure 212. View of North Square in the evening showing the contextual building forms and continuous building heights.
Figure 213. Close up of South Square from High Street Bridge, note the timber surface that rises out of the ground to enclose the square from High Street.

Figure 214. View showing ramped surfaces that fold down into the Central Building Complex.

Figure 215. Diagram showing ramped surfaces that enter the Central Building Complex.

Figure 216. View looking east of the green roof atop the Central Building Complex.

Figure 217. Isometric diagram showing the green space relative to the square.

Figure 218. Aerial view of Central Building Complex green roof.

Figure 219. Partial view of OGB from South Square.

Figure 220. View from inside the porous High Street Bridge building.

Figure 221. Diagram showing the separation of flows with porous urbanism.

Figure 222. Aerial view of Concept Three at night.

Figure 223. Pioneer Courthouse Square, Portland, Oregon. Scale $1: 1000$

Figure 224. The Octagon, Dunedin, New Zealand. Scale 1:1000

Figure 225. Union Square, San Francisco, California. Scale 1:1000 Figure 226. Federation Square, Melbourne, Australia. Scale 1:1000 Figure 227. Nathan Philips Square Toronto, Canada. Scale 1:1000 Figure 228. Cathedral Square, Christchurch, New Zealand. Scale 1:1000 


\section{Appendix 1}

Comprehensive List of Precedent Case Studies

\begin{tabular}{|c|c|c|c|}
\hline Square & Location & Designer & Completion Date \\
\hline Barking Town Square & $\begin{array}{l}\text { Barking, Greater London, } \\
\text { England }\end{array}$ & Muf Architecture/Art & 2010 \\
\hline Federation Square & Melbourne, Australia & $\begin{array}{l}\text { LAB Architecture \& Bates } \\
\text { Smart }\end{array}$ & 2002 \\
\hline Union Square & San Francisco, California & $\begin{array}{l}\text { April Phillips Design Works } \\
\text { \& Forthingham Landscape } \\
\text { Architects }\end{array}$ & 2002 \\
\hline Meeting House Square & Temple Bar, Dublin, Ireland & Sean Harrington Architects & 2011 \\
\hline Town Hall Square & Toronto, Canada & Janet Rosenberg \& Associates & 2005 \\
\hline Pioneer Courthouse Square & Portland, Oregon & Will Martin & 1984 \\
\hline Place Jacques Cartier & Montreal, Canada & Gh3 Design & $\mathrm{N} / \mathrm{A}$ \\
\hline Malvern Square & Melbourne, Australia & Rush Wright Associates & 2006 \\
\hline Dorchester Square & Montreal, Canada & $\begin{array}{l}\text { Claude Cormier Architects, } \\
\text { Paysagistes Inc \& Groupe } \\
\text { Cardinal Hardy }\end{array}$ & 2010 \\
\hline Federal Plaza & San Francisco, California & $\begin{array}{l}\text { Della Valle \& Bernheimer } \\
\text { Design }\end{array}$ & 2000 \\
\hline Royal Victoria Square & London, England & Patel Taylor & 2000 \\
\hline $\begin{array}{l}\text { Piazza del Duomo e il Muni- } \\
\text { cipio (Piazza a Sennai) }\end{array}$ & Sinnai, Cagliari Italy & $\begin{array}{l}\text { Delogu - } \\
\text { Lixi Architetti Associati }\end{array}$ & 1999 \\
\hline Plaza de los Fueros & Estella, Spain & Francisco Jose Mangado & 1993 \\
\hline Ole Bulls Plass & Bergen, Norway & Arkitekten Gruppe Cubus & 1993 \\
\hline Louis Jeantet Foundation & Geneva, Switzerland & Domino Architects & 1995 \\
\hline Pershing Square & Los Angeles, California & Ricardo Legorreta & 1994 \\
\hline Todos Santos Plaza & Concord, California & Georges Hargreaves & 1993 \\
\hline
\end{tabular}




\begin{tabular}{|c|c|c|c|}
\hline $\begin{array}{l}\text { Urban Garden in Norresund- } \\
\text { by }\end{array}$ & $\begin{array}{l}\text { Stigsborg, Norresundby, Aal- } \\
\text { bory, Denmark }\end{array}$ & Stig L. Andersson (SLA) & 2005 \\
\hline $\begin{array}{l}\text { Almost Nothing (Mies van } \\
\text { der Rohe Plaza) }\end{array}$ & Detroit, Minessota & $\begin{array}{l}\text { PLY Architecture \& } \\
\text { PEG Office of landscape } \\
\text { architecture }\end{array}$ & 2004 \\
\hline Stadtlounge (Urban Lounge) & St. Gallen, Switzerland & $\begin{array}{l}\text { Carlos Martinez with Pipilotti } \\
\text { Rist }\end{array}$ & 2006 \\
\hline Main Town Square & Caernarfon, Wales & Taylor Young LTD & 2008 \\
\hline Mint Plaza & San Francisco, California & CMG Landscape Architecture & 2008 \\
\hline Jesse Square & San Francisco, California & $\begin{array}{l}\text { Handel Architects LLP \& } \\
\text { Cliff Lowe \& Associates }\end{array}$ & 2008 \\
\hline Saint Patricks Square & Auckland, New Zealand & Boffa Miskell & 2007 \\
\hline Square Four & Beirut, Lebanon & $\begin{array}{l}\text { Vladimir Djurovic Landscape } \\
\text { Architects }\end{array}$ & 2004 \\
\hline Victoria Square & Adelaide, Australia & $\begin{array}{l}\text { Kevin Taylor - Taylor, Cullity } \\
\text { Lethlean. }\end{array}$ & 2005 \\
\hline Bonn Square & Oxford, England & Greame Massie Architects & 2008 \\
\hline Lyric Square & Hammersmith, England & $\begin{array}{l}\text { Gross Max Landscape Archi- } \\
\text { tects }\end{array}$ & 2005 \\
\hline Main Square & Pag, Croatia & Nenad Fabijanic & 1995 \\
\hline Michaelerplatz & Vienna, Austria & Studio Hollein Architecture & 1992 \\
\hline $\begin{array}{l}\text { Schouwburgplein } \\
\text { (Theatre Square) }\end{array}$ & Rotterdam, The Netherlands & $\begin{array}{l}\text { Adriaan Geuze and West } 8 \\
\text { Architects }\end{array}$ & 1996 \\
\hline Garden Place & Hamilton, New Zealand & $\begin{array}{l}\text { Hamilton City Council, Reset } \\
\text { Design \& Downer Edi Works }\end{array}$ & 2010 \\
\hline Aotea Square & Auckland, New Zealand & $\begin{array}{l}\text { Ted Smyth \& Associates; Rod } \\
\text { Barnett }\end{array}$ & 2010 \\
\hline Civic Square & $\begin{array}{l}\text { Palmerston North, New } \\
\text { Zealand }\end{array}$ & Guy Cleverley CCM & 2005 \\
\hline Plaza del Torico & Teruel, Spain & $\begin{array}{l}\text { Fermin Vazquez/b720 Arqui- } \\
\text { tectos }\end{array}$ & 2007 \\
\hline Square in Bari & Bari, Italy & $\begin{array}{l}\text { Ma0 \& Emmeazero studio } \\
\text { d'architettura }\end{array}$ & 2001 \\
\hline Woerman Plaza & $\begin{array}{l}\text { Las Palmas de gran Canaria } \\
\text { (Canary Islands) Spain } \\
\end{array}$ & Abalos and Herreros & 2003 \\
\hline $\begin{array}{l}\text { FUZI (FuBganger zone In- } \\
\text { nichen) }\end{array}$ & Innichen San Candido, Italy & AllesWirdGut ZT GmbH & 2002 \\
\hline
\end{tabular}




\begin{tabular}{|c|c|c|c|}
\hline Cathedral Square & Almeria, Spain & Alberto Campo Baeza & 2000 \\
\hline Desert Plaza & Barakaldo, Spain & Eduardo Arrogo & 2002 \\
\hline LUX - Stahlhof Belval Ouest & Esch-sur-Alzette Luxembourg & Alles Wird Gut Architektur & 2007 \\
\hline $\begin{array}{l}\text { Flowers Stands Tirso de Mo- } \\
\text { lina Square }\end{array}$ & Madrid, Spain & Galan/Lubuscher Arquitectos & 2006 \\
\hline Evolution Square & Switzerland & Vogt landschaftsarchitekenay & 2011 \\
\hline The City Dune & $\begin{array}{l}\text { Seb Bank, Copenhagen, } \\
\text { Denmark }\end{array}$ & SLA & 2010 \\
\hline $\begin{array}{l}\text { Chess park at the brand } \\
\text { boulevard passageway }\end{array}$ & Glendale, California & Rios Clement: Hale Studios & 2004 \\
\hline Piazza Garibaldi & Naples, Italy & $\begin{array}{l}\text { Dominique Perrault architec- } \\
\text { ture }\end{array}$ & 2008 \\
\hline New Street Square & London, England & Grontmij & $\mathrm{N} / \mathrm{A}$ \\
\hline Gillet Square & Hackney, England & Hawkins/Brown & 2006 \\
\hline The Old Bailey & London, England & Burns \& Nice & 2006 \\
\hline Leichester Square & London, England & Burns \& Nice & 2012 \\
\hline Brogard Square & Copenhagen, Denmark & Stig L. Andersson (SLA) & 2001 \\
\hline Blue Carpet & $\begin{array}{l}\text { Newcastle upon Tyne, Eng- } \\
\text { land }\end{array}$ & Thomas Heatherwick Studio & 2004 \\
\hline Stortorget Square & Kalmar, Sweden & $\begin{array}{l}\text { Caruso St John \& Eva Lof- } \\
\text { dahl }\end{array}$ & 2003 \\
\hline Market Place & Stuttgart, Germany & Nimbus Design & 2003 \\
\hline USF Square & Bergan, Norway & 3RW Architects & 2003 \\
\hline Capitol Plaza & New York & Thomas Balsley Associates & $\mathrm{N} / \mathrm{A}$ \\
\hline Plaza de Dali’ & Madrid, Spain & $\begin{array}{l}\text { Francisco Mangado, LA HIS- } \\
\text { PANICA }\end{array}$ & 2005 \\
\hline Rakvere Central Square & Rakvere, Estonia & Kosmos & 2004 \\
\hline Plaza Pius XII & $\begin{array}{l}\text { Sant Adria de Besos, Barce- } \\
\text { lona, Spain }\end{array}$ & Ricardo Flores y Eva Prats & 2004 \\
\hline Frederiksberg's New Squares & $\begin{array}{l}\text { Solbjergvej, Frederiksberg, } \\
\text { Denmark }\end{array}$ & Stig L. Anderson (SLA) & 2005 \\
\hline Gammeltorv/Nytorv & Copenhagen, Denmark & $\begin{array}{l}\text { Stadsarkitektens Direktorat } \\
\text { with Sanne Maj Anderson \& } \\
\text { Leif Dupont Laursen }\end{array}$ & 1992 \\
\hline Axeltorv & Copenhagen, Denmark & $\begin{array}{l}\text { Mogens Moller \& Mogens } \\
\text { Breyen }\end{array}$ & 1991 \\
\hline Rathausplatz St. Polten & St. Polten, Austria & Boris Podrecca & 1997 \\
\hline
\end{tabular}




\begin{tabular}{|c|c|c|c|}
\hline $\begin{array}{l}\text { Three Squares in Qasr-Al- } \\
\text { Hokm }\end{array}$ & Riyadh, Saudi Arabia & $\begin{array}{l}\text { Buro Happold, Ali M. Shoabi, } \\
\text { Stefanno Bianca \& Rasem } \\
\text { Badran }\end{array}$ & 1992 \\
\hline Grand Plaza - Tokyo Midtown & Central Tokyo, Japan & EDAW & 2007 \\
\hline Grand Canal Square & Dublin, Ireland & Martha Schwartz Partners & 2007 \\
\hline Olympic Sculpture Park & Seattle, Washington & Weiss/Manfredi & 2007 \\
\hline Hafen City Hamburg & Hamburg, Germany & $\begin{array}{l}\text { Benedetta Tagliabue \& Mi- } \\
\text { ralles Tagliabue EMBT }\end{array}$ & 2005 \\
\hline $\begin{array}{l}\text { Urbanisation of the old quar- } \\
\text { ter of Banyoles }\end{array}$ & Banyoles, Spain & Josep Mias & 2007 \\
\hline Tram Stop & Alicante, Spain & Subarquitectura & 2007 \\
\hline Virrei Amat Square & Barcelona, Spain & Arriola \& Fiol arquitectos & 2007 \\
\hline Gate City Osaki & Tokyo, Japan & Thomas Balsley Associates & 2000 \\
\hline $\begin{array}{l}\text { RMIT University Urban } \\
\text { Spaces }\end{array}$ & Melbourne, Australia & $\begin{array}{l}\text { Peter Elliott Architecture \& } \\
\text { City of Melbourne }\end{array}$ & Ongoing \\
\hline Gustav Adolfs Torg & Malmo, Sweden & $\begin{array}{l}\text { Sven-Ingvar Andersson, lb } \\
\text { Rasmussen \& Sivert Lindblom }\end{array}$ & 1997 \\
\hline Rathausplatz St. Polten & St. Polten, Austria & Boris Podrecca & 1997 \\
\hline Place Vendome & Paris, France & Pierre Prunet & 1992 \\
\hline Place des Terreaux & Lyon, France & $\begin{array}{l}\text { Christian Drevet \& Daniel } \\
\text { Buren }\end{array}$ & 1994 \\
\hline Cloud Gardens & Toronto, Canada & $\begin{array}{l}\text { Milus, Bollenberghe, Topps, } \\
\text { Watchorn \& Margaret Priest }\end{array}$ & 1993 \\
\hline Pau Casals Square & Bilbao, Spain & ACXT & 2007 \\
\hline Cental Plaza Chiang Rai & Chiang Rai, Thailand & Shma Company LTD & 2011 \\
\hline Leyteire Square & Bordeaux, France & Debarre Duplantiers Associes & 2011 \\
\hline Square of the Seasons & La Défense, France & OLM \& Sereo Architect & 2011 \\
\hline Town Hall Square & Solingen, Germany & scape Landschaftsarchitekten & 2008 \\
\hline Lorenskog Central Square & Lorenskog, Norway & $\begin{array}{l}\text { Østengen \& Bergo AS land- } \\
\text { scape architects MNLA }\end{array}$ & 2011 \\
\hline Plaza Del Milenio & Valladolid, Spain & EXP Architects & 2011 \\
\hline Plaza de Santo Domingo & Madrid, Spain & $\begin{array}{l}\text { Marinas Arquitectos Asocia- } \\
\text { dos }\end{array}$ & 2007 \\
\hline Plaza Espana & Santa Cruz de Tenerife, Spain & Herzog \& de Meuron & 2008 \\
\hline Goerlitz Marien Square & Gorlitz, Germany & $\begin{array}{l}\text { Rehwaldt Landschaft- } \\
\text { sarchitekten }\end{array}$ & 2002 \\
\hline $\begin{array}{l}\text { Front Square of St Charles } \\
\text { Station }\end{array}$ & Marseille, France & Ilex Paysages \& Urbanisme & 2009 \\
\hline New Amsterdam Plein & Manhattan Island, New York & UN Studio & 2008 \\
\hline
\end{tabular}




\section{Appendix 2}

Initial hand drawn precedent analysis. Presented for the first one week thesis workshop. 

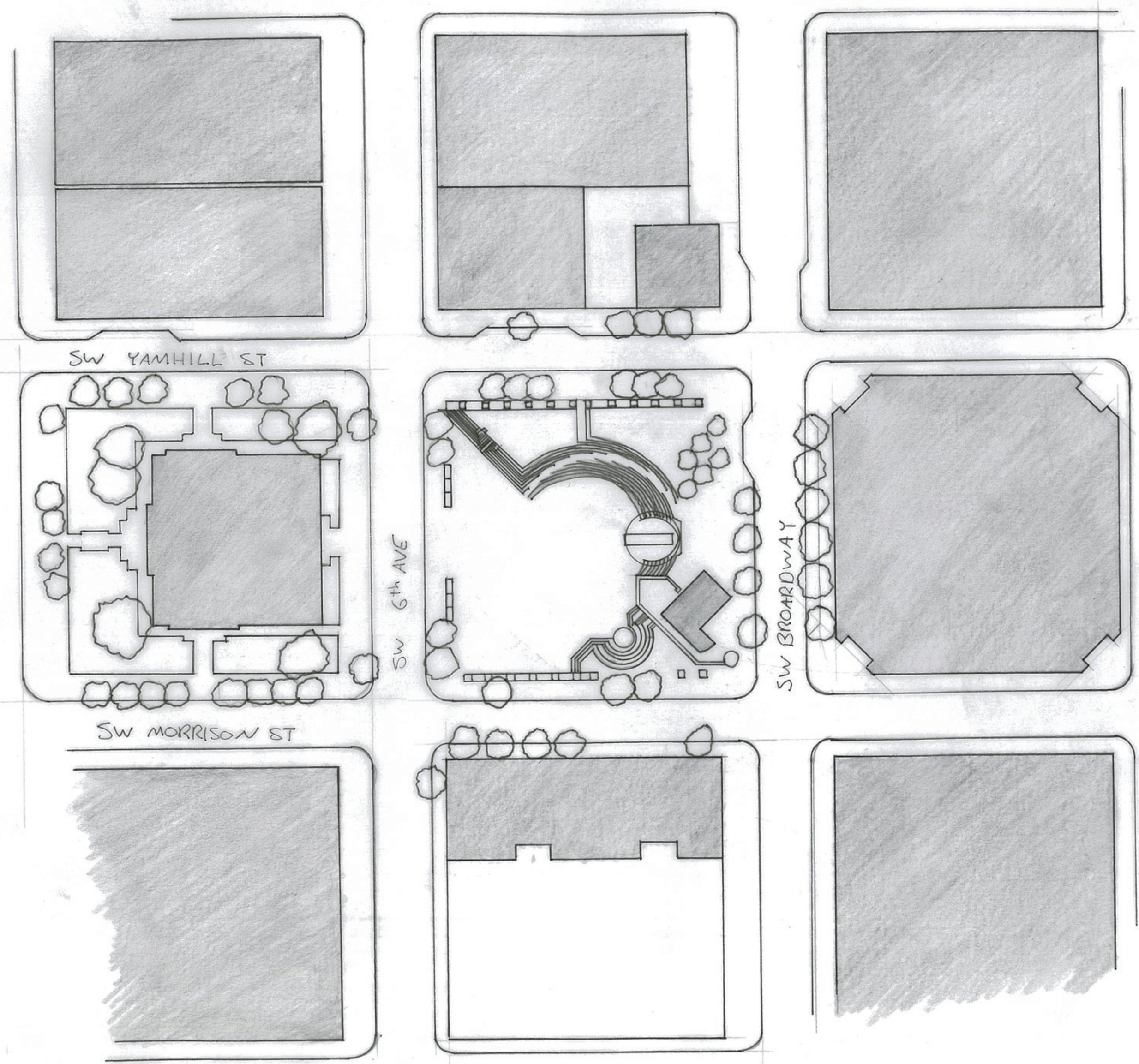
Figure 223. Pioneer

Courthouse Square,

Portland, Oregon.

Scale 1:1000
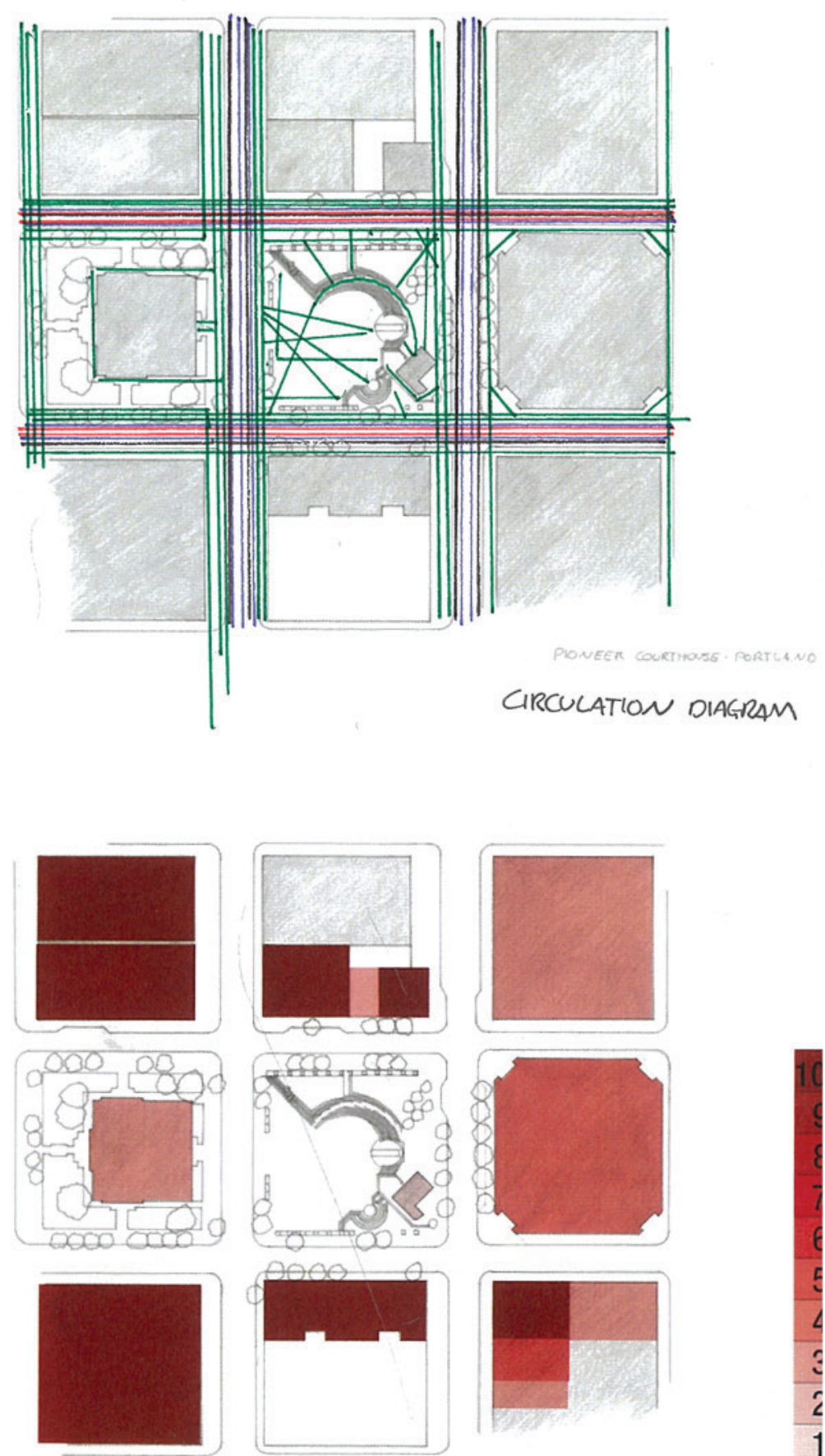

BUILDWG HEIGHT BY STOREY 

Figure 224. The

Octagon, Dun-

edin, New Zealand.

Scale 1:1000
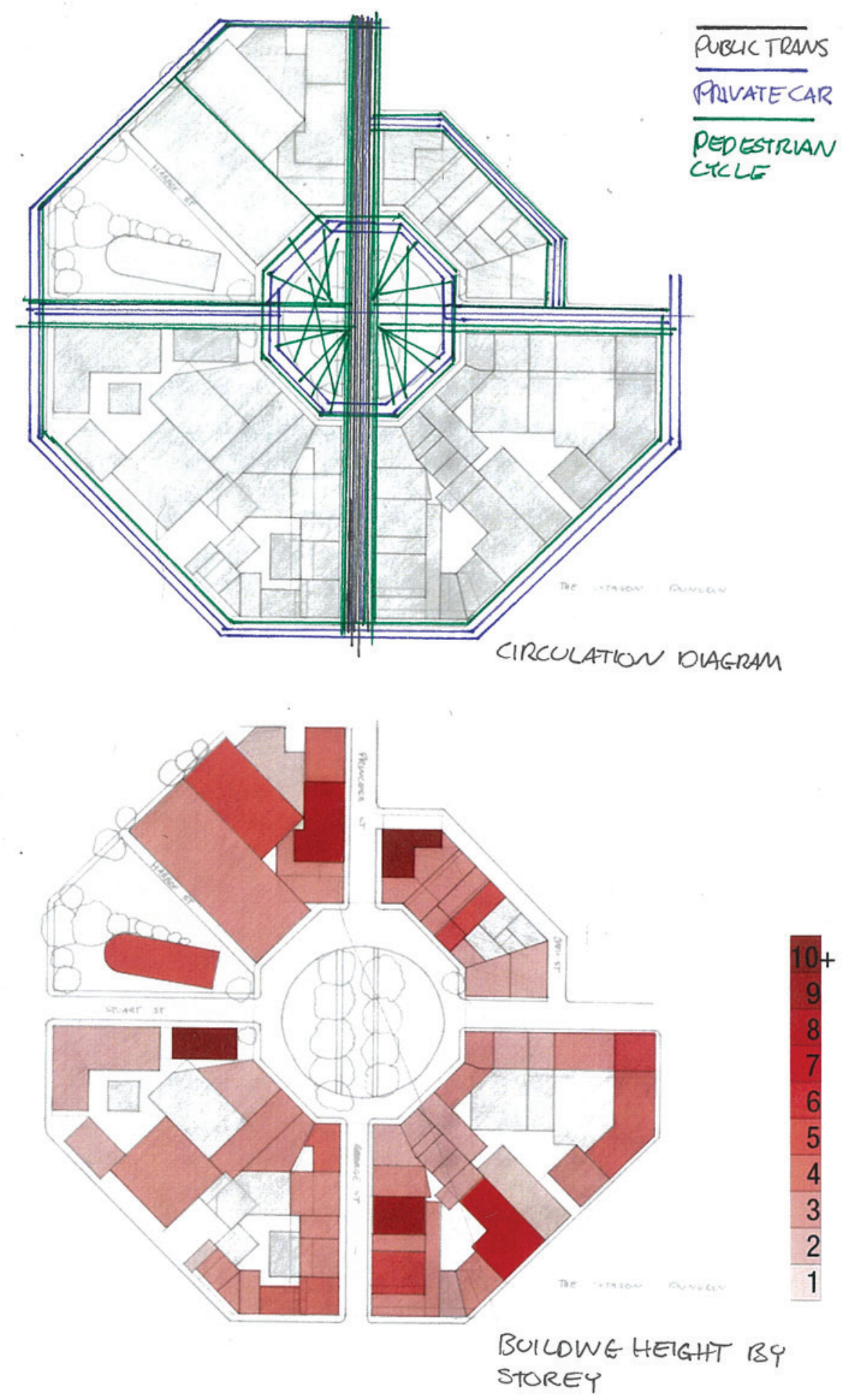

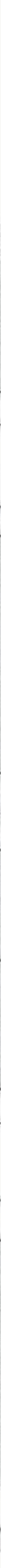
Figure 225. Union

Square, San Fran-

cisco, California.

Scale 1:1000
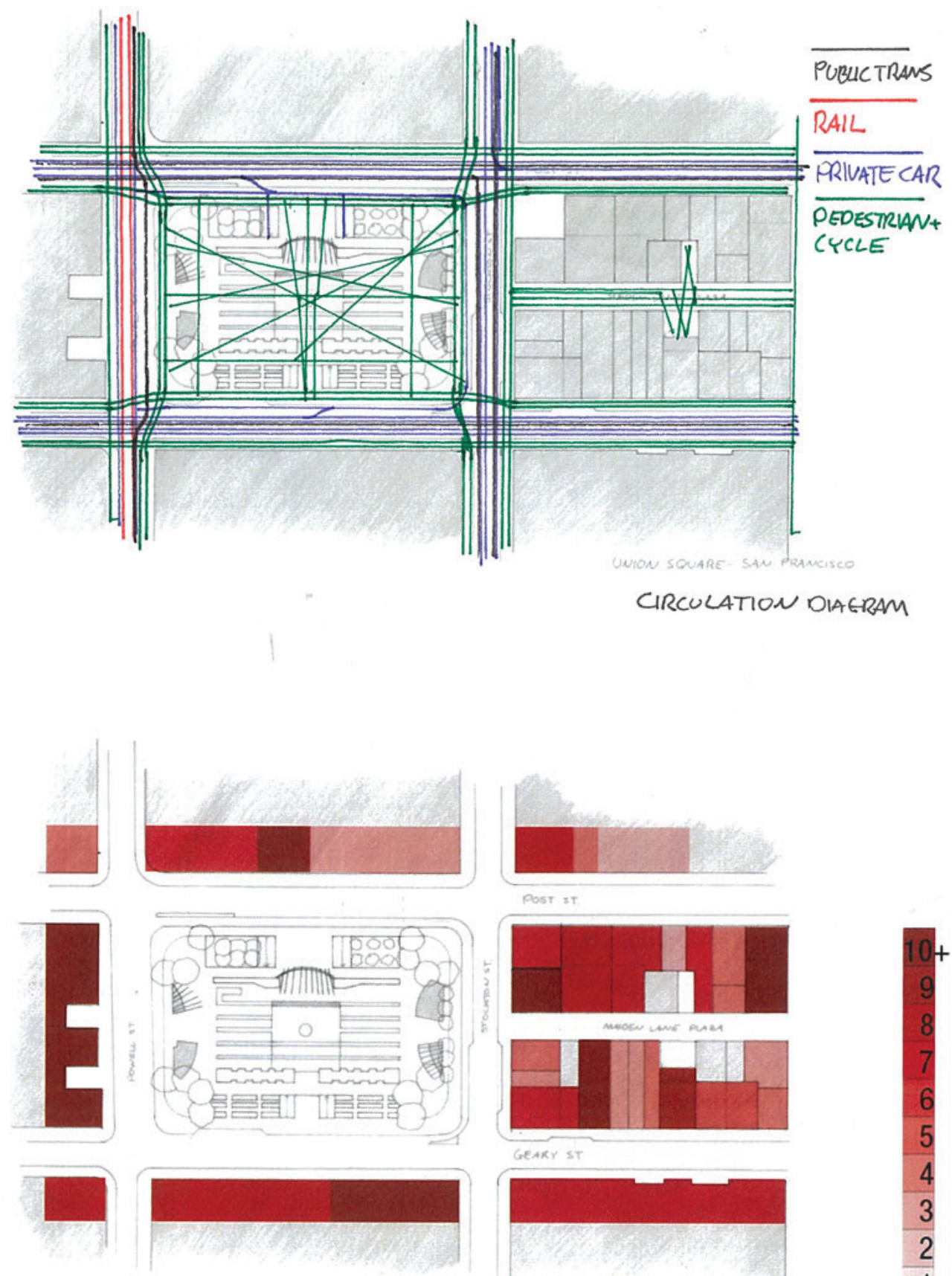

GenkY ST

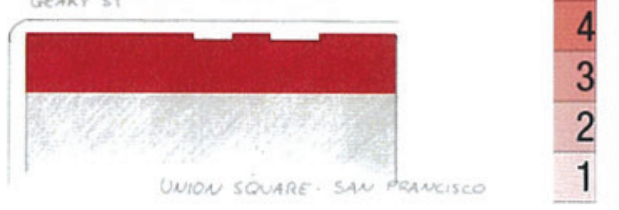

BUILDWG HEIGHTISY STORET 
Figure 226. Fed-

eration Square, Mel-

bourne, Australia.

Scale 1:1000

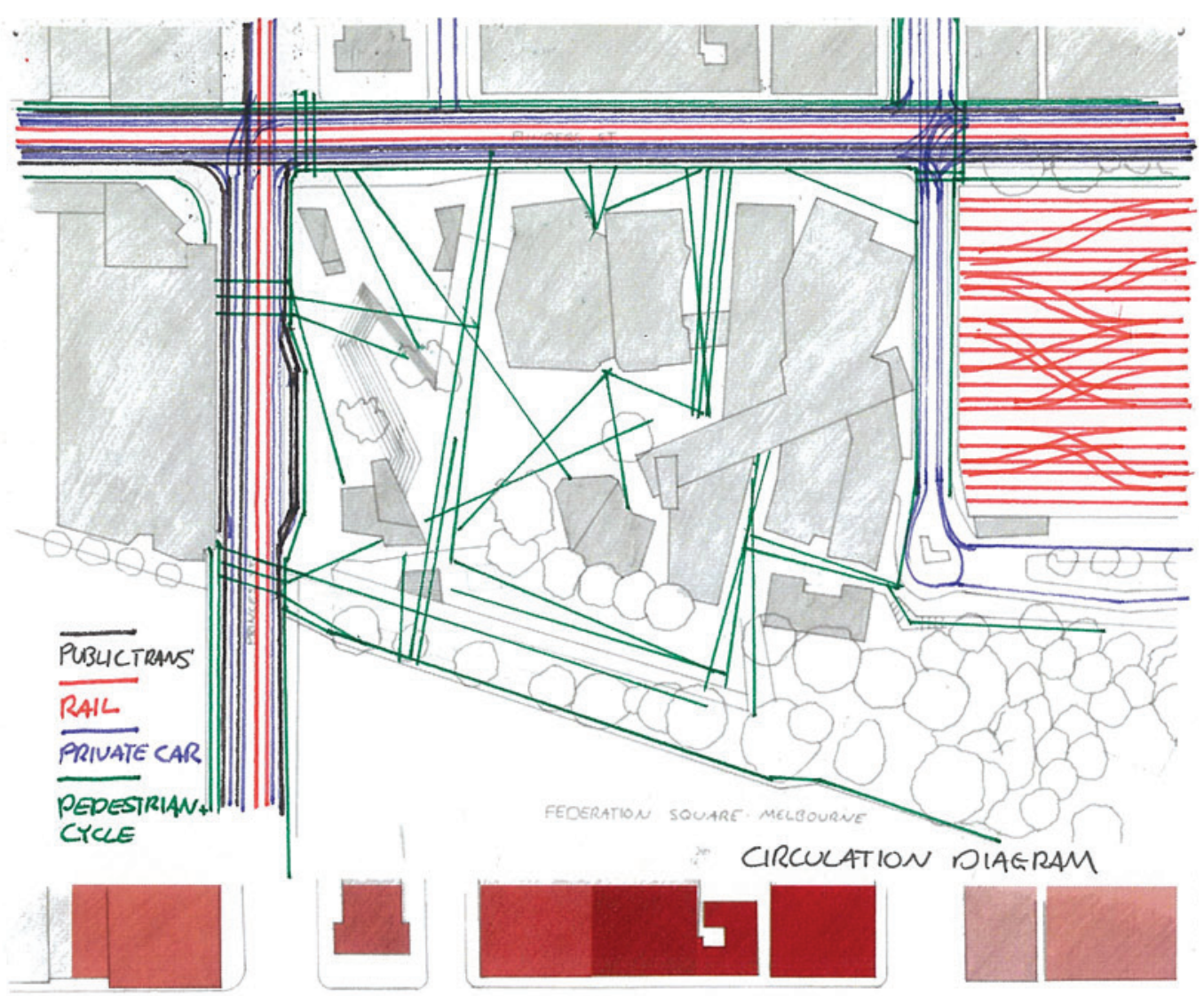

PWorks ST:

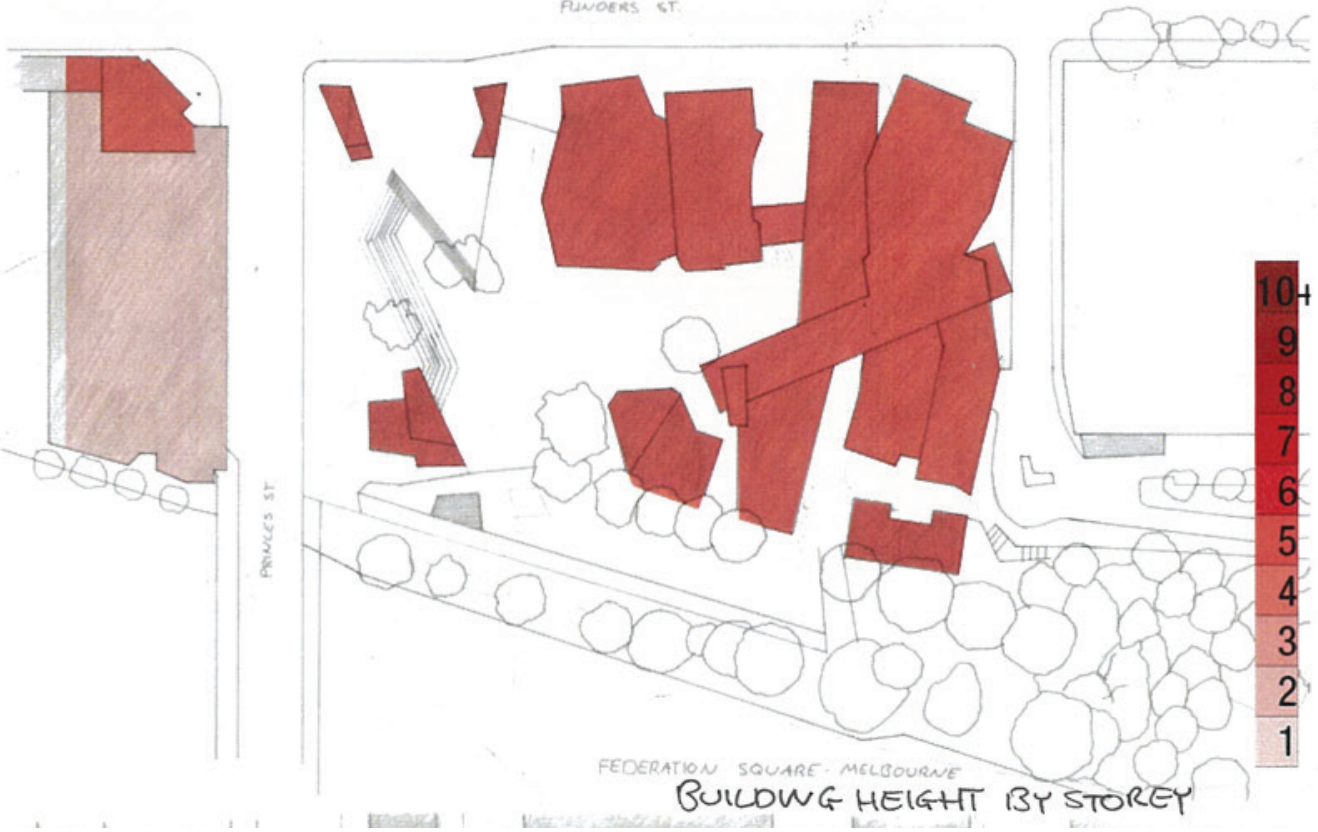




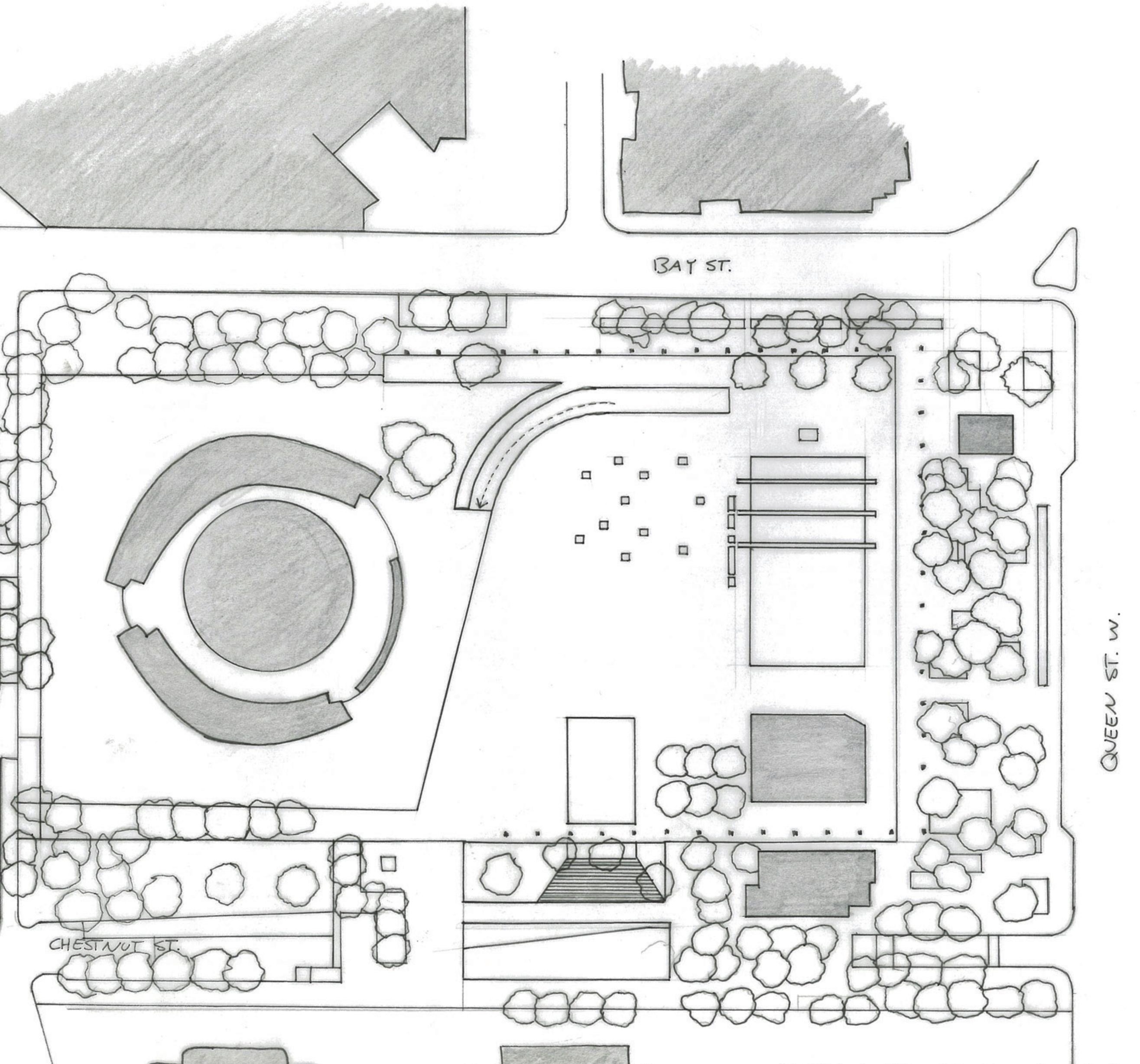


Figure 227. Nathan

Philips Square

Toronto, Canada.

Scale 1:1000
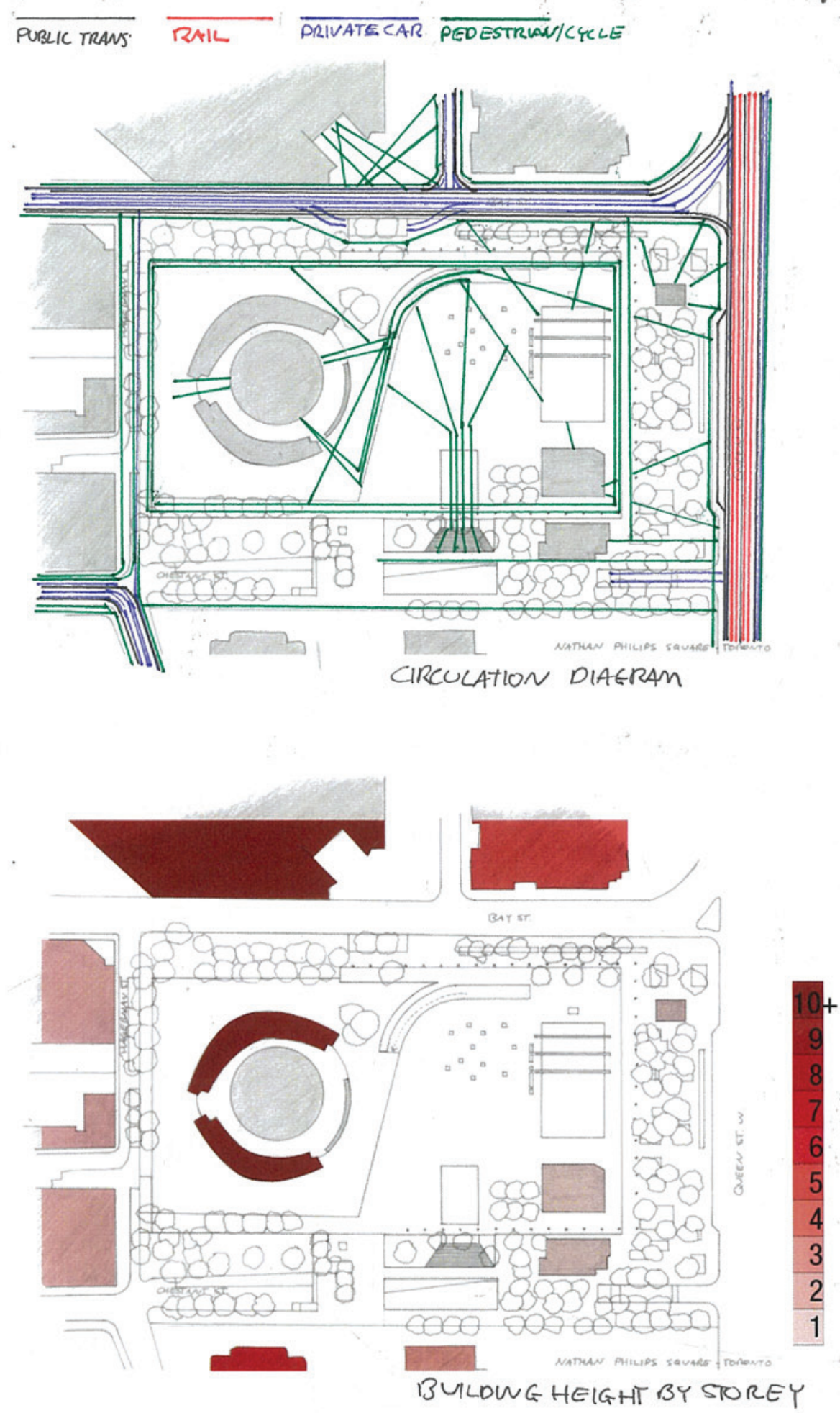

Figure 228. Ca-

thedral Square,

Christchurch,

New Zealand.

Scale 1:1000

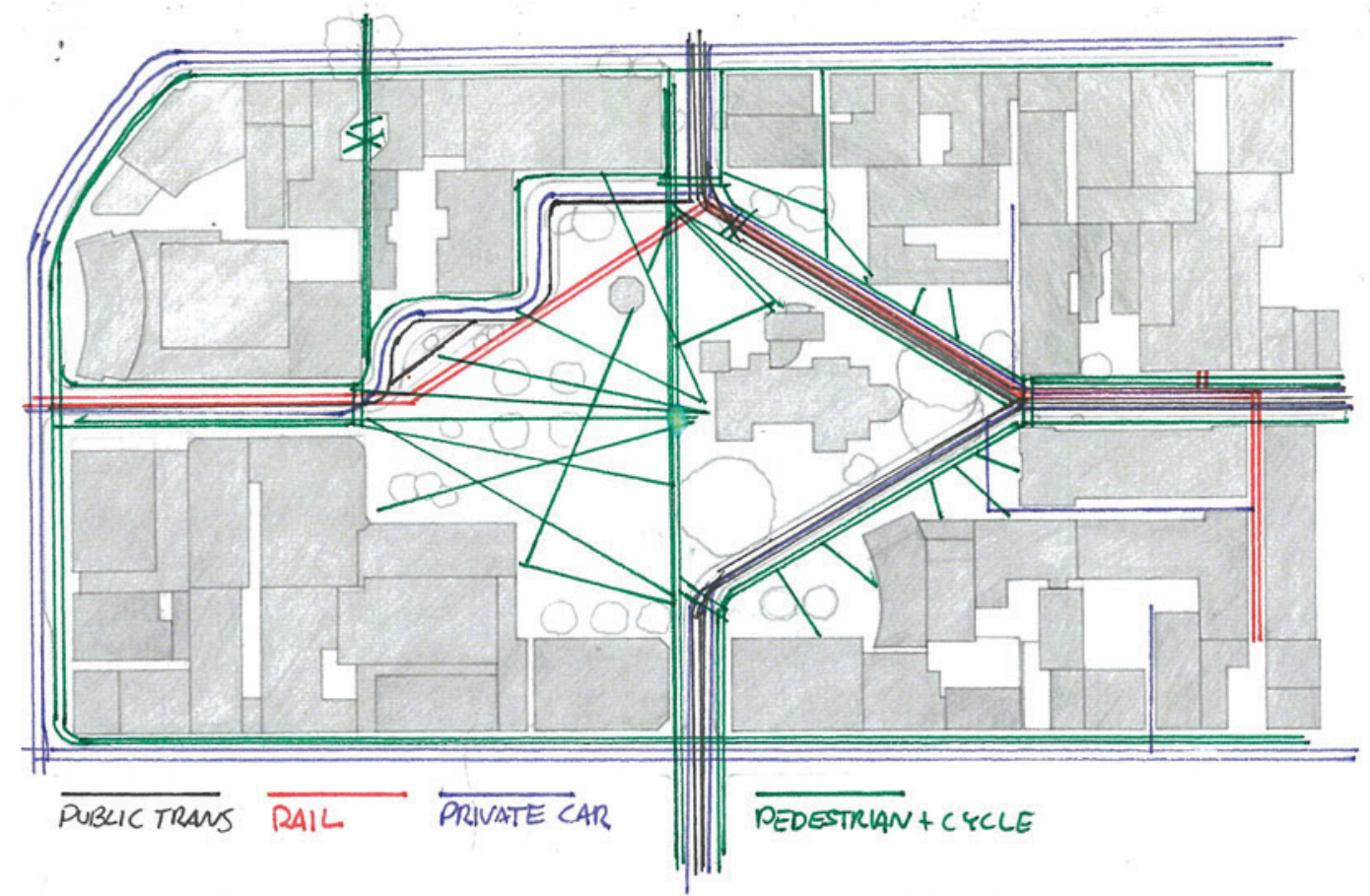

CIRCULATION DIAGRAM

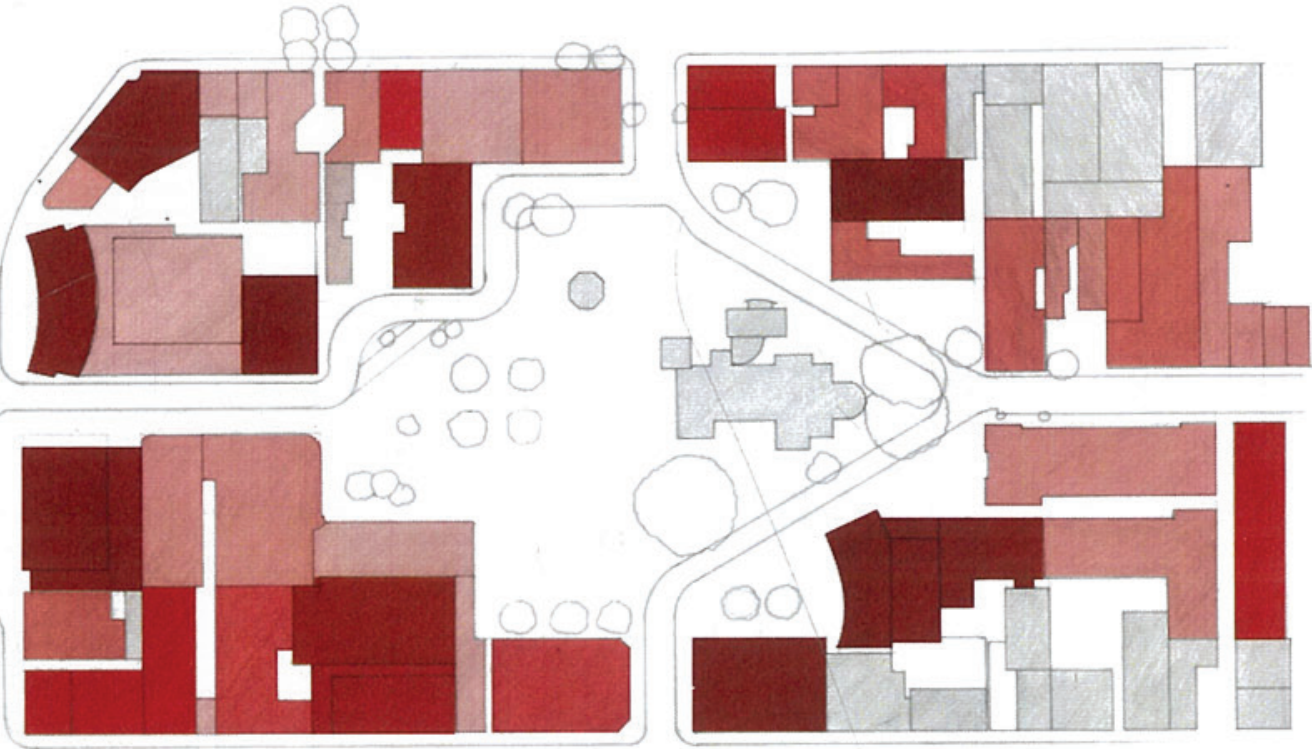

BUILDING HEETHT BY FLOOR

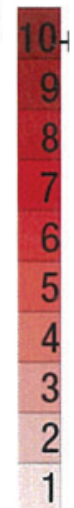

